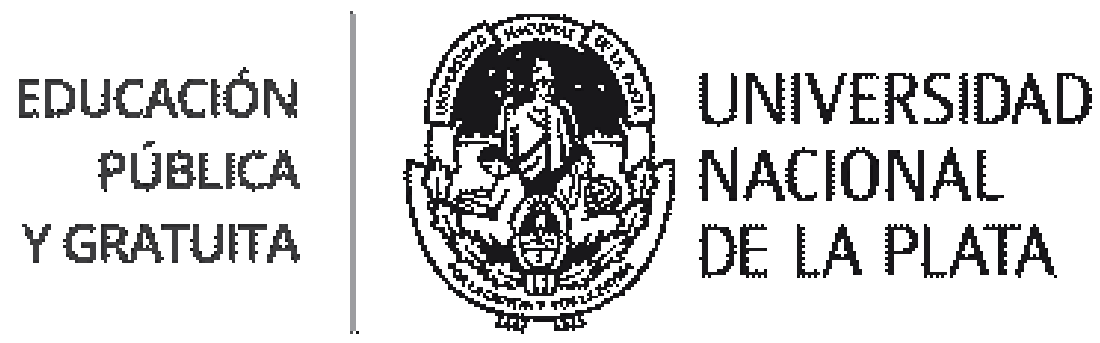

FACULTAD DE PERIODISMO Y COMUNICACIÓN SOCIAL

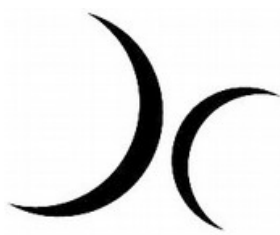

Doctorado en Comunicación Social

Trabajo de Tesis para aspirar al título de Doctora en Comunicación Social

\title{
Título:
}

La televisión digital: ¿dispositivo para la inclusión digital?

Un Estudio Exploratorio sobre el Plan "Mi TV Digital" en el Partido de José C. Paz de la Provincia de Buenos Aires (2014-2015)

\author{
Doctoranda: \\ Georgina González Gartland
}

Directora:

Dra. Roxana Cabello 


\section{Siglas Utilizadas}

AFSCA: Autoridad Federal de Servicios de Comunicación Audiovisual

AMBA: Área Metropolitana de Buenos Aires

AUH: Asignación Universal por Hijo

BACUA: Banco Audiovisual de Contenidos Universales Argentino

EDT: Estaciones Digitales de Transmisión

INDEC: Instituto Nacional de Estadísticas y Censos

ISDB-T: Integrated Services Digital Broadcasting Terrestrial - Radiodifusión Digital de Servicios Integrados

LCD: Liquid Crystal Display - Pantalla de Cristal Líquido

LED: Light-Emitting Diode - Diodo Emisor de Luz

UMI: Programa de Usos de Medios Interactivos

PNUD: Programa de las Naciones Unidas para el Desarrollo

SATVD-T: Sistema Argentino de TV Digital Terrestre

STB: Set Top Box

TDA: Televisión Digital Abierta

TDI: Tecnologías Digitales Interactivas

TDS: Televisión Digital Satelital

TDT: Televisión Digital Terrestre

TDTI: Televisión Digital Terrestre Interactiva

TIC: Tecnologías de la Información y la Comunicación

TV: Televisión

UNGS: Universidad Nacional de General Sarmiento

UNLP: Universidad Nacional de La Plata

UNQ: Universidad Nacional de Quilmes 


\section{Índice General}

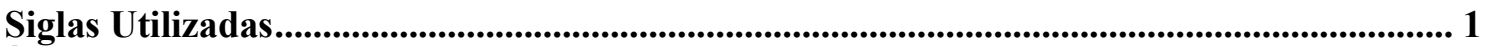

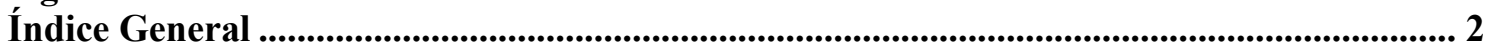

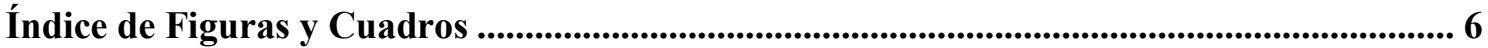

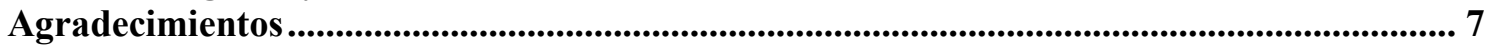

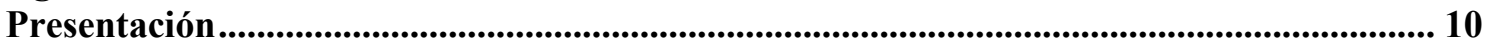

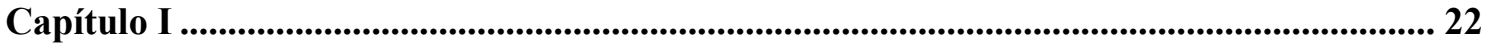

Políticas públicas y tecnologías digitales: las bondades de la inclusión y los peligros de la

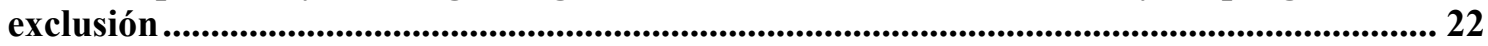

1.1 Las políticas y las tecnologías digitales para la Sociedad de la Información .................. 24

1.2 La inclusión digital para no quedar fuera de la Sociedad de la Información................. 30

1.2.1 De la brecha digital a la inclusión digital: entre apocalípticos e integrados ................ 32

1.3 Las políticas públicas de comunicación para la inclusión digital...................................... 35

1.3.1. La televisión digital para la inclusión digital ......................................................................... 39

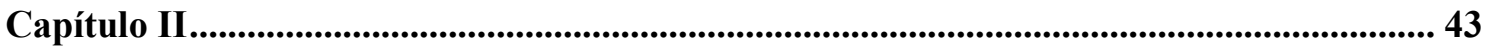

Televisión Digital Abierta: política de Estado para la transición digital ................................ 43

2.1 La TDT: de las estructuras técnicas a las definiciones .......................................................... 44

2.2 La TDT en Argentina: ¿De las reglas del mercado hacia el protagonismo del Estado?49

2.3 El desarrollo de la política pública: Televisión Digital Abierta ......................................... 56

2.3.1 La televisión digital terrestre en transición. Contexto normativo .................................. 60

2.3.2. El Sistema Argentino de Televisión Digital Terrestre ........................................................ 65

2.4 El Plan "Mi TV Digital”": características e implementación ............................................... 68

2.4.1 La comunicación del Plan "Mi TV Digital" ............................................................................ 72

2.5 TDA: $\Varangle y$ los destinatarios? ....................................................................................................... 80

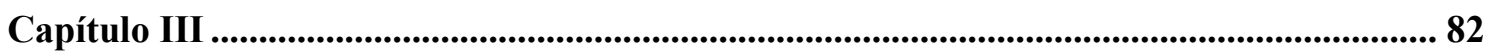

Los estudios sobre la televisión digital, sus usos y las propuestas de inclusión digital......... 82

3.1 Los estudios sobre televisión digital............................................................................. 83

3.1.1 Estado de la cuestión en el estudio de la digitalización de la televisión en Europa y América 83

3.1.2 La Televisión Digital Terrestre (TDT) como objeto de estudio ..................................... 86

3.1.3 Investigaciones regionales y locales sobre televisión digital ............................................ 88

3.1.4 Televisión Digital Argentina: estudios de caso ........................................................................... 90

3.2 Usos y prácticas de la televisión digital terrestre..................................................................... 94

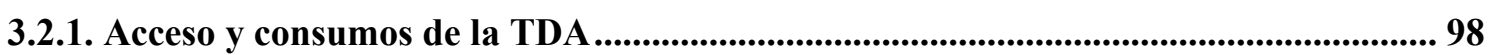

3.3 Los estudios sobre televisión digital e inclusión digital................................................... 103

3.4 Principales referencias en torno a los usos de la televisión digital terrestre e inclusión

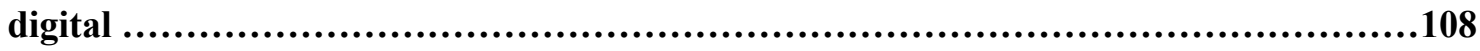

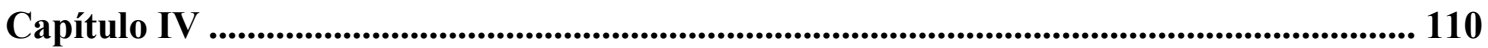

Tecnologías, usos, inclusión digital: problematizando los conceptos...................................... 110

4.1 El problema de la tecnología y cambio social .......................................................................... 114

4.2 La tecnología en contexto: su uso como dimensión cultural............................................. 120

4.2.1 Los términos del debate: Economía Política de la Comunicación y la Cultura vs.

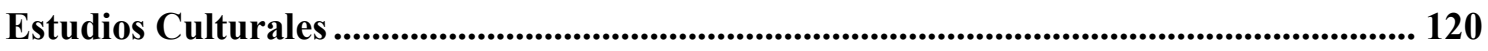


4.2.1.2 La(s) cultura(s), comunicación y política en foco

4.2.1.3 Tensiones y articulaciones del análisis económico cultural de la comunicación: propuesta para comprender los usos y consumos de la tecnología ................................ 128

4.3 Perspectivas teóricas sobre usos de las tecnologías ....................................................... 132

4.3.1. El concepto de uso de las tecnologías digitales........................................................... 134

4.3.2 Interactividad: apertura y clausura de un término polisémico.................................. 139

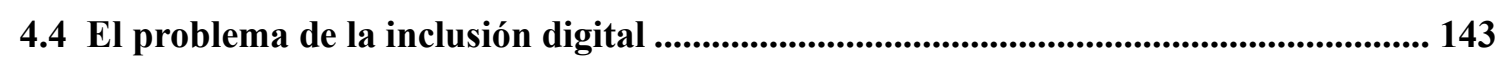

4.4.1 La inclusión digital: sus dimensiones .................................................................... 146

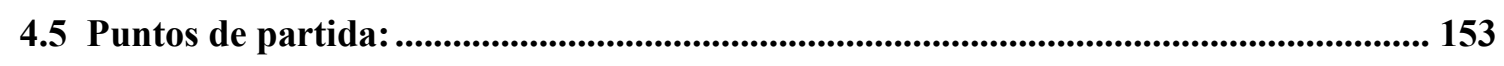

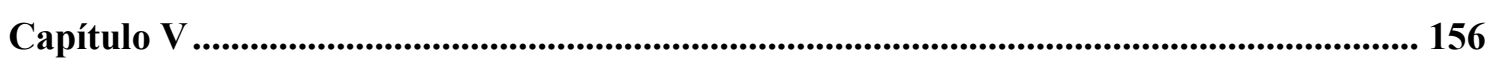

Estrategia metodológica de la investigación ..................................................................................... 156

5.1 Propuesta metodológica............................................................................................................... 156

5.1.1 Estrategia metodológica: Estudio de caso ............................................................ 158

5.1.2 Unidades de análisis y técnicas de recolección de la información................................ 160

5.2 Características del universo de estudio: El contexto social, económico y cultural del partido de José C. Paz (provincia de Buenos Aires) ............................................................ 170

5.2.1 Los números del territorio..................................................................................... 174

5.2.2 Disponibilidad y uso de tecnologías en el Conurbano Bonaerense ............................ 178

5.2.3 La televisión digital en José C. Paz: mucho ruido, pocos datos .................................. 181

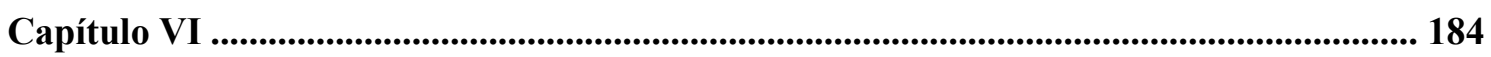

Los textos de la televisión digital en Argentina ......................................................................... 184

6.1 Puntos de partida para el análisis de la política pública de inclusión digital ................ 187

6.2 La definición del problema de las tecnologías y la televisión digital en las políticas

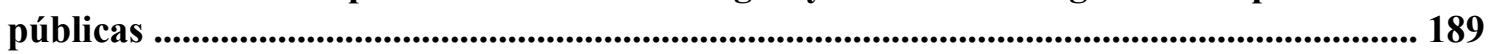

6.2.1 Las TIC como uno de los motores hacia la Sociedad de la Información.................... 195

6.2.2 Las brechas y las tecnologías digitales...................................................................... 198

6.2.3 El acceso universal a las tecnologías ............................................................................ 200

6.2.4 La televisión digital para la inclusión digital ......................................................... 201

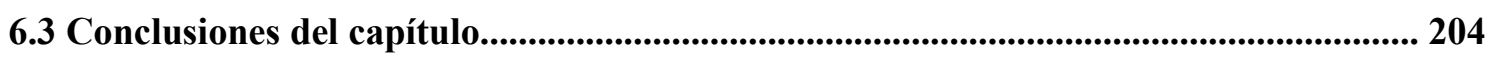

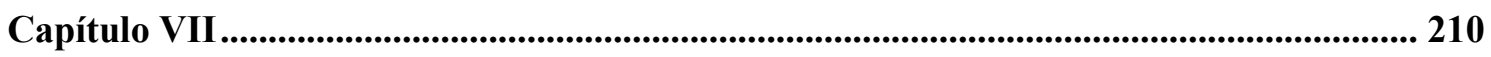

Usos y expectativas sobre la TDA en el Partido de José C. Paz para la inclusión digital. 210

Parte I. Acceso, usos y expectativas sobre la televisión digital en transición....................... 211

7.1 Disponibilidad y acceso de la TDA en José C. Paz ................................................................. 211

7.1.1 Los modos de acceso previstos por el Plan "Mi TV Digital" ....................................... 211

7.1.2 Cómo accedieron los entrevistados a la TDA ........................................................ 213

7.1.2.1 Trámites para obtener el receptor digital de TDA............................................... 215

7.1.2.2 Instalación del decodificador digital de TDA ................................................ 219

7.2 Decodificadores digitales: operación, funciones, ventajas y desventajas ....................... 223

7.2.1 Operación de la Televisión Digital ....................................................................... 223 
7.3 Dieta televisiva: disponibilidad física, preferencias y contenidos del visionado ........... 228

7.3.1 Espacio y tiempo de la televisión digital en los hogares ............................................ 228

7.3.2 Preferencias de visionado y de géneros televisivos ............................................... 231

7.3.2.1 Productos audiovisuales elegidos por los usuarios de TDA.............................. 232

7.4 La función de la interactividad en la TDA...................................................... 235

7.5 Otros usos de las tecnologías: asociaciones y efectos de desplazamiento ................... 239

7.6 Los usos de la TDA y las expectativas de inclusión digital .................................... 242

PARTE II. La TDA en el territorio: la televisión digital llega a casa................................ 250

7.7 Lo bueno y lo malo de la TDA: infraestructura, oferta y ACCESO ........................ 250

7.8 Sobre los USOS y consumos de la televisión digital ...................................................... 257

7.8.1 Situaciones de usos de la TDA: prácticas de usos, no usos, usos poco frecuentes y usos frecuentes ..................................................................................................... 257

7.8.2 Otros usos de las tecnologías: asociaciones y efectos de desplazamiento .................. 263

7.8.3 La interactividad es la novedad: sentidos atribuidos y prácticas con la televisión digital en transición.

7.8.4 ¿Qué ves cuando ves televisión digital?: similitudes y diferencias con la televisión analógica.

7.9 La AUTOCONFIANZA para no quedarse afuera......................................................... 269

7.10 La PARTICIPACIÓN de los usuarios de TDA en el entorno tecnocultural .............. 274

7.11 Oportunidades y expectativas para la inclusión personal y social................................. 277

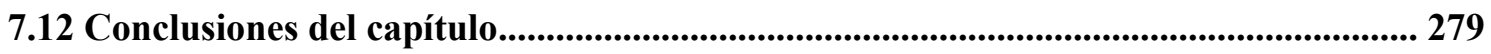

Capítulo VIII ..................................................................................................................................................... 284

La televisión digital en contexto: ¿más y mejor incluidos? .................................................... 284

8.1 La TDA: ¿dispositivo de inclusión digital? .............................................................................. 290

8.1.1 La cobertura y la distribución para la inclusión digital ................................................. 291

8.1.2 Información y comunicación para la transición digital ................................................... 294

8.1.3 La concepción sobre "inclusión digital" y sobre "acceso a las tecnologías" ............. 295

8.1.3.1 Sobre la oferta de contenidos ........................................................................... 296

8.1.4 Usos de TDA e inclusión digital ............................................................................................. 297

8.1.4.1 Televisión digital y televisión analógica..................................................................... 298

8.1.5 Los vínculos de las personas con las tecnologías ............................................................ 299

8.2 La transición digital. Derechos e inclusión ...............................................................301

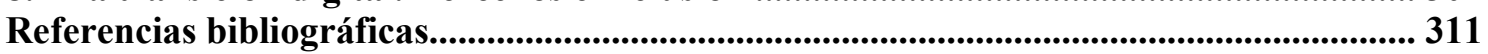

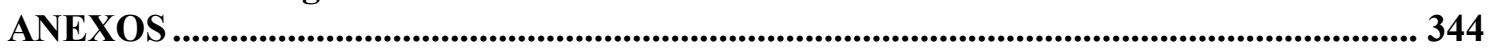

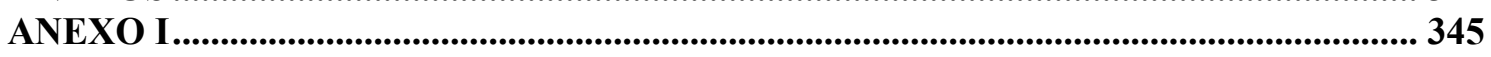

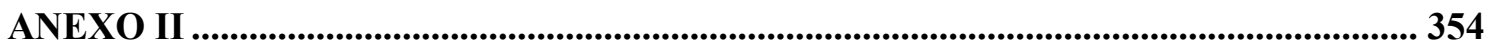

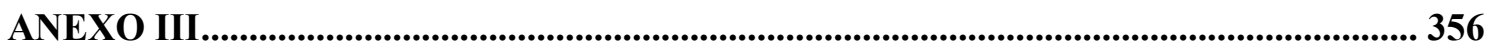

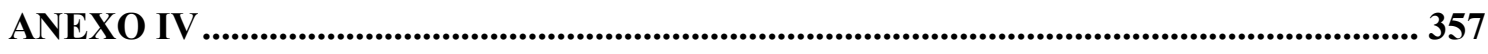

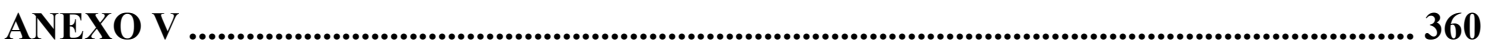




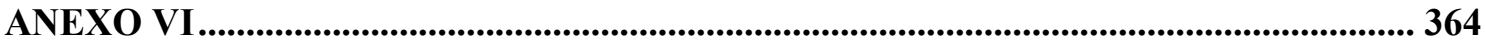




\section{Índice de Figuras y Cuadros}

Figura 1.Coronas de la Región Metropolitana de Buenos Aires. OC. ICO. UNGS ....

Figura 2. Densidad poblacional Región Metropolitana de Buenos Aires. Censo 2010.

OC. ICO. UNGS

Cuadro 1. Principal perceptor de ingresos del hogar...................................

Cuadro 4. Distribución de los hogares por régimen de tenencia de vivienda según

partido.

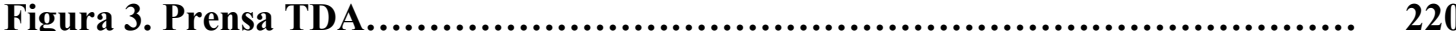

Figura 4. Prensa TDA.............................................................. 220

Figura 5. ENCCyED, año 2013 .................................................. 250

Figura 6. Tipo de servicio de TV en hogares de los Partidos de José C. Paz,

Malvinas Argentinas, Moreno y San Miguel, año 2013. 


\section{Agradecimientos}

Esta tesis forma parte importante de mi trayectoria como investigadora docente aunque no es la única instancia. Por eso estos agradecimientos comprenden mis inicios en la enseñanza y en la investigación universitaria.

Desde 1998, la Dra. Roxana Cabello generosamente guio mi formación como docente en la Licenciatura en Comunicación de la Universidad Nacional de General Sarmiento. Resulta difícil agradecerle su enorme dedicación y compromiso para que mi práctica en el aula produjera distancia crítica y reflexiva con nuestros estudiantes de grado. No obstante, también me acompañó en los primeros pasos en investigación que alcanza uno de los puntos más relevantes con esta tesis de doctorado. Su dirección académica, en estos largos años, no solo me permitió elaborar este trabajo sino que me permitió profundizar sobre el abordaje metodológico del trabajo. Al margen de su labor como directora de esta tesis, Roxana Cabello es una de las personas más importantes tanto en mi formación profesional como en mi vida personal.

Agradezco la oportunidad que me proporcionó la Facultad de Periodismo y Comunicación Social de la Universidad Nacional de La Plata y su proyecto académico del Doctorado en Comunicación para desarrollar este trabajo, para seguir aprendiendo y realizar intercambios significativos con los docentes e investigadores y mis compañeros de cohorte. Sin esa experiencia esta tesis seguramente no habría llegado hasta aquí.

La lectura atenta y las recomendaciones de la tesis de calificación, evaluada por el Dr. Gustavo Cimadevilla, la Dra. Silvina Pauloni y de la Profesora Silvia Delfino, me permitieron reordenar parte de la propuesta y profundizar aspectos analíticos del objeto de estudio que enriquecieron el trabajo.

La beca Docto.ar del Programa de Mejora de las Ciencias Sociales de la Secretaría de Políticas Universitarias me permitió contar con los tiempos necesarios para realizar el trabajo de campo (para contactar, para desplazarme y concretar las entrevistas).

No puedo dejar de expresar mi agradecimiento a varios integrantes del Instituto del Desarrollo Humano que me han acompañado y alentado en cada nuevo desafío que he encarado en mi vida académica. 
Mi reconocimiento al Dr. Daniel Lvovich, ex director del Instituto, que me convocó para participar de la beca Doctorar y habilitó las instancias institucionales para la preparación de este trabajo.

Mi gratitud para Silvana Lucero, que es una de esas personas que con sus preguntas afiladas me suele sacar del lugar de la comodidad de las certezas pero fundamentalmente, es mi compañera en la docencia y en la investigación.

A mis compañeros del Programa de Usos de Medios Interactivos, dirigido por Roxana Cabello, cuyos comentarios y observaciones enriquecieron sistemáticamente desde el inicio esta propuesta.

A todos los estudiantes de la Licenciatura en Comunicación de mi universidad que, aún sin saberlo, con sus intervenciones en diferentes instancias colaboraron con el proceso de esta investigación. Especialmente, agradezco a María Florencia Moreno y Mónica Noriega que participaron de la organización de los materiales de las entrevistas.

A María Soledad Burghi Cambón, compañera de trabajo y amiga que siempre tiene una palabra de aliento y un aporte valioso para seguir pensando en el aula o en la investigación.

Un especialísimo agradecimiento a Cora Escolar por su apoyo incondicional y la palabra precisa para cada momento de este proceso de escritura. Aprendí mucho y sigo aprendiendo con vos.

A mis amigos y compañeros de trabajo que me escucharon pacientemente durante años hablar de la tesis y que me contuvieron cuando la meta parecía cada vez más lejos.

A Victor Lenarduzzi con quien me une una amistad profunda que se cruza con nuestros intereses y trayectos académicos. Muchas gracias por estar presente siempre.

A Iván, mi compañero de esta parte de la vida, con quien proyectamos una relación en la que compartimos formas de mirar el mundo que coinciden en un proyecto político y que nos unen más allá de las distancias.

A mis padres, Alicia y Carlos, por enseñarme a valorar y respetar a los otros, por transmitirme la necesidad de continuar la lucha para transformar la sociedad, para que no haya excluidos, para que no haya "algunos más iguales que otros". Mi amor incondicional y agradecimiento profundo por seguir estimulándome para que mi tarea personal y 
profesional sirva para mejorar la vida de otros. A mi hermana Sole que me conoce, que sabe de mis desvelos y que siempre tiene ese abrazo listo que reconforta, que aliviana la vida. Y a Gude, que con su palabra cuidadosa y su consejo oportuno acompaña mi crecimiento personal e intelectual desde hace 35 años. Gracias por tu generosidad y por querer tanto a Mateo.

A mi amado hijo Mateo. Sobran las palabras para retribuir su amor, para considerar su sensibilidad social y política pero especialmente, para agradecerle su enorme tolerancia con mis reiteradas ausencias a causa de esta tesis. Confieso que su presencia me sostuvo en los momentos aciagos y me alentó a culminar este proceso. 


\section{Presentación}

La investigación en el campo de estudios de comunicación, a la luz de las transformaciones tecnológicas y culturales actuales, supone comprender las relaciones entre las tecnologías, sus usos y sus implicaciones en la esfera social, política y económica de nuestras sociedades. El académico De Moragas sostiene que para avanzar en la indagación de estas temáticas se debe responder “(...) doblemente, a los retos que plantea tanto la evolución de las teorías como los cambios estructurales del sistema mediático / tecnológico" (De Moragas, 2017: 26). Los efectos de la digitalización (producción, difusión, consumo y almacenamiento) en las prácticas culturales de las personas, la vinculación de las tecnologías digitales con los procesos de democratización de las sociedades o las características de la convergencia tecnológica y mediática son algunos de los problemas que se recortan en el escenario de la comunicación digital.

Los inicios del siglo XXI se caracterizan por el desarrollo de diversas tendencias tecnológicas que proponen desafíos a los modos de investigar las tecnologías digitales en nuestras sociedades. Estas tendencias se expresan en la digitalización, la capacidad de las memorias electrónicas y magnéticas, el uso de la fibra óptica, la extensión de la red de internet de banda ancha, las pantallas planas, los captadores digitales (dispositivos para captar imágenes en soporte electrónico) y en la red mixta de ondas y cable (TV por cable o satelital, redes wifi) (Majó, 2012: 69-72).

En el ámbito académico, estas modificaciones tecnológicas se han problematizado en el marco de las discusiones sobre la Sociedad de la Información que, desde mediados del siglo XX, han permeado las investigaciones sobre los medios de comunicación y las tecnologías. En ellas, la caracterización de la Sociedad de la Información reconocía el protagonismo de las tecnologías digitales en el desarrollo económico con vistas a generar un impacto social positivo. En la actualidad, la preocupación por sus consecuencias y derivaciones han adquirido un lugar cada vez más central en los estudios de la sociedad, la cultura y la comunicación. Entre las cuestiones que han suscitado un importante interés y una prolífera producción en la comunidad académica se encuentran tanto la identificación de las estrategias que colaboren con la superación de la brecha digital como aquellas maneras de conseguir la inclusión digital en los países centrales y en los periféricos. En 2007, la Comisión Económica para América Latina y el Caribe (CEPAL) afirmaba: 
"Hoy en día existe consenso en que disminuir la brecha digital es un imperativo fundamental de las políticas públicas, a fin de incorporar a todos los sectores sociales al manejo de los nuevos códigos que permiten aprovechar las TIC para abrirse oportunidades laborales y sociales. (...) En la actualidad, saber usar y tener acceso a las tecnologías es una condición de base para poder ampliar las capacidades de acción en el ámbito productivo y laboral, en la activación de redes sociales de cooperación, en la sociabilidad y en la definición de la identidad personal". (CEPAL, 2007:32)

Buena parte de los trabajos de investigación se han ocupado del papel de los Estados, del mercado y de la sociedad civil en torno a la definición de instrumentos para suturar la brecha e incluir digitalmente a sectores sociales excluidos. De hecho, ambos problemas se configuran como las metas para lograr avances significativos hacia la Sociedad de la Información.

En esta tesis nos proponemos focalizar en la construcción de sentidos en torno a los procesos de inclusión digital expresados tanto en el discurso de las políticas públicas de comunicación como en los relatos de los destinatarios de las mismas. En ese marco, nos interesa comprender algunos aspectos de las condiciones de producción de las políticas públicas de inclusión digital, teniendo en cuenta sus definiciones así como también las prácticas y discursos de los usuarios de las tecnologías digitales.

El interrogante principal que guía esta tesis refiere a la relación entre los usos y las prácticas de la Televisión Digital Abierta (TDA) y los procesos de inclusión digital, a partir de las expectativas expresadas en la política pública y de los discursos y prácticas de los usuarios de la población del partido de José C. Paz de la provincia de Buenos Aires, durante 2014 y 2015.

Nuestra investigación apunta a explorar los modos en que pueden ser diferenciados, analítica y políticamente aquellos esfuerzos para universalizar el servicio, alcanzar a la población identificada como en "riesgo de exclusión", la producción de contenidos específicos, el desarrollo de infraestructura técnica de la TDA respecto de la generación de procesos de inclusión con vistas a saltar la brecha digital entre los destinatarios de la política pública. Nos interesa conocer si la formulación de la política pública TDA construyó una definición de los destinatarios como productores con objetivos propios y autónomos, desde la toma de decisiones y en relación con los usos, los consumos y prácticas relativos a la televisión digital, con la posibilidad efectiva de integrarla a sus prácticas sociales, culturales y políticas. 
En este contexto, entendemos a la política pública como movimiento que involucra la participación del Estado, del mercado y de la sociedad civil que pone en la agenda pública la cuestión de la inclusión digital como estrategia nacional para dirigirse hacia la Sociedad de la Información.

Esta tesis se inscribe en la línea de trabajo: "Comunicación, Sociedad y Cultura” y, en particular, se adecua al área "Construcción y reflexión teórica" del plan de cursada del Doctorado en Comunicación de la Universidad Nacional de La Plata (UNLP). Dentro de este marco nos proponemos situar el problema de la tecnología como dimensión cultural en el campo de estudios de comunicación. Y en el caso particular de la televisión digital, en relación con los sentidos que le atribuyen los sujetos como práctica social y comunicativa, contemplando las definiciones de política pública involucradas. Esta inscripción se funda en la presunción de que la reflexión sobre las limitaciones y alcances de los procesos de apropiación de tecnologías requiere superar cierta visión instrumental y tecnocrática a fin de incorporar una mirada integral que abarque la complejidad de los usos y las prácticas de los sujetos.

El propósito de la investigación es contribuir, a través de un estudio de caso, al análisis y comprensión del propósito de inclusión digital de las políticas públicas (en este caso, de la televisión digital terrestre) de acceso a tecnologías digitales entre los sectores sociales “en riesgo de exclusión” en nuestro país.

Ahora bien, nos interesa precisar la forma en que comprendemos en esta tesis la noción de sectores o grupos sociales en "riesgo de exclusión digital". Es probable que este término se confunda o se pueda emparentar con las categorías de nivel socioeconómico ${ }^{1}$ o de vulnerabilidad social ${ }^{2}$. Sin embargo, nosotros optamos por considerar este concepto en los términos que la política pública la construye, es decir, como aquellos sectores, grupos o colectivos sociales que debido a diferentes factores: sociales, económicos, culturales pueden quedar relegados o fuera del entorno digital. Entonces, dichos grupos son percibidos o se autoperciben con escasas o nulas capacidades y habilidades para

\footnotetext{
${ }^{1}$ El nivel socioeconómico es una categoría integrada por dos dimensiones: económica y social que se expresa a través de 3 variables: ingresos, educación y empleo de una persona, familias o grupos cuyos grados son: alto-medio-bajo (y sus combinaciones según los criterios utilizados).

${ }^{2}$ El enfoque vulnerabilidad social, según Pizarro: “(...) tiene dos componentes explicativos. Por una parte, la inseguridad e indefensión que experimentan las comunidades, familias e individuos en sus condiciones de vida a consecuencia del impacto provocado por algún tipo de evento económico social de carácter traumático. Por otra parte, el manejo de recursos y las estrategias que utilizan las comunidades, familias y personas para enfrentar los efectos de ese evento" Pizarro (2001: 11).
} 
integrar y/o aprovechar las tecnologías digitales tanto en su desarrollo personal como social. Volveremos sobre esta definición en el capítulo IV y en los capítulos VI y VII donde analizamos los discursos de la política pública y de los usuarios de la TDA respectivamente.

La decisión de estudiar la introducción de la televisión digital en Argentina en el período 2014-2015 obedece a que creemos relevante conocer las características y modalidades que adoptó la implementación de la TDA a 4 años de la creación del Sistema Argentino de TV Digital Terrestre (SATVD-T) y cuando restaban 5 años del denominado "apagón analógico" previsto para septiembre de $2019^{3}$. A meses del plazo establecido para el apagón analógico, el gobierno del presidente (MC) Mauricio Macri (2015-2019) lo postergó, mediante el Decreto 173/2019, hasta el 31 de agosto de 2021.

Como hemos señalado, este trabajo de investigación profundiza su análisis entre fines del 2014 e inicios de 2015, no obstante resulta significativo contextualizarlo en relación con las rupturas y continuidades de las políticas públicas de inclusión digital, en este caso, la televisión digital terrestre. Es decir, nos interesa introducir una descripción de los cambios producidos en la TDA durante la administración de la Alianza Cambiemos (PRO-Unión Cívica Radical-Coalición Cívica) que abre un abanico de preguntas sobre el desarrollo de la televisión digital en nuestro país y su vinculación con los procesos de inclusión digital.

Desde inicios de 2016, la gestión de Macri fue desatendiendo la política pública TDA. Dice la investigadora Pauloni (2018:1):

“Tras 9 años de su implementación sólo quedan vestigios del olvido. La infraestructura, construida en su inmensa mayoría entre 2010 y 2015, sigue en pie, pero (...) no sólo no avanzó en su despliegue, sino que las 88 estaciones terrestres para transmitir TDT, que cubren al 82 por ciento de la población, carecen de mantenimiento y parecen ser condenadas al abandono".

Mediante el Decreto $N^{\circ}$ 12/2015, la administración macrista creó el Sistema Federal de Medios y Contenidos Públicos (SFMyCP), concentrando en la Jefatura de Ministros la

\footnotetext{
${ }^{3}$ El "apagón analógico" es la denominación que se le asigna al cese de las emisiones analógicas de los operadores de televisión en el mundo. Una vez completado el apagón analógico, se prevé que será indispensable disponer de un televisor con un sintonizador digital, o en su defecto utilizar un sintonizador TDT (ATSC, ISDB-T o DVB-T) externo, que procese la señal digital y la envíe a un televisor que carezca de este, para poder sintonizar y ver la transmisión en la pantalla. El proceso de transición es variable en cada país y en algunos está siendo implementado en etapas. En el caso de Argentina, en el Decreto 1148/2009 art. $4^{\circ}$ se establece que el plazo para la finalización del proceso de transición de TV analógica al Sistema Argentino de Televisión Digital Terrestre (SATV D-T) se extiende hasta el año 2019.
} 
planificación del sistema público de medios. Así, entonces, la TDA se desvincula de la órbita del ex Ministerio de Planificación Federal, Inversión Pública y Servicios.

Entre las principales medidas que marcarían el rumbo de la política de comunicación de esa nueva gestión se destaca que, a menos de un mes de la asunción, se modificó vía el decreto de necesidad y urgencia $N^{\circ} 267 / 16$ la Ley de Servicios de Comunicación Audiovisual (LSCA) $N^{\circ}$ 26.522. Este decreto tiene varias implicancias pero la más relevante es que favorece la concentración de medios que regulaba la ley votada en el congreso en 2009. Por ejemplo, con la vigencia de esa norma “(...) Ya no hay límites de concentración, no hay obligación de emitir una señal propia, no hay obligación de pasar las señales locales de TV, ni de respetar el orden de la grilla de señales" (Loreti, De Charras y Lozano, 2019: 13). Prorroga los plazos de las licencias de servicios de comunicación audiovisual de 10 a 15 años; amplía el límite de 10 a 15 licencias de radiodifusión (TV abierta o radio) en el territorio nacional y en el orden local, establece que un licenciatario puede tener un máximo de 4 licencias, en lugar de 3, entre otras reformas.

En ese escenario la TDA sufrió el mismo destino: estancamiento y desmantelamiento. A mediados de 2016, la distribución de decodificadores digitales (Set Top Box) se fue demorando hasta interrumpir la entrega a grupos en "riesgo de exclusión digital", además de que se suspendió la venta en comercios para quienes sí podían adquirirlos (Krakowiak, 2018). Por otro lado, cambió la gestión del plan ya que las escasas entregas ya no se realizaron por las delegaciones de ANSES o mediante el Correo Argentino a domicilio, sino que se concentraron en la sede de Tecnópolis o en los exhibidores de ARSAT en diferentes puntos del país. La producción de contenidos se desplazó de las plataformas BACUA $^{4}$ y $\mathrm{CDA}^{5}$, y transfirió los canales Encuentro, PAKA PAKA y DeporTV ${ }^{6}$ a Contenidos Públicos Sociedad del Estado.

En relación con la gestión de la TDA, entre otras medidas, el Consejo Asesor del SATVD$\mathrm{T}$ (que también fue modificado por el decreto $\mathrm{N}^{\circ} 257 / 17$ ) -dependiente del ex Ministerio de Planificación Federal- se convirtió en un Foro Consultivo integrado por actores de la industria de la televisión y por organizaciones sociales invitadas por el gobierno cambiemita.

\footnotetext{
${ }^{4}$ BACUA: Banco Audiovisual de Contenidos Universales Argentinos.

${ }^{5}$ CDA: Contenidos Digitales Abiertos.

${ }^{6}$ Hasta 2015, estos canales estaban nucleados en Educ.Ar, Sociedad del Estado, perteneciente al ex Ministerio de Educación (renombrado actualmente como "Ministerio de Educación y Deportes").
} 
Si bien el por entonces titular del Sistema Federal de Medios y Contenidos Públicos, Hernán Lombardi, anunció un importante incremento en el alcance de la cobertura nacional de la TDA, sumando nuevas antenas (del $82 \%$ a un $90 \%$ en menos de un año), según Maglieri (2018: 15): "Lo cierto es que la inversión en el desarrollo de infraestructura no fue la anunciada".

Hasta aquí hemos dejado planteados, en sentido amplio, las discontinuidades que se evidenciaron a partir del desmantelamiento, con decisiones pro-mercado y las escasísimas continuidades (casi inexistentes) de las políticas públicas de comunicación durante el macrismo.

Retomamos ahora nuestra propuesta para estudiar las políticas públicas de inclusión digital, considerando los usos y los vínculos que las personas establecen con las tecnologías digitales. El interés profesional de indagar sobre estas problemáticas se vincula con mi participación en el equipo de trabajo del Programa de Usos de Medios Interactivos (UMI) del Instituto del Desarrollo Humano de la Universidad Nacional de General Sarmiento (UNGS) (Provincia de Buenos Aires), dirigido por la Dra. Roxana Cabello, y dedicado a investigar usos de las tecnologías digitales interactivas desde el año 2000. En dicho espacio, no sólo he participado de iniciativas y publicaciones académicas sino que he colaborado con la implementación de proyectos de intervención en el territorio de referencia de la universidad. Esta experiencia con la generosa dirección de la Dra. Cabello han generado las condiciones indispensables para afrontar el proceso de elaboración de este trabajo que recoge las discusiones y avances en esta materia, en el seno del equipo de investigación.

La preocupación por entender los procesos de inclusión digital, a través del análisis de las formulaciones y modalidades de implementación de la política pública, y teniendo en cuenta los usos de la televisión digital por parte de la población en estudio nos permitió formular las siguientes preguntas que guían esta investigación:

¿Cuáles son las principales definiciones y expectativas en relación con las tecnologías digitales interactivas, la TDA, sus usos y apropiaciones presentes en los documentos de la Televisión Digital Abierta (TDA)? ¿Y cuáles son aquellas definiciones y expectativas en relación con el propósito de la inclusión digital presentes en esos documentos de la TDA?

¿Cuál es la situación de penetración de la TDA en los hogares del partido de José C. Paz (disponibilidad y acceso de aparatos receptores de TDT) durante 2014 y 2015 ? 
¿Cuáles son los usos de la televisión digital que realizan las personas que residen en José C. Paz de la provincia de Buenos Aires? (Situaciones de uso; motivaciones; tipos de aplicaciones más usadas, complementación con otros medios; definición de ventajas y desventajas; dificultades percibidas; tiempo de trabajo y tiempo libre; evaluación y expectativas en relación con su vida cotidiana.)

¿Es posible identificar diferentes tipos de usos de la televisión digital entre la población estudiada? ¿Cuáles son los más frecuentes? ¿Qué características y finalidades detentan? ¿Cómo se diferencian de los usos de la televisión analógica?

¿Cuáles son los condicionantes socioeconómicos demográficos y las prácticas vinculadas de esos usos entre la población en estudio?

Entre la población en estudio: ¿Existen usos vinculados con otros dispositivos (computadora, telefonía móvil, etc.)? ¿Cuáles son los efectos de desplazamiento en las prácticas de consumo de medios y tecnologías de información y comunicación? Estos desplazamientos: ¿Modifican la centralidad de la televisión en la vida cotidiana de los sujetos en estudio?

¿Cuáles son los sentidos atribuidos a la noción de inclusión digital y sus vinculaciones con los usos de la TDA presentes en los discursos de los usuarios de la televisión digital en la localidad de José C. Paz de la provincia de Buenos Aires?

Considerando estas inquietudes y que los procesos de inclusión digital son procesos complejos que se desarrollan en varias dimensiones complementarias: acceso, uso, autoafirmación y participación, esta tesis se organiza en relación con el siguiente supuesto inicial, que funciona como hipótesis de trabajo: La política pública Televisión Digital Abierta (TDA) (su estructura normativa y técnica, junto a las prácticas vinculadas con sus usos), que privilegia el acceso físico a las tecnologías para sectores sociales "en riesgo de exclusión digital", resulta insuficiente para promover procesos de inclusión digital entre sus destinatarios.

Al respecto, nos proponemos los siguientes objetivos de investigación:

\section{Objetivo General:}

- Analizar la relación que se constituye entre los usos de la Televisión Digital Abierta (TDA) y los procesos de inclusión digital de acuerdo con las expectativas expresadas en la política pública, por un lado; y los discursos y prácticas de los usuarios de la población del partido de José C. Paz de la provincia de Buenos Aires durante 2014 y 2015, por el otro. 


\section{Objetivos Específicos:}

- Identificar las principales definiciones y expectativas respecto de las tecnologías digitales interactivas, la TDA, sus usos y apropiaciones así como sobre el propósito de inclusión digital presentes en documentos de la Televisión Digital Abierta (TDA).

- Caracterizar los tipos de usos de la televisión digital que realiza la población de José C. Paz de la provincia de Buenos Aires.

- Indagar las condiciones y prácticas vinculadas con los usos de la televisión digital entre la población en estudio.

- Identificar usos complementarios de otros dispositivos y posibles efectos de desplazamiento en las prácticas de consumo de medios y tecnologías de información y comunicación.

- Analizar los sentidos atribuidos a la noción de inclusión digital, así como sus vinculaciones con los usos de la Televisión Digital Abierta (TDA), tal como se manifiestan en los discursos de los usuarios.

Para abordar nuestro problema de investigación, en primer lugar, comenzamos a ajustar el diseño de la investigación cualitativa desde de la construcción del marco teórico, de una primera sistematización de los antecedentes sobre los temas y problemas objeto de la tesis, sumado a las exploraciones de las características del trabajo de campo.

Dichas exploraciones sobre nuestro universo de estudio contribuyeron con la caracterización del contexto social, económico y cultural donde se sitúa nuestro objeto de estudio. El punto de partida de tal caracterización fue guiado por la producción y difusión de información sobre las condiciones socioeconómicas, políticas, urbanas y ambientales ofrecidas por el Observatorio del Conurbano Bonaerense de la Universidad Nacional de General Sarmiento y distintas caracterizaciones complementarias, que desarrollan otras investigaciones que abordan la Región Metropolitana de Buenos Aires como objeto de estudio y en relación con sus rasgos de heterogeneidad.

La decisión de estudiar los vínculos entre los usos de la TDA y los procesos de inclusión digital, a través de los discursos y prácticas de los usuarios de la población de José C. Paz, en el marco de la TDA y, en particular, el Plan "Mi TV Digital", requiere de un abordaje teórico-metodológico de tipo cualitativo desde la construcción de un estudio de caso. En ese sentido, nos permite comprender de qué modo los usos y las prácticas de los usuarios de televisión digital se asocian con los procesos de inclusión digital. Debido a la 
complejidad de nuestro objeto de estudio, hemos construido un diseño metodológico flexible que admite el diálogo entre la contextualización del problema, los presupuestos teóricos y las dimensiones de análisis identificadas. Con la lectura problematizadora de nuestros presupuestos teóricos construimos las siguientes categorías de análisis que ordenan nuestra investigación: tecnologías digitales interactivas, televisión digital, usos y procesos de inclusión digital.

Para avanzar en la propuesta teórico-metodológica, decidimos analizar un conjunto de documentos con el fin de explorar las definiciones y expectativas sobre las tecnologías digitales, la televisión digital, sus usos y la inclusión digital en la política pública, junto al plexo normativo que la incluye. Asimismo, realizamos una exploración a través de la implementación de técnicas cualitativas -entrevistas abiertas- que recogen la perspectiva de los usuarios de la televisión digital en el contexto estudiado. El diseño del instrumento de recolección de datos y la preparación del trabajo de campo fueron realizados durante la primera parte del año 2014. Entre finales de 2014 e inicio de 2015 implementamos 15 entrevistas abiertas entre la población estudiada (diferentes sexos, grupos de edad y localidades de residencia, usuarios de TDA en la zona de referencia) que admitieron la saturación de las categorías construidas. Esta estrategia metodológica prevé la construcción de un corpus de información diverso compuesto por entrevistas abiertas, los documentos oficiales que conforman la política pública, notas periodísticas y producción audiovisual acerca del lanzamiento de la TDA.

Nuestro encuadre conceptual dialoga con los enfoques que ofrecen la Economía Política de la Comunicación y la Cultura y los Estudios Culturales sobre la compleja relación entre las tecnologías digitales, la economía, la política y la cultura. Creemos que resulta enriquecedor pensar la trama social y cultural en la que se inscriben los procesos de inclusión digital en el contexto de las industrias infocomunicacionales y según las definiciones que establecen las políticas públicas de comunicación en la materia.

Entendemos la investigación como proceso de producción de conocimientos que se desarrolla con diferentes niveles de complejidad y que está en relación con los problemas al interior de los campos disciplinares. A la vez que polemiza con los procesos formales del diseño (recorte del tema, planteo del problema y definición de los objetivos de investigación, elaboración del estado de la cuestión y desarticulación del mismo para rearticular los conceptos en el marco teórico) y las condiciones sociales que lo hacen posible y le fijan límites (Escolar, 2000: 24). En estos términos, el método de investigación y el método de exposición son parte del mismo movimiento del proceso 
investigativo. En sentido analítico, el primero propende a estar en diálogo con los materiales investigados y sus condiciones de existencia (recuperación de las articulaciones entre los niveles de lo real sobre un objeto de estudio particular); y mediante el segundo, se construye el discurso de exposición que debe dar cuenta de la/s toma/s de decisiones respecto de lo real que se procura estudiar. Ese real que se manifiesta independientemente del proceso de investigación: los usos y prácticas de las tecnologías digitales de los beneficiarios de las definiciones de las políticas públicas de inclusión digital.

La construcción del objeto de estudio necesita de las preguntas y los modos de analizar lo real en un movimiento entre la teoría, el método y la técnica. Para situarnos en la delimitación y construcción teórica del objeto de conocimiento hemos realizado un trabajo de revisión bibliográfica sobre la problemática, el objeto propiamente dicho, la deconstrucción/construcción teórica y el abordaje teórico-metodológico.

En principio, elaboramos una presentación de la problemática que aborda esta tesis que desarrollamos en el capítulo I: Políticas públicas y tecnologías digitales: las bondades de la inclusión y los peligros de la exclusión. En el mismo, introducimos las relaciones que nos interesan abordar en este trabajo y que plantean los elementos presentes en el recorrido teórico-metodológico que orienta esta tesis.

En el capítulo II Televisión Digital Abierta: política de Estado para la transición

digital nos proponemos contextualizar y caracterizar la transición de la televisión analógica a la digital en nuestro país, centrándonos en el rol del Estado a partir de la implementación de la política pública TDA.

Dado que nos interesa abordar la relación que las personas establecen con las tecnologías, en particular con la televisión digital, hemos realizado una revisión bibliográfica para construir el estado de la cuestión sobre los procesos de digitalización de las industrias culturales y sus consecuencias en los usos y prácticas.

Por una parte, revisamos los aportes del campo de estudios críticos de la comunicación sobre los procesos de digitalización de la comunicación audiovisual que nos permitieron hacer foco en nuestro objeto de estudio. Entre ellos, encontramos investigaciones que caracterizan los escenarios de transición del modelo analógico al modelo digital de las industrias infocomunicacionales que proponen superar los análisis instrumentales vinculados a las lógicas del mercado. Por otro lado, acuerdan que dicha transición analógica-digital debe articularse en políticas públicas que incorporen a la sociedad en tanto audiencia activa para el desarrollo y apropiación de las tecnologías digitales 
interactivas. En la misma línea analítica, incluimos los trabajos académicos que se enmarcan en el campo de conocimiento de la Economía Política de la Comunicación y que dan cuenta del rol del Estado, el mercado y la sociedad como actores clave para la digitalización de la televisión en Europa, América del Norte y América Latina. Finalmente, relevamos estudios de caso en nuestro país que permiten entender las características de la implementación de la política pública de televisión digital en Argentina y que abren preguntas sobre la manera en que se integra la perspectiva de los usuarios a través de sus usos y prácticas.

Por otra parte, identificamos bibliografía especializada sobre la relación que las personas establecen con las tecnologías digitales interactivas, y que se enfocan en el modo en que los usos de la televisión digital ofician de herramienta para promover procesos de inclusión digital entre la población. Varias de las investigaciones equiparan el acceso a la televisión digital (posesión del dispositivo) con los usos, sin embargo, otras sostienen que resulta necesario abrir líneas de indagación que profundicen estudios sobre la inclusión digital como principal eje de las políticas púbicas de integración y usos de tecnologías digitales interactivas.

Esta revisión bibliográfica se puede consultar en el capítulo III de la tesis: Los estudios sobre la televisión digital, sus usos y las propuestas de inclusión digital en el que presentamos los antecedentes sobre el tema que adjuntamos más adelante.

Con el propósito de desarticular los temas y problemas abordados en nuestra tesis, hemos realizado una rearticulación de los principales conceptos que ordenan nuestra reflexión teórica. En este sentido, construimos nuestro objeto de estudio situando los debates entre posiciones que analizan las estructuras y los contenidos mediáticos, así como las formas en que los sujetos se vinculan con los mensajes, los usos, las apropiaciones y las prácticas: la Economía Política de la Comunicación y aquellas constituidas en la tradición de los Estudios Culturales. Estas perspectivas abordan la relación entre los medios de comunicación y las tecnologías con los sujetos y se inscriben en el campo de los estudios críticos sobre consumo y recepción pero, fundamentalmente, nos permiten situar el problema de la tecnología en su dimensión cultural. Este desarrollo se presenta en el capítulo VI: Tecnologías, usos, inclusión digital: problematizando los conceptos, que ofrece el encuadre teórico para abordar nuestro problema de investigación.

En el capítulo $\mathbf{V}$ de la tesis explicitamos la Estrategia metodológica de la investigación de tipo cualitativa, mediante un estudio de caso, con el objetivo de conocer las relaciones de las personas con las tecnologías que se manifiestan en un contexto singular, para 
explorar cómo las integran a sus prácticas sociales, culturales y políticas en términos de procesos de inclusión digital. En ese marco, se analizaron los documentos de la política pública y se implementaron entrevistas abiertas a usuarios de la TDA en la localidad de José C. Paz.

El análisis de la política pública de inclusión digital: TDA, atendiendo el enfoque de la Economía Política de la Comunicación y la Cultura, se elaboró a partir de un corpus analítico compuesto por la normativa y los documentos de la presentación de los planes y programas incluidos en esta. Dicho análisis se vincula permanentemente con el abordaje de las entrevistas abiertas en perspectiva con la contextualización de nuestro universo de estudio. A este desarrollo lo presentamos en el capítulo VI: Los textos de la televisión digital en Argentina.

El capítulo VII: Usos y expectativas sobre la TDA en el Partido de José C. Paz para la inclusión digital recupera los aportes de los Estudios de la Cultura y la Comunicación para indagar las relaciones entre los usos, las prácticas asociadas a la TDA y los procesos de inclusión digital, a través de los discursos que los usuarios establecen con la televisión digital en una zona del periurbano bonaerense.

Finalmente, en el último capítulo presentamos las conclusiones del proceso de investigación, haciendo foco en la preocupación por entender el trabajo analítico de las entrevistas abiertas junto a la recuperación de las consideraciones sobre las características del discurso oficial de la TDA. El análisis de los datos obtenidos oficia de punto de partida para delinear las reflexiones emergentes, producto del proceso de investigación y abrir posibles líneas de indagación sobre las características y definiciones de las políticas públicas de inclusión digital y sus derivas en tiempos de transición digital. 


\title{
Capítulo I
}

\section{Políticas públicas y tecnologías digitales: las bondades de la inclusión y los peligros de la exclusión}

\author{
La brecha digital no es otra cosa \\ que el reflejo de la brecha social \\ en el mundo digital. (Pimienta, 2007:1)
}

Desde mediados del siglo XX, las promesas sobre el potencial de las tecnologías digitales sobre la vida de las personas en nuestras sociedades comenzaron a ser proclamadas desde diversos ámbitos: los mercados, los gobiernos y la academia depositaban su confianza en la informática y las telecomunicaciones como motores del desarrollo económico, social y cultural. En palabras de De Moragas (2011: 233) la información se transforma en un recurso que adquiere un valor económico y estratégico en el sistema capitalista contemporáneo.

Numerosos discursos se construyeron en torno a la denominada "Sociedad de la Información", en cuyo marco las tecnologías digitales se prefiguraban como instrumentos de difusión de la información y vendrían a generar modificaciones que se plasmarían en un tipo diferente de estructura social, política, económica y cultural. A partir de esta caracterización se manifiestan al menos dos grandes posiciones que fueron instalándose en los círculos académicos: una optimista (oportunidad de desarrollo económico, social, cultural y político a nivel global) y otra pesimista (refuerza el predominio del poder económico en tanto deslocaliza el capital).

Revisando la genealogía del concepto de la "Sociedad de la Información"7 reparamos en que es desde la década del setenta que varios países industrializados “(...) se apropian de la noción (...) y formulan una estrategia para acceder a ella” (Mattelart, 2002: 105). En 1972, el economista japonés Yoneji Masuda presenta ante su gobierno el informe conocido como JACUDI (Japan Computer Usage Development Institute) en el que

\footnotetext{
${ }^{7}$ Existen ingentes cantidades de investigadores académicos que se ocupan de registrar y analizar el surgimiento de la noción de la sociedad de la información, así como sus consecuencias en las sociedades occidentales. Entre las más conocidas y referidas en esta tesis se encuentran: De Moragas (2013), Becerra (2003), Mattelart (2002), Castells (1998, 2000, 2001, 2004), Garnham (2004), Webster (2014), entre otras.
} 
establecen los aspectos centrales de una sociedad futura. En esta sociedad se crearía un banco de datos y centros de documentación científica y técnica de propiedad estatal o privada constituyendo un "reservorio de pensamiento" que permitiría el acceso a la información y la participación de los ciudadanos.

En el otro lado del mundo, los economistas Fritz Machlup (1962) y Marc Porat (1977) anuncian que Estados Unidos había entrado en la era de la información. El diagnóstico que presentaron daba cuenta del paso de una economía de productos a una economía de información, identificando el porcentaje del PBI del país que provenía de la industria de la información y de servicios ${ }^{8}$.

En Europa, Francia presenta el informe elaborado por Simon Nora y Alain Minc (1978) que “(...) advertía acerca del carácter central que el complejo de la microinformática adquiría en esos años en los países avanzados" (Becerra, 2003: 8). Este informe, según refiere Mattelart (2002), pone el acento en que la informatización de la sociedad debe ser guiada por el servicio público.

En esta cartografía que ubica los comienzos de la Sociedad de la Información a mitad del siglo XX se distingue la preeminencia de los análisis económicos para definir un tipo de sociedad centrada en la información y el conocimiento como valor de cambio. En general, fueron los economistas quienes presentaron estudios y documentación que anunciaban la mutación del modo de producción del capital y las tecnologías como factor necesario para el desarrollo del sistema capitalista contemporáneo. De tal modo que en 1975 la Conferencia sobre Informática y Telecomunicaciones de la Organización para la Cooperación y el Desarrollo Económico (OCDE) les comunicaba a los gobiernos sobre las derivaciones del desarrollo de la industria de la electrónica que pronosticaba una economía asentada en la información que cambiaría la organización del trabajo y de la producción industrial hacia el sector de los datos y los servicios.

Estos estudios y diagnósticos permearon las decisiones económicas de los países desarrollados de forma tal que “(...) a finales de los años `80, los gobiernos empiecen a

\footnotetext{
${ }^{8}$ Según De Moragas Spá (2011: 237), Marc Port identifica tres tipos de trabajadores informacionales: "productores y vendedores de conocimiento (científicos, inventores, profesores, vendedores de libros, periodistas y creadores), recopiladores y diseminadores de información (gerentes, secretarias, abogados, mecanógrafos) y operadores de máquinas y tecnologías que posibilitan las anteriores actividades (informáticos, operarios de telefonía e instaladores de televisiones, etc.)".
} 
crear sus propios "ministerios" para la gestión de la nueva sociedad de la información" (De Moragas, 2011: 234).

\subsection{Las políticas y las tecnologías digitales para la Sociedad de la Información}

Entrada la década del noventa se produjo una importante cantidad de documentos encargados por organismos estatales de Estados Unidos y Europa que se centraron en examinar y proponer estrategias de acción en virtud de las modificaciones que la Sociedad de la Información produciría no sólo en las economías sino en el ámbito social, político y cultural de los respectivos países.

Dichos informes se sostenían en tres ideas fuerza: liberalización, desregulación y competencia global (Becerra, 2003; Mattelart, 2002). Dichas ideas, que se fueron construyendo a partir de la crisis del capitalismo de los años `70, trazan el surgimiento de la etapa denominada "neoliberalismo" caracterizada, en términos económicos, por la expansión internacional de los flujos de capitales y por el desarrollo de un proyecto democrático que privatiza el poder político. Perry Anderson (1999) ubica los inicios de las transformaciones económicas en la Inglaterra de Margaret Thatcher en el '79 y en Estados Unidos con Ronald Reagan un año después, así como también a comienzos de los '90 su extensión hacia Oriente y América Latina. Asimismo, se va dando la subordinación de la política a la economía a través de la disminución de la soberanía de los Estados con la consigna del achicamiento de las cuentas públicas y el gasto social, privatización de las empresas públicas, desregulación de los mercados internos y apertura al capital internacional. Estos movimientos del capital internacional y sus derivas en la vida social, cultural y política de los países se ven facilitados por el proceso que Samir Amin (2001) llama "mundialización" cuyo carácter requiere la articulación de cinco monopolios: “(...) I ) el monopolio de las nuevas tecnologías; II) el del control de los flujos financieros a escala mundial; III) el control del acceso a los recursos naturales del planeta; IV) el control de los medios de comunicación y V) el monopolio de las armas de destrucción masiva" (Ibidem, 25). En este contexto, las decisiones de los Estados quedan

\footnotetext{
${ }^{9}$ Los orígenes y caracterización de la era denominada neoliberal han sido registrados y discutidos desde diversas posturas y autores. Para profundizar en ellos, véanse: Borón (1999), Anderson (1996, 1999), Coraggio (1999), Ezcurra (1998), Svampa (2005), entre otros.
} 
subordinadas a los mandatos de estos monopolios y el autor señala la importancia de aquellos cuya naturaleza no es eminentemente económica como el de las tecnologías y el de los medios de comunicación.

Según Mattelart (2002 citado en Becerra, 2003), promediando la década del ' 80 comienza el acercamiento de dos imaginarios: la "era de la información" y la "era global", que confluyen verbigracia al desarrollo de las tecnologías que habilitan la conformación de un mercado global interconectado.

En los países industrializados, el desarrollo de las tecnologías de información y comunicación (TIC) se ubica en el centro de la escena y producen grandes expectativas sobre su potencial para mejorar las condiciones materiales y simbólicas de las personas. "Las TIC, afirmaba un documento de la Comisión Europea publicado en 1993, son el núcleo del modelo de desarrollo del siglo XXI” (Levis, 2017: 282).

En un principio, las “autopistas de la información", promocionadas por el gobierno de Estados Unidos $^{10}$, asociadas con la expansión de internet ${ }^{11}$ constituyen uno de los principales hitos de la Sociedad de la Información. Sin embargo, será internet la que se extenderá internacionalmente a mediados de los `90 y según señala Levis (2017), la noción de "autopistas de la información” se irá desvaneciendo de los discursos públicos pero seguirá manteniendo el modelo de negocio comercial.

Retomando el concepto "Sociedad de la Información", como advertimos en párrafos anteriores, hallamos diferentes usos extendidos en el orden político, económico, social tanto como variados abordajes críticos en el ámbito universitario.

La descripción de las características de la Sociedad de la Información, la identificación de sus hitos así como la revisión de las principales perspectivas analíticas de la investigación académica tuvo una prolífera producción entre fines del siglo XX y la

10 En la década del '90, el vicepresidente de Bill Clinton (1993-2001), Al Gore, fue el encargado de promocionar la iniciativa de "Superautopistas de la Información" a través de un conjunto de medidas que estimulaban el sector de las tecnologías, las telecomunicaciones y los recursos de información. El tendido de red de fibra óptica por todo el país fue uno de los puntos sobresalientes anunciados por dicha administración. El gobierno norteamericano contaba con la participación de grandes empresas en la iniciativa que se orientaba a posicionarse como una gran oportunidad de negocios de expansión y competencia en mercados internacionales.

${ }^{11} \mathrm{La}$ internet se desarrolla en torno a las universidades y movimientos contraculturales en Estados Unidos. Si bien sus orígenes se remontan a los años `60 entre investigaciones del Departamento de Defensa (DOD) y de universidades que se materializaron en ARPANET (red de computadoras encargada por el DOD para comunicar institutos académicos y estatales), aquí nos interesa señalar que en 1991 se inaugura la Web (WWW) como un servicio público disponible que permite la interacción y comunicación de personas e instituciones en diferentes tiempos y espacios además de la posibilidad de disponer y almacenar un gran volumen de información. Hasta el 2001, las empresas denominadas puntocom tuvieron un crecimiento exponencial dada la novedad del sector y sus vínculos con la "nueva economía global" que hemos reseñado anteriormente. 
primera década del siglo XXI. Debido a la abundancia y profundidad de dicho material sumado a que en esta tesis tratamos el problema de la inclusión digital como uno de los objetivos para alcanzar la Sociedad de la Información, presentaremos a continuación las grandes líneas conceptuales que abordan su análisis.

Becerra (2003) ordena unas cinco líneas de reflexión advirtiendo la heterogeneidad de los métodos junto a sus resultados como las fronteras imprecisas entre cada una de ellas.

La primera corriente que presenta Becerra es la de los postindustrialistas representados por Daniel Bell (1964, 1976, 1977, 1981), Alain Touraine (1971, 1993), Zbigniew Brzezinski (1979), Marc Porat, Alvin Toffler (1967, 1980) y Fritz Machlup (1984) que, como señalamos anteriormente, ubicaron el fin del capitalismo industrial a la luz de la centralidad de la información. Ya en esta perspectiva encuentra gérmenes de la segunda línea que se destaca el rol de los gobiernos como actores centrales en generar las condiciones necesarias para la Sociedad de la Información. La tercera posición es la que el autor denomina "Los gurús": autores con una fuerte orientación tecnofílica que reflexionan "(...) a partir de los cambios tecnológicos y su efecto sobre una masa presuntamente neutra e indiferenciada, que sería la sociedad" (Idem, 9), tales como N. Negroponte o Bill Gates. Por otra parte, releva una cuarta corriente que hace foco en el análisis de las políticas de comunicación y quienes las ejecutan, algunos de sus autores son: Régis Debray (1983, 1995, 2001), Mauro Wolf (1991, 1994), Dominique Wolton (1992, 1997, 2000), Antonio Pasquali (1978, 1990), Luis Ramiro Beltrán (1980), Valerio Fuenzalida (1986, 2002), Héctor Schmucler (1981), Mattelart y Schmucler (1983), Aníbal Ford (1999), Mario Kaplún (1987, 1998) Jesús Martín Barbero (1987 y 1999) y Néstor García Canclini (1989, 1990, 1995, 1998, 1999), entre otros, según señala Becerra. Estos académicos produjeron investigaciones orientadas al estudio de las políticas públicas y las agendas gubernamentales que se construyen. Finalmente, la investigación crítica, desde la perspectiva de la economía política de la comunicación, subraya la centralidad de la economía en los procesos culturales, comunicacionales e informacionales. Entre los más destacados autores se encuentran: Herbert Schiller (1971, 1974, 1976, 1986, 1993 , 1996), Armand Mattelart (1982, 1983, 1993, 1998, 2002), Vincent Mosco (1988, 1994, 1996), Nicholas Garnham (1990, 1996), César Bolaño (2000), Mastrini y Bolaño, (1999), Heriberto Muraro (1987), etc. (Idem, 10).

Por otro lado, el investigador Webster (2006) revisa las acepciones sobre la Sociedad de la Información, que proliferaron en documentos gubernamentales, identificando al menos 
cinco de las que se distancia críticamente debido a que suponen que el aumento de la información en nuestras sociedades conlleva a un nuevo orden social y para demostrarlo cuantifican algún fenómeno en particular para fundamentar los cambios cualitativos en la organización social. La innovación y el desarrollo de la tecnología es uno de los indicadores que muchos autores toman como factores de cambio de la sociedad industrial. Coincide con la caracterización de la corriente postindustrialista que presenta Becerra (2003:7). El cambio ocupacional es otra concepción que se centra en el corrimiento del trabajo manual hacia uno que requiere del conocimiento y de mayor cantidad de información ("analista simbólico"; "trabajadores de la información”) y que, por lo tanto, se necesita el capital humano enriquecido por la educación superior. Por otra parte, el valor económico de la información mide el crecimiento de la economía cuando la mayor parte de las actividades se producen a partir y a través de la información. Otro rasgo que las tecnologías modifican es la categoría de tiempo y espacio, produciendo redes de información que conectan sin limitaciones. Según esta mirada, los flujos de información preanuncian grandes transformaciones en el orden social: "sociedad de redes". El aumento de circulación de información y de los medios de comunicación en la vida cotidiana produce un ambiente informacional diferente. Finalmente, el autor presenta la última categoría: conocimiento teórico que más allá de que la califica como imprecisa admite que resulta más adecuada para reflexionar sobre la Sociedad de la Información. Por lo tanto, sostiene que el cambio es cualitativo: lo importante es el lugar que ocupa el conocimiento teórico y cómo se usa la información para tomar decisiones en diferentes espacios de la vida de las personas, tanto privados como públicos.

Estos análisis y estados de la cuestión sobre la Sociedad de la Información necesariamente se encuentran inmersos en la contemporaneidad de los procesos y de la velocidad de los cambios producidos. Sin embargo, entendemos que desarrollos posteriores recuperan la mirada crítica y abren la discusión para perfilar abordajes y puntos de vista diferentes sobre la misma (González Frígoli y Poiré, 2011).

Más allá de los diversos esfuerzos de delimitar el concepto de Sociedad de la Información Mattelart (2002: 72) asegura que:

"La vaguedad que rodea la noción de información también nimbará la de "sociedad de la información" (...) Se acentuará la tendencia a asimilar la información con un término procedente de la estadística (data/datos) y a no querer ver información sino allí donde hay un dispositivo técnico. De este modo se implantará un concepto meramente instrumental de sociedad de la información". 
Mencionamos en párrafos anteriores que hacia fines del siglo $\mathrm{XX}$, los Estados y los organismos supranacionales se apropiaron del discurso de la Sociedad de la Información y asumieron el desafío de diseñar estrategias para acceder a la misma (Mattelart, 2002: 105). El compromiso de los Estados para avanzar hacia este nuevo tipo de sociedad fue “(...) primero los desarrollados desde los años ochenta, y a partir de la segunda mitad de los noventa también los periféricos (...)" (Becerra, 2003: 9).

Por lo tanto, la instalación de la "Sociedad de la Información" en las agendas gubernamentales de los países de América Latina es subsidiaria de la discusión y puesta en escena de los países industrializados.

Variados trabajos de investigación sobre las estrategias diseñadas e implementadas por los Estados de países latinoamericanos entre fines de los noventa e inicios de los 2000 dan cuenta de los diferentes momentos en que se materializaron en políticas públicas: de la decisión política, la formulación, la implementación y hasta la evaluación de las mismas. Entre las investigaciones han primado aquellas que se ocuparon de describir y analizar la introducción de las tecnologías en los procesos y los diferentes niveles educativos a partir del modelo 1 a 1 (una computadora por alumno) ${ }^{12}$. Dugharte (2015: 13-24) presenta un mapeo que agrupa los estudios que indagan las representaciones y usos de las tecnologías por parte de los destinatarios de los planes 1:1 (Cabello y Levis, 2007; Sancho et al., 2011; Dussel y Quevedo; 2010; Tedesco, 2000; Zidán, 2010; Claro, 2010; Pedró, 2011); otros que evalúan la implementación de las políticas públicas ejecución, financiación y unidades responsables- (Sucker, 2005; Cuban, 2001; Penuel, 2006; Warschauer, 2006; Valiente González, 2011; Dussel, 2014; Ministerio de Educación de la Nación, 2011 y 2012; Sunkel, Trucco y Espejo, 2012 y 2013; Kozma, 2008; Vachieri, 2013); los que refieren a la dimensión pedagógico-didáctica-tecnologías en el aula, cómo enseñan los docentes y cómo aprenden los alumnos-(Jeroski, 2003; Hill y Reeves, 2004; Kerr et al., 2003; Zucker y Mc. Ghee, 2005); aquellos trabajos que reflexionan sobre la incorporación de tecnologías en los sistemas educativos en general (Morales, 2007; Dussel y Quevedo, 2010; Cabello, 2013; Dughera, 2013); y, por último,

\footnotetext{
${ }^{12}$ El modelo 1 a 1 fue impulsado por el Instituto de Tecnología de Massachusetts (MIT) de Estados Unidos a fines del siglo XX. Más precisamente, Nicholas Negroponte, desde el MediaLab, desarrolla el proyecto "One laptop per child" que consistía en distribuir computadoras personales de bajo costo en el sistema educativo formal. El modelo propone que cada estudiante y docente disponga de una computadora en el contexto de enseñanza y aprendizaje. Para ello, los Estados invirtieron en la compra del equipamiento informático, conexión a internet, formación docente, actualizaciones de software, seguridad, etc.
} 
los que analizan la relación entre los planes del modelo 1:1 y las instituciones educativas en particular -factores organizacionales que habilitan u obstaculizan la inserción de tecnologías en las escuelas- (Dussel, 2014; Lugo y Kelly, 2011; 2012; Vega García y Merchán Jaramillo, 2011; Finquelievich, Dughera y Feldman, 2014).

Algunas de las conclusiones que han arrojado los análisis de diferentes aspectos de la Sociedad de la Información en el ámbito educativo se pueden resumir en la propuesta de Area Moreira (2009) que sostiene que las tecnologías digitales por sí solas no logran producir innovaciones sustanciales en la enseñanza y el aprendizaje. Si bien, al principio estimulan el interés y motivan especialmente entre los estudiantes son los docentes quienes sienten que se enfrentan a un poderoso "adversario" de sus prácticas educativas. Del mismo modo en que se mide en el mercado, el acceso a las tecnologías en el área de educación se piensa más en términos de disponibilidad, de conectividad y mucho menos como generadoras de procesos de apropiación que redunden en propuestas de enseñanza y aprendizaje acordes con los contextos tecnoculturales en los que se insertan.

En este marco, la preocupación de los Estados por la introducción de tecnologías digitales en diversos espacios de las sociedades latinoamericanas sigue los lineamientos programáticos de organismos regionales (CEPAL y la Asociación Latinoamericana de Integración (ALADI)) e internacionales (Naciones Unidas -ONU-, Organización de las Naciones Unidas para la Educación, la Ciencia y la Cultura -UNESCO-, Organización para la Cooperación y el Desarrollo Económicos -OCDE-) cuyas primeras propuestas se orientaron a acortar la brecha digital. Luego el interés fue virando hacia el propósito de incluir digitalmente a aquellos sectores de la población en riesgos de exclusión.

Andonegui y Samaniego (2019: 17) aclaran que:

"En 2005 se realiza la I Conferencia Ministerial Regional de América Latina y el Caribe, donde se aprueba el primer plan de acción: eLAC2007, con el compromiso de reducir la brecha digital y promover el acceso y uso de las TIC como herramientas del desarrollo. A estos planes le continuaron el eLAC2010, el eLAC2015 y el eLAC2018, donde se observan además de los objetivos expuestos, un gran número de ejes programáticos" (CEPAL, 2015a).

A partir de estas reuniones sumadas a lo acordado en la Cumbre Mundial de la Sociedad de la Información ${ }^{13}(2003,2005)$ las gestiones centrales de los países de la región

\footnotetext{
${ }^{13}$ La Cumbre Mundial de la Sociedad de la Información (CMSI) fue organizada por la Unión Internacional de Telecomunicaciones (UIT) de ONU y se desarrolló en dos fases: Ginebra en 2003 y Túnez en 2005. El objetivo principal
} 
comenzaron a formular políticas públicas de distribución de equipamiento tecnológico y redes de conectividad entre los habitantes con escasas o nulas posibilidades de disponer de los mismos (Plan Ceibal en Uruguay, Conectar Igualdad en Argentina, Plan de acceso Universal y Alistamiento digital en Ecuador, Proyecto Huascarán en Perú, entre otras). A la vez, los gobiernos desarrollaron planes de capacitación para destinatarios y ejecutores de las políticas públicas (docentes, funcionarios, ciudadanos) y experiencias de gobierno electrónico para comunicarse con la ciudadanía, entre otras iniciativas.

Estas estrategias de acción diseñadas y gestionadas por los gobiernos de los países latinoamericanos se apoyaron en la instalación de infraestructura (equipos, redes, antenas, etc.) -que en algunos casos trató de cubrir la mayor parte de los territorios-, propuestas de formación de agentes públicos y actores sociales así como la promoción de hardware y software libre en sus mercados internos. A la luz de la agenda global de la Sociedad de la Información los programas y planes de incorporación de tecnologías digitales empezaron a introducir la idea de la inclusión digital para todos aquellos ciudadanos sin acceso.

A lo largo de las primeras dos décadas del siglo XXI, tanto en la academia como en las políticas públicas, la inclusión digital se fue integrando a la noción de inclusión social: “(...) se incorpora la exclusión al acceso y manejo de las tecnologías digitales como parte de la exclusión social", Lago Martínez (2019: 10). Esta afirmación condensa numerosas reflexiones y análisis críticos sobre las modalidades en las que se asocia la inclusión digital a la inclusión social y que son solidarias con el presente proceso de investigación.

\subsection{La inclusión digital para no quedar fuera de la Sociedad de la Información}

En la década de los `90 tomó fuerza la incorporación del concepto de exclusión en el discurso de la política y de la academia con explícitas referencias a aquellos procesos ubicados en el ámbito social y económico. Las primeras definiciones se inscriben en los análisis de la crisis del Estado de Bienestar y el carácter excluyente del proceso de modernización que expulsa a millones de personas fuera de los sistemas de protección social.

declarado fue eliminar la brecha digital en el acceso a las tecnologías y preparar planes de acción para reducir esa desigualdad. Luego se acordaron los mecanismos de implementación y seguimiento de la CMSI en el mundo. 
En el ámbito de las ciencias sociales, las categorías exclusión e inclusión se explican a partir de la diferencia que establece los límites que definen un adentro y un afuera, un centro y un margen, un interior y un exterior. Pero siempre en términos relacionales ya que necesariamente para distinguir estas nociones deben estar consideradas ambas: la exclusión tiene su correlato en la inclusión y viceversa. Particularmente, la teoría de los sistemas sociales autopoiéticos de Nicolas Luhmann (1994) afirma que exclusión/inclusión son aspectos de una unidad de la diferencia: “(...) se puede construir el término inclusión: Inclusión designa el lado interno de la forma; el externo, la exclusión. Razonablemente, sólo podemos hablar de la inclusión cuando existe la exclusión” (Luhmann, 1994: 16).

La noción de exclusión se sostiene sobre la idea de cohesión e integración de la sociedad donde deben existir oportunidades y capacidades para todos los integrantes de participar en las esferas materiales y simbólicas (económicas, sociales, culturales). Entre las diferentes definiciones sobre exclusión social que se centran en la dimensión económica asimilada a la noción de pobreza se suman otras que abordan su carácter relacional junto a la dimensión política como expresión de derechos civiles, políticos y sociales. De este modo, la idea de exclusión social tiene un carácter multidimensional en la que se interrelacionan diferentes factores: precariedad laboral, bajos ingresos, debilidad de redes de contención familiar y social, migraciones, no reconocimiento de los derechos humanos básicos, falta de participación, etc. (Subirats, 2004; Balla y Lapeyre, 1997; Cabrera Cabrera, 2005, entre otros).

En este marco el eje exclusión/inclusión en relación con las tecnologías digitales se centra en estudiar el modo en que estos procesos afectan las relaciones sociales, económicas, políticas y culturales.

Por una parte, la denominada exclusión digital refiere al acceso desigual a las tecnologías y a la información que, según muchas investigaciones y posturas teóricas, limitan las posibilidades de los sujetos de integración social, económica, cultural y política. Ejemplos de exclusión digital: la dificultad en el ejercicio de nuevas modalidades de ciudadanía como el voto electrónico, el acceso a información relevante, a nuevas formas de consumo y comunicación, etc.

Por otra parte, la noción de inclusión digital se define frente a la exclusión digital en tanto comprende la integración e incorporación de las tecnologías por parte de todos los miembros para gozar de los beneficios de la sociedad contemporánea, una de cuyas principales características es la digitalización de la cultura. 
En este sentido, podemos señalar dos posiciones en relación con la inclusión digital: aquella que sostiene que el acceso a las tecnologías deriva en una disminución de la brecha digital lo que promoverá el desarrollo de servicios universales en vistas a la democratización de los contenidos; y otra que señala que la idea brecha digital oculta otras brechas: económicas, sociales y culturales por lo que el acceso equitativo a la información y a las tecnologías no aseguraría la igualdad social, política o económica. A la vez, ambas posturas coinciden en señalar la preocupación por la brecha digital y los modos en que cada caso se requiere resolverla.

\subsubsection{De la brecha digital a la inclusión digital: entre apocalípticos e integrados}

En el marco de los estudios críticos sobre la relación entre las tecnologías y la sociedad, una de las nociones que se ponen en cuestión es la referida a la divisoria o brecha digital. Tal como señalamos anteriormente, la preocupación inicial por la brecha digital en la agenda internacional surge, durante el siglo XX, ligada al discurso sobre el desarrollo donde la tecnología se presenta como el motor de cambio social y conlleva la promesa de superación de sociedades y países "en desarrollo".

Desde posiciones críticas, Stillo (2012), Camacho (2006), Serrano y Martínez (2003) y Rodríguez Gallardo (2006), entre otros, realizan revisiones históricas y teóricas de este término para examinar sus limitaciones conceptuales a la hora de analizar procesos de introducción de tecnologías digitales en las sociedades actuales. Si bien aquí no nos proponemos realizar un análisis histórico creemos necesario contextualizar su surgimiento en el ámbito de los organismos internacionales para situar la genealogía del debate sobre la brecha digital.

En principio, estos autores señalan que el término fue utilizado por primera vez en 1978 por la UNESCO cuando “(...) crea un organismo intergubernamental de informática cuyo objetivo fue crear condiciones para que los países pobres lograran un crecimiento informático" (Sotillo, 2010: 44). El reporte explica que la adopción de la informática por los países del Tercer Mundo les permitirá alcanzar los niveles de desarrollo de los países industrializados. En el 2000, el G8 se reúne en Japón y presenta la denominada “Carta de Okinawa sobre la Sociedad Global de la Información" que estableció la agenda de temas de la sociedad de la información, a la vez que forma un equipo de trabajo sobre oportunidades digitales (Digital Opportunity Task Force). Este equipo elabora el informe 
“Oportunidades Digitales para Todos: superar el desafío”, presentado en la Cumbre del G8 realizado en Génova en 2001 que ofrece una serie de líneas de acción basada en la Carta de Okinawa. Estos documentos expresan el compromiso de los países industrializados de realizar esfuerzos, alentando tanto al sector privado como público, a fin de concluir con la brecha de información y brecha digital a escala mundial. La Cumbre de la Sociedad de la Información (CMSI) de 2003 (Ginebra) declara que:

“(...) las TIC deben considerarse un medio, y no un fin en sí mismas. En condiciones favorables, estas tecnologías pueden ser un instrumento eficaz para acrecentar la productividad, generar crecimiento económico, crear empleos y fomentar la ocupabilidad, así como mejorar la calidad de la vida de todos" (CMSIDocumentos, 2005: 10).

Y se toma como objetivo "colmar la brecha digital" a partir de la necesidad de generar compromisos de todos los actores involucrados para la solidaridad digital entre países ricos y pobres. La segunda fase de la CMSI se celebra en Túnez en el año 2005 y plantea metas para el 2015, pero principalmente reconoce que el “(...) problema vinculado al cierre de la brecha digital, que necesitará durante muchos años inversiones adecuadas y duraderas en la infraestructura y los servicios de las TIC, así como en el fomento de capacidades y la transferencia de tecnología" (CMSI-Documentos, 2005: 67). Los principios expresados en Túnez se centran en instar a gobiernos y partes interesadas a promocionar las TIC para el desarrollo; a invertir en infraestructura de la información y la comunicación; a promover el acceso a la información y al conocimiento; a crear condiciones necesarias para la utilización de las TIC; aplicar las TIC al gobierno electrónico; negocios electrónicos, aprendizaje electrónico, cibersalud, ciberempleo, ciberecología, ciberagricultura, ciberciencia; entre otras. Al respecto, el discurso incorpora la idea de uso de las TIC, que no obedece exclusivamente a la infraestructura o conexión, introduciendo la preocupación por el desarrollo de capacidades y habilidades para utilizarlas.

Sobre esta nueva manera de abordar la brecha digital, Stillo (2012: 15) señala que “(...) se empiezan a distinguir en la literatura las primeras discriminaciones y enfoques que enriquecen el concepto (...)" y retoma la clasificación que desarrolla Camacho (2006) para diferenciar tres tipos de brecha digital. En primer lugar, la brecha digital de acceso que es aquella generada por desequilibrios económicos, sociales o geográficos, o sea la posibilidad o dificultad para disponer de computadoras conectadas. Este es un enfoque centrado en la infraestructura. La brecha digital de uso refiere a la capacidad o no de usar las computadoras. Es decir, no basta con disponer de los dispositivos tecnológicos sino 
aprovechar las tecnologías. Esta idea de brecha se asocia a la capacitación para el uso de tecnologías. Por último, la brecha digital de calidad de uso es entendida como acceso básico o elemental de los usuarios de TIC sin la obtención de mejores resultados. Esta visión se concentra en el aprovechamiento de las oportunidades que ofrecen las tecnologías.

De este modo, estas categorías han orientado las políticas de un modelo de desarrollo tecnológico que continúa ponderando la inversión en infraestructura a partir de la provisión de equipamiento y del crecimiento de conectividad.

Frente al discurso de los organismos internacionales y de la puesta en la agenda pública, desde el campo académico diversos autores se proponen estudiar el problema de la brecha digital en diferentes contextos sociales y culturales. Un repaso sobre el origen del término en la literatura especializada permite advertir que existen gran cantidad de trabajos pero carecen de precisiones conceptuales que permitan abarcar la complejidad del tema. Por lo tanto, y siguiendo el planteo de Pérez Zalazar (2004), entendemos que el término no ha sido claramente definido ni conceptualizado.

Pero más allá de las inconsistencias conceptuales, es posible identificar las principales propuestas teóricas que se ocupan de estudiar la brecha digital. Una postura ligada a la idea de que el problema de la brecha digital es producto de la diferencia que existe entre individuos y sociedades que tienen acceso a los recursos tecnológicos (telefonía, computadora, internet) y que pone el acento en el desarrollo de infraestructura para salvar dicha diferencia (Compaine, 2001; Powel, 2001; Lull, 1997, entre otros). Y otra, que pretende complejizar analizando distintos aspectos de la brecha tales como los culturales, educativos y contextuales (Crovi Druetta, 2002; Castellón y Jaramillo, 2002; Pérez Zalazar, 2004; Servon, 2002; entre otros). Entre las distintas clasificaciones se encuentran: brecha entre países (ricos y pobres), brecha generacional (entre jóvenes y adultos), brecha de acceso (material) y brecha de uso (apropiación significativa) (Buckingham, 2008; Levis, 2007, 2009, entre otros).

Según explica Busaniche (2004), la brecha digital es apenas una expresión más de la divisoria entre quienes poseen o no tecnologías digitales pero sustancialmente las diferencias entre aquellos que acceden a satisfacer las necesidades básicas y los que no lo pueden hacer.

"En un planeta con más de 800 millones de personas sin alfabetización básica, hablar de la 'brecha digital' como prioridad parece un despropósito. (...) Ciertamente, el acceso a la infraestructura es fundamental para reducir la brecha digital, pero no es suficiente. Los programas de conectividad no parecen ser 
efectivos si no se los acompaña con políticas educativas, sanitarias y de comunicaciones para que las personas se apropien y hagan un uso socialmente significativo de las nuevas TIC. ¿Qué significa el uso socialmente significativo? Eso puede discutirse según los contextos sociales y culturales, pero una cosa es clara y cierta: sin una política general de inclusión, el cableado y la instalación de TIC no garantiza la reducción de la brecha digital, si es que se toma la decisión política de trabajar para angostar la publicitada brecha" (Busaniche, 2004: 5-6).

La brecha digital como tema y problema en el campo de estudio de las tecnologías pero fundamentalmente en los ámbitos de decisión por parte de los Estados, ha promovido la formulación de políticas públicas de introducción de tecnologías orientadas principalmente a la distribución de dispositivos (computadoras, decodificadores digitales de TV, antenas) y de conexiones (cableados de fibra óptica, internet). Sin embargo, muchos estudios e informes advierten que la provisión de recursos tecnológicos no alcanza para saldar la brecha existente y disminuir la desigualdad entre quienes están incluidos y aquellos excluidos de la llamada "cultura digital" (Cabello, 2001, 2008; Morales, 2011; Dusell y Quevedo, 2011; entre otros).

En este sentido, Dusell (2014: 40) plantea que es necesario “(...) abandonar la idea de que la brecha digital es una línea clara y distinta que separa el acceso y el no acceso, o los usuarios de los no usuarios (Burrell, 2012)", debido a que delimita una frontera lineal que va en una sola dirección. En cambio, considera la noción de inclusión digital “(...) como un proceso complejo y multidimensional que avanza en una topografía muy heterogénea, poblada de instituciones y culturas con su propia densidad (Couldry, 2013)”. (Dusell, 2014: 40). Desde esta perspectiva, se pone en cuestión la homogeneización de la cultura digital y centra su atención en el modo en que las tecnologías vinculan, construyen y deconstruyen las relaciones sociales y culturales en las que se inscriben.

\subsection{Las políticas públicas de comunicación para la inclusión digital}

Como señalamos en la presentación de esta tesis, el problema de la inclusión digital se constituye como uno de los objetivos para alcanzar la Sociedad de la Información que adquiere centralidad en la formulación e implementación de políticas públicas. Nuestro interés se centra en reflexionar sobre el discurso de las políticas públicas que tematiza la inclusión digital -focalizadas en la generación de condiciones de acceso y la producción de infraestructura de tecnologías digitales- en relación con los usos y prácticas que manifiestan los destinatarios de las mismas. 
La asociación de la inclusión digital con la inclusión social tiene un significativo desarrollo en el ámbito de discusión académica y en los últimos años se han ido produciendo trabajos que abordan dicha relación. Los grandes interrogantes que surgen en torno a esta vinculación van desde qué significa la inclusión digital, cuáles son las dimensiones que tienen en común la inclusión digital con la inclusión social hasta de qué modo y por qué la inclusión digital posibilita la inclusión social.

Algunos autores, a partir de la problematización de ambos conceptos, acuerdan con que hablar de inclusión digital no supone ni lineal ni literalmente la inclusión social. Sostienen que la exclusión digital tiene una complejidad diferente a la exclusión social y que las tecnologías digitales por sí solas no tienen la capacidad de resolver las brechas sociales (Travieso y Planella, 2008; Andrade Castro y Campo Redondo, 2007; Cruz García, 2016; entre otros).

En palabras de Lago Martínez (2016), las nociones de inclusión digital e inclusión social son ambiguas y relacionales. La incorporación del acceso y el manejo de las tecnologías se entienden como una pieza que forma parte de la exclusión social y “(...) depende de la orientación política e ideológica de que se trate se priorizarán diferentes estrategias para las políticas públicas" (Ídem, 84). Zermeño Flores (2017) en un extenso estudio sobre las teorías, las propuestas y experiencias de inclusión digital para la inclusión social concluye que no existe una determinación entre la primera y la segunda:

“(...) pues se acepta que las personas que tienen suficientes capitales sociales, económicos, culturales y personales, aun cuando no sean competentes en el uso de las TIC, negociarán mejor su posición en el campo de la vida social — puede ser que pierdan el acceso a ciertos beneficios pero eso no significará su exclusión-, mientras que aquellos que no tienen dichos capitales, aun cuando sí tengan destrezas digitales, estarán en condiciones de vulnerabilidad” (Zermeño Flores, 2017: 261).

Por ende, esta relación no sólo no resulta evidente sino que además requiere de análisis que indaguen los aspectos que una y otra manifiestan en los diferentes contextos en los que se estudian. En esta dirección, la autora británica Helsper (2012) elaboró un modelo teórico para reconocer áreas comunes entre la inclusión digital y la inclusión social (económica, cultural, social y personal) a partir de suponer que la exclusión social y la digital tienen influencias recíprocas.

La dificultad de llegar a acuerdos sobre la definición y el sentido de ambos términos tiene pregnancia en el campo de acción del Estado, en particular en relación con el diseño y formulación de políticas públicas. 
Como hemos señalado anteriormente, los debates de académicos y especialistas tanto de los defensores como detractores de la Sociedad de la Información presentan cierta convergencia en que el problema de la inclusión digital requiere de la potestad de los Estados, es decir, que son estos quienes deben diseñar e implementar estrategias y programas de promoción de tecnologías digitales dirigidas a diferentes sectores de la sociedad.

Sin embargo, la definición de las políticas públicas de inclusión digital no está exenta de tensiones propias de cada uno de los campos de conocimiento que involucra. A la complejidad propia de la formulación de políticas por parte de los Estados se le adicionan las diferentes visiones sobre la inclusión digital y a la excesiva confianza en las tecnologías digitales para remediar la exclusión social. En efecto, Ribeiro Rosa (2013) afirma que se suele comprender la inclusión digital como área de políticas públicas en términos de mayor acceso a las tecnologías y en cierta medida, “(...) como un área en cuyo centro es necesario colocar a los sujetos, a las prácticas y a las habilidades necesarias para su desarrollo" (Ibidem, 33).

Ya hemos señalado que en América Latina la agenda digital comenzó a visibilizarse en la primera década del siglo XXI. Para inicios de 2008 un tercio de los países no tenían documentos preliminares sobre la agenda de la Sociedad de la Información en tanto otro tercio definieron “(...) por primera vez una agenda digital recién durante el año 2007” (CEPAL, 2008: 49). La mayoría de los países latinoamericanos se encontraban diseñando políticas digitales de primera generación, es decir, aquellas que se preocupaban por generar la infraestructura básica de acceso a las tecnologías digitales, en tanto la minoría ya estaban implementando las políticas de segunda generación cuyo objetivo es incorporarlas a los procesos productivos y sociales.

Por otra parte, el plan de acción eLAC $2015^{14}$ presentó una lista de indicadores para monitorear las políticas digitales y definió que las tecnologías digitales son instrumentos de desarrollo económico e inclusión social.

\footnotetext{
${ }^{14}$ Este plan, como estrategia a largo plazo, fue aprobado en la III Conferencia ministerial sobre la Sociedad de la Información en América Latina y el Caribe en 2010 en la ciudad de Lima (República de Perú). Se propuso un mecanismo de seguimiento conformado por la conferencia ministerial de seguimiento, la mesa de coordinación y los puntos focales de los países miembros, además de observadores (sociedad civil, el sector privado y la comunidad técnica de internet de la región). El plan se ordena en catorce grupos de trabajo en las áreas de acceso e infraestructura, gobierno electrónico e interoperabilidad, desechos tecnológicos, TIC y salud, innovación y apropiación de TIC en la MPYME, contenidos digitales, software y servicios de tecnología de la información, teletrabajo, marco normativo de la sociedad de la información, comercio electrónico, gobernanza de internet, género, financiamiento y desarrollo digital para la educación (CEPAL, 2013: 5).
} 
En el Informe sobre Medición de la Sociedad de la Información (2015) ${ }^{15}$, Argentina subió cuatro puestos en la región y seis en el mundo respecto del mismo documento de 2014. Este índice que calcula la presencia de las TIC sirve para comparar el desarrollo de las tecnologías de los países a través de la medición del acceso, utilización y aptitudes. En nuestro país, la Encuesta Nacional sobre Acceso y Uso de Tecnologías de la Información y la Comunicación (ENTIC) 2015 arroja un 61,8\% de los hogares urbanos que accede a internet, un 67\% tiene computadora, el 89,6\% dispone de teléfono móvil y un 97,7 \% posee algún servicio de televisión ${ }^{16}$. Estos números, a la luz de las iniciativas por parte del Estado con la implementación de un conjunto de políticas públicas para garantizar la infraestructura necesaria (dispositivos y conectividad), tales como CONECTAR IGUALDAD, NAC, TDA, etc., que sumado a la dinámica propia de los mercados de las tecnologías dan cuenta de cierto crecimiento de la presencia de las tecnologías digitales en el país aunque con la consecuente reproducción de desigualdades territoriales.

En esta tesis nos interesa conocer las características de las políticas de inclusión digital tanto en su formulación como en las repercusiones (usos y prácticas) entre los sectores de la población a las que se encuentran dirigidas. Para ello, partimos de la convicción de que la definición de políticas públicas comprende tensiones desde la toma de decisiones, la gestión, la implementación hasta la evaluación de las mismas. Consideramos que para comprender los procesos involucrados en la implementación de políticas públicas inclusión digital -tanto desde su formulación como en las expectativas de sus destinatarios- debemos reconocer los discursos, las prácticas y los dispositivos que visibilizan los usos y sentidos atribuidos a las tecnologías digitales en sectores sociales en "riesgo de exclusión".

Ahora bien, entendemos que la discusión sobre las políticas públicas en materia de inclusión digital requiere adelantar sobre nuestra posición en relación con los discursos dominantes sobre las tecnologías digitales.

En este sentido, retomamos el punto de vista de Cimadevilla (2007) sobre las falacias del modelo de la Sociedad de la Información que justifican la incorporación de

\footnotetext{
${ }^{15}$ Este informe, elaborado por la Unión Internacional de Telecomunicaciones (UIT) de ONU, analiza la evolución de esas tecnologías en los últimos cinco años. Los resultados muestran que, entre 2010 y 2015, 167 países mejoraron sus valores en el índice.

${ }^{16} \mathrm{Si}$ bien, este estudio focaliza el período 2014-2015, cabe señalar que según el Informe MAUTIC 2019 (EPH-INDEC) registró que el 80,3\% de los hogares urbanos accede a internet, el 63\% tiene computadora, el 83,5\% dispone de telefonía móvil.
} 
tecnologías digitales con vistas a superar las desigualdades sociales. Discute con las siguientes premisas: 1) la mera existencia de tecnologías supone disponibilidad, 2) que la disponibilidad lleva directamente al acceso, 3) que el uso del dispositivo técnico resuelve una necesidad, 4) que la virtualidad que ofrece las tecnologías digitales permite resolver diversos temas sociales, culturales, políticos y 5) dicha virtualidad equivale a producir procesos de comunicación.

Acordamos en sentido amplio con la postura crítica que desarrolla el autor pero, en particular, queremos detenernos en el desplazamiento analítico que propone desde los dispositivos tecnológicos hacia “(...) las políticas de las instituciones y las políticas de los actores" (Idem, 115). En nuestro caso, se trata de desarticular los discursos y las prácticas de las políticas públicas para indagar las derivas que producen las tecnologías digitales entre sus destinatarios.

\subsubsection{La televisión digital para la inclusión digital}

Esta tesis busca dialogar críticamente con enfoques que sugieren que la inclusión digital se logra con la distribución y acceso a dispositivos tecnológicos. En nuestro caso, se trata de un estudio sobre la introducción de televisión digital en Argentina a través de la implementación de un conjunto de planes y programas de inclusión digital. Durante 2014, la implementación de la televisión digital en Argentina alcanzó su quinto año. En 2009, la gestión de Cristina Fernández anunció la adopción de la norma brasileña-japonesa y la primera transmisión digital con TDT (televisión digital terrestre) se realizó en abril de 2010 a cargo de la emisora pública Canal 7. En este escenario, el proceso de digitalización de la televisión adquiere una fuerte impronta con la gestión de la televisión por parte del Estado argentino como cabeza de serie que se ofrece, principalmente, garantizar la participación e inclusión de grupos excluidos con vistas a la integración, comunicación e igualdad de oportunidades. De este modo, la política pública integrada por la planificación estratégica del Sistema Argentino de TV Digital Terrestre (SATVD-T ), cuyo marco regulatorio es la Ley de Servicios de Comunicación Audiovisual (ley 26.522 ), tiene entre sus objetivos cubrir el territorio nacional con un servicio de calidad de contenidos gratuitos para cuatro millones de hogares que no tienen cable ni satélite, a través de la distribución de decodificadores a beneficiarios de planes sociales, organizaciones sociales y a jubilados. Se trata de una 
propuesta de inclusión material, por un lado, a través de la provisión de decodificadores digitales y por otro, de inclusión simbólica debido a las posibilidades de acceso de estos sectores excluidos no sólo a los contenidos sino también a la producción de los mismos.

En este sentido, se plantea que la TV digital viene a saldar una deuda con los grupos “en riesgo de exclusión digital” para que logren acceder a las tecnologías digitales a fin de eliminar la brecha digital existente.

A nivel global, la preocupación por la brecha digital se ubica en las postrimerías del siglo XX junto a la expansión de las tecnologías digitales. En el marco de los primeros debates e intercambios entre especialistas, gestores de políticas públicas y referentes del sector tecnológico, la brecha digital era definida por el acceso. Según Castellón y Jaramillo (2002), este abordaje fue de cierta utilidad para abrir las aristas de la discusión pero posteriormente no fue suficiente. Las primeras ideas sobre el acceso surge ligada la existencia y disponibilidad sumados al uso de los dispositivos técnicos (telefonía, computadoras, televisión) y aplicaciones tecnológicas.

Solucionar los problemas de acceso de las personas a las tecnologías y acortar las distancias entre poseedores y no poseedores de dispositivos técnicos fueron los núcleos centrales de los discursos de la Sociedad de la Información que pregonaban la necesidad de inversiones públicas y privadas en el desarrollo de infraestructura tal como el tendido de líneas telefónicas, provisión de servicios de telecomunicaciones, dotación de computadoras, y conexión a internet.

Esta retórica formó parte del modelo de desarrollo que caracterizó la última década del siglo pasado y que organismos internacionales como el PNUD (Programa de las Naciones Unidas para el Desarrollo) presentaban en sus informes anuales. "Las nuevas tecnologías de información y comunicaciones están impulsando la mundialización, pero están polarizando al mundo entre los conectados y los aislados” (PNUD, 1999: 5). En este tipo de enunciados se describe y manifiesta el tono de época: la visión en la que la medición de la incorporación de las tecnologías a las distintas esferas de la vida de las personas formaba parte del índice de Desarrollo Humano, a la vez que enfocaba la mirada en las diferencias entre los países según su infraestructura tecnológica como hacia el interior de los mismos.

Ahora bien, la preocupación por la brecha digital coincide con el surgimiento de un discurso que justifica e impulsa el consumo de productos y servicios de las industrias digitales por un lado y que por otro, que se apoya en la entiende que las tecnologías 
digitales promueven prácticas y habilidades para la formación de ciudadanía. De este modo, comienza a delinearse la idea de la inclusión digital como una de las etapas para consolidar la inclusión social de los sectores o grupos excluidos del mercado, así también, en tanto una dimensión de la ciudadanía. Es decir, la inclusión digital como derecho social y político. Estas definiciones, en mayor o menor medida, ha permeado las decisiones por parte de los Estados que bajo las directrices de las discusiones globales sobre las tecnologías digitales se comprometieron a diseñar y ejecutar planes y programas públicos para incluir digitalmente a partir de la dotación de equipos, desarrollo de infraestructura, capacitación de recursos humanos, incentivos al mercado tecnológico y a la producción de contenidos locales. Estas acciones deben ser implementadas por los gobiernos con un propósito superior que es lograr la democratización de las comunicaciones.

En esta dirección, el discurso oficial de la "Televisión Digital Abierta" (TDA) se funda en la convicción de que la distribución de decodificadores digitales entre los grupos sociales "con riesgos de exclusión" permitirá incluirlos digital y culturalmente en un mundo cada vez más conectado y globalizado. Esta tesis se pregunta sobre el modo en que esta inclusión se logrará. En principio, encontramos referencias explícitas a la necesidad de incluir “(...) a todos los habitantes de la Nación a las nuevas tecnologías de la Sociedad de la Información (...)" (Planificación Estratégica para la implementación del SATVD-T (2009-2019: 3), observando los fundamentos establecidos en el art. 3 de la Ley 26.255. Asimismo, plantea garantizar el acceso universal a las TIC para promover la inclusión social y diversidad cultural, la democratización de la información, fortalecer la industria cultural y promoción del empleo, el desarrollo científico-tecnológico y la protección de derechos y libertades de los ciudadanos.

Al momento de detallar los ejes estratégicos, advertimos que se pone el énfasis en el acceso al equipamiento para la recepción de la televisión digital como medio para alcanzar la sociedad de la información sin embargo, nos interesa indagar si aparecen propuestas específicas de "inclusión digital” para los grupos "en riesgo de exclusión digital" de la sociedad. El supuesto central radica en que las transformaciones que se generan a partir de la difusión de las tecnologías digitales son consideradas procesos inevitables en los que esas tecnologías son reconocidas como agentes difusores neutrales con capacidad para transmitir y multiplicar la información pero, fundamentalmente, siendo herramientas para achicar la brecha digital entre quienes poseen dispositivos 
digitales y quienes no los poseen. En este esquema el usuario de televisión digital sería visto como un sujeto hábil que podría realizar acciones distintas a las que viene realizando hasta ahora con la televisión analógica o tradicional.

En este contexto, nos interesa indagar si se producen procesos de inclusión digital y cuáles son sus alcances y características según las definiciones de la iniciativa de la TDA. Para ello consideraremos tanto las formulaciones y rasgos de implementación de dicha política pública como los discursos, las prácticas y los vínculos que los usuarios establecen con la TDA en una zona del periurbano bonaerense donde los indicadores sociales, económicos y culturales muestran que rasgos de vulnerabilidad: el partido de José C. Paz, en la segunda corona del Área Metropolitana de Buenos Aires (AMBA), a fines de 2014 e inicios de 2015. 


\section{Capítulo II}

\section{Televisión Digital Abierta: política de Estado para la transición digital}

Hacia finales del siglo $\mathrm{XX}$, en el campo de las telecomunicaciones, se producen modificaciones sustantivas como consecuencia de la digitalización de las industrias infocomunicacionales. En este contexto, el impulso de la televisión digital, especialmente de la conocida como TDT (televisión digital terrestre), concita una compleja relación entre todos los actores involucrados en su desarrollo: el Estado, el sector audiovisual (la industria electrónica, los operadores de telecomunicaciones, etc.) y las audiencias.

Por lo tanto, la transición de la televisión hertziana o analógica a la digital constituye un problema complejo de reciente desarrollo que plantea dificultades y desafíos al momento de analizar un proceso que está en marcha. Diversos estudios sobre casos-país, inscriptos en la Economía Política de la Comunicación y la Cultura, se ocupan de describir y evaluar las transformaciones políticas, económicas, sociales y culturales de la introducción de la TDT. (Albornoz y García Leiva, 2012). Una de las principales conclusiones de estos trabajos sostienen que en la carrera hacia la digitalización integral de la televisión, la acción de los gobiernos junto a los sectores de radiodifusión, telecomunicaciones y las empresas fabricantes de equipamiento han postergado la participación de los ciudadanos: en última instancia aquellos supuestos beneficiados con la introducción de la TDT.

En Argentina, la introducción de la TDT plantea un cambio en las relaciones del sector audiovisual que "(...) ha tenido históricamente una estructuración marcadamente comercial con prestatarios privados, ausencia de servicio público y una fluctuante intervención del poder político en los contenidos informativos" (Bizberge, Mastrini, y Becerra, 2011: 194). En tanto la expansión de la TDT supone la puesta en escena de los distintos actores involucrados no debemos perder de vista que cada uno detenta intereses propios que le imprimen unas características distintivas al proceso que todavía se encuentra en ciernes. Como plantea Prado (2010) la digitalización de la cultura a nivel planetario no está garantizada y tomará un largo tiempo.

A efectos de esta tesis nos proponemos contextualizar y caracterizar la transición de la televisión analógica a la digital en nuestro país, haciendo foco en el rol del Estado a partir 
de la implementación de la política pública TDA. Para ello recurrimos a la vasta experiencia en estudios de la economía política de la comunicación desarrollados por el Programa de investigación: "Industrias culturales y espacio público: comunicación y política en la Argentina” de la Universidad Nacional de Quilmes, dirigido por Martín Becerra y Guillermo Mastrini ${ }^{17}$.

A continuación caracterizamos las definiciones conceptuales y técnicas acerca de la televisión digital, en particular, de la televisión digital terrestre (TDT) con el objeto de aclarar cierta confusión sobre los términos: televisión digital como sinónimo de contenidos de alta definición (High Definition - HD) o como televisión interactiva y con el objeto de revisar los principales ejes de debate sobre las ventajas y desventajas de su implementación en el contexto internacional. Luego registramos las fases del proceso de digitalización de la televisión en Argentina llevado adelante por el Estado. Por último, nos detenemos en las características y la implementación de la política pública TDA, centrando nuestra atención en el Plan "Mi TV Digital".

\subsection{La TDT: de las estructuras técnicas a las definiciones}

En los inicios de la segunda década del siglo XXI, la transición de la televisión analógica a la digital, en el plano internacional, ha avanzado de modo marcadamente desigual tanto en relación con los principales actores que intervienen en las escalas nacionales así como también en los procesos que se desarrollan entre los denominados países centrales y los periféricos. De esta manera lo demuestran los estudios reunidos en una publicación editada por Albornoz y García Leiva (2012) que ofrece un panorama sobre las estructuras televisivas y resume las tendencias que emergen de esos análisis.

Según estos autores, en la actualidad existen cuatro modalidades de emisión-recepción de señales televisivas:

- Terrestre o hertziana: su difusión emplea frecuencias radioeléctricas y alcanza aproximadamente un cien por ciento de penetración en la mayoría de los países del mundo.

\footnotetext{
${ }^{17}$ La perspectiva conceptual definida por dicho Programa de investigación refiere a las transformaciones propias del sector industrializado de la producción cultural e informacional en el país que dan cuenta de las constituciones mutuas entre los procesos industrializados de la producción cultural e informacional, por un lado, y la estructura económica y el tipo de formación social, por el otro (www.unq.edu.ar/proyectosprogramas).
} 
- Cable: la señal es transportada a través de redes de fibra óptica y/o cable coaxial. Tiene un alto grado de penetración a nivel mundial ocupando el segundo lugar luego de la señal tradicional.

- Satélite: transmisión televisiva que consiste en retransmitir desde un satélite de comunicaciones una señal de televisión emitida desde un punto del planeta a fin de que pueda llegar a otras zonas geográficas. Existen tres tipos de televisión por satélite: recepción directa por el telespectador (DTH), recepción para las cabeceras de televisión por cable (para su posterior redistribución) y servicios entre clientes de televisión local.

- Internet: señal televisiva que se transmite a través de conexiones de banda ancha sobre el protocolo IP.

Otras formas de televisión son aquellas que se transmiten por redes de telefonía móvil (visionado en dispositivos móviles) que complementan las cuatro modalidades descriptas anteriormente.

Finalmente, la digitalización y compresión de la señal televisiva da como resultado la televisión digital que, a diferencia de la televisión analógica o hertziana, codifica la señal en forma binaria, produciendo la gestión más eficiente del servicio ya que expande la posibilidad de brindar más y mejores opciones: creación de vías de retorno entre consumidor y productor de contenidos (aplicaciones interactivas), capacidad de transmitir varias señales en un mismo canal asignado, sumado a una mejor calidad de imagen y sonido. Existen diversos tipos de televisión digital:

- Televisión digital por cable: a través de cable de tipo coaxial, proporciona resolución en alta definición y puede ofrecer servicios tales como: programación pay per view (pagar para ver), acceso a internet y telefonía por cable.

- Televisión por ADSL (IPTV): aplicación de la tecnología digital a la señal televisiva para transmitirla por medio de protocolos asimétricos (xDSL) hasta llegar a través de la línea telefónica. Permite mayor velocidad de conexión y la transmisión de centenares de canales, además de diversas posibilidades interactivas. Necesita un módem router $^{18} \mathrm{y}$ un

\footnotetext{
${ }^{18}$ Un router es un dispositivo que proporciona conectividad a nivel de red. Su función principal consiste en enviar o encaminar paquetes de datos de una red a otra, es decir, interconectar subredes, entendiendo por subred un conjunto de máquinas IP que se pueden comunicar sin la intervención de un encaminador y que tienen prefijos de red distintos.
} 
receptor externo. Se personaliza la oferta a cada cliente de modo que no hay horarios predeterminados. Esta es la principal diferencia con la TDT y el cable.

- Televisión digital por satélite: transmisión de señales satelitales en formato digital a través de satélites dispuestos al efecto, requiere la instalación de una antena parabólica y conexión al televisor un receptor externo.

- Televisión Digital Terrestre (TDT): plataforma de televisión digital cuya transmisión se realiza mediante antenas situadas en la superficie de la tierra. Emite todos los canales a la vez y es preciso tener una antena instalada además de un decodificador o Set Top Box (STB).

La TDT utiliza un sistema de transmisión que codifica las imágenes en un flujo de datos binarios dispuesto sobre la red de distribución de la televisión hertziana analógica y puede ser recibido por las mismas antenas de recepción con un cierto costo de adaptación. (Bizberge, 2010). Por otro lado, el usuario debe poseer un receptor especial que demodula la señal digital y la descomprime para que pueda ser visualizada de forma adecuada por el televisor. Los receptores digitales (Set Top Box - STB) varían según la función que realiza (oferta abierta, acceso a los canales de pago, grados de interactividad, posibilidad de grabar, etc.): el STB que se conecta al televisor analógico y el IDTV $^{19}$ que recibe directamente la señal sin necesidad de ningún receptor externo.

En este punto se precisa aclarar cierta confusión sobre la televisión digital como término equivalente a la transmisión de contenidos de alta definición. La televisión digital permite emitir en alta definición pero también lo puede hacer en lo que se llama definición estándar $^{20}$ (Standar Definition - SD). Por otra parte, se suele entender que el uso de la televisión interactiva es similar al de internet. Más allá de que la televisión interactiva permite navegar entre contenidos, estos están preelaborados y no se encuentran en internet sino en el dispositivo (hardware) propio de la televisión digital.

Ahora bien, dadas las características técnicas reseñadas anteriormente, con frecuencia se enumeran las ventajas de la TDT que van desde un mejor aprovechamiento del espectro

\footnotetext{
${ }^{19}$ IDTV: Televisor con decodificador integrado.

${ }^{20}$ La "definición estándar" ofrece una calidad de imagen similar a la analógica pero con mejor recepción sin interferencias, es una definición que equivale a la imagen de calidad DVD (Digital Versatile Disc en inglés -y Disco Versátil Digital traducido al español- es un disco óptico de almacenamiento de datos que se desarrolló a mitad de la década del 90 como reemplazo del formato VHS para la distribución de video a los hogares).
} 
radioeléctrico, la posibilidad de multiplicar las señales hertzianas, mejor calidad de la señal, almacenamiento de contenidos en el disco duro de los receptores digitales y, por ende, la posibilidad de consumo diferido, así como también la oferta de servicios interactivos.

En sentido amplio, existe cierto acuerdo entre la comunidad académica, el sector de telecomunicaciones y los gobiernos de la región sobre las ventajas de la TDT con relación a la televisión analógica. En principio, estos acuerdos se centran en los aspectos estrictamente técnicos. La posibilidad de aplicar tecnologías digitales para realizar transmisiones por ondas hertzianas terrestres, sin necesidad de cables o satélites, por medio de antenas UHF convencionales logra solucionar los problemas de calidad de imagen y sonido propios de la televisión analógica. La TDT ofrece imagen y sonido sin ruidos ni interferencias, asegurando una recepción nítida ya que la digitalización impide que la señal se degrade tal como sucede con la televisión hertziana.

Además, la TDT tiene un costo menor en relación con otros sistemas (televisión por cable, satelital, etc.) ya que requiere de un equipo decodificador digital de precio accesible ${ }^{21}$ y recibe la señal con antenas UHF y/o interiores o en su defecto, de un televisor con el sintonizador incorporado. El hecho que la distribución de la señal se realice mediante el espectro radioeléctrico asegura una alta penetración en los hogares. En este sentido, la compresión de la señal consigue una mayor eficiencia en el uso del espacio radioeléctrico debido a que es posible utilizar el ancho de banda que actualmente ocupa un canal analógico para brindar más canales: de cuatro a seis de baja resolución, o un canal HD (alta definición) junto a uno de baja resolución (Bizberge, 2010: 61). Esta posibilidad se traduce en un incremento de la oferta audiovisual, aumentando la cantidad de programas dentro de un mismo canal radioeléctrico. A la vez, el dispositivo ofrece la función de grabación de los contenidos audiovisuales para el consumo asincrónico que habitualmente se lo conoce en el mercado de servicios de televisión pagos como "on demand" o "a demanda".

Otra característica de la TDT es la oferta de servicios interactivos -que necesitan de un canal de retorno- para otorgar a los usuarios cierto grado de interacción con los contenidos audiovisuales tales como: guías de programación, información de servicios públicos

\footnotetext{
${ }^{21}$ En Argentina en el año 2015, la adquisición del sintonizador digital en establecimientos comerciales costaba entre 150 y 250 dólares estadounidenses según el modelo.
} 
(tráfico, meteorología, etc.) hasta votaciones, encuestas o transacciones financieras. En este aspecto, hoy y aún en los países centrales la TDT sólo proporciona la modalidad local que permite al usuario acceder a los datos almacenados en el receptor y que se actualizan periódicamente (estado del tiempo, del tráfico, noticias locales). Si bien, la modalidad remota, a partir de la cual el usuario mediante el uso de un canal de retorno puede interaccionar con un proveedor remoto de servicios, tiene un relativo desarrollo tecnológico y aún no están dadas las condiciones técnicas ni de penetración suficientes para un uso extendido.

Más allá de los acuerdos sobre las ventajas técnicas de la TDT, los desacuerdos provienen de la comunidad académica en relación con su desarrollo y potencialidades como gran democratizadora de la cultura y como herramienta para ingresar a la sociedad de la información.

Las principales críticas de numerosos investigadores y académicos se centran en los discursos oficiales de organismos internacionales y de los Estados nacionales que depositan en la TDT la promesa de acceso universal a la cultura digital, de achicamiento de la brecha digital y de pluralismo de voces. En esa línea, los estudios de la Economía Política de la Comunicación y la Cultura señalan que el primer efecto de la digitalización de la televisión es económico y obedece a la “(...) transición hacia una nueva economía global como corolario de la crisis del régimen de acumulación basado en el patrón fordista" (Rodríguez Miranda, 2011: 34). Son los países centrales los que lideraron el desarrollo de la televisión digital a partir de la definición de los estándares digitales: ATSC $^{22}$-EE. UU.-, DVB ${ }^{23}$-Europa-, ISDB $^{24}$-Japón- y DMB ${ }^{25}$-China-.

No es posible comprender el desarrollo de la TDT sin entenderlo en relación con el agotamiento del mercado de la televisión analógica (generalista y destinada a grandes audiencias) que producen, entre otras, la necesidad de recambio de los receptores (tanto el parque de televisores como sintonizadores digitales) junto a la expansión de los negocios del sector de la electrónica (videojuegos, computadoras) y de telecomunicaciones (telefonía móvil, radio, etc.).

En el caso de América Latina, Crovi y Toussaint $(2011,2014)$ señalan que el ingreso de la TDT se ha hecho con tropiezos y torpezas pero bajo la urgencia de las trasnacionales

\footnotetext{
${ }^{22}$ Advanced Television System Committee - Comité de Estándares Avanzado de Televisión.

${ }^{23}$ Digital Video Broadcasting - Transmisión de Video Digital Terrestre.

${ }^{24}$ Integrated Services Digital Broadcasting - Transmisión Digital de Servicios Integrados.

${ }^{25}$ Digital Terrestrial Multimedia Broadcast - Transmisión Digital Terrestre Multimedios.
} 
para relanzar un negocio que parecía agotado, especialmente, cuando los dispositivos móviles se generalizan y constituyen una opción sustitutiva de la televisión tradicional. Asimismo, la idea de la TDT como dinamizadora de la inclusión social y el acceso a las tecnologías digitales ingresa en la agenda de los gobiernos regionales que articulan políticas públicas de inclusión digital basadas en planes de acceso a través de la distribución de decodificadores digitales entre la población con "riesgos de exclusión". Sin embargo, Bustamante (2008) afirma que el desarrollo de la TDT sigue beneficiando a las elites de cada país y, por tanto, termina reproduciendo las desigualdades sociales y culturales previas a su introducción. En este sentido, este autor pone en duda el discurso de los organismos internacionales (particularmente de la Unión Europea) que proclaman que la TDT representa una puerta a la sociedad de la información para todos los ciudadanos.

Las posiciones mencionadas en los párrafos anteriores cuestionan los argumentos que legitiman las políticas públicas llevadas a cabo por los Estados que ponen el acento en que la llegada de la televisión digital permite el acceso universal a una oferta multicanal y a los servicios interactivos propios de la sociedad de la información, saltar la brecha digital e incluir a todos los sectores de la población que actualmente están fuera de la denominada cultura digital.

\subsection{La TDT en Argentina: ¿De las reglas del mercado hacia el protagonismo del Estado?}

El proceso de digitalización de la televisión en los países centrales aún se encuentra incompleto y reproduce las mismas características que su par analógico: no ha modificado los desequilibrios del sector audiovisual ni ha democratizado la comunicación en las sociedades actuales (Albornoz y Leiva, 2011, 2012). En este contexto, en América Latina pero especialmente en Argentina, el pasaje de la televisión analógica a la digital adquiere rasgos distintivos que merecen la atención para abordar nuestro objeto de estudio.

Entendemos que analizar un proceso en marcha implica siempre acceder a un mapa incompleto y en permanente movimiento. Por esa razón, tal como mencionamos anteriormente, recurrimos a los estudios críticos que desarrollan Becerra y Mastrini, en la Universidad Nacional de Quilmes debido a que abordan los cambios en el sector infocomunicacional desde distintos niveles de análisis en relación con la introducción de 
la TDT en nuestro país, analizando las determinaciones de carácter económico, político, social y cultural de la evolución de las industrias culturales. Estos estudios permiten ubicar los contrapuntos o paradojas -en palabras de Becerra (2015)- de un proceso en curso e inacabado que requiere de abordajes complejos e interdisciplinarios.

Desde la mitad del siglo XX y hasta la primera década del siglo XXI, la transmisión de la televisión en el país fue analógica, es decir, a través de un conjunto de señales que utilizan el espectro radioeléctrico. Sin embargo, se muestra el predominio de la televisión hertziana donde la televisión paga (por cable o satelital) tiene una alta penetración que llega a casi un ochenta y cuatro por ciento $(83,46 \%)$ de los hogares en todo el país (LAMAC, 2015 26). Mientras la televisión de pago crecía, el Estado argentino, durante el período estudiado en esta tesis, se dedicó a impulsar el proceso de implementación de la televisión digital abierta de la mano de la TDT.

Durante el siglo XX, la lógica del sistema de medios audiovisuales en Argentina “(...) adoptó un modelo comercial, competitivo, basado en la publicidad para su sostenimiento económico" (Becerra y Mastrini, 2011: 2), y con una fuerte concentración de la producción de contenidos en las principales ciudades, particularmente en Buenos Aires. La consolidación de este modelo se concretó en la década del '90 con el desarrollo de las políticas neoliberales consumadas por la gestión de los dos mandatos de Carlos Menem. Una de las primeras medidas, a partir de la Reforma del Estado de 1989²7, fue el otorgamiento de privilegios impositivos y la ampliación de licencias de prensa, radio y televisión para un mismo operador que devino en la creación de grandes grupos multimedia nacionales como Clarín y Editorial Atlántida como puerta de entrada a capitales extranjeros como Telefónica de España, Prime o Prisa (Becerra, 2014: 5). Estas medidas se realizaron a partir de modificaciones al Decreto-Ley $N^{o} 22.285 / 80$ de la dictadura cívico-militar que produjeron una alta concentración y monopolización de los

\footnotetext{
${ }^{26}$ LAMAC es una asociación sin fines de lucro formada y financiada por 56 cadenas televisivas pertenecientes a los grupos más importantes: A+E Networks Latin America, AMC Networks International Latin America, Discovery Latin America, FOX One Stop Media, Sony Pictures Television, Turner Broadcasting System Latin America, Universal Networks International y Viacom International Media Networks-The Americas.(www.lamac.org).

${ }^{27}$ La Reforma del Estado se materializó a través de la Ley 23.696 que comprende principalmente: declaración del estado de emergencia para toda la administración pública nacional; intervención de todos los entes públicos nacionales centralizados y descentralizados, con excepción de las Universidades; privatización o participación del capital privado en empresas públicas; desregulación del mercado; entre otros.
} 
medios en pocos grupos económicos, a la vez que se conforma un esquema desigual de distribución en el territorio nacional ${ }^{28}$.

Durante el gobierno de De La Rúa de 1999 (coalición entre UCR y FREPASO) “(...) el sistema de medios estaba protagonizado por los grupos Clarín y Telefónica. Clarín basó su estrategia en la expansión conglomeral a distintos medios de comunicación (tiene posesiones en casi todas las actividades de las industrias mediáticas) y en particular en su dominio del apetecible mercado de televisión por cable, que al finalizar la década de 1990 le aportaba ya más de la mitad de sus ingresos totales" (Becerra, 2014: 6). Desde la crisis del 2001 y hasta la presidencia de Néstor Kirchner, según Becerra (2014) se desplegó una segunda fase de "concentración defensiva" en la que los sucesivos gobiernos ${ }^{29}$ ayudaron a los grupos más concentrados e importantes del mercado local con políticas de medios diseñadas a medida. La excusa de parte de gobiernos y empresarios fue que se trataba de una estrategia para impedir la intrusión de operadores extranjeros en el mercado local. A partir de los procesos señalados anteriormente, el escenario mediático audiovisual concentra la propiedad y centraliza el capital y la producción (Becerra, 2014: 7).

El gobierno de Néstor Kirchner y la primera parte de la gestión de Cristina Fernández consolidan la estructura concentrada y quienes quedan fuera del esquema del mercado mediático son los sectores sociales no lucrativos “(...) concibió un esquema de ayuda estatal a cambio de apoyo editorial, incentivó la mejora en la programación de Canal 7 , creó la señal Encuentro ${ }^{30}$ " (Becerra, 2014: 8). Más allá de ciertas concesiones a las principales empresas mediáticas, el gobierno inició un enfrentamiento con esos

\footnotetext{
28 "Con la transformación estructural que se produce, cambian las reglas de juego y se termina de construir un nuevo esquema de comunicaciones. Un total de 45 canales de TV abierta quedan operativos en todo el país. La desproporción es total, ya que son sólo diez de las veinticuatro provincias tienen más de una señal de televisión. Es ahí donde también se vuelve a ver la mano del mercado y los intereses políticos en diálogo con él, generando la concentración de canales abiertos en las grandes ciudades y conglomerados. Otra vez, ciudadanos de primera y de segunda, algunos capaces de tener televisión y otros no; la lógica imperante es simple de develar: donde más se puede vender, más canales habrá. Mientras que en toda la provincia de Catamarca no hay señales y sólo se reciben canales de aire de otros sitios, en ciudades como Santa $\mathrm{Fe}$, Córdoba, Rosario o Mar del Plata hay dos canales de televisión abierta, que además terminan entregados por el gobierno de Menem y sus privatizaciones a manos de Clarín y de Telefe-Telefónica. En consecuencia, se dio una concentración de emisoras de televisión en la Argentina cuyos principales grupos son Clarín, Telefónica y el Grupo UNO" (Pauloni, 2014: 66).

${ }^{29}$ La Ley de Preservación de Bienes Culturales, impulsada por el gobierno de Eduardo Duhalde y aprobada en la gestión de Néstor Kirchner fue una de las medidas que pone "(...) un tope del $30 \%$ de capital extranjero en las industrias culturales argentinas (...)" (Becerra, 2014: 8), que frenó la posibilidad de que acreedores extranjeros ejecutaran las deudas contraídas por las empresas de medios argentinas.

${ }^{30}$ Martín Becerra (2015) realiza una lectura crítica sobre las causas y consecuencias del proceso de concentración y convergencia del mercado audiovisual en Argentina en el libro: "De la concentración a la convergencia. Políticas de medios en Argentina y América Latina", Paidós. Buenos Aires; particularmente en los capítulos 1,2 y 3.
} 
conglomerados -que perduró hasta la finalización del segundo mandato de Cristina Fernández-. Uno de los hechos detonantes fue la "crisis del campo" "31 que agudizó la disputa de la gestión de Fernández con el Grupo Clarín.

En 2009, se promulga la Ley de Servicios de Comunicación Audiovisual N 26.522/09 con gran apoyo de sectores de la sociedad civil que desde el año 1983 reclamaban el reemplazo del Decreto-Ley 22.285 de la dictadura cívico-militar del '76. Estos actores sociales provenientes de diferentes espacios (sindicatos, medios comunitarios, universidades, organizaciones de derechos humanos, etc.) se reunieron en la Coalición para una Radiodifusión Democrática y acordaron 21 puntos para la regulación del sector ${ }^{32}$ y en sentido amplio sus propuestas fueron incorporadas a la letra de la norma.

Esta ley inaugura un escenario regulatorio en una estructura de medios históricamente caracterizada por la hegemonía de los intereses privados y comerciales, concentrada “(...) en su estructura de propiedad, centralizado en la generación de contenidos, y con participación relevante de capitales extranjeros" (Marino et.al., 2015: 2).

Algunos de los principales cambios que propone la Ley $\mathrm{N}^{\circ} 26.522 / 09$ son: los límites a la concentración de medios; crea nuevos órganos de control independientes del Poder Ejecutivo como la Autoridad Federal de Servicios de Comunicación Audiovisual (AFSCA), Consejo Federal de Servicios de Comunicación Audiovisual, Consejo Asesor de la Comunicación Audiovisual y la Infancia, Comisión Bicameral de Promoción y Seguimiento de la Comunicación Audiovisual, Defensor Nacional del Público, Radio y Televisión Argentina S.E. y Consejo Consultivo Honorario de los Medios Públicos; reserva el 33\% del espectro para el sector privado no comercial; la fijación de cuotas de pantalla para la producción de contenidos nacionales; la garantía del acceso universal a todos aquellos contenidos y programación considerada de interés relevante; la promoción del federalismo, el aliento a la diversidad de voces; entre otros.

\footnotetext{
${ }^{31}$ La denominada "crisis del campo" comenzó en marzo de 2008 con un paro patronal (lock-out) convocado por las organizaciones del sector productivo agro-ganadero: Sociedad Rural Argentina, Confederaciones Rurales Argentinas, CONINAGRO y Federación Agraria Argentina, contra la Resolución no 125/2008 que establecía un sistema móvil para las retenciones impositivas a la soja, el trigo y el maíz. A estas medidas se sumó el paro de transporte que complicó el conflicto. El 17 de junio de ese año, la presidenta (mandato cumplido) Cristina Fernández envía al Congreso el proyecto de ley sobre las retenciones que no prospera y que dejó sin efecto dicha resolución.

${ }^{32}$ Algunos de los puntos son: acceso a licencias a organizaciones sociales, promoción de la diversidad, no gubernamentalización de la gestión de los medios del Estado y de sus contenidos, limitar la concentración de la propiedad, etc. Se puede consultar: http://21puntos.blogspot.com.ar/; http://www.elforjista.com/21 puntos.pdf; $\quad$ http://conadu.org.ar/21-puntos-basicos-por-el-derecho-a-lacomunicacion/; http://www.telam.com.ar/advf/imagenes/especiales/documentos/2012/11/509435587ec92.pdf.
} 
Sin embargo, el debate social y político posterior a la sanción de la ley no estuvo exento de tensiones que redundaron en la suspensión judicial ${ }^{33}$ de su aplicación plena durante cuatro años cuando la Corte Suprema de Justicia se expidió sobre la validez de 4 artículos referidos al régimen de licencias y a la adecuación de los topes para los grupos concentrados a la vez que señaló que el incumplimiento por parte del gobierno. En 2013 se abre otro capítulo en la disputa en relación con el escenario nacional de comunicación. Más allá de las modificaciones que le imprime al mercado mediático, la vigencia de la Ley $\mathrm{N}^{\circ} 26.522 / 09$ establece la gratuidad de la televisión digital, ofrece lineamientos generales respecto de la tecnología digital que se refieren a las licencias, elaboración de informes bianuales que revisen el régimen de multiplicidad de licencias, ingreso de nuevas tecnologías que no están activas y la transición a los servicios digitales (Mastrini, Becerra, Bizberge y Krakowiak, 2012: 72-73). En 2010, el gobierno comienza a desarrollar la TDT que inauguró con la primera transmisión digital a través de la señal del Canal 7.

Pero tal como hemos señalado, la implementación de la televisión digital en Argentina aún se encuentra en proceso y podemos ubicar su inicio en 1997 como señalan Mastrini, Becerra, Bizberge y Krakowiak:

"El desarrollo de la televisión digital argentina se extiende desde 1997 hasta la actualidad. Es un período corto, pero muy significativo de la historia del país, (...). En primer lugar, la etapa final del período neoliberal (1997-2001) que tuvo lugar en los gobiernos de Carlos Menem (1989-1999) y Fernando de la Rúa (1999-2001); seguida por la crisis económica y política que arrimó al Estado argentino a los mínimos de su legitimidad social, con varios gobiernos de corta duración (20012003); para finalizar con un período de reconstrucción económica y política, basado en un tibio industrialismo, equilibrio fiscal y obtención de excedentes por venta de commodities en el mercado internacional". Mastrini, Becerra, Bizberge y Krakowiak (2012: 70-71)

Argentina fue el primer país de América Latina que adoptó un estándar técnico para TDT y el cuarto en el mundo (Bizberge et al., 2011). En 1997, en el marco del proceso de

\footnotetext{
${ }^{33}$ El conflicto comenzó con el reclamo judicial del Grupo Clarín sobre los artículos 41, 45, 48 y 161 de la Ley Servicio de Comunicación Audiovisual, aduciendo que su aplicación restringía el pleno ejercicio de la libertad de expresión. Con la convalidación de la Corte Suprema de Justicia se establece la vigencia de la Ley y el AFSCA inicia el procedimiento establecido para la readecuación o transferencia de oficio del Grupo Clarín. Sin embargo, en los siguientes años se presentaron medidas cautelares que suspendieron el proceso de adecuación previsto por la Ley y confirmado por la Corte en 2013. En relación con el señalamiento al gobierno, la Corte Suprema de Justicia advirtió que el gobierno tampoco cumplió, al menos, con la apertura de concursos de licencias, utilización de los medios estatales para propaganda oficial, falta de información sobre los licenciatarios, etc.
} 
privatización de empresas públicas ${ }^{34}$, se introdujeron modificaciones al Decreto-Ley de Radiodifusión 22.285/80 que limitaron a “(...) 3 licencias de televisión o una de radio a una misma persona física o jurídica en distintas áreas de cobertura, puso fin a la restricción que impedía a sociedades diferentes de radiodifusión presentarse a concurso de una licencia (...)" (Bizberge et al., 2011: 198-199). Estas y otras medidas permitieron el ingreso al mercado audiovisual de empresas o personas jurídicas procedentes de otros sectores de la actividad económica y la posibilidad de las empresas de medios gráficos de obtener licencias audiovisuales. Se privatizan los canales 11 y $13^{35}$ (Ciudad de Buenos Aires) y se constituyen los dos multimedios más grandes del país.

Con la presencia de capital extranjero, la incorporación de tecnología y el desarrollo de servicios de televisión por cable y satelital ${ }^{36}$, se sitúan los inicios de la televisión digital en el país.

Los comienzos de la televisión digital anclan en un mercado mediático en camino a la consolidación del duopolio de composición nacional-extranjera-vinculados al capital financiero- $\mathrm{y}$ tendiente a la convergencia a partir de la prestación de servicios cruzados por parte de un mismo operador que permite la integración de servicios audiovisuales.

En principio, la elección del estándar técnico de la televisión digital es el primer paso. La Asociación de Teledifusoras Argentinas (ATA) ${ }^{37}$ eligieron el estándar técnico norteamericano ATSC, adquirieron equipamiento para realizar transmisiones experimentales e iniciaron las gestiones con el gobierno de Menem para lograr las condiciones regulatorias acorde a sus intereses (Bizberge, 2010). El rumbo de la adopción de la norma contó con la mediación de las resoluciones de la Secretaría de Comunicación

\footnotetext{
${ }^{34}$ La privatización de empresas públicas comenzó en 1989 con la sanción de la Ley de Reforma del Estado $\mathrm{N}^{\circ} 23.696 / 89$ que autorizaba la privatización de empresas estatales y a la fusión y disolución de distintos entes públicos. Se declaró en emergencia la prestación de servicios públicos. Entre sus objetivos se fundamentó que estas privatizaciones "se requerían para obtener recursos para disminuir el déficit fiscal y equilibrar el presupuesto del Estado". Entre las consecuencias, se pueden mencionar la redefinición de las relaciones entre el sector privado y el sector público e impone restricciones a las funciones del Estado de Bienestar (Zeller, 1997).

${ }^{35}$ Canal 11 comprado por el Grupo Telefe conformado por Editorial Atlántida (familia Vigil) y el Grupo de Televisoras Provincianas S.A. (administrado por Alejandro Massot de Bahía Blanca). Canal 13 fue vendido a Artear, Grupo Clarín (Noble-Magneto).

${ }^{36}$ Según Albornoz y Hernández (2008) a fines de la década del ' 90 se produce el ingreso de Goldman \& Sachs al Grupo Clarín y de CEI-Telefónica al Grupo Telefe en el marco de la televisión abierta. En cambio, en la televisión por pago a Cablevisión ingresa el Grupo Telefónica y los grupos norteamericanos Galaxy, DIRECTV y Sky se apuntalan en la televisión satelital. Para profundizar el análisis del mapa mediático concentrado se puede consultar: Mastrini (editor) (2009): Mucho ruido, pocas leyes. Economía y políticas de comunicación en la Argentina, Segunda edición ampliada, La Crujía. Buenos Aires.

${ }^{37}$ ATA agrupa a los radiodifusores privados argentinos.
} 
(SECOM) para evaluar los sistemas de televisión digital ${ }^{38}$ que resulta en la decisión de acoger el estándar técnico norteamericano y que contradijo el compromiso asumido con el MERCOSUR de elección conjunta. ${ }^{39}$ Sin embargo, a inicios de 2000 la SECOM declara públicamente la suspensión del sistema ATSC pero dado que no se reflejó en una resolución continuó vigente hasta $2009 .{ }^{40}$

En medio de la crisis político-institucional de fines de 2001 y del posicionamiento de Telefónica como el principal operador de televisión abierta en el territorio nacional impulsor de la norma europea DVB-, el embrionario desarrollo de la televisión digital se detuvo.

Sólo a fines del primer gobierno de Néstor Kirchner (2003-2007) se renueva el debate sobre la elección de la norma de televisión digital, comenzando una etapa en la que el Estado adquiere protagonismo en la regulación y, en particular, en la producción y distribución de contenidos audiovisuales.

Uno de los hitos de esta fase se da en 2006 cuando se reedita la Comisión de Estudio y Análisis de los Sistemas de Televisión Digital en la órbita de la SECOM, que reproduce la conformación de integrantes del gobierno y sector privado de la del `97, cuyo informe final no realiza ninguna recomendación y excluyó la norma japonesa ISDBT. En tanto, Brasil eligió el estándar técnico nipón con la particularidad de que el desarrollo de un middleware abierto desarrollado por la industria brasilera: el Ginga.

Durante el primer mandato de Cristina Fernández (2007-2011) con la propuesta de modificación del Decreto-Ley 22.285/80 y el acuerdo sobre el estándar técnico con el gobierno de Lula Da Silva (2003-2010) le imprime un nuevo impulso al desarrollo de la televisión digital. El anuncio de la adopción de la norma nipona brasilera produjo la

\footnotetext{
${ }^{38}$ Bizberge (2010) describe y analiza el proceso de adopción del estándar técnico para la televisión digital. Entre las características de esta fase señala: “(...) la Secretaría de Comunicaciones creó la Comisión la Comisión de Estudios sobre Sistemas de Televisión Digital (...) [el] Comité Consultivo sobre Televisión Digital, quedó confirmada por la Secretaría de Prensa y Comunicación de la Presidencia de la Nación, el Comité Federal de Radiodifusión (COMFER), Asociación de Teledifusoras Argentinas (ATA), Asociación de Televisión por Cable (ATVC) y la Cámara Argentina de Aplicaciones Satélites (CADAS). Cabe notar que los integrantes provienen del gobierno y de empresas privadas, excluyendo cualquier tipo de participación por parte de la sociedad civil (...) (Bizberge, 2010: 138). Finalmente, “(...) la SECOM se comprometió a impulsar un sistema que permita el desarrollo de la televisión digital de alta definición (...) y sin que los futuros operadores estén obligados a transmitir en HDTV” [y en octubre de 1998], “(...) mediante la resolución 2357/98, Argentina adoptó el estándar ATSC" (Bizberge, 2010: 139-140).

${ }^{39}$ Esta medida provoca la acusación de Brasil de violación de la Resolución 24/94 del MERCOSUR que establecía que la adopción debía ser notificada con el mayor tiempo de anticipación posible a los miembros a fin de alcanzar un consenso al respecto.

${ }^{40}$ Bizberge et al. (2011) señalan que los fundamentos de dicha declaración fueron la inexistencia de pruebas y fundamentos, sin coordinación con Brasil y basándose en consideraciones falsas sobre la norma DVB.
} 
revisión de otros países de la región que finalmente se inclinaron por dicho estándar técnico de televisión digital ${ }^{41}$.

Por lo tanto, el desarrollo regulatorio y de producción y distribución de contenidos de la televisión digital de la mano del Estado empieza en septiembre de 2009 con la oficialización de la norma ISDB-T en el Decreto N 1148/2009.

De aquí en más, el protagonismo del Estado fue in crescendo a partir de la decisión de liderar el proceso de digitalización de la televisión con la expectativa de promover la inclusión digital de sectores de la población "con riesgos de exclusión". Y en este movimiento se enfrenta un escenario de convergencia en proceso que presenta tensiones y desafíos.

\subsection{El desarrollo de la política pública: Televisión Digital Abierta}

Los inicios del siglo XXI se caracterizan por una tendencia disruptiva en la actuación por parte del Estado argentino en torno al mercado audiovisual. A diferencia de la tradicional intervención esporádica y subsidiaria respecto de la lógica de mercado, el Estado comienza a realizar esfuerzos institucionales y políticos (con diferentes matices) para modificar el patrón de regulación, producción y distribución del escenario audiovisual a partir de la implementación de un conjunto de políticas públicas orientadas a la democratización de las comunicaciones.

De la mano de los llamados "gobiernos progresistas", tanto en Argentina como en América Latina en general se produce una redefinición del rol del Estado, que según ciertos autores comienza a dar un "giro a la izquierda" (Arditi, 2009; Cheresky, 2007; Nazareno, 2010), que asume el reclamo de las mayorías excluidas en la década del `90 que demandan inclusión económica, política y social a través de mayor regulación del mercado y políticas públicas universales. Se trata de un Estado que se erige como actor privilegiado que interviene en el plano económico, político, social y cultural para alcanzar el bienestar de la sociedad en general en el contexto de crisis global del capitalismo ${ }^{42}$.

\footnotetext{
${ }^{41}$ Chile, Venezuela, Ecuador y Uruguay adoptaron la norma nipona brasilera.

${ }^{42}$ No pretendemos en esta tesis abordar el debate sobre la caracterización de los Estados latinoamericanos, sin embargo, en sentido amplio, consideramos las posiciones teóricas de Borón (2003, 2008, 2012) y Gambina (2013), que caracterizan al Estado posneoliberal en el marco de la crisis capitalista global que se pueden consultar en: Gambina (2013): Crisis de capital (2007/2013). La crisis capitalista contemporánea y el debate sobre alternativas. Buenos Aires, FISyP (Fundación de Investigaciones Sociales y Políticas),
} 
Más allá que es un Estado que no se orienta a modificar radicalmente la matriz productiva ni la estructura distributiva, se ocupa de incrementar la administración de los recursos públicos y su capacidad de definir políticas públicas (Mancebo y Dieguez, 2015).

En términos de De Moraes (2011), en América Latina el ascenso de gobiernos de signo progresista $^{43}$ se dispusieron a enfrentar al neoliberalismo a partir de la “(...) reconstrucción del Estado como espacio institucional y ético-político, con capacidad de interactuar con la sociedad y las comunidades locales y para frenar y disciplinar el mercado, regulando las aspiraciones a partir del consenso obtenido junto a un amplio conjunto de clases que ven sus expectativas reflejadas en la acción gubernamental" (De Moraes, 2011: 28).

Y continúa señalando que parte sustantiva de los esfuerzos de estos gobiernos por avanzar en la democratización general de las sociedades latinoamericanas se centró en generar acciones estratégicas en relación con los medios de comunicación, en oposición con la concepción neoliberal de la cultura como mercancía, cristalizadas en políticas públicas que difieren según los contextos nacionales de los que se trate.

En esa dirección y en contextos complejos de transformación política, económica, social y cultural, estos gobiernos impulsaron políticas públicas de tono inclusivo con declarados fines de democratización en los diferentes ámbitos de las sociedades latinoamericanas. Estas políticas públicas -entendidas en el sentido que las define Aguilar Villanueva (2009) como acciones de corresponsabilidad a través de las cuales gobierno y sociedad enfrentan variada y conjuntamente los problemas colectivos ${ }^{44}-$ se proponen quebrar el poder concentrado del mercado mediático en manos de corporaciones nacionales y

Borón (2003): Estado, capitalismo y democracia en América Latina. Colección Secretaría Ejecutiva, Clacso, Buenos Aires. ISSN: 950-9231-88-6. Disponible en: http://www.clacso.org/español/libros/estado/estado.

${ }^{43} \mathrm{El}$ autor distingue dos bloques de gobiernos progresistas en la región: uno compuesto por la "Alianza Bolivariana de las Américas" o ALBA. Fundada en 2004 por Venezuela y Cuba, y con la posterior adhesión de Bolivia, Ecuador, Nicaragua, Dominica, etc. que prioriza agendas y asociaciones que viabilicen programas de desarrollo independiente. Rehúsan a tratados de libre comercio, y prestigian una integración económica y cultural por fuera del circuito liderado por EE. UU. Esta integración no se basa en la competencia sino en la complementariedad y la cooperación solidaria. Y otro que está integrado por Brasil, Uruguay, Argentina y Chile (este último hasta el término del mandato de Michelle Bachelet en 2010). Estos países fluctúan entre la defensa de la inclusión social y políticas económicas que, con variaciones, atienden las razones de los mercados y postergan la reversión estructural de la pobreza. No escapan de ambigüedades y contradicciones más acentuadas y complejas (De Moraes, 2011: 29).

${ }^{44}$ En el capítulo VI planteamos qué entendemos por políticas públicas para abordar el análisis de las principales definiciones y expectativas respecto de las tecnologías digitales interactivas, la TDA, sus usos y apropiaciones como así también sobre el propósito de inclusión digital presente en documentos de la política pública directamente relacionados con el dispositivo técnico. 
trasnacionales a partir de la descentralización económica y geográfica de los medios de comunicación y la participación de sectores de la sociedad civil en la gestión de los contenidos.

Y en este contexto, en Argentina la aprobación de la Ley 26.522 de Servicios de Comunicación Audiovisual que regulaba el sistema de medios -incluida la televisión digital - es un punto de inflexión en el rol de Estado con voluntad explícita de intervenir en el mercado mediático en particular y de la cultura en general. La implementación de la política pública de televisión digital, liderada exclusivamente por el Estado argentino, se propuso, en sentido amplio, la ampliación de los derechos de la ciudadanía y la participación efectiva en la cultura digital.

Esta política denominada TDA se ubicaba en la órbita del Ministerio de Planificación Federal, Inversión Pública y Servicios (MINPLAN) quien se encargaba de la implementación del SATVD-T, a través de la Planificación Estratégica 2009-2019, aprobada por el Consejo Asesor del SATVD-T que definía las estrategias y las acciones específicas para el desarrollo de la televisión digital en Argentina.

En primer lugar, el MINPLAN desarrolla la infraestructura técnica: el tendido de la red, la instalación de las plantas transmisoras y antenas (TDT y TDS) y la distribución de los decodificadores digitales. Desde 2010 se instalaron antenas operativas en cada provincia del país junto a operativos de distribución gratuita de decodificadores digitales que se gestionaban a través de las oficinas de ANSES como también de oficinas intermedias en las provincias del país (direcciones municipales).

Por otro lado, en relación con la producción de contenidos se dispusieron los lineamientos y especificaciones técnicas de la plataforma digital que, entre otras cuestiones, organizaba la grilla de canales. Pero la apuesta fuerte estuvo en el Plan Federal de Fomento a la Producción de Contenidos que desarrolla el Programa Polos Audiovisuales Tecnológicos cuyo propósito principal fue el impulso a la producción audiovisual de contenidos culturales, pedagógicos, científicos e informativos.

Esta política pública se materializó en el plan de acceso "Mi TV Digital" que fue la primera implementación masiva del sistema de transmisión digital abierta (TDT y TDS) por parte del Estado que ofrecía paquetes de señales públicas y privadas a aquellos sectores identificados como "en peligro de exclusión digital". 
Si bien el Estado se erige como el único promotor de políticas digitales orientadas a promover el cambio tecnológico en la televisión abierta y la universalización del servicio, varios autores se interrogan sobre la gestión de la TDA y su alcance entre la población destinataria.

Uno de los datos que señala Rodríguez Miranda (2013) es que la construcción y desarrollo del sistema TDA fue diseñada herméticamente en la órbita del MINPLAN “(...) que asumió una dirección verticalista de carácter técnico productivo, lo que plantea dudas a la hora de cumplir con las metas sociopolíticas -pluralismo informativo y diversidad de contenidos- para la democratización de las comunicaciones. No obstante, es menester destacar la expansión de la red para garantizar el acceso universal a la televisión digital abierta" (Rodríguez Miranda, 2013: 8).

Becerra (2015) señala diferentes aspectos que preocupan acerca de la implementación de la TDA tales como por ejemplo que el Estado invierte en infraestructura, en el acceso y la producción de contenidos audiovisuales pero no se interroga sobre los usos de la televisión digital entre sus destinatarios. Que "la gestión de la TDA, además, está descoordinada del Plan Argentina Conectada (red de fibra óptica que enlaza todo el país) con el que se superpone plataformas de distribución de contenidos" (Becerra, 2015: 43). O las dificultades para la recepción en los grandes centros urbanos como el AMBA y la competencia con altos índices de penetración del sistema de pago digital (Direct TV, Telecentro, Cablevisión, etc.). Más adelante abordaremos particularmente cada uno de estos aspectos de la implantación de la TDA.

Por su parte, Rossi (2013:6-7) sostiene que:

“(...) la persistencia de un mapa de medios analógicos de similares características al preexistente al dictado de la Ley, y las expectativas puestas por diversos actores que durante décadas estuvieron excluidos de cualquier posibilidad de incidir en decisiones públicas, son (...) aspectos que generan inquietudes sobre la profundidad de las medidas y los plazos de cumplimiento para el cambio necesario en el mapa de producción y distribución de contenidos de televisión digital”.

La identificación de los nudos críticos que la normativa deja a merced de futuras discusiones como por ejemplo, el uso del dividendo digital y la incorporación de la voz de los ciudadanos, se suman a las preguntas sobre el modo y las características de la transición digital de la televisión en nuestro país. 
En relación con la participación de los destinatarios de la TDA, Labate (2013: 6) afirma que no se generaron instancias para la inclusión de la ciudadanía lo que “(..) conlleva a un desconocimiento de la población sobre las potencialidades de la TDT. Más allá de las cuestiones conceptuales, se debe preparar a la sociedad para los nuevos usos, consumos y habilidades que la TV digital exige".

En resumen, estos análisis apuntan a caracterizar a la TDA como una política de corte reactivo frente a la concentración del mercado mediático que, en principio, resultó cortoplacista y que no incluyó la evaluación de los avances y los usos de la televisión digital entre la población que se propone cubrir. A la vez, coinciden en que los desafíos para la efectiva implementación de la TDT se centran en el diseño de políticas públicas que incorporen los intereses sociales y culturales de la ciudadanía, el monitoreo con la definición de indicadores precisos sobre su desarrollo y la consolidación de la institucionalidad de dichas políticas que excedan las gestiones gubernamentales.

Y finalmente, una de las críticas más fuertes señaladas es la desarticulación de las políticas públicas de comunicación “(...) con competencias repartidas y superpuestas entre el Ministerio de Planificación Federal, la Secretaría de Comunicaciones, la Comisión Nacional de Comunicaciones, la Secretaría de Medios de Comunicación, la Autoridad Federal de Servicios de Comunicación Audiovisual, la Secretaría de Cultura de la Nación, el Instituto Nacional de Cine y Artes Audiovisuales, el Ministerio de Educación, la Jefatura de Gabinete y la Presidencia misma, con otras dependencias subordinadas a las citadas también involucradas" (Becerra y Mastrini, 2016: 24). Esta disgregación junto a ciertas iniciativas truncas sirven para describir las principales dificultades que encontró el Estado para desarrollar la TDA en Argentina.

\subsubsection{La televisión digital terrestre en transición. Contexto normativo}

Como hemos señalado anteriormente, en Argentina el proceso de implementación de la TDT, por parte del Estado, comenzó a mediados de 2009 con la creación del Sistema Argentino de Televisión Digital Terrestre (SATVD-T), basado en el estándar denominado 
ISDB-T (conjunto de patrones tecnológicos para la trasmisión y recepción de señales digitales terrestres, radiodifusión de imágenes y sonido $)^{45}$. Entre sus objetivos se señalan:

a) Promover la inclusión social, la diversidad cultural y el idioma del país a través del acceso a la tecnología digital, así como la democratización de la información.

b) Facilitar la creación de una red universal de educación a distancia.

c) Estimular la investigación y el desarrollo, así como fomentar la expansión de las tecnologías e industrias de la República Argentina relacionadas con la información y comunicación.

d) Planificar la transición de la televisión analógica a la digital con el fin de garantizar la adhesión progresiva y gratuita de todos los usuarios.

e) Optimizar el uso del espectro radioeléctrico.

f) Contribuir a la convergencia tecnológica.

g) Mejorar la calidad de audio, video y servicios.

h) Alentar a la industria local en la producción de instrumentos y servicios digitales.

i) Promover la creación de puestos de trabajo y la capacitación de los trabajadores en la industria tecnológica ${ }^{46}$.

Asimismo, el decreto de creación del SATVD-T establece la conformación del Consejo Asesor, en la órbita del Ministerio de Planificación Federal, Inversión Pública y Servicios, integrado por representantes de diferentes organismos públicos nacionales (Jefatura De Gabinete de Ministros, Ministerio del Interior, Ministerio de Relaciones Exteriores, Comercio Internacional y Culto, Ministerio de Economía y Finanzas Públicas, Ministerio de Producción, Ministerio de Trabajo, Empleo y Seguridad Social, Ministerio de Desarrollo Social, Ministerio de Educación y Ministerio de Ciencia, Tecnología e Innovación Productiva). Por último, determina el plazo de 10 años para desarrollar el proceso de transición de la televisión analógica a la digital.

En octubre del mismo año, se sancionó y promulgó la Ley $\mathrm{N}^{\circ} 26.522$ de Servicios de Comunicación Audiovisual con el objeto de regular el sistema de los servicios de comunicación audiovisual, promoviendo el acceso de nuevos actores y fomentando la

\footnotetext{
${ }^{45}$ Según Krakowiak, Becerra, Mastrini (2012) la decisión de adopción del estándar tecnológico de la TDT en Argentina estuvo basada en un criterio geopolítico regional orientado por Brasil que "(...) eligió el estándar japonés por una política de desarrollo industrial que no interfería con los intereses de los radiodifusores privados" (Brittos y Bolaño, 2009; Krakowiak, 2009).

${ }^{46}$ Decreto $N^{\circ} 1148 / 2009$. Creación el Sistema Argentino de Televisión Digital Terrestre (1/9/2009). Boletín Oficial de la República Argentina, N³1.727. Pp. 5.
} 
universalización de las tecnologías de la información y la comunicación (TIC). Esta norma es el marco legal para el desarrollo de la industria audiovisual que incluye la TDT en diferentes artículos que establecen, entre otros: la no concurrencia de licencias (artículo 46), la adecuación por incorporación de nuevas tecnologías (artículos 47 y 92), transición a los servicios digitales (artículo 93).

Por otro lado, también en 2009 se sanciona la Ley $\mathrm{N}^{\circ}$ 26.539, que estableció la modificación de impuestos internos con beneficios para productos electrónicos producidos en Tierra del Fuego, con el objeto de impulsar la industria local en la producción, desarrollo de dispositivos y servicios digitales, creación de puestos de trabajo además de la capacitación adecuada.

Un año después se crea el Plan Nacional de Telecomunicaciones "Argentina Conectada":

“(...) con el fin de articular el desarrollo de las TIC en la República Argentina con los objetivos de crecimiento económico con inclusión social (...)"47. Este plan tiene "(...) como ejes estratégicos la inclusión digital; la optimización del uso del espectro radioeléctrico; el desarrollo del servicio universal; la producción nacional y generación de empleo en el sector de las telecomunicaciones; la capacitación e investigación en tecnologías de las comunicaciones; la infraestructura y conectividad; y el fomento a la competencia; todo ello abordado desde una óptica universal e inclusiva con el fin de fortalecer la inclusión digital en la República Argentina" 48 .

El decreto dispone la conformación de la Comisión de Planificación y Coordinación Estratégica del Plan Nacional de Telecomunicaciones "Argentina Conectada", bajo la órbita del Ministerio de Planificación Federal, Inversión Pública y Servicios ${ }^{49}$; y sus objetivos tales como elaborar la propuesta de implementación del Plan, analizar y

\footnotetext{
${ }^{47}$ El decreto $\mathrm{N}^{\circ}$ 1552/2010 crea el Plan Nacional de Telecomunicaciones "Argentina Conectada" y la Comisión de Planificación y Coordinación Estratégica de dicho Plan. Declara de interés público el desarrollo, implementación y la operación de la Red Federal de Fibra Óptica. Consultado en www.argentinaconectada.gob.ar/

${ }^{48}$ Artículo $1^{\circ}$ del Decreto 1552/2010.

${ }^{49}$ Dicha comisión es presidida por el titular del Ministerio de Planificación Federal, Inversión Pública y Servicios e integrada por: Jefatura de Gabinete de Ministros, Ministerio de Industria, Ministerio de Trabajo, Empleo y Seguridad Social, Ministerio de Educación, Ministerio de Ciencia, Tecnología e Innovación Productiva, Ministerio de Salud, Ministerio de Relaciones Exteriores, Comercio Internacional y Culto, Secretaria de Comunicaciones Dependiente del Ministerio de Planificación Federal, Inversión Pública y Servicios, Comisión Nacional de Comunicaciones, Organismo Descentralizado en la órbita de la Secretaría de Comunicaciones dependiente del Ministerio de Planificación Federal, Inversión Pública y Servicios, Administración Nacional de la Seguridad Social (ANSES), organismo descentralizado en la órbita del Ministerio de Trabajo, Empleo y Seguridad Social, Comisión Nacional de Defensa de la Competencia, organismo descentralizado en la órbita de la Secretaria de Comercio Interior del Ministerio de Economía y Finanzas Públicas.
} 
recomendar políticas y estrategias en el desarrollo de las telecomunicaciones y la inclusión digital, asesorar a diferentes organismos sobre acciones para fortalecer las políticas públicas en esa materia, relevar proyectos y demandas del sector público, privado y de organizaciones sociales para articularlos e implementarlos, promover mecanismos de coordinación entre organismos con competencia en la materia y complementar los lineamientos estratégicos del Documento Base para la Estrategia de Agenda Digital de la República Argentina y las propuestas surgidas del Grupo de Trabajo Multisectorial $^{50}$.

"Argentina Conectada" se propuso promover el desarrollo, implementación y operación de infraestructura y provisión de equipamientos para brindar conectividad al 97 por ciento de la población del país, previendo la conexión satelital al 3 por ciento restante para 2015. Según el decreto, el plan se crea como marco que pretende articular “(...) las políticas públicas orientadas a reducir la brecha digital generando acciones para lograr la inclusión digital de distintos grupos poblacionales" $(\operatorname{Idem}, 3)^{51}$. En este contexto, la norma señala que la iniciativa es complementaria con el Sistema Argentino de Televisión Digital Terrestre (SATVD-T) a fin de optimizar los recursos y equipamientos, fomentando la utilización de servicios interactivos; y con el Programa Conectar Igualdad ${ }^{52}$ a partir de la provisión de servicios de conectividad a los establecimientos educativos públicos.

A cinco años de la sanción de la Ley de Servicios de Comunicación Audiovisual, la Autoridad Federal de Servicios de Comunicación Audiovisual (AFSCA) dio a conocer la convocatoria de audiencia pública para definir el Plan Nacional de Servicios de Comunicación Audiovisual Digitales. La resolución $N^{0}$ 938/2014 establece las condiciones de la transición de las emisoras de televisión hacia el apagón analógico

\footnotetext{
${ }^{50}$ El decreto 512/2009 crea el Grupo de Trabajo Multisectorial cuya finalidad es concertar e impulsar la "Estrategia de Agenda Digital de la República Argentina". Este Grupo es presidido por el Jefe de Gabinete de Ministros, su dirección ejecutiva estará a cargo del Secretario de Gabinete y Gestión Pública, e integrantes de los Ministerios de Ciencia, Tecnología e Innovación Productiva, de Educación, de Planificación Federal, Inversión Pública y Servicios, de Producción, de Relaciones Exteriores, Comercio Internacional y Culto, de Justicia, Seguridad y Derechos Humanos, de Salud, de Trabajo, Empleo y Seguridad Social, del Interior, de Desarrollo Social y de la Secretaria de Gabinete y Gestión Pública de la Jefatura de Gabinete de Ministros, e igual número de representantes por las entidades del sector privado, de la sociedad civil y del sector científico académico, cuya incorporación resolverá el Jefe de Gabinete de Ministros.

${ }^{51}$ Cita extraída de los Considerandos del Decreto No 1552/2010.

${ }^{52}$ El Programa Conectar Igualdad creado en 2010 mediante la firma del decreto $\mathrm{N}^{\circ} 459 / 10$, cuyo propósito es desarrollo de competencias para la integración en la cultura digital de estudiantes de escuelas secundarias y de institutos de formación docente públicos. A partir de la distribución y uso de equipamientos informáticos portátiles en las escuelas busca un impacto social más allá del educativo. Ver: https://www.argentina.gob.ar/educación.
} 
previsto para 2019 y fijó la fecha 19 de septiembre de 2014 para la realización de la audiencia pública para recoger opiniones sobre el proyecto de decreto de dicho plan.

Con el objetivo de avanzar en el ordenamiento del espectro radioeléctrico ${ }^{53}$, este proyecto dispone los derechos y las obligaciones de los licenciatarios actuales y futuros que presten servicios de televisión digital terrestre abierta. También, “(...) reasignará parámetros técnicos a las Universidades Nacionales para la prestación del servicio de televisión digital terrestre abierta, considerando la disponibilidad de espectro" 54 .

En diciembre de 2014, se aprobó y promulgó la Ley N²7.078 “Argentina Digital” que reemplaza la Ley $\mathrm{N}^{\circ} 19.798$ de Telecomunicaciones y regula la infraestructura del transporte de las comunicaciones: redes telefónicas, conexiones de banda ancha y de televisión por cable. Dispone la "neutralidad de la red", es decir, que no restringe los contenidos, sitios y plataformas o cantidad de datos descargados. Permite el ingreso de las compañías telefónicas para brindar servicios de comunicación audiovisual, planteando una excepción a la LSA que lo prohíbe y abre la posibilidad de generar un mercado convergente dominado por los grandes grupos de medios de comunicación. Aprueba la conformación de una nueva autoridad regulatoria: Autoridad Federal y Tecnologías de la Información y las Comunicaciones (AFTIC) pero no determina explícitamente sus funciones, misión y objetivos. Define como "servicio público en competencia" al segmento de mercado que alcanza a la distribución y de "interés público" al resto de los servicios (telefonía móvil).

Según Mastrini y Becerra (2016: 47), esta es una ley compleja que incorpora novedosamente la convergencia en la regulación argentina y que abre interrogantes sobre “(...) la vasta infraestructura de red de fibra óptica construida por el Estado a través del Programa "Argentina Conectada". (...) con la ventaja de que su tendido es más federal y no se reduce a los grandes centros urbanos. No obstante, a fines de 2015 estas redes de fibra óptica no estaban casi operativas y se desconocía cuál sería su modelo de gestión (...)".

El intrincado entramado normativo que sostiene la transición de la televisión digital terrestre muestra, por un lado, los esfuerzos de la política pública de mano del Estado por

\footnotetext{
${ }^{53}$ El espectro radioeléctrico utilizado para la difusión de un canal de televisión con tecnología analógica permite, con estas nuevas tecnologías, la transmisión de hasta 6 programas. En la práctica, esto significa que lo que antes se transmitía en seis canales radioeléctricos, mediante la utilización de la tecnología digital puede ser emitido ahora en un único canal radioeléctrico.

54 Artículo 10. Resolución $N^{\circ}$ 938/2014. Plan Nacional de Servicios de Comunicación Audiovisual Digitales.
} 
ampliar la base de regulación del escenario mediático y la cobertura a los sectores sociales postergados. Y, por otro, pone en evidencia la dificultad de adecuar ciertas decisiones tomadas en el devenir de la implementación de la TDA en relación con la Ley 26.255. Nos referimos particularmente a la regulación de la convergencia y el Triple Play ${ }^{55}$ que promueve "Argentina Digital" y colisiona con la prohibición de concentración del mercado mediático expresada en la Ley 26.255. Entre otras, estas inconsistencias abren preguntas sobre el desarrollo de la televisión digital terrestre.

El conjunto del plexo normativo de la TDA, junto a otras regulaciones de políticas de medios, con sus ventajas y desventajas ponen de relevancia la intervención del Estado para acompañar los cambios tecnológicos y culturales y avanzar en una propuesta de inclusión digital para los sectores más postergados de la sociedad. Dicha intervención no estuvo exenta de disputas con los grupos mediáticos concentrados y de acuerdos con sectores de la sociedad civil que pujaban por la desconcentración del mercado audiovisual.

\subsubsection{El Sistema Argentino de Televisión Digital Terrestre}

A partir de la conformación y puesta en funciones de los miembros del Consejo Asesor del SATVD-T ${ }^{56}$, mediante el Acta Aprobatoria $N^{o} 2(9 / 12 / 2009)$ se aprueba la Planificación Estratégica para la Implementación del SATVD-T, que define estrategias y acciones para desarrollar la ejecución del sistema de televisión digital terrestre y la realización del Plan Nacional de Servicios de Comunicación Audiovisual Digital del art. 93 de la ley 26.255 .

En abril del 2010, el Consejo Asesor aprueba el Reglamento General Operativo de acceso al equipamiento para la recepción de la Televisión Digital Abierta "Mi TV Digital" que se propone generar políticas y acciones para facilitar la universalización del beneficio vinculado con la transición tecnológica y la convergencia digital y, a la vez, producir mecanismos de integración dirigidos a aquellos grupos sociales que presentan riesgos de exclusión durante el proceso de transición tecnológica de la televisión analógica a la

\footnotetext{
55 Triple Play consiste en el permiso para las empresas telefónicas brinden servicios de comunicación audiovisual.

${ }^{56}$ Resolución $\mathrm{N}^{\circ}$ 1785/2009. Acuerdo para la conformación del Consejo Asesor del Sistema Argentino de Televisión Digital Terrestre. (24/9/2009). Boletín Oficial de la República Argentina, №31.744.
} 
televisión digital. Este reglamento determina el modo en que se distribuyen los equipos receptores digitales (STB) y los requisitos para definir el universo de población en riesgo de exclusión en el proceso de transición tecnológica. En este punto, determina dos grupos de destinatarios: establecimientos estatales y las organizaciones sociales por un lado, y hogares en situación socioeconómica vulnerable, por otro. Además, describe la operatoria para que los beneficiarios tengan la posibilidad de acceso a toda la información referida al Plan (proceso de solicitud, los trámites administrativos a cumplimentar, las características del equipo receptor, etc.).

La modalidad para acceder al equipamiento consiste en que, en primer lugar, el interesado lo solicite ante las delegaciones de la Unidad de Logística y Distribución ${ }^{57}$. La solicitud es evaluada por el Consejo Asesor, a través del Centro Único de Evaluación del Consejo Asesor (CUECA), en conjunto con el Instituto de Altos Estudios Sociales y la Escuela de Humanidades de la Universidad Nacional de San Martín (UNSAM) y con la colaboración de una Red de Universidades Metropolitanas. Una vez que se establezca el carácter de beneficiario, el decodificador digital es entregado en el domicilio del interesado en comodato con una vigencia de cinco años renovable por igual término si no se presentan inconvenientes.

Por otro lado, en junio de 2010, mediante el Acta Aprobatoria $N^{\circ} 7$, el Presidente del Consejo Asesor aprobó el Reglamento General del Plan Operativo de Fomento y Promoción de Contenidos Audiovisuales Digitales que establece los lineamientos operativos del Subprograma Polos Audiovisuales Tecnológicos. El mismo se propone fomentar la producción nacional de contenidos audiovisuales digitales, a partir de la promoción y constitución de nueve polos ${ }^{58}$ de investigación y perfeccionamiento de

\footnotetext{
${ }^{57}$ De la Unidad de Logística y Distribución intervienen Correo Argentino (mediante Convenio de Servicio de Distribución de Paquete Logístico [STB]), Identificación de Destinatario y Suscripción de Contrato de Comodato, firmado el 02/06/2010 con su Adenda firmada 05/10/2012; Convenio Servicio de Distribución de Paquete Logístico (STB), Soporte Técnico, Instalación Antenas, firmado el 28/02/2011 con sus dos Adendas firmadas el 16/12/2011 y el 11/01/2012 respectivamente; y el Convenio de Digitalización y Archivo firmado el 04/03/2011) y Correo Andreani S. A. (mediante el Contrato de Servicios Logísticos y Distribución de Receptores y Digitalización y Guarda de Documentos firmado el 27/09/2011).

${ }^{58}$ Los nueve polos son: Centro (Córdoba, San Luis y La Pampa, con cabecera en la Universidad Nacional de Villa María); Cuyo (San Juan, Mendoza y La Rioja, con cabecera en la Universidad Nacional de Cuyo); Litoral (Entre Ríos y Santa Fe, con cabecera en la Universidad Nacional de Entre Ríos); Metropolitano (Ciudad Autónoma de Buenos Aires y el Conurbano Bonaerense, con cabecera en la Universidad Nacional del Arte (UNA) y en la Universidad Nacional de Tres de Febrero); NEA (noreste argentino - Misiones, Formosa, Chaco y Corrientes, con cabecera en la Universidad Nacional de Misiones); NOA (noroeste argentino - Jujuy, Salta, Tucumán, Santiago del Estero y Catamarca, con cabecera en las Universidades Nacionales de Jujuy y Tucumán); Patagonia Norte (Neuquén y Río Negro, con cabeceras en las Universidades Nacionales de Río Negro y Comahue); Patagonia Sur (Chubut, Santa Cruz y Tierra del Fuego, con cabecera en las Universidades Nacionales Patagonia Austral y San Juan Bosco); Provincia de Buenos Aires (integrado por las localidades de esta provincia, con cabecera en la Universidad Nacional del
} 
tecnologías audiovisuales digitales regionales con un sistema federal en red para la capacitación, equipamiento, promoción, investigación y desarrollo, y testeo $\mathrm{y}$ demostración de contenidos, integrando a los diferentes actores de la sociedad civil vinculados a la producción audiovisual. La organización regional de los Polos Audiovisuales Tecnológicos -integrados por Universidades nacionales junto a organizaciones sociales- contiene a su vez a los Nodos que funcionan como sistemas productivos locales. El objetivo último es la producción de contenidos para fortalecer la televisión digital con una mirada regional a partir de la participación de universidades nacionales, productoras independientes, organizaciones sociales, organismos públicos locales.

Asimismo, en vistas a la promoción de contenidos audiovisuales para TV, el fortalecimiento de las capacidades productivas en el territorio nacional y la generación de empleo se crearon las siguientes plataformas digitales abiertas:

- ACUA FEDERAL (Árbol de Contenidos Universales Argentino): una señal que reúne contenidos elaborados por pequeños y grandes productores de las provincias argentinas. La grilla incluye formatos de entretenimiento, música, cultura, ficción y espacios de experimentación e hibridación de géneros.

- ACUA MAYOR: un espacio donde los contenidos están dirigidos a desmitificar las representaciones instaladas sobre los adultos mayores.

- BACUA (Banco de Contenidos Universales Digitales): dispone de contenidos audiovisuales para nuevos espacios de emisión como para los ya existentes, de libre acceso y de distribución gratuita. Reúne a productores independientes de todas las provincias, organismos gubernamentales y no gubernamentales, universidades, agrupaciones sociales, culturales y señales que cuenten con producciones propias para ser distribuidos gratuitamente a los canales de televisión del territorio nacional.

- CDA (Contenidos Digitales Abiertos): plataforma que integra las políticas de promoción de contenidos audiovisuales digitales que lleva adelante el Estado Nacional, a través del Ministerio de Planificación Federal, Inversión Pública y

Centro). Para ampliar la información sobre la estructura e implementación de Polos Audiovisuales Tecnológicos se recomienda consultar el Reglamento Operativo de los Polos de Investigación y Perfeccionamiento de Tecnologías Audiovisuales Digitales en http://www.unl.edu.ar/tvdigital/wpcontent/uploads/2012/03/REGLAMENTO_OPERATIVO_POLOS.pdf. 
Servicios. CDA ofrece la modalidad video bajo demanda de manera gratuita. Permite acceder a series de ficción, documentales, unitarios, películas, deportes, eventos especiales y contenidos exclusivos, entre otros. Se sustenta con las producciones ganadoras de los concursos del Plan de Fomento TDA, disponibles actualmente en el Banco Audiovisual de Contenidos Universales Argentino (BACUA), y de otros actores del sector audiovisual.

La puesta en marcha del SATVD-T junto a la producción de contenidos digitales con rasgos de federalismo (productores independientes, organizaciones sociales, universidades, etc., del todo el país) requirió de una fuerte inversión económica, tecnológica y política, uno de sus principales fines fue incidir en el mercado televisivo a la vez que integrar a aquellos sectores sociales con riesgos de exclusión al proceso de transición digital.

\subsection{EI Plan "Mi TV Digital”: características e implementación}

En el marco del SATV-D, el plan de acceso gratuito "Mi TV Digital" ha entregado, hasta fines de 2015, más de $1.000 .000^{59}$ equipos receptores terrestres a hogares, establecimientos y organizaciones sociales y 28.448 kits satelitales. Como complemento, también se instalaron más de 5.000 antenas de TV Digital Satelital (TDS) en parajes rurales y más de 12.000 en escuelas rurales y de frontera.

El objetivo del Plan es distribuir receptores digitales entre la población “(...) con riesgos de exclusión durante el proceso de transición tecnológica" ${ }^{60}$. Los potenciales destinatarios son:

- Establecimientos estatales que tengan por finalidad y/o función el desarrollo de actividades sociales, culturales, educativas y/o de promoción de contenidos audiovisuales.

- Organizaciones sociales: asociaciones civiles sin fines de lucro, fundaciones o cooperativas, que tengan por objeto el desarrollo de actividades sociales, culturales, educativas y/o de promoción de contenidos audiovisuales.

\footnotetext{
${ }^{59}$ Dado que hemos encontrado fuentes que ofrecen datos que difieren entre sí (van desde 1.200.000 hasta 1.600.000 de receptores digitales repartidos) optamos por ubicar la cantidad en más de 1.000.000.

60 Fragmento extraído del sitio oficial de la TDA: www.tda.gob.ar. Recuperado antes del cambio de gobierno en diciembre de 2015.
} 
- Hogares: titulares de alguna de las siguientes condiciones: pensiones no contributivas: pensión a la vejez (mayores de 70 años, madres de 7 o más hijos, invalidez/ discapacidad- personas que presenten $76 \%$ o más); Asignación Universal por Hijo (AUH); jubilaciones y/o pensiones con haberes mínimos nacionales y/o provinciales; beneficiarios de planes sociales de algún tipo que se encuentren contemplados en alguno de los padrones de los organismos gubernamentales; aquellos integrantes de hogares en situación de vulnerabilidad que no se encuentren contemplados en las nombradas categorías.

Para recibir el beneficio, el interesado debe completar un formulario de solicitud ${ }^{61}$ al que se puede acceder en oficinas del Correo Argentino y Correo Andreani S. A.; en el sitio web del Consejo Asesor; instituciones públicas y/u organizaciones sociales que adhieran al Plan; eventos especiales organizados por autoridades nacionales y/o locales para tal fin. La presentación de la solicitud debe estar acompañada de documentación respaldatoria ${ }^{62}$ para que el CUECA proceda a su evaluación. Admitida dicha solicitud, los beneficiarios reciben un equipo receptor en comodato compuesto por: un receptor STB en UHF; un control remoto con las baterías correspondientes; una antena para interiores de UHF; un cable de $220 \mathrm{~V}$; un cable RCA para conexión: audio y video; un cable antena coaxil 75 Ohm para TV (será definido de acuerdo a las necesidades técnicas y disponibilidad); un manual del usuario en idioma español con teléfono de atención al cliente.

Entre las responsabilidades del beneficiario se encuentran: garantizar el cumplimiento de las condiciones de uso y comprometerse con el debido cuidado del equipamiento por lo tanto los equipos receptores no pueden ser vendidos, ni enajenados, ni transferidos parcial o totalmente, en forma transitoria o permanente, ni arrendados a terceros en forma gratuita ni onerosa, ni bajo ningún otro título. Si el receptor se daña o funciona mal, el responsable debe comunicarse con el fabricante para ejecutar la garantía que se otorga en caso de encontrarse dentro del período de vigencia. Cualquier otra situación se debe comunicar al Centro de Atención Telefónica al Público para que se le informe el procedimiento a seguir. En el caso de los establecimientos estatales y las organizaciones sociales deben asegurar que el o los receptores se encuentren destinados a actividades sin fines de lucro, y que sean de acceso libre y gratuito, no pudiendo ser objeto de comercialización. Y las organizaciones sociales deben realizar al menos una actividad comunicacional con el

\footnotetext{
${ }^{61}$ Ver en Anexo I.

62 Ver en Anexo I.
} 
objetivo de difundir en la comunidad en la que intervienen los beneficios de la TDT, en la que se efectúe una demostración de imágenes y contenidos en señal digital.

Los beneficiarios del Plan "Mi TV Digital”, entre 2014 y 2015, dispusieron del siguiente paquete de señales de distribución nacional: Encuentro, PAKA PAKA, TATETI, INCAA TV, Tecnópolis, TV Pública HD, Construir, DEPORTV HD, Vivra, Arpeggio, Viajar, CN23, C5N, TeleSur, 360. Para Buenos Aires -Canales adicionales: DIGO TV HD y TV Universidad HD. Para CABA y AMBA -Canales adicionales: Canal 26 HD, Telemax, C5N HD, Stars HD, Telefe HD, ACUA Mayor, Canal 9 HD, ACUA Federal, América HD, A24. Para la provincia de Chaco - Canales adicionales: Chaco TV. Para Córdoba Canales adicionales: Cba24N, Canal 10 de Córdoba. Para Formosa-Canales adicionales: Lapacho TV. Para Jujuy -Canales adicionales: Canal 7 Jujuy. Para La Pampa -Canales adicionales: Canal 3 Santa Rosa. Para La Rioja -Canales adicionales: Canal 9 La Rioja. Para Mendoza - Canales adicionales: Acequia TV, Señal U. Para Misiones -Canales adicionales: TV Canal 12 Posadas. Para Santa Fe -Canales adicionales: Canal 5 Rosario. Para Santiago del Estero -Canales adicionales: CAS TV Sgo. Del Estero HD.

La implementación de este plan de acceso se previó en varias etapas cuyo inicio se centró en el área metropolitana de Buenos Aires para luego expandirse hacia las ciudades del resto de Argentina. El objetivo principal fue repartir 1.200.000 decodificadores digitales durante 2010 “(...) pero sólo se distribuyeron poco más de 200 mil y a mediados de 2011 la cifra se había elevado a 300 mil. Además, a los fabricantes de televisores y celulares, el gobierno les pidió que empezaran a fabricar y comercializar dispositivos aptos para captar la TDT destinados fundamentalmente a los sectores que no son subsidiados por el Estado" (Krakowiak, Mastrini, Becerra, 2012: 74). Según estos autores, esos retrasos se debieron a la dilación en la ampliación del área de recepción del dispositivo y al escaso interés entre la población beneficiaria dada la oferta limitada de contenidos en los inicios de la TDA.

Por otro lado, un informe de la Auditoria General de la Nación de 2014, que auditó la adquisición y distribución de decodificadores para Televisión Digital Terrestre entre el $1^{\circ}$ de mayo de 2012 y el 30 de junio de 2013, advierte que existen ciertas dificultades en la entrega de receptores digitales en el territorio nacional.

El informe observa imprecisiones ${ }^{63}$ en la adquisición de los STB por parte de ARSAT (Empresa Argentina de Soluciones Satelitales Sociedad Anónima), a la vez que centra la

63 "Respecto al accionar en la adquisición de los equipos receptores para la señal de la Televisión Digital Terrestre (TVDT) Set Top Box (STB). La empresa ARSAT no justificó la decisión de llevar adelante una 
auditoría en la distribución de los decodificadores digitales. Al respecto señala que en las notas emitidas por el Consejo Asesor SADTV-T se utilizan indistintamente los términos receptor, decodificador y requirente (o sea beneficiario y equipo receptor STB) como también receptores liberados y/o entregados.

En relación con las entregas de los STB, el informe indica que el Consejo Asesor SADTV$\mathrm{T}$ no posee documentación que permita establecer la cantidad de decodificadores entregados desde el inicio del Plan hasta el mes de abril de 2012:

"Con referencia, a los equipos receptores STB (...) existe el impedimento de afirmar con certeza la cantidad a la cual asciende, y en cuanto a la información que suministra ARSAT sobre estas entregas carece de la documentación sustentatoria suficiente.

Respecto a los datos personales que debe completar el beneficiario, en el formulario de adhesión al Plan Operativo de Acceso al Equipamiento (Comodato), no consta su domicilio personal, además de verificarse que en gran número no poseen los datos personales completos para el resguardo necesario del equipo entregado.

Por su parte, se ha verificado la ausencia de una base de datos informática, unificada y completa, la cual incluya la totalidad de los datos relacionados con la distribución de los equipos receptores STB relacionada con los datos de los beneficiarios y de los equipos entregados a cada uno". (Informe AGN N 80/2012, 2014: 55)

Estas observaciones concluyen señalando que el Consejo Asesor SADTV-T informó su compromiso para llevar a cabo las “(...) medidas necesarias para mejorar u optimizar los procedimientos de seguimiento y/o control del SATVD-T, las que quedan sujetas a verificaciones en futuras auditorías por parte de esta AGN" (Informe AGN N 80/2012, 2014: 56).

Tomando en cuenta este informe, resulta difícil determinar con precisión la cantidad de decodificadores digitales distribuidos en el país como tampoco se ha informado oficialmente el monto invertido en su desarrollo (Becerra, 2015: 42).

contratación directa con INVAP, más aún, en esta contratación para la provisión del sistema de SATVD-T, se realizaron modificaciones en el contrato original que alteraron los precios pactados y las cantidades autorizadas; constatándose además, la indebida participación de un miembro del Directorio que aprobó este contrato y las seis adendas suscriptas, a excepción de la Adenda 4; verificándose que no se han adoptado medidas ante el incumplimiento de INVAP de la prohibición impuesta de subcontratar el objeto principal del contrato suscripto entre las partes. Asimismo, en la ejecución del contrato refrendado como Acuerdo Específico entre ARSAT e INVAP no respeta lo acordado en el Convenio Marco de Colaboración, no obstante haberse basado en este último.

Por su parte, la composición de la garantía de cumplimiento del contrato no se ajusta al Reglamento para la Adquisición, Enajenación y Contratación de Bienes y Servicios de ARSAT, sin dejar de mencionar que se incumplió con la obligación de llevar adelante una auditoria de precios y adquisiciones, por parte de su Auditor Interno y una Universidad o Consultora Internacional de primer nivel" (Informe AGN No 80/2012, 2014: 54). 


\subsubsection{La comunicación del Plan "Mi TV Digital”}

Finalmente, otro de los aspectos del lanzamiento e implementación de la TDA en Argentina incluyó campañas de difusión en medios gráficos, audiovisuales e interactivos sobre las principales características del Plan: presentación de la política pública, destinatarios, modos de acceso al beneficio y contenidos.

En este punto, nos interesa describir los rasgos generales de la estrategia comunicativa ${ }^{64}$ de lanzamiento de la TDA (objetivos, modalidad de comunicación, destinatarios) ya que nos permite aportar elementos de análisis tanto en relación con el discurso oficial de la política pública como con la perspectiva de los usuarios de la televisión digital en el período estudiado. Para ello, tomaremos la difusión de la política pública en medios gráficos, audiovisuales e interactivos ${ }^{65}$.

En los principales medios gráficos de circulación nacional en su versión online (Clarín, La Nación, Página 12) las notas periodísticas (entre mediados de 2009 y mediados de $2011^{66}$ ) destacaron el anuncio de la puesta en marcha de la televisión digital y el reparto de decodificadores digitales.

Más allá de los perfiles editoriales de cada uno de los periódicos mencionados ${ }^{67}$, la cobertura informativa estuvo orientada a presentar datos sobre la inversión presupuestaria del Estado nacional, precisiones sobre el plan tales como destinatarios, cantidad de decodificadores digitales e instalación de antenas.

\footnotetext{
${ }^{64}$ Entendemos a la estrategia comunicativa o de comunicación como la define Uranga: "La aplicación adecuada y coherente de medios y recursos de comunicación, con la finalidad de generar, en primer lugar, los sentidos (políticos, sociales y culturales) que le den sustento argumental a la misma y, en segundo término, de forjar procesos a través de los cuales la política pública en cuestión alcance los objetivos y las metas propuestas, produciendo resultados que modifiquen adecuada y satisfactoriamente el ámbito de acción sobre el cual se está trabajando e impacto positivo en la calidad de vida de los ciudadanos y ciudadanas involucrados" (Uranga, 2011: 9).

${ }^{65}$ En el apartado 5.1.2. del capítulo $\mathrm{V}$ detallamos los criterios con los que analizamos el material periodístico y audiovisual. En el anexo IV se encuentra la ficha de análisis de las notas periodísticas.

66 Entre las notas periodísticas que consultamos se encuentran: https://www.lanacion.com.ar/politica/empezo-el-reparto-de-decodificadores-de-tv-del-gobierno-

nid1274826; https://www.lanacion.com.ar/politica/el-gobierno-abrira-mas-canales-de-tv-nid1350154; https://www.clarin.com/politica/cristina-presento-internet-tv-digital_0_HJdOdqipDQx.html;

https://www.pagina12.com.ar/diario/economia/2-145087-2010-05-04.html;

https://www.pagina12.com.ar/diario/elpais/1-170592-2011-06-22.html;

https://www.pagina12.com.ar/diario/elpais/1-170593-2011-06-22.html;https://fortuna.perfil.com/2010-

03-24-23058-la-tv-digital-oficial-debutara-con-los-beneficiarios-de-planes-sociales-y-cinco-canales/.

${ }^{67}$ En el campo de estudios de comunicación existe cierto acuerdo entre los investigadores críticos que identifican las posiciones de enfrentamiento con el gobierno por parte de Clarín y La Nación durante la gestión de Cristina Fernández. En el caso de Página 12, reconocen que este periódico adoptó una postura de cierto acuerdo con las políticas gubernamentales durante dicho período.
} 
La presentación de la política pública TDA en los diferentes medios gráficos de circulación nacional (La Nación, Clarín, Página 12) fueron publicados entre marzo y octubre de 2010 .

LA NACION POLITICA

\section{Empezó el reparto de decodificadores de TV del Gobierno}

Entreagaron 10.000 conversores en la Capital y el GBA antes del Mundial; hay listas de espera

Mariano Obarrio

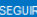

14 de junio de 201

\section{(Q) (13)}

(125) Me gusta compar

1 reparto de los decodificadores digitales comenzó. A paso cansino, pero se largó antes del Mundial. El gobierno de Cristina Kirchner comenzó la semana última el reparto de los conversores Set Top Box (STB) para televisión digital y entregó 10.000 aparatitos entre sectores de menores recursos de la Capital Federal y del conurbano

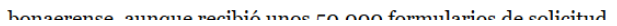

RECOMEI

Villa Gesell: I memes contr de los acusa

Murió Claudi juez federal c Divina comid Rincón sobo azafata para

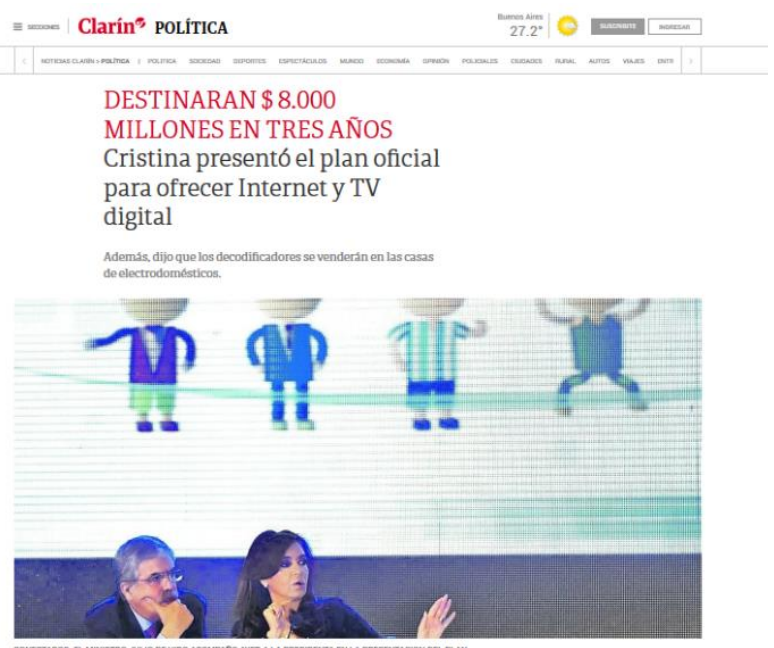




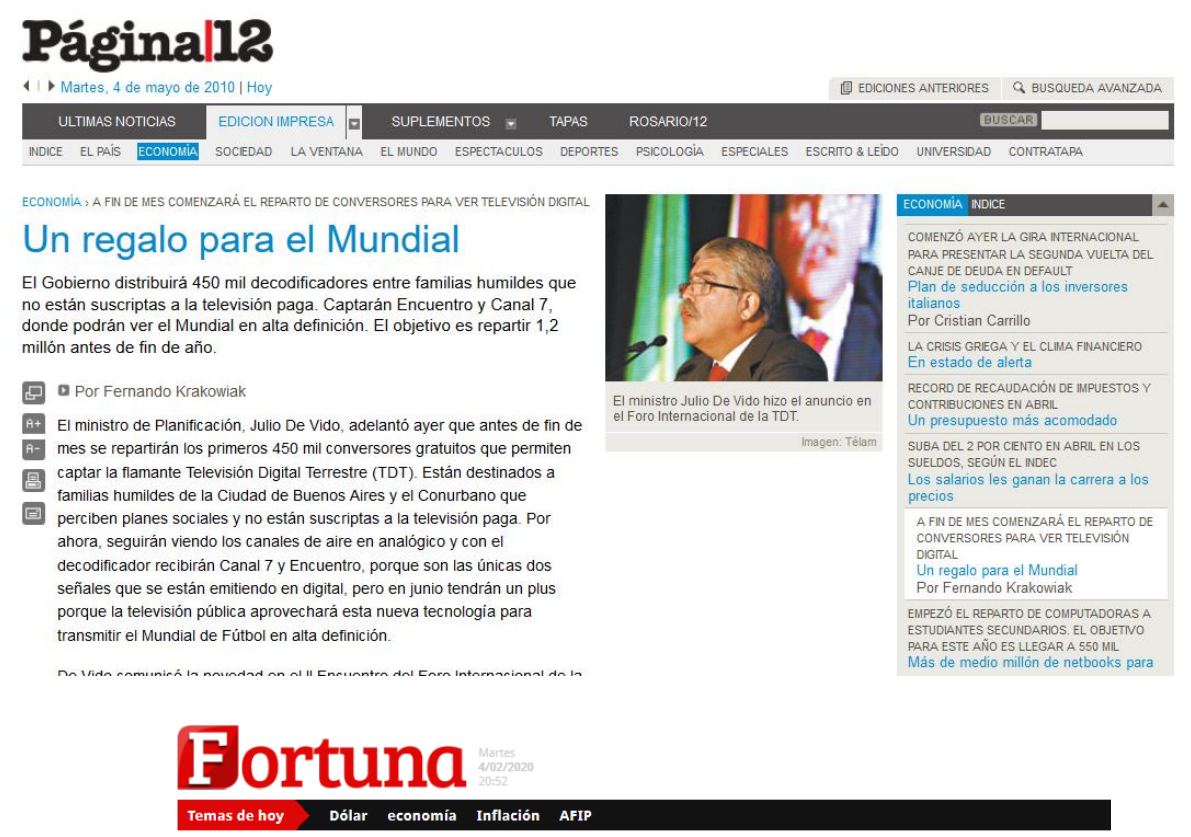

\section{La TV digital oficial debutará con los beneficiarios de planes sociales y cinco canales}

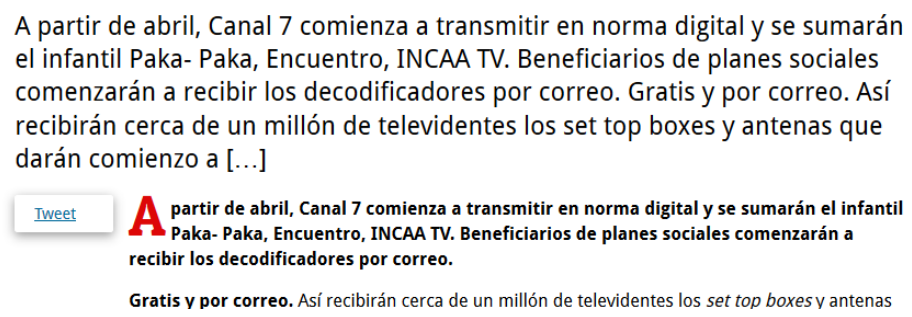

Como mencionamos más arriba, la información se centró en el presupuesto asignado a la política pública, la cantidad de decodificadores digitales y antenas repartidos o a repartir entre los beneficiarios, localidades y señales de TV digital.

En un inicio, la presentación de la información sobre la TDA estuvo orientada a dar a conocer los rasgos principales: modalidades de distribución (a domicilio, en ANSES, en Tecnópolis) o características de los set top box pero fundamentalmente, se ocuparon de subrayar que la decisión del gobierno de dar a conocer la entrega de los kits digitales estaba vinculada con la proximidad del Mundial de Fútbol de 2010.

En el año 2011, se fueron publicando notas que mostraban los avances de la TDA tanto en cobertura territorial como en contenidos y programación. También hacen referencias a la intersectorialidad de la política pública, como por ejemplo: el avance del Plan de Telecomunicaciones "Argentina Conectada" para consolidar un modelo de desarrollo con 
inclusión social o el lanzamiento del Plan "TV Para Todos", que en sus orígenes estuvo dirigido particularmente a jubilados y pensionados.

\title{
Páginal12
}

\begin{tabular}{|c|c|c|}
\hline 1) Sába & 目 EDICIONES & SANTERIORES \\
\hline SUPLEMENTOS $=$ TAPAS & ROSARIO/12 & BUSCAB [ \\
\hline $\begin{array}{l}\text { INDICE EL PAIS ECONOMIA SOCIEDAD CULTURA DIGITAL LA VENTANA EL MUND } \\
\text { DE TAPA }\end{array}$ & ES PSICOLOGI & A UNIVERSIDAD CONTRATAPA PIRULO \\
\hline EL PAís , EMPEZŹ AYER EL PRIMER ENCUENTRO NACIONAL DE COMUNICACIÓN AUDIOUISUAL & & EL PAIS INDICE \\
\hline Poniéndole contenidos a la ley & & LA CAMMARA FEDERAL CO \\
\hline $\begin{array}{l}\text { Funcionarios y representantes de los distintos sectores de la comunicación } \\
\text { debatieron sobre las posibilidades que abre la televisión digital y la } \\
\text { exigencia de la ley de cubrir el } 70 \text { por ciento de la grilla con producción } \\
\text { nacional. }\end{array}$ & & $\begin{array}{l}\text { AVIADORES Y UN ABOGADO POR LOS } \\
\text { VUELOS DE LA MUERTE } \\
\text { Pilotos, cada vez más cerca del juicio } \\
\text { oral } \\
\text { Por Diego Martinez } \\
\text { DELLTOS SEXUALES Y DICTADURA }\end{array}$ \\
\hline 回 D Por Ailín Bullentini & & \\
\hline A+ Desdes Mar del Plata & & $\begin{array}{l}\text { PANoRAma PoLitico } \\
\text { Las explicaciones de Obama } \\
\text { Porluis Bryuschtein }\end{array}$ \\
\hline $\begin{array}{l}\text { En el marco del Primer Encuentro Nacional de Comunicación Audiovisual, el } \\
\text { ministro de Planificación. Julio De Vido. destacó gue 'uno de los mayores }\end{array}$ & SUENOT & $\begin{array}{l}\text { Por Luis Bruschtein } \\
\text { Nueve años de condena }\end{array}$ \\
\hline 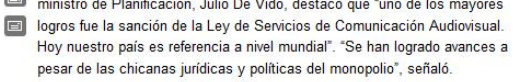 & $\begin{array}{l}\text { SUNDOAS } \\
\text { "El Iimpetu de la TV digital } \\
\text { Por Alilin Bullentini }\end{array}$ & 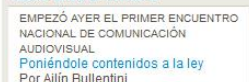 \\
\hline Acompañado por el secretario de Medios, Juan Manuel Abal Medina, y el & & Por Allin Bullentini \\
\hline $\begin{array}{l}\text { titular de la Autoridad Federal de Servicios de Comunicación Audiovisual } \\
\text { (Afsca), Gabriel Mariotto, el ministro anunció que "para julio del año próximo }\end{array}$ & & $\begin{array}{l}\text { POLÉMICA ENTRE LOS RADACALES } \\
\text { GERARDO MOOALES Y SANDRA AROBOÓ } \\
\text { Palabras CUZZadas en la UCR }\end{array}$ \\
\hline el 90 por ciento de los hogare & & Plan para un avión sudamericano \\
\hline Abierta" (ver recuadro). & & 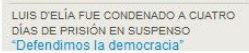 \\
\hline
\end{tabular}

\section{El Gobierno abrirá más canales de TV}

\author{
En el año electoral, planifica distribuir 12 señales en la Capital \\ Jesica Bossi \\ (2) (0) \\ 15 de febrero de 2011

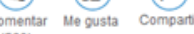 \\ E $\mathrm{n}$ el comienzo del año electoral, el Gobierno quiere competir con la TV por cable \\ y cambiar el mapa de medios con 12 nuevas señales en la Capital y un centenar \\ en el interior.
}

Así, el kirchnerismo avanza en el otorgamiento de una enorme cantidad de nuevos canales de televisión abierta, como parte de una movida que modificará el panorama de

\section{Páginal12}

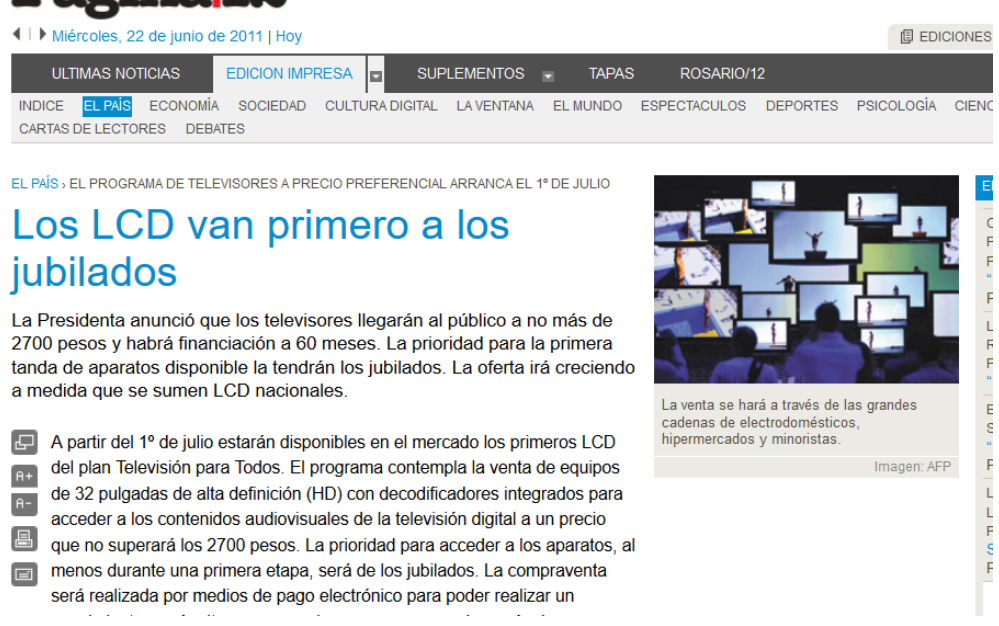


Finalmente, el encuadre informativo de los diarios argentinos de circulación nacional se enfocó en los datos que surgían de la implementación de la TDA. En el caso de dos de ellos: La Nación y Clarín pusieron en su agenda los conflictos que mantenían con la gestión de Cristina Fernández a partir de la opinión de especialistas que no acordaban con la política pública. Por otro lado, Página 12 desarrolló las noticias con cierto detalle consultando a los funcionarios y a expertos en la materia con afinidad política con el gobierno.

Sin embargo, debemos advertir que la prensa no fue la principal vía de difusión del Plan. En cambio, los spots en televisión abierta (particularmente, emitidas en la TV Pública) y en internet (YouTube, Facebook, Twitter) ${ }^{68}$ fueron una fuerte apuesta en la difusión de "Mi TV Digital".

En la fase de lanzamiento de la TDA (2010), la producción audiovisual tuvo como objetivo presentar el Plan "Mi TV Digital" con especial énfasis en los destinatarios (beneficiarios de $\mathrm{AUH}$, jubilados y pensionados, organizaciones sociales, entre otros); en el modo de acceso al beneficio así como también en las características técnicas y de contenidos de la televisión digital. Por ejemplo, en el spot audiovisual denominado "Plan de Acceso"69, TDA expresa en voz en off:

Seguimos democratizando las comunicaciones. Llega TDA. Televisión Digital Abierta. Una nueva manera de ver tele para todo el país con mayor calidad y sin pagar abono. Esta nueva tecnología la vas a poder ver en tu televisión de siempre. Solo necesitas un equipo receptor y ya podés ver la tele digital. En una primera etapa se van a entregar los receptores en la Ciudad de Buenos Aires y en el Conurbano Bonaerense. Lo van a recibir gratis, entre otros, quienes perciban una asignación universal por hijo, jubilados o pensionados con remuneración mínima, organizaciones sociales sin fines de lucro, establecimientos educativos estatales y quienes sean beneficiarios de cualquier otro plan social. Para pedir tu equipo tenés que ir a una oficina del Correo Argentino, completar la solicitud y te lo van a entregar en tu domicilio. Si tenés alguna duda o querés más información sobre cómo recibir tu equipo gratis podés llamar al 130, al 0800-888-6488 o podés ingresar a www.mitvdigital,gov.ar. El país cambió, la tele también. La estamos cambiando entre todos. TDA Televisión Digital Abierta.

\footnotetext{
${ }^{68}$ La mayoría de los productos audiovisuales se encuentran en el canal de YouTube "Prensa TDA": Cuenta Oficial de Contenidos TDA BACUA (disponible, con spots de propaganda, entrevistas a funcionarios ligados al Plan, videos sobre el avance en la implementación de la TDA y de las diferentes ediciones del programa federal "Panorama Argentino"). Para el análisis, hemos identificado y nos centramos en las piezas audiovisuales que formaron parte del lanzamiento de la televisión digital durante el período estudiado en esta tesis.

69 "Plan de Acceso". Spot de propaganda de TDA, con fecha 24/09/2010, disponible en https://www.youtube.com/watch?v=_Q2xucl1B2I (Consultado el 9 de septiembre de 2015).
} 
Pero más allá de la presentación y de las características de la política pública, podemos observar que en el texto de las piezas audiovisuales se destacan ideas fuerza que por un lado, aluden a la televisión digital como herramienta para la democratización de la comunicación y la inclusión social; y por otro, como generadora de empleos y desarrollo tecnológico. En el spot "Institucional"70, la voz en off refiere lo siguiente:

Una televisión que nos une. Más nuestra. Más plural. Más federal. Producción nacional. Más tecnologías. Televisión móvil. Más contenidos. Información. Cultura. Entretenimiento. Mejor televisión. Servicios Interactivos. Más funciones. Una televisión que evoluciona. Alta definición. Mejor imagen. Mejor sonido. Gratis para todos. Más nuestra. Más canales que hablan de lo nuestro. Inclusión social. Generación de empleo. 200.000 puestos de trabajo directos y 360.000 indirectos. Nuevas voces, Desarrollo Tecnológico. Gratis. 10 millones de hogares, 12 millones de televisores. Nuestra televisión. SATVD-T (Sistema Argentino de Televisión Digital Terrestre).

En 2011, la producción audiovisual se compuso de algunas piezas explicativas para la conexión del decodificador digital en los domicilios y el uso de la televisión digital con indicaciones sencillas y breves $^{71}$. Con imágenes simples y texto instruccional guía al interlocutor para realizar las operaciones necesarias y llevar adelante el proceso de instalación y/o modalidades de uso de la televisión digital a partir del manejo de los menús de la interface.

Pero fundamentalmente, la estrategia de difusión de la TDA puso el centro de atención en la gratuidad de la TDA, la cantidad de beneficiarios alcanzados, la calidad de imagen y la producción local de los contenidos televisivos. En este marco, las ideas fuerza que se manifiestan en estas piezas remiten al acceso a las tecnologías, en este caso la televisión digital, como vía hacia la inclusión social en tanto interpelan a aquellos ciudadanos comprendidos en la política pública en la que son identificados como: "en riesgo de exclusión digital". Los siguientes spots audiovisuales, "TV Digital” y "TDA" 72 , enuncian:

\footnotetext{
70 "Institucional". Spot de propaganda de TDA, con fecha 24/09/2010, disponible en https://www.youtube.com/watch?v=bis9DR0o9Ew (Consultado el 20 de agosto de 2015).

${ }^{71}$ Entre las piezas audiovisuales de este tipo se encuentran: "TV Digital Argentina. Mi TV Digital", Spot de propaganda de TDA. 24/8/2011, disponible en https://www.youtube.com/watch?v=1jCr_cvujUQ.; "Como conecto mi Deco", Spot de propaganda de TDA. 19-8-2011, disponible en https://www.youtube.com/watch?v=-nEhj-NDgKs (Consultados el 12 de noviembre de 2014).

72 "TV digital", Spot de propaganda de TDA. 18/3/2011, disponible en https://www.youtube.com/watch?v=OruVZK4J__U; "TDA”, Spot de propaganda TDA. 27/10/2011, disponible en https://www.youtube.com/watch?v=2ymopEdvaOY (Consultados el 12 de noviembre de 2014).
} 
Noticias, cultura, música, arte, cine, infantiles. La televisión pública y todo el fútbol. Gratis. En calidad digital. Esto y mucho más es TDA (Televisión Digital Abierta). Una nueva forma de ver televisión. Ya son 14 los canales que podés ver con la mejor calidad y sin pagar abono. Y muy pronto se agregarán más señales y los canales de aire de cada localidad. "La televisión digital argentina, más plural, más diversa. A la que tengamos acceso todos y en la que todos tengamos voz porque hay un mundo nuevo" (voz e imagen de Cristina Fernández en lanzamiento de la TDA). 1.000.000 de argentinos ya disfrutan de la Televisión Digital Abierta. Si sos jubilado o pensionado con remuneración mínima, recibís AUH o sos beneficiario de cualquier plan social podés acceder a tu decodificador, gratis. Llamá al 0800888-6488 o entrá en www.tvdigitalargentina.gov.ar y averiguá si ya está disponible en tu localidad. Para democratizar las comunicaciones: Televisión Digital Abierta no te cuesta nada. Finaliza con placa: Argentina con vos siempre. Presidencia de la Nación.

Este año entre todos ya logramos que más de 3 millones de argentinos tengan acceso a la TDA. Casi 10 veces más que en 2010. Una televisión para todos. Otra forma de inclusión. ¿Sabés por qué lo conseguimos? Por nuestra gente. Finaliza con placa: Argentina. Un país con buena gente. Presidencia de la Nación.

Entre 2012 y 2015, la difusión de la TDA fue reforzando la gestión de la política pública, aludiendo a la distribución de los decodificadores digitales, la suma de canales a la grilla de programación, la producción de contenidos locales haciendo foco en los beneficios del acceso a la televisión digital por parte de los beneficiarios. Por ejemplo, el spot "Más de 6 millones de argentinos disfrutan el Mundial gratis y en HD por TDA"73 presenta el caso de Loma Blanca (Provincia de Jujuy), que a través de testimonios de niños muestra que gracias a la TDA sus habitantes pudieron ver el Mundial de 2014.

Otro de los rasgos que nos interesa describir de la estrategia comunicativa de la TDA es la/s modalidad/es de comunicación construida/s desde la gestión de la política pública y que podemos identificar en las piezas audiovisuales difundidas mediante el sistema de televisión pública abierta así como también en sitios de internet. Entre las modalidades de comunicación se encuentran: comunicación política, comunicación institucional, comunicación de campaña, comunicación gubernamental, comunicación pública ${ }^{74}$. En

\footnotetext{
73 Spot de propaganda de TDA, con fecha 25/06/2014, disponible en https://www.youtube.com/watch?v=IoVFIWgSmg8 (Consultado el 9 de septiembre de 2015).

${ }^{74}$ Para pensar la comunicación en y desde la gestión de gobierno, como plantea Vargas, T. (2018) se deben diferenciar modalidades y propósitos específicos de la comunicación en el ámbito público. Entendiendo que su objetivo es la interpelación de los ciudadanos se distinguen: comunicación política, institucional, pública, de campaña y gubernamental propiamente dicha. Para ampliar sobre esta clasificación se puede consultar: Vargas, T. (2018): “Comunicación de gobierno: aportes para su comprensión”, en Massoni, S., Uranga, W., Longo, V. (2018). Políticas Públicas y Comunicación. Una cuestión estratégica. Nueva Editorial Universitaria - U.N.S.L., ISBN 978-987-733-122-6. San Luis. Provincia de San Luis.
} 
nuestro caso, tanto la comunicación pública como la comunicación de gobierno resultan pertinentes a efectos de la caracterización de la estrategia de comunicación de la televisión digital en Argentina.

Entendemos a la comunicación pública como aquella cuyas acciones están orientadas a construir ciudadanía a través del “(...) el encuentro y el diálogo comunitario en relación a asuntos públicos; todo esto, desde una amalgama de estrategias comunicativas, que finalmente lo que están promoviendo es el desarrollo de una sociedad políticamente activa desde el ejercicio pleno de la participación ciudadana" (Cuadros Rodríguez et al., 2015: 114). En las diferentes piezas audiovisuales que hemos analizado más arriba, identificamos la construcción de un abanico de significaciones centrado en la democratización de las comunicaciones y el rol de la televisión digital como herramienta de inclusión social y digital. Por ejemplo, se pueden apreciar en pasajes del spot institucional: "Una televisión que nos une.(...) Mejor televisión.(...) Gratis para todos. Más nuestra. Más canales que hablan de lo nuestro. Inclusión social. Generación de empleo. 200.000 puestos de trabajo directos y 360.000 indirectos. Nuevas voces, Desarrollo Tecnológico". Asimismo dichas significaciones tienen como interlocutores a los ciudadanos que son interpelados como participantes activos de la política pública de inclusión digital. En el spot "TDA" subraya: "Una televisión para todos. Otra forma de inclusión. ¿Sabés por qué lo conseguimos? Por nuestra gente”.

Por otro lado, la comunicación gubernamental tiene como objetivo generar consenso en torno al gobierno a partir de propuestas constantes y permanentes de comunicación con la sociedad que visibilicen la gestión y la administración pública. En la estrategia comunicacional de la TDA se advierten indicios de la comunicación de la gestión de gobierno, por ejemplo, a través del slogan que formaba parte de la marca-país ${ }^{75}$ y que apelaba al acompañamiento de un Estado presente en la vida de sus ciudadanos. De hecho, a mediados de 2011 el slogan mutó de "Argentina. Siempre con vos" por "Argentina. Un país con buena gente" y en 2014 se definió “Argentina nos incluye". Particularmente, el último slogan refuerza la idea de inclusión sostenida en las acciones de un Estado como garantía del goce de los derechos para todos los argentinos.

En definitiva, podemos concluir que la estrategia comunicativa de la TDA se caracterizó por incorporar, en cada momento y soporte comunicacional (gráfico, audiovisual y/o interactivo), la idea de ciudadanía y la alusión a un "otro" excluido que con la ejecución

\footnotetext{
${ }^{75}$ Marca-país es un signo identificador gráfico elaborado por los gobiernos de cada nación con el objetivo de distinguir sus productos, su cultura, su turismo, sus empresas, sus organismos públicos, etc.
} 
de políticas públicas de acceso a las tecnologías pretendía zanjar la brecha digital, disminuyendo las desigualdades sociales y culturales. Estas construcciones de sentidos también procuraron acentuar las definiciones políticas de una gestión de gobierno que había recuperado la función del Estado como regulador de la vida social y económica del país, con una fuerte apuesta a la política de derechos humanos, la reivindicación de la soberanía y la integración regional.

\subsection{TDA: ¿y los destinatarios?}

Al inicio de este capítulo sosteníamos que tanto en los países centrales como en nuestra región, el desarrollo de la televisión digital forma parte de un movimiento que involucra la participación del Estado, del mercado y de la sociedad civil. Sin embargo, esta participación claramente ha sido desigual: ha estado marcada por la postergación de los ciudadanos y por el predominio de las reglas del mercado audiovisual. En este sentido, el surgimiento de la TDT se enmarca en el agotamiento de la televisión analógica y en la expansión del sector de las telecomunicaciones y la electrónica.

A su vez, los organismos internacionales sostienen que la televisión digital es la puerta de entrada a la sociedad de la información al permitir el acceso de todos los ciudadanos a la cultura digital. En el caso de los gobiernos de nuestra región, incorporaron esta premisa en sus agendas y comenzaron a desarrollar políticas públicas de inclusión digital basadas en la distribución de dispositivos técnicos entre la población con "riesgos de exclusión".

En el concierto de la región, entre 2009 y hasta 2015 el Estado argentino, como actor privilegiado, ha desarrollado la televisión digital y ha invertido esfuerzos institucionales, políticos y económicos en la articulación de planes y programas de inclusión digital.

Parte de los instrumentos de las políticas públicas de inclusión digital (dispositivo normativo, de gestión y los recursos básicos) $)^{76}$ se orientaron a intervenir en el escenario mediático comercial concentrado que se consolidó en la década del `90, en particular, de la mano de la entrada en vigencia de la Ley 26.522. A la vez que se fueron planificando

\footnotetext{
${ }^{76}$ Consideramos los instrumentos de política pública en los términos planteados por Isuani: "Esos instrumentos o condiciones necesarias pueden ser agrupados en tres tipos de instrumentos: un dispositivo normativo que estructure y oriente sus actividades, un dispositivo de gestión que las sostenga y concrete, y un conjunto de recursos básicos que las torne viables" (Isuani, 2012: 58).
} 
las estrategias y las acciones específicas para el desarrollo de la televisión digital en la órbita del MINPLAN: el plan de acceso: "Mi TV Digital".

A lo largo de este capítulo hemos dado cuenta de que las iniciativas del Estado en relación con la inclusión digital no han estado exentas de cierta desarticulación de las políticas públicas de comunicación que, entre otros efectos, devino en la descoordinación en la gestión de la TDA en el territorio. Sin embargo, podemos afirmar que pusieron en evidencia la necesidad de estudiar y evaluar los avances de la implementación de la televisión digital como dispositivo de inclusión digital.

En principio, uno de los principales aspectos comprendidos en las políticas públicas de inclusión digital en el período estudiado, que nos interesa problematizar es la incorporación de los destinatarios considerando sus intereses, expectativas, habilidades, usos y prácticas. Tal como indicamos más arriba, encontramos que la ejecución de la TDA no ha considerado a sus beneficiarios tanto desde la toma de decisiones como en relación con el uso, consumo y prácticas concernientes a la televisión digital. O sea, si bien notamos que se realizaron esfuerzos para universalizar el servicio, alcanzar a la población identificada como en "riesgo de exclusión", producción de contenidos específicos, desarrollo de infraestructura técnica, etc., estos no parecen suficientes para generar procesos de inclusión con vistas a saltar la brecha digital entre los destinatarios de la política pública en estudio.

De allí que en esta tesis nos importa comprender los procesos de integración de tecnologías digitales interactivas, específicamente la televisión digital, y los vínculos que establecen los usuarios con ésta, a partir del reconocimiento de estos usuarios como sujetos con intereses y objetivos autónomos, que se apropian de la tecnología con la posibilidad efectiva de integrarla a sus prácticas sociales, culturales y políticas.

A fin de avanzar en la indagación de nuestro objeto de estudio presentamos, en el próximo capítulo, una revisión bibliográfica que nos permitió construir el estado de la cuestión sobre los procesos de digitalización de las industrias culturales y sus consecuencias en los usos y prácticas. 


\section{Capítulo III}

\section{Los estudios sobre la televisión digital, sus usos y las propuestas de inclusión digital}

Los estudios sobre la introducción de tecnologías digitales en las sociedades actuales trazan el mapa de preocupaciones en torno a las modificaciones, perspectivas y proyecciones en el escenario comunicacional internacional, regional y local.

En la última década, una de las cuestiones que suscita interés es la transición de la televisión analógica o hertziana a la televisión digital y sus diferentes dimensiones, tales como la infraestructura técnica, política, social, cultural y económica. A la vez que para abordar dicha problemática se recurre y recuperan los estudios de la televisión desarrollados durante el pasado siglo XX.

En principio, la televisión “(...) como medio del siglo XX y lugar privilegiado de la cultura y la sociedad contemporánea comenzó a estudiarse en los años ‘40” (Rincón, 2005: 16). La televisión como objeto de estudio se enmarca en el campo más amplio de la investigación en medios de la comunicación de masas abordada desde la hipótesis de la aguja hipodérmica, la corriente empírico-experimental o de la persuasión, los estudios empíricos sobre el terreno o de los efectos limitados, la teoría funcionalista, la teoría crítica, la perspectiva de los estudios culturales y las teorías comunicativas (Rincón, 2005: $17)^{77}$. Pero las propuestas de digitalización de la televisión construyen una escena diferente que resulta necesario escrutar desde múltiples miradas y cruces disciplinares.

A partir de este contexto nos interesa revisar las investigaciones que nos permitan abordar nuestro objeto de estudio y que contribuyan a su análisis. Para ello, sistematizamos los antecedentes que tematizan los conceptos clave incluidos en esta tesis: televisión digital, usos y prácticas e inclusión digital. En general, se efectuó una revisión bibliográfica dentro del ámbito de los estudios en comunicación. El origen geográfico de las referencias abarca Europa, América del Norte, América Latina y, particularmente, Argentina. A la vez que se exploraron revistas académicas del campo de la comunicación, publicaciones,

\footnotetext{
77 Para este trabajo no resulta relevante explicar específicamente cada una de las perspectivas mencionadas dado que requeriría dispersar el foco de la atención para abordar nuestro objeto de estudio. Sin embargo, para revisar los aspectos centrales de dichas posiciones teóricas sugerimos ver Mattelart y Mattelart (1997), Moragas (2011), Galindo Cáceres (2008), Wolf (2007, 1994).
} 
proyectos y resultados de investigación nacionales, estudios de caso nacionales e internacionales e informes de observatorios sobre tecnologías y comunicación.

Por lo tanto, los aportes que presentamos provienen, en su mayoría, del campo de estudios críticos de la comunicación que analizan y caracterizan los distintos aspectos de los procesos de digitalización de la televisión en la sociedad contemporánea.

En primer lugar, exponemos las principales líneas de investigación en materia de digitalización de las industrias culturales y, en especial, de la televisión digital terrestre como objeto de estudio. También incluimos análisis de casos que caracterizan la implementación de la televisión digital en América Latina y Argentina.

En segundo lugar, recuperamos trabajos que abordan los usos y las prácticas de las tecnologías digitales en las agendas de investigación de América Latina y Argentina. En relación con los usos y consumos de la televisión digital, presentamos estudios que se proponen relevar los usos del dispositivo en distintas localidades de Argentina.

Por último, presentamos documentos de organismos internacionales e investigaciones que problematizan la noción de acceso a las tecnologías como vía para alcanzar procesos de inclusión digital por parte de los sectores sociales “en riesgos de exclusión digital”.

\subsection{Los estudios sobre televisión digital}

\subsubsection{Estado de la cuestión en el estudio de la digitalización de la televisión en Europa y América}

El estado del conocimiento sobre la televisión digital alcanza diversas etapas de desarrollo en el ámbito internacional, y aborda diferentes aspectos del problema tales como la estructura económica de la industria cultural, las políticas de medios, las características y consecuencias de la digitalización de la televisión, entre otros.

Dado que el cambio digital de la televisión está en proceso de desarrollo resulta un importante desafío analizar y reconocer la gran cantidad de estudios realizados. Mientras que es posible identificar las principales tendencias en investigación que abordan aspectos relevantes del tema que nos interesa abordar en esta tesis.

Desde fines del siglo XX, el interés de la comunidad académica internacional por estudiar la digitalización de las industrias infocomunicacionales ha trazado diversas coordenadas de análisis, que posibilitan relevar un escenario complejo que aún se encuentra en proceso 
de configuración debido a los cambios en las formas de producción, de contenidos, de gestión de los medios de comunicación.

Una de las contribuciones que sistematiza diversos trabajos de investigación sobre los procesos de digitalización de la comunicación audiovisual se encuentra reunida en la publicación "Pensar los medios en la era digital. Iberoamérica frente al desafío de la convergencia" $(2010)^{78}$, que presenta un estado de la producción de conocimiento sobre los procesos de convergencia digital ${ }^{79}$ actuales, en España y en América Latina.

En principio se muestran las características generales de la fase de digitalización de las industrias infocomunicacionales, en particular, acerca de la televisión digital. A efectos de esta investigación, repasaremos sólo aquellas propuestas que nos permiten hacer foco en nuestro objeto de estudio.

El autor colombiano Omar Rincón ubica la televisión digital en el ámbito de lo público como lugar del ejercicio de la ciudadanía y propone pensarla a partir de los roles de seis actores: el sistema -los avances tecnológicos de la televisión digital, los mercaderes de los aparatos-; el negocio del cambio de sistema analógico al digital; los operadores de televisión -la multiplicación de señales y servicios-; los consumidores; las industrias nacionales -creadores de tecnología local-; y los ciudadanos. Describe a cada uno de los actores y afirma que: (...) "la televisión digital es brillante en 4 aspectos: tecnología, mercaderes de los aparatos, operadores de la televisión y marketing; y fracasa en 2 ámbitos: la creación de la industria cultural y tecnológica y en ciudadanía” (Rincón, 2010: $31)$.

Ante este escenario señala tres salidas posibles para correr el eje de discusión del usuario/consumidor hacia el ciudadano: la necesidad de políticas públicas que preserve al

\footnotetext{
${ }^{78}$ El libro resume los debates producidos en el marco del I Encuentro Iberoamericano de Comunicación: lo digital y la digitalización, realizado en Buenos Aires en octubre de 2008. Reunió a expositores de Brasil, Chile, Colombia, España, México, Uruguay y Argentina. Para la publicación se sumaron trabajos de Bolivia, Ecuador y Venezuela.

${ }^{79}$ En el campo de estudios de los medios de comunicación se incorpora la idea de "convergencia" alrededor de la década del '70. Becerra (2000) ubica la noción de convergencia para analizar la construcción del modelo de la sociedad de la información a fines del siglo XX y afirma que: "La idea de la convergencia descansa en la homogeneización de los soportes, productos, lógicas de emisión y consumo de las industrias infocomunicacionales (...). En los hechos, los grupos y plataformas multimedia suponen la posibilidad de imbricación de tecnologías, culturas y tradiciones de producción y procesamiento informativo, y distribución de las diferentes actividades infocomunicacionales que suscita el concepto de convergencia (...)" (Becerra, 2000: 2). La noción de convergencia digital incluye diferentes niveles de análisis: “(...) la convergencia de índole tecnológico; la convergencia económica (alianzas, integraciones y concentración de grupos); la convergencia reglamentaria (tarea que sintetiza la Comisión Europea); la convergencia de aplicativos de consumo, entre otras" (Becerra, 2000: 3). Más allá de esta caracterización, el término aún resulta esquivo a la hora de analizar procesos de integración de tecnologías, sin embargo, en esta tesis consideramos que la convergencia no sólo se expresa en la dimensión tecnológica, económica o normativa sino que se trama en los usos y las prácticas de los usuarios.
} 
ciudadano; de una televisión pública (como lugar de encuentro de los ciudadanos) y de otras ciudadanías (lo femenino, lo étnico, lo juvenil, etc.).

Otro aporte es el de Emili Prado, catedrático español, que a lo largo de su artículo advierte que a pesar de la digitalización, el consumo televisivo sigue siendo sincrónico a la emisión y lo demuestra con datos del mercado televisivo estadounidense. Y afirma que: "En este nuevo escenario, las políticas de comunicación deben articularse sobre nuevas herramientas. Más que tratar de interferir en los flujos de circulación o en condicionar el acceso a los contenidos, debe invertir en la competencia creativa de su industria de contenidos y en la capacitación de los ciudadanos para buscar con criterio y autonomía en el bosque de la oferta" (Prado, 2010: 51-52).

Por su parte, el especialista argentino Guillermo Mastrini analiza la existencia de tres tipos de brechas que produce la digitalización. Una es la brecha de integración a la sociedad de la información que, según el autor, “(...) se resuelve con inversión en infraestructura" (Mastrini, 2010: 62). La segunda brecha es la conectividad y el acceso a internet que se supera generando "(...) políticas que mejoren y faciliten el acceso a la banda ancha” (Mastrini, 2010: 62). Finalmente, la tercera brecha es la de la producción de aplicación de software y contenidos que “(...) es uno de los problemas más importantes que tenemos. Si aumentamos la conectividad de la gente, si le damos más banda ancha, si tiene mejor acceso a internet y no generamos nada en términos de contenidos y software, nuestros ciudadanos consumirán los productos que ya se producen en los países desarrollados" (Mastrini, 2010: 62). Consecuentemente, el autor recomienda la necesidad de integración regional latinoamericana para desarrollar y aprovechar el potencial de las tecnologías de la información. Y para lograrlo requiere articular políticas de Estado de la región que aborden las problemáticas propias de los procesos de digitalización de las industrias infocomunicacionales.

A estos planteos le siguen artículos que se encargan de estudiar los procesos de formulación, implementación y regulación en diferentes países latinoamericanos: en Brasil (Leal y Haje, 2010: 83-104), en Chile (Navarrete, 2010: 106-117), en Uruguay (Gómez, 2010: 118-126), entre otros ${ }^{80}$. En general, estos trabajos coinciden en que dado el incipiente cambio tecnológico, político y cultural, sostenido en la transición de un modelo analógico a otro digital, aún no es posible dar cuenta acabada de las características

\footnotetext{
${ }^{80}$ Para más detalle todos los trabajos se pueden consultar en Miranda, Santagata y Guérin (Ed.) (2010): Pensar los medios en la era digital. Iberoamérica frente al desafio de la convergencia. $1^{\circ}$ ed. Colección: Inclusiones. La Crujía. Buenos Aires.
} 
de un nuevo paradigma digital. Acuerdan en que las primeras consecuencias comienzan a surgir $\mathrm{y}$, por lo tanto, requieren de análisis pormenorizados que superen aquellas visiones instrumentales centradas de manera exclusiva en las lógicas del mercado.

Finalmente, las diferentes propuestas desarrolladas a lo largo del libro concuerdan en que los procesos de digitalización y, en particular, de la televisión digital deben pensarse, planificarse e implementarse a partir de políticas públicas de comunicación que articulen las demandas de la sociedad civil y que se orienten a formar audiencias activas (Rincón, Becerra, Sanguinetti, Jaffrot, 2010).

Hasta aquí revisamos líneas de investigación generales sobre el campo de problemas que delimita la digitalización de las industrias infocomunicacionales y que avanzan en la exploración de las características de los procesos de convergencia digital. Principalmente, problematizan el abordaje de los procesos de digitalización de la televisión, desplazando la discusión de un usuario considerado como consumidor hacia un ciudadano reconocido como interlocutor y productor. En ese marco, reclaman la necesidad de articular políticas públicas que integren a la sociedad civil como audiencia activa para el desarrollo y apropiación de las tecnologías digitales interactivas. Estos trabajos nos permiten comprender los rasgos elementales que constituyen el escenario a partir del cual construimos nuestro objeto de estudio.

\subsubsection{La Televisión Digital Terrestre (TDT) como objeto de estudio}

Entre las primeras preocupaciones en torno a la televisión digital, centradas en la televisión digital terrestre (TDT), encontramos investigaciones provenientes del campo de la Economía Política de la Comunicación en Europa y Estados Unidos de América.

El proceso de migración digital en Europa fue regulado mínimamente por la Unión Europea (Bizberge, 2010: 91): su intervención se limitó a un tratamiento técnico y económico (utilización y reutilización del espectro, receptores, redes, pautas publicitarias, colocación de productos, contenidos, etc.). De allí que Bizberge (2010) señala que la TDT no es una preocupación central en las políticas europeas más allá de liberar espectro: "Lejos de apostar a la digitalización de la televisión abierta y generalista, cuasi universal en toda la Unión Europea, se impulsan otras opciones técnicas individualistas (3G, por ejemplo), que requieren de una alfabetización digital mínima y se sustentan en la lógica de pago" (Bizberge, 2010: 93). 
En este caso, se han desarrollado investigaciones específicas que abordan la implantación de la TDT en el Reino Unido (Goodwin, 2005; Bell, 2010; Stark, 2011); en Francia (Lange, 2005; Bouquillion, Miège, Morizet, 2006; Badillo, 2012); en España (Caballero, 2007; Ribés, 2007; García Leiva, 2008) y en los países nórdicos -Suecia, Finlandia, Dinamarca, Noruega e Islandia-(Jonsson, 2001; Gröndahl, 2002; Hass 2004; Severson, 2004; Brown, 2005). Estas investigaciones detallan el paso de la televisión analógica a la digital, centrando el análisis en el rol desempeñado por el Estado y el sector privado en cada uno de los casos nacionales.

A estos trabajos se suman otros y varias tesis doctorales que realizan estudios comparados de las políticas públicas entre países como el Reino Unido y España (García Leiva, 2008); Suecia y España (Suárez Candel, 2010); Reino Unido, Francia, Italia y Alemania (Fernández Alonso, Capurro Robles, Sanmartín Navarro, Blasco Gil, 2009), entre otros. Estas investigaciones comparadas aportan gran cantidad de datos sobre los distintos sistemas televisivos a la vez que se proponen trazar el mapa de las políticas públicas aplicadas en los casos analizados.

Sobre la televisión digital en Estados Unidos encontramos obras que analizan la transición de la televisión analógica a la digital que consideran que dicho proceso no ha estado exento de dificultades debido a la falta de mecanismos para la coordinación de políticas y la preeminencia de las reglas del mercado. Toma un modelo de implantación de televisión digital terrestre que se sostiene sobre los operadores ya existentes en el mercado mediático. La estrategia de implantación de la televisión digital terrestre se apoyó en las emisiones en HD, aplazando para el futuro el uso de otras ventajas (como las características interactivas), en espera de que madure el proceso mismo y de que los televisores digitales estén dotados de mecanismos eficaces para la interactividad. En términos regulatorios se observa una continuidad con el modelo de televisión analógica (Larrégola, 1998; Segovia, 2001; Prado, y García, 2003; Galperín, 2004; Hart, 2004 y 2010; Urquiza García, 2009, entre otros).

La bibliografía revisada tanto en el caso de Europa como de Estados Unidos se enmarca en el amplio campo de conocimiento de la Economía Política de la Comunicación como enfoque en el que coexisten diferentes modos de abordaje de los objetos de estudio. 


\subsubsection{Investigaciones regionales y locales sobre televisión digital}

A diferencia de los países centrales, América Latina tiene una historia relativamente reciente en relación con la implementación de la televisión digital por lo que la producción de conocimiento va creciendo a medida que los diferentes países van introduciendo las tecnologías digitales. Al respecto existen distintos trabajos (Rodríguez Miranda, 2010; García Leiva, 2010; Albornoz y García Leiva, 2012; Hernández Aguirre, 2010; Castro, 2008 , entre otros) que caracterizan esos procesos de adopción de la norma digital y analizan el papel del Estado, de los radiodifusores y de la sociedad civil como actores clave en dicha elección. Estos estudios concuerdan en que es el Estado, a partir de la generación de políticas públicas de acceso universal, el que debe liderar el proceso de digitalización de las industrias infocomunicacionales para construir un modelo de televisión digital inclusivo con el fin de acortar la brecha digital existente. Del mismo modo, el Observatorio Latinoamericano de Regulación, Medios y Convergencia ${ }^{81}$ (Observacom) se ocupa de realizar estudios actualizados sobre la regulación y normativa de la transición de la televisión digital en Argentina, Brasil, Bolivia, Chile, Colombia, Costa Rica, Ecuador, México, Perú y Uruguay. Los informes de cada país, elaborados por expertos, caracterizan el desarrollo regulatorio de la conversión a la televisión digital, aspectos técnicos y de infraestructura a la vez que describen las políticas públicas inherentes a cada sistema de comunicación. Estos trabajos forman parte del Programa de Medios de Open Society Foundation ${ }^{82}$ que financia un proyecto de investigación mundial que comprende a sesenta países, el cual explora los cambios de medios de comunicación tradicionales a digitales "que afectan el servicio democrático básico que cualquier sistema de comunicación debe tener: noticias sobre asuntos políticos, económicos y sociales" ${ }^{83}$. En el contexto latinoamericano, el caso de Argentina adquiere características particulares que lo distinguen del conjunto de los países de la región, cuyo rasgo más notorio es el modo de intervención del Estado en el desarrollo de la televisión digital. Por un lado, la

\footnotetext{
81 El Observatorio reúne a investigadores y especialistas de comunicación de diferentes países de Latinoamérica que estudian y monitorean los desarrollos normativos y políticas públicas de comunicación de la región para "(...) evaluar el impacto en la libertad de expresión, la diversidad y el pluralismo en los sistemas de medios de la región" (www.observacom.org).

82 Open Society Foundations (OSF) es una red de organizaciones fundada por George Soros para promover políticas públicas que promuevan la democracia, los derechos humanos, reforma social, económica, etc. (www. opensocietyfoundations .org).

83 Informe Mapping Digital Media Argentina, en www.opensocietyfoundations.org/reports/mappingdigital-media-argentina.
} 
opción de adoptar la norma nipona en 2009 desde un criterio geopolítico regional y, por otro, la decisión de realizar en 2010 la primera transmisión digital con TDT a través de la emisora estatal -Canal 7-forman parte de una estrategia estatal que gana protagonismo tanto en la regulación como en la generación y distribución de contenidos audiovisuales. Como otros gobiernos de la región, el argentino lleva las riendas de la digitalización de la televisión hertziana, desarrollando políticas activas en el campo de la comunicación tendientes a reorganizar los medios estatales y apoyar los comunitarios y alternativos (Albornoz y García Leiva, 2012).

El reporte de Mapping Digital Media ${ }^{84}$ correspondiente a Argentina detalla, por una parte, los objetivos de la transición de la televisión digital en el país, el estándar técnico, las condiciones para los operadores de televisión, las políticas públicas (de cobertura universal, de acceso a receptores, de diversidad de contenidos), la regulación de la concentración y la televisión digital, la participación de la ciudadanía, entre otros aspectos. Por otra parte, enumera recomendaciones para los problemas surgidos del diagnóstico. En relación con la televisión digital señala que los primeros pasos para la transición digital “(...) han sido dados por medio de un conjunto de medidas dispersas e incluso contradictorias. Por ejemplo, la sanción de la Ley SCA tuvo lugar en forma desarticulada con el proceso de despliegue de la televisión digital" (Informe Mapping Digital Media Argentina, 2012: 89). Por lo tanto, recomienda la necesidad de implementar una política articulada de servicios audiovisuales analógicos y digitales que implicaría la discusión de una ley de servicios convergentes, complementaria a la mencionada Ley. Este informe se encuentra actualizado en el sitio Observacom que completa el análisis y agrega que a diferencia de lo que sucedió con la Ley de Comunicación Audiovisual, la sociedad civil fue excluida de la discusión sobre la elección del estándar técnico (STVDTB, la variante brasileña de la norma ISDB-T). Por otro lado, si bien el Estado ha distribuido receptores digitales entre la población de bajos recursos, todavía la penetración de la televisión digital es baja y la gestión de las señales que operan es mayoritariamente estatal aunque existen pruebas experimentales de señales privadas, afirma.

Análisis pormenorizados del caso argentino se pueden encontrar, en principio, en libros, capítulos de libros y artículos que llevan adelante Mastrini (2006, 2009, 2011, 2012);

\footnotetext{
${ }^{84}$ El informe argentino se puede consultar en el sitio del Observatorio Latinoamericano de Regulación, Medios y Convergencia (Observacom - www.observacom.org) y en el sitio de la Open Society Fundations (OSF- www.opensocietyfundations.org).
} 
Becerra (2003, 2006, 2009, 2011, 2012); Bizberge (2010, 2012); Krakoviak (2012), Postolski (2000, 2003, 2007, 2009); entre otros.

Estos autores argentinos coinciden en que las nuevas regulaciones establecidas por el Estado (Ley de Comunicación Audiovisual, Argentina Conectada, SATVD-T, etc.) sobre el sistema de medios y de información que tratan de romper la tradicional concentración de medios en el país abren, además, ventanas de oportunidades para la participación de nuevos actores. Sin embargo, estos autores señalan la necesidad de poner en el centro de la discusión el servicio público audiovisual para garantizar el acceso universal y gratuito a toda la población sostenido en la independencia económica del gobierno y de los grandes anunciantes. Por lo tanto, la pregunta que se hacen es si aún falta abordar aspectos centrales del mapa de medios ¿por qué pensar que la televisión digital tiene el potencial para democratizar la comunicación en Argentina?

Tal como planteamos en el apartado anterior, gran parte de los trabajos e investigaciones que abordan la digitalización de la televisión, y en particular la TDT, se alinean con la economía política de la comunicación. Entendemos que plantean alcances y limitaciones a la hora de analizarla relación de la televisión digital con los procesos de inclusión digital así como también su vinculación con los usos y prácticas que involucra. Muchos de estos trabajos abordan la implementación de la televisión digital, poniendo el centro de atención en el mercado, las políticas públicas y analizando la incidencia de las nuevas tecnologías en la organización (técnica, productiva, financiera o administrativa) de las actividades económicas. Sin embargo, sus propuestas requieren de otros enfoques a la hora de comprender los procesos de integración de tecnologías digitales interactivas: los vínculos que establecen los usuarios con estas tecnologías en términos de inclusión digital.

\subsubsection{Televisión Digital Argentina: estudios de caso}

En los últimos años se iniciaron varias investigaciones en diferentes universidades públicas argentinas que estudian la implementación y las características de la televisión digital terrestre en el país.

Una de ellas es: "La Televisión Digital Argentina: una mirada crítica entre lo técnico y lo político", dirigida por Pauloni, en la Facultad de Periodismo y Comunicación Social de la Universidad Nacional de La Plata, que analiza la situación en la que se encuentra la televisión digital en Argentina sobre el supuesto de que “(...) no se agota en un mero 
avance tecnológico sino que más bien, abre una discusión sobre políticas de estado en materia comunicacional y sobre un nuevo mapa de relaciones de poder" (Pauloni, 2012: 10). El estudio pone en contexto la implementación de la televisión digital terrestre, actualizando el mapa comunicacional, evalúa diferentes políticas públicas y compara la situación nacional con la de otros países latinoamericanos. El foco de interés está puesto en el plan Mi TV Digital, Polos Tecnológicos de Producción, BACUA, y el Plan de Fomento y Promoción de Contenidos Audiovisuales para Televisión Digital. Para llevar adelante la investigación se realizó, principalmente, análisis de contenido de documentos relacionados con la implementación de la televisión digital en Argentina, estudios de casos de otros países latinoamericanos y europeos, y el análisis de los discursos sobre el objeto de estudio. Entre los resultados obtenidos se señala que el desarrollo del Sistema Argentino de Televisión Digital Terrestre (SATVD-T) se desarrolló:

“(...) desde una clara concepción de política pública y, por tanto, con miras a terminar con la desigualdad en la Argentina. La instalación de infraestructura de transmisión, la entrega de decodificadores en forma gratuita y la producción de horas de televisión para ser ofertadas como un nuevo contenido cultural (...) para que el principal medio de comunicación de la Argentina sea cada vez más accesible e inclusivo". (Pauloni, 2014: 7)

Particularmente, en relación con el Plan Mi Tv Digital se afirma que: “(...) se garantizó la igualdad de posibilidades de acceso a esta nueva tecnología a partir de la entrega de decodificadores de manera gratuita a hogares, establecimientos educativos y organizaciones sociales" (Pauloni, 2014: 7). Finalmente, concluye que resulta necesario pensar una conceptualización de la televisión que incluya las lógicas de inclusiónexclusión pero también como lugar de las tensiones y la disputa de poder. Como producto de investigación, en 2013 se publica el libro "TV Digital: Un diálogo entre disciplinas y multipantallas" 85 que recoge los aspectos centrales abordados en la investigación citada. La publicación presenta el mapa de la televisión digital a nivel nacional y regional desde el aporte de diferentes disciplinas tales como la informática, telecomunicaciones, comunicación, sociología, etc. A lo largo del libro, se propone la reflexión sobre el rol social, cultural y político de los medios de comunicación donde la televisión digital se constituye en una herramienta democratizadora.

Continuando la misma línea de trabajo, el investigador González (2013) desarrolla el proyecto "La TV Digital Argentina y un nuevo mapa en materia comunicacional.

\footnotetext{
${ }^{85}$ Libro publicado por Centro de Investigación y Desarrollo en Medios, Industrias Culturales y Televisión (CEID-TV) de la Facultad de Periodismo y Comunicación de la Universidad Nacional de La Plata.
} 
Escenario de disputas de poder", en el Centro de Investigación y Desarrollo en Comunicación, Industrias Culturales y Televisión (CEID-TV) realizado durante los años 2013-2014. El estudio reflexiona sobre el recorrido que atraviesa la aparición de la televisión digital a partir del supuesto según el cual el proceso abre la discusión sobre políticas de Estado en materia comunicacional y sobre un nuevo mapa de relaciones de poder en la Argentina. Entre los avances producidos González (2013) recupera la conceptualización de "hegemonía discursiva" de Ernesto Laclau para analizar el escenario comunicacional nacional mediante los significados que entran en disputa no sólo con la transición de la televisión analógica a la digital sino, principalmente, con la implementación de la política pública TDA, cuyo propósito primario se dirige a asegurar el acceso a las tecnologías digitales de la población “(...) que presenta riesgos de exclusión durante el proceso de transición tecnológica” (González, 2014: 180).

El libro Construyendo Historia (S). Ver para creer en la Televisión. Relatos y Narraciones en la Televisión Digital Argentina (2012), compilado por Lía Gómez, ubica los inicios de la TDA tomando en cuenta el marco jurídico, los instrumentos de política pública y las políticas de promoción de producción de los contenidos. A lo largo de los 5 capítulos se van presentando crónicas y memorias de los nuevos contenidos producidos para la grilla de la televisión digital terrestre. Esta publicación tiene su eje en el modo en que el Estado avanza en materia de derechos ciudadanos a través de la TDA para democratizar la comunicación.

Por otra parte, un equipo de trabajo convocado por el NeoTVLab de la Universidad Nacional de Tres de Febrero (UNTREF) ${ }^{86}$ publica la investigación “Televisión Digital interactiva: desarrollo y perspectivas" (2013), que estudia la dimensión de la interactividad en la televisión digital con el objeto de precisar algunos puntos clave de la emergencia de dicha tecnología. Kantor, Marcaletti, y Pafundi (2013) presentan un estudio exploratorio para comprender el surgimiento de la televisión interactiva “(...) a través de la realización de entrevistas a referentes claves del sector televisivo argentino, productores, gerentes de programación, investigadores, diseñadores de software y de contenidos" (Kantor et al., 2013: 15) y a referentes de otros países (Brasil, Reino Unido, Japón y Finlandia ${ }^{87}$. El punto de partida del trabajo se centra en el análisis de la

\footnotetext{
${ }^{86}$ El Neo TVLab es el laboratorio de la Universidad Nacional de Tres de Febrero (UNTREF), dedicado a la investigación, desarrollo y difusión de las nuevas tecnologías aplicadas a la televisión.

${ }^{87}$ El trabajo de campo de la investigación fue “(...) realizado entre mayo y agosto de 2012, consistió en la realización de entrevistas a: 14 referentes de los canales públicos; 5 entrevistados del sector privado; 5 especialistas; 3 docentes e investigadores; 8 referentes de Brasil, Reino Unido y Japón”. La elección de los
} 
perspectiva de los entrevistados en torno a las tendencias, oportunidades, ventajas y desventajas de la interactividad de la televisión digital junto a la caracterización del desarrollo del incipiente caso argentino de la televisión digital terrestre. Recuperan las ideas de Cassetti y Di Chio (1999) ${ }^{88}$ en torno al estudio de la televisión como objeto complejo que implica su carácter de “(...) dispositivo tecnológico, cultural, político, ideológico, comercial" (Kantor et al., 2013: 90), orientando esta investigación cuyo aporte radica en los diferentes enfoques sobre la noción de interactividad y que expone las tensiones inherentes al proceso de implementación de la televisión digital. El libro realiza un recorrido por las características de la televisión digital en general y en particular en Argentina; de la política del sector (aplicación de la Ley de Comunicación Audiovisual, dificultades técnicas, políticas, jurídicas y económicas); posteriormente revisa los casos de Brasil, Reino Unido, Japón y Finlandia. En último lugar, concluye con un apartado que revisa los perfiles profesionales requeridos para la televisión digital interactiva, las áreas de vacancia y líneas de investigación posibles. En esa dirección, los autores afirman:

"A nuestro criterio, es un momento más que oportuno para generar investigaciones e indagaciones que acompañen la transición hasta el apagón analógico en 2019, sumado al particular interés en consolidar un modelo de inclusión digital por medio de la TDT. Es necesario acompañar la implementación de políticas públicas con indagaciones de seguimiento, monitoreo, evaluación y análisis crítico que den cuenta de los procesos que acontecen en la transición”. (Kantor et al., 2013: 91)

Estas investigaciones, que realizan análisis de documentos como de la perspectiva de entrevistados vinculados a la implementación de la televisión digital, proponen reflexionar sobre las dimensiones social, cultural y política entretejidas en el dispositivo. Consideran a la televisión digital como un objeto complejo que se constituye en una herramienta de democratización dirigida a integrar digitalmente a la población con riesgos de exclusión. E introducen la discusión sobre las políticas públicas de comunicación como lugar privilegiado de digitalización de la televisión. Sin embargo, uno de los temas que ponen en agenda es la necesidad de realizar aportes sustantivos de investigación en las diferentes fases de implementación de políticas públicas de televisión digital (formulación, planificación, gestión, seguimiento y evaluación). En el caso de nuestra tesis, la revisión de dichos estudios nos permite asegurar que se requiere la

casos analizados se debió a que Brasil, Reino Unido, Finlandia y Japón “(...) son algunas de las regiones del mundo en donde la tecnología está más desarrollada y ya han surgido usos sociales derivados de la innovación material” (Kantor et al., 2013: 17).

${ }^{88}$ Casetti y Di Chio (1999): Análisis de la televisión. Instrumentos, métodos y prácticas de investigación. Paidós. Barcelona. 
complejización de las indagaciones en torno a la implementación de la televisión digital tanto en Argentina como en la región. Y agregamos que no es suficiente el análisis de las políticas públicas de distribución de decodificadores digitales desde su formulación sino que exige de la perspectiva de los beneficiarios a través de sus usos y prácticas.

\subsection{Usos y prácticas de la televisión digital terrestre}

Ahora bien, con el objeto de analizar los usos y prácticas que involucra la televisión digital hallamos bibliografía especializada que centra su atención en los usuarios y considera la TDT como puerta de acceso a la sociedad de la información.

Entre las investigaciones alineadas desde la Teoría de Difusión de las Innovaciones norteamericana $^{89}$, que analizan el modo en que es adoptada por los usuarios la televisión digital, se encuentran los trabajos de Dupagne (2002) o Weber y Evans (2002) que advierten que el potencial de adopción entre los usuarios está vinculado a diversos factores externos a estos tales como el papel desempeñado por los medios de comunicación masivos. Atkin, Neuendorf, Jeffres y Skalki (2003); y Freeman y Lessiter (2003) analizan los factores psicológico-motivacionales implicados en la decisión de adopción de la televisión digital.

Otra tendencia se encuentra en Europa, en especial, en los países nórdicos. Los estudios desarrollados se apoyan en técnicas etnográficas para analizar los usos y las relaciones que se establecen en el hogar con la televisión digital interactiva y se hallan reunidos en el informe del Seminario Nórdico de la Televisión Digital (2002). Las experiencias descriptas en dicho informe, compilado por Tarkka (2003), revelan que las prácticas de producción de televisión pasan de la programación audiovisual a la multimedia, y que las empresas de radiodifusión fueron experimentando una importante reestructuración organizativa. Ante esta situación, identifican una considerable resistencia del usuario para adquirir la televisión digital. Las personas, especialmente los jóvenes, están utilizando más medios pero menos televisión. Ésta se está convirtiendo en un medio ambiente, un fondo para otras actividades domésticas. El uso de la televisión digital se entrelaza con el

\footnotetext{
${ }^{89}$ La Difusión de las Innovaciones es una teoría sobre el proceso por el cual los integrantes de los sistemas sociales adoptan innovaciones, un cambio de comportamiento en el que, según lo demostró Everett Roger, la comunicación cumple un papel primordial. Se estima que puede ser la obra más influyente en el pensamiento mundial en materia de comunicación en los últimos cuarenta años. Para ampliar se puede consultar: Roger, E.: (1962) Difusión de Innovaciones. Free Press. New York.
} 
uso del tiempo, el espacio y el dinero de la familia. Algunas fuentes para la resistencia contra los servicios interactivos se pueden encontrar en el "sistema de la familia", la economía moral del hogar. La televisión digital cambia los patrones de uso de medios de las familias: los adultos todavía pueden tener el poder económico, mientras que los jóvenes y niños son cada vez más los expertos de los medios en el hogar. En general, estas investigaciones comparten el reclamo de la necesidad de diagnósticos cualitativos que comprendan los contextos sociales y culturales y los significados implicados en el consumo de medios.

En la misma línea pero más alejados de las técnicas etnográficas, otros autores realizan estudios sobre el perfil de los abonados de televisión digital (Theodoropoulou, 2002), trabajos experimentales sobre servicios interactivos (Bjoerner, 2003; Brandao Joly, 2003; Hanley y Viney, 2003), y otros aplicados a la educación (Damásio, 2003) o al entretenimiento (Vorderer, Knobloch y Schramm, 2001).

También hallamos indagaciones enfocadas en el rol del usuario-ciudadano en las transformaciones de las televisiones públicas dentro del contexto de digitalización, tratando de identificar las causas de la desconexión de las audiencias (Himmelstein y Aslama, 2002; Boyd, 2003; Picard, 2004; Wiio, 2004; Gunter, 2004; Sourbati, 2004). Estos autores plantean que resulta necesario potenciar la participación de las personas en el proceso creativo de los contenidos pero, fundamentalmente, afirman que no resulta suficiente la disponibilidad y acceso a la televisión digital. Entienden que se trata de producir una nueva disposición hacia los medios digitales por parte del usuario y que se deben generar propuestas de inclusión y formación del ciudadano.

El panorama en el continente americano presenta ciertas áreas de vacancia sobre los usos de la televisión digital en particular. Sin embargo, existen investigaciones que abordan la apropiación de las tecnologías en distintos ámbitos de la vida cotidiana. Desde México, la antropóloga argentina Winocur (2007) explica que hay poco espacio para la reflexión sobre estos problemas ya que las preocupaciones se encuentran focalizadas en el diagnóstico de la llamada "brecha digital" y el impacto en el espacio social, cultural y político de las comunidades. Esta autora ha realizado estudios sobre la incorporación de las tecnologías en la vida cotidiana de los jóvenes mexicanos a partir de "entender la apropiación de una nueva tecnología como el conjunto de procesos socio-culturales que intervienen en el uso, socialización y significación de las TIC en diversos grupos socioculturales que puede contribuir de manera fundamental a realizar diagnósticos y pronósticos mucho más confiables en cuanto a las posibilidades de desarrollo de la SIC" 
(Winocur, 2007). Y considera a la escuela, los medios de comunicación y la familia como mediadores elementales en la incorporación de las tecnologías en la vida cotidiana.

En Argentina, la diversidad de trabajos sobre usos y apropiación de las tecnologías es más notoria aunque podemos mencionar investigaciones que se desarrollan en el ámbito de las universidades públicas. Morales y Cabello (2011) analizan la incorporación de las tecnologías y sus apropiaciones en el ámbito educativo planteando que no basta con el acceso sino que los esfuerzos deben estar dirigidos hacia un uso con sentido, apropiación social, capacitación y contenidos apropiados.

Por su parte, Cabello (2008 y 2009) aborda el uso de las tecnologías en las zonas periurbanas del conurbano bonaerense, tanto en el espacio de la educación como en el del entretenimiento. En el ámbito de la educación, la autora tiene una vasta experiencia acumulada en investigación que da cuenta de que la introducción de las TIC en los diferentes niveles educativos requiere del impulso de estrategias y políticas públicas tendientes a favorecer procesos de apropiación por parte de todos los actores involucrados (docentes, estudiantes, directivos) (Cabello, 2012). En el caso del entretenimiento, analiza las prácticas que despliegan los jóvenes de zonas periféricas cuando juegan en red en espacios públicos. En esta dirección, Cabello (2008a) explica que los jugadores desarrollan estrategias de aprendizaje con los pares y que el vínculo que establecen entre ellos está mediado entre otros factores, por la tecnología. Advierte que los jóvenes parecen apropiarse de las posibilidades ofrecidas por el entorno tecnocultural para recuperar los tradicionales modos de estar con el otro.

En la misma línea de investigación, Cabello (2011) realiza un primer estudio para inaugurar el Observatorio de Medios Interactivos (OUMI) ${ }^{90}$ con el propósito de producir información de primera mano sobre la penetración y los usos de los medios interactivos (en particular, la computadora, internet y el teléfono celular) en una zona del periurbano bonaerense para analizar los condicionamientos sociales, y económicos de estas prácticas. Entre los resultados de acceso se identifica un aumento en la penetración de la computadora en hogares en comparación con estudios anteriores; aumento del uso de internet pero en locales de acceso público y a través del teléfono celular; amplia cobertura de telefonía celular en detrimento de la telefonía fija. Estos datos dan cuenta de que la

\footnotetext{
${ }^{90}$ El Observatorio de Medios Interactivos (OUMI) es un espacio del Instituto del Desarrollo Humano de la Universidad Nacional de General Sarmiento, dirigido por la Dra. Roxana Cabello, cuyo propósito es la producción de conocimiento sobre los usos de los medios digitales interactivos y la formación de competencias para esos usos.
} 
brecha digital parece estar más trazada por la conexión a banda ancha que por la posesión de computadora. En cambio, la información recogida de la instancia cualitativa señala que el conocimiento respecto del uso se construye siempre bajo el acompañamiento de algún otro y a través de experimentación y aproximaciones sucesivas. En los jóvenes con mayor facilidad que en las personas mayores, pero sin demasiadas diferencias entre sexos. La principal motivación que determina el inicio del uso de internet es el entretenimiento, sobre todo, a través de las redes sociales. Las actividades que los actores realizan en la red son poco complejas. Estos entrevistados en general no logran construir representaciones claras y lógicas sobre el funcionamiento técnico del medio. El sitio más utilizado es la red social Facebook (Cabello, 2014: 4).

Benítez Larghi y otros (2012), dentro de un proyecto de investigación perteneciente al Programa de Becas de Investigación "Amy Mahan”, financiado por el Centro Internacional de Investigaciones para el Desarrollo (IDRC/CDRR) de Canadá, se ocupan de los procesos de apropiación de los espacios de acceso público a las tecnologías de información y comunicación en la vida cotidiana de jóvenes de sectores populares urbanos de la Argentina. Para estudiar dichos procesos seleccionan “(...) tres modelos distintos de acceso público situados en el municipio de La Matanza, (...) con uno de los mayores índices de pobreza del país: 1) una iniciativa comunitaria de una organización social; 2) un Centro Tecnológico Comunitario (CTC), ubicado en un centro de adolescentes y sostenido conjuntamente por el Estado Nacional y el municipio; y 3) un centro privado con fines comerciales o cibercafé. Los tres se enmarcan en un contexto de pobreza y marginalidad urbana que impacta de manera especial a las juventudes de sectores populares, causando un déficit de integración social" (Aguerre, 2010: 2). Entre los principales hallazgos del estudio se puede señalar que los lugares de acceso público y los centros comunitarios contribuyen a la inclusión social de los jóvenes pobres en los entornos urbanos y que a la vez satisfacen necesidades de formación que no son colmadas por las instituciones de educación formal u orientadas al mercado.

La Tesis "Hegemonía de los sentidos y usos de las tecnologías de la comunicación por parte de jóvenes del Conurbano Bonaerense Sur. Estudio realizado en Quilmes 20112014" de Murolo (2014) se propone indagar usos de las tecnologías de la comunicación por parte de jóvenes en ámbitos públicos y privados. Los usos son estudiados en el ámbito educativo (específicamente, en el colegio secundario), en el ámbito del entretenimiento (series, películas, música, libros, videojuegos), en el cibercafé y en las redes sociales virtuales (Facebook, Twitter). Y señala que estos usos de conocimiento, de comunicación 
o de entretenimiento “(...) tienen la impronta de la lucha hegemónica en su configuración. Algunos de ellos son propuestos por el mercado (...) usos dominantes. Otros usos están propuestos por el Estado, en medio de programas de inclusión digital (...)” (Murolo, 2014: 13). Para ello, presenta el resultado de las entrevistas cualitativas, observaciones, registros fotográficos y audiovisuales. Finalmente, Murolo (2014: 346) afirma que: "Las disputas por la hegemonía de los sentidos se encuentran presente en los usos de las tecnologías de la comunicación por parte de jóvenes. En estas disputas intervienen las perspectivas de clase social y comunicacional, de género, etaria y de posicionamiento en el espacio público. Estas disputas no son nuevas sino constantemente novedosas”.

\subsubsection{Acceso y consumos de la TDA}

Un conjunto de investigadores pertenecientes al área de Sistemas Económicos Urbanos del Instituto del Conurbano de la Universidad Nacional de General Sarmiento lleva adelante una serie de estudios sobre la producción y consumo audiovisual en el Noroeste del Conurbano. Abramovich y González (2014) presentaron una caracterización del consumo audiovisual y uso de TIC en los partidos de José C. Paz, Malvinas Argentinas, Moreno y San Miguel en las VIII Jornadas de Sociología de la Universidad Nacional de La Plata (UNLP). El trabajo reúne los resultados iniciales de la encuesta realizada entre agosto de 2012 y enero de 2013 que busca “(...) avanzar en un acercamiento empírico a los consumos culturales de los hogares de la Región Noroeste del Conurbano Bonaerense, en particular en los partidos de José C. Paz, Malvinas Argentinas, Moreno y San Miguel. La intención fue relevar los aspectos vinculados a los equipamientos audiovisuales, la posibilidad de acceso a la oferta de bienes culturales y los usos y decisiones de consumos culturales de cada hogar" (Abramovich y González, 2014: 1). Entre el equipamiento que releva la encuesta y nos interesa distinguir en este apartado, se encuentra el televisor, la computadora - además de otros como consola de videojuegos, telefonía celular, etc. - y lo relaciona con los servicios audiovisuales que cuentan los hogares de los partidos estudiados. En este sentido, miden un bajo nivel de acceso a la computadora y a servicio de internet pero en el caso de la televisión se observa alta concentración de servicio por cable y la TDA alcanza apenas el 2\% de los hogares, a pesar de los más de 40.000 decodificadores entregados en las cuatro localidades. Este es un dato relevante que se evidencia en el $32 \%$ de hogares que no tiene TV por cable ni satelital y que según los 
autores, son hogares que pueden convertirse en un público objetivo de la TDA. Y en esta dirección, el análisis general muestra que la posesión de tecnologías no implica necesariamente el uso efectivo de las mismas.

Por otra parte, el área Investigación y Desarrollo (I+D) del Programa Polos Audiovisuales Tecnológicos ${ }^{91}$ publica 5 informes sobre el desarrollo de la producción audiovisual de la televisión digital en el territorio nacional con el objetivo de aportar conocimientos acerca de dicho sector y de la implementación de la televisión digital argentina ${ }^{92}$. Se diseñaron 5 líneas de trabajo: relevamiento de recursos de la producción audiovisual nacional; derechos de propiedad intelectual para producciones audiovisuales argentinas; sustentabilidad y nuevos mercados; consumos y audiencias televisivas y, finalmente, desarrollo de la TV digital argentina.

En este caso, nos interesa, en especial, la última línea de trabajo que contiene distintos ejes: un panorama general del conocimiento y uso de la TDA, un mapa de disponibilidad y consumo de equipamientos receptores de la TDA y un estudio exploratorio del uso de la TDA en escuelas públicas. Este informe presenta los resultados de 3 estudios durante el año 2013: un sondeo de opinión sobre conocimiento, uso y valoración de TDA, una encuesta sobre usos del equipamiento de TDA en escuelas y un relevamiento de la oferta comercial de equipamiento para TDA (tanto equipos receptores como equipamiento externo) en todo el territorio nacional.

En este marco, se realizó una encuesta telefónica en 42 ciudades con cobertura de TDA para conocer el grado de penetración que el sistema tiene en esas poblaciones y analizar el impacto logrado con la difusión. Los datos obtenidos muestran que “(..) se trata de

\footnotetext{
${ }^{91}$ El Programa Polos Audiovisuales Tecnológicos “(...) es una política de integración impulsada por el Ministerio de Planificación Federal, Inversiones Públicas y Servicios. El Programa Polos busca instalar y fortalecer las capacidades para la producción nacional de contenidos para la TV Digital, promoviendo la igualdad de oportunidades y la disminución de asimetrías entre provincias y regiones, materializando así el artículo 153 de la Ley 26.522 de Servicios de Comunicación Audiovisual, que expresa la necesidad de crear nuevos conglomerados productivos para la promoción y defensa de la industria audiovisual nacional". www.tda.gob.ar/141/11162/polos.html (última consulta diciembre de 2015).

92 "La coordinación de cada línea de trabajo fue encargada a equipos de investigadores universitarios con reconocida experiencia en cada temática. Para la implementación de los estudios específicos se designaron 9 enlaces territoriales: personas propuestas por los Polos, con experiencia en investigación en comunicación y/o producción audiovisual, que facilitaron en cada región la participación de los Nodos en el desarrollo del eje (Centro: Daniela Monje, Centro Este: Karina Arach Minella, Cuyo: Juan Cruz Groisman, Metropolitano: Alejandra Pia Nicolosi y Leandro González, NEA: Ruben Zamboni, NOA: Marcelo Brunet, Patagonia Norte: Ariel Barbieri, Patagonia Sur: Horacio Avedaño, Provincia de Buenos Aires: María Virginia Morazzo).Con el fin de garantizar la adecuada ejecución de la primera etapa del eje I+D, representantes de la conducción del Programa y la Comisión Orientadora diseñaron un sistema de seguimiento que permitió acompañar el desarrollo de los estudios específicos, reajustarlos en función de emergentes operativos y extraer enseñanza para el diseño de futuras actividades de I+D" (Bulla y Hernández, 2013: 7).
} 
una política con alta legitimidad y buena valoración, pese a lo cual el porcentaje de usuarios es menor a lo esperable. Las falencias principales en ese sentido tienen que ver con la escasa y poco clara información sobre la TDA. Sin embargo, el estudio demuestra la existencia de un alto porcentaje de potenciales usuarios dispuestos a incorporar el sistema" (Bulla y Hernández, 2013: 12). Complementariamente, se realizaron 2 grupos focales a potenciales usuarios (jubilados que perciben el haber mínimo y adultos de sectores populares [C3D] con televisión de aire) cuyo análisis plantea que existe desconocimiento y desinformación sobre la TDA (tanto acerca de sus características como las modalidades de acceso) y esa es la razón por la cual parte de la población no ha accedido al beneficio.

La encuesta llevada a cabo en establecimientos educativos da cuenta del escaso uso pedagógico de la TDA y ausencia de equipamientos en las aulas vinculado con la falta de material de apoyo pedagógico para docentes e información referida a la programación. Por último, el relevamiento de la oferta comercial de la infraestructura para el acceso a la TDA (equipos receptores, televisores LED, tabletas y GPS; y equipamiento externo, antenas y decodificadores) no arroja datos concluyentes debido a la dificultad de acceso a fuentes oficiales y de los proveedores comerciales pero en términos estimativos señala que (...) la oferta de equipamiento para TDA parece estar al alcance de la demanda en términos de equilibrio cobertura acceso" (Bulla y Hernández, 2013: 49).

Los resultados de estos estudios proporcionan una primera valoración cuantitativa de la política pública TDA en materia conectividad y de acceso al equipamiento, a la vez que complementa la información con datos cualitativos sobre el conocimiento y las expectativas existentes entre ciertos usuarios (en particular, jubilados que perciben el beneficio de la TDA). Pero fundamentalmente y, en el marco de esta tesis, nos permiten obtener datos contextuales sobre los inicios de la implementación de la televisión digital terrestre en el conurbano bonaerense.

En 2014 se publicaron los resultados de la investigación "Uso y consumo de la Televisión Digital Terrestre en Argentina. Un estudio en los municipios de San Fernando y Quilmes", realizada por un equipo de investigadores de la Maestría en "Industrias Culturales: políticas y gestión” y del Programa de Investigación “Industrias Culturales y espacio público: comunicación y política en la Argentina” de la Universidad Nacional de 
Quilmes $^{93}$. Este trabajo relevó y documentó información sobre el uso y consumo de la TDT del Plan Televisión Digital Abierta (TDA) en dos partidos del conurbano bonaerense (Quilmes y San Fernando) entre 2011 y 2013. Para ello, se aplicaron técnicas cuantitativas y cualitativas en tres etapas: dos para realizar las encuestas y una para el desarrollo de las entrevistas etnográficas. La finalidad de la investigación fue evaluar el impacto de las políticas públicas diseñadas para el desarrollo de la TDA en el Gran Buenos Aires, poniendo el centro de atención en los televidentes/usuarios. "Los ejes principales de análisis giraron en torno al acceso real al equipamiento y a la valoración de la TDA como nueva plataforma de distribución televisiva. Adicionalmente, también se analizaron la convivencia de las plataformas de televisión paga y abierta, la oferta de contenidos, y el consumo en general" (Mastrini et al., 2014: 4).

Las categorías que explora la investigación refieren a "uso y consumo" con el foco en el modo en que la población accede a la televisión: “(...) Este análisis particular del consumo televisivo se centra en la consideración de las diversas plataformas de que disponen los usuarios; y (...) se profundizará en los contenidos consumidos. La comparación de las diferentes plataformas de transmisión de la televisión permite observar la incidencia de la televisión digital en la región analizada" (Mastrini et al., 2014: 27). La indagación pone atención en el promedio de horas de encendido de la televisión (tanto analógica como digital) en los hogares estudiados; la preferencia de contenidos entre un sistema y el otro; y los nuevos hábitos de simultaneidad o complementariedad de consumo de televisión e internet.

Entre las conclusiones se destaca que aún es incipiente la tendencia al recambio de dispositivos digitales (LED, LCD, etc.), que existen nuevos hábitos de consumo televisivo debido a internet pero no aparecen hábitos diferentes en relación con la TDA respecto de la TV tradicional o de cable. Además, hay “(...) una fuerte tendencia a la complementariedad entre el sistema de pago y la TDA" (Mastrini et al., 2014: 80).

Este estudio avanza en aspectos que nos interesan en esta tesis debido a que es uno de los primeros trabajos que se propone evaluar los resultados de la política pública de implementación de televisión digital terrestre en Argentina a través del análisis de pautas de uso y consumo de televisión en diferentes sectores poblacionales de la provincia de Buenos Aires. Por otra parte, el artículo “Casos de estudios: 'Mi TV Digital'. Apropiación

\footnotetext{
${ }^{93}$ Con el apoyo del Ministerio de Ciencia, Tecnología e Innovación Productiva de la Nación Argentina. El contenido del informe fue compartido con las autoridades de dicho Ministerio como aporte al diseño y evaluación de políticas públicas de comunicación.
} 
y uso del decodificador digital en la ciudad de Paraná”, de Deharbe (2014), publicado en la Revista Trampas de la Comunicación y la Cultura $\mathrm{N}^{\circ} 77$ sigue esta línea de trabajo a partir de un "(...) estudio de corte cuantitativo a base de encuestas con cuestionarios semicerrados sobre los alcances del plan nacional de entrega de equipamiento de recepción gratuita, 'Mi Tv Digital'” (Deharbe, 2014: 135). Entre los objetivos de investigación se propone diagnosticar el grado de penetración de la televisión digital, medir el nivel de apropiación del medio y conocer los usos y expectativas de los beneficiarios del plan "Mi TV Digital” en la capital de la provincia de Entre Ríos. La autora encuentra resultados coincidentes con el estudio desarrollado por Mastrini et al. (2014) en dos partidos de la provincia de Buenos Aires. En primer lugar, señala que uno de los problemas para la implementación de la televisión digital es la alta penetración de la televisión por cable, la preferencia de los usuarios por los contenidos ofrecidos por la grilla comercial y las dificultades técnicas al momento de instalar los decodificadores o de operarlos. Para comenzar a superar los obstáculos identificados sugiere que el Estado debe definir un modelo de servicios audiovisuales fuertemente orientado a la inclusión social además de “(...) revisar los planes de asistencia técnica para la instalación de los decodificadores, destinando su ayuda a aquellas franjas etáreas que no están familiarizadas con el uso de aparatos interactivos" (Deharbe, 2014: 142-143). Si bien esta investigación tiene entre sus objetivos conocer los usos y expectativas de los beneficiarios sobre el plan "Mi TV Digital", arriba a resultados cuantitativos que proporcionan información sobre distribución, posesión y uso de los decodificadores digitales y el consumo de los contenidos de la grilla de la televisión digital.

En este apartado comenzamos con los estudios europeos y norteamericanos que se ocupan de los usos de la televisión digital y que hacen foco en la relación que las personas establecen con esta tecnología. En cambio, en América y Argentina encontramos investigaciones que centran su atención en la incorporación de las tecnologías en diferentes ámbitos: educación, entretenimiento o la vida cotidiana a partir de abordajes críticos que ponen en cuestión el discurso dominante sobre las potencialidades brindadas por tales tecnologías. En sentido amplio, proponen mirar al sujeto que las usa, tratando de entender los sentidos atribuidos, los modos de apropiación y las prácticas que despliega en el contexto cotidiano. Sin embargo y, en particular, en aquellos trabajos que plantean analizar los usos y consumos de la Televisión Digital Argentina (TDA) predominan los abordajes cuantitativos a la vez que evalúan el impacto de la política pública "Mi TV Digital”, pero no avanzan en la operacionalización de la noción de usos y apropiaciones 
de las tecnologías digitales por lo que los resultados van desde la distribución y posesión de los receptores digitales hasta las preferencias en los contenidos de la grilla de programación.

Por lo tanto, entendemos que resultan necesarios trabajos de investigación cuyo eje sea la relación que establecen las personas con las tecnologías -en este caso con la televisión digital-, que profundicen la mirada sobre las dimensiones analíticas involucradas en los usos y las prácticas.

\subsection{Los estudios sobre televisión digital e inclusión digital}

La noción de inclusión digital se origina en el desarrollo de la primera Cumbre Mundial de la Sociedad de la Información en el año 2003. Esta definición es tematizada en las agendas públicas de los Estados latinoamericanos que comienzan a incorporarla tanto en sus discursos como en sus políticas públicas. La adopción de este concepto, junto a las recomendaciones de acciones de organismos regionales tales como la Comisión Económica para América Latina y el Caribe (CEPAL) y la Asociación Latinoamericana de Integración (ALADI), componen las estrategias de los países de la región para incorporar tecnologías digitales a la sociedad a través de proyectos financiados por organismos multilaterales nacionales e internacionales. En este contexto, surgen líneas de investigación que describen las características y se interrogan sobre las consecuencias de las propuestas de inclusión digital.

El ámbito de la educación es uno de los principales espacios donde se estudia el impacto de la inclusión digital. Encontramos diversos trabajos, tanto en Europa como en América, que reflexionan sobre la introducción de tecnologías y las transformaciones que producen en la estructura edilicia, la infraestructura, en las relaciones de la comunidad escolar así como también en la modalidad pedagógico-didáctica y sus contenidos. En menor medida se ubican otros análisis en el ámbito de la ciudadanía (Vera Balanza y Subires Mancera, 2013; Lacruz y Clavero Galofré, 2010 y 2011; Sena Correa, 2009; Cubillos Vargas, 2009).

Dado que nuestro objeto de interés se circunscribe a los procesos de inclusión digital vinculados a la implementación de la televisión digital terrestre, creemos que no resulta necesario revisar en profundidad aquellas investigaciones dedicadas al análisis en el 
ámbito escolar. Sin embargo, nos detenemos en algunos trabajos que reflexionan sobre aspectos significativos para nuestra investigación.

En principio y en sentido amplio, consideramos documentos de organismos internacionales con sede en Argentina que producen información que contribuye a la incorporación de tecnologías digitales en educación. El Instituto Internacional para la Planeación Educativa de UNESCO (IIPE) -Regional Buenos Aires- publica el informe: "La integración de las Tecnologías de la Información y la Comunicación en los Sistemas Educativos. Estado del arte y orientaciones estratégicas para la definición de políticas educativas en el sector" (2006), y UNICEF Argentina difunde: "Estado del arte sobre el desarrollo cognitivo involucrado en los procesos de aprendizaje y enseñanza con integración de las TIC" (2013). Ambos reportes abordan la gestión de las políticas TIC en educación y analizan la integración de las TIC en los procesos de enseñanza y aprendizaje en diferentes niveles educativos del país. A la vez que ponen en foco el papel del Estado para llevar adelante los procesos de incorporación de las tecnologías en educación con el principal objetivo de resolver la brecha digital para avanzar hacia la inclusión digital.

En el ámbito de la política pública argentina también existe una línea de estudios y evaluación sobre la inclusión de las TIC del Programa Conectar Igualdad. Entre las investigaciones, el proyecto: "Políticas públicas de Inclusión tecnológico/digital. Procesos formativos en escuelas públicas de la provincia de Buenos Aires: TV digital y Conectar Igualdad"94, dirigido por Leandro González en la Universidad Nacional de La Plata (UNLP), se propone explorar las prácticas educativas que se vinculan con las tecnologías y producciones televisivas: Programa Conectar Igualdad y Televisión Digital, pensadas como políticas públicas que favorecen y contribuyen a la formación pedagógica de los jóvenes. Para el informe de avance se relevaron 136 establecimientos educativos de La Plata y en la mayoría de estos se hace uso de las computadoras distribuidas por el Programa Conectar Igualdad. En el caso de "Mi TV Digital", apenas un 7\% de los establecimientos escolares cuenta con la antena y señal de televisión digital. El aporte de este proyecto reside en examinar la articulación entre ambos programas a fin de avanzar en el estudio de la incorporación de medios y tecnologías digitales en la escuela. En este sentido, advierte que resulta de interés reparar en que la mayoría de los colegios

${ }^{94}$ El proyecto comienza a desarrollarse en 2014 en el Centro de Investigación y Desarrollo en Comunicación, Industrias Culturales y Televisión (CEID-TV) de la Universidad Nacional de la Plata (UNLP). 
encuestados reconocieron el uso de la computadora para mirar TDA además de otros contenidos audiovisuales. Esta es una entrada interesante para repensar el uso de las computadoras y el potencial de la televisión digital terrestre en el ámbito educativo.

Si bien, nuestro estudio se circunscribe al período 2014-2015 no queremos dejar de reseñar dos importantes trabajos académicos de la Universidad de Buenos Aires y de la Universidad Nacional de La Plata junto a un consorcio de otras universidades latinoamericanas que fueron publicados entre 2016 y 2019.

El libro Inclusión digital: una mirada crítica sobre la evaluación del modelo Uno a Uno en Latinoamérica coordinado por los investigadores Benítez Larghi y Winocur, recoge los resultados de diferentes evaluaciones de políticas públicas de inclusión digital basadas en el modelo Uno a Uno en la región con especial atención al Plan Conectar Igualdad de Argentina y al Plan Ceibal de Uruguay. En ese marco, los autores que participan de la publicación ponen en discusión los encuadres teórico-metodológicos y los parámetros con los que se suelen evaluar las estrategias de incorporación de tecnologías digitales en América Latina.

En una publicación de la Universidad Nacional de Quilmes, el investigador González (2017: 44-60) registra el derrotero de la TDA a inicios de la gestión macrista, describiendo y analizando las decisiones tomadas que modificaron estructuralmente el proceso de digitalización. Entre las principales conclusiones, el autor afirma que las políticas beneficiaron a las corporaciones mediáticas y desaceleraron el proceso de democratización de los medios de comunicación masiva y el acceso a las tecnologías digitales por parte de los sectores más relegados de la sociedad argentina.

En 2019, Lago Martínez, junto a su equipo "Sociedad, Internet y Cultura" del Instituto Gino Germani, presentó los resultados de investigación sobre la experiencia de un programa específico en Argentina, los Núcleos de Acceso al Conocimiento (NAC). El libro Políticas públicas e inclusión digital: un recorrido por los Núcleos de Acceso al Conocimiento a lo largo de cinco capítulos evidencia las numerosas políticas públicas destinadas a la inclusión digital, impulsadas por el paradigma de la Sociedad de la Información, que se han generado en América Latina y en Argentina, en particular. Realizaron observaciones en los espacios de funcionamiento y entrevistas a coordinadores de diecinueve NAC de la Ciudad Autónoma de Buenos Aires, del Gran 
Buenos Aires, de la provincia de Buenos Aires y de la ciudad de Córdoba, además de la aplicación de encuestas al público que asistían a diez del total de los NAC estudiados.

Hasta aquí revisamos distintos análisis sobre las propuestas de inclusión digital, particularmente, en el espacio de la educación, que combinan metodologías cuantitativas y cualitativas para su estudio y que tratan de distanciarse del discurso dominante de la promesa de inclusión a la Sociedad de la Información a través de las tecnologías digitales.

En relación con nuestro objeto de estudio, encontramos la monografía: "La Televisión Digital Terrestre interactiva (TDTI). Herramienta de inclusión digital en Argentina" de Argarañaz et al. (2010), cuyo objetivo es trazar un mapa conceptual para identificar y organizar enfoques de la inclusión digital en el caso de la televisión digital en Argentina. Para ello, revisa principalmente las nociones de televisión digital terrestre, brecha digital, uso social de la TDTI. El trabajo plantea una serie de recomendaciones sobre la televisión digital terrestre interactiva como instrumento de inclusión digital, centrándose en sus características técnicas (norma, decodificadores, antenas, aplicaciones, etc.), en los usos de los televidentes (información, entretenimiento, aprendizaje, etc.) y en la regulación de la televisión digital que, según los autores, debe “(...) abarcar el conjunto del sector audiovisual" (Argarañaz et al., 2010: 25). Más allá del desarrollo conceptual expuesto en el artículo y la fecha de publicación ${ }^{95}$ consideramos que este artículo pone en evidencia que se requiere avanzar en investigaciones que problematicen la discusión sobre la inclusión digital pero, fundamentalmente, como contenido sustantivo de las políticas públicas de integración de tecnologías digitales en diferentes ámbitos de la sociedad.

García Vargas, Ficoseco, Gaona, López y Zubia (2014) publicaron los resultados de una investigación sobre experiencias de reconocimiento de la televisión digital y de sus contenidos en contextos populares urbanos de la provincia de Jujuy. En el artículo: “Democratización, políticas de acceso y vida cotidiana. Experiencias de reconocimiento de la TDA en contextos populares urbanos (San Salvador de Jujuy, Argentina)", los autores relevan y analizan los procesos de constitución material y simbólica de prácticas, en relación con el acceso y con el reconocimiento de contenidos audiovisuales vinculados a la TV digital y a las políticas públicas que la fomentan.

\footnotetext{
${ }^{95}$ La monografía fue publicada en agosto de 2010 a pocos meses de la implementación de la Televisión Digital Argentina (TDA), por lo tanto, posiblemente muchas de las afirmaciones vertidas sobre la modalidad que debería asumir la televisión digital como herramienta de inclusión digital se encontraban en el nivel de la conjetura.
} 
En octubre del mismo año, Vila presentó una ponencia en XVIII Jornadas Nacionales de Investigadores en Comunicación realizadas en la Universidad de las Artes (UNA) que estudia las políticas comunicacionales de la Televisión Digital Abierta (TDA) y, a partir de la selección de casos, se propone interpretar las prácticas de recepción y mediación que este medio genera en familias beneficiarias de la Asignación Universal por Hijo (AUH) de dos municipios de la provincia de San Juan, al acceder al gratuitamente a un equipo receptor de TDA.

La tesis de maestría: “Televisión Digital Abierta en la escuela pública. Desafíos actuales y locales del campo comunicación y educación", indaga la vinculación entre la TDA y las escuelas secundarias públicas en la ciudad de La Plata, en el marco de un proceso global de convergencia digital de la televisión, encarado por el Estado nacional entre los años 2009 y 2015, como derecho humano a la comunicación. Su autora, Suárez Baldo (2017) analiza e identifica las intencionalidades del Estado por garantizar la inclusión de los sectores más vulnerables. Y concluye que la convergencia digital de la televisión fue llevada adelante por un Estado que entendió la comunicaciones como derecho humano y en función de ello, planificó políticas públicas inclusivas de acceso universal y comenzó a promover la producción nacional de bienes culturales y tecnologías.

Finalmente, el Programa de Usos de Medios Interactivos (UMI) de la Universidad Nacional de General Sarmiento desarrolló la investigación: "Sentidos y contrasentidos de la inclusión digital como inclusión social. El caso de la provincia de Buenos Aires", dirigido por la Dra. Roxana Cabello. Se planteó estudiar los sentidos construidos en torno a la noción de inclusión digital en la formulación e implementación de las políticas públicas de inclusión digital, con sede en la provincia de Buenos Aires, en el período 2010-2015. El proyecto se propuso avanzar en la complejización de la noción de inclusión digital a partir de la recuperación de estudios sobre usos y representaciones de las tecnologías que Roxana Cabello ha desarrollado desde el año 2000. La investigación presenta una propuesta que sostiene que el análisis complejo de procesos de inclusión digital no se resuelve con la contemplación del primer nivel de acceso a la infraestructura técnica, sino que debe abordar cuatro dimensiones complementarias: disposición, usos, autoafirmación y participación.

Este es uno de los principales aportes de esta investigación ya que buscó indagar en profundidad una noción que aún tanto en la formulación de las políticas públicas como 
en algunos trabajos del campo académico suele asociarse a la idea de acceso a las tecnologías.

\subsection{Principales referencias en torno a los usos de la televisión digital terrestre e inclusión digital}

En este capítulo nos propusimos reconocer los principales antecedentes sobre el tema que nos ocupa. La búsqueda de bibliografía especializada, investigaciones y estudios estuvo orientada en función de los conceptos clave que construyen nuestro objeto de estudio: televisión digital, usos y prácticas e inclusión digital. Recordamos que nuestro interés es comprender la relación que se constituye entre los usos de la TDA y los procesos de inclusión digital de acuerdo con las expectativas expresadas en la política pública, por un lado, y los discursos y prácticas de los usuarios, por el otro.

En sentido amplio, encontramos que la literatura sobre la digitalización de la televisión proviene predominantemente de estudios de la Economía Política de la Comunicación tanto en el plano internacional como regional y local. Tal como advertimos en los apartados anteriores, estos análisis plantean ventajas y desventajas al momento de abordar el problema de la inclusión digital y su vinculación con los usos y prácticas de la televisión digital. Esto se debe a que se ocupan de indagar los efectos de las tecnologías digitales interactivas en la organización (técnica, productiva, financiera o administrativa) de las actividades económicas en el mercado y en las políticas públicas. Si bien aportan información sobre el escenario comunicacional en el que se inscriben estas tecnologías y sobre la implementación de las políticas públicas, sus propuestas requieren de perspectivas cualitativas para comprender los vínculos que establecen los usuarios en términos de inclusión digital.

Por otra parte, revisamos líneas de investigación en América Latina y en Argentina, especialmente, que enfocan sus trabajos sobre los usos y apropiaciones de las tecnologías digitales en diferentes ámbitos y sectores socio-económicos. En general, varios homologan la noción de acceso a las tecnologías digitales con los usos pero otros profundizan la mirada y sostienen que los procesos de usos y apropiaciones son complejos y requieren del análisis de otras categorías analíticas complementarias (acceso, uso, empoderamiento y participación). 
Finalmente, en relación con la idea de inclusión digital hallamos estudios que enuncian cierta distancia crítica a los discursos hegemónicos pero que no alcanzan a diferenciar la letra de los documentos de organismos internacionales y de las políticas públicas de comunicación en Argentina. Además, presentan información producto de técnicas cuantitativas y, en menor medida, de técnicas cualitativas que le restan riqueza analítica a los resultados de investigación.

Por estos motivos, entendemos que se requiere abrir líneas de investigación que problematicen y profundicen la noción de inclusión digital como contenido sustantivo de las políticas públicas de integración y usos de tecnologías digitales en diferentes ámbitos de la sociedad. 


\title{
Capítulo IV
}

\section{Tecnologías, usos, inclusión digital: problematizando los conceptos}

\author{
"Teorizar es un modo \\ de actuar para actuar \\ mejor".(González, 2008:52)
}

En sentido amplio, en esta tesis partimos de la consideración de que las tecnologías en general y, en particular, las tecnologías digitales interactivas, adquieren significado de acuerdo a las prácticas históricas y sociales que los sujetos entretejen con los dispositivos tecnológicos. Antes de proseguir, necesitamos diferenciar el uso de los términos dispositivo técnico y dispositivo tecnológico en relación con nuestro objeto de estudio. En el caso del primero, se trata de aquel o aquellos artefactos físicos preparados para producir una acción específica (transmitir, emitir, proyectar, conectar, comunicar, etc.) cuyo funcionamiento puede ser analógico o digital. En cambio cuando nos referimos a los dispositivos tecnológicos lo hacemos en el marco del análisis de medios de comunicación. Siguiendo a Aprea, G. (2004: 20):

"En este campo un dispositivo implica un conjunto de productos, una manera de pensar la articulación de varios elementos en virtud de la solidaridad que los vincula y combina. Estos elementos se sostienen sobre distintos tipos de materialidad y se vinculan a través de diferentes tipos de redes conceptuales. En ese sentido puede señalarse que los dispositivos tienen componentes materiales y organizacionales. En el caso de los medios de comunicación los componentes materiales se encuentran condicionados por las tecnologías que intervienen en sus procesos de producción y circulación".

Es decir, que los dispositivos tecnológicos comprenden los elementos técnicos propiamente dichos (ingenios físicos, analógicos o digitales, funciones específicas y generales) junto a los usos efectivos, posibles y proyectados; al modo en que fueron diseñados, construidos y distribuidos en la sociedad y las relaciones de poder que los atraviesan y que se construyen a su alrededor. 
En sentido estricto, nos interesa problematizar los presupuestos dominantes sobre las tecnologías digitales como herramientas ${ }^{96}$ de democratización de la comunicación cuyo fin es disminuir la llamada "brecha digital" que se plantea, al menos en el discurso de organismos internacionales y gobiernos, como política a largo plazo; en vistas a la “inclusión digital” de los grupos excluidos de las sociedades actuales.

En este marco, nuestra propuesta es analizar la relación entre los procesos de integración de tecnologías digitales, en particular, de la televisión digital y los vínculos que establecen los usuarios con estas - a partir del reconocimiento de estos usuarios como sujetos que actúan con intereses y objetivos, que se apropian de la tecnología con la posibilidad efectiva de integrarla a sus prácticas sociales, culturales y políticas-. De allí que nos interesa indagar si se producen procesos de inclusión digital de acuerdo con las expectativas expresadas en la política pública TDA en una zona del periurbano bonaerense, donde los indicadores sociales, económicos y culturales muestran rasgos de vulnerabilidad en la población: el partido de José C. Paz, en la segunda corona del AMBA durante el año 2014 y 2015.

La investigación sobre las vinculaciones entre las tecnologías y la sociedad constituye un campo de problemas complejo y amplio en el que coexisten diferentes abordajes disciplinarios tales como sociología, filosofía, economía, antropología, entre otros. Desde la mitad del siglo XX, los estudios de comunicación se han preguntado acerca de la relación entre las tecnologías y los procesos sociales, culturales y políticos que producen. Por eso, creemos necesario ubicar las principales discusiones y conceptos clave en el marco general del campo de investigación para revisar posteriormente las perspectivas de la comunicación que nos permitirán abordar nuestro objeto de estudio. De esta manera, la construcción de este marco teórico se propone la rearticulación de conceptos y categorías de perspectivas críticas del campo de estudios de la comunicación. Nuestro abordaje conceptual se sitúa en las discusiones entre los Estudios Culturales y la Economía Política de la Comunicación y la Cultura para reflexionar sobre la dimensión cultural de las tecnologías.

Los aportes de ambas perspectivas permiten comprender la relación entre el poder y la cultura: el modo en que los sujetos se vinculan con las tecnologías en el marco de los procesos de digitalización de las industrias infocomunicacionales. Estos enfoques resultan pertinentes para problematizar la idea de las tecnologías como dispositivos que

\footnotetext{
${ }^{96}$ En este caso, respetamos el término "herramientas" para caracterizar las tecnologías digitales tal como se encuentra expresado en los documentos analizados de las políticas públicas, objeto de esta tesis.
} 
podrían generar o influir en la generación de procesos de inclusión digital: en nuestro caso, la televisión digital.

Sin embargo, es necesario aclarar que en principio nos interesa poner el acento en las zonas de acuerdo y desacuerdo en torno a las conceptualizaciones y los análisis que se proponen para estudiar las modificaciones que produce el desarrollo de las tecnologías digitales interactivas, en el espacio de las relaciones sociales y, especialmente, enfocados en la vida cotidiana.

Estos puntos de partida nos permiten pensar las dimensiones culturales, políticas y económicas de los usos de la televisión digital y el modo en que estos usos proporcionan condiciones y prácticas orientadas hacia la efectivización de procesos de inclusión digital, según las expectativas expresadas en la política pública TDA.

De allí que entendemos que la pregunta por la noción de inclusión digital requiere recuperar puntos de vista que analizan los modos en que los usos y apropiaciones de las tecnologías digitales interactivas configuran procesos complejos que no sólo implican la relación con los sujetos sino que también comprenden las acciones del Estado materializadas en la implementación de políticas públicas, cuyo propósito declarado es promover la difusión de estas tecnologías entre la población en general pero con especial énfasis en aquellos sectores en riesgo de exclusión digital.

Por consiguiente, las categorías conceptuales que proponemos para conocer si es posible afirmar que se producen procesos de inclusión digital a partir de la implementación del Plan "Mi TV Digital" entre la población de José C. Paz (localidad del conurbano bonaerense) plantean situar las condiciones y prácticas de usos de las tecnologías digitales en el contexto de implementación de políticas públicas, sin desconocer los modos de producción y distribución de los productos culturales.

La perspectiva desde la cual abordamos este problema recupera la tradición de estudios de la cultura y la comunicación en relación con el desarrollo y expansión de medios y tecnologías de la comunicación. Por ende, sostenemos que resulta relevante situar el problema de las tecnologías digitales interactivas como forma y parte de la cultura. Y en el caso particular de la televisión digital, en relación a los sentidos que le atribuyen los sujetos como práctica social y comunicativa.

En principio, los Estudios Culturales ofrecen un marco de temas y problemas desde el que es posible observar en las interacciones sociales de las personas con las tecnologías digitales interactivas en su contexto de vida cotidiana. Señala Morley que "todos los abordajes de la geografía subjetiva de la tecnología y su lugar en nuestras vidas 
comienzan su análisis no examinando directamente una tecnología y sus supuestos efectos, sino el sistema interaccional en juego en un contexto particular, y luego cómo las tecnologías particulares encajan en ese contexto, o qué se hace para que encajen" (Morley, 2008: 193). Por lo tanto, desde esta perspectiva y en pos de la construcción de nuestro objeto de estudio, nos proponemos retomar las categorías de usos de las tecnologías y de la televisión digital, prácticas sociales y comunicativas como marco para pensar los procesos de inclusión digital.

En cambio, la Economía Política de la Comunicación y la Cultura brinda descripciones y análisis que nos permiten caracterizar el contexto social y político en el que se inscriben las políticas públicas de difusión de tecnologías digitales interactivas. Este enfoque nos permite contextualizar los procesos de transición analógica a digital de la televisión y las políticas que los promueven.

Entendemos que pensar la relación entre los sujetos y la tecnología implica no sólo situar la genealogía de los debates sobre dicho vínculo, sino que amerita ensayar un abordaje interdisciplinario que oriente la reflexión acerca de las modificaciones que la transición de las tecnologías analógicas a las digitales opera en la vida cotidiana. Se trata de dirigir la mirada en torno a lo que Grossberg denomina "conversaciones interdisciplinarias": "Sé que tenemos que encontrar un camino hacia la interdisciplinaridad, y por el momento sólo puedo conceptualizar el diálogo dentro de las disciplinas y entre ellas o, aún mejor, las posibles conversaciones en los espacios existentes entre ${ }^{97}$ las disciplinas" (Grossberg, 2010: 37). Esta propuesta sostiene que: "La interdisciplinaridad no significa adoptar sin ningún tipo de criterio una sola fuente, teoría o descripción de otra disciplina para rellenar parte de la propia investigación. (...) Mientras que la interdisciplinaridad implica un auténtico trabajo, tampoco se trata de dominar una y otra disciplina. (...) Los límites disciplinares inevitablemente definen el punto de partida y de dirección que toma una investigación cuando trata de dar respuesta a un planteamiento" (Grossberg, 2010: 5860). Sin embargo, este autor afirma que resta recorrer un largo camino para responder a la pregunta por el modo en cómo se deben llevar a cabo estudios interdisciplinarios.

Debido a la dificultad de desarrollar trabajos académicos estrictamente interdisciplinarios creemos que estamos en condiciones de atender a las articulaciones entre nociones de enfoques que estudian los usos de las tecnologías digitales interactivas en la complejidad de los contextos en que se producen. Por esta razón, los Estudios Culturales y su discusión

\footnotetext{
${ }^{97}$ El resaltado es del autor.
} 
con la Economía Política de la Comunicación y la Cultura ofrecen un terreno fértil para construir categorías analíticas para abordar nuestro objeto de estudio que se presenta complejo y, por ende, decidimos no ceñirlo a alguna corriente teórica en particular aunque siempre nos mantenemos en el marco del campo de estudios de comunicación. Por el contrario, tratamos de identificar aquellas nociones teóricas que retoman las propuestas de estas perspectivas y amplían su mirada para indagar las transformaciones que las tecnologías digitales (en nuestro caso, la televisión digital terrestre) producen en las prácticas sociales y comunicativas de los sujetos en tiempos de transición digital.

Presentamos nuestro encuadre teórico comenzando con una rápida revisión del problema de la tecnología y cambio social, considerando enfoques enmarcados en los "estudios sociales de la tecnología", que discuten sobre la manera en que la tecnología produce modificaciones en el espacio social y cultural. Estos debates ofician de punto de partida para entender algunos aspectos del escenario en el que los estudios de comunicación abordan la relación de las personas con las tecnologías.

Pero nuestro mayor interés se centra en ubicar el análisis de la tecnología en el campo de investigación de la comunicación por lo que identificamos los encuentros/desencuentros entre las tradiciones teóricas de los Estudios Culturales y la Economía Política de la Comunicación y la Cultura, a fin de construir un abordaje conceptual que nos permita comprender los usos de las tecnologías en el marco de los procesos de inclusión digital. Desde estos contextos conceptuales, nos dedicamos a reconocer los debates acerca de las perspectivas que estudian los usos de las tecnologías digitales, centrándonos en las características de la televisión digital. Por último, consideramos las definiciones de brecha digital y de inclusión digital con el objeto de orientar nuestro análisis.

\subsection{El problema de la tecnología y cambio social}

En sentido amplio, el estudio de las tecnologías configura un marco de comprensión lo suficientemente extenso como para incluir distintas perspectivas disciplinares tales como la sociología de la tecnología, la filosofía de la tecnología, historia de la tecnología, la economía de la tecnología, la antropología, la educación, entre otras. Respecto de ello, Thomas, Fressoli y Lalouf afirman:

"Los estudios sociales de la tecnología no parecen encuadrarse bien entre las descripciones académicas tradicionales. Lo que intenta representar esa etiqueta 
parece mucho más amplio que cualquier esfuerzo académico. Si bien están incluidos en el campo de las ciencias sociales, los saberes implicados en estas producciones exceden las fronteras disciplinarias acotadas. No solo porque muchas de las producciones implican fértiles cruces entre sociología, historia, economía, antropología, ciencias políticas, administración de empresas, administración gubernamental (...), sino también porque integran conocimientos de ingeniería, así como diversas ciencias exactas, (...) y aún los saberes de culturas locales". (Thomas, Fressoli y Lalouf, 2008: 60)

Estos trabajos abordan temas y problemas que adquieren una complejidad tal que requieren de enfoques lo suficientemente amplios a la hora de analizar las relaciones entre la tecnología y los procesos sociales y culturales actuales. Por lo tanto, nos encontramos con algunas agendas de investigación que se circunscriben a los clásicos campos disciplinares (sociología, economía, política, historia, etc.) como con otras que apelan a posiciones interdisciplinarias.

Según Elizalde (2006) el campo de estudios de la tecnología está caracterizado por dos clases de debates distintos: por un lado, aquel que se pregunta por el tipo de mecanismos que causa cambios sobre la tecnología, y por otro, el que se preocupa por los efectos de la tecnología en la sociedad. En el primer caso, las líneas argumentativas dan lugar a respuestas por parte de autores que se encuadran en una perspectiva internalista, frente a otros que sostienen un punto de vista denominado externalista. Asimismo, el segundo debate se manifiesta en la discusión entre los deterministas tecnológicos y los institucionalistas. Presentaremos sólo las principales características de cada una de las posturas mencionadas, por lo que no ahondaremos en sus desarrollos teóricos. Entendemos que existen dificultades a la hora de encuadrar autores en una u otra posición debido a que no se encuentran definiciones unánimes y que, en muchos casos, tampoco se muestran claramente sus propuestas en uno u otro sentido.

En principio, en el marco de las discusiones entre las posiciones internalistas y externalistas del conocimiento y de la técnica, las preguntas se vinculan a la manera en que se organiza la técnica, cómo se origina cierta tecnología en un momento histórico dado, etc. Para el enfoque internalista, la ciencia y la técnica tienen su propia lógica de producción (Bunge, 1998: 22), deslindada de cualquier vinculación con procesos sociales, políticos, económicos o culturales. Esta concepción cientificista y positivista de la ciencia ${ }^{98}$ plantea que la técnica está determinada por criterios de eficacia racional y que responde exclusivamente a procesos lógicos utilizados por el investigador, a los

\footnotetext{
${ }^{98}$ Los referentes de esta posición son Sarton (1884-1956), Koyré (1892-1964), Popper (1902-1994).
} 
sistemas de verificación que usa, las teorías que sostiene, los experimentos que realiza, etc. (Medina, 1983: 57). Por otra parte, quienes se alinean con el externalismo ${ }^{99}$ entienden que la ciencia y la técnica, sus efectos y usos no se pueden analizar sin comprender las características de las épocas y la estructura de las sociedades en las que se producen.

Pero, a la vez, aquellos estudios cuyos interrogantes se centran en la manera que la tecnología modifica el ámbito social, cognitivo y cultural de los sujetos, los efectos e impactos de esa tecnología sobre la sociedad se dividen entre las discusiones del "determinismo tecnológico": los cambios tecnológicos producen indefectiblemente cambios sociales; es decir, la tecnología provoca modificaciones en la sociedad y del "institucionalismo": las tecnologías por sí solas no pueden causar modificaciones en la sociedad sino que están condicionadas por las instituciones sociales que las organizan ${ }^{100}$. En el ámbito de los estudios de los medios de comunicación alineados con el determinismo tecnológico, encontramos las posturas de Innis, Ong, McLuhan que sostienen que las tecnologías transforman directamente las competencias corporales, cognitivas, sociales y culturales de los sujetos ${ }^{101}$. La mirada se centra en el medio mismo más que en los contenidos que transmite, es decir, en las determinaciones de los medios de comunicación en la percepción humana a través de la superación de la era de la escritura y del advenimiento de la era de la imagen ${ }^{102}$.

Por otra parte, varios autores acuerdan que uno de los principales representantes de la posición institucionalista es Raymond Williams, quien sostiene que “(...) la tecnología es dependiente de la compleja textura social y política del mundo en el cual surge" (Williams, 2011: 7). Como así también Jesús Martín Barbero (1987) coincide en que las

\footnotetext{
${ }^{99}$ Bujarin (1888-1938), Hessen (1893-1936), Merton (1910-2003), entre otros autores de esta perspectiva. ${ }^{100}$ Las tecnologías se organizan “(...) dentro de una serie de reglas sociales formales e informales, caracterizadas por ciertos valores, significados, atributos simbólicos de mayor o menor reputación, que es lo que definitivamente determinan el mundo social humano" (Elizalde, 2006: 124). Los desarrollos teóricos de Berger y Luckmann (1989), Searle (1997), Schelsky (1967), Elías (1998) señalan que las tecnologías se institucionalizan a través de complejos procesos de objetivación y tipificación de normas sociales, expectativas y sentidos atribuidos que determinan el contexto social.

${ }^{101}$ Debemos advertir que existen autores que distinguen matices en la perspectiva determinista entre una postura dura y otra blanda. Al respecto, Smith y Marx señalan: “En el extremo 'duro' del espectro, el poder causal (el poder para provocar un cambio) se atribuye a la propia tecnología o algunos de sus atributos intrínsecos; los avances tecnológicos llevan, pues, a una situación de inevitable necesidad. (...) En el otro extremo del espectro, los deterministas 'blandos' comienzan recordándonos que la historia de la tecnología es una historia de las acciones del hombre. Para comprender el origen de un determinado tipo de poder tecnológico debemos conocer primero a los actores. (...) En lugar de concebir la 'tecnología' per se como el agente causal histórico, los deterministas blandos los sitúan en una matriz social, económica, política y cultural mucho más variada y compleja" (Smith y Marx (1996: 14-16).

102 Existe una vasta bibliografía que explica y profundiza esta posición sobre las tecnologías de los medios de comunicación que se puede consultar en estudios sobre el determinismo tecnológico tales como: De Moragas Spá (2011); Wolf (1994, 2007); Mattelart y Mattelart (1997); Galindo Cáceres (2008), entre otros.
} 
mediaciones sociales intervienen entre las tecnologías y los cambios sociales. En definitiva, es la dimensión social y/o cultural de los procesos lo que produce cambios en la sociedad.

Sin embargo, y como señalamos al inicio de este apartado, en la agenda de investigación sobre las tecnologías coexisten diversas perspectivas disciplinares que requieren también de la contribución de herramientas conceptuales de los llamados "estudios sociales de la ciencia y la tecnología”. En esta dirección Pinch y Bijker (2008); Feenberg (2005); Hughes (1996), Latour (1992) y Callon (2001) ${ }^{103}$ realizan aportes sustantivos explicando que el desarrollo de las tecnologías no es lineal “(...) sino que constituye un entramado en el que se integran, de manera compleja, hechos heterogéneos (artefactos, instituciones, reglas, conocimientos...) y actores diversos (ingenieros, empresarios, agentes políticos, usuarios...), (...)" (Thomas, Fressoli y Lalouf, 2008: 66).

Estas propuestas abordan las tecnologías en su relación con procesos sociales y culturales en los que se entretejen: historizando los hechos, relativizando valores y reconstruyendo las trayectorias de artefactos y los sistemas. De esta manera, lo social y lo técnico son consideradas dimensiones equivalentes a la hora del análisis. El objetivo principal de este enfoque, denominado sociotécnico, es captar la complejidad de los procesos tecnológicos, oponiéndose a encontrar causalidades entre la sociedad y las tecnologías. En este sentido, “(...) estos estudios intentaron mostrar el carácter social de la tecnología y el carácter tecnológico de la sociedad, generando un nivel de análisis complejo: lo 'sociotécnico"' (Thomas, Fressoli y Lalouf, 2008: 67).

En el marco de esta perspectiva, Thomas (2012) estudia las relaciones que se construyen y reconstruyen entre las tecnologías y los procesos de inclusión/exclusión social. Para ello, se propone comprender cómo se diseñan, adoptan y evalúan las tecnologías orientadas a la resolución de problemas sociales: tecnología para la inclusión social como herramienta analítica ${ }^{104}$.

Las características principales de las tecnologías para la inclusión social o los sistemas tecnológicos sociales están orientados a posibilitar el acceso a toda la población, pero

\footnotetext{
${ }^{103}$ Un extenso desarrollo teórico explica las características teórico-metodológicas del abordaje sociotécnico y el reconocimiento de alcances y limitaciones de este enfoque. Para más detalle se puede consultar: Thomas (1999); Álvarez, Martínez y Méndez (1993), así como también las propuestas de los referentes de esta postura mencionados más arriba.

${ }^{104}$ Ver: Thomas, 2012: Tecnología, Desarrollo, Democracia. Sistemas Tecnológicos Sociales y Ciudadanía Socio-Técnica, en Juárez, P. (Coord.): Tecnología, Desarrollo y Ciudadanía. Cinco años de la iniciativa Feria de tecnologías sostenibles. Pp. 14-39. Universidad Nacional de Quilmes, Bernal. ISBN: 978-987-558292-7.26.
} 
fundamentalmente permiten la participación de los beneficiarios y potenciales afectados en el diseño e implementación. Según Thomas (2012), estos sistemas deberían ser un elemento clave en las estrategias de desarrollo social y técnico, sumado a la democratización política. Y en esa línea argumentativa propone a las tecnologías para la inclusión social como eje central de una estrategia de democratización de nuestras sociedades.

Hasta aquí rastreamos los principales ejes de debate entre los estudios sociales de las tecnologías que nos permiten ubicar la genealogía de las problemáticas que se configuran en la relación entre la sociedad y la tecnología en sentido amplio.

Dado que nuestra investigación se propone realizar un aporte crítico en relación con el vínculo que establecen las personas con las tecnologías digitales y, en particular, con la televisión digital, partimos de un marco de comprensión general en el que las tecnologías no solo forman parte de los procesos sociales, culturales, políticos y económicos sino que en su uso y apropiación se expresan las expectativas, las prácticas sociales, culturales, y las disputas de sentidos atribuidos por los diferentes grupos sociales.

De ahí, que nos posicionamos críticamente ante las visiones instrumentales de las tecnologías que sostienen que son herramientas o artefactos construidos para diferentes tareas independientemente de los contextos socio-históricos donde se utilizan. En estas perspectivas, las tecnologías son calificadas como aparatos neutrales y autónomos con las que se puede hacer cualquier cosa, ignorando los intereses políticos, sociales y económicos que diseñan, producen, financian y distribuyen esos dispositivos. Asimismo, nos alejamos de las posturas que sostienen que el desarrollo tecnológico es un proceso determinado por la sociedad, en el que la dinámica social es la que orienta el cambio tecnológico. Estos enfoques estudian la influencia de la sociedad en los cambios tecnológicos. Los abordajes de ambas posiciones separan las esferas de las tecnologías y de la sociedad y viceversa, hecho que le resta complejidad al análisis ya que se encuentran las causas del cambio social o tecnológico en una u otra esfera.

En tanto, encontramos variados esfuerzos por sistematizar conocimientos en torno al vínculo de las tecnologías y la sociedad. Los modos en que plantean sus descripciones y análisis suelen ir detrás de los cambios producidos en esta relación que obliga a repensar constantemente los enfoques vigentes. Entendemos que nos enfrentamos a un fenómeno complejo y variable que requiere de la construcción de un corpus teórico relativamente flexible para el estudio de las tecnologías y, en especial, cuando se trata de sus usos y apropiaciones en términos de inclusión digital. La construcción de este encuadre teórico 
necesita de categorías críticas para abordar nuestro objeto de estudio desde conceptualizaciones que permitan aproximarnos a la comprensión de las características de los usos de la televisión digital en los contextos cotidianos así como también de las dimensiones de los procesos de inclusión digital.

Entonces reafirmamos que, en el marco de nuestra investigación, nos alejamos de las posiciones deterministas e instrumentales que naturalizan la aparente autonomía y neutralidad de las tecnologías al margen de la dinámica social. Estas tesis apuntan a plantear una relación unidireccional entre las tecnologías y la sociedad, vínculo que se estudia luego de los impactos o efectos que producen las primeras sobre la segunda. Se concibe que la influencia de las tecnologías en la sociedad se da desde una posición de exterioridad que poco tiene que ver con los procesos producidos en esta relación. Conectados con estos planteos existen otros que sostienen que los cambios tecnológicos son los que afectan los modos de existencia de lo social.

Por el contrario, aquí nos ubicamos dentro del campo de las perspectivas críticas de las tecnologías, entendiendo que estas son producto social de las relaciones humanas y que esas relaciones sociales están atravesadas por las tecnologías. Creemos que las condiciones socio-históricas en las que se desarrollan las tecnologías les otorgan un sentido singular y característico propio en cada momento histórico (Feenberg, 1991, 2005). Por lo tanto, el desafío primordial es comprender el modo en que las tecnologías son construidas, socialmente y viceversa, en un proceso dialéctico y complejo. En este sentido, ponemos en el centro de la escena los modos en que se dan las interpretaciones sociales de las tecnologías, según los contextos socioculturales e históricos y variables como la pertenencia de clase, edad, género, etc.

Así es como podemos encontrar variados enfoques que necesariamente requieren ser deslindados y definidos a efectos de esta tesis. En este sentido, debemos identificar los principales debates en torno al problema de la tecnología que, en este caso, ubicamos como una de las preocupaciones centrales en el campo de estudios de comunicación a principios del siglo XXI. 


\subsection{La tecnología en contexto: su uso como dimensión cultural}

Tal como hemos reseñado, hasta aquí el problema de la tecnología no es nuevo en el vasto campo de las Ciencias Sociales. Desde distintas disciplinas (sociología, antropología, economía, etc.) y perspectivas analíticas (determinismo, institucionalismo) se han examinado los modos en que se diseñan, se producen y se adoptan las tecnologías en diferentes contextos socioculturales.

El ámbito de estudios de comunicación no ha sido la excepción a la hora de realizar análisis dicotómicos de los enfoques dominantes en relación con las tecnologías. Una de las más extendidas y criticadas es la visión del determinismo tecnológico de la comunicación, subsidiaria principalmente del trabajo de Marshall McLuhan y, posteriormente, de Derrick De Kerckhove, director del Programa McLuhan en Cultura y Tecnología de la Universidad de Toronto. Frente a estos planteos se ubican los Estudios Culturales y la Economía Política de la Comunicación y la Cultura, entre otros enfoques. Sin embargo, no pretendemos abarcar todos los abordajes teóricos que constituyen el campo de la comunicación. Por el contrario, nos detenemos en aquellos que nos permiten ubicar nuestro análisis de las tecnologías según el objetivo de esta tesis. En esta propuesta persiste la pregunta por las formas en que la tecnología participa en la configuración de los procesos sociales y culturales, a la vez que éstos organizan contextos particulares donde se insertan y desarrollan las tecnologías.

Por lo tanto, reflexionar sobre los usos de la tecnología como expresiones simbólicas y materiales del terreno de la cultura implica recurrir a diferentes aproximaciones teóricas solidarias que permitan contextualizar el problema.

\subsubsection{Los términos del debate: Economía Política de la Comunicación y la Cultura vs. Estudios Culturales}

En el contexto más general de los estudios de comunicación abordamos particularmente dos de las grandes corrientes: la Economía Política de la Comunicación y la Cultura y los Estudios Culturales. Ambas se inscriben en el campo de estudios interpretativos y críticos de la comunicación a finales del siglo XX y ponen en el centro de la escena los modos en que se consumen los productos de las industrias culturales. Pero a la vez, establecen 
límites o fronteras en las condiciones que estudian dichos consumos por lo que revisitar estas diferencias permite situar los puntos de encuentro/desencuentro entre estas tradiciones teóricas a fin de construir nuestro propio abordaje conceptual.

\subsubsection{Enfoques económicos de la comunicación y la cultura}

En principio, la preocupación por la modificación de las industrias culturales ${ }^{105} \mathrm{y}$, particularmente, de las infocomunicacionales, a través del pasaje de un modelo analógico a otro digital, ha surgido como problema de investigación en el ámbito de la Economía Política de la Comunicación.

Desde la década del '90 al presente, la agenda de los estudios de Economía Política de la Comunicación y la Cultura ha renovado su interés por “(...) producir información, conocimientos, reflexiones y suscitar debates sobre la estructura y los movimientos del dinámico sector de la información, la comunicación y la cultura" (Becerra y Mastrini, 2006: 2). Esta revitalización obedece a las transformaciones de la economía mundial con consecuencias visibles sobre las industrias culturales, especialmente, en las formas de producción y consumo. Algunas de las causas se pueden ver en la digitalización de los contenidos y en los avances de las tecnologías de las telecomunicaciones que provocan que la cultura pase a ser vista como una actividad clave en los mercados internacionales del ocio.

La Economía Política de la Comunicación y la Cultura estudia la dinámica “( ...) del sector de la producción del proceso comunicativo, examinando el crecimiento del negocio y sus conexiones más amplias con la economía política” (Mosco, 1996: 74).

En sus orígenes, esta corriente problematiza la influencia del sistema capitalista en la comunicación y, fundamentalmente, surgió en respuesta a las perspectivas funcionalistas preocupadas por los efectos de los medios, pero relegando el análisis del carácter de industria de esos medios. Se trata de una variante de la teoría marxista ${ }^{106}$ y es sucesora de

\footnotetext{
105 Entendemos la noción de "industrias culturales" en los términos de Ramón Zallo: como un sector socioeconómico en que se desarrollan las actividades de creación de contenidos para prensa, radio, televisión y nuevos medios. Zallo explica que industrias culturales son "un conjunto de ramas, segmentos y actividades auxiliares industriales productoras y distribuidoras de mercancías con contenidos simbólicos, concebidas por un trabajo creativo, organizadas por un capital que se valoriza y destinadas finalmente a los mercados de consumo, con una función de reproducción ideológica y social" (Zallo, 1988: 26).

${ }^{106}$ La teoría marxista de los medios de comunicación se origina en la afirmación de Marx en La ideología alemana de que "las ideas de la clase dominante son en todas las épocas las ideas dominantes" (citado por
} 
la Escuela de Frankfurt y la noción de industria cultural. Sin embargo, deja en segundo plano el análisis del contenido ideológico transmitido por los medios de comunicación masiva, poniendo el centro de atención en la propiedad y estructura de dichos medios. Su principal propósito es desentrañar la forma en que los dueños de los medios de comunicación masiva y sus intereses logran influir sobre el contenido que difunden. Y como señala McChesney:

"El estudio académico de la Economía Política de la Comunicación implica dos dimensiones fundamentales. En primer lugar, llama la atención sobre la naturaleza de la relación de los sistemas de medios y comunicaciones con la estructura más amplia de la sociedad. En otras palabras, examina cómo los sistemas y contenidos de los medios (y las comunicaciones) refuerzan, se enfrentan o influyen las relaciones y clases sociales existentes. En segundo lugar, la Economía Política de la Comunicación observa específicamente cómo la propiedad, sus mecanismos de soporte (como por ejemplo la publicidad) y las políticas gubernamentales influyen en la manera de actuar y contenido de los medios de comunicación". (McChesney, 1998: 3)

Más allá de sus inicios, no es posible hablar de una teoría sino de un enfoque que no es homogéneo, en el cual coexisten diferencias significativas y convergen en sus posiciones institucionales que es un referente de la teoría crítica de la comunicación (De Moragas, 2011: 219). Se pueden distinguir tres tradiciones: la norteamericana, la europea y la latinoamericana.

Uno de los fundadores de la economía política norteamericana es Dallas Smythe ${ }^{107}$ que investiga sobre el poder de las empresas de comunicación y subraya que los sistemas de comunicación de masas deben ser analizados como parte integral de la estructura (base económica) como así también de la superestructura. Específicamente, se centra en el modo en que los medios crean audiencias como mercancías que adquieren cierta disposición ante el consumo y los inducen a una respuesta favorable hacia los productos que anuncian.

\footnotetext{
McQuail, 1983: 70). También se puede buscar en Elementos para la crítica de la economía política (1857 y 1858) donde “(...) critica la concepción liberal que consideraba armónicas y naturales las relaciones sociales existentes, olvidando las determinaciones de las formas de producción y confundiendo las relaciones burguesas con leyes naturales de la sociedad" (De Moragas Spá, 2011: 217).

${ }^{107}$ Investigador canadiense " (...) transmisor de la corriente en EE. UU. Fue él quien impartió el primer curso universitario en este campo y quien influyó decisivamente sobre la obra de su colega Herbert Schiller y sobre la de sus discípulos, entre ellos Thomas Guback y Vincent Mosco" (Segovia, 2001: 14).
} 
El continuador de su obra Hebert Schiller ${ }^{108}$ analiza las relaciones entre los medios y las corporaciones multinacionales, financieras y militares. "La producción teórica de Schiller viene a cubrir la inmensa laguna de las investigaciones críticas sobre la función de las comunicaciones de masas en EE. UU. y, en consecuencia, de las circunstancias políticas y económicas que condicionan la comunicación de masas norteamericana" (Segovia, 2001: 17). A su vez, este autor tuvo una gran influencia en Europa y en América Latina tras el reclamo de un "nuevo orden internacional de la información" en el contexto internacional, a la vez que situó los estudios de comunicación en el amplio campo de la economía política.

En Europa, la Economía Política de la Comunicación surgió entre los años 1974 y 1983 de la mano de los aportes teóricos de Murdock (1974), Golding (1974) y Garnham (1979). Estos autores establecen relaciones con la tradición norteamericana y también con la británica de los Estudios Culturales. Plantean que el estudio de la comunicación, la cultura y los medios debe situarse a partir del uso crítico de la teoría marxista.

Nicholas Garnham analiza los modos de producción y consumo cultural dentro de las sociedades capitalistas.

"[La economía política de la cultura] siempre sostuvo, y sigue haciéndolo, que el modo de producción capitalista tiene ciertas características estructurales fundamentales, sobre todo el hecho de que el trabajo asalariado y el intercambio de mercancías constituyen las condiciones de existencia necesarias e inevitables del pueblo. Estas condiciones modelan el terreno en el que se llevan a cabo las prácticas culturales." (Garnham, 1997: 45-46)

En esta idea es posible distinguir el modo en que se combinan lo ideológico, lo económico y lo político. En esta relación se asientan en los análisis de la economía política.

En principio, el interés de Graham y Murdock se centró en la cultura popular y juvenil trabajando desde la sociología crítica y la Economía Política de la Comunicación en el Centro Leicester, ${ }^{109}$ donde conoció a Peter Golding que realizó una crítica de las teorías de la modernización aplicadas al Tercer Mundo.

Para Murdock y Golding (1974), la idea fundamental se ubica en el reconocimiento de que los medios son empresas comerciales que producen y distribuyen bienes, analizan los

${ }^{108}$ En 1969 publicó su primer libro, surgido de diversos artículos y escritos realizados entre 1965 y 1967 a los que dio una conexión: "Comunicación de masas e Imperialismo Yanqui".

${ }^{109}$ El Center for Mass Communication Research de Leicester se fundó con el objeto de estudiar cuestiones como la violencia juvenil y el impacto de la televisión. 
procesos de consolidación, integración y diversificación en la publicidad, la edición, la prensa, la radio, la televisión, el cine, etc., bajo la premisa de la internacionalización del sector. Estos análisis incluyen las relaciones de clase y sus contradicciones como punto de partida.

Una de las diferencias más notables entre las tradiciones norteamericanas y europeas está dada en el debate entre los británicos Garnham, Golding y Murdock vs. Smythe surgido a partir de la publicación de: "Las comunicaciones, agujero negro del marxismo occidental" (Smythe: 1983/1977) en el Canadian Journal of Political and Social Theory, vol. 1, No 3. En ese artículo, Smythe señaló las carencias de la postura marxista europea que privilegiaba el estudio de la superestructura ideológica por sobre la estructura económica. A estas críticas, Murdock le responde en la misma revista con una réplica del propio Smythe, detallando las diferencias de perspectiva con la situación europea.

En el caso de Latinoamérica encontramos un terreno fértil en el cruce de la teoría económica marxista, las teorías de la dependencia, del imperialismo cultural y los estudios sobre las políticas de comunicación. El análisis se ajusta a una mirada económica de la comunicación y las industrias culturales con el acento puesto en el poder y la dominación.

Según Mattelart (1997: 77) la Economía Política de la Comunicación se desarrolla en la década del sesenta cuya preocupación apuntó al desequilibrio de los flujos de información y de los productos culturales entre países centrales y periféricos. Se centró fundamentalmente en cuestiones de dependencia cultural e imperialismo cultural en el sistema de información mundial, denunciando que las desigualdades entre los países se deben a la posición que cada uno ocupa en el sistema. En esos tiempos surge el debate internacional de la información expresado en el "nuevo orden mundial de la información y la comunicación" (NOMIC), llevado a cabo principalmente por el Movimiento de Países No Alineados, con el sustento de la $\mathrm{UNESCO}^{110}$ y al que apoyaron algunos de los investigadores de la economía política tales como Hebert Schiller o Kaarle Nordenstreng. Inaugurada la década del '80, se instala, en el marco del discurso de organismos

\footnotetext{
110 Sobre el NOMIC se pueden consultar, entre otros, los trabajos de: Mastrini y De Charras (junio de 2005), "20 años no es nada: del NOMIC a la CMSI". Anuario ININCO/Investigaciones de la Comunicación N N 17, vol. 1, Caracas, Venezuela; Schmucler (1997), "Recuerdo de lo que no fue". Quaderns del CAC, No 21. (http://www.cac.cat/pfw_files/cma/recerca/quaderns_cac/Q21schmucler_ES.pdf) y particularmente el "Informe MacBride", MacBride et al. (1980). "Ūn solo mundo, voces múltiples: comunicación e información en nuestro tiempo", Informe de la UNESCO. Fondo de Cultura Económica, México.
} 
internacionales, la idea de que ese "nuevo orden" debía orientarse a eliminar los desequilibrios a fin de redistribuir y balancear los flujos de información entre países ricos y pobres.

A fines de la década del `90, aparecen nuevos aportes a la Economía Política de la Comunicación de la mano del brasileño Cesar Bolaño y los argentinos Martín Becerra y Guillermo Mastrini, entre otros. Estos investigadores estudian los efectos del capitalismo global en las industrias culturales y de la información, la concentración y estructura económica de los grandes grupos multimedia y realizan una revisión histórica de las políticas de comunicación y cultura latinoamericanas.

Becerra y Mastrini (2006) proponen una síntesis de las tradiciones norteamericana, europea y latinoamericana, luego del reconocimiento del aporte de Heriberto Muraro, quien en los '80 elaboró una agenda de prioridades para la investigación crítica en comunicación en América Latina. En ese trabajo, señalan:

"La necesidad de analizar la producción de comunicación/cultura, más allá de la mera descripción de la propiedad, teniendo en cuenta los efectos de la macroeconomía sobre los procesos de comunicación (...), la incidencia de las nuevas tecnologías en la organización (técnica, productiva, financiera o administrativa) de las actividades económicas, el papel de los medios masivos, o de circulación restringida, en la toma de decisiones de los agentes económicos, recuperando también la necesidad de aplicar estos conocimientos a la política y a la legislación sobre las industrias culturales, en el contexto de convergencia tecnológica y de la concentración económica”. (De Moragas, 2011: 225-226)

Con este trabajo, los autores se dedican, fundamentalmente, a dar cuenta de la zona de vacancia que existe en relación con investigaciones que contribuyan con abordajes integrales y regionales en el análisis del desarrollo de la estructura de la concentración de las industrias culturales.

\subsubsection{La(s) cultura(s), comunicación y política en foco}

Los Estudios Culturales conforman un campo de investigación vasto y amplio que incluye la tradición británica, norteamericana y latinoamericana, así como integra el análisis sociológico, de la economía política, literario, antropológico cultural, entre otros. 
Sus inicios se encuentran en Gran Bretaña entre los años `50 y `60 con los desarrollos teóricos de Richard Hoggart $(1957,1969,1972)$, Edward Thompson $(1963,1975,1978)$ y Raymond Williams $(1958,1974,1977)$ que estudiaron la cultura en la vida de la clase obrera inglesa. Los aportes metodológicos al estudio de la cultura consistieron en:

“(...) nueva aproximación desde la perspectiva marxista, estructuralismo renovado, etnográfica, estudios sobre el lenguaje y la subjetividad. Estos métodos se aplican a una gran diversidad de temas, estudios sobre la clase trabajadora, pero también sobre las amas de casa o los jóvenes y una dedicación ya importante a los estudios sobre los medios". (De Moragas, 2011: 148)

Desde estas variadas perspectivas, esta corriente se propone abordar los modos en que la vida cotidiana de las personas se encuentra articulada por la cultura; cómo las prácticas culturales, en tanto configuraciones de poder, se articulan a las trayectorias del poder político y económico. En estos términos, la cultura es la esfera donde se naturalizan y representan las diferencias de clase, género, etnicidad, etc., pero a la vez oficia de medio a través del cual los distintos grupos sociales tienen la posibilidad de supervivencia, lucha, resistencia y cambio: es el terreno de la lucha por la hegemonía, de las luchas culturales.

En 1964, se crea el Centro de Estudios Culturales Contemporáneos en la Universidad de Birmingham (Reino Unido) en el que se investigaban las culturas populares y su relación con los medios masivos de comunicación, y luego identidades étnicas y sexuales.

Stuart Hall $(1973,1980,1994)$ se concentra en los medios de comunicación y cuestiona el análisis de la sociología funcionalista en "Codificación y Decodificación del discurso televisivo" (1973), a la vez que propone que siempre existe interpretación activa y dialéctica en las audiencias en relación a la posición social que ocupan. El aporte de este autor es que reconoce un sujeto crítico de la recepción dentro de un orden cultural específico. Tomando las categorías del trabajo de Hall, David Morley realiza un análisis empírico de la recepción en The Nationwide Audience (1980), donde estudia las lecturas que realizan un grupo de personas sobre un programa de televisión. Una de sus conclusiones es que todo proceso de consumo debe ser comprendido en su contexto y que no sólo importa el modo en que los sujetos recepcionan los contenidos de los medios sino cómo los integran a su vida cotidiana. Después continúa con su trabajo en Family television (1986) y Television, Audiences and Cultural Studies (1992) que dan inicio a la “etnografía de audiencia". 
A inicios de 1960, el norteamericano James Carey empieza a adoptar la denominación de Estudios Culturales para agrupar un conjunto de estudios académicos que hacían foco en las crecientes culturales populares en las sociedades occidentales. Según, Rosas Pineda:

“(...) los estudiosos de la cultura empezaron a buscar en la cultura popular síntomas de resistencia que no encontraban en la política. En los EE. UU., los Estudios culturales surgirán básicamente como una respuesta al dominio, en el mundo académico, de las ciencias positivistas y de la conducta”. (Rosas Pineda, 20122013: 10-11)

Sin embargo, mientras que para la perspectiva británica la categoría de "clases" es fundamental para las investigaciones norteamericanas, estaba ausente ya que la consideran como producto y consecuencia de la iniciativa individual y privada; enfocándose en el análisis de los medios de comunicación.

Entre los representantes de la corriente norteamericana se encuentran: James Lull (1980, 1990, 1997), que estudia las audiencias a través de la etnografía; Fredric Jameson $(1971,1972,1989)$, que realiza una lectura sobre la teoría cultural del marxismo para encontrar una íntima relación entre economía y cultura, y Donna Haraway $(1989,1991)$, que, desde la mirada de género, realiza una crítica al discurso científico sobre la naturaleza humana que deshistoriza las categorías a través de las que los sujetos piensan el mundo.

Sin embargo, en la actualidad, Lawrence Grossberg $(1997,2006,2010,2012)$ es uno de los más importantes referentes de esta perspectiva que sostiene:

“(...) lo que hace único a los Estudios Culturales es su compromiso con el contextualismo. Los Estudios Culturales consisten en un intento riguroso de contextualizar la política y el trabajo intelectual. Esto significa que los Estudios Culturales tienen que evolucionar con su propio contexto, un contexto que es tanto histórico como político por un lado, e institucional y teórico, por otro. En consecuencia, toda definición se lleva a cabo en un espacio totalmente abierto e impredecible. Cualquier versión o formación concreta de los Estudios Culturales aparecerá siempre como respuesta a un proyecto político determinado y contextualmente definido, basada en las mejores fuentes empíricas y teóricas que estén contextualmente al alcance". (Grossberg, 2010: 77)

Finalmente, los Estudios Culturales llegan a Latinoamérica entre la década del ' 70 y del ' 80 de la mano de Jesús Martín Barbero $(1987,1990,1997)$ y Néstor García Canclini $(1982,1986,2002,2010)$, quienes se interesan por el potencial de las culturas populares 
para alcanzar la democratización de la comunicación y la cultura. A la vez que destacan las características propias de las culturas latinoamericanas en relación con las europeas y norteamericanas. Como afirma Rosas Pineda:

“(...) a la par de estos dos estudiosos, surge el concepto de frentes culturales los cuales son considerados los espacios en los que los grupos, las clases, las diferentes regiones, etc., se palpan para establecer diferencias y similitudes y con ello hegemonizar el sentido de sus prácticas y enfrentar los procesos de transformación de la cultura popular frente a las tendencias globalizantes de modernidad y tecnología”. (Rosas Pineda, 2012-2013: 20)

Existen variados planteamientos más que recuperan los Estudios Culturales anglosajones y que sumados a los estudios de la recepción conforman los llamados Estudios Culturales Latinoamericanos. Este campo de estudios es diverso e interdisciplinario y político. Szurmuk y Mckee Irwin afirman:

"En América Latina la marca de lo político a partir de los años treinta ha sido tradicionalmente marxista y se institucionalizó en 1959 con la revolución cubana y los movimientos revolucionarios de los años sesenta y setenta. Estos movimientos crearon una narrativa continental que imagina a América Latina como unidad y que se ocupa de la relación entre la cultura y los destinos políticos". (Szurmuk y Mckee Irwin, 2009: 9)

Sin embargo, no nos detendremos en su genealogía dado que no constituye el objeto de nuestra propuesta conceptual ${ }^{111}$.

\title{
4.2.1.3 Tensiones y articulaciones del análisis económico cultural de la comunicación: propuesta para comprender los usos y consumos de la tecnología
}

\begin{abstract}
Ahora bien, como planteamos al inicio, nos interesa particularmente revisar los debates que se han dado entre la Economía Política de la Comunicación y los Estudios Culturales ya que nos permiten situar el problema de la tecnología como dimensión cultural.
\end{abstract}

\footnotetext{
${ }^{111}$ Para profundizar sobre los Estudios Culturales Latinoamericanos se puede consultar: Szurmuk y Mckee Irwin (2009): Diccionario de Estudios Culturales Latinoamericanos. Siglo XXI. Instituto Mora. México, que sistematiza la genealogía y los principales conceptos y aportes de estos estudios en el campo académico.
} 
En un esquema muy general podemos afirmar que las principales críticas provienen de la Economía Política de la Comunicación hacia los Estudios Culturales. En esa línea, Mosco indica:

"La economía política se aparta de la tendencia de los Estudios Culturales a exagerar la importancia de la subjetividad, así como de su inclinación a rechazar el pensar en términos de prácticas históricas y totalidades sociales. La economía política se aparta también de la tendencia de los defensores de los Estudios Culturales a utilizar un lenguaje poco claro, que contradice la visión original de este planteamiento de que el análisis cultural debería ser accesible a aquellos individuos ordinarios que son los responsables de crear cultura". (Mosco, 2006: 74)

Además, una de las acusaciones más enérgicas es que los Estudios Culturales terminan por reproducir los condicionantes político-ideológicos del ilusionismo postmoderno.

La crítica que realiza Garnham (1997) de los Estudios Culturales se desvía de los supuestos iniciales orientándose hacia el estudio de los consumos culturales en menoscabo del análisis de las condiciones de producción.

"Al centrarse en el consumo y la recepción, y en el momento de la interpretación, los Estudios Culturales han exagerado las libertades del consumo y de la vida cotidiana [...]. Pero ¿puede alguien que haya producido un texto o una forma simbólica creer que la interpretación es enteramente azarosa o que el placer no puede ser usado para fines manipuladores? Si el proceso de interpretación fuese enteramente azaroso o si, en consecuencia, tuviésemos que abandonar por completo la noción de intencionalidad en la comunicación, la especie humana habría dejado la actividad de la producción cultural hace mucho tiempo." (Garnham, 1997: 37).

Para este autor, los Estudios Culturales deben volver a la economía política para poder explicar las incidencias sobre los cambios a nivel de la cultura, ya que las tendencias de la economía global se reflejan en la esfera de la comunicación y la cultura (Garnham, 1997: 32).

Desde la perspectiva de los Estudios Culturales, Grossberg (1997: 53) afirma que se pone el acento en "(...) la complejidad y las contradicciones, no sólo dentro de la cultura, sino también las relaciones entre el pueblo, la cultura y el poder". Y aunque señala estar de acuerdo con Garnham en que existen varias investigaciones que desde los Estudios Culturales no toman muy en cuenta la economía, también afirma que, muchas veces, desde la economía política tampoco se realizan estudios serios sobre la cultura. Y destaca que la mirada de Garnham es reduccionista ya que en la crítica cae en el "economicismo". 
"Es posible que los Estudios Culturales hayan prestado demasiada atención al consumo, pero me temo que lo que subyace a tales acusaciones es una tendencia a descartar el consumo (o el ocio) por considerarlo menos importante que la producción, o tal vez incluso una trivialidad [...] quizás los Estudios Culturales hayan exagerado el valor del consumo (y la recepción) en cuanto a su posibilidad de ofrecer placer, libertad y poder, pero nuevamente, me temo que lo que subyace a tales críticas es un deseo de volver a un modelo de dominación más simple en el cual se considera a las personas como 'ingenuotes culturales, que se dejan manipular pasivamente'." (Grossberg, 1997: 51)

En este punto, Kellner (1998) propone tender un puente entre la Economía Política de la Comunicación y los Estudios Culturales, sosteniendo que se deben articular diferentes análisis para no concebir a las audiencias como víctimas culturales ni tampoco como siempre activas y capaces de producir sus propios significados. Según Kellner, se debe completar la visión de que los medios de comunicación reproducen la ideología dominante, comprendiendo que la cultura es un terreno de disputa simbólica sustantivo. Es necesario que se analice todo aquello que les permita tanto señalar los mecanismos de reproducción, como valorar y reforzar aquellos que pueden albergar un gesto de resistencia (Kellner, 1998: 190).

Plantea que no es posible realizar lecturas aisladas de todo lo que se emite en los medios ya que el contexto económico, político y social influye en la producción y la recepción de esos contenidos. Y da diversos ejemplos de la importancia de contextualizar toda práctica de consumo.

Para Kellner: "El hecho de situar los artefactos de la cultura de los medios de comunicación en el sistema de producción y de la sociedad que los genera, puede ayudar a dilucidar sus estructuras y significados”. Para ello, afirma que resulta imperioso acudir a "una amplia gama de métodos para explicar cada dimensión y mostrar cómo encaja en los sistemas textuales" (Kellner, 1998: 193).

Estos debates dan cuenta de que se requiere de una reconciliación entre ambas corrientes para avanzar hacia crecientes niveles y profundización de conocimiento del campo de problemas de la comunicación y la cultura. Y esto exige una labor intelectual interdisciplinaria que privilegie la práctica sistemática de la reflexión tanto sobre los contextos de producción como de la recepción.

En este marco, recuperamos el análisis general sobre los medios y las tecnologías de Silverstone (1990). Un análisis que trata de unir las perspectivas de los Estudios 
Culturales y de la Economía Política de la Comunicación y la Cultura, mirando la dinámica sociocultural de la acción que se despliega alrededor de las tecnologías y de la televisión en particular, siempre teniendo en cuenta la estructura de las industrias de medios y el sistema de distribución de la televisión.

El autor sostiene que las tecnologías deben estudiarse desde el modo o forma en que han sido socialmente (política y económicamente) configuradas. Para ello, es necesario comprender cómo “(...) su producción técnica y su comercialización han contribuido a su estatus no sólo de objetos materiales con funciones específicas y significados o valores sociales o culturales, sino también cómo esa configuración, esa obra, se continúa en consumo y en uso" (Silverstone, 1990: 4). Este modo de abordar la manera en que las tecnologías se incorporan al ámbito cotidiano permite comprenderlas como objetos materiales y simbólicos “(...) que están constantemente sujetos a una reconstrucción, a la afirmación o al rechazo y a una articulación múltiple, ya que su importancia y su propósito aparecen con su utilización cotidiana en los hogares, diferentes entre sí por la cultura, la clase social, la composición o la geografía” (Silverstone, 1990: 4).

Por otra parte y en un marco más general Becerra y Mastrini incorporan el análisis de las estructuras socioeconómicas al análisis cultural señalando que:

"Puede ensayarse la hipótesis de que esta línea de exploración permite construir articulaciones entre los aportes de los estudios de la cultura y los de la economía política en un mundo cuyos trazos de globalización son ineludibles para abordar rutinas culturales de los diferentes grupos sociales, en las distintas latitudes". (Becerra y Mastrini, 2006: 120)

De este modo, los autores señalan que para integrar los abordajes de la Economía Política de la Comunicación y la Cultura y de los Estudios Culturales se requiere comprender esas tensiones que se configuran entre las estructuras socioeconómicas y la producción cultural.

La identificación de los principales puntos de encuentros entre estas perspectivas nos conduce a plantear nuestra postura a la hora de construir nuestro objeto de estudio. En esta dirección, consideramos a las tecnologías como resultado de procesos de construcción sociocultural, económica y política en los que se incluyen dispositivos técnicos, las prácticas culturales, los discursos, los modos y la producción de conocimiento. Pensar las tecnologías como productos culturales y parte de la trama de las industrias infocomunicacionales implica reflexionar sobre su carácter de objetos 
materiales y simbólicos que se manifiestan en los usos y prácticas de los sujetos según los grupos sociales y los diversos entornos culturales.

Teniendo en cuenta las contribuciones que ofrecen estos enfoques sobre la dimensión cultural de las tecnologías y las estrategias metodológicas para estudiarlas en contexto, incorporamos a nuestro marco conceptual los aportes de aquellas perspectivas teóricas que caracterizan y analizan los usos de las tecnologías. Considerar los desarrollos teóricos sobre los usos de las tecnologías digitales nos permite ir construyendo nuestro marco interpretativo para abordar las relaciones que se establecen entre los actores sociales estudiados y la televisión digital.

\subsection{Perspectivas teóricas sobre usos de las tecnologías}

En relación con los procesos de integración de tecnologías digitales interactivas y los vínculos que establecen los sujetos con estas tecnologías, entendemos que la noción de uso debe ser ubicada en un marco analítico e interpretativo pertinente y situado en relación con nuestra posición conceptual.

Cuando revisamos los desarrollos teóricos entre los estudios de comunicación, encontramos que la idea de uso se ha caracterizado y analizado desde una variedad de marcos interpretativos.

En principio, repasamos el modelo de Difusión de Innovaciones ${ }^{112}$ que ubicó al sociólogo norteamericano Everett Rogers (1962) como uno de los fundadores de la "comunicación para el desarrollo" en medio del predominio del paradigma de la modernización ${ }^{113}$. Según los teóricos del desarrollo, los países de América Latina no habían alcanzado niveles de desarrollo para lograr la modernización de sus sociedades. En este contexto, Rogers a lo largo de cinco ediciones de su obra: Difusión de Innovaciones (1962, 1971, 1983, 1995,

\footnotetext{
${ }^{112}$ Uno de los principales supuestos del difusionismo es que toda innovación tecnológica (objetos, ideas, prácticas) implica necesariamente un cambio social que puede comprenderse a partir de un proceso que contiene: la innovación propiamente dicha, los canales de comunicación, el tiempo y el sistema social donde se produce la difusión. En este esquema, la innovación consiste en transmitir información a futuros usuarios sobre la conveniencia de utilizar una tecnología, adoptar una idea o una práctica en particular. El rechazo o la no adopción están vinculados con la persistencia de características propias de las sociedades tradicionales. Para analizar la difusión de innovaciones Rogers (1962) caracteriza diferentes "categorías de adoptantes": innovadores, primeros adoptantes, mayoría precoz, mayoría rezagada y tradicional.

${ }^{113}$ La idea central del paradigma de la modernización se sostiene sobre una perspectiva del desarrollo lineal, acumulativo y progresivo que requiere la transferencia de tecnología y de la cultura sociopolítica desde las sociedades desarrolladas hacia las sociedades tradicionales. "La modernización se concibe aquí como un proceso de difusión en el cual los individuos transitan de un modo de vida tradicional a otro más complejo, más técnicamente desarrollado y más rápidamente cambiante" (Servaes, 2000: 18).
} 
2003) estudia la adopción de ideas, objetos, tecnologías en la sociedad y distingue diferentes fases en el proceso de difusión: conocimiento, interés, evaluación, prueba y adopción. Servaes (2000) describe el enfoque difusionista ubicando su punto de partida en las propuestas de Shannon y Weaver de la ingeniería de la información (modelo lineal: fuente -transmisor- receptor y destinatario) y en la sociología funcionalista norteamericana (flujo de la comunicación en dos pasos [Lazarsfeld, 1944]). Según este modelo, los medios de comunicación tienen un rol importante en la primera etapa del proceso: difusión de la información, en tanto la función de la comunicación interpersonal o fuentes personales son más necesarias en el momento de evaluación de la adopción.

De este modo, en el modelo difusionista la idea de usuario se encuentra limitada y subordinada a la propuesta de innovación y adopción, más allá que Rogers trata de atribuirle un rol significativo. Por lo tanto, la idea de "uso" se encuentra linealmente vinculada a los efectos de persuasión que los medios de comunicación y la comunicación interpersonal (en manos de los líderes de opinión). Supone un uso determinado en primer lugar, por agentes externos al contexto social y cultural (medios de comunicación) en el que se produce la difusión de nuevas ideas o tecnologías y, en menor medida, por fuentes de información personales.

Por otro lado, uno de los desarrollos empíricos más consistentes dentro de la perspectiva funcionalista de los medios es la hipótesis de los Usos y las Gratificaciones que se propone revisar y superar el esquema informacional de la comunicación. Este enfoque trata de explicar el modo en que los medios masivos son utilizados para satisfacer necesidades, a la vez que busca comprender las motivaciones para el comportamiento mediático. Para ello, relaciona el consumo, el uso y los efectos de los medios con la estructura de necesidades que caracteriza al destinatario (Wolf, 2004: 80). Estos estudios destacan la relación entre el uso de los medios de comunicación y la disposición psicológica y su ubicación social.

En esta perspectiva se centra en el estudio de los contextos y las interacciones sociales de los destinatarios y, particularmente, en la actividad de la audiencia. Una audiencia que se entiende como un conjunto de individuos que seleccionan contenidos o se exponen a los medios de comunicación para satisfacer diferentes necesidades $\mathrm{y} / \mathrm{u}$ obtener gratificaciones.

"El receptor es también un iniciador, tanto en el sentido de dar origen a mensajes de retorno, como en el sentido de realizar procesos de interpretación con un cierto 
grado de autonomía. El receptor 'actúa' sobre la información de la que dispone y la 'usa'." (McQuail, 1975: 17)

Desde este punto de vista, la idea de uso se asocia a la decisión de los sujetos de exponerse a los medios según sus propias motivaciones para satisfacer necesidades y/o para obtener algún tipo de gratificación.

A diferencia de la hipótesis de los Usos y Gratificaciones, el enfoque de los Estudios Culturales europeos y latinoamericanos complejizan la noción de uso, descentrando la discusión que pone énfasis en los medios de comunicación para hacer foco en los procesos de consumo, situando el análisis comunicacional en el contexto de los procesos socioculturales. De este modo, entienden que "el comportamiento del público destinatario está orientado por factores estructurales y culturales que, por otra parte, influencian el contenido de los media (...) Estos factores estructurales favorecen además la institucionalización de los modelo 'aprobados' de uso de los media y de consumo de los productos culturales" (Wolf, 2004: 122-123). Es en las prácticas de recepción donde se pueden comprender los usos que hacen de los medios y sus contenidos en relación con su vida cotidiana. Por esta razón, proponen considerar la noción de consumo como práctica cultural que se expresa en la apropiación y uso de los bienes culturales.

\subsubsection{El concepto de uso de las tecnologías digitales}

A partir de las perspectivas teóricas revisadas en el apartado anterior pretendemos poner el acento en la noción de uso que oficiará de categoría analítica para indagar el vínculo que entablan los sujetos en estudio con las tecnologías digitales y, en particular, con la televisión digital terrestre.

Para comenzar definimos la noción de tecnologías digitales interactivas como aquellas:

“(...) utilizadas para el almacenamiento, tratamiento, gestión, creación, transmisión y recepción de informaciones y mensajes en todo tipo de formatos. Una de las principales características de estas tecnologías es la interactividad, que permite a los usuarios operar con ellas no solamente usándolas como herramientas sino interactuando con otros en el medio tecnológico, desarrollando procesos, creando a través de la tecnología y en ella. (...) implican entonces -al igual que otras tecnologías- el desarrollo de prácticas, discursos y saberes" (Cabello, 2008b: 8). 
En nuestra investigación consideramos a las tecnologías digitales interactivas como objetos materiales y simbólicos que forman parte de procesos sociales, culturales, políticos y económicos a la vez que sus usos producen, reproducen y expresan prácticas comunicativas, disputan sentidos en condiciones socio-históricas específicas. Entre las diferentes tecnologías digitales interactivas se encuentra la televisión digital que se constituye en uno de los objetos de estudio de la convergencia digital pero, fundamentalmente, como una tecnología en transición que en los discursos hegemónicos promete cambios sustantivos en la vida social -condensados en la idea de inclusión digital-y en el modo de vinculación con y entre las personas.

Por lo tanto, en este caso, estudiar las tecnologías digitales interactivas y sus usos implica explorar esa relación con el objeto de evidenciar si esos usos producen procesos de inclusión digital tal como lo expresan los discursos dominantes y, en particular, la política pública TDA.

Asimismo, la indagación de los usos de las tecnologías digitales interactivas involucra el reconocimiento de las prácticas comunicativas que se despliegan en esos procesos. En este marco, consideramos que estas prácticas en tanto prácticas sociales situadas históricamente tienen una dimensión material basada en las “ (...) tecnologías disponibles en su época, el libro, el cine, la radio, la televisión, las computadoras, los videojuegos, la telefonía móvil; aunque no siempre son mediáticas" (Murolo, 2014: 60), así como también una dimensión simbólica a partir de la cual se producen, reproducen y disputan los sentidos manifestados en los usos de las tecnologías en sentido amplio, y en nuestro caso, especialmente, centrados en las tecnologías digitales interactivas. Para precisar el concepto de prácticas comunicativas recuperamos la propuesta de Roxana Cabello:

“(...) aquellas que forman parte de la práctica real de los hombres, que involucran la producción, circulación y recepción (apropiación y usos) de significados en el marco de una sociedad mediatizada y que expresan elementos de sensibilidades compartidas. De este modo, se incluirían tanto las que se valen de medios técnicos como las que no. Existe una relación dialéctica entre prácticas comunicativas (actividad simbólica) y vida social." (Cabello, 2006: 184)

Esta conceptualización permite identificar las formas que adquieren los usos de las tecnologías a partir de las transformaciones en la experiencia cotidiana de los sujetos como los sentidos y contrasentidos que articulan en el contexto social y cultural. 
Necesariamente se requiere considerar la inscripción de estas prácticas comunicativas en el ámbito cotidiano en diálogo con la trama sociocultural en la que se producen ${ }^{114}$.

A partir de estos y otros trabajos académicos Roxana Cabello ha construido una mirada compleja a la hora de abordar la relación entre los sujetos y las tecnologías en general y en particular, las denominadas "digitales e interactivas" que se propone superar los enfoques deterministas e instrumentales. Claramente, la autora se posiciona críticamente frente a las posiciones que naturalizan los modos en que las tecnologías se piensan en las sociedades contemporáneas.

En esta dirección, retomamos la noción de "entorno tecnocultural" de Cabello:

"La oferta y disposición de un conjunto cada vez más variado de dispositivos tecnológicos -en este caso, en general, digitales- contribuye con la configuración de un tipo particular de escenario en el cual se desarrollan los intercambios sociales, que se diferencia sustantivamente de otros que predominaron en otros momentos históricos". (Cabello, 2008: 2)

La autora señala que uno de los rasgos de este entorno es su carácter de inestabilidad dado por la marca de la obsolescencia propia de los dispositivos tecnológicos (nuevos productos en el mercado que varían en sus aspectos funcionales o estéticos, nuevos usos generados por los sujetos que se vuelven más competentes con su propia práctica); y que, por lo tanto, resulta cambiante convirtiéndose en un "telón de fondo". Un escenario heterogéneo que se torna "medio" y que "asume un carácter envolvente que se materializa en cada uno de los espacios y momentos en que las personas interactúan entre sí, realizan sus actividades y además, se relacionan interactivamente con las máquinas" (Cabello, 2008: 2). Y afirma que el advenimiento de la televisión digital conforma uno de los puntos más altos de este entorno tecnocultural ya que la posibilidad de mejorar la imagen y la interactividad puede modificar el tipo de relacionamiento de los públicos con el medio. Pero advierte que no hay que perder de vista que este ambiente se apoya en la lógica del mercado que a través de la producción y distribución de tecnologías a escala

\footnotetext{
${ }^{114}$ En esta línea, retomamos el desarrollo conceptual que la investigadora argentina Roxana Cabello viene construyendo desde el año 2000 en el Programa Usos de Medios Interactivos (UMI) de la Universidad Nacional de General Sarmiento. La autora se ha interesado "(...) por los productos de la cultura de masas y por las relaciones que las personas establecen con ellos (...)" (Cabello, 2008: 17). Una de las primeras investigaciones que dirigió explora las características que asume la relación que establecen algunos maestros con las tecnologías informáticas de la enseñanza. En el caso del ámbito del entretenimiento, la investigadora ha realizado distintos estudios sobre las características de los usos de los videojuegos y las prácticas que se desarrollan en torno a ellos. Tanto Las redes del juego (2008) como Ciberjuegos. Escritos sobre usos y representaciones de los juegos en red (2009) reúnen los resultados de investigación cuyo propósito fue producir una caracterización en profundidad sobre los usos de los videojuegos en localidades del conurbano bonaerense.
} 
mundial produce una gran penetración de los dispositivos a la vez que profundiza las desigualdades en el acceso social.

Ahora bien: Cabello (2008) reconoce que ese nuevo tipo de escenario adquiere características distintas según se trate de centros urbanos o de lo que llama "paisajes periurbanos" como por ejemplo, la Ciudad de Buenos Aires en relación con el Área Metropolitana (conurbano bonaerense). En el caso de los paisajes periurbanos, la investigadora sostiene que el entorno tecnocultural se manifiesta como "discontinuo" debido a que se encuentra más despojado de imágenes y de dispositivos tecnológicos y donde persiste la presencia de medios de comunicación de masas (TV, radio o libros) y, en menor medida, medios informáticos. Este paisaje tecnocultural discontinuo ligado al acceso desigual a las tecnologías digitales, a diferentes grados de apropiación de los dispositivos y expectativas de inclusión digital, reviste algunos de los atributos que distinguen el entorno tecnocultural en las zonas periféricas.

Esta conceptualización sobre los rasgos de la cultura actual nos permite situar nuestro objeto de estudio en el contexto socioeconómico del conurbano bonaerense. Particularmente, en el caso del Partido de José C. Paz, ya que encontramos ciertas características compartidas tales como ubicación geográfica y aspectos sociales, culturales y económicos.

Mencionamos anteriormente que dentro del campo de estudios encontramos diferentes tradiciones sobre el concepto de uso, entre las cuales identificamos la perspectiva de Usos y Gratificaciones y los Estudios Culturales. En el primer caso, la idea de uso se vincula con las necesidades humanas y se orienta a la búsqueda de gratificación en los medios o en otras fuentes. Se trata de una audiencia activa de la cual depende, en gran parte, la iniciativa de conexión de las necesidades y la elección de los medios. Desde esta mirada, se explican los modos en que se originan ciertos usos individuales de los medios de comunicación masiva para satisfacer sus necesidades conscientemente (Katz, BlumlerGurevitch, 1974). En el caso de los Estudios Culturales interesará entender el contexto de ver, de usar los medios de comunicación, los sujetos en su propia cotidianeidad donde asignan sentido a lo percibido. Introducen los condicionamientos culturales a partir de los cuales el sujeto afronta las prácticas de recepción.

El sentido que le atribuimos a la noción de uso tiene en cuenta los aportes de estudios sobre la recepción de medios, en general (Cantú y Cimadevilla, 1998), y otros abordajes relacionados con el contacto con tecnologías informáticas en particular (Renaud, 1990 y Cabello, 2007). En este contexto, consideramos que la idea de uso hace referencia al 
sentido (reelaboración y resignificación) que le atribuyen los sujetos en recepción a los productos de los medios de comunicación en vinculación con sus prácticas cotidianas. Pero cuando se trata de tecnologías digitales interactivas:

“(...) la noción de uso se torna más compleja ya que no solamente se juegan aspectos vinculados con contenidos sino que se agregan las múltiples posibilidades que se desprenden de la interactividad. A partir de la idea de praxis operativa (Renaud, 1990) (...) los usos de estas tecnologías implican una praxis a partir de la cual los usuarios pueden efectivamente reelaborar contenidos conforme a su experiencia cultural (esto es, incluso, más allá de su actividad simbólica). Pero pueden también realizar otro tipo de operaciones que viabilizan el establecimiento de relaciones de intercambio entre diferentes agentes y, con ellas, la actualización de diversos tipos de prácticas comunicativas. Desde este punto de vista, los usos de las tecnologías (...) incluyen también todas aquellas operaciones que refuerzan el lugar de mediación de la tecnología respecto del establecimiento de vínculos sociales y de la producción colectiva de conocimiento". (Cabello, 2007: 179)

Según Cabello (2007), esta perspectiva permite abordar los usos no solamente en recepción sino también en producción y, a la vez, entender a las tecnologías digitales como dispositivo tecnológico-social que media positivamente prácticas de conectividad y de producción de conocimiento.

En principio, desde estas categorías conceptuales planteamos explorar usos vinculados a las tecnologías digitales, más precisamente a la televisión digital en el Partido de José C. Paz de la provincia de Buenos Aires.

Entonces, cuando hablamos de uso, entendemos que los sujetos inmersos en una situación sociocultural determinada reelaboran y resignifican los contenidos según su experiencia cultural (Cantú y Cimadevilla, 1998) y en el caso de las tecnologías digitales en la noción de uso se incorporan las múltiples posibilidades que se desprenden de la interactividad. Comprendemos la idea de interactividad en la línea del planteo de Rausell Köster (2005) ${ }^{115}$ que señala que "se define como la actividad (física) requerida por parte del receptor para la recepción del mensaje en la interacción entre el hombre y la máquina, que implica necesariamente una ampliación del campo de elección del receptor”. Desde esta mirada la interactividad que permite un soporte “(...) está en función de la pluralidad de opciones de mensajes disponibles y de una estructura que haga posible la gestión de esos mensajes" (Cabello, 2006: 179).

Por ende, la indagación en torno a los problemas de los usos de las tecnologías digitales requiere de la identificación de aspectos involucrados en la noción de uso tales como:

${ }^{115}$ En el próximo apartado abordamos la noción de interactividad que propone esta autora. 
situaciones de uso; motivaciones; tipos de aplicaciones más usadas, complementación con otros medios y efectos de desplazamiento; definición de ventajas y desventajas; dificultades percibidas; tiempo de trabajo y tiempo libre; evaluación y expectativas en relación con la vida cotidiana.

\subsubsection{Interactividad: apertura y clausura de un término polisémico}

La perspectiva de los usos de las tecnologías digitales que asumimos en esta tesis requiere recuperar la noción de interactividad debido a que constituye uno de los rasgos distintivos de la tecnología digital que nos proponemos estudiar: la TDT.

La definición de interactividad adquiere diferentes sentidos en el campo de las ciencias sociales $\mathrm{y}$ ha sido empleada para caracterizar diferentes dispositivos técnicos: telecomunicaciones, computadoras, medios de comunicación, etc. Pero más allá de su uso para identificar un tipo de tecnología consideramos, junto a Ribés Alegría, que “(...) ha provocado que se desvirtúe su significado real. Esto sumado al hecho que el concepto de interactividad procede de interacción, un vocablo polisémico y bastante impreciso (...)" (Ribés Alegría, 2007: 124). De este modo, debemos tratar de delimitar su significado así como también sus características particulares para el caso de nuestro estudio.

Desde distintas disciplinas del campo de las ciencias sociales y exactas, varios autores han realizado aproximaciones al término interacción (Simmel, 2002; Goffman, 1972; Mead, 1934; entre otros.). Encontramos desarrollos conceptuales en la sociología, la comunicación, la informática, la ingeniería y la electrónica. En este apartado, repasaremos algunas de estas conceptualizaciones para detenernos en aquellas que proporcionan elementos para definir la interactividad en el caso de la televisión digital interactiva.

Ribés Alegría (2007) y Scolari, (2008), entre otros investigadores, coinciden en ubicar en la década del `60 uno de los primeros trabajos que definen la relación entre el hombre y la computadora como un tipo específico de vínculo entre un sujeto y un dispositivo tecnológico. El informático estadounidense Joseph Licklider (1960), en su artículo "Simbiosis hombre-ordenador", presenta elementos analíticos para definir la interacción entre las personas y las máquinas como una relación cooperativa en la toma de decisiones y el control de situaciones complejas. En esta relación las personas fijan los criterios para 
la resolución de problemas y las máquinas realizan las tareas rutinarias básicas para el logro de los objetivos preestablecidos por los sujetos. El ingeniero Douglas Engelbart (Instituto de Investigación de Stanford, EE.UU.) retoma esta idea y desarrolla “(...) el primer sistema digital de producción colectiva (groupware) basado en la idea de hipertexto (...) constituyó una etapa fundamental en la historia que llevó a la construcción de las actuales máquinas digitales interactivas" (Scolari, 2008: 94).

A su vez, en el campo de estudios de comunicación encontramos los estudios culturales, de recepción y sociología de la comunicación. En general, estos enfoques analizan el vínculo que establecen los sujetos con los medios de comunicación masiva desde distintas perspectivas teórico-metodológicas. Por ende, nos detenemos en los principales aportes de los Estudios Culturales debido a que constituye un marco solidario con nuestra propuesta conceptual.

Los Estudios Culturales ${ }^{116}$ se ocupan de explorar el proceso social que corresponde a la atribución de sentido, al desarrollo de la cultura, de prácticas sociales compartidas. Como enfoque interdisciplinar entiende los procesos culturales mediante las intersecciones entre las estructuras sociales y las prácticas culturales. Estudian las relaciones surgidas de la interacción entre los sujetos (el público) y los medios de comunicación: la relación entre el usuario y el medio. De ahí que consideran que la recepción siempre es activa ya que en el proceso el sujeto no recibe los mensajes de los medios pasivamente sino que negocia, resiste o acepta los significados en el marco de los contextos de interpretación propios (Hall, 1980).

Por lo tanto, la idea de interacción de esta perspectiva es el punto central de análisis que permite estudiar las relaciones entre los productores y los consumidores de cultura en los contextos cotidianos de recepción de los medios de comunicación. Y con la idea de “audiencia activa" (Ang, 1985; Fiske, 1987; Morley, 1993; Hall, 1980) se puede analizar el proceso por el cual se produce el encuentro entre el usuario y el texto contextualmente situado.

Este sucinto panorama acerca de las conceptualizaciones sobre la interacción en las ciencias sociales nos permite establecer ciertos elementos para acercarnos a la noción de interactividad.

${ }^{116}$ En este caso, tomamos las premisas generales de abordaje que permiten definir, en sentido amplio, la idea de interacción. 
Decíamos más arriba que la interactividad resulta un término indefinido y utilizado en distintos sentidos y contextos. Varios autores han realizado revisiones sobre los orígenes y los usos del término en las ciencias sociales y, en particular, en relación con la televisión interactiva (Ribés Alegría, 2007; Franquet, Ribes, Soto, Fernández Quijada, 2008; Fonseca Hidalgo, 2013; Rost, 2004).

Una de las definiciones de interactividad que encontramos en dichos estudios es la que propone Kerchove (1999) que la concibe como "la relación entre la persona y el entorno digital definido por el hardware que los conecta a los dos" (Ribés Alegría, 2007: 124). Otro concepto de interactividad revisado es el que desarrollan Bettetini, Colombo y otros: “(...) la imitación de la interacción por parte de un sistema mecánico o electrónico, que contemple como su objetivo principal o colateral también la función de comunicación con un usuario (o entre varios usuarios)" (Bettetini, Colombo y otros, 1995: 17). Muchos autores coinciden en señalar la dispersión de las definiciones sobre interactividad y sus aplicaciones a diferentes binomios: sujeto-máquina, sujeto-sujeto (Durlak, 1987; Rafaeli, 1988; Jensen, 1998; Sádaba Chalezquer, 2000; Schultz, 2000; Dholakia y otros, 2000; entre otros).

A la vez, algunos investigadores se detienen en la propuesta de Jensen (1998) que sostiene que: "La interactividad es una medida de la capacidad potencial del medio para dejar al usuario ejercer una influencia en el contenido y/o en la forma de la comunicación mediatizada" (Lacabanne, 2010: 144). Este autor repasa los antecedentes del término y reconoce tres modos de abordarlo: desde la sociología, de la comunicación y de la informática. En el primer caso, se trata del estudio de las relaciones entre personas en una situación dada que adaptan mutuamente su comportamiento y acciones. En el segundo, contiene el vínculo que entablan los receptores y los medios de comunicación. Finalmente, el tercer abordaje es el que considera la relación entre los sujetos y las computadoras. Y clasifica cuatro modalidades de interactividad:

"1. Interactividad de transmisión (transmissional interactivity). Consiste en que el usuario elige de un flujo de información en un medio unidireccional. Ejemplo: el teletexto o los sistemas multicanales.

2. Interactividad de consulta (consultational interactivity). El usuario pregunta y el sistema responde en un medio bidireccional. Ej.: CD-ROM, Web, videos a pedido.

3. Interactividad de conversación (conversational interactivity). El usuario produce y envía su propia información. Ej.: correo electrónico, sistemas de conferencia, grupos de noticias. 
4. Interactividad de registro (registrational interactivity). El medio registra información del usuario y por lo tanto también adapta y/o responde a las necesidades y acciones del usuario. Ej.: agentes autómatas, interfaces inteligentes". (Lacabanne, 2010: 145).

Este rápido repaso sobre el término interactividad da cuenta de la complejidad y la multidimensionalidad del concepto y que aún resta explorar sus diferentes aspectos (Rost, 2004; Lacabanne, 2010; Fonseca Higalgo, 2013; entre otros).

Entre los diversos desarrollos conceptuales que revisamos -y muchos más que existennos inclinamos por recuperar la noción de Rausell Köster (2005) que reconoce la dispersión sumada a cierta confusión terminológica y señala que para estudiar la interactividad es necesario “(...) rescatar el concepto de discurso interactivo para aludir a aquellos itinerarios de lectura propuestos por un emisor mediante enlaces capaces de crear un todo coherente, en mensajes vehiculados a través de medios y soportes interactivos" (Rausell Köster, 2005: 148). De este modo, ubica a la interactividad como la interrelación entre el sujeto y la máquina en la que existen muchos grados de interactividad según el medio o soporte tecnológico. Esos grados se dan en función de la diversidad de mensajes disponibles que ofrece el dispositivo tecnológico. Por lo tanto, afirma que: "La interactividad de un discurso dependerá del grado de actividad que ese determinado discurso ofrece y requiere entre el usuario y la máquina, propia o ajena (como en el caso de internet), en contacto, entendiendo actividad como acción o actividad física por parte del usuario y del sistema. Y especificamos 'actividad física"” (Rausell Köster, 2005: 151-152).

En nuestro caso, entendemos que esta propuesta sobre la interactividad nos permite abordar los usos de la televisión digital entre la población en estudio ya que sostiene que es en la relación entre el proceso de lectura del usuario y las opciones ofrecidas por el emisor donde se construyen los diferentes grados de interactividad. Y subraya: “(...) que el medio o el aparato que permite manipular el soporte permita la interactividad no implica que todos los discursos que se vehiculan a través de ellos se sirvan de esta cualidad y sean interactivos" (Rausell Köster, 2005: 153). En esta dirección, consideramos la idea de la interactividad de la televisión digital como aquella relación entre el dispositivo y el sujeto en la que existen diferentes grados de actividad, según el proceso de lectura por parte del usuario a partir de las funciones que ofrece el receptor digital: consulta de programación, estado del tiempo, tránsito, etc.; grabación de 
programas; descarga de datos; etc. Es una relación que se establece mediante los itinerarios de lectura propuestos por el emisor pero que necesariamente completa y le da sentido el sujeto receptor en el uso de la televisión digital.

\subsection{El problema de la inclusión digital}

Hemos explicitado en varias ocasiones en esta tesis que nos preocupa la noción de la inclusión digital y el modo en que dicha cuestión es definida y promovida a través de la implementación de políticas públicas dirigidas a sectores sociales "en riesgo de exclusión”.

En el apartado 1.2 del capítulo I introdujimos el problema de la inclusión digital en relación con la idea de exclusión. Entendemos que para explicar la cuestión de la inclusión resulta necesario conocer su nexo con la noción de exclusión.

Desde la teoría de los sistema autopoiéticos se comprende a la inclusión y a la exclusión como una unidad de la diferencia inclusión/exclusión. Parafraseando a Luhmann (2007) el par inclusión/exclusión es una diferencia que se torna unidad en tanto ninguno se puede reconocer si no se tiene en cuenta la otra parte. Es decir, la unidad de la diferencia entre los términos tiene un carácter dinámico en tanto depende de su interrelación y en el tipo de sistema donde opere. Ramos Calderón lo explica del siguiente modo:

“(...) no se puede indicar y distinguir lo que está incluido, sino se tiene el referente de lo que está excluido; por lo tanto, conviene subrayar que la posibilidad de observar uno u otro lado se debe a que ambos están presentes. Lo anterior puede considerarse como la evolución que han tenido los sistemas sociales, hasta convertir a la inclusión y a la exclusión en una unidad: la unidad de la diferencia inclusión/exclusión y que en el momento actual, es algo que se ha instaurado y que se encuentra presente en su operar”. Ramos Calderón (2012: 96)

Si bien, es necesario identificar esta relación del par inclusión/exclusión creemos necesario detenernos brevemente en el término de exclusión.

Decíamos al inicio de la tesis que este concepto fue objeto de estudios muy intensivos por la década del ` 90 y que las primeras definiciones surgieron a la luz de las transformaciones producidas por un modelo económico competitivo que derivaron en crecientes grados de desigualdad y situaciones de pobreza en amplios sectores de la población mundial. El cariz que toma la noción de exclusión está referido a su carácter social. Ramos Calderón 
(2012: 78) retoma la propuesta teórica de la autora Silver (2000) que caracteriza la idea de exclusión social desde tres paradigmas: de la solidaridad, de especialidad y de monopolio. En el primero, relacionado con el republicanismo, la exclusión social es vista como la desviación de la norma pero contiene a la vez su opuesto: la integración, es decir, amenaza y refuerza a la vez la cohesión social. En el caso del segundo paradigma, que se emparenta con el liberalismo, es una consecuencia de la especialización, o sea, lleva a la: “(...) diferenciación social, división económica del trabajo y separación de esferas” (Idem, 79), y como en el primer caso, tiene su opuesto que es la inclusión. Finalmente, el tercero, que se vincula con la perspectiva socialdemócrata, la exclusión social es efecto de la formación de sectores que tratan de tener privilegios que comparten una cultura e identidad que legitiman la exclusión de quienes no pertenecen. Estas perspectivas se presentan separadas pero en el contexto social se van solapando y combinando. Lo que nos interesa destacar es que en cada uno de estos paradigmas a la exclusión siempre se le opone la inclusión por lo que una u otra categoría opera de telón de fondo según desde dónde se analice la situación.

Otra de las cuestiones que planteamos en el capítulo I es que la exclusión social tiene un carácter multidimensional en la que los factores económicos, políticos, culturales se interrelacionan.

Estas precisiones nos permiten contar con ciertos elementos analíticos para considerar estas nociones en relación con las tecnologías digitales.

En principio, cuando nos referimos a exclusión digital estamos aludiendo a las limitaciones (de acceso, de usos, sociales, culturales) que pueden tener o percibir personas, grupos, países, regiones para aprovechar, integrar o neutralizar las tecnologías digitales por diferentes causas: demográficas, económicas, sociales, educativas.

La noción de inclusión digital entonces, a las condiciones (de acceso, usos, sociales, culturales) por las cuales personas, grupos, países o regiones pueden, son o se perciben con capacidad para integrar y/o aprovechar las tecnologías digitales para su desarrollo.

En el contexto de las discusiones en organismos internacionales y en los ámbitos académicos la definición de la inclusión digital sucede a la problematización sobre la brecha digital. Como hemos referido en anteriores capítulos, desde la década del '80 en diferentes documentos comienzan a referir a la brecha digital en el marco de la Sociedad de la Información. En ese marco, la brecha digital se tematiza en términos de acceso a las tecnologías vinculado al modelo de desarrollo. Esta noción gravita en el discurso de organismos y académicos que sostienen que la digitalización de la sociedad requiere de 
la planificación de estrategias políticas orientadas a suturar la brecha digital entre países, regiones y/o entre personas, grupos o colectivos ${ }^{117}$. Sin embargo, como plantea Olarte Encabo:

“(...) al admitir la categoría teórica de brecha digital, se acepta implícitamente que la revolución tecnológica no tiene un efecto unidireccional -generación de riqueza, oportunidades y bienestar- sino ambivalente (...) ya que, a la vez que brinda nuevas oportunidades, incide de forma negativa en la dimensión y características de la pobreza y la exclusión social". (Olarte Encabo, 2017: 292)

Lo que muchos autores sostienen es que la brecha digital se suma a las ya existentes producidas por el modelo de desarrollo donde se producen desigualdades que las tecnologías digitales no están en condiciones de superar.

Sobre el acceso, Van Dijk (2006) desarrolló una tipología para hacer mediciones entre países. Los accesos que diferencia son: motivacional, físico, habilidades y uso que deben abordarse secuencial y progresivamente. A su vez, identifica subtipos de acceso, por ejemplo:

"El concepto de acceso a habilidades, se divide en tres tipos: primero, un usuario de computadora tiene que adquirir habilidades operativas, entonces (él/ella) tiene que desarrollar y aplicar habilidades de información y, finalmente, habilidades estratégicas (la capacidad de usar computadoras y fuentes de red como medios para objetivos particulares en la sociedad). El acceso al uso es la etapa final y el objetivo final del proceso de apropiación tecnológica en forma de aplicaciones particulares (...)”. (Cruz García, 2016)

En relación con el tipo de brechas digitales que se pueden encontrar en la literatura, en el capítulo I mencionamos el desarrollo de Camacho (2006) que diferencia tres tipos de brecha digital: de acceso, de uso y de calidad.

Diferentes revisiones académicas coinciden en que junto a los análisis que se realizan sobre la brecha digital tanto entre países como fronteras adentro, coexisten imprecisiones conceptuales que restringen abordajes complejos del tema (Pérez Zalazar, 2004).

Ahora bien, desde sus inicios los debates sobre la brecha digital fueron madurando y superando el análisis dicotómico hasta que el término comenzó a complejizarse y fue mutando hacia la idea de inclusión digital.

${ }^{117}$ En el apartado 1.2.1 del capítulo I describimos el derrotero del concepto y las posiciones teóricometodológicas sobre la de brecha digital. 
De hecho, el principal acuerdo en la comunidad académica sobre el concepto de inclusión digital es que no se restringe a los niveles o grados de acceso físico sino que se deben considerar también los usos, las prácticas, las habilidades, las actitudes que se juegan en la relación de las personas, grupos, colectivos con las tecnologías digitales. De allí que la idea de inclusión digital abarca otros espesores que se manifiestan en los vínculos que se entretejen con las tecnologías y que permiten formar parte, acceder, usar y producir en el entorno tecnocultural.

\subsubsection{La inclusión digital: sus dimensiones}

La inclusión digital es una noción en construcción en el campo académico a la vez que en la formulación de las políticas públicas de los países en desarrollo se presenta con límites difusos. En ambos casos, las definiciones no coinciden y resulta difícil encontrar cierto consenso (Medeiros Neto, 2007: 3).

En correlación con los abordajes asociados con la brecha digital es posible identificar conceptos de inclusión digital con mayores o menores limitaciones: aquellos que se centran en la disponibilidad de recursos materiales (computadoras, conexión a internet) y acceso al proceso de producción de información o bien, sumado al acceso físico, a la tecnología la formación de habilidades y capacidades para el uso significativo a fin de participar de la sociedad de la información.

Los estudios de educación y tecnologías cuentan con un vasto desarrollo en la definición de las características y los aspectos de los procesos de inclusión digital en los diferentes niveles educativos. ${ }^{118}$ Por otro lado, en el ámbito de las políticas públicas se están implementando evaluaciones de los planes y programas de inclusión digital para conocer las prácticas y los procesos sociales, culturales y económicos que comprenden. ${ }^{119}$

El discurso de la inclusión digital tiene su punto de partida en las discusiones sobre el concepto de brecha, impuesto en la agenda internacional por las dos ediciones de la CMSI (2003 y 2005). Tal como señalamos en el apartado anterior se definen diferentes tipos de brecha: entre los países centrales y en desarrollo, entre generaciones, de acceso material

\footnotetext{
118 Ver en capítulo III.

${ }^{119}$ Por ejemplo, en Argentina, el Ministerio de Educación de la Nación lleva adelante estudios evaluativos del Programa Conectar Igualdad. En Brasil, el Ministerio de Comunicaciones evalúa el desarrollo del programa Gobierno Electrónico - Servicio de Atención Ciudadana (GESAC); en el caso de Colombia, Computadores para Educar; en Uruguay, el Plan Ceibal; en Venezuela, Canaima Educativo; entre otros.
} 
a las tecnologías, de uso y apropiación significativa. También revisamos las investigaciones que definen dos tipos de posturas: una integrada, enfocada al acceso de los dispositivos técnicos; y otra crítica, que sin desconocer que el acceso es una condición necesaria advierte que no es posible pensar la superación de la brecha si no se produce un uso significativo y una apropiación social de las tecnologías digitales.

La posición integrada toma el indicador de acceso que “(...) consolida una mirada limitada de la brecha digital en base a la cual se fundamentaron políticas de expansión del acceso, la infraestructura y la conectividad" (Pittaluga y Rivoir, 2013: 53). Por lo tanto, presume que la tecnología es neutral y ahistórica -donde las prácticas sociales, culturales y políticas no son consideradas- y que es la variable de desarrollo que con su inserción redunda en bienestar social: se trata de una lectura lineal y ligada al determinismo tecnológico.

En cambio, la postura crítica entiende que el acceso no explica por sí mismo la brecha digital y que no alcanza para reducirla sino que se requiere considerar la multidimensionalidad de las prácticas sociales, culturales y políticas donde las tecnologías se insertan. Se trata de complejizar la mirada en un escenario en movimiento. En tal sentido, entendemos que no basta con detenernos en los términos que delimita el concepto de brecha digital para definir la inclusión digital, sino que es necesario avanzar en la problematización de las dimensiones que la conforman.

Robinson (2006), Sampaio (2004), Seale (2009), Lago Martínez (2012), Rivoir (2013), entre otros, complejizan la idea de la inclusión digital poniendo en discusión los discursos dominantes de los organismos internacionales centrados en el acceso como principal modo de alcanzar procesos de incorporación tecnológica y estudiando las propuestas de inclusión digital a partir de sus aspectos socioeconómicos, políticos y jurídicos.

Por su parte, Robinson analiza críticamente las consecuencias económicas y políticas de la inclusión digital llevada adelante por las élites de los países latinoamericanos según los intereses trasnacionales. Y señala que "la inclusión digital es una política implementada de facto, cuyas reglas de negociación están ancladas en los usos y costumbres entre las elites relevantes en cada país, pero no para servir a los excluidos, sino a las mismas elites en los sectores de los medios de comunicación (...)" (Robinson, 2006: 13).

Desde el punto de vista del mercado, la inclusión digital se mide en relación con la posesión y acceso a los recursos digitales por parte de los usuarios. Se considera inclusión 
digital "precaria" cuando existen grandes segmentos de la población que dominan de modo limitado o restringido los recursos digitales.

Por otro lado, Sampaio (2004) entiende que la inclusión digital es un "proceso que se desarrolla por acciones volcadas hacia la universalización del acceso físico a los recursos de las TIC (léase ordenador + software + herramientas de la internet) y los conocimientos y habilidades necesarios para utilizar tales recursos con un mínimo de competencia”. Partiendo de esta noción, diferencia la inclusión digital restringida e inclusión digital ampliada. En la primera, prevalece la instrucción para operar hardware y software a fin de que el usuario acceda al entorno digital en calidad de consumidor de contenidos disponibles en el mercado. En la segunda, a partir de la posesión y uso de los recursos digitales se reconoce al sujeto que actúa con intereses y objetivos propios. Ambos tipos de inclusión digital coinciden en la universalización del acceso físico pero no en los objetivos.

Teniendo en cuenta estos autores, la inclusión digital, en palabras de Robinson, refiere al:

“(...) conjunto de políticas públicas relacionadas con la construcción, administración, expansión, ofrecimiento de contenidos y el desarrollo de capacidades locales y apoyos cognoscitivos en las redes digitales públicas, alámbricas e inalámbricas, en cada país y en la región entera. Abarca el adiestramiento y el incentivo para desarrollar herramientas nuevas (como software de fuente abierta, por ejemplo)". (Robinson 2006: 2)

Esta definición, en sentido amplio, sostiene y justifica programas y/o políticas públicas que expresan la necesidad de que cualquier estrategia de inclusión digital debe estar vinculada fundamentalmente a la inclusión económica y social: la pretensión de incluir económica y socialmente a los sectores o países pobres en un mercado global cuya principal promesa es la democratización de todas las relaciones sociales (Sampaio, 2004). Amado retoma la definición de Robinson y sostiene que “(...) surge como un concepto adecuado para pensar la incorporación de tecnologías digitales, ya que no sólo piensa la superación de la brecha de acceso, sino que permite tener una perspectiva multidimensional respecto de la implementación de las tecnologías (...)” (Amado, 2015: 192).

Por su parte, Pittaluga y Rivoir parten de la idea de brecha digital para señalar que: "Se utiliza el término inclusión digital cuando la brecha digital es entendida como multidimensional, relacionándola con otras desigualdades sociales que limitan las posibilidades de aprovechar las TIC para el desarrollo" (Pittaluga y Rivoir, 2013: 54). 
Una de las dimensiones que destacan de la inclusión digital es la que refiere a los tipos y calidad de usos de las tecnologías. Explican que la finalidad del uso es central para entender la inclusión digital: “(...) no es tan trascendente cuánta gente utiliza internet, sino por qué y para qué lo utiliza" (Castells y otros, 2007: 54). Por lo tanto, una de las cuestiones que se debe enfocar es conocer si se realiza un "uso significativo" con las tecnologías digitales. Y a la vez agregan que:

"Este tipo de uso está condicionado por la capacidad y posibilidad de producir contenidos propios, de acceder a información y conocimiento útil y en el propio idioma y tener capacidad para analizar críticamente la información. Esto se constata cuando el usuario hace propias las TIC, las incorpora a su vida cotidiana y a partir de ello se producen nuevas acciones y prácticas. Si un grupo dispone de las TIC, sabe cómo utilizarlas y las utiliza con un sentido que le permita resolver necesidades o problemas, se habrá producido apropiación social de las TIC (Camacho, 2001; Martínez, 2001; Warshcauer, 2003; Selwyn, 2004; Siles, 2006)". (Pittaluga y Rivoir, 2013: 55).

En este sentido, las autoras sostienen que para contribuir con la inclusión digital es prioritario implementar políticas públicas que propicien procesos de apropiación que tengan en cuenta los conocimientos y capacidades de las personas para el uso de las tecnologías para el desarrollo individual y colectivo. En tal sentido, entienden que dado que “(...) la brecha digital está condicionada y en interacción con la estructura económica, social, cultural y política y, por lo tanto, con otras brechas o desigualdades" (Ibidem), sólo puede ser abordada desde diferentes niveles y dimensiones en relación con los procesos de desarrollo.

La investigadora británica Jean Seale señala que la inclusión digital es un término ubicuo que rara vez se define de forma explícita que está en “(...) peligro de convertirse en un concepto sin sentido que en el mejor de los casos es ignorado, y en el peor es rechazado" (Seale, 2009: 3). Caracteriza a la inclusión digital como un concepto complejo y multifacético que involucra aspectos sociales, económicos y culturales.

En sentido amplio, acordamos con los términos de la perspectiva de esta autora que señala que las “(...) definiciones explícitas e implícitas de la inclusión digital abarcan una serie de conceptos relacionados entre sí: acceso; uso; empoderamiento y participación" (Ibidem).

En principio, la autora realiza una crítica al acceso como el único modo de lograr la inclusión digital y señala algunos ejemplos de fracasos de iniciativas públicas y privadas, en las que la mera disponibilidad de tecnologías no modificó las condiciones sociales y 
culturales previas. Por el contrario, entiende la idea de acceso a las tecnologías atravesada por dos cuestiones: “(...) si el Estado debe o no proporcionar las tecnologías más avanzadas y en segundo lugar el tema de mantenimiento y actualización de esas tecnologías una vez que se han proporcionado" (Seale, 2009: 4). En este sentido, asegura que propiciar el acceso de las personas (a través de asesores capacitados que ayuden a las personas excluidas para que accedan a los servicios tecnológicos) resulta tan importante como el acceso a la tecnología propiamente dicha. Pero para que el acceso se materialice es necesario que las personas “(...) tenga(n) la motivación, las habilidades y la oportunidad de participar en la tecnología" (Seale, 2009: 3). Y por otro lado, se requiere que exista sostenibilidad del acceso en el tiempo por lo que el Estado debe procurar ofrecer permanentemente tecnologías digitales actualizadas.

En relación con el uso cree que "así como el acceso a la tecnología como un concepto ha sido con frecuencia excesivamente simplificado; así también, cuenta como el uso de la tecnología. Sin embargo, hay un creciente reconocimiento de que es necesario abordar cuestiones como la calidad del uso, el mejor uso, uso significativo y no uso" (Seale, 2009: 4). Y señala algunas investigaciones que identifican gradaciones de usos en diferentes grupos etarios que van desde el no uso al uso frecuente y el uso poco frecuente.

Finalmente, Seale sostiene que para estudiar los usos de las tecnologías es necesario ampliar la mirada sobre las decisiones de las personas a la hora de usar o no las tecnologías hacia factores tecnológicos (problemas de acceso), personales (habilidades desarrolladas), contextuales (modos de vida). Por lo tanto afirma que es preciso lograr que las personas puedan realizar lo que denomina: uso "inteligente" de las tecnologías digitales, es decir, utilizar tecnologías cómo y cuándo crean apropiado en sus contextos cotidianos.

Ahora bien, en el caso de las dos dimensiones restantes que analiza Seale desarrollamos en el Programa Usos de Medios Interactivos (UMI) una distinción operativa, apoyada en la experiencia acumulada en estudios anteriores, para problematizar la relación entre inclusión digital e inclusión social. ${ }^{120}$ En términos generales, Cabello acuerda con la posición de la investigadora británica pero señala que no se propone discutir con el discurso de la inclusión digital y de la inclusión social, sino comprender las

\footnotetext{
${ }^{120}$ El abordaje se explicitó en la investigación "Sentidos y contrasentidos de la inclusión digital como inclusión social. El caso de la provincia de Buenos Aires", dirigida por Cabello. Este estudio se propuso comprender los sentidos construidos en torno a la noción de inclusión digital en la formulación e implementación de las políticas públicas de inclusión digital con sede en la provincia de Buenos Aires, en el período 2010-2015.
} 
manifestaciones y su eficacia material y simbólica (Cabello, 2014: 4). Para ello, toma en cuenta los estudios sobre usos y representaciones de TIC en diferentes ámbitos, realizados junto a su equipo de investigación desde el 2000, que proponen un modo complejo de comprender el acceso y los usos de las tecnologías. Por lo tanto, se propone definir operativamente las dimensiones de empoderamiento y participación.

En primer lugar, Cabello recupera la dimensión de empoderamiento presentada por Seale (2009), pero adopta el término autoafirmación ya que, en esta dimensión, le interesa considerar el aspecto individual y no el rasgo colectivo implicado en la conceptualización del empoderamiento asociado al proceso dinámico de actores que buscan recuperar su autoestima, crear conciencia de sujetos de derecho a partir del rol de otros actores (agencias y programa de cooperación para el desarrollo). "No estamos interesados en analizar la construcción de ese tipo de condiciones desde un ámbito exógeno (...) Por el contrario, buscamos reconocer en los discursos de los usuarios de TDI algunas marcas que puedan eventualmente hacer visibles ciertos 'efectos de autoafirmación' en los cuales los usos de las TDI puedan estar involucrados (entre otros factores)." (Cabello, 2014: 7) Entonces la noción de autoafirmación que presenta Cabello es la siguiente:

“(...) proceso por el cual las personas, haciendo uso de TDI, experimentan sensaciones, construyen conocimientos, producen creaciones, conectan con otros, formulan ideas, expresan valores, realizan experiencias que contribuyen con el hecho de que puedan sentirse cada vez más seguras de sí, objetivarse de esa manera y disfrutar". (Cabello, 2014: 9)

En este marco, detalla 3 subdimensiones: autopercepción de la competencia como usuario de TDI (evaluaciones del sujeto sobre su competencia tecnológica y comunicativa, repercusiones que tienen esas evaluaciones respecto de la autoconfianza); objetivación de la relación que establece con las TDI (reconocimiento de situaciones de uso que producen placer, confianza, temor, etc., de usos y situaciones que producen empatía/rechazo, que favorecen o dificultan la autoescenificación) y actitud respecto de la propia capacidad para conformar redes (evaluaciones del sujeto sobre las redes en general y digitales en particular, autopercepción respecto de la capacidad de integrar redes digitales, sensaciones que produce para la conformación de redes: confianza, contención, integración, temor, etc.) (Cabello, 2014: 9-10).

Por último, avanza en la definición de participación vinculada a la idea de ciudadanía e incorporando, en términos de Cabello: “(...) aspectos colectivos vinculados tanto con la participación en estructuras políticas y de acción colectiva basada en la cooperación, el 
acceso de los sujetos a la toma de decisiones que afectan su vida" (Cabello, 2014: 10). Explica que esta dimensión se conforma con 2 subdimensiones: ciudadanía y política que alude a la noción de empoderamiento en sus aspectos colectivos de participación política y toma de decisiones para alcanzar el bienestar social y personal, que se considera un factor de inclusión social a partir del dominio efectivo de las tecnologías digitales. Por otra parte, precisa la subdimensión denominada entorno tecnocultural que refiere a “(...) la existencia de una cultura digital interactiva, fuertemente marcada por la disposición y por las prácticas sociales y culturales asociadas a sus usos" y que permite considerar "(...) los modos de participación y las distancias que median entre las personas y ese ambiente cultural" (Cabello, 2014: 10).

La revisión del debate sobre los procesos de inclusión digital y, en particular, aquellos posicionamientos teóricos-metodológicos que distinguen las limitaciones de los enfoques instrumentales sobre las tecnologías nos permiten explorar nuestro objeto de estudio desde sus desplazamientos y contrapuntos en la trama de una relación compleja de los usos y las prácticas de los sujetos de esas las tecnologías digitales.

Consecuentemente, nos proponemos abordar la noción de inclusión digital, incorporando una mirada integral que comprenda la multidimensionalidad que presenta en relación con los sujetos en sus contextos cotidianos en el marco de la implementación de las políticas públicas digitales que promocionan la difusión de tecnologías entre la población en general y, en especial, entre aquellos sectores en riesgo de exclusión digital.

Para indagar si se producen procesos de inclusión digital de acuerdo con las expectativas expresadas en la política pública TDA, consideraremos los aportes presentados en las posturas críticas de Seale (2009) y Cabello (2014). Por lo tanto, las dimensiones que abordaremos son las siguientes:

- Acceso: referida a la disponibilidad de tecnologías digitales promovida por las acciones del Estado a través de políticas públicas de inclusión digital (distribución, mantenimiento y actualización del equipamiento y los servicios tecnológicos digitales) que propicien usos efectivos en cada contexto para el logro de objetivos individuales y colectivos de creación, expresión e intercambio cultural y de participación ciudadana.

- Usos: a partir de la definición de Cabello, refiere a la utilización de tecnologías digitales por parte de los sujetos que incluye diferentes “(...) operaciones que refuerzan el lugar de mediación de la tecnología respecto del establecimiento de vínculos sociales y de la producción colectiva de conocimiento" (Cabello, 2008a: 
179). Los tipos y calidad de usos se ubican entre los no usos, usos poco frecuentes y usos frecuentes.

- Autoafirmación: como el “(...) proceso por el cual las personas, haciendo uso de TDI, experimentan sensaciones, construyen conocimientos, producen creaciones, conectan con otros, formulan ideas, expresan valores, realizan experiencias que contribuyen con el hecho de que puedan sentirse cada vez más seguras de sí, objetivarse de esa manera y disfrutar" (Cabello, 2014: 9).

- Participación: refiere a la oportunidad de que la equidad en el acceso a las tecnologías, junto a usos significativos, permite mecanismos de participación activa en la vida social y política así como la producción y consumo de productos y servicios en los diferentes entornos tecnoculturales.

Finalmente, a partir de entender la inclusión digital como procesos complejos en estrecha vinculación entre las políticas públicas y las prácticas sociales nos interesa indagar la relación entre los usos de la televisión digital y los procesos de inclusión digital de acuerdo con las expectativas expresadas en la política pública, por un lado, y los discursos y prácticas de los usuarios de la población estudiada, por el otro.

\subsection{Puntos de partida:}

Consideramos la práctica de investigación como proceso de construcción y reconstrucción teórica de nuestro objeto de estudio a partir “(...) de la ruptura con la apariencia del fenómeno que se investiga (...) y el establecimiento de nuevas relaciones" (Escolar, 2000: 25). En esa dirección a lo largo de este capítulo partimos de una revisión de las discusiones sobre la relación entre tecnología y sociedad para enfocar nuestra atención sobre los análisis de la tecnología en general y, en particular, los usos de las tecnologías digitales interactivas en el campo de estudios críticos de la comunicación. Esta decisión nos permitió desarticular los conceptos desarrollados por las distintas perspectivas teóricas abordadas para explorar relaciones posibles guiadas en todo momento por las preguntas de investigación.

En este sentido, la lectura problematizadora de los conceptos que hemos realizado se vincula con la problemática de investigación y orienta nuestra indagación que se materializa en el diseño de la estrategia de abordaje de la realidad en estudio que presentaremos en el próximo capítulo. 
Por lo tanto, nos interesa explicitar las rearticulaciones entre los conceptos que problematizan los usos y prácticas de la televisión digital en el marco de políticas públicas de inclusión digital. Estas rearticulaciones se cristalizan en categorías que abren “(...) el horizonte empírico sin sujeción a contenidos a priori pero constituyen la posibilidad de contenidos teorizables (...)" (Zemelman, 1994: 14). Sobre esta base hemos incorporado conceptos ordenadores que permiten entrar y salir del campo problemático configurado a lo largo de nuestro proceso de investigación, con el fin de no perder riqueza interpretativa de nuestro objeto de estudio.

Al respecto, los conceptos ordenadores básicos propuestos para construir nuestro problema de investigación son: tecnologías digitales interactivas, usos y procesos de inclusión digital. A partir de estos conceptos ordenadores básicos es posible abrir un campo de preguntas que atraviesa todo el proceso de construcción, reconstrucción y recorte del objeto de estudio.

En tal sentido, y tal como lo hemos afirmado al inicio de este capítulo, nuestro interés es situar, en general, el problema de las tecnologías digitales interactivas como forma y parte de la cultura, y en el caso particular de la televisión digital, en relación con los sentidos que le atribuyen los sujetos como práctica social y comunicativa.

Este desafío se integra a la decisión de hacer foco en las articulaciones en las discusiones entre los Estudios Culturales y la Economía Política de la Comunicación y la Cultura con el fin de explorar las relaciones que se establecen entre las tecnologías digitales, en nuestro caso la televisión digital terrestre, con los sujetos en el marco de las acciones del Estado cristalizadas en la implementación de políticas públicas de inclusión digital.

En principio, hablar de tecnologías digitales interactivas implica entenderlas como objetos materiales y simbólicos propios de los procesos sociales, culturales, políticos y económicos cuyos usos producen, reproducen, expresan prácticas comunicativas y disputan sentidos situados en condiciones sociohistóricas específicas. Una de las tecnologías digitales interactivas que se constituye como objeto de estudio de la convergencia digital y como tecnología en transición es: la televisión digital terrestre que, en el marco de los discursos de las políticas públicas, aparece como uno de los dispositivos que pueden generar procesos de inclusión digital.

Por lo tanto, para comprender la trama en la que se inscriben los procesos de inclusión digital a partir de los usos de la televisión digital terrestre en la población en estudio tenemos en cuenta la estructura de las industrias infocomunicacionales y el sistema de 
distribución de la televisión, las estrategias y políticas públicas de la televisión digital por parte del Estado y los diferentes modos en que esa tecnología se incorpora al ámbito cotidiano en tanto objeto material y simbólico.

De modo que la noción de inclusión digital que hemos desarrollado en el apartado anterior nos permite abordar los aspectos políticos, sociales, culturales y económicos de los usos de la televisión digital terrestre en relación con las expectativas expresadas en la política pública TDA y los discursos y prácticas de los usuarios. Para ello, nos centramos en las dimensiones de: acceso, usos, autoafirmación y participación como conceptos que, relacionados entre sí, conforman una mirada compleja y multifacética que comprende los aspectos políticos, sociales, culturales y económicos de la integración de las tecnologías digitales interactivas en poblaciones en general y, en particular, con riesgo de exclusión digital. 


\title{
Capítulo V
}

\section{Estrategia metodológica de la investigación}

\begin{abstract}
“(...) la investigación es una práctica necesariamente política, en el sentido de implicar tomas de decisión y modos de argumentación -que, aunque racionales y respetuosos de los cánones de la coherencia que algunos gustan llamar lógica, no por eso dejan de tener como objetivo persuadir a las audiencias de lectores y legitimar posturas teóricas y metodológicas en el campo académico." (Escolar, 1998)
\end{abstract}

\subsection{Propuesta metodológica}

En el marco del proceso de estudiar los usos de las tecnologías digitales interactivas como parte de las estrategias de políticas públicas de inclusión digital, entendemos que la necesidad de plantear un problema de investigación tiene como objetivo cuestionar y reformular el proceso de construcción teórica del objeto de conocimiento y también “(...) es un proceso de búsqueda de relaciones posibles" (Escolar, 1998). De este modo, es posible pensar que los conceptos desarrollados por diferentes perspectivas disciplinarias pueden ser utilizados en el proceso de construcción del objeto de investigación que cada investigador se proponga. Es así como nuestra preocupación básica fue pensar, en primera instancia, en los “conceptos ordenadores básicos" (COB).

Se entiende los COB, según Zemelman (1964), Saltalamacchia (1992) y Escolar (2000): - $\quad$ en un nivel epistemológico: como un recorte particular de lo "real", es decir, la idea no es buscar una estructura teórica para obtener una verificación, sino que lo que se busca son los modelos de relaciones posibles para construir el objeto de estudio;

- $\quad$ en un nivel teórico: pretenden hacer afirmaciones válidas sobre aquella porción de la realidad que se ha tomado como objeto de estudio, es decir, pretenden realizar aseveraciones para realizar una verificación empírica.

Siguiendo a Escolar (1998), los conceptos ordenadores tienen una función de búsqueda de relaciones posibles para lo cual deben desarticularse de los corpus teóricos de los cuales provienen. A partir de esa desarticulación conceptual se trata de hacer una lectura problematizadora del concepto, tanto en su contenido como en sus relaciones y jerarquías 
con otros conceptos. Esta búsqueda de relaciones posibles entre los conceptos desde la problematización de los mismos permite delimitar y construir el objeto de investigación. De esta manera, "lo real" -en términos de Bachelard (1984) como "real científico"- sólo es visible cuando es invocado por una pregunta.

Los conceptos ordenadores básicos propuestos para construir nuestro problema de investigación son: tecnologías digitales interactivas, televisión digital, usos y procesos de inclusión digital. A partir de estos conceptos ordenadores básicos es posible abrir un campo de preguntas que atraviesa todo el proceso de construcción, reconstrucción y recorte del objeto de estudio.

De allí que el modo en que construimos el objeto de investigación en esta tesis se encuadra en una perspectiva que, siguiendo las posiciones de Bourdieu (2002, 1987), problematiza la construcción del objeto de estudio. Esta problematización implica comprender que investigar: “(...) no se reduce nunca a una simple lectura de lo real (...)” (Bourdieu, 2002: 29) sino que requiere de una ruptura con lo real para construir una nueva matriz de relaciones entre los diversos elementos que lo organizan. Por lo tanto, se trata de desarticular los saberes previos a fin de establecer nuevas vinculaciones, recuperando las articulaciones entre diferentes niveles de lo real.

De ahí que entendemos que la producción de conocimiento requiere:

“(...) diseñar un proceso de investigación cuyo efecto sea la construcción reconstrucción de la arquitectura del saber- lo cual exige la ardua tarea de explicitar lo implícito en todo sistema de pensamiento. Este ordenamiento de lo implícito y su articulación con lo explícito aparece, generalmente, tanto en los supuestos utilizados, como en las formas de derivación y el instrumental formal construido, como en los problemas que son tales para cada lectura metodológica". (Escolar, 1998: 2)

Es una tarea compleja que desafía nuestra práctica de investigación en sus diferentes componentes: teoría, métodos y técnicas, desde cuyas relaciones o anudamiento crítico nos interesa aprehender la complejidad de lo real. De este modo, la construcción del objeto es deliberada, corresponde a las preguntas que se le hagan a lo real y es el investigador el que selecciona métodos particulares para llevar adelante el proceso de investigación. "Aquí se decide cómo se va a seleccionar la parte de lo real que se pretende estudiar, cuáles serán los métodos analíticos, cómo se va a formular el problema, qué tipos de instrumentos específicos se van a construir, etc.” (Escolar, 2000: 26) 
Sin embargo, ante el riesgo de que el método se convierta en "receta de cocina u objeto de laboratorio" en palabras de Bourdieu (2002: 16), comprendemos que este desafío requiere de la vigilancia epistemológica que consiste en someter el uso de las técnicas y conceptos a un permanente análisis que impida la aplicación automática de procedimientos y que cada operación sea repensada en función del caso particular.

En esta línea y junto a Samaja (2004), entendemos que el proceso de investigación se construye mediante todas las acciones conscientes e inconscientes, individuales e institucionales en el curso de dicho proceso en sentido amplio. Cuando investigamos planteamos unas preguntas y nos proponemos unos objetivos a la vez que elaboramos instrumentos que permitirán alcanzar los mismos. En este sentido, hablamos de "estrategia teórico-metodológica" que “(...) subsume, en su mismo fraseo, ambos momentos del diseño de investigación y reconoce al proceso de investigación como el locus en el que se anudan, en el tiempo tanto lógico del sujeto como cronológico de la práctica, la teoría, el método y la técnica” (Besse, 2011: 105).

\subsubsection{Estrategia metodológica: Estudio de caso}

El abordaje teórico metodológico es de tipo cualitativo a partir de la construcción de un estudio de caso, dado que habilita la contrastación de los alcances y limitaciones de los supuestos teóricos generales y la pertinencia de los conceptos ordenadores propuestos para abordar el objeto de estudio (Saltalamacchia, 2005).

El estudio de caso tiene por finalidad no sólo describir sino también comprender los fenómenos en sus contextos reales, mediante diferentes modos de obtener los datos y sobremanera la forma en que esos datos se usan para investigar temas de interés a partir de situaciones particulares.

Según Martínez Carazo (2006: 168), en las Ciencias Sociales el estudio de caso ${ }^{121}$ ha sido un método adecuado para indagaciones exploratorias, sin embargo, indica que: “(...)

\footnotetext{
121 Algunos autores (Stoeker, 1991; Venkatraman \& Grant 1986, Rouse \& Daellenbach, 1999; Bower \& Wiersema, 1999), consideran que el estudio de caso tiene limitaciones y que no se considera una estrategia pertinente en las prácticas de investigación. Entre los problemas que identifican es su baja fiabilidad y validez.Sin embargo, otros investigadores han dado cuenta del fuerte desarrollo que ha tenido en las áreas de educación, políticas, estudios de familias, desarrollo tecnológico e investigaciones sobre problemas sociales. Ver en: Díaz De Salas, S., Mendoza Martínez, V.M., Porras Morales, C. M. (2011)
} 
Eisenhardt (1989) ha identificado otros usos de este método en la descripción (Kidder, 1982), en la contrastación de teoría (Pinfield, 1986; Anderson, 1983) y en la generación de teoría (Gersick, 1988; Harris y Sutton, 1986)". Entre sus características encontramos que: “(...) examina o indaga sobre un fenómeno contemporáneo en su entorno real; las fronteras entre el fenómeno y su contexto no son claramente evidentes; se utilizan múltiples fuentes de datos y puede estudiarse tanto un caso único como múltiples casos" (Yin, 1989: 23, citado en Martínez Carazo, 2006: 174).

La elección del método de estudio de caso como estrategia de investigación obedece a la necesidad de conocer las relaciones de las personas con las tecnologías que se manifiestan en un contexto singular para explorar la manera en que las integran a sus prácticas sociales, culturales y políticas en términos de procesos de inclusión digital.

En esta tesis decidimos investigar la relación que se constituye entre los usos de la televisión digital y los procesos de inclusión digital, particularmente, en una zona del periurbano bonaerense donde los indicadores socioeconómicos y culturales muestran rasgos de vulnerabilidad ${ }^{122}$ : el partido de José C. Paz, en la segunda corona del AMBA, durante el año 2014 e inicios del 2015.

La decisión de estudiar esta población en el período indicado obedece a la convicción de que resulta de sumo interés interrogar los modos en que se vinculan las personas que residen en esta región, y en dichas condiciones socioeconómicas y culturales, con la televisión digital como dispositivo de acceso y apropiación tecnológica propuesto desde el Estado. Pero, fundamentalmente, nos interesa indagar esos usos a 4 años de la creación del Sistema Argentino de TV Digital Terrestre (SATVD-T), ya que creemos relevante conocer la forma en que se fue llevando a cabo la implementación de la TDA cuando restaban 5 años del denominado “apagón analógico" previsto para 2019 ${ }^{123}$. Es decir, el desafío de esta tesis es estudiar los procesos de transición digital en el escenario social, político, económico y cultural en los que se están desplegando. Un contexto de transición digital puesto en marcha a través de políticas públicas que apuestan, particularmente, a la integración de las tecnologías digitales entre los sectores socioeconómicos con riesgos de exclusión.

\footnotetext{
${ }^{122}$ El partido de José C. Paz cuenta con 265.981 habitantes. El 87\% de la población de este distrito no cuenta con agua corriente, el $94 \%$ no tiene cloacas y el $60 \%$ no cuenta con red de gas (www.censo2010.indec.gov.ar).

${ }^{123}$ Recordamos que el "apagón analógico" está previsto en el Decreto 1148/2009 que en su art. $4^{\circ}$ establece que el plazo para la finalización del proceso de transición de TV analógica al Sistema Argentino de Televisión Digital Terrestre (SATV D-T) se extiende hasta el año 2019.
} 
Tal como mencionamos más arriba, tomamos como punto de partida las preguntas de investigación y los conceptos ordenadores básicos para realizar la recolección de datos a fin de explicitar las fuentes de información y los instrumentos utilizados (que se detallan más adelante) para, finalmente, establecer las relaciones entre los datos obtenidos en función de las proposiciones teóricas que contienen los constructos o conceptos que guían el estudio.

Entre nuestros objetivos de investigación nos propusimos conocer las principales definiciones y expectativas respecto de las tecnologías digitales interactivas, la televisión digital, sus usos y apropiaciones; y el propósito de inclusión digital.

\subsubsection{Unidades de análisis y técnicas de recolección de la información}

La primera parte del estudio está apoyado en la técnica de análisis de documentos con el fin de realizar “(...) la exploración del conjunto de opiniones y representaciones sociales sobre el tema que se pretende investigar" (Gomes, 2007: 85). En esta dirección, entendemos que para afrontar el análisis de definiciones y expectativas sobre las tecnologías digitales debemos partir de algunas representaciones previas asequibles en un grupo de discursos que encontramos en los documentos producidos por instancias normativas y técnicas, vinculadas con las políticas públicas de inclusión digital en el país, en especial, con aquellos referidos al sistema de televisión digital argentina.

El análisis cualitativo de documentos se “(...) caracteriza por la clasificación sistemática, descripción e interpretación de los contenidos del documento, que se llevará a cabo de acuerdo con los objetivos del estudio (...) En general, los datos obtenidos de los documentos pueden usarse de la misma manera que los derivados de las entrevistas y las observaciones y su utilización (...) enriquece los hallazgos del estudio" (Navarrete y da Silva et al., 2006: 74).

Las fuentes secundarias fueron: todos los documentos y el plexo normativo que componen la política pública de inclusión digital TDA.

Para ello, trabajamos con un corpus analítico compuesto por los documentos de la política pública, así como también el plexo normativo que la incluye. Los materiales 
textuales vinculados con nuestro objeto de estudio y nuestro recorte analítico comprenden los siguientes documentos:

Sobre infraestructura en telecomunicaciones

- Argentina Conectada. Planificación Estratégica Plan Nacional de Telecomunicaciones. Comisión de Planificación y Coordinación Estratégica del Plan Nacional de Telecomunicaciones.

Producidos por Consejo Asesor del Sistema Argentino Televisión Digital Terrestre (www.tda.gob.ar/contenidos/normativa_tda.):

- Planificación Estratégica de la implementación del SATVD-T (vigencia 20092019).

- Reglamento General del Plan Operativo de Acceso al Equipamiento para la Recepción de la Televisión Digital Abierta "Mi TV Digital”.

- Manual Operativo para la Implementación del Plan de Acceso a la Televisión Digital Abierta Satelital "Mi TV Digital Satelital”.

Asimismo, este análisis se complementa y se entiende a la luz de la Ley 26.522/09 de Servicios de Comunicación Audiovisual; Normativa nacional: Decretos: 835/2011,364/2010,1148/2009 y Resoluciones de Autoridad Federal de Servicios de Comunicación Audiovisual.

Artículos periodísticos sobre el lanzamiento de la TDA en el país

- Krakowiak (4 de mayo, 2010). Un regalo para el Mundial. Sección Economía. Página 12. Recuperado de: https://www.pagina12.com.ar/diario/economia/2-145087-2010-0504.html

- La TV digital oficial debutará con los beneficiarios de planes sociales y cinco canales. (24 de marzo, 2010). Revista Fortuna. Recuperado de: https://fortuna.perfil.com/201003-24-23058-la-tv-digital-oficial-debutara-con-los-beneficiarios-de-planes-sociales-ycinco-canales/

- $\quad$ Obarrio (14 de junio, 2010). Empezó el reparto de decodificadores de TV del Gobierno. Sección Política. La Nación. Recuperado de: https://www.lanacion.com.ar/politica/empezo-el-reparto-de-decodificadores-de-tv-delgobierno-nid1274826

- Bossi, J. (15 de febrero, 2011) El Gobierno abrirá más canales de TV. Sección Política. La Nación. Recuperado de: https://www.lanacion.com.ar/politica/el-gobierno-abriramas-canales-de-tv-nid1350154 
- Los LCD van primero a los jubilados. (22 de junio, 2011). Sección El País. Página 12. Recuperado de: https://www.pagina12.com.ar/diario/elpais/1-170592-2011-06-22.html

- Dos antenas más, y ya llegan a 19. (22 de junio, 2011). Sección El País. Página 12. Recuperado de: https://www.pagina12.com.ar/diario/elpais/1-170593-2011-06-22.html

- Cristina presentó el plan oficial para ofrecer Internet y TV digital. (19 de octubre, 2010). Sección política. Clarín. Recuperado de: http://www.clarin.com/politica/cristinapresento-internet-tv-digital_0_HJdOdqipDQx.html

Producción audiovisual sobre el lanzamiento y desarrollo de la TDA en el país

- "Plan de Acceso". Spot de propaganda de TDA, con fecha 24/09/2010, disponible en https://www.youtube.com/watch? $\mathrm{v}=$ _Q2xucl1B2I (Consultado el 9 de septiembre de 2015).

- "Institucional". Spot de propaganda de TDA, con fecha 24/09/2010, disponible en https://www.youtube.com/watch?v=bis9DR0o9Ew (Consultado el 20 de agosto de 2015).

- “TV Digital Argentina. Mi TV Digital”, Spot de propaganda de TDA. 24/8/2011, disponible en https://www.youtube.com/watch?v=1jCr_cvujUQ. (Consultado el 12 de noviembre de 2014).

- "Como conecto mi Deco", Spot de propaganda de TDA. 19-8-2011, disponible en https://www.youtube.com/watch?v=-nEhj-NDgKs (Consultado el 12 de noviembre de 2014).

- "TV digital", Spot de propaganda de TDA. 18/3/2011, disponible en https://www.youtube.com/watch?v=OruVZK4J__U; "TDA" (Consultado el 12 de noviembre de 2014).

- Spot de propaganda TDA. 27/10/2011, disponible en https://www.youtube.com/watch?v=2ymopEdvaOY. (Consultado el 12 de noviembre de 2014).

- Spot de propaganda de TDA, con fecha 25/06/2014,disponible enhttps://www.youtube.com/watch?v=IoVFIWgSmg8 (Consultado el 9 de septiembre de 2015).

La selección de los documentos gráficos y audiovisuales se realizó teniendo en cuenta el momento de surgimiento y las primeras fases de la implementación de la política pública: surgimiento, gestión y vinculación con otros planes o programas como “TV Para Todos”. 
El tratamiento de los artículos periodísticos junto al material audiovisual nos ayudó a contextualizar el análisis del discurso oficial de la política pública y de la perspectiva de los usuarios de la televisión digital en el período estudiado. Particularmente, en el caso del material periodístico, nos interesó relevar la información que difundían sobre el funcionamiento y la cobertura del Plan. Nos centramos en diferentes momentos comunicacionales de la política pública: presentación, lanzamiento y difusión propiamente dicha (valores, beneficios, desventajas, etc.).

Para los documentos audiovisuales hemos analizado el nivel verbal, icónico y sonoro para indagar las características de la estrategia comunicativa de la política pública. Nos detuvimos en los objetivos, los canales y los destinatarios de las piezas audiovisuales.

A partir de este recorte, establecimos relaciones con las preguntas y los objetivos de investigación para identificar las categorías analíticas que hemos planteado en nuestro marco conceptual y organizar el análisis del material seleccionado.

El análisis se propuso identificar términos clave que surgen del abordaje teórico de la tesis: referencias explícitas, la frecuencia de aparición y la relación entre los temas tratados. Del conjunto documental se seleccionaron los segmentos afines a los siguientes términos clave: tecnologías digitales, inclusión digital, exclusión digital, acceso, brecha digital, beneficiarios. Esta propuesta de análisis se encuentra detallada en la "Ficha básica de documentos escritos: Políticas Públicas de Inclusión Digital de Argentina”, presentada en el Anexo IV.

Como mencionamos más arriba, en nuestro marco teórico hemos considerado los conceptos de tecnologías digitales interactivas, la televisión digital y sus usos como dispositivo de procesos de inclusión digital, que ofician de orientadores para identificar los temas presentes en la producción documental del marco normativo y de la política pública TDA. De este modo, nos propusimos señalar las referencias a los temas que se relacionan con el problema abordado en esta tesis, mediante el análisis del corpus discursivo seleccionado.

El objetivo del análisis documental escrito es identificar las principales definiciones y expectativas respecto de las tecnologías digitales, la TDA, sus usos y apropiaciones, así como el propósito de inclusión digital de las políticas públicas sobre nuestro objeto de estudio. De este modo, junto al análisis de los discursos y prácticas entre los usuarios de 
la población de José C. Paz nos permitió analizar la relación entre los usos de la televisión digital y los procesos de inclusión digital en el período estudiado.

Asimismo, con el fin de indagar con profundidad el objeto de estudio que hemos recortado, en dirección a alcanzar una comprensión interpretativa de los vínculos que los usuarios establecen con la Televisión Digital Terrestre y otros dispositivos tecnológicos y sus implicancias en términos de inclusión digital, decidimos implementar otra técnica de recolección: la Entrevista abierta. La implementación de esta técnica nos condujo a la comprensión de los usos de las tecnologías, en particular, la exploración de las condiciones y prácticas vinculadas con los usos de la televisión digital, a través de la flexibilidad que presenta esta técnica y la apertura a la información. Es decir, se trata de una técnica que permite la alteración del orden y de la cantidad de preguntas como la incorporación "sobre la marcha" de nuevos interrogantes que no habían sido anticipados por el investigador.

La decisión de implementar la entrevista reside en la convicción de que contribuye a comprender nuestro problema de investigación, comenzando con el acceso a la perspectiva de los actores involucrados. Es decir, resulta necesario para abordar el objeto de estudio relevar aquellos hechos que "refieren directamente al individuo entrevistado; se trata de informaciones vinculadas a la reflexión del propio sujeto sobre la realidad que vivencia (...) y que sólo pueden ser conseguidas con la colaboración de la persona. Constituyen una representación de la realidad: ideas, creencias, formas de pensar, opiniones, sentimientos, maneras de sentir; maneras de actuar; conductas; proyecciones hacia el futuro; razones conscientes e inconscientes de determinadas actitudes y comportamientos" (De Souza Minayo, 2009: 216). De ahí que indagar los usos y los vínculos que establece con los dispositivos tecnológicos la población objetivo requiere acceder a la información contextualizada desde la perspectiva de los actores a fin de captar los significados, las perspectivas, definiciones y el modo en que los participantes experimentan y describen su mundo.

Las entrevistas cualitativas se centraron en el tema de referencia donde se privilegió la modalidad "abierta" para explorar los principales emergentes en relación con el problema de investigación. Dichas entrevistas no serán directivas con el objetivo de que el orden de los temas tratados sea “( ...) determinado (...) por las propias preocupaciones, relevancias y énfasis que el entrevistado manifiesta respeto del tema pautado" (De Souza Minayo, 2009: 218). 
El instrumento de trabajo de campo fue una guía de entrevista semiestructurada que colaboró en orientar el abordaje empírico desde el punto de vista de los entrevistados. El registro in situ se llevó a cabo a través de un dispositivo de audio digital y se completó con anotaciones manuscritas que volcamos en nuestras notas de campo, cuya finalidad fue obtener un adecuado registro del lenguaje no verbal del entrevistado.

Para el diseño de la muestra cualitativa aplicamos la técnica de muestreo teórico enmarcada en la tradición de investigación cualitativa conocida como Grounded Theory o teoría fundamentada en los datos (Glasser y Strauss, 1967; Vieytes, 2004). Por lo tanto, el número total de entrevistas se estableció teniendo en cuenta el índice de saturación teórica de la categoría en tanto:

"El criterio para juzgar cuándo detener el muestreo de grupos pertinentes a una categoría es la saturación teórica de la categoría. Saturación significa que no se hallará ninguna información adicional por medio de la cual (...) se pueda desarrollar propiedades de la categoría. Al ver instancias similares una y otra vez el investigador adquiere confianza empírica de que una categoría está saturada" (Glasser y Strauss, 1967).

El diseño cualitativo privilegia la captación de los integrantes de los estratos poblacionales que presentan el estatuto de usuario de los dispositivos tecnológicos. A partir de este criterio, la distribución de las entrevistas dentro de un esquema de muestreo teórico se orientó a representar a personas de diferentes sexos y edades, y residentes en diversas localidades del partido de José C. Paz de la provincia de Buenos Aires.

De conformidad con esta definición operacional de la población objetivo que oficia como plataforma para la aplicación de la entrevista individual en profundidad, durante la etapa de ejecución del trabajo de campo buscamos entrevistar a aquellas personas beneficiarias del plan "Mi TV Digital” que se caracterizaban por ser destinatarias de pensiones no contributivas correspondiente a: invalidez, vejez y/o madre de 7 o más hijos; de Asignación Universal por Hijo (AUH); de jubilaciones y/o pensiones, con haberes mínimos nacionales y/o provinciales; de programas o planes sociales a nivel nacional, provincial y/o local que se encontraban contemplados en alguno de los padrones de organismos gubernamentales.

Las unidades de análisis fueron las siguientes:

- Un conjunto de jubilados y/o pensionados: mayor grupo alcanzado por la política pública: "Mi TV Digital". 
- Otro conjunto de familiares de jubilados y/o pensionados: aquellos que recibieron los decodificadores digitales de sus padres y/o abuelos pensionados y/o jubilados debido a que adquirieron televisores LED con TDA incorporado.

- Integrantes de la organización social: Mutual Primavera y beneficiarios de planes sociales.

A continuación presentamos un cuadro donde se muestra la composición de cada uno de los conjuntos de unidades de análisis señalado en diferentes colores: Verde para Jubilados/pensionados; Amarillo para familiares de jubilados/pensionados y Celeste para miembros de la mutual y beneficiarios de planes sociales. El número total de entrevistas realizadas en cada uno de estos grupos corresponde al criterio de saturación teórica de categorías.

\begin{tabular}{|c|c|c|c|c|}
\hline Nombre & Edad & Barrio & Ocupación & Fecha \\
\hline Ernesto & 79 años & $\begin{array}{l}\text { Mariano } \\
\text { Moreno }\end{array}$ & Jubilado/Cuentapropista & $16 / 10 / 2014$ \\
\hline Daniel & 66 años & La Pilarica & Jubilado & $11 / 03 / 2015$ \\
\hline María & 65 años & Villa Altube & Jubilada & $12 / 11 / 2014$ \\
\hline Ana María & 61 años & $\begin{array}{l}\text { José C. Paz } \\
\text { Centro }\end{array}$ & Jubilada & $19 / 06 / 2015$ \\
\hline Germán & 26 años & $\begin{array}{c}\text { José C. Paz } \\
\text { Centro }\end{array}$ & Estudiante universitario/ & $27 / 03 / 2015$ \\
\hline Fátima & 35 años & $\begin{array}{l}\text { José C. Paz } \\
\text { Centro }\end{array}$ & Empleada administrativa & $15 / 05 / 2015$ \\
\hline Graciela & 46 años & $\begin{array}{c}\text { Barrio Santa } \\
\text { Rita }\end{array}$ & Empleada de comercio & $22 / 05 / 2015$ \\
\hline Nicolás, A. & 20 años & $\begin{array}{c}\text { Altos de José C. } \\
\text { Paz }\end{array}$ & $\begin{array}{c}\text { Estudiante } \\
\text { universitario/Empleado de } \\
\text { comercio }\end{array}$ & $8 / 04 / 2015$ \\
\hline Paula & 44 años & $\begin{array}{c}\text { José C. Paz } \\
\text { Centro }\end{array}$ & Trabajadora Social & $4 / 03 / 2015$ \\
\hline Mónica & 51 años & $\begin{array}{c}\text { Barrio Santa } \\
\text { Rita }\end{array}$ & Empleada de comercio & $22 / 09 / 2014$ \\
\hline Nicolás, N. & 17 años & Villa Altube & Estudiante secundario/Progresar & $12 / 06 / 2015$ \\
\hline Verónica & 45 años & $\begin{array}{c}\text { Barrio. } \\
\text { Primavera }\end{array}$ & Integrante de Mutual Primavera & $11 / 10 / 2014$ \\
\hline Érica & 20 años & $\begin{array}{c}\text { Barrio } \\
\text { Primavera } \\
\end{array}$ & Integrante de Mutual Primavera & $18 / 10 / 2014$ \\
\hline Adriana & 44 años & $\begin{array}{c}\text { Barrio } \\
\text { Primavera }\end{array}$ & Integrante de Mutual Primavera & $21 / 10 / 2014$ \\
\hline Marcela & 32 años & $\begin{array}{c}\text { Barrio } \\
\text { Primavera }\end{array}$ & Integrante de Mutual Primavera & $21 / 10 / 2014$ \\
\hline
\end{tabular}


El desarrollo de la tesis contó con condiciones favorables y también con algunas dificultades. Entre las primeras, destacamos el hecho de que la investigación se desarrolló desde la Universidad Nacional de General Sarmiento que, con más de veinte años de actividad en la zona y con una explícita orientación hacia la promoción de procesos de Desarrollo, ha consolidado una red de relaciones y una presencia sostenida en la comunidad de referencia. Esta situación, en cierta medida, facilitó el contacto con equipos que realizan actividad de investigación y de intervención en diferentes barrios del partido de José C. Paz y que están vinculados con una multiplicidad de organizaciones de la sociedad civil que pueden orientar y acompañar el contacto con los potenciales entrevistados. Por otra parte, este estudio se asocia al Programa de Usos de Medios Interactivos (UMI), coordinado por la directora de la tesis, cuyo equipo realiza investigación sobre usos de las tecnologías digitales interactivas desde el año 2000.

Entre los factores que generaron dificultades para la implementación del estudio destacamos al menos dos: el más relevante es el que se relaciona con la identificación de personas que efectivamente usen la TDA. Desde los inicios del planteo de esta tesis y hasta fines de 2015, se produjeron avances en este sentido: más personas recibieron e instalaron el dispositivo y algunas de ellas comenzaron a usarlo. Pero se trata de un proceso lento y desigual.

El otro factor es el que refiere a la información sobre penetración de la TDA, que suele referir más a la instalación de antenas que al registro de decodificadores en hogares, especialmente, atendiendo a cada uno de los partidos de la provincia. Sin embargo, si bien el estudio no se propone realizar una investigación sobre penetración strictu sensu, se puede reconstruir la información que oriente la identificación de los hogares a través del Municipio, la Universidad y otros agentes que hayan oficiado como distribuidores de decodificadores.

Por estas razones, nos encontramos con algunos obstáculos al momento de realizar el trabajo de campo. En principio, la búsqueda de los potenciales entrevistados se inició en el seno de la universidad, desde el trabajo desarrollado en el marco del UMI con estudiantes y egresados de la Licenciatura en Comunicación.

Los primeros pasos para contactar entrevistados los hicimos a través de algunos estudiantes que se ofrecieron para colaborar con la tarea. Sin embargo, los resultados no fueron los esperados ya que realizaron la búsqueda entre sus contactos de redes sociales (Facebook e Instagram): la enorme mayoría no poseía TDA y quienes disponían del servicio no eran beneficiarios. Es decir, se trataba de personas que habían comprado la 
antena y el decodificador o que habían comprado recientemente un televisor que ya tenía incorporado el servicio. Incluso tomando en cuenta las personas que habían comprado la tecnología para acceder al servicio, el número no llegaba a diez. Lo que nos llamó la atención en los relatos de los estudiantes es que muchas personas, tanto adolescentes como adultos jóvenes, respondían a los mensajes que consultaban acerca de la disponibilidad de TDA en sus hogares haciendo referencias a que la TDA era un servicio destinado a "pobres", "villeros" o "peronistas kirchneristas", entre otras asociaciones en las cuales se pone de manifiesto la asociación entre la TDA con sectores populares y políticas partidarias de gobierno. Si bien, decidimos desestimar esta estrategia de búsqueda de entrevistados, resolvimos prestar atención a los dichos relevados por los estudiantes al momento de realizar el análisis del material colectado porque suponemos que estas representaciones pueden manifestarse de algún modo a lo largo de nuestro estudio.

Finalmente, contactamos a nuestros entrevistados a partir del vínculo sostenido, a través de la implementación de proyectos de investigación y de intervención, con la organización Mutual Primavera ${ }^{124}$ que desarrolla su actividad en el Barrio Primavera de la localidad de José C. Paz (provincia de Buenos Aires). Esta organización se propone recuperar la dignidad del trabajo y la identidad barrial a la vez que llevar adelante un proyecto de Economía Social y desarrollo que permita a sus integrantes y asociados vivir mejorar sus condiciones de vida. La relación construida con los miembros de la mutual nos facilitó la realización de las primeras entrevistas debido a que nos ayudaron a identificar personas que cumplieran con las condiciones necesarias para la realización de esta investigación. De este modo, pudimos continuar contactando a personas que aceptaron participar del estudio.

\footnotetext{
${ }^{124}$ Desde el año 2006 venimos trabajando en distintos proyectos de comunicación con los miembros de la Mutual Primavera que nos ha permitido establecer relaciones de mutuo aprendizaje, han enriquecido nuestras prácticas de investigación y docencia y han contribuido a la producción de conocimientos compartida. Algunos de los proyectos que desarrollamos: "Implementación de un proyecto de comunicación externa: caso Mutual Primavera". Convocatoria 2006. Centro de Servicios. Universidad Nacional de General Sarmiento. De agosto de 2007 a mayo de 2008. Proyecto de Voluntariado Universitario: "Programa de intervención en comunicación para una organización social del Conurbano Bonaerense". Convocatoria 2007. Secretaría de Políticas Universitarias. Ministerio de Educación, Ciencia y Tecnología. Universidad Nacional de General Sarmiento. Septiembre de 2007 a octubre de 2008. Proyecto de Voluntariado Universitario: "Comunicar para democratizar". Convocatoria 2013. Secretaría de Políticas Universitarias. Ministerio de Educación, Ciencia y Tecnología. Universidad Nacional de General Sarmiento. Septiembre de 2013 a septiembre de 2014.
} 
Por lo tanto, las primeras entrevistas las realizamos en la sede de la Mutua (Nueva Granada 559, Barrio Primavera) y luego proseguimos con la identificación de los demás entrevistados en otros barrios de la localidad de José C. Paz tales como: Santa Rita, Mariano Moreno, Pilarica, etc. De allí que, con el propósito de realizar una exploración en profundidad sobre los usos de la TV digital, fueron entrevistadas personas de diferentes sexos, grupos de edad y localidades de residencia, usuarios de TDA en la zona de referencia.

La mayoría de las entrevistas en profundidad las efectuamos en menor medida en los hogares de las personas contactadas debido a la reticencia a recibir al entrevistador en sus domicilios y en muchos casos dificultades para coordinar encuentros en algún espacio público. Por otra parte, pudimos contactar a 4 familias que habían tramitado y recibido el decodificador pero que manifestaron falta de interés en el servicio, por dificultades en la recepción o porque ya disponían de televisión por cable, no deseaban cambiar a TDA y nunca instalaron el servicio. Por ende, si bien cumplían las condiciones requeridas para ser entrevistadas, decidimos que no formarían parte de la muestra debido a la falta de experiencia en relación al objeto de estudio.

Asimismo, otro de los aspectos del trabajo de campo que nos interesa señalar es que las personas entrevistadas cumplían con las condiciones requeridas para recibir el benefício del Plan "Mi TV Digital” y, sin embargo, varias adujeron que tenían instalada la TDA debido a que sus padres y/o abuelos jubilados les cedieron los dispositivos digitales. Según los entrevistados, se debió a que habían adquirido televisores LED con TDA incorporado y/o a problemas con el uso de los dispositivos del Plan. Aunque entre las obligaciones del beneficiario se encuentra "no transferir el decodificador digital parcial o totalmente", resolvimos continuar con la indagación cualitativa dado que los entrevistados residían en la misma unidad habitacional y compartían el ámbito doméstico. De allí que nuestra muestra se compone en su mayor parte de jubilados o pensionados y, en menor medida, de beneficiarios de planes sociales o miembros de organizaciones sociales.

Por último y, complementariamente, para enriquecer el trabajo de investigación se consultaron encuestas e informes del INDEC (Instituto Nacional de Estadísticas y Censos) para analizar información sobre penetración de la televisión digital en la población en estudio. 


\subsection{Características del universo de estudio: El contexto social, económico y cultural del partido de José C. Paz (provincia de Buenos Aires)}

Tal como hemos afirmado, el objeto de investigación es construido y recortado de un universo donde unas variables quedan fuera del interés de la investigación y otras son focalizadas, pero siempre teniendo en cuenta el contexto en el que se sitúa dicho objeto. En nuestro caso, nos interesó investigar los usos de la televisión digital en la Argentina, particularmente, en una zona del periurbano bonaerense donde los indicadores socioeconómicos y culturales señalan vulnerabilidad: el partido de José C. Paz, en la segunda corona del Área Metropolitana de Buenos Aires, durante los años 2014 y 2015. Como dijimos más arriba, reiteramos que nuestra decisión de estudiar esta población en el período indicado obedeció a la convicción de que nuestro foco se centró en conocer los modos en que se vinculan las personas que residen en esta región y, en dichas condiciones socioeconómicas y culturales, con la televisión digital como dispositivo de acceso y apropiación tecnológica propuesto desde el Estado a medio término de la implementación de la TDA en el marco de la puesta en marcha de la transición digital en Argentina.

Por estas razones a continuación, presentamos las principales características del espacio demográfico, social, cultural y económico en el cual se desarrolló la presente investigación.

El partido de José C. Paz se encuentra ubicado en la Región Metropolitana de Buenos Aires (RMBA) $)^{125}$. El rasgo principal de esta región, según sostiene Rofman: “(...) no sólo se basa en el tamaño de su territorio $-12.600 \mathrm{~km} 2$, menos del $0,5 \%$ de la superficie nacional continental- y la cantidad de población, ya que alberga a 14.000 .000 de habitantes, alrededor del $35 \%$ de la población total del país, sino también por la escala de sus principales actividades y de los flujos de población y de intercambio de bienes y servicios que la recorren cotidianamente y que atraviesan -y en cierta medida,

\footnotetext{
${ }^{125}$ La RMBA comprende la Ciudad de Buenos Aires y los 24 partidos del Gran Buenos Aires (GBA), y partidos ubicados fuera de esta pero que tienen fuertes interrelaciones con el resto de la metrópoli. Se destaca entre ellos el denominado Gran La Plata (La Plata, Berisso y Ensenada). Por lo tanto, la RMBA está constituida por los siguientes partidos (en orden alfabético): Alte. Brown, Avellaneda, Berazategui, Berisso, Brandsen, Campana, Cañuelas, Ensenada, Escobar, Esteban Echeverría, Ezeiza, Exaltación de la Cruz, Florencio Varela, Gral. Las Heras, Gral. Rodríguez, Gral. San Martín, Hurlingham, Ituzaingó, José C. Paz, La Matanza, La Plata, Lanús, Lobos, Lomas de Zamora, Luján, Marcos Paz, Malvinas Argentinas, Mercedes, Merlo, Moreno, Morón, Navarro, Pilar, Pte. Perón, Quilmes, San Fernando, San Isidro, San Miguel, San Vicente, Tigre, Tres de Febrero, Vicente López y Zárate (Rofman, 2014: 2).
} 
desconocen- los límites jurisdiccionales entre municipios” (Rofman, 2014: 2). A esta vasta estructura político-institucional, se suman diferentes definiciones: "Aglomeración Gran Buenos Aires", “Área Metropolitana de Buenos Aires” (AMBA), "Zona Metropolitana de Buenos Aires" o "Conurbano Bonaerense", con las consecuentes delimitaciones espaciales que abarcan más o menos jurisdicciones según de cuál se trate $^{126}$.

Tomando en cuenta el trabajo de Rofman (2014), la distribución de la población de la RMBA concentra un $20 \%$ en la Ciudad Autónoma de Buenos Aires, un $75 \%$ en la primera y segunda corona, mientras un $5 \%$ se ubica en la tercera corona. Y la estructura productiva sigue pautas de comportamiento similares:

“(...) consistente en un proceso de "periferización” desde el centro de la Ciudad de Buenos Aires y los municipios de la "primera corona" hacia los partidos del conurbano más alejados (Borello et al., 2002). De esta manera, en el primer anillo del conurbano se aglutina una proporción mayor de establecimientos como también de trabajadores, por lo que -según datos de 2004- un tercio del PBG provincial se producía en esta subregión, que contenía la mayoría de los establecimientos industriales, mientras que en los partidos de la segunda y tercera corona predominan los comercios y las actividades de servicios". (Rofman, 2014: 11)

La diversidad de la actividad económica de la región compuesta - al menos hasta 2015por una cierta reactivación industrial (pequeñas y medianas empresas) de la primera corona y la proliferación de parques industriales de menor tamaño en los partidos más alejados de la Ciudad de Buenos Aires ${ }^{127}$, se le suma la intensificación del sector informal (emprendimientos, economía popular, etc.) en la mayor parte de su territorio. Por otra parte, la expansión de mancha urbana, caracterizada por el aumento de población con necesidades básicas insatisfechas a medida que se distancia de la Ciudad Autónoma de Buenos Aires, tiene rasgos “(...) de descoordinación y escasa planificación de ese crecimiento" (Soldano, 2014: 12). Estos datos se cruzan indefectiblemente con una fuerte desigualdad habitacional ${ }^{128}$ que se combina con un

\footnotetext{
${ }^{126}$ Por ejemplo, la denominación AMBA incluye a la CABA y 32 partidos de la provincia de Buenos Aires, Conurbano Bonaerense que excluye a la Ciudad de Buenos Aires de los partidos del Gran Buenos Aires o, según el INDEC, el conjunto Aglomeración Gran Buenos Aires contiene además de la Ciudad de Buenos Aires 24 partidos del Gran Buenos Aires.

${ }^{127}$ Blanco (2006) en Rofman (2014: 12).

${ }^{128}$ A grandes rasgos podemos identificar grandes manchas urbanas con asentamientos precarios (villas, barrios populares, etc.), colindando con conjuntos habitacionales cerrados (countries, barrios cerrados).
} 
déficit de infraestructura básica ${ }^{129}$, en medio de una seria degradación ambiental, producto de una presencia discontinua y clientelar de planificación estatal.

La combinación de estos aspectos de la vida social, política, económica y demográfica en esta región de la provincia de Buenos Aires genera, en cierto sentido, la coexistencia de:

“a) Un conurbano bonaerense "rico", conformado por los partidos de la zona Norte (San Isidro y Vicente López) que funcionan como un continuum de los barrios prósperos de la zona Norte de la Ciudad de Buenos Aires: Palermo, Belgrano, Núñez.

b) Un conurbano con indicadores aún tolerables, conformado a grandes rasgos por el anillo de partidos más próximo a la ciudad capital: Avellaneda, La Matanza, Morón, Hurlingham, Ituzaingó, General San Martín y Tres de Febrero.

c) Un conurbano de peores índices que el anterior, ubicado en el primer o segundo cordón de la zona Sur del Gran Buenos Aires: Lanús, Lomas de Zamora, Almirante Brown, Quilmes y Berazategui.

d) Un conurbano de máxima relegación, conformado por partidos alejados de la ciudad capital: Tigre, Malvinas Argentinas, José C. Paz, San Miguel, Moreno, Merlo, La Matanza 2, Ezeiza, Esteban Echeverría y Florencio Varela”. (Carman, 2017: 132)

En el marco de este agrupamiento socioespacial Rofman (2014) señala que la problemática social en la RMBA se presenta con características de gravedad particular dada la suma de habitantes y la "visibilidad política de los problemas". La convivencia de los factores socioeconómicos, demográficos y espaciales inscribe la lógica del barrio entre las poblaciones de la región donde las respuestas a los problemas sociales, habitacionales o ambientales se producen y se afirman en las redes de proximidad ${ }^{130}$.

Otra de las características que nos interesa señalar es la estructura político-institucional que combina centralidad económica, heterogeneidad socioeconómica, el peso demográfico-electoral que, sumados al poder mediático, ubica al área metropolitana en la escena nacional. En la gestión de gobierno concurren cuatro niveles estatales de competencia: Gobierno Federal, Provincial de la Provincia de Buenos Aires y los gobiernos municipales tanto del Gran Buenos Aires como de la Ciudad Autónoma de Buenos Aires ${ }^{131}$. Este tipo de organización genera que las ciudades como unidades

\footnotetext{
${ }^{129}$ Según datos del Censo Nacional de Población y Vivienda (2010): 67 \% de las viviendas estaba conectada a la red pública de agua, $38 \%$ con desagües cloacales y un $61 \%$ con gas natural.

${ }^{130}$ Las organizaciones sociales y los gobiernos locales se configuran como ámbitos de ordenamiento para el acceso a recursos, servicios y participación en el espacio público.

${ }^{131}$ La Ciudad Autónoma de Buenos Aires tiene un estatus semejante a los gobiernos provinciales y a los municipios. Posee un status jurídico excepcional como municipio federal y autónomo. Su condición de capital federal influye y su autonomía configura un estado intermedio entre la de las provincias y la de los municipios ordinarios.
} 
funcionales no dispongan de "un ámbito institucional de articulación de intervenciones públicas", a la vez que el poder económico central del país no establece una estrategia concertada que atienda integralmente los problemas del territorio. Esta desarticulación se traduce en que “(...) las capacidades institucionales del Estado Municipal se encuentran sumamente restringidas. Se priva a los municipios de organizarse institucionalmente de acuerdo a sus necesidades y posibilidades" (Bennardis, 1999: 6). Estos factores, entre otros, debilitan los municipios para afrontar la diversidad de problemáticas que se cruzan en el territorio.

En este contexto, la lógica de la política pública se establece en relación con el orden jurisdiccional por lo que cada gobierno tiene atribuciones parciales desarticuladas de las demás agendas que coexisten en el área metropolitana, sumado a la discrecionalidad en la distribución de los recursos desde el centro hacia los diferentes niveles de gestión (provincial, municipal).

Asimismo, el nivel de los gobiernos locales del conurbano resulta el que tiene menor autonomía institucional, económica y fiscal sostenido, principalmente, por la jurisdicción provincial que lo encorseta en: “(...) en tres campos: la construcción y mantenimiento de la infraestructura urbana, la regulación de actividades económicas que se realizan en su territorio, y la atención a población en riesgo, dejando en manos nacionales o provinciales la iniciativa sobre buena parte de las cuestiones que conforman hoy la agenda local" (Rofman, 2014: 19).

Asimismo, según la autora, la gestión de programas sociales de los municipios en el territorio está transpuesta por la intervención directa de los niveles de gobierno nacional y/o provincial, y se profundizó durante la gestión kirchnerista. La relevancia de la región en el escenario electoral nacional ${ }^{132}$, la superposición de niveles de gobierno, entre otros rasgos, intensifica la dificultad de los gobiernos locales de implementar políticas públicas que atiendan las demandas socioeconómicas de la población del conurbano bonaerense.

${ }^{132}$ La provincia de Buenos Aires representa el 37,01\% del padrón electoral nacional con 11.867.979 electores según la Cámara Nacional Electoral (disponible en http://www.electoral.gov.ar). 


\subsubsection{Los números del territorio}

En 1994 fue creado el partido de José C. Paz debido a la división del ex partido de General Sarmiento (creado en 1889 con tierras de Pilar, Moreno y Las Conchas).

Teniendo en cuenta la Región Metropolitana de Buenos Aires, el partido de José C. Paz se ubica en la segunda corona, ocupando una superficie de 50,16 km2. Según datos del Censo Nacional de Población y Vivienda (2010), cuenta con 265.981 habitantes (77.752 menores de 14 años y 18.078 mayores de 65 años) en una superficie de $50 \mathrm{~km}^{2}$. La densidad poblacional es de $5.302 \mathrm{hab} / \mathrm{km} 2$.

Entre los 74 barrios que posee la localidad, el $70 \%$ de las viviendas corresponden a hogares de nivel medio-bajo, 2 barrios cerrados y un country. El $45 \%$ de las calles se encuentran asfaltadas.

El $87 \%$ de la población de este distrito no cuenta con agua corriente, el $94 \%$ no tiene cloacas y el 60 \% no cuenta con red de gas, según datos del Censo Nacional de Población y Vivienda (2010).

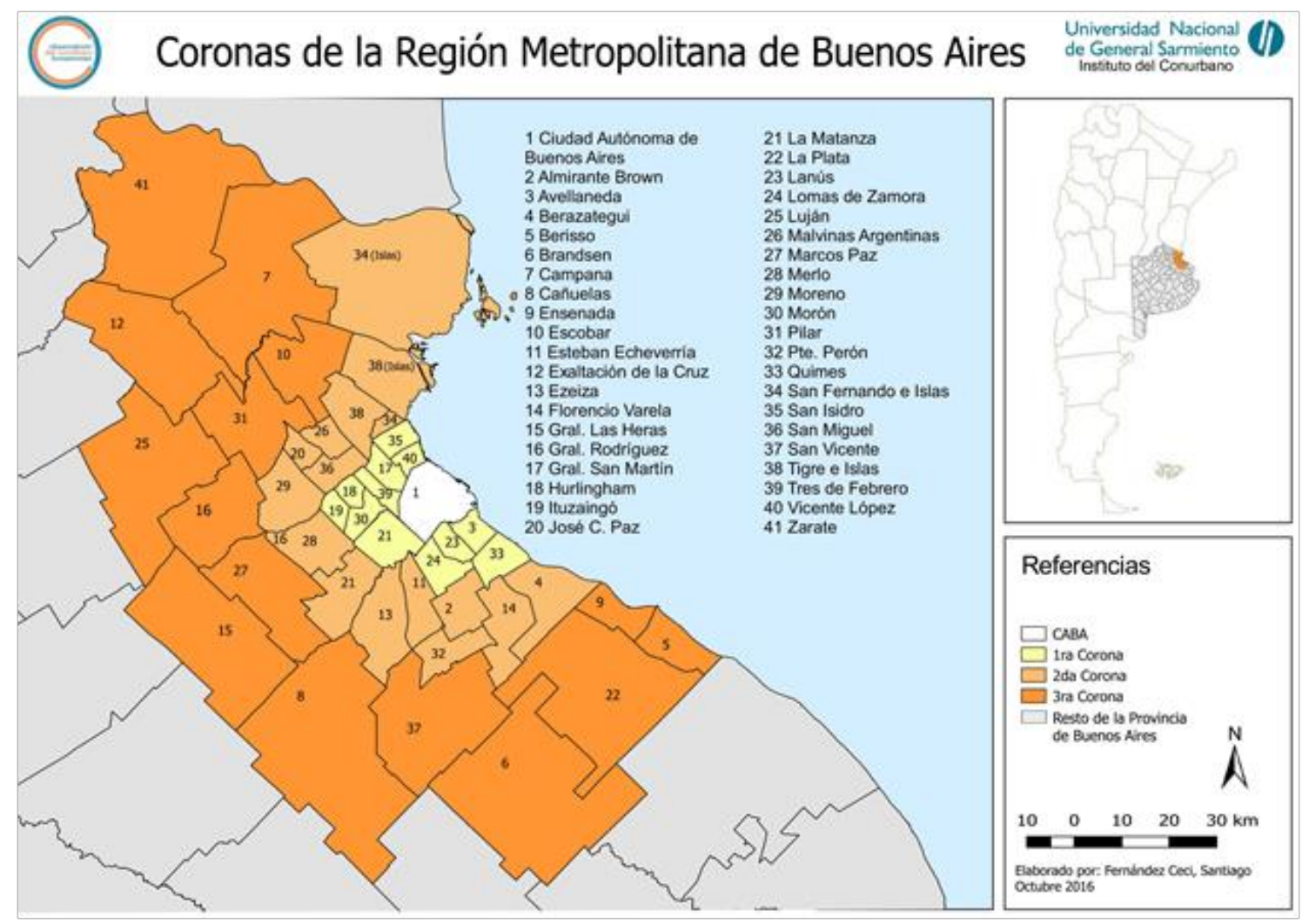

Figura 1: Coronas de la Región Metropolitana de Buenos Aires. Observatorio del Conurbano. ICO. UNGS. 


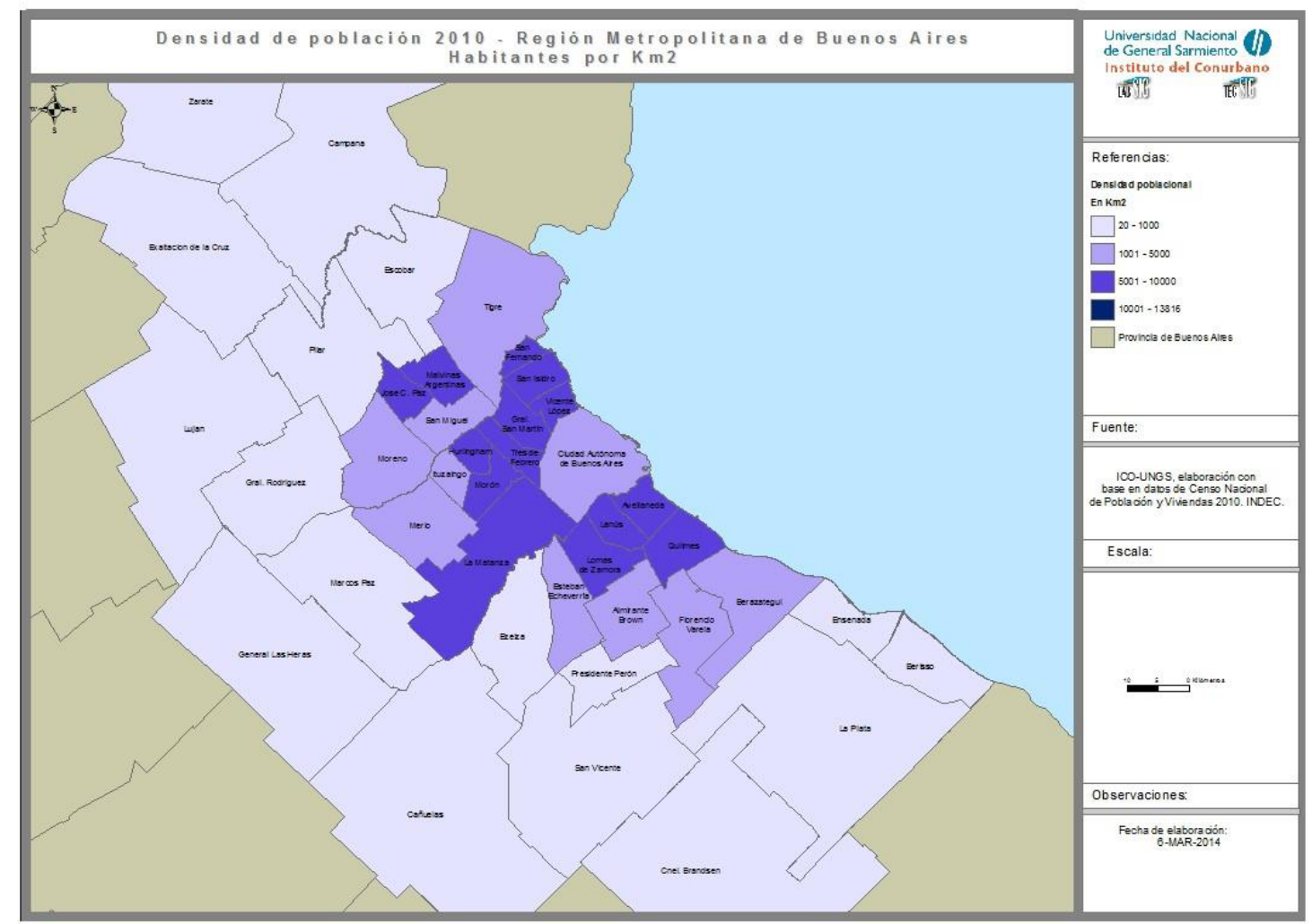

Figura 2: Densidad poblacional Región Metropolitana de Buenos Aires. Censo 2010. Observatorio del Conurbano. ICO. UNGS.

Con el fin de abordar nuestra población en estudio, creímos necesario explorar los aspectos más importantes de las condiciones de vida de los habitantes de José C. Paz. Para ello, tomamos como referencia un conjunto de resultados de investigación sobre las condiciones sociales para el desarrollo en los municipios del conurbano bonaerense de la Universidad Nacional de General Sarmiento (Provincia de Buenos Aires, Argentina) ${ }^{133}$.

Las autoras Suárez y Palma Arce (2010) analizan una encuesta socioeconómica realizada en 2007 en 4 (cuatro) municipios ${ }^{134}$ para indagar rasgos sociodemográficos, condiciones habitacionales, situación de niños y adolescentes, situación educativa y la inserción laboral de los habitantes. Los datos que relevan de José C. Paz nos permiten distinguir aspectos generales de las condiciones de vida de la población para comprender el modo

\footnotetext{
${ }^{133}$ Los trabajos académicos consultados pertenecen al proyecto: "Escalas del desarrollo en la Región Metropolitana de Buenos Aires", bajo la dirección de Adriana Rofman; con Ana Lourdes Suárez y Rodrigo Carmona como grupo responsable y Daniela Soldano como investigadora colaboradora. También participaron como investigadoras asistentes Lara González Carvajal y Mirtha Anzoategui; y Carolina Palma Arce y Viviana Moreno, como becarias.

${ }^{134}$ Las autoras estudian los municipios de San Miguel, José C. Paz, Moreno y Morón del Conurbano Bonaerense.
} 
en que dichas situaciones se vinculan con los consumos culturales y, en particular, con la televisión digital como dispositivo de acceso a la inclusión digital.

Uno de los datos que nos interesaron conocer fue el principal perceptor de ingresos de los hogares en el municipio. En José C. Paz, en similares medidas que en los partidos vecinos, “(...) el principal perceptor de ingreso PPI del hogar es el jefe de hogar. Es de destacar sin embargo que las/los cónyuges, los hijos y otros miembros representan más de un cuarto de los PPI del hogar. A su vez, más de un tercio de los PPI está compuesto por mujeres. Estos datos indican el peso de las mujeres en las economías de los hogares del conurbano" (Suárez y Palma Arce, 2010: 45).

\section{Cuadro 1}

Principal perceptor de ingresos del hogar. Relación de parentesco con el jefe, sexo y monto promedio del ingreso mensual según partido. Partidos José C. Paz, Moreno, San Miguel y Morón. Diciembre 2007.

\begin{tabular}{|c|c|c|c|c|c|}
\hline \multirow[b]{2}{*}{$\begin{array}{l}\text { Principal perceptor de } \\
\text { ingresos }\end{array}$} & \multicolumn{4}{|c|}{ Partido } & \multirow[b]{2}{*}{ Total } \\
\hline & $\begin{array}{c}\text { José C. } \\
\text { Paz }\end{array}$ & Moreno & $\begin{array}{c}\text { San } \\
\text { Miguel }\end{array}$ & Morón & \\
\hline \multicolumn{6}{|c|}{ Relación de parentesco con el jefe de hogar (\%) } \\
\hline Jefe & 64,4 & 74,1 & 72,4 & 78,6 & 72,6 \\
\hline Cónyuge & 13,7 & 14,1 & 10,3 & 10,0 & 12,5 \\
\hline Hijo/hijastro & 15,1 & 8,9 & 17,2 & 8,6 & 11,6 \\
\hline Otro & 6,9 & 2,9 & 0,0 & 2,9 & 3,3 \\
\hline Total & 100 & 100 & 100 & 100 & 100 \\
\hline $\mathrm{N}$ & 73 & 135 & 58 & 70 & 336 \\
\hline \multicolumn{6}{|l|}{ Sexo $(\%)$} \\
\hline Hombre & 64,4 & 63,7 & 60,3 & 60,0 & 62,5 \\
\hline Mujer & 35,6 & 36,3 & 39,7 & 40,0 & 37,5 \\
\hline Total & 100 & 100 & 100 & 100 & 100 \\
\hline $\mathrm{N}$ & 73 & 135 & 58 & 70 & 336 \\
\hline \multicolumn{6}{|l|}{ Fuente del ingreso (\%) } \\
\hline Trabajo & 79,5 & 72,6 & 75,9 & 65,7 & 73,2 \\
\hline Jubilación o pensión & 13,7 & 17,8 & 22,4 & 32,9 & 20,8 \\
\hline Seguro de desempleo & 0 & 1,5 & 0 & 1,4 & 0,9 \\
\hline Subsidio de ayuda social & 5,5 & 5,2 & 0 & 0 & 3,3 \\
\hline Otro & 1,4 & 2,9 & 1,7 & 0 & 1,8 \\
\hline Total & 100 & 100 & 100 & 100 & 100 \\
\hline $\mathrm{N}$ & 73 & 135 & 58 & 70 & 336 \\
\hline $\begin{array}{l}\text { Monto del ingreso mensual } \\
\text { (Promedio) }\end{array}$ & 944,5 & 947,3 & 1401,4 & 1278,2 & 1094,0 \\
\hline
\end{tabular}

Fuente: Elaboración propia en base a Encuesta Proyecto Escalas territoriales del desarrollo en la Región Metropolitana de Buenos Aires (PICT 2005) ICO-UNGS, 2007.

Otra de las estimaciones que arrojan datos sobre las condiciones de vida de los habitantes de una localidad tiene que ver con la vivienda. En nuestro caso, nos encontramos con que José C. Paz tiene un alto porcentaje de propietarios. Según Suárez y Palma Arce:

"Este dato es relevante; indica que pese a los magros ingresos con los que cuentan los hogares han podido hacerse de un bien indispensable para su bienestar. El dato refleja asimismo que el conurbano se fue poblando de la mano de políticas que 
facilitaban el acceso a la vivienda. Solo el 10 por ciento de los hogares alquilan su vivienda. El 15 por ciento restante registra situaciones de irregularidad en la tenencia de su vivienda. Este dato indica que existe un porcentaje relevante de la población que soluciona su situación habitacional vía la informalidad”. (Suárez y Palma Arce, 2010: 42)

\section{Cuadro 4}

Distribución de los hogares por régimen de tenencia de la vivienda según partido. Partidos José C.

Paz, Moreno, San Miguel y Morón. Diciembre 2007.

\begin{tabular}{|c|c|c|c|c|c|}
\hline \multirow[b]{2}{*}{ Régimen de tenencia } & \multicolumn{4}{|c|}{ Partido } & \multirow[b]{2}{*}{ Total } \\
\hline & José C. Paz & Moreno & $\begin{array}{c}\text { San } \\
\text { Miquel }\end{array}$ & Morón & \\
\hline Propietario de vivienda y terreno & 68,8 & 67,4 & 79,2 & 81,7 & 73,5 \\
\hline Propietario de vivienda solamente & 10,0 & 7,6 & 1,4 & 1,0 & 5,2 \\
\hline Inquilino & 5,0 & 8,3 & 15,3 & 9,6 & 9,2 \\
\hline Ocupante & 15,0 & 15,3 & 0,0 & 6,7 & 10,2 \\
\hline Otra situación & 1,2 & 1,4 & 4,2 & 1,0 & 1,8 \\
\hline Total & $100 \%$ & $100 \%$ & $100 \%$ & $100 \%$ & $100 \%$ \\
\hline $\mathrm{N}$ & 80 & 144 & 72 & 104 & 400 \\
\hline
\end{tabular}

Fuente: Elaboración propia en base a Encuesta Proyecto Escalas territoriales del desarrollo en la Región Metropolitana de Buenos Aires (PICT 2005) ICO-UNGS, 2007-

Cuando se indaga la cantidad de miembros que conviven en las viviendas del partido, las autoras sostienen que resulta alto el número en relación con las otras localidades analizadas y, además, se compone de una mayor población infantil.

En relación con la situación educativa de la población del municipio, las autoras sostienen que: "Al analizar la distribución de la población por nivel de instrucción según partido, se observa que las situaciones de mayor vulnerabilidad tienden a concentrarse en el partido de José C. Paz (cuadro 4.2). En este partido, uno de cada cinco habitantes mayores de 20 años no concluyó la primaria” (Suárez y Palma Arce, 2010: 80).

El estudio de Suárez y Palma Arce (2010) concluye que los rasgos de vulnerabilidad están fuertemente extendidos en el partido de José C. Paz ya que se caracteriza por poseer hogares con mayor cantidad de miembros en viviendas que, salvo aquellas ubicadas en la zona céntrica, carecen de provisión de servicios básicos (agua potable, red cloacal, gas natural, etc.). La mayoría de los barrios cuentan con bajo porcentaje de servicio de alumbrado público, deficiente recolección de residuos y escasas calles pavimentadas. Además, la mayoría de los hogares situados en barrios periféricos de la localidad condensa altos porcentajes de población con bajo nivel de instrucción, con gran cantidad de adolescentes que trabajan con una percepción de bajos ingresos y con muchos otros 
denominados generación "Ni-Ni"135. Esta situación se agrava con la presencia de un alto porcentaje de desocupados y de trabajadores con empleos precarios que invierten mucho tiempo y dinero para llegar a los lugares de trabajo.

Finalmente, debemos señalar que esta caracterización de los aspectos sociodemográficos y económicos más sensibles de la población de la localidad de José C. Paz se combinan con un territorio intervenido por complejos habitacionales (barrios cerrados, privados, countries) de altísimo poder adquisitivo, junto al desarrollo de centros comerciales, autopistas de vinculación con la Ciudad de Buenos Aires. En este punto nos interesa evidenciar el modo en que se expresan los procesos de exclusión social que integran precariedad laboral, bajos ingresos, debilidad de redes de contención familiar y social, migraciones, entre otros, para la mayor parte de la población de José C. Paz, en coexistencia con sectores de altos ingresos, expresando una gran fragmentación sociodemográfica del territorio que estudiamos en esta tesis.

Entre las dificultades que nos encontramos a la hora de relevar las estimaciones demográficas, sociales, económicas, etc. del partido de José C. Paz tuvimos que referirnos y apoyarnos en datos del Censo Nacional de Población y Vivienda (2010), lo que limitó la posibilidad de obtener indicadores actualizados que den cuenta de los diferentes aspectos involucrados en las condiciones de vida de la población (servicios sanitarios, educativos, infraestructura, etc.).

No obstante, a efectos de esta tesis, pretendimos reconocer algunos de los principales consumos culturales de nuestra población en estudio, observando la disponibilidad de tecnologías en sentido amplio (telefonía fija, móvil, computadoras, internet) y, especialmente, tanto televisión analógica como digital (TDA).

\subsubsection{Disponibilidad y uso de tecnologías en el Conurbano Bonaerense}

En este punto, consideramos la Encuesta Nacional de Consumos Culturales y Entorno Digital (ENCCyED) $)^{136}$, la Encuesta Nacional de Tecnologías de la Información y la

\footnotetext{
135 Se llama generación "Ni-Ni" de jóvenes de entre 16 y 30 años que no estudian ni trabajan que según diversas opiniones se debe a la falta de oportunidades, desinterés o condiciones estructurales.

${ }^{136}$ La Encuesta Nacional de Consumos Culturales y Entorno Digital (ENCCyED) que se realizó en 2013, fue una iniciativa de la Secretaría de Cultura de la Nación, llevada adelante por el SInCA (Sistema Información Cultural de la Argentina) dependiente de la Dirección Nacional de Industrias Culturales del
} 
Comunicación (ENTIC) ${ }^{137}$ y una síntesis de investigaciones de la Universidad Nacional de General Sarmiento sobre consumos culturales y producción audiovisual en el Noroeste del Conurbano ${ }^{138}$. En términos genéricos, estos estudios consultan los gustos, usos y valoraciones sobre consumos culturales y tecnologías digitales de distintas provincias y localidades de la Argentina durante 2011 y 2013. Por ende, la información que obtuvimos nos permite considerar características generales referidas a prácticas culturales tales como: lectura, escuchar radio, mirar televisión, ir al cine, al teatro, entre otras; así como también, a usar computadora, telefonía móvil, internet, jugar videojuegos, etc. en la provincia de Buenos Aires. Específicamente, tuvimos la posibilidad de consultar trabajos académicos del Instituto del Conurbano de la Universidad Nacional de General Sarmiento, que hacen foco en 4 partidos del conurbano bonaerense y que nos permitieron conocer algunos datos sobre la situación de nuestra población en estudio.

Para empezar, tomamos las cifras generales de la ENCCyED (2013) en lo que respecta al visionado de televisión, cine o videos, disponibilidad y uso de telefonía móvil, computadora, internet de la población argentina.

Según esta encuesta, casi el 98 \% de los argentinos miraron televisión durante el 2013 y lo hicieron a través del televisor; en menor medida usaron otros dispositivos tales como computadora o el teléfono móvil. La extensión de la televisión de pago en el territorio es alta alcanzando un $68 \%$ mientras un $13 \%$ consume algún tipo de servicio satelital. El cruce de estos datos en función del segmento social indicó que "(...) se observa un incremento del consumo de televisión a medida que disminuye el nivel socioeconómico. (...) las clases bajas presentan valores más altos que el resto, con un 98,7\%; mientras que las clases altas se encuentran al final del ranking” (SInCA, 2013: 6). Y, específicamente, en el AMBA, un 98 \% de sus habitantes consumieron televisión durante 2013.

\footnotetext{
Ministerio de Cultura de la Nación Argentina. Disponible en: https://www.sinca.gob.ar/VerDocumento.aspx?IdCategoria=10.

${ }^{137}$ La Encuesta Nacional de Tecnologías de la Información y la Comunicación se desarrolló por primera vez durante el tercer trimestre de 2011 para obtener información de usos y accesos de hogares y personas a dichas tecnologías en Argentina.

${ }^{138}$ Este trabajo fue elaborado por: Abramovich, Barnes, Borello, González, Martínez, Poplavsky y Quintar. Área de Sistemas Económicos Urbanos, Instituto del Conurbano, Universidad Nacional de General Sarmiento.
} 
El $40 \%$ de los habitantes del país concurrieron al cine al menos una vez durante el año; a la vez, el consumo hogareño de películas y/o videos contaron con un $84 \%$ de referencias y el medio privilegiado de ese visionado fue a través del televisor (81\%).

La posesión de computadoras en los hogares argentinos alcanzó un $71 \%$, con un $68 \%$ de usuarios activos y un $65 \%$ que se conectaron a internet. La disponibilidad y el uso de telefonía móvil tuvo una alta penetración ( 85 \% de las personas tienen una línea activada y cerca del $40 \%$ tiene un dispositivo de tipo inteligente conectado a internet).

Haciendo foco en nuestro interés por la televisión digital, los datos de la encuesta señalan que el 7,5\% de la población del AMBA posee TDA (con decodificador / sintonizador digital incorporado en la TV) y entre ellos, quienes dicen disponer de este tipo de televisión fueron personas mayores de 49 años. En relación con el visionado de televisión digital, los adultos entre 50 y 64 años sumados a los adultos mayores fueron quienes indicaron que miraron en mayor medida canales que ofrece la parrilla de "Mi TV Digital". Por otra parte, nos interesó en particular el trabajo producido por Abramovich et al. (2014) que presenta los resultados de una encuesta realizada en 2014 sobre los consumos audiovisuales y uso de TIC en los partidos de San Miguel, José C. Paz, Moreno y Malvinas Argentinas de la Provincia de Buenos Aires ${ }^{139}$. El objetivo del estudio fue: “(...) relevar aspectos vinculados a los equipamientos audiovisuales, la posibilidad de acceso a la oferta de bienes culturales, y los usos y decisiones de consumos culturales de cada hogar" (Abramovich et al., 2014: 17). Este análisis de datos contribuyó con nuestra tarea de conocer y reconocer, en cierta medida, la disponibilidad, el acceso y los usos de la televisión analógica y digital en el partido de José C. Paz.

En coincidencia con la ECCyED, la información colectada en esta investigación refiere que los hogares de estos cuatro partidos cuentan con una amplia disponibilidad de televisores, DVD y cámaras digitales: "El televisor es un bien disponible prácticamente en la totalidad de los hogares. Se destaca, sin embargo, el relativamente bajo nivel de acceso a la computadora, que en la actualidad ya puede considerarse una tecnología de consumo masivo" (Ibídem: 19). De los hogares que poseen computadoras apenas un tercio tienen algún tipo de conexión a internet, situación que demuestra que la posibilidad

\footnotetext{
${ }^{139}$ Según los autores, el universo de estudio fue la población situada en los cuatro partidos, que pertenecía a radios censales con más de 100 viviendas, según el Censo Nacional de Población, Hogares y Viviendas de 2001.
} 
efectiva de acceder al servicio orienta los usos más efectivos de los dispositivos: "Por ejemplo, en los hogares que tienen acceso a internet, el $71 \%$ de los individuos respondió que utiliza la computadora; mientras que en aquellos que no tienen acceso, el porcentaje es del 32 \%" (Ibídem: 20). De estas cifras podemos inferir que la posesión de computadoras no es equivalente al uso de los dispositivos y que esos usos están directamente relacionados con la posibilidad de conexión a internet.

Finalmente, la telefonía móvil cumple un papel importante al momento de disponer de conexión a internet vía wifi ya que condiciona el servicio de las cooperativas proveedoras o en el caso de la empresa Speedy ${ }^{140}$. Según el estudio consultado, casi la mitad de los hogares no poseen teléfono fijo debido no sólo al costo de la línea sino a que las empresas proveedoras aducen la falta de cobertura o la identificación de lo que llaman: "zonas rojas o peligrosas" $" 141$.

Los datos colectados hasta aquí expresan no sólo una heterogénea disponibilidad y exiguos usos de tecnologías sino que trazan un mapa de acceso desigual a la provisión de servicios tanto por parte del mercado como por el Estado.

\subsubsection{La televisión digital en José C. Paz: mucho ruido, pocos datos}

Tal como hemos indicado en el capítulo II de esta tesis, la transición digital en nuestro país ha sido impulsada por políticas de Estado de equipamiento, distribución y conectividad a través de diferentes planes y programas: Conectar Igualdad, TDA, Argentina Digital, etc. Sin embargo, nos resultó dificultoso hallar estadísticas oficiales (MINPLAN, AFSCA, Ministerio de Cultura) generales y, en particular, en el partido estudiado, que ofrezcan datos precisos sobre la distribución y consumo del equipamiento de televisión digital. Por lo tanto, a efectos de esta investigación hemos reconstruido la información a partir de la consulta de trabajos académicos, encuestas y algunas notas periodísticas de medios digitales de la zona de referencia.

\footnotetext{
${ }^{140}$ Speedy es un servicio de internet por telefonía fija y wifi que ofrece la empresa Telefónica de Argentina (compañía de telefonía fija y móvil).

${ }^{141}$ Las "zonas peligrosas o rojas" son aquellas que presentan características de vulnerabilidad de la población residente entre las que se destaca un alto índice de delitos como robos, hurtos, asesinatos, precariedad edilicia y escasos servicios públicos (calles pavimentadas, alumbrado y limpieza, etc.).
} 
Desde el año 2010 se instalaron antenas transmisoras de TDT en cada provincia del país junto a operativos de distribución gratuita de decodificadores digitales gestionadas a través de las oficinas de ANSES y oficinas intermedias en las provincias del país (direcciones municipales).

El inicio del Plan "Mi TV Digital" fue anunciado por la presidenta (mandato cumplido) Cristina Fernández en octubre de 2010. A partir de esa fecha se comenzaron a realizar las entregas de receptores digitales a través del ANSES, oficinas de los gobiernos locales y organizaciones de la sociedad civil para cubrir la población en "riesgos de exclusión".

En el marco de nuestro estudio, recogimos algunos datos difundidos en algunos medios digitales locales y de circulación nacional además del sitio oficial del municipio sobre los operativos de distribución de TDA en el partido de José C. Paz. Según estas fuentes, durante la intendencia de Carlos Urquiaga (2011-2015) se realizaron varias entregas de decodificadores: por ejemplo, unos 300 en el Barrio Santa Paula ${ }^{142}$; otros 1.000 en el Mercado Concentrador de la localidad ${ }^{143}$. Los escasos resultados producto de nuestra búsqueda de noticias en medios locales y nacionales, sumados a la falta de estadísticas oficiales de entregas realizadas efectivamente, obstaculizaron la posibilidad de contar con estimaciones precisas para conocer la población alcanzada por el beneficio del Plan.

Las dificultades de contar con información precisa que hemos venido señalando hasta aquí son compartidas con otros estudios (Becerra, 2014; Abramovich et al., 2014; Deharbe, 2013, entre otros) que se proponen investigar diferentes aspectos de la TDA en Argentina.

Por último, según las encuestas consultadas, en el AMBA un 7,5 \% de la población posee TDA (con decodificador / sintonizador digital incorporado en la TV). En los partidos de San Miguel, José C. Paz, Moreno y Malvinas Argentinas de la provincia de Buenos Aires se entregaron al menos 40.000 decodificadores pero apenas un $2 \%$ de los hogares tenía ese servicio en 2014 (Abramovich et al., 2014: 9). Este dato adquiere importancia cuando

\footnotetext{
142 Disponible en: http://prensajosecpaz.blogspot.com/2014/04/entrega-de-decodificadores-de-tda.html).

143 Disponible en: (http://www.masenlineanoticias.com/entregan-1000-decodificadores-de-televisiondigital-abierta-en-jose-c-paz) y en: https://www.infobae.com/2012/05/19/648587-entregaron-mildecodificadores-la-tv-digital-abierta-jose-c-paz/.
} 
lo comparamos con la alta penetración de la TV de pago: Telered ${ }^{144}\left(68\right.$ \%), Cablevisión ${ }^{145}$ (8\%) y $\operatorname{DIRECTV}^{146}(24 \%)$ en la zona por lo que podemos indicar la reducida penetración de la TDA, más allá de los esfuerzos del Estado por invertir en equipamientos, en infraestructura técnica y en la distribución de los dispositivos digitales.

En estas condiciones, la indagación de la disponibilidad y acceso a la TDA en el partido de José C. Paz abre un abanico de preguntas en torno no sólo a la implementación de la política pública (infraestructura, distribución y recepción), cuyo propósito es la inclusión digital de los sectores "en riesgos de exclusión", sino, en particular, en relación con los efectos producidos a medio término del "apagón digital” de 2019.

\footnotetext{
${ }^{144}$ Telered es un grupo cable operador cuyo contenido es de programación local que transmite para las ciudades de San Miguel, José C. Paz, Malvinas Argentinas, Pilar, Escobar, Mercedes, Suipacha, Moreno, Luján, General Rodríguez, Tres de Febrero y Lincoln, por lo que la empresa propietaria del canal tiene estas ciudades como áreas de cobertura.

${ }^{145}$ Cablevisión es una compañía argentina que brinda servicios de televisión por cable, pertenece al Grupo Clarín y que a partir de 2017 se fusionó con Telecom Argentina (compañía de telefonía fija y móvil que opera desde 1990 en el país).

${ }^{146}$ DIRECTV Argentina es una empresa proveedora de televisión satelital en el país.
} 


\section{Capítulo VI}

\section{Los textos de la televisión digital en Argentina}

Tal como planteamos en el marco teórico en esta tesis el análisis que presentamos a continuación se apoya en la tradición de la Economía Política de la Comunicación y la Cultura con el objeto de identificar los principales rasgos de las definiciones presentes en una política pública de comunicación, en este caso, cuyo objetivo es promover la inclusión digital y es objeto de este trabajo.

La Economía Política de la Comunicación y la Cultura brinda herramientas de análisis para abordar estas políticas en materia de inclusión digital en el contexto de la transición analógica a la digital. Como señalamos en el capítulo IV, este enfoque estudia las transformaciones de las industrias infocomunicacionales tras la digitalización de los contenidos y la expansión de las telecomunicaciones que producen escenarios diferentes a aquellos caracterizados por las tecnologías analógicas.

Dentro de esta perspectiva, nos interesa la línea que llevan adelante los especialistas argentinos Martín Becerra y Guillermo Mastrini ${ }^{147}$ quienes, junto a un nutrido equipo de trabajo, tienen una extensa experiencia en la investigación de políticas de comunicación en América Latina, que analiza la producción de comunicación y cultura a partir de la incidencia de las tecnologías, el mercado y los marcos regulatorios específicamente en nuestro país.

Mastrini (2014a: 10) retoma la definición de políticas de comunicación de Freedman (2008) como aquel: “(...) proceso que se refiere a la interacción entre los diferentes actores, las estructuras institucionales en las que trabajan y los objetos que persiguen" y "se refiere a la variedad de formas en las que los participantes interesados buscan desarrollar mecanismos formales e informales para dar forma a la conducta de los sistemas de medios de comunicación".

Por lo tanto, las políticas de comunicación son políticas públicas caracterizadas por ocuparse de los temas propios del campo de la comunicación masiva en las que intervienen tres actores: Estado, las empresas del sector y la sociedad civil. En esta

\footnotetext{
${ }^{147}$ Los autores investigan sobre las dinámicas de las industrias culturales, la concentración y convergencia infocomunicacional en la región. En el capítulo IV hemos revisado sus aportes a la tradición de la Economía Política de la Comunicación en América Latina. Ambos dirigen y codirigen, respectivamente, el Programa Industrias Culturales y Espacio Público: comunicación y política en la Argentina en la Universidad Nacional de Quilmes. Provincia de Buenos Aires. Argentina.
} 
dirección, Mastrini (2014a) advierte que para estudiar estas políticas es necesario centrarse en "lo público" en tanto "(...) espacio de conflicto y de lucha de intereses, como el lugar de la heterogeneidad y de la visibilidad de la diversidad social" (Ídem). La investigadora Califano (2015: 281-282) avanzó en una propuesta para analizar las políticas de comunicación que reúne un conjunto de cuestiones a tener en cuenta: la cuestión problematizada, es decir, la agenda institucional que el Estado construye; el rol y tipo de actores (estatales y no estatales) y dinámicas institucionales, sociales, económicas y tecnológicas; los recursos asignados para la ejecución así como también la caracterización de las relaciones de poder en juego, entre otros. Estos lineamientos ofician de marco general para encuadrar la presente indagación ya que, por un lado, nos proporciona las pistas necesarias para identificar los procesos económicos, políticos y culturales en los que se inscribe la formulación de la política de inclusión digital y, por otro, nos ofrece elementos analíticos para abordar la TDA.

Ahora bien, entre las distintas estrategias metodológicas de la Economía Política de la Comunicación y la Cultura ${ }^{148}$, hemos elegido para abordar nuestro objeto de estudio, aquella basada en un análisis político histórico del desarrollo de la política pública (origen, formulación, ejecución, evaluación) que se encarga de realizar una lectura y análisis de corpus normativos y legales.

“(...) se trabaja específicamente con la lectura de normas que regulan la actividad mediática y sirven como referente empírico para el análisis. Esta revisión de documentos no es solo una lectura diferente sino que es otra arista empírica del diverso material metodológico que enfrenta la economía política de la comunicación.” (Iturralde y Lingeri, 2015: 13)

Nos interesa aquí destacar que Iturralde y Lingeri (2105: 13-14) señalan que las producciones académicas de la Economía Política de la Comunicación y la Cultura necesariamente apelan al análisis de datos secundarios: estadísticas, marcos legales y normativas producidas por organismos del Estado así como también requieren del uso de un lenguaje técnico específico de la ingeniería o informática. Y concluyen que estos rasgos del trabajo de investigación que explora otras disciplinas y metodologías permiten la construcción de escenarios complejos desde donde abordar las industrias culturales en nuestras sociedades.

\footnotetext{
${ }^{148}$ Iturralde y Lingeri (2015) relevan algunas de las estrategias metodológicas o técnicas de investigación utilizadas en las producciones de la Economía Política de la Comunicación en Argentina. Identifican al menos cuatro: Concentración de medios de comunicación, Medios públicos, Televisión Digital Terrestre y Marcos normativos regulatorios.
} 
Entonces, el estudio de la política pública de inclusión digital que presentamos aquí tiene como marco de referencia la estrategia de investigación del enfoque de la Economía Política de la Comunicación y la Cultura, sostenido en la técnica de análisis de documentos con el fin de identificar aquellos términos clave que surgen del abordaje teórico de la tesis: referencias explícitas, la frecuencia de aparición y la relación entre los temas tratados. Tal como señalamos en el capítulo $\mathrm{V}$, analizamos las referencias a los temas vinculados a nuestro problema de investigación: de tecnologías digitales interactivas, la televisión digital y sus usos, procesos de inclusión digital.

La selección de este corpus discursivo está determinada por nuestros objetivos de investigación y en los textos que lo componen se tematiza una definición de tecnologías digitales, algunos supuestos sobre la influencia de estas en la sociedad y de la televisión digital, en particular, en post de producir procesos de inclusión digital en sectores de la población "en riesgos de exclusión digital".

El corpus analítico, a partir del marco que construye la Ley de Servicios de Comunicación Audiovisual y el Plan Nacional de Telecomunicaciones "Argentina Conectada", incluye el documento Planificación Estratégica para la implementación del SATVD-T (vigencia 2009-2019), el Reglamento General del Plan Operativo de Acceso al Equipamiento para la Recepción de la Televisión Digital Abierta "Mi TV Digital” de la Planificación Estratégica del Sistema Argentino de Televisión Digital Terrestre y el Manual Operativo para la Implementación del Plan de Acceso a la Televisión Digital Abierta Satelital "Mi Tv Digital Satelital"; todos producidos por el Consejo Asesor del Sistema Argentino Televisión Digital Terrestre.

A la vez, incluimos algunos comentarios que pudimos obtener del ex coordinador general del Consejo de Televisión Digital Terrestre de Argentina, Lic. Osvaldo Nemirovsci ${ }^{149}$, por el período 2009-2015, en una entrevista exclusiva para esta tesis. El resultado del diálogo que hemos mantenido con el ex funcionario nos permitió complementar el análisis documental así como también enriqueció los hallazgos de esta investigación.

\footnotetext{
${ }^{149}$ Según el ex coordinador, la principal tarea que realizó en su gestión fue coordinar a los espacios públicos y privados que participaban del proyecto. Desde los ministerios de la Nación hasta las universidades, cámaras empresariales vinculadas, provincias, organismos públicos descentralizados y empresas como INVAP y ARSAT. Además, la coordinación del equipo de profesionales, técnicos y empleados del Consejo de TDA. Y, básicamente, darle una comprensión política a esta decisión tecnológica.
} 


\subsection{Puntos de partida para el análisis de la política pública de inclusión digital}

En Argentina, el desarrollo de la televisión digital nace de la mano de la intervención del Estado en el mercado mediático a partir de la formulación de políticas públicas con declarados objetivos de democratización de la comunicación e inclusión digital. Un Estado que manifiesta, en su retórica, que las tecnologías digitales interactivas constituyen un eje estratégico para lograr el acceso y la inclusión digital de la sociedad con especial énfasis en aquellos sectores "con riesgos de exclusión".

Nos interesa aquí examinar las políticas públicas y el rol del Estado en torno a las tecnologías digitales interactivas, los usos de la televisión digital y los procesos de inclusión digital. En principio, presentamos el modo en que entendemos la relación Estado-políticas públicas para, posteriormente, realizar una caracterización de las políticas públicas de integración digital en el período estudiado. Este marco nos ofrece un escenario de análisis para abordar las definiciones y expectativas expresadas en los documentos normativos y técnicos comprendidos en la TDA.

En términos de Escolar: “(...) toda política pública es el producto del enfrentamiento y la negociación entre diferentes proyectos, los que a su vez emergen de diferentes actores sociales. En este sentido, si interpretamos a las políticas públicas como resultado de estas negociaciones sociales, podemos considerarlas como indicadores de la distribución del poder dentro del mismo Estado, así como de la sociedad" (Escolar, 1995: 35). Este modo de comprender las políticas públicas coloca en el centro de la escena la presunción de que el análisis de éstas da cuenta de características de un determinado momento histórico y de aspectos de la coyuntura política en la que se desarrollan.

El especialista mexicano en políticas públicas, Aguilar Villanueva (2009) plantea un marco de referencia para el análisis de las mismas, comenzando con cuatro operaciones: el análisis jurídico (legalidad de la política), el económico (eficiencia de los recursos públicos), el organizacional-administrativo (estilo de dirección, sistema de trabajo y cultura de la organización) y el politológico (grados de aceptación y/o rechazo de la política). Y explica a las políticas públicas como:

“(...) a) un conjunto (secuencia, sistema, ciclo) de acciones, estructuradas en modo intencional y causal, en tanto se orientan a realizar objetivos considerados de valor para la sociedad o a resolver problemas cuya solución es considerada de interés o beneficio público; b) acciones cuya intencionalidad y causalidad han sido definidas 
por la interlocución que ha tenido lugar entre el gobierno y sectores de la ciudadanía; c) acciones que han sido decididas por autoridades públicas legítimas; d) acciones que son ejecutadas por actores gubernamentales o por éstos en asociación con actores sociales (económicos, civiles); y e) que dan origen o forman un patrón de comportamiento del gobierno y de la sociedad". (Aguilar Villanueva, 2009: 14)

Esta definición es lo suficientemente amplia -que el autor la categoriza como "descriptiva"- e incluye variados aspectos de las políticas públicas que permiten una primera lectura analítica. Tomamos como referencia esta noción para abordar nuestro objeto de estudio y comprendemos que, en este caso, profundizar sobre el campo de estudios de políticas públicas tal como lo propone Aguilar Villanueva (1993, 2009) excede nuestros objetivos de investigación.

En este punto, Shore aporta una mirada analítica desde la antropología social para las políticas públicas que trata de “(...) explorar los sistemas de gobierno mutables; (...) rastrear el ascenso del neoliberalismo y la manera en que está reformulando la relación entre individuos, Estados y sociedad" (Shore, 2010: 31). Pero, fundamentalmente, sostiene que la antropología contribuye para entender cómo funcionan las políticas públicas: “(...) como símbolos, estatutos de legitimidad, tecnologías políticas, formas de gubernamentalidad e instrumentos de poder que a menudo ocultan sus mecanismos de funcionamiento" (Shore, 2010: 21), y que para abordarlas se requiere problematizarlas en sus contextos de surgimiento y aplicación. Esta perspectiva invita a considerar la complejidad y el desorden de la formulación de las políticas y el modo en que los destinatarios las reciben en el territorio, así como también desnaturaliza la idea de linealidad y de etapas de las mismas.

El estudio del entramado y los posicionamientos de los actores institucionales (gubernamentales y no gubernamentales, partidos políticos, referentes sociales, etc.) presentes en el diseño y formulación de las políticas públicas proporciona pistas sobre la génesis y ciertos efectos de estas. Shore afirma que “(...) las políticas tienen efectos que sobrepasan los diseños e intenciones de sus autores (si en verdad un "autor de políticas" puede ser identificado)" (Shore, 2010: 36).

Entre los aspectos de las políticas públicas que se pueden analizar desde esta perspectiva se encuentra el modo en que presentan sus propósitos: “(...) ofrecen narrativas retóricas que sirven para justificar — o condenar - el presente, y algo más usual, para legitimar a quienes están en posiciones de autoridad establecidas. (...) a su vez proveen de medios 
para unificar el pasado y el presente, de tal manera que otorguen coherencia, orden y certeza a las acciones (...) del gobierno.

Finalmente, (...) las políticas también proveen una zona de alianza, una manera de unir a la gente en pro de una meta o finalidad común (...)” (Ibídem: 32).

Estos criterios se suman al marco de análisis para la política pública de integración digital denominada TDA que nos interesa abordar en este capítulo.

\subsection{La definición del problema de las tecnologías y la televisión digital en las políticas públicas}

En principio, nos interesa conocer el rol que ha cumplido el Estado a través de las políticas públicas de inclusión digital. Tal como hemos sostenido a lo largo de los capítulos anteriores, hasta 2015 en Argentina -como en otros países de América Latina-advertimos que el Estado, a partir de medidas específicas, se propuso cuestionar, a partir de diferentes estrategias de política pública, que la concentración mediática y las reglas de mercado en la economía se encuentren ubicados por sobre el interés público.

En sentido amplio, se trata de un Estado que -de la mano de los denominamos "gobiernos progresistas" $" 150$ - recoge el descontento y las voces contra las políticas neoliberales del siglo XX, expresado por variados movimientos sociales. Como señala Thwaites Rey:

"(...) comienza a cuestionarse la "bondad del mercado" como único asignador de recursos y se recuperan resortes estatales para la construcción política sustantiva. Se conjuga así una retórica crítica frente a las políticas neoliberales, el diseño de propuestas para transformar los sistemas políticos en democracias participativas y directas y una mayor presencia estatal en sectores estratégicos". (Thwaites Rey, 2010: 30)

Este cambio de rumbo se realizó también a partir de una estrategia regional que se cristaliza en las alianzas en bloques regionales como MERCOSUR, UNASUR y CELAC, donde buena parte de los gobiernos latinoamericanos ${ }^{151}$ se propusieron generar un nuevo esquema de correlaciones de fuerza en el continente.

\footnotetext{
${ }^{150}$ La cuestión sobre los "gobiernos progresistas" en América Latina se abordó en el apartado 2.3 del capítulo II de esta tesis.

${ }^{151}$ Nos referimos a los gobiernos que abren una etapa posneoliberal como Venezuela (1999), Brasil (2003), Argentina (2003), Uruguay (2004), Bolivia (2006), Ecuador (2007), Nicaragua (2007), Paraguay (2008), Salvador (2009).
} 
Surge, entonces, una articulación diferente entre Estado, el mercado y la sociedad civil sostenida en la implementación de un amplio espectro de políticas públicas de inclusión social $^{152}$ en la región latinoamericana. El objetivo de estas políticas se orienta a la reducción de desigualdades al mismo tiempo que a la ampliación de ciudadanía y derechos con una marcada intervención del Estado en diferentes aspectos de la vida de los ciudadanos: social, economía, cultura, política.

En Argentina, entre 2003 y 2015, el Estado recupera márgenes de autonomía en relación con el mercado interno y externo; a la vez que se generaron como señala De Piero:

“(...) políticas públicas activas (...) En el campo económico, en líneas generales puede hablarse de políticas de protección al mercado interno, tipo de cambio administrado, no liberalización de los mercados (regulando los precios de servicios internos por ejemplo, mediante subsidios o imponiendo retenciones a las exportaciones de materias primas), intervención del Estado frente a conflictos laborales con políticas de subsidio al empleo, garantía en la realización de paritarias salariales; en suma, medidas que en conjunto implican un Estado con mayor injerencia en el proceso de toma de decisiones económicas y políticas". (De Piero, 2012: 173)

Así como se implementaron políticas de corte económico se promovieron otras orientadas a lograr mayores niveles de inclusión a partir de acciones en el ámbito de la seguridad social, de la educación, de la salud, etc., que según De Piero (2012: 174) “(...) fortalecieron la centralidad del Estado Nacional". Este fortalecimiento estuvo acompañado con la incorporación de organizaciones sociales que presentaron demandas que fueron tomadas en cuenta en la gestión de las políticas públicas. Es el caso de la Ley de Matrimonio Igualitario, la Ley de Niños y Niñas o la Ley de Servicios de Comunicación Audiovisual, entre otras.

En tal sentido, como hemos señalado en el capítulo II, apartado 2.2, en el campo de la comunicación, desde fines de la dictadura cívico-militar de 1976, sindicatos de trabajadores de medios, movimiento de radios comunitarias, académicos $\mathrm{y}$ organizaciones de derechos humanos problematizaron y debatieron sobre las políticas de comunicación neoliberales hasta que en 2004 se reunieron en "Coalición por una Radiodifusión Democrática". Es en 2008 que este debate es incorporado a la agenda pública que se tradujo en la sanción de una ley sobre radio y televisión que regula el

\footnotetext{
${ }^{152}$ Algunos ejemplos: el Programa Bolsa Familia en Brasil, Tarjeta Social en Uruguay, Bono Juancito Pinto en Bolivia, Bono de Desarrollo Humano en Ecuador, entre otros.
} 
mercado mediático, pero además “(...) respetuosa, en su letra, de los contenidos y de la libertad de opinión" (Becerra, 2013: 50).

Esto tiene su correlato en las estrategias políticas llevadas adelante tanto en materia de comunicación como de tecnologías digitales interactivas por los gobiernos de la región.

En ese nuevo escenario político los medios de comunicación adquirieron una progresiva centralidad que se visibilizó en la preocupación de la academia y de la sociedad civil, reclamando espacios de participación y pluralidad de voces pero, fundamentalmente, en los tomadores de decisión de las gestiones estatales de Latinoamérica. Mastrini (2014b: 156) recupera una cita de Becerra que suscribe:

"En el caso de América Latina, su inmersión en el siglo XXI combinó su estructural y distintiva fractura socioeconómica (es la región más desigual del planeta, donde la distancia entre ricos y pobres es mayor [Cepal, 2010]) con una lectura crítica por parte de los gobiernos electos en los últimos años, acerca del impacto que tuvieron las políticas neoliberales ejecutadas al calor del Consenso de Washington en la última década del siglo pasado. Algunos autores, aluden a estos gobiernos como populistas de izquierda (Kitzberger, 2008), nacional-populares o de nueva izquierda (Vilas, 2005), lo cierto es que su modo de intervención estatal es muy diferente del que se había practicado en las democracias latinoamericanas en las décadas anteriores". (Becerra, 2011: 15)

En el caso argentino, el 2005 es el antecedente a partir del cual la televisión digital ingresa en la agenda de gobierno a partir de un acuerdo bilateral con Brasil para trabajar en la materia. El Ministerio de Planificación Federal, Inversión Pública y Servicios se puso a la cabeza del desarrollo de la televisión digital con el tendido de infraestructura de red, la provisión de equipamientos y la producción de contenidos.

Hubo varios motivos que impulsaron la digitalización de la televisión abierta en Argentina. Uno de ellos es que la República Federativa de Brasil avanzaba en su proyecto digital y eso ponía a nuestro país en una posición demorada en el marco del MERCOSUR, señaló el Lic. Nemirovsci ${ }^{153}$.

En este contexto, se crearon e implementaron distintas políticas públicas tendientes a trabajar de manera articulada las diversas cuestiones relacionadas con las tecnologías en conjunto con los pilares de educación, trabajo, salud, industria, inclusión y desarrollo. Entre estas políticas se destacan el Plan Nacional de Telecomunicaciones "Argentina

\footnotetext{
${ }^{153}$ Estas ideas alrededor del surgimiento y funcionamiento de la TDA fueron fruto de una consulta con el Lic. Osvaldo Nemirovsci, ex coordinador general de la SDTV-T, en una entrevista exclusiva brindada para esta tesis.
} 
Conectada" que enmarca el Programa Conectar Igualdad, la implementación de los Núcleos de Acceso al Conocimiento, el desarrollo de Software Libre creado en Argentina, la puesta en marcha de la Televisión Digital Abierta, el lanzamiento de PROGRAM.AR, entre otras iniciativas.

En el marco de este conjunto de estrategias identificamos, en los textos de los documentos de la TDA, aquellos enunciados que explícitamente plantean la posición del Estado argentino respecto de las demandas de diferentes actores gubernamentales y no gubernamentales sobre la necesidad de incorporar la agenda digital a la formulación de políticas públicas de comunicación.

Uno de los documentos que evidencia con claridad las respuestas del Estado ante las interpelaciones tanto de organismos internacionales y regionales como la dinámica de desarrollo de tecnologías digitales impulsada por los mercados es el Plan "Argentina Conectada":

"En consonancia con estos fundamentos e iniciativas internacionales (...) como así también en el análisis de las necesidades específicas que presenta la República Argentina en materia de desarrollo de la banda ancha e inclusión digital, el presente documento presenta la estrategia del actual gobierno para promover el desarrollo de la infraestructura de telecomunicaciones a lo largo del territorio nacional y universalizar el acceso a los servicios de Internet. Dicha estrategia está centrada en el Plan Nacional de Telecomunicaciones Argentina Conectada, un plan estratégico en el que se definen las metas y se articulan las políticas públicas para su alance". (Plan "Argentina Conectada", 2010: 14)

Estos propósitos permiten advertir que entre los antecedentes de la política pública se encuentran distintos tipos de demandas pero también se presentan diagnósticos sobre el Estado y desarrollo de las telecomunicaciones en el país en los cuales las tecnologías digitales tienen un lugar destacado. Es decir, encontramos allí la presencia de alusiones sobre los factores tecnológicos propiamente dichos, que refieren a los dispositivos técnicos y sus características como internet, televisión digital, computadoras, etc.

Sumado a las necesidades definidas por los compromisos asumidos por el Estado en materia de agenda digital y en términos técnicos (migración digital y el apagón analógico previsto para 2019), en una parte del documento Planificación Estratégica para la implementación del SATVD-T (2009-2019) se destaca la gravitación que deberá tener la televisión digital para garantizar a toda la población argentina un acceso democrático y plural a los servicios digitales y a los contenidos producidos. 
"Procurar las condiciones para que se desarrolle de manera equitativa la producción de contenidos, servicios y recursos digitales desde la variedad y diversidad de sectores de la sociedad que se interesen en dicho desarrollo." (SATVD-T, 20092019: 11)

En palabras del ex coordinador general del Consejo de Televisión Digital Terrestre de Argentina: la TDA tuvo como objetivo llegar a más personas, que más personas vieran mejor televisión a partir de la producción de contenidos con las universidades nacionales mediante el Subprograma Polos Audiovisuales Tecnológicos.

Estos elementos colaboran con la caracterización de la definición del problema público que refiere a las iniciativas de inclusión digital y que se expresan en el encuadre de la Ley de Servicios de Comunicación Audiovisual. En el artículo $\mathrm{N}^{\circ} 1$ se muestra el propósito del Estado de regular el mercado mediático a fin de democratizar las comunicaciones desde la producción tecnológico-mediática hasta la recepción entre los ciudadanos.

Artículo $1^{\circ}$ - Alcance. El objeto de la presente ley es la regulación de los servicios de comunicación audiovisual en todo el ámbito territorial de la República Argentina y el desarrollo de mecanismos destinados a la promoción, desconcentración y fomento de la competencia con fines de abaratamiento, democratización (1) y universalización del aprovechamiento de las nuevas tecnologías de la información y la comunicación. (Ley de Servicios de Comunicación Audiovisual 26.522, 2009: 1)

Entonces, el objetivo enunciado es poner un límite a la concentración mediática, juntamente con la explicitación del problema del acceso referido tanto a la disponibilidad de las tecnologías digitales y conectividad como a la producción y recepción de contenidos culturales de factura local y regional.

Garantizar el acceso de todos los habitantes de la Nación al servicio de televisión digital $\mathrm{y}$, en consecuencia, el acceso universal a las nuevas tecnologías de la información y la comunicación, en el marco de un modelo que contempla la inclusión social y la diversidad cultural, el fortalecimiento de la industria nacional y la promoción del empleo, el desarrollo científico-tecnológico, y la protección de los derechos y libertades de todos los argentinos. (SATD-T, 2009-2019: 11)

De allí que observamos que en la redacción del objetivo general de la planificación estratégica en el documento SATVD-T (2009-2019) se manifiesta el modo en que, mediante el acceso a la televisión digital terrestre y satelital, el Estado contribuiría a asegurar el derecho ciudadano a la comunicación y a la inclusión social. 
El propósito declarado en la letra de los documentos oficiales es confirmado por el ex funcionario que el mundo iba cerrando su ciclo analógico y Argentina no podía quedarse afuera. La TDA cubrió espacios del país donde no llegaba nada, existían para entonces millones de habitantes a los que un sistema como el que se impulsaba les garantizaría ver más señales en forma gratuita. Y el plan de entregar conversores gratuitos, les permitiría acceder a la televisión digital sin tener que cambiar su viejo televisor (el hecho de que la digitalización permita que de $6 \mathrm{MHZ}$ en sistema VHF y se puedan emitir 3 o señales en UHF era la clave del programa), aseguró Nemirovsci.

Entre los aspectos que nos interesó relevar de este conjunto documental, reparamos en las modalidades de administración y gestión propuestas por la política de comunicación. Una de las características principales es la articulación de diferentes iniciativas orientadas al fortalecimiento de la infraestructura y conectividad tecnológica para alcanzar a la ciudanía argentina. En los diferentes instrumentos de la política pública se detallan los organismos, dependencias y sus funciones asociadas al cumplimiento de la agenda digital definida por el Estado argentino. Entre algunos de los ejemplos se encuentran: la creación del Consejo Asesor del Sistema de Televisión Digital Abierta que lista representantes de los ministerios con competencias en la materia y el espacio de participación de la sociedad civil organizado en un foro consultivo; la Ley de Comunicación Audiovisual comprende: la Autoridad Federal de Servicios de Comunicación Audiovisual (AFSCA), la Defensoría del Público y la Comisión Bicameral del Congreso o la conformación del subprograma Polos Audiovisuales Tecnológicos, integrados por universidades nacionales y organizaciones sociales que a la vez contiene a los Nodos que funcionaban como sistemas productivos locales.

Finalmente, en el corpus analítico pudimos reconocer que la posición del Estado se presenta como regulador, a partir de la intervención de distintas áreas del escenario tecnomediático que, como hemos señalado en esta tesis, en particular en el apartado 2.2 del capítulo II, no estuvo exento de tensiones y disputas con los grupos mediáticos concentrados.

Otro rasgo del lugar que ocupa el Estado es el de promotor de la función social de las tecnologías y de los medios de comunicación como puntos de anclaje para promover procesos de inclusión social y digital. A la vez que el Estado asume la promoción del desarrollo económico nacional mediante el impulso de la industria de tecnologías digitales y/o la creación de empleos especializados en el rubro. 


\subsubsection{Las TIC como uno de los motores hacia la Sociedad de la Información}

En octubre de 2009, el Congreso Nacional aprueba la Ley 26.522 de Servicios de Comunicación Audiovisual que regula el sistema de medios -incluida la televisión digital-, incorporando nuevos actores al sistema para fomentar el ejercicio de la libertad de expresión, derecho a la información, reducir la brecha tecnológica en un marco de pluralismo y diversidad. Asimismo, tal como hemos señalado anteriormente, la política de televisión digital se ubicó en la órbita del Ministerio de Planificación Federal, Inversión Pública y Servicios, el que se encargó de la implementación del SATVD-T, a través de la Planificación Estratégica 2009-2019, aprobada por el Consejo Asesor del SATVD-T que define las estrategias y las acciones específicas para el desarrollo de la televisión digital en Argentina.

En este contexto, la Ley de Servicios de Comunicación Audiovisual ofrece lineamientos generales respecto de la tecnología digital que se refieren a las licencias, elaboración de informes bianuales que revisen el régimen de multiplicidad de licencias, ingreso de nuevas tecnologías que no están activas y la transición a los servicios digitales (Mastrini, Becerra, Bizberge y Krakowiak, 2012: 72-73).

Como punto de partida, esta ley se propone como la expresión de un movimiento que refunda el sistema de medios de comunicación audiovisuales, que reemplaza una norma de la dictadura de 1976, y cuyo principal objetivo es el de desmonopolizar el acceso a la información a la vez que se constituye como una herramienta jurídica apta para regular los principios y el ejercicio de la comunicación social o la libertad de expresión a través de los medios audiovisuales. En este texto legal se pueden hallar las bases de la política general sobre los diferentes aspectos de la comunicación audiovisual, entre ellos, las tecnologías y la televisión digital.

Dentro de este marco se pueden identificar referencias a las tecnologías de la información y la comunicación (TIC) como herramientas para alcanzar niveles más elevados de desarrollo económico, social, cultural y político de la sociedad. Y, principalmente, la Ley enuncia la idea de que las TIC permiten achicar la brecha digital entre los países y dentro de ellos, incidiendo en las diferencias económicas, sociales, culturales, educacionales, de salud y de acceso al conocimiento. 
Si bien, no hace referencia explícita a las tecnologías digitales se las considera integradas a la noción de TIC. En términos generales, las TIC son vistas como uno de los motores hacia la Sociedad de la Información que tienden a promover el diálogo entre las personas y las naciones. Se trata de unas tecnologías que dan cuerpo a la Sociedad de la Información para la cual el actor impulsor por excelencia se constituye en los Estados (nacionales, provinciales o municipales), quienes “(...) mediante asociaciones entre los sectores público y privado, deben promover tecnologías y programas de investigación y desarrollo (...)" (Ley de Servicios de Comunicación Audiovisual 26.255, 2009: 4).

En relación con la Sociedad de la Información, la norma se apoya en los mandatos expresados en las declaraciones y planes de acción de la Cumbre Mundial de la Sociedad de la Información (CMSI, 2003 y 2005). En la nota del Artículo $\mathrm{N}^{\circ} 1$ se señalan las características de la Sociedad de la Información consideradas en las CMSI (2003, 2005) que reconocen a la educación, el conocimiento, la información y la comunicación como principios fundamentales para "(...) el progreso, la iniciativa y el bienestar de los seres humanos" (Ley de Servicios de Comunicación Audiovisual 26.255: 2). Asimismo, la Ley retoma las afirmaciones sobre el papel de las tecnologías como instrumentos para “(...) acrecentar la productividad, generar crecimiento económico, crear empleos y posibilidades de contratación, así como mejorar la calidad de vida de todos” (Ídem).

En este marco, encontramos una línea argumental ligada al discurso de los países centrales que vinculan a las nuevas tecnologías de la información y la comunicación a una serie de transformaciones sociales, económicas, políticas y culturales que permiten hablar de una Sociedad de la Información cuantitativa y cualitativamente distinta a la conocida hasta su aparición. Estas tecnologías tienen un fuerte impacto en la producción de bienes y servicios, en especial, en nuevas formas de relaciones sociales. Pero, fundamentalmente, estas tecnologías se piensan como herramientas sustantivas para achicar la brecha digital (entre inforicos e infopobres) en la que no se señalan sus causas, sino que se plantean sus consecuencias, tornándose una situación naturalizada sobre la cual resta operar acciones puntuales para su superación. En este aspecto, la norma asume las recomendaciones de las CMSI que alientan a los gobiernos, además de los organismos multilaterales y donantes públicos bilaterales, a invertir en infraestructura en tecnologías y a generar políticas públicas en vistas a lograr una Sociedad de la Información integradora. Consecuentemente, la Ley toma el discurso dominante de la Sociedad de la Información donde la aparición de las tecnologías, el desigual acceso a tecnologías 
digitales, sus innovaciones y consecuencias son vistos como productos inevitables de un nuevo modelo de sociedad.

Asimismo, el Plan Nacional de Telecomunicaciones "Argentina Conectada" (Decreto 1552/2010: 1), en sus considerandos, argumenta que:

“(...) la generación, procesamiento y transmisión de información se ha vuelto un factor determinante en el funcionamiento de las sociedades y el acceso a las tecnologías de la información y comunicación, una fuente de crecimiento y desarrollo".

En esa línea, también se enuncia el rol del Estado que en este caso tiene la función de definir estrategias que colaboren con la producción de tecnologías para fortalecer la infraestructura y los servicios de telecomunicaciones en todo el país.

Que el Servicio Universal es el conjunto de servicios y programas, variables en el tiempo, definidos por el Estado Nacional, destinados a la población en general con una determinada calidad y a precios accesibles, a los que se deberá tener acceso con independencia de su localización geográfica y sus condiciones sociales, económicas y las referidas a impedimentos físicos; encontrándose comprendidos todos los servicios de telecomunicaciones sin importar la tecnología. (Decreto 1552/2010: 2)

El desarrollo del sector de telecomunicaciones es clave para alcanzar los principios básicos del "Programa Nacional para la Sociedad de la Información".

El documento Planificación Estratégica de "Argentina Conectada" (2010) se sustenta en uno de los pilares expresados en la Cumbre Mundial de la Sociedad de la Información (CMSI): el fortalecimiento de la infraestructura de telecomunicaciones que "deviene" en “(...) la ampliación en el ejercicio de los derechos de todos los ciudadanos; al incrementar las oportunidades de acceso a la información, educación, servicios de salud, comercio y entretenimiento" (CMSI, 2003: 13). En esta dirección, en el documento se argumenta que la ampliación de infraestructura en telecomunicaciones está directamente relacionada con el desarrollo económico-productivo del país y que es el Estado -junto al sector privado más la sociedad civil-, el que debe generar políticas proactivas en ese sentido. 


\subsubsection{Las brechas y las tecnologías digitales}

Uno de los rasgos de la Sociedad de la Información en los que coinciden defensores y detractores es la existencia de la brecha de acceso a las tecnologías tanto entre países como hacia el interior de estos. La Ley $\mathrm{N}^{\circ}$ 26.255, retomando las declaraciones de las CMSI, señala la necesidad de la reducción o eliminación de la brecha producida por el desigual acceso a las tecnologías en la nota del Artículo $\mathrm{N}^{\circ} 1$ :

“(...) Estamos plenamente comprometidos a hacer de esta brecha digital una oportunidad digital para todos, especialmente aquellos que corren peligro de quedar rezagados y aún más marginalizados. (Declaración Cumbre Mundial de la Sociedad de la Información - CMSI- Ginebra 2003)". (Ley de Servicios de Comunicación Audiovisual 26.255, 2009: 2)

A la vez, en la nota de los Artículos 2 y 3: "Se agregan aspectos relacionados con expresiones de la Cumbre de la Sociedad de la Información en orden a la eliminación de la llamada brecha digital entre ricos y pobres" (Ibídem: 6).

Los documentos operativos del SATVD-T guardan correspondencia formal con los objetivos de la Ley $\mathrm{N}^{\circ} 26.255$ (Artículo 3), es decir, no explicitan o explican el modo en que esta estrategia de implementación de la televisión digital terrestre colabora con la disminución de la brecha digital más allá de la provisión y distribución de dispositivos técnicos (receptores digitales) e instalación de antenas transmisoras.

El Decreto 1552/2010 afirma que:

“(...) el fuerte crecimiento en el acceso a las Tecnologías de la Información y Comunicación, se plantea la necesidad de profundizar y complementar las políticas públicas orientadas a reducir la brecha digital, generando acciones para lograr la inclusión digital de distintos grupos poblacionales". (Decreto 1552/2010: 3)

Asimismo, la Planificación Estratégica del Plan Nacional de Telecomunicaciones plantea que:

"Los objetivos generales del presente documento son establecer los lineamientos generales, definir los ejes estratégicos de gestión y las principales líneas de acción (...) orientadas a promover el despliegue de infraestructura y el desarrollo de contenidos para masificar la adopción de las nuevas tecnologías de información y comunicación en todo el territorio nacional”. (“Argentina Conectada", 2010: 15)

En este documento, aparecen menciones sobre la relación entre la brecha digital y otro tipo de brechas tales como las económicas, sociales o culturales como la siguiente: 
"No hay duda que la brecha digital mayormente refleja la persistencia de las brechas socioeconómicas que caracterizan a las naciones, y en especial a las de América Latina, desde hace varios siglos. No obstante, y más allá de los objetivos naturales de justicia social, existen diversos factores que justifican la acción estatal orientada a reducir la brecha digital". (“Argentina Conectada", 2010: 18)

Las consecuencias del modelo de desarrollo sobre las sociedades latinoamericanas que producen diferentes tipos de brechas aparecen aludidas en el texto pero sigue primando una perspectiva que pone de relevancia la potencialidad de las tecnologías digitales como el factor necesario para disminuir las desigualdades e incluir a las personas y/o grupos en la sociedad digital.

Tanto en el Decreto 1552/2010 como en la Planificación Estratégica del Plan Nacional de Telecomunicaciones, las referencias a la reducción de la brecha digital están asociadas al desarrollo de infraestructura de telecomunicaciones y constituyen un eje central de la política pública de inclusión digital. También aparece alguna mención a la competencia del Estado en pos de acortar la brecha digital a partir de la promoción del uso de tecnologías.

"El acceso al conocimiento y a los servicios convergentes de comunicación constituye un derecho fundamental de los ciudadanos, y por lo tanto compete al Estado asegurarlo mediante instrumentos de política pública orientados a intensificar el uso y reducir desigualdades en la apropiación de las nuevas tecnologías de la información y comunicación." (“Argentina Conectada", 2010: 17)

Retomando las categorías de análisis que hemos identificado para revisar los documentos que integran la política pública de televisión digital, notamos que las menciones que se realizan sobre la brecha digital se encuentran enmarcadas en los discursos que sostienen el rol incuestionable de la tecnología en el cambio social y donde se simplifica la idea de la/s brecha/s como un elemental problema de acceso o disposición de infraestructura. Si acudimos a algunas de las clasificaciones del tipo de brecha digital, podemos señalar que en estos documentos se alude, en mayor medida, a la denominada "brecha de acceso" (Stillo, 2012: 15-16), en tanto priorizan la provisión de infraestructura mientras que, en menor medida, apenas consideran la "brecha de uso" que supone el desconocimiento, por parte de la población que tiene acceso, a la potencialidad de las tecnologías.

En este caso, la formulación y por tanto la implementación de la política pública centrada en la infraestructura tecnológica desdibuja e invisibiliza los procesos y condiciones económicas, sociales y culturales por los cuales una parte de la población mundial queda 
"excluida" de la Sociedad de la Información. A la vez que ubica el problema en el acceso material, sosteniendo el discurso de la neutralidad de la tecnología que supone que las personas y las organizaciones son libres de elegir las tecnologías que crean más adecuadas a sus necesidades sin ningún tipo de condicionamiento. Es decir, esta idea se basa en lo que en el apartado 4.1 del capítulo IV hemos referido como "determinismo tecnológico": las tecnologías provocan cambios sociales, culturales, políticos y económicos, o sea, los cambios en las tecnologías producen cambios en la sociedad sin mediaciones, sin matices.

\subsubsection{El acceso universal a las tecnologías}

La preocupación por la brecha implica el problema del acceso a los bienes y servicios infocomunicacionales por parte de las personas. Por lo tanto, el acceso no refiere solamente a las tecnologías digitales sino también a aquellas denominadas "analógicas o tradicionales" como los servicios de radiodifusión y la comunicación audiovisual.

En el cuerpo de la Ley $\mathrm{N}^{\circ} 26.255$ se hacen menciones a la necesidad de promover marcos jurídicos, políticas y estrategias orientados a garantizar el acceso a las tecnologías tanto analógicas como digitales. En ese sentido, entre los puntos del plan de acción de las CMSI, se retoma la propuesta de: "f) Proporcionar contenido pertinente para las culturas y los idiomas de las personas en la Sociedad de la Información, mediante el acceso a servicios de comunicación tradicionales y digitales". También considera los principios y temas prioritarios en el marco de la Sociedad de la Información que manifiestan la

“(...) necesidad de generar igualdad de oportunidades en el acceso y uso de las tecnologías de la información y comunicación, se comprometen a desarrollar acciones tendientes a superar la brecha digital, la cual refleja e incide en las diferencias económicas, sociales, culturales, educacionales, de salud y de acceso al conocimiento, entre los países y dentro de ellos". (Ley de Servicios de Comunicación Audiovisual 26.255, 2009: 8).

Asimismo, en el Artículo $\mathrm{N}^{\circ} 3$ alude al acceso como uno de los objetivos de los servicios de comunicación audiovisual: “e) La construcción de una Sociedad de la Información y el conocimiento, que priorice la alfabetización mediática y la eliminación de las brechas en el acceso al conocimiento y las nuevas tecnologías". (Ibídem: 5)

Acerca de la universalidad en el acceso a los servicios de comunicación audiovisual la referencia se encuentra en el Artículo $\mathrm{N}^{\circ} 2$ : 
"El objeto primordial de la actividad brindada por los servicios regulados en la presente es la promoción de la diversidad y la universalidad en el acceso y la participación, implicando ello igualdad de oportunidades de todos los habitantes de la Nación para acceder a los beneficios de su prestación. En particular, importa la satisfacción de las necesidades de información y comunicación social de las comunidades en que los medios estén instalados y alcanzan en su área de cobertura o prestación". (Ídem)

En "Argentina Conectada" y su documento de Planificación, el acceso universal a las tecnologías es el punto central en el que se apoya el Plan Nacional. En este marco, uno de sus ejes estratégicos como el desarrollo del servicio universal, de la infraestructura y la conectividad se orientan a fortalecer la inclusión digital de aquellos sectores sociales excluidos.

En estos documentos se afirma que la política pública digital debe asegurar el acceso a las tecnologías con el fin de democratizar el conocimiento. La idea de acceso incluye: acceso personal a través de la infraestructura y conectividad residencial y acceso público en los Núcleos de Acceso al Conocimiento (NAC) ${ }^{154}$. Consecuentemente, el desarrollo de la infraestructura y conectividad a partir del impulso de la política pública tiene beneficios en la producción de hardware y software nacional y regional.

En estos documentos y en otros incluidos en la política pública digital, el acceso es entendido como la disponibilidad material de tecnologías digitales y conectividad asegurada por parte de las personas en sus hogares y en espacios públicos. Es decir, la noción de acceso está centrada en el desarrollo y distribución de infraestructura y servicios tecnológicos entre la población del país.

\subsubsection{La televisión digital para la inclusión digital}

El proceso de digitalización de la televisión ocupa los Artículos $\mathrm{N}^{\circ} 92$ y $\mathrm{N}^{\circ} 93^{155}$ de la Ley de Servicios de Comunicación Audiovisual y enmarca la transición de los servicios

\footnotetext{
154 “(...) definidos como espacios comunitarios que permitirán, entre otros usos, brindar a los asistentes acceso a tecnologías de la información y comunicaciones (TIC), capacitación y entretenimiento y así propiciar un espacio a través del encuentro comunitario como instrumento de desarrollo humano, por su carácter transversal como herramienta de acceso a la educación, salud, cultura, bienestar, empleo, y asimismo estimular el aprendizaje mediante herramientas lúdicas y de esparcimiento" (Planificación Estratégica del Plan Nacional de Telecomunicaciones "Argentina Conectada", 2010: 62).

${ }^{155}$ En el capítulo III "Nuevas Tecnologías y Servicios” de la Ley 26.255/09, se alude a la televisión digital en dos artículos (92 y 93) y una nota aclaratoria.
} 
digitales que, entre otras pautas, propone garantizar el acceso universal a las nuevas tecnologías y la participación ciudadana:

"A fin de garantizar la participación ciudadana, la universalización del acceso a nuevas tecnologías y la satisfacción de los objetivos previstos en la presente ley, previo a cualquier toma de decisión se deberán cumplir con la sustanciación de un procedimiento de elaboración participativa de normas y otro de audiencias públicas, de acuerdo a las normas y principios pertinentes". (Ley de Servicios de Comunicación Audiovisual 26.255, 2009: 58)

Sin embargo, expertos en Economía Política de la Comunicación advierten que:

“(...) en el mismo momento que es creada la Ley SCA se convierte en obsoleta porque no se ajusta al impacto del escenario digital. No establece delineamientos precisos sobre el movimiento de los viejos y nuevos actores y los servicios convergentes. Aunque es menester aclarar que la Ley 26.522 es democrática y perfectible, un paso hacia adelante respecto de la antigua Ley de Radiodifusión, que aún tiene resistencias para su reglamentación, representadas por actores que se amparan en la seguridad jurídica y libertad de expresión tras el velo del gran negocio en que se han transformado los medios de comunicación en las últimas décadas". (Rodríguez Miranda, 2010: 98)

El Plan Nacional "Argentina Conectada" incluye y complementa el diseño e implementación de la Televisión Digital Abierta cuyo objetivo es alcanzar a toda la población argentina, reduciendo la brecha digital e incluyendo a todos los grupos sociales con riesgos de exclusión tanto en el aspecto de infraestructura (antenas y receptores digitales) como en el de producción de contenidos educativos, culturales y científicos (Programa Polos Audiovisuales). Entonces, a través del desarrollo de la infraestructura tecnológica y la garantía de acceso universal a diferentes dispositivos digitales (computadoras, telefonía móvil, televisión digital, etc.) sostiene que se logra el fortalecimiento de la inclusión digital para todos los habitantes del territorio argentino. En particular, argumenta que ligado a la coordinación de la provisión de infraestructura, servicios y contenidos se debe impulsar “(...) el desarrollo de capacidades de adopción por parte de potenciales usuarios" (Argentina Conectada, 2010: 18-19). En este sentido, para lograr la inclusión digital se requiere avanzar en el desarrollo de los servicios de telecomunicaciones digitales para tender a la eliminación de las disparidades geográficas, pero básicamente las desigualdades sociales y la falta de oportunidades para todos los ciudadanos.

Finalmente, nos detenemos aquí para referirnos al modo en que en estos textos aluden a la necesidad de incluir a los sectores en "riesgo de exclusión digital". 
En "Argentina Conectada", tras la iniciativa de la televisión digital terrestre (TDA), refiere a aquellos grupos sociales que no se encuentran incluidos digitalmente del siguiente modo:

"Los avances en materia de políticas de inclusión digital colocan a la Argentina como pionera en el desarrollo de políticas de masificación de servicios tecnológicos. El caso saliente a nivel mundial, lo constituye el proyecto de Televisión Digital Abierta, el cual ha contemplado un programa de acceso gratuito a los sintonizadores digitales para todos los individuos e instituciones públicas que presentan riesgos de exclusión en el proceso de transición tecnológica". ("Argentina Conectada", 2010: 39)

"El Plan Operativo de Acceso 'Mi TV Digital' tiene como meta desarrollar las acciones que resulten necesarias a fin de procurar el acceso al equipo sintonizador de la Televisión Digital Terrestre, sin costo, para aquellos ciudadanos e instituciones que presentan riesgos de exclusión durante el proceso de transición tecnológica." (Ibídem: 70)

En los dos tramos del documento que presentamos más arriba se pueden identificar las características de los beneficiarios designados como criterio de selección de la política pública de inclusión digital.

En este sentido, la definición de los destinatarios presenta rasgos emparentados con la noción de la exclusión digital que reseñamos en el capítulo IV. Decíamos que la idea de exclusión digital se vincula con las limitaciones (de acceso, de usos, sociales, culturales) que pueden tener o percibir personas, grupos, países, regiones para aprovechar, integrar o neutralizar las tecnologías digitales. En este caso, si bien no avanzan explícitamente en el planteamiento de qué se entiende por "riesgo de exclusión" presumimos que se trata de que esas personas o grupos sociales no cuentan con las condiciones y capacidades necesarias para acceder, usar y aprovechar los beneficios que brindan las tecnologías digitales.

En palabras del Lic. Nemirovsci, la TDA priorizó a los sectores marginados tanto en lo geográfico, social y económico: jubilados con haberes mínimos, poblaciones alejadas de los centros urbanos, escuelas rurales, pueblos originarios. Hacia ellos, afirma, se volcaron los esfuerzos para que tuvieran acceso a una televisión con calidad de imagen y mejores contenidos. 


\subsection{Conclusiones del capítulo}

A partir de los anteriores análisis, revisamos el conjunto documental de la TDA para identificar las referencias sobre las tecnologías digitales y, en particular, la televisión digital.

En líneas generales, la Planificación Estratégica para la implementación del SATVD-T (vigencia 2009-2019), aprobada por el Consejo Asesor, define estrategias y acciones para desarrollar la ejecución del sistema de televisión digital terrestre y la realización del Plan Nacional de Servicios de Comunicación Audiovisual Digital del art. 93 de la Ley 26.255/09. El documento se divide en dos capítulos: el primero, dedicado a presentar el marco general, objetivos, glosario y contexto estratégico; y el segundo, destinado a la organización estratégica, definición de los ejes y acciones para el desarrollo del sistema de la televisión digital en el territorio nacional.

En el marco general, sitúa el punto de partida en los objetivos de la Ley 26.255/09 y en el Decreto 1.1487/2009, las obligaciones de los tratados incorporados y a ser integrados en la Constitución Nacional además de aquellos dispuestos por autoridades y organismos creados para tal fin. El contexto estratégico presenta la situación de los procesos de digitalización a partir de la transición de la televisión analógica a la digital. En el capítulo II, define la política general que se desagrega en seis ejes estratégicos que van desde la transmisión hasta las normas y derecho digital. ${ }^{156}$

En principio, encontramos referencias explícitas a la necesidad de incluir “(...) a todos los habitantes de la Nación a las nuevas tecnologías de la Sociedad de la Información (...)" (Planificación Estratégica para la implementación del SATVD-T, vigencia 20092019: 3), observando los fundamentos establecidos en el art. 3 de la Ley 26.255/09.

Las referencias a la Sociedad de la Información presentes en este documento se muestran alineadas en la idea de que la expansión de las tecnologías digitales (infraestructura, industria, producción de contenidos, etc.) asegura el acceso de la sociedad "(...) a la información y a los servicios que actualmente existen en el mundo vinculados a las telecomunicaciones". (Ibídem: 14)

${ }^{156} \mathrm{El}$ desarrollo de los ejes estratégicos se puede consultar en las páginas 12 y 13, y 19 a 22 del documento analizado. 
Asimismo, plantea garantizar el acceso universal a las TIC para promover la inclusión social y diversidad cultural, la democratización de la información, fortalecer la industria cultural y promoción del empleo, el desarrollo científico-tecnológico y la protección de derechos y libertades de los ciudadanos. Al momento de detallar los ejes estratégicos, advertimos que se pone el énfasis en el acceso al equipamiento para la recepción de la televisión digital como medio para alcanzar la Sociedad de la Información (particularmente, se puede consultar en el Eje 3: 20).

En general, los principios generales de la planificación estratégica establecen la promoción de accesibilidad universal a las tecnologías digitales, señalando ventajas tales como el estímulo de la industria nacional de producción de contenidos, la generación de empleo y el desarrollo más la formación de capital humano en la materia.

El Reglamento General del Plan Operativo de Acceso al Equipamiento para la Recepción de la Televisión Digital Abierta "Mi TV Digital" (de la Planificación Estratégica del Sistema Argentino de Televisión Digital Terrestre) establece lineamientos generales para garantizar la implementación del sistema de recepción nacional de televisión digital terrestre, es decir, la distribución de los equipos receptores digitales. Detalla los objetivos del plan de acceso y toda la operatoria que comprende los sujetos intervinientes y sus responsabilidades, las unidades de planeamiento y coordinación de la plataforma de la televisión digital, los beneficiarios directos e indirectos, los modos de acceso al beneficio, metodología para el seguimiento y control del plan de acceso, entre otras acciones. ${ }^{157}$

Este documento también dispone las acciones para facilitar la universalización del beneficio a través del cual se integran a “(...) aquellos grupos sociales que presentan riesgos de exclusión de transición tecnológica de la televisión analógica a la televisión digital" (Reglamento General del Plan Operativo de Acceso al Equipamiento para la Recepción de la Televisión Digital Abierta "Mi TV Digital": 3). Estos son definidos en función de su rol social y grado de vulnerabilidad en el proceso de transición tecnológica: establecimientos estatales (cuya finalidad o función sea el desarrollo de actividades educativas, culturales, sociales, etc.), organizaciones sociales y hogares en situación socioeconómica vulnerable, según lo que estipula dicho reglamento.

El Manual Operativo para la Implementación del Plan de Acceso a la Televisión Digital Abierta Satelital "Mi TV Digital Satelital” especifica la modalidad de acceso al

\footnotetext{
157 Todos estos puntos se encuentran desarrollados exhaustivamente en el documento.
} 
equipamiento de recepción televisión digital satelital (TDS). Este manual define las acciones tendientes a ofrecer TDS en aquellas zonas del país que por condiciones geográficas o baja densidad poblacional no se encuentren alcanzadas por la TDT.

Al igual que en el Reglamento General Operativo de Acceso al Equipamiento para la Recepción de la Televisión Digital Abierta "Mi TV Digital” se detallan las acciones precisando los actores intervinientes y los mecanismos de articulación y coordinación para el desarrollo del sistema de televisión satelital.

Todos los documentos analizados dan cuenta de que la política pública de SATVD-T tiene entre sus objetivos alcanzar todo el territorio nacional con un servicio de calidad de contenidos gratuitos, a través de la distribución de decodificadores a beneficiarios de planes sociales, organizaciones sociales y a jubilados. En este sentido, se plantea que la televisión digital viene a saldar una deuda con los grupos más vulnerables de la sociedad para que puedan acceder y apropiarse de las tecnologías digitales a fin de eliminar la brecha digital existente.

Decíamos en el capítulo I que en el mundo la problematización de la brecha digital se fue desarrollando en las postrimerías del siglo XX junto a la expansión de las tecnologías digitales. Las primeras discusiones “(...) caracterizan la brecha digital como la consecuencia de un solo factor: el acceso. Esta definición resultó útil en su tiempo, porque abrió el debate sobre el tema, pero en la actualidad, nos resulta insuficiente" (Castellón y Jaramillo, 2002). De ahí, que la problemática del acceso aparece atada a índices de posesión y uso de aparatos y aplicaciones tecnológicas. En esta dirección, Géliga Vargas (2006) explica que el acceso y, por ende la brecha, fueron vinculados discursivamente a la "nueva economía" que "con el impulso del llamado Bangemann Report en 1994 y de la cumbre del G7 el año siguiente, cedía el timón de la Sociedad de la Información al sector privado y los designios del 'libre' mercado global” (Géliga Vargas, 2006: 48). Por ende, para reducir la brecha se planteó que era necesario el desarrollo de infraestructura (líneas telefónicas, inversiones en telecomunicaciones, dotación de PC y conexión a internet).

La definición de brecha digital concebida como desigualdad y distancia en el acceso a las tecnologías permeó los fundamentos de las políticas públicas de los países latinoamericanos que lanzaron diferentes iniciativas para modernizar la infraestructura y asegurar el acceso a las tecnologías por parte de los ciudadanos. Esta lectura dominante 
se complementó con la retórica del subdesarrollo avalada por el discurso oficial de organismos internacionales. En 1992, CEPAL y UNESCO difundieron un documento que sostenía que para generar procesos de desarrollo resultaba imprescindible progresar en el campo científico-tecnológico. En 1996, en "La educación encierra un tesoro" de UNESCO se listaban los retos del ámbito educativo frente a las nuevas tecnologías así como, en 1999, el PNUD (Programa de las Naciones Unidas para el Desarrollo), en su Informe anual realiza un diagnóstico sobre la influencia e impacto de las tecnologías en el proceso de mundialización. En ese contexto, las tecnologías son calificadas a partir de sus potencialidades para alcanzar mejores niveles de Desarrollo Humano, o sea, son conceptualizadas como los motores del desarrollo para ampliar la inclusión de los sectores de la población mundial que se encuentran excluidos.

Entrado el siglo XXI, en torno a la problematización de la brecha digital en el marco de la globalización se fue surgiendo un discurso que justificaba y promovía el consumo de productos y servicios de las industrias culturales. Como hemos referido en otros capítulos de esta tesis, este discurso es el de la "inclusión digital" que interpela al ámbito público y privado a impulsar el desarrollo social, económico y cultural a través de la administración, expansión y oferta de infraestructura, dispositivos, servicios y contenidos digitales en cada uno de los países y en las diferentes regiones. En el caso de los Estados nos referimos al conjunto de políticas públicas de inclusión digital, cuyos propósitos pretenden incluir económica y socialmente a los sectores o países pobres a un mercado global que ofrece la democratización de los procesos sociales, políticos, económicos y culturales.

En esta línea se monta el discurso oficial de la TDA que sitúa toda la confianza en que la distribución y provisión de decodificadores digitales, entre los grupos sociales más vulnerables, logrará no sólo la denominada “inclusión digital” sino que éstos podrán apropiarse de las tecnologías digitales e interactivas, dándoles sentido en sus contextos cotidianos. En este esquema, el usuario de televisión digital sería visto como un sujeto hábil que podrá realizar acciones distintas a las que viene realizando hasta ahora con la televisión analógica o tradicional.

Iniciamos nuestro análisis a partir de la consideración de algunas de las diversas formas que adquieren las representaciones sociales sobre las tecnologías digitales, en particular, sobre la televisión digital. El discurso oficial brinda una serie de informaciones y conocimiento sobre las nuevas tecnologías y sus posibilidades para la vida de las personas. Estos conocimientos parciales, múltiples, y muchas veces contradictorios, están 
en la base de los usos posibles y efectivos que se plantean entre los usuarios de estas tecnologías digitales.

La revisión de los diferentes documentos de la política pública de integración digital permite dar cuenta de que la enunciación sobre la Sociedad de la Información se construye a partir de un grupo de discursos que describen un tipo nuevo de organización social producto de la acción de las tecnologías digitales. Explicitan que el cambio hacia una sociedad distinta se produce a partir de la difusión de dichas tecnologías en relación también con los medios de comunicación. Y los términos en los que definen ese cambio son predominantemente cuantitativos: crecimiento económico, promotor del desarrollo, incremento del acceso a tecnologías, etc. aunque se presenten vagas alusiones a la ampliación de derechos de los ciudadanos como consecuencia directa del nuevo tipo de organización social. Fundamentalmente, el eje de las transformaciones que producen las tecnologías digitales está puesto en el mandato de generar infraestructura suficiente para garantizar el acceso, obturar la/s brecha/s digitales y alcanzar la inclusión digital de aquellos grupos sociales excluidos.

El discurso institucional define una serie de rasgos que marcan ciertas características que conforman representaciones sociales sobre el lugar que las tecnologías digitales, en particular, la televisión digital, ocupan o deberían ocupar en la sociedad.

En primera instancia se puede señalar el predominio de una concepción instrumental de estas tecnologías. Esta postura hace que las transformaciones que se generan a partir de la difusión de las tecnologías digitales son vistas como productos inevitables, como agentes difusores neutrales con capacidad para transmitir y multiplicar la información pero, por sobre todo: como herramientas para achicar la brecha digital entre quienes poseen dispositivos digitales y quienes no los poseen.

Otra característica recurrente de este discurso institucional está relacionada con el modo en que se alude a la apropiación de estas tecnologías y el rol que se le otorga al usuario.

Se lo ubica en un lado de la brecha digital: en el lugar donde no puede acceder, no sabe usar, no aprovecha las tecnologías en general y, en particular, la TDT. Y, por otra parte, en el caso en que el destinatario de la política pública disponga de las tecnologías digitales, se le atribuye un lugar central en el que se prevé que -a través de las mismas y en este caso la televisión digital- pueda mejorar su calidad de vida y alcance la equidad en el acceso a la información y al conocimiento. 
Entendemos que estos rasgos definitorios actúan como condicionantes, tanto de las representaciones como de los usos que realizan los usuarios de tecnologías digitales en sus contextos cotidianos. 


\section{Capítulo VII}

\section{Usos y expectativas sobre la TDA en el Partido de José C. Paz para la inclusión digital}

En varias ocasiones a lo largo de esta tesis, hemos explicitado que nos interesa indagar los alcances en términos de inclusión digital que consigue la política pública TDA entre los sectores sociales identificados como "en riesgo de exclusión" dentro de nuestras sociedades. Con ese propósito avanzamos en este capítulo con la indagación sobre las relaciones entre los usos, las prácticas asociadas a la TDA y los procesos de inclusión digital a partir de los discursos más los vínculos que los usuarios establecen con la televisión digital en una zona del periurbano bonaerense.

Como hemos señalado en el capítulo IV de esta tesis, para abordar los usos, las prácticas y el problema de la inclusión digital decidimos recuperar categorías conceptuales provenientes de la perspectiva de los Estudios de la Cultura y la Comunicación para focalizar en las manifestaciones y tensiones producidas por las vinculaciones de los sujetos con las tecnologías digitales en contextos de transición.

A continuación, presentamos nuestras observaciones sobre las entrevistas cualitativas realizadas a beneficiarios del Plan "Mi Tv Digital” en el partido de José C. Paz. Para ordenar la exposición hemos decidido organizar los resultados de la indagación en dos partes.

La primera parte denominada: “Acceso, usos y expectativas sobre la televisión digital en transición”, enfocada en un análisis descriptivo, explora la disponibilidad, los tipos de usos y las perspectivas que genera la integración de la TDA a la vida cotidiana entre los usuarios. Estos apartados se plantean registrar las modalidades que adquirió la obtención del beneficio, usos y consumos de la televisión digital según la voz de los entrevistados. La segunda parte: "La TDA en el territorio: la televisión digital llega a casa” sondea los sentidos atribuidos y las prácticas que le asignan los entrevistados a la televisión digital en sus contextos cotidianos con vistas a una participación en el entorno digital.

Se trata de conocer y comprender las significaciones que le otorgan los entrevistados a la televisión digital como uno de los dispositivos para alcanzar la inclusión digital. En este sentido, se focaliza en la propuesta analítica que hemos desarrollado en nuestro abordaje teórico sobre la inclusión digital cuyas dimensiones son: acceso, uso, 
autoafirmación y participación. Por último, se presentan las consideraciones finales producto del proceso analítico de las entrevistas realizadas en el trabajo de campo.

\section{Parte I. Acceso, usos y expectativas sobre la televisión digital en transición}

\subsection{Disponibilidad y acceso de la TDA en José C. Paz}

\subsubsection{Los modos de acceso previstos por el Plan "Mi TV Digital"}

El Plan Operativo de Acceso al equipamiento para la recepción de la Televisión Digital Abierta se ejecutó, desde sus inicios, en varias etapas, a cargo del Consejo Asesor del SADTV-T en la órbita del Ministerio de Planificación Federal, Inversión Pública y Servicios. Los objetivos generales de este plan se centran en la universalización del beneficio y la integración de los grupos sociales en riesgo de exclusión en el proceso de transición digital.

Como señalamos en el capítulo II de esta tesis, la distribución de receptores digitales entre la población objetivo comenzó en el año 2010 en la zona metropolitana de Buenos Aires con diferentes modalidades: la realización de eventos especiales u "operativos de entrega" de decodificadores o receptores digitales en territorio, en Tecnópolis ${ }^{158}$, en los establecimientos escolares del país y a través de la solicitud de los beneficiarios vía Correo Argentino o Correo Andreani S.A. A la vez, y a partir de la presentación del Plan Nacional de Telecomunicación Argentina Conectada y el despliegue de la TDA ${ }^{159}$, comenzó una campaña institucional ${ }^{160}$ en diferentes medios de comunicación (TV abierta y de pago, radio, internet) que difundía el lanzamiento del Plan "Mi TV Digital", explicaba quiénes y el modo en que podían acceder al beneficio, cuáles eras las ventajas del plan, cómo se instalaba el decodificador, etc.

La distribución por medio de los operativos en territorio se realizó a partir de la articulación - mediante la firma de convenios específicos - del Consejo Asesor con

\footnotetext{
158 Tecnópolis es una gran muestra de ciencia, tecnología, industria y arte, con sede en Argentina, y según la gestión kirchnerista, la más grande de América latina, que se realizó de julio a noviembre de cada año a partir del 2011y hasta 2015.

${ }^{159}$ El Plan Nacional TDA fue presentado por la Presidenta Cristina Fernández el día 18 de octubre de 2010. (disponible en: https://www.youtube.com/watch?v_PBzbrswOcgg)

${ }^{160}$ Los diferentes spots de difusión se encuentran disponibles en el canal de YouTube: Prensa TDA.
} 
organismos públicos provinciales, municipales y organizaciones sociales de los distritos o partidos en el AMBA. Según información obtenida en el sitio web de la TDA, en medios de circulación nacional y en algunos periódicos digitales de la zona: en el Partido de José C. Paz se entregaron unos 1.300 kit de instalación de TDA. En cambio, en la sede de Tecnópolis la entrega de receptores digitales se realizó por medio de la Unidad Móvil de Inclusión Digital (UMID) durante el período de apertura al público: de julio a noviembre de cada año desde 2011 hasta la última edición de 2015. Como indicamos en el capítulo $\mathrm{V}$, no pudimos obtener datos precisos sobre la distribución debido a la inexistencia de estadísticas oficiales tanto de los operativos en territorio como en Tecnópolis.

Cada entrega se formalizaba a través del llenado de un formulario específico ${ }^{161}$ que se complementaba con documentación respaldatoria (fotocopia de DNI del solicitante, copias de resolución de otorgamiento de personería jurídica, de comprobante de cobro de haberes, de certificado de discapacidad, de comprobante del último cobro de Plan o Programa Social y/o Vivienda, de tarjeta de Asignación Universal por Hijo). Las solicitudes se rellenaban en el sitio web del Consejo Asesor; en instituciones públicas y/u organizaciones sociales que adhirieran al Plan o en los eventos especiales organizados por autoridades nacionales y/o locales para tal fin.

Dado que hemos focalizado nuestra investigación entre los años 2014-2015, en primer lugar, nos interesó conocer el modo en que nuestros entrevistados se enteraron y accedieron al Plan de acceso "Mi TV Digital".

Desde octubre de 2009 la TDA se encontraba disponible, pero fue en el transcurso del año 2010 que comenzó la distribución de los decodificadores digitales en los hogares tanto en la zona metropolitana de Buenos Aires como en el resto del país. La entrega de los decodificadores digitales fue acompañada, como mencionamos anteriormente, con la difusión a través de los medios de comunicación gráficos y audiovisuales sobre el Plan y el modo de acceder al beneficio.

${ }^{161}$ El formulario de solicitud de Establecimientos Estatales y Organizaciones Sociales y otro para Hogares para la TV Digital Terrestre se puede consultar en Anexo 1. 


\subsubsection{Cómo accedieron los entrevistados a la TDA}

En el apartado 2.4 del capítulo II presentamos la definición de los destinatarios tal como expresa el Plan "Mi TV Digital" como aquellos sectores de la población con "riesgos de exclusión digital": titulares de pensiones no contributivas; jubilados; hogares en situación socioeconómica vulnerable que no se encuentren contemplados en las demás categorías; beneficiarios de AUH y planes sociales; establecimientos estatales y las organizaciones sociales. En nuestro caso, del conjunto de entrevistados presentamos una mayor proporción de pensionados y jubilados, en menor medida, un conjunto de familiares de pensionados y jubilados y otro grupo conformado por integrantes de la organización social: Mutual Primavera del Partido de José C. Paz.

Una de las situaciones que encontramos en el momento de contactar a los potenciales entrevistados fue que algunos de ellos manifestaron que tenían instalada la TDA porque sus padres o abuelos jubilados decidieron cederles los decodificadores digitales y antenas debido a que adquirieron un televisor LED con TDA incorporado mediante el Plan "TV Para Todos"162 o adujeron que encontraban dificultades a la hora de utilizar la televisión digital debido a que dejó de funcionar el decodificador digital. Pese a que entre las responsabilidades del beneficiario se encuentra "no transferir el decodificador digital parcial o totalmente" resolvimos, tal como manifestamos en el apartado 5.1.2 del capítulo $\mathrm{V}$, continuar con la indagación cualitativa dado que los entrevistados residían en la misma unidad habitacional y compartían el ámbito cotidiano. Es decir, se trataba de hijos que convivían con sus padres o nietos que vivían junto a sus abuelos.

Por lo tanto, nuestras unidades de análisis fueron las siguientes

- Un conjunto de jubilados y/o pensionados: mayor grupo alcanzado por la política pública: "Mi TV Digital".

- Otro conjunto de familiares de jubilados y/o pensionados: aquellos que recibieron los decodificadores digitales de sus padres y/o abuelos pensionados y/o jubilados debido a que adquirieron televisores LED con TDA incorporado.

\footnotetext{
${ }^{162}$ El Plan "TV Para Todos", que se puso en marcha en el mes de julio de 2011, tuvo por objetivo renovar el parque de televisores que facilitó la compra de un LCD de 32 pulgadas Full HD (alta definición), apto para TDA, a un precio bajo en las cadenas comerciales de electrodomésticos del país. Entre los beneficios se encontraba no sólo que el dispositivo permitía el acceso a la TDA sino que también se podía adquirir mediante una financiación del Banco Nación (una línea de créditos que ofrecía planes hasta 60 cuotas).
} 
Por mi abuelo que es jubilado. Por mi abuelo. (Fátima, 35 años, José C. Paz Centro)

Mira, por intermedio de mi suegro, él es jubilado, mis suegros son jubilados, y bueno, le habían dado el tema de la antena y todo eso. El gobierno viste, primeramente lo de la televisión, lo había dicho la presidenta. (Paula, 44 años, José C. Paz Centro,)

La antena la recibí mediante mi abuelo, él hizo el trámite, le dieron el decodificador y después la antena. Como al poco tiempo se compró un televisor LED que ya venía incorporado los canales digitales me lo dio. Lo habrá tenido un mes. (Nicolás N., 17 años, Villa Altube)

- Integrantes de la organización social: Mutual Primavera y beneficiarios de planes sociales.

En este sentido, podemos señalar que el grupo etario de adultos mayores es aquel que fue más beneficiado por la implementación de la TDA ya que son unos de los principales destinatarios del plan de acceso gratuito, aunque como se evidencia en nuestro estudio, lo hayan cedido a alguno de sus familiares por las razones esgrimidas más arriba.

Ahora bien, en relación con el año en que accedieron a los receptores digitales, varios de nuestros entrevistados los recibieron durante 2010 mientras que en el resto de los casos los obtuvieron entre 2011 hasta mediados de 2015.

En el 2010 que salió la primera, ehh... la primera vez que salió lo de la televisión digital y todo lo demás...Mitad de año para atrás, porque había empezado Tecnópolis, como dato, no? entonces ahí entregaban, en algunos centros...Entonces, nosotros fuimos, lo retiramos en Tecnópolis. Fuimos como unas 10 familias y los retiramos allá. (Verónica, 45 años, Barrio Primavera)

En principio sí, como que se empezó a correr la voz de que había una TV digital que el Gobierno había... pero no sabíamos cómo acceder ni nada, entonces un día de paseo en Tecnópolis, fuimos a Tecnópolis y ahí había un...una casita de TDA y bueno ahí nos acercamos para ver cómo era el tema y bueno ahí nos dijeron que había una televisión digital que había sacado el Gobierno. (Érica, 20 años, Barrio Primavera)

5 años, cuando recién salieron. Por la televisión. No, yo me fui anotar al correo, en realidad lo hice anotar a mi marido que ya se había jubilado, se fue al correo, llenó el papelito y yo creo que a los 15 días lo trajeron. (Graciela, 46 años, Barrio Santa Rita) 
La estrategia de comunicación de la TDA $^{163}$ en su etapa de lanzamiento se caracterizó por una profusa difusión de piezas audiovisuales en el sistema de televisión abierta y en medios interactivos (en el sitio web institucional, canal de YouTube). Como señalamos en el apartado 2.4.1. del capítulo II, en un primer momento, la línea de comunicación se dedicó a presentar la política pública, a explicar el modo de acceso e instalación de los decodificadores digitales, es decir, dar a conocer la TDA y el modo de obtener el beneficio. Cuando les preguntamos cómo conocieron el Plan "Mi TV Digital” muchos lo hicieron a través de los spots en televisión o radio.

Vi la promoción que hacían por la televisión y hablando con jubilados cuando vamos a cobrar al banco, esas cosas, y nos anotamos. (Ernesto, 79 años, Mariano Moreno)

Sin embargo, en general, varios se informaron y conocieron la TDA a través del comentario de algún familiar o vecino por lo que se enteraron del beneficio.

Me acuerdo que mi mamá hizo el trámite, se habrá enterado por una amiga supongo. (Nicolás A., 20 años, Altos de José C. Paz)

Me enteré por un vecino. Por la misma persona que me dijo que podía acceder a los beneficios que podía tener decodificador. (Daniel, 66 años, La Pilarica)

Por mi abuelo que es jubilado. Por mi abuelo. (Fátima, 35 años, José C. Paz Centro)

Yo me enteré por una vecina de la cuadra, ella me dijo que en el Centro de jubilados estaban anotando y haciendo los papeles para tener el aparato para ver la tele gratis. (María, 65 años, Villa Altube)

\subsubsection{Trámites para obtener el receptor digital de TDA}

Tal como describimos en los apartados 2.3 y 2.4 del capítulo II, el proceso de solicitud por parte de los interesados consistía en completar un formulario, junto a documentación respaldatoria, en oficinas del Correo Argentino; en el sitio web del Consejo Asesor; instituciones públicas y/u organizaciones sociales que adhieran al Plan y/o en eventos especiales organizados por autoridades nacionales y/o locales para tal fin.

163 En el apartado 2.4.1 del capítulo II desarrollamos una descripción general de la comunicación de la TDA. 
Al momento de realizar la solicitud, obtener el equipo receptor digital, e instalarlo, algunos de los entrevistados refirieron haberlo ido a buscar a la oficina de Correo Argentino de José C. Paz.

Por internet. Llené una planilla en el correo y me lo mandaron. Lo tuve que ir a retirar al correo después. Y llené la planilla, la mandé por correo y después me avisaron que ya estaba ahí y lo fui a buscar. (Mónica, 51 años, Barrio Santa Rita)

Mandamos una nota, fuimos al correo, depositamos el pedido y después recibimos por correo, también, la entrega del aparato. (...). Sí, llenar un formulario que lo hizo mi hijo por internet y nada más. Poner los datos nuestros, los de mi esposa, los míos, como jubilados, porque ganábamos la mínima, por ejemplo, lo que cobrábamos de sueldo, esas cosas, todo eso, los datos que requería el formulario. (...) Me presenté con una tarjeta que me llegó por correo también y fui a retirarlo ahí. (Ernesto, 79 años, Mariano Moreno)

Por mi abuelo. Mi mamá lo fue a retirar al Correo Argentino. En el correo argentino. (Fátima, 35 años, José C. Paz Centro)

Después fuimos varios vecinos juntos al correo y nos acompañó la sobrina de la Señora Elisa y llenamos unos papeles y les dimos fotocopias de mi documento y otra cosa más que no recuerdo y después nos dieron el aparato para poner en la tele. (María, 65 años, Villa Altube)

En otros casos, los entrevistados lo recibieron en sus domicilios mediante el servicio de correo luego de completar los formularios correspondientes.

En realidad, lo hice anotar a mi marido que ya se había jubilado, se fue al correo, llenó el papelito y yo creo q a los 15 días lo trajeron. No preguntó. Llenar un formulario y nada más. (Graciela, 46 años, Barrio Santa Rita)

Y hacés todo un trámite que lo mandas al correo, presentas documentación y después te lo envían. En el domicilio. (Daniel, 66 años, La Pilarica)

Ambas modalidades de obtención del beneficio estaban establecidas por la política pública para la distribución de los sets top box. Quienes recibieron los decodificadores en sus domicilios y aquellos que lo fueron a buscar a las oficinas del correo debieron completar los mismos formularios.

Mientras que en el caso de las entrevistadas que pertenecen a la Mutual Primavera realizaron los trámites de solicitud del beneficio en la UMID en Tecnópolis o en algún operativo de entrega en el barrio.

Fuimos a Tecnópolis y ahí había un...una casita de TDA y bueno ahí nos acercamos para ver cómo era el tema y bueno ahí nos dijeron que había una televisión digital que había sacado el Gobierno. Que era un aparatito con una 
antena y bueno teníamos que poner tus datos y te los entregaban, y bueno por eso, por ese medio es que accedimos a la TV digital. (Érica, 20 años, Barrio Primavera)

Estaba trabajando en Tecnópolis, hace dos años y te lo daban. (Adriana, 44 años, Barrio Primavera)

Se gestionaba desde acá desde la organización (la mutual). Hicieron toda la parte de tramiterío y todo eso para poder adquirirlo para la gente de acá, del barrio. (Marcela, 32 años, Barrio Primavera)

La Mutual Primavera ${ }^{164}$, desde sus inicios en 2002, promovió el empleo solidario y la organización comunitaria con el objetivo de recuperar la dignidad del trabajo y la identidad barrial en el contexto de la denominada "crisis del 2001". En ese contexto, la organización se propuso llevar adelante un proyecto de Economía Social y Desarrollo “(...) con un encuadre político con diferentes instancias de gobierno (nacional, provincial y municipal) y el armado de redes interdistritales dentro del campo popular."165 (Mónica Mendoza, responsable política) La modalidad de ese encuadre político se materializaba en el barrio a partir de convertirse en sede de las políticas públicas, según los dichos de Sonia Mendoza (presidenta de la Mutual). ${ }^{166}$ Entre los planes y programas del gobierno Kirchnerista, la Mutual Primavera fue la intermediaria entre la gestión de la TDA y los habitantes del barrio tanto organizando los operativos de entrega de equipamiento en la sede de la organización como el traslado a Tecnópolis para conseguirlo en la UMID .

Los entrevistados manifestaron que el proceso de tramitación para obtener el beneficio fue relativamente fácil (claridad en el pedido de información, trámite sencillo y rápido) tanto en el caso de quienes lo solicitaron a través de correo como aquellos que lo hicieron en Tecnópolis o en algún operativo de entrega en el barrio. Indicaron que no tuvieron mayores inconvenientes a la hora del llenado del formulario como la presentación de información complementaria (copia del DNI, LC, LE del solicitante, comprobante de cobro de haberes, certificado de discapacidad, comprobante del último cobro de Plan o

\footnotetext{
${ }^{164}$ La Mutual Primavera se define como una empresa social territorial proveedora de diferentes servicios al barrio homónimo: transporte, club deportivo, biblioteca popular, comedor comunitario, centro de desarrollo infantil.

${ }^{165}$ Extracto del programa "Megáfono" de UniTV (canal de la Universidad Nacional de General Sarmiento). Disponible en: https://www.uni-tv.com.ar/ondemand/megafono/mutual-primavera, consultado el 15 de noviembre de 2018.

${ }^{166}$ Dichos expresados en el programa "Megáfono" de UniTV (canal de la Universidad Nacional de General Sarmiento). Disponible en: https://www.uni-tv.com.ar/ondemand/megafono/mutual-primavera, consultado el 15 de noviembre de 2018.
} 
Programa Social y/o Vivienda, tarjeta de Asignación Universal por Hijo) y en todo caso, recurrieron a la ayuda de un familiar.

En otro orden, entendemos que las políticas públicas, sus expresiones en planes y programas, sus significados y las representaciones sociales, involucran la construcción de identidades de los beneficiarios. (Gradin y Hoop, 2007:4) Teniendo en cuenta que esa construcción se compone de la definición que establece la política (reconocimiento formal) y a la vez con la identificación de los destinatarios como beneficiarios, los dichos de nuestros entrevistados nos permiten reconocer que los jubilados y las integrantes de la organización social se auto perciben no sólo como receptores de la televisión digital sino como "sujetos de derecho".

Por un lado, los jubilados y/o pensionados enunciaron que cuando se enteraron de la iniciativa reconocieron que cumplían con las condiciones para disponer del beneficio.

Escucho mucha radio, más que tele en realidad y escuche en la radio que estaban haciendo esta campaña, este plan y ahí empecé a averiguar como para anotarme porque en realidad no tenemos otro cable, nunca tuvimos otro tipo de cable. Y empecé a averiguarlo y lo hice. (Ana María, 61 años, José C. Paz Centro)

Vi la promoción que hacían por la televisión y hablando con jubilados cuando vamos a cobrar al banco, esas cosas, y nos anotamos. (Ernesto, 79 años, Mariano Moreno)

En estas respuestas podemos advertir el reconocimiento formal de estos dos (2) grupos de beneficiarios de la TDA dado que se identifican con los criterios que los incluyen en la política pública: como perceptores de jubilaciones y/o pensiones y/o como miembros de organizaciones sociales.

Por otra parte, la interpelación del Plan "Mi TV Digital" como "sujetos de derecho" se evidencia abiertamente en las expresiones de las integrantes de la organización social:

No, el tema económico, no pagás tele y básicamente que uno, el que tiene conciencia es que uno está haciendo uso de un derecho. (Verónica, 45 años, Barrio Primavera)

Es un cambio de cultura, acceder por medio de la TV a otras culturas, saber que existen otros países y no uno dominante, uno puede elegir lo que le gusta, conocer otras culturas, otra clase de gente, otras realidades. (Érica, 20 años, Barrio Primavera) 
Asimismo, en relación con la valoración de la TDA -específicamente sobre el acceso a la televisión digital- los jubilados y las integrantes de la Mutual Primavera lo hicieron positivamente. Estas valoraciones refuerzan la idea del beneficio de la política pública como un derecho ciudadano a percibir por la mayor parte de la población argentina.

Finalmente, los familiares de jubilados y/o pensionados mencionaron que obtuvieron el decodificador digital de sus padres y/o abuelos ya que estos se encontraban entre los beneficiarios establecidos en el Plan "Mi TV Digital". En este sentido, tienden a reconocer que disponer del decodificador digital les permite acceder a un servicio de televisión con algunas diferencias al sistema analógico. Más adelante, volveremos sobre este tema.

\subsubsection{Instalación del decodificador digital de TDA}

Según el plan de acceso gratuito "Mi TV Digital”, el kit de instalación de televisión digital contiene: un receptor STB en UHF, un control remoto con baterías, diferentes cables para la conexión, una antena para interiores, una antena exterior (según las necesidades) ${ }^{167}$ y un manual de instrucciones. El beneficiario recibía el paquete digital y debía proceder a la instalación en pocos pasos que podía consultar tanto en el manual del usuario como mediante el teléfono de atención al cliente.

${ }^{167}$ De acuerdo con la ubicación geográfica entre el lugar de emisión y de recepción el kit se complementa con una antena exterior para mejoramiento de la calidad de la señal. 


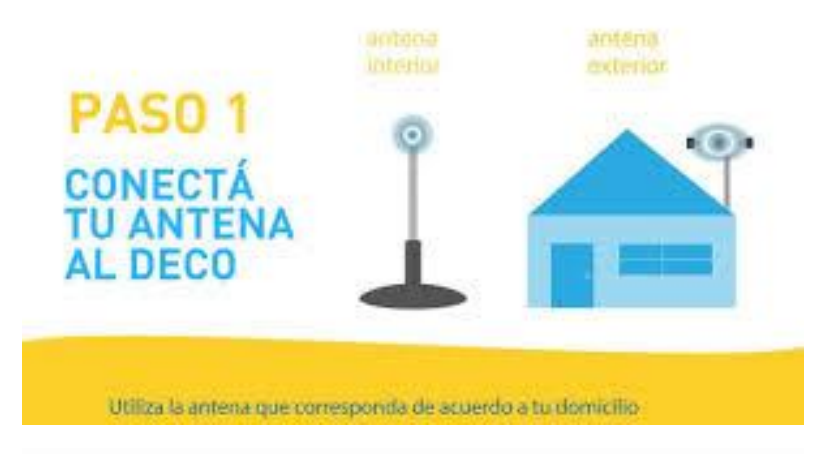

\section{PASO 2 \\ CONECTÁ EL DECO AL TELEVISOR}

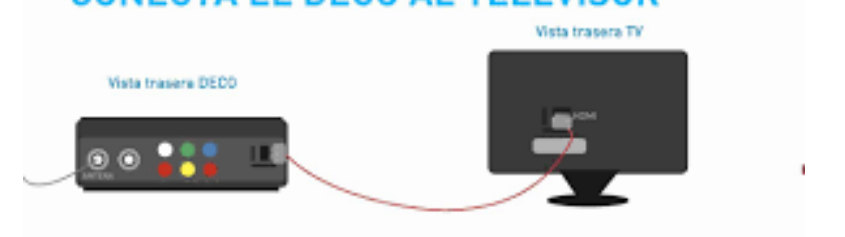

Figuras 3 y 4: Prensa TDA (www.youtube.com/user/tdaargentina)

En general, el proceso de instalación de los decodificadores digitales fue llevado a cabo por los entrevistados con la ayuda de algún familiar, amigo o vecino. Cuando se refirieron a la instalación no incluyeron el paso de la configuración del set top box sino lo hicieron exclusivamente a la conexión de los diferentes componentes de la TDT: receptor digital, televisor, antena.

Sí, la instalación la hicimos nosotros. Sí, me ayudó mi hijo, que es un poco más práctico que yo para colocar la antena y esas cosas, para conectarlo al televisor. Todo para conectar los cables lo hizo él. No, la parte de la antena y esas cosas fue fácil, lo que no entendía yo era la parte de la conexión. Pero al hacerlo mi hijo que él entiende un poco de esas cosas. (Ernesto, 79 años, Mariano Moreno)

De eso se ocupó mi tío, solo. (Fátima, 35 años, José C. Paz Centro)

No, un vecino lo instaló. Nos fijamos en internet. Y lo instaló un vecino, yo no sé esas cosas. (Mónica, 51 años, Barrio Santa Rita )

En mi casa. No, lo hizo mi hijo. Fácil. No, para nada. No, no yo de eso no entiendo nada. Pero sé que lo hicieron rápido. (Graciela, 46 años, Barrio Santa Rita)

Y tenía configuración automática. Equilibrada, ni fácil ni difícil. O sea, no es tan relativamente fácil, pero como estoy relativamente un poquito en el tema, resultó levemente fácil. (Daniel, 66 años, La Pilarica)

Eh, nos explicaron las personas que nos entregaban, pero igualmente venía con un manualcito. Sí, sí, sí, en ese mismo lugar te pedían el DNI, algunas preguntas y ya 
accedías a la TDA. Sí, sí porque te explico, el manual era muy sencillo muy legible y entonces podías acceder rápidamente. (Érica, 20 años, Barrio Primavera)

En el caso de los integrantes de Mutual Primavera, que recibieron la TDA al inicio de la implementación del plan mencionaron que debieron dedicarle un tiempo considerable a la instalación de los decodificadores digitales, lo hicieron junto a otros integrantes de la familia o amigos y luego ayudaron a los vecinos del barrio a conectar los suyos.

Lo hicimos en la familia, entre todos. Empezamos a ver qué era y después cuando uno aprendía empezaba a enseñar a los otros. Porque ahora no es tanto, pero en su momento, en 2010 vos tenías que hacer un proceso de instalación, que lea la tele, de qué tipo de tele era y todas esas cosas. Y bueno, nosotros le dedicamos todo un día a aprender y salimos a enseñar. (Verónica, 45 años, Barrio Primavera)

Más allá de que los entrevistados, en principio, manifestaron que no tuvieron mayores dificultades para realizar la instalación de la TDA, en algunos de los casos debieron acudir a la asistencia de familiares o vecinos que eran percibidos con conocimientos y competencias suficientes para resolver la instalación. Quienes ayudaron en el proceso de puesta en marcha de los decodificadores digitales fueron varones y nuestros entrevistados los caracterizaron con cierta: "practicidad", "manejo" y "entendimiento" para realizar la instalación. En este sentido, la puesta en funcionamiento de la televisión digital no estuvo exenta de complicaciones técnicas sin embargo, los usuarios desplegaron estrategias para solucionarlas: por un lado, identificaron quienes forman parte del mundo de las tecnologías: maridos (los hombres), los chicos o los jóvenes a quienes recurrieron para pedir ayuda y por otro, se dispusieron a aprender para después compartir con otros y ayudarlos a realizar la instalación en sus domicilios.

Solo en dos casos la instalación la realizó un técnico: uno en forma gratuita y otro que cobró honorarios por el trabajo realizado.

Vino un técnico que mandaron de ahí mismo, de la TV digital y la colocó junto con la antena nuestra, con la antena de siempre, con la antena común, la conectaron ahí y ya se pudo ver perfecto, eso es lo que vemos, ese cable tenemos. (Ana María, 61 años, José C. Paz Centro)

Lo fue a buscar mi vieja, yo no estaba, cuando yo llegué ya estaba instalado en la tele de la cocina que es una tele de tubo. El técnico que vino les ofreció conectarle la antena, bajar el cable y conectárselos al deco, no me acuerdo cuánto les cobró, pero ponéle $\$ 100$, el deco se dejó en la caja hasta que vino la antena, el deco se 
conectó cuando vino la antena y ahí se configuró. (Germán, 26 años, José C. Paz Centro)

A los problemas con la instalación de la televisión digital los beneficiarios agregaron que en algunos casos los receptores dejaron de funcionar y en otros, tuvieron muchos inconvenientes para la recepción de la señal.

Entre los decodificadores digitales entregados en 2010, al menos 3 (tres) dejaron de funcionar o tuvieron dificultades para recibir la TDA y según los entrevistados esperaron el reemplazo o algún tipo de solución con pocos resultados. En el resto de los casos, los decodificadores digitales funcionaron y fueron usados en los domicilios.

Sí, además el decodificador no duró tanto, ya se nos quemó. Así que ahora estamos con la antena de aire y no se ve muy bien por el hecho de que está rota. (Nicolás A., 20 años, Altos de José C. Paz)

(...) lo que pasa que, se me quemó el aparato y nadie se hizo responsable. y después bueno, para que me dieran otro, no podía sacarlo (...) y ese sí lo instale todo bien, hasta música podía escuchar y después de golpe y porrazo se cortó todo y no, no hay caso no quiere agarrar, no, no. Engancha uno o dos canales nada más, los canales de aire no los quiere agarrar, solamente canal 13. y hasta ponía el pen drive y escuchaba la música lo mas bien.(...) para conseguir la antena, tuve que poner la antena todo viste $\mathrm{y}$, hasta ponía el pen drive, escuchaba música y ahora ni siquiera no ... (Adriana, 44 años, Barrio Primavera)

Entonces como nosotros acá tenemos el "Argentina Trabaja", nos dieron. Lo que pasó con eso que como fue la primera experiencia se quemaron muy pronto, la mayoría de los que retiramos se quemaron y los que no pasó es que todavía no podemos retirar otro. (Verónica, 45 años, Barrio Primavera)

En estos comentarios distinguimos al menos (3) tres motivos (técnicos, de gestión, político) por los que los destinatarios de la TDA advierten haber tenido inconvenientes con los decodificadores o con la recepción de la televisión digital. La primera afirmación se enfoca en los aspectos técnicos: los decodificadores se quemaron y dejaron de funcionar. Por otra parte, el segundo testimonio señala que el problema con el sintonizador y la recepción de la señal digital no tuvo resolución debido a que su reclamo a la asistencia técnica del Plan no obtuvo respuesta satisfactoria. Al final, la alusión en el tercer relato a las dificultades técnicas de los receptores que fueron entregados en el marco del programa de ingreso social "Argentina Trabaja ${ }^{168 "}$ y pone el acento en la

${ }^{168}$ El Programa de ingreso social con trabajo "Argentina Trabaja”, del Ministerio de Desarrollo Social, se puso en marcha en 2009 cuyo objetivo fue la generación de trabajo genuino, a través de la creación de cooperativas de trabajo, orientadas al mejoramiento de la infraestructura barrial y la calidad de vida de familias vulnerables (Argentina, Res. MDS N³182/09). 
intermediación de los planes sociales para la obtención del beneficio de la televisión digital.

En este punto, presumimos que estas experiencias negativas en cuanto al funcionamiento de los decodificadores y a la recepción de la señal podría tener ciertas consecuencias y efectos en el uso de la TDA en nuestro caso de estudio, los cuales nos proponemos analizar más adelante.

\subsection{Decodificadores digitales: operación, funciones, ventajas y desventajas}

\subsubsection{Operación de la Televisión Digital}

En relación con la operación, nos interesó conocer el relato de los entrevistados respecto al contacto y manejo de la televisión digital: encender y apagar el decodificador digital, búsqueda de programas o emisoras o grabar programas.

En principio, varios dijeron conocer las funciones básicas como encender/apagar, buscar canales o programas, escuchar música que reconocen como las operaciones elementales que realizaban a la hora de utilizar la televisión analógica.

Por lo menos las básicas, por ahí no me puse a investigar demasiado si tiene más opciones. (...) verlo por internet, lo del portal, yo no lo sabía. Configurar canales, buscar otros canales. Tiene un buscador de señales, volverlo a poner a ver si capta más canales, cosas básicas. (Nicolás A., 20 años, Altos de José C. Paz)

No, sé apagarla y prenderla. Después lo llamo a mi hijo porque le falta color o porque hace rayas. Nos pasa lo mismo con el telefonito. Con lo digital, andamos prenderlo y apagarlo. Cuando teníamos el aparato prendíamos, apagábamos y cambiábamos los canales pero cuando teníamos un inconveniente ya se nos quemaban los papeles, llamábamos al técnico porque teníamos técnico en casa, en la familia digamos. (Ernesto, 79 años, Mariano Moreno)

Sí, sí. Apretás un botón, aparece la imagen, cambias de canal con el otro botón, es muy simple. (Daniel, 66 años, Barrio La Pilarica)

Sí, porque son fáciles de manejar los canales, lo básico. (Mónica, 51 años, Barrio Santa Rita )

Sí. La prendo y después voy cambiando los canales hasta que encuentro lo que a mí me gusta. (Graciela, 46 años, Barrio Santa Rita)

Sí, al principio no entendía mucho cómo era, te imaginas que yo me críe con un televisor blanco y negro a botones, que no existía control remoto, después fuimos 
teniendo lógicamente el control remoto, pero ahora eran ya dos controles remotos. $\mathrm{Y}$ al principio me costó un poco, me costó como me pudo haber costado aprender lo del celular, pero bueno, rápidamente después ya está. Me costaba entender o enganchar prender con un control, después buscar con el otro control los canales, me parecía como raro todo, era algo nuevo y desconocido para mí. /[Trataba] Con mi marido que más o menos entendía lo mismo que yo y sino con mi hijo, sí, recurríamos a él más que nada, él fue el que nos explicó en realidad. (Ana María, 61 años, José C. Paz Centro)

Claro, sí, sí. La verdad que es fácil, no, no, no tuve ninguna complicación. Lo único colocar la antena y orientarla./ Claro si alguien que se pueda trepar o alguien que sepa conectar eso, pero más que eso no. (Érica, 20 años, Barrio Primavera)

Sin embargo, observamos que el grado de dificultad para operar el dispositivo técnico crece en relación con los grupos etarios: entre los jóvenes y los jóvenes adultos predomina cierta facilidad en el manejo básico de la TDA mientras que entre los adultos mayores aumenta la dificultad y las operaciones se reducen a: encender /apagar y cambiar de canales y cuando encuentran limitaciones acuden a la ayuda o auxilio de algún familiar o conocido.

Ahora bien, cuando consultamos sobre los otros servicios ofrecidos por la TDA como grabar contenidos, actualización del software o uso de los puertos USB, en general, adujeron cierto desconocimiento.

La verdad es que más que cambiar de canales mucho no hago, así que no. Y tengo entendido, hace poco, que se puede rebobinar o grabar, pero esas funciones no las sé usar (Fátima, 35 años, José C. Paz Centro)

No, no, todas [las funciones] no. No, conocía que estaban. Conozco por ejemplo que hay actualización de software, por el puerto USB pero... cosas así pero... que por ahí las sabría usar pero... en general no... (Daniel, 66 años, Barrio La Pilarica)

La operación de las funciones vía un comando o control remoto de la televisión analógica $^{169}$ (encendido y apagado, selección de canales, apagado programable, silenciar la emisión, entre otras) parece ser una práctica incorporada por los televidentes que no distingue edades. Los dichos de los entrevistados no hacen referencias a inconvenientes con el manejo del televisor tradicional y dan por sentado que su uso les resulta fácil. Sin embargo, a la hora de aludir al empleo de la televisión digital, integrantes del grupo de adultos mayores admiten que no podían resolver los problemas técnicos (pérdida de señal,

169 La compañía canadiense Viewstar desarrolló el modelo infrarrojo popularizando el uso del comando o control remoto en la década de 1980 durante el Siglo XX. 
no sintonizar la programación deseada, actualización de software, etc.) a la vez que ignoraban otras funciones como grabación de contenidos, uso de puertos USB, conexión de computadoras personales, entre otras). De esta manera, entendemos que la operación de la TDA en la experiencia de los usuarios no difiere de aquella que han construido con la televisión analógica.

En este punto, podemos inferir que a medida que se complejizan las funciones para manejar el dispositivo técnico, disminuye considerablemente el conocimiento para realizar operaciones tales como grabar los contenidos o buscar y actualizar el software del decodificador digital.

\subsubsection{Percepción de ventajas y desventajas técnicas de la TDA}

Entre las características técnicas de la televisión digital se cuentan un mejor aprovechamiento del espectro radioeléctrico, la multiplicación de las señales hertzianas, mejor calidad de la señal, almacenamiento de contenidos en el disco duro de los decodificadores digitales que permite la posibilidad de consumo diferido, así como también la oferta de servicios interactivos.

Sobre estos rasgos existe acuerdo en la comunidad académica sobre el hecho de que la TDT ofrece imagen y sonido sin ruidos ni interferencias asegurando una recepción nítida ya que la digitalización impide que la señal se degrade tal como sucede con la televisión analógica. Cuando le preguntamos a los entrevistados sobre esta característica de la televisión digital, varios respondieron que la imagen mejoraba sustancialmente en relación con la emitida por la televisión tradicional.

No, sí la imagen es perfecta, me encanta. (Adriana, 44 años, Barrio Primavera)

Me parece que se ve mejor, en cuanto a la imagen. (Graciela, 46 años, Barrio Santa Rita)

Y como te decía, se ve la imagen re linda parece que tenés una tele nueva y es la misma, la vieja, de siempre pero se ve hermoso, colorido y muy vivos los colores. (María, 65 años, Villa Altube) 
La grilla de TDA para $\mathrm{AMBA}^{170}$ ofrecía al menos unas 9 (nueve) señales en alta resolución o HD. Este rasgo técnico de la TDT (transformación de la señal en alta resolución, más conocida como $\mathrm{HD}$, mediante el decodificador digital) también fue identificado por los usuarios como una ventaja ofrecida por el Plan en relación con la calidad de imagen.

Lo que está bueno los canales HD se ve full HD, 1080, perfecto, cosa que sólo lograrías teniendo alguna señal paga con el paquete HD, cosa que esto es gratuita, eso me parece bueno. O sea, la calidad de imagen es muy buena. Hay canales que continúan siendo HD, no full HD, que tienen 368 de alto por ahí, de resolución de la transmisión, y cuando lo ves en una TV de tubo de 14 pulgadas se ve joya igual pero la pones en un LED y medio que pierde y se nota mucho el contraste entre las señales que son HD y las que no. (...). (Germán, 26 años, José C. Paz Centro)

No obstante, algunos de los usuarios señalaron fallas técnicas en la transmisión que en ciertos momentos producía cierta oscilación o inestabilidad en la sintonización de la imagen que impidieron la recepción normal.

Lo bueno es que es una imagen más nítida, más variedad de canales y lo malo es que a veces la señal es inestable y se corta, así como es una señal digital a veces encontrás que se paraliza y después se vuelve a retomar, o se paraliza y hasta dentro de una hora no vuelve la señal, en ciertos canales...(...). (Daniel, 66 años, La Pilarica)

Salvo cuando me dejan sin señal que yo no sé si será la antena o no será la antena, pero hay momentos que no tengo señal en ninguno de los canales, tengo señal por ahí solamente en el 13, (...) y por ahí, la Teve Pública no tengo señal, no tengo señal en Encuentro, no tengo señal, pero no sé si será por la orientación de la antena. (Graciela, 46 años, Barrio Santa Rita)

Otra de las cuestiones que se evidenció en las respuestas sobre las ventajas o desventajas de la televisión digital fueron alusiones de algunos usuarios de TDA sobre las opciones a las que recurrieron cuando la señal digital se veía interrumpida: sintonizar la emisora o canal en el sistema de cable. Por lo que aparece un modo de resolver el problema de la deficiencia de la señal apelando a alternar entre uno y otro sistema (digital y analógico de sistema pago). Si bien esta alternativa aparece menos referida en el discurso de nuestros entrevistados y entrevistadas, queda clara la percepción respecto de la diferencia de calidad en la recepción, como se observa en el siguiente comentario:

Sí, muchísimas, sí, sí, por eso te digo cuando quiero ver algo, hay días que por ahí se ve perfecto, por ejemplo, en la televisión común o hay días que se ve bastante

${ }^{170}$ Ver en el apartado 2.4 del capítulo II. 
borroso. Entonces lo pongo ese mismo canal, pero en el cable y ahí se ve impecable. (Ana María, 61 años, José C. Paz Centro)

Otra característica que los entrevistados le adjudicaron a la televisión digital aludía al aumento en el número de emisoras ofrecidas en la grilla de la TDA que a su vez, y según sus dichos, se evidenciaba en la diversidad de contenidos en la programación.

Si más programación, me parece que es diferente a la televisión, esta es diferente a la otra, por eso es mi idea es ponerla en la pieza de los chicos. (Marcela, 32 años, Barrio Primavera)

Es un buen servicio, es mejor que la televisión analógica, que eran cuatro canales, poca información y mala imagen. La digital te ofrece más información, más variedad gratuitamente. / En cuanto a lo técnico es eso, la mejor imagen, la mayor cantidad de canales. (...) Y como decíamos antes, es una mejor calidad, la diferencia buena. Mejor calidad y variedad. Y la analógica es peor calidad, pero es estable, que nunca se te corta la señal analógica, nunca se pixela, nunca tiene esos problemas técnicos. (Daniel, 66 años, La Pilarica)

A partir del análisis de los dichos de los entrevistados advertimos una recurrencia que nos interesa destacar: la gratuidad asociada a las características técnicas de la televisión digital. En otras palabras, los usuarios aprecian positivamente que las mejoras técnicas ofrecidas por la TDA (imagen, sonido, programación) vaya de la mano de la gratuidad del servicio.

Recapitulando. Por un lado, los entrevistados perciben las ventajas de la televisión digital vs. la televisión hertziana están vinculadas a su estructura técnica: calidad de imagen, sonido, ampliación de la grilla de programación. Entre las desventajas aluden a defectos en la demodulación de la señal cuya consecuencia resulta en una sintonización deficiente y que algunos usuarios adjudican a problemas con las antenas externas. Un punto de interés para nuestro análisis es que en el relato de los entrevistados se manifiesta una alusión al modo en que ante las dificultades de recepción normal de la señal suelen optar el servicio pago que en varios de los hogares coexiste con la TDA. Recordemos que en el Partido de José C. Paz como en los partidos vecinos existe una alta cobertura del sistema de televisión por cable.

En este sentido, las ventajas atribuidas por los entrevistados a la TDA se relacionan con las características del dispositivo técnico y con el acceso gratuito a la televisión digital. Y las desventajas están más vinculadas a deficiencias en la infraestructura técnica necesaria para la recepción de la TDT: las plantas transmisoras y antenas retransmisoras aunque los entrevistados no lo explicitan claramente quizás debido a cierto 
desconocimiento de la estructura general de funcionamiento de la televisión digital terrestre.

Finalmente, más allá de la descripción de la diferencia en la calidad de imagen entre la televisión analógica y la digital como nitidez, resolución o la intensidad de los colores; una mejor reproducción del sonido, en general varios entrevistados se dedicaron a responder subrayando las diferencias en la programación, a describir los contenidos y su preferencia en el visionado de la TDA. Estas características las analizaremos con más detalle más adelante en el apartado 7.3.2.

\subsection{Dieta televisiva: disponibilidad física, preferencias y contenidos del visionado}

La descripción de la dieta televisiva permite conocer permanencia, alternativas, estilo de visionado, covisionado, aparatos y disponibilidad física, contenido de la conversación, permanencia/referencia por determinados géneros televisivos; asistir como público o protagonista a determinados programas (Medrano, Palacios y Aierbe, 2007). En el discurso de los entrevistados aparecen referencias que nos permiten reconocer aspectos relacionados con la disponibilidad física y el modo de distribución en el espacio doméstico de los televisores, permanencia (horas de visionado), el estilo de visionado, la preferencia de géneros televisivos de los entrevistados.

\subsubsection{Espacio y tiempo de la televisión digital en los hogares}

La recepción del sistema de Televisión Digital Terrestre (TDT) requiere de decodificadores denominados "Set Top Box" (STB) que se conectan al televisor analógico o bien, funciona en aquellos televisores que lo tienen incorporados y que reciben la señal sin necesidad del receptor externo. En el caso de la política pública TDA, la recepción se realiza a través de decodificadores digitales (STB) que se conectan al televisor tradicional, LCD o LED que no tengan TDA incorporado.

La distribución y el equipamiento televisivo junto a los horarios de encendido y de visionado de emisoras y programas permiten identificar aspectos descriptivos y analíticos sobre las modalidades que adquiere la dieta televisiva en los hogares. 
Al momento del estudio, en la mayoría de los hogares de los entrevistados había al menos dos televisores, generalmente ubicados en alguna habitación y/o en el espacio compartido entre los integrantes de la familia como living, comedor o cocina-comedor. La posesión de tres (3), cuatro (4) y cinco (5) aparatos de televisión es menos frecuente. Cuando se da, están distribuidos de modo similar a los demás grupos familiares, es decir, en habitaciones, living y/o cocina-comedor.

En relación con la posesión del tipo de televisores (analógico o digital) encontramos que suelen corresponder a equipos tradicionales que requieren de un decodificador externo para la recepción de la TDA. Algunos entrevistados afirmaron que además poseen un televisor LCD o LED que tienen TDA incorporado. Como indicamos en el aparado 1.2. estos usuarios son adultos mayores, que perciben una jubilación y/o pensión, que adquirieron el equipamiento televisivo por medio del Programa "TV Para Todos" implementado a partir de julio de 2011.

Otro aspecto descriptivo para analizar la dieta televisiva teniendo en cuenta la cantidad es el modo de distribución de televisores en el hogar. Como mencionamos anteriormente, en nuestro estudio, los entrevistados manifestaron poseer 2 aparatos de televisión por unidad familiar ubicados en el espacio compartido con los demás integrantes del hogar y/o en una habitación. En general, el decodificador digital de TDT se situaba en el living o cocina-comedor donde los miembros de la vivienda comparten parte del tiempo cotidiano.

Uno, en el comedor, tradicional (con TDA). (Daniel, 66 años, Barrio La Pilarica)

Hay 1 en mi pieza, 1 en la pieza de mi vieja, 1 en la cocina y 1 en el living. El deco está en uno de 14 pulgadas en la cocina, el que tengo yo es un LED y ahí está el otro cable de la antena. (Germán, 26 años, José C. Paz Centro)

Está en el living de mi casa, porque como mi abuelo no quiso el decodificador lo instalamos en mi casa. Hay otros, 4. (Fátima, 35 años, José C. Paz Centro)

Uno en la pieza de mis papás y otro en el comedor, Son los de antes, los tradicionales. / ¿En qué lugar (espacio físico) de su hogar se encuentra el aparato que posee receptor para televisión digital? En el comedor. (Nicolás, N., 17 años, Villa Altube)

1 (en el comedor). Sí, sí tiene todas las funciones. Al principio agarraba pocos canales como te digo para orientar la antena y cuando se orientó la antena ya se empezó a agarrar todos los canales. (Érica, 20 años, Barrio Primavera) 
En Argentina, la televisión de pago (cable y satélite) alcanza casi un $84 \%$ de penetración en los hogares de todo el país (LAMAC, 2015) y que si miramos los niveles en el Partido de José C. Paz incluso exceden las cifras nacionales. (Abramovich, et.al.,2014:7)

Teniendo en cuenta estos datos, para conocer las modalidades de hábitos de consumo televisivo de la TDA nos interesó consultar entre los entrevistados la permanencia (cuanto tiempo) y en qué momento del día le dedican al visionado.

La cantidad de horas de exposición a la televisión (permanencia) se distribuye entre los entrevistados donde la mayoría le dedicaba entre 2 y 3 horas durante el día y en menor medida, otros lo hacían entre 4 y 5 horas diarias. Sin embargo, el dato que nos interesa destacar es en qué momento del día lo hacían ya que nos permite dar cuenta del modo en que se compone la dieta televisiva en nuestro estudio.

Considerando el tiempo dedicado al visionado de TDA, la mayor parte de los entrevistados le destinaban un promedio de 3 horas diarias.

Si observamos las horas de exposición en relación con la edad de los usuarios y sus actividades diarias notamos que la cantidad asciende según el rango etario. Los más jóvenes (entre 17 y 25 años, que estudian y trabajan junto a los adultos, entre 30 y 50 años), que realizan tareas fuera del hogar (horario laboral de 8 horas o más) le dedicaban menos horas que los adultos mayores jubilados y/o pensionados (entre 60 y 80 años).

En general, los entrevistados afirmaron mirar televisión por la noche a partir de las 20 horas, es decir, en la franja prime-time y entre ellos, algunos lo hacían en menor medida por la mañana o la tarde.

Cuando llego a mi casa que por lo generas suele ser tipo 8 y pico, miro un rato alguna pavada a la noche hasta la 1, 1:30. (Germán, 26 años, José C. Paz Centro)

En general a la noche. Por ahí al mediodía cuando me siento a almorzar y después a la noche, ya a partir de las 8 hs. o 9 hs. de la noche. (Graciela, 46 años, Barrio Santa Rita)

A la noche de 9 hs. a 11 hs., porque al otro día tengo que ir al colegio. A no ser en el verano que sí veo tres veces al día. (Nicolás, N., 17 años, Villa Altube)

No, muy poco, más que nada en las vacaciones miraba un poco más, pero como yo trabajo, en épocas así de todos los días no, la verdad muy poco tiempo, a la noche pero un rato nada más. / Y ponéle a las 8 hs., por ahí si trabajo al mediodía veo un ratito y ya está, durante la tarde no veo nada. (Paula, 44 años, José C. Paz Centro) 
Y generalmente a partir de las 6 hs. de la tarde hasta las 9 hs., 10 hs. de la noche. (Érica, 20 años, Barrio Primavera)

Durante el día jamás pongo la televisión por ejemplo, a la nochecita a lo mejor la veo pero intercaladamente, mientras estoy haciendo alguna otra cosa, mientras hago la cena, voy y vengo, a lo mejor son dos o tres horas. Pero no junto te quiero decir, a lo mejor veo quince minutos, a lo mejor estoy haciendo algo y bueno, así, interrumpido. Durante el día no, a la mañana menos que menos, a lo mejor a la tarde algún noticiero, pero a veces. Durante la mañana nunca. (Ana María, 61 años, José C. Paz Centro)

Como dijimos más arriba, los adultos mayores relatan que suelen mirar televisión por la mañana y a veces, en la tarde.

Y puede ser de 10 hs. a 2 hs. de la tarde, (...) Y los de la mañana (Daniel, 66 años, Barrio La Pilarica)

A la mañana temprano ponemos a veces las noticias, nos levantamos temprano, a las $6 \mathrm{hs}$. o a las $7 \mathrm{hs}$., estamos mirando un rato mientras tomamos mate. (...) Después al mediodía miramos noticias otra vez, y después ella mira alguna novela a la tarde. (Ernesto, 79 años, Mariano Moreno)

Por lo tanto, según los dichos de nuestros entrevistados observamos que el visionado de televisión se concentra en horario nocturno debido a que parte de nuestra muestra se compone de trabajadores y estudiantes que pasan muchas horas fuera del hogar. En tanto, por otro lado, los jubilados o pensionados que permanecen más tiempo en sus casas reconocían que encendían la televisión por la mañana y por la tarde.

\subsubsection{Preferencias de visionado y de géneros televisivos}

La elección de qué mirar: emisora o canal, programas y géneros televisivos (noticiero, película, serie, documental) conforman otra parte de los rasgos que nos permite conocer la experiencia televisiva que describe la dieta televisiva en los hogares.

Al momento de consultar sobre las preferencias de visionado de TDA, en general, predominaban los programas de las emisoras de aire: Canal 9, TELFE, Canal 13 y TV Pública; de cable: C5N, CN23 y Canal Encuentro o PAKA-PAKA.

Canal 13, mucha variación no había tampoco, de lo que había ponía el 13, era el 13, 11 o TV pública y elegía el 13. (Nicolás, N., 17 años, Villa Altube) 
Me gusta mirar Duro de domar, me gusta TVR, me gusta Bendita. El que me gusta el 11 no lo puedo ver porque tampoco tengo señal en el 11 a esta hora, por ejemplo, la novelita de... "Viudas e Hijos". Me gusta ver los noticieros, 678, me gusta ver $\mathrm{C} 5 \mathrm{~N}$ a la noche con Navarro, me gusta ver canal 23 los noticieros. Bueno esas cosas, o si hay películas sobre todo si son españolas. (Graciela, 46 años, Barrio Santa Rita)

Y vemos PAKAPAKA, Encuentro, Telefe, a veces Canal 13. / Y no hay un horario fijo, por ahí al mediodía si estoy acá, que no estoy trabajando, al mediodía mientras almorzamos vemos el noticiero. $Y$ a la noche vemos la novela de Telefe y el programa de entretenimiento, que hay uno en Telefe. (Mónica, 51 años, Barrio Santa Rita )

Yo veo mucho el noticiero de canal 7 o el de canal 11, el noticiero del cable también, C5N también vemos mucho. (María, 65 años, Villa Altube)

En escasos casos refirieron a las propuestas de producción exclusiva de la TDA como DeporTV, Aqua Mayor, Aqua Federal, Arpegios, Telesur.

Miro un poco de DeporTV, veo un poco de C5N y a veces miro un poco de TELEFE también. Y a mí me rotan los horarios del trabajo, así que no tengo horario fijo, suele ser por la tarde. Y de 4 a 6 más o menos. La televisión la uso a veces para mirar Los Simpson, los fines de semana. Y bueno, C5N es todo noticias, suelo mirar un poco para informarme nada más. No, me acordé un canal que no mencioné, hay un canal que pasa orquestas, todo ese tipo de música que no me salía el nombre, tampoco me sale ahora. (Nicolás, A., Barrio Altos de José C. Paz)

Y mirá, el programa Aquamayor, el canal de la tercera edad, el canal de viajes donde te mostraban los diferentes lugares: la costa, la sierra, Bariloche. Viste había dos o tres canales buenos lo otro no era de interés viste. El de viajes, Aquamayor, específicamente esos dos. (Paula, 44 años, José C. Paz Centro)

En principio, encontramos algunas posiciones que enuncian el predominio de lo que entendemos como visionado tradicional, es decir, aquel que se realiza según la programación horaria emitida por cada emisora o canal. Esta oferta programática es diseñada por la televisión generalista que: “(...) se dirige al público masivo, abarcando todo el espectro de audiencia (edad, sexo, clase social) y cuyo contenido incluye variedad de géneros y formatos.” (Izquierdo Castillo, 2017:33).

\subsubsection{Productos audiovisuales elegidos por los usuarios de TDA}

En la programación de televisión encontramos distintos tipos de géneros distribuidos en cuatro categorías con diferentes formatos: entretenimiento (magazines y reality shows, talk shows, concursos, musicales, humor, entre otros); ficción (películas y series); 
informativos (noticias, documentales y de divulgación) y deportes (programas deportivos).

Cuando hablamos de géneros televisivos nos referimos a un conjunto de “(...) elementos semánticos, sintácticos y morfológicos recurrentes, que son mecanismos que generan la repetición, la previsibilidad y la estabilidad" (Gordillo, 2009: 29) que permiten el reconocimiento e interpretación por parte del telespectador. En este sentido, los géneros construyen estrategias discursivas vinculadas a los temas que proponen a través de: “(...) los anuncios promocionales de los diversos espacios, las cabeceras de presentación, los títulos de crédito o el sumario en telediarios o magacines". (Gordillo, 2009: 30)

En este punto y en primer lugar, pudimos reconocer las preferencias de visionado de los diferentes géneros que ofrece la TDA. Para ello, recuperamos las alusiones a los temas que se expresan en los contenidos que eligen a la hora de mirar televisión digital. Nos dedicamos a identificar los contenidos que mencionaron cuando respondieron sobre las emisoras o programas que acostumbran a mirar en la televisión digital.

En principio, encontramos que la preferencia más fuerte se inclina hacia canales que concentran programas informativos tales como: TN, C5N, CN23, Canal Encuentro, Telesur y a otras emisoras de entretenimiento y en particular, las que se focalizan en el entretenimiento infantil como: PAKA-PAKA o TATETÍ. Aquí recuperamos algunos pasajes de las conversaciones con los usuarios de TDA.

La digital te ofrece más información, más variedad gratuitamente (...) Y en la digital encontrás canales educativos para chicos, de 24 horas todo el día, donde casi no hay publicidad, hay publicidad por ahí del mismo canal y no de los canales... publicidades de afuera, como en PAKAPAKA o en Tatetí. (Daniel, 66 años, Barrio La Pilarica)

Vemos el noticiero. Y a la noche vemos la novela de Telefe y el programa de entretenimiento, que hay uno en Telefe. (...) Miraba Capusotto [programa de humor], es el único que miraba con frecuencia digamos y después algunos documentales en Encuentro. (Mónica, 51 años, Barrio Santa Rita)

Me gustaba mirar uno de noticias que es del Sur, me parece que es, Telesur. Me gustaba mirarlo porque era una panorámica internacional (...) Como PAKAPAKA, todos los dibujitos de chicos son artesanales, programas que hay para la construcción que le enseña a gente a trabajar, carpintería y un montón de cosas que son instructivas. (Ernesto, 79 años, Mariano Moreno) 
En segundo lugar, los usuarios de TDA se refirieron a su preferencia por canales emisores de programas de deportivos y de ficción como lo expresan Nicolás, A. (20 años, Barrio Altos de José C. Paz) o Graciela (46 años, Barrio Santa Rita).

Y los partidos de básquet en DeporTV me los miro casi todos, los que no puedo mirar me los grabo (...) DeporTV miro mucho por el básquet, después miro los canales que están en HD que por lo general son los que pasan los partidos de fútbol. (Germán, 26 años, José C. Paz Centro)

Por otro lado, advertimos que algunas usuarias de televisión digital diferenciaron la propuesta de contenidos de la TDA en relación con la televisión abierta, de cable y vía satelital. Las integrantes de la Mutual Primavera señalaron que encontraban diferencias en relación con el tipo de canales mencionaron que la TDA ofrece contenidos de producción nacional o regional de noticias, de entretenimiento infantil, de películas, etc. en contraposición con productos enlatados extranjeros en su mayoría, de origen norteamericano. En ese sentido, sostuvieron que preferían la programación de la TDA a la ofrecida por el sistema de aire, de cable o satelital.

Sí, sí, yo no soy muy consumidora de la televisión, cuando era más chica tenía cable Telered, que es, era el único canal de cable, claro que...,...) hay programaciones que otros cables no te lo ofrecen, te ofrecen todos los canales de, de yanquis, de otros países, puntualmente de Estados Unidos. y muy pocos de Latino-América. Entonces este, este cable. (...) más Latino-América, otra cultura. (Érica, 20 años, Barrio Primavera)

Y las características que tiene es que podés ver canales de otras provincias, inclusive de otros países que no tenés en el cable privado porque a ver... acá en el barrio se dio la situación de que te daban el DIRECTV prepago. (...) después te das cuenta que es lo mismo, que te sale más caro, que no ves nada, que llueve y se corta. (...). (Verónica, 45 años, Barrio Primavera)

Podemos señalar que, entre nuestra población en estudio, cuando decidían mirar televisión digital mediante la TDA predominaba el visionado de géneros informativos y de entretenimiento. Y particularmente, dentro del género entretenimiento algunos mencionaron que preferían emisiones centradas en espectáculos deportivos o películas y series. En sentido amplio, entre las preferencias de visionado de los usuarios de TDA distinguimos la elección de productos audiovisuales de elaboración nacional o regional emitidos por canales como PAKA-PAKA, C5N, TeleSur, DeporTV, etc. dado que es una de las apuestas de la política pública: la producción nacional de programas televisivos. 
No obstante, cuando indagamos el visionado que refieren los entrevistados también se manifiestan las preferencias entre la televisión analógica y la digital. En este sentido, algunos beneficiarios de la TDA señalaban que optaban por mirar la televisión analógica o de aire debido a la escasez de canales para sintonizar en la plataforma TDA además de señalar problemas de conexión, que la señal se disipaba y la imagen se perdía o se pixelaba.

Sé que tiene un montón de canales a parte de los canales de aire, como C5N, PAKAPAKA.(...) La verdad que los canales extra digamos son muy pocos (...). (Fátima, 35 años, José C. Paz Centro)

La verdad que los canales extra digamos son muy pocos. (Mónica, 51 años, Barrio Santa Rita)

Básicamente eran esos canales que eran los que siempre mirábamos. Y si podías ver los dos no podías verlos bien en HD, te daba la opción para verlo en HD y se pixelaba. La diferencia es que se ve mejor en cuanto a la antena que vos tengas, por ejemplo, nosotros probamos como 6 antenas porque las palomas las rompían las del aire, entonces por eso veíamos mal, por ahí si tenés una buena antena me quedaría con la de aire porque no si va a pixelar nunca y se ve bien. (Nico, N., Villa Altube)

No se ve bien la televisión, generalmente se cortaba una vez cada tanto. (Paula, 44 años, José C. Paz Centro)

Estas referencias respecto de las dificultades técnicas de visionado de la TDA (problemas de conexión, de imagen o de sintonización), presentes en diferentes pasajes de los dichos de los entrevistados, nos conducen a interrogarnos si tienen efectos sobre la preferencia entre la televisión analógica y la digital. Dicho de otro modo, nos interesa entender si las fallas técnicas de la TDA conducen a varios de los beneficiarios de nuestro estudio a elegir la oferta de contenidos de la televisión tradicional comercial de pago en relación con la aquella que brinda la televisión digital.

\subsection{La función de la interactividad en la TDA}

Una de las funciones de la televisión digital es la interactividad que permite cierto grado de interacción con contenidos audiovisuales tales como: consulta de guías de programación, información de servicios públicos (tráfico, meteorología, etc.), despertador hasta votaciones, encuestas o transacciones financieras. 
Según Kantor, Marcaletti y Pafundi (2013:46) existen diferentes tipos de interactividad teniendo en cuenta las propiedades técnicas de la televisión digital: interactividad básico o de primer nivel (no es necesario canal de retorno y el usuario se vincula a través del control remoto mediado por el set-top box para consultar servicios básicos, el clima, la información local); de segundo nivel (información asociada a la emisión de los programas, como por ejemplo estadísticas deportivas, juegos, gestiones de gobierno); de tercer nivel (requiere una aplicación con contenidos adicionales de un programa para cuyo uso el conductor del programa ofrece instrucciones específicas) y de cuarto nivel (el usuario influye durante la emisión del programa interviniendo en tiempo real).

En el caso de la TDA, a partir de la adopción de la norma técnica japonesa-brasileña, se requirió el desarrollo del Ginga para las aplicaciones y herramientas interactivas e internet para optimizar los servicios interactivos. No obstante, es necesario señalar que los contenidos a los que podía acceder el usuario están preelaborados, no se encontraban alojados en la web sino en el hardware del decodificador o receptor de la televisión digital. Es decir pertenece, según la clasificación de Kantor, Marcaletti y Pafundi, (2013), al primer nivel o al segundo nivel de interactividad donde no se necesita un canal de retorno (vía conexión a internet o mediante un servicio de telefonía). Al momento de nuestro estudio (finales de 2014 e inicios de 2015) esta función estaba limitada aunque el Estado había puesto en marcha el Plan "Argentina Conectada"171 para desarrollar infraestructura y servicios de conectividad en todo el territorio nacional.

En los documentos que forman parte de la política pública de inclusión digital TDA, las referencias a la interactividad son amplias, están relacionadas a la idea de inclusión digital y no explicitan las características y funciones que le suman a la televisión digital. Por ejemplo. el Plan "Argentina Conectada" señala que la estrategia de implementación del SATVD-T, entre sus objetivos, fomenta el uso de los servicios interactivos con vistas a extender el intercambio de datos entre los ciudadanos. Por otra parte, entre los lineamientos generales para ejecutar la política pública de inclusión digital propone desarrollar contenidos digitales interactivos para diferentes actividades productivas, sociales y culturales.

\footnotetext{
${ }^{171}$ El Plan "Argentina Conectada" previó difundir banda ancha a través de la construcción de la Red Federal de Fibra Óptica (Decreto 1552/10) para otorgar conectividad residencial (disponibilidad y uso en los hogares ) y en los espacios públicos a través de los NAC (Núcleos de Acceso al Conocimiento) o de PAD (Puntos de Acceso Digital). Ver Apartado 6.2.4 en el capítulo VI.
} 
Cuando le preguntamos a los entrevistados si conocían los servicios ofrecidos por la TDA, $\mathrm{y}$ en particular la de interactividad, adujeron desconocerlos. En este punto, no encontramos diferencias etáreas entre las respuestas de los usuarios: tanto jóvenes como adultos y adultos mayores ignoraban las prestaciones interactivas tales como: consulta del estado del tiempo, del tránsito, entre otras.

No, no sabía eso. No nos manejamos con computadora ni nada de eso. O sea, ni mi marido ni yo te estoy hablando, porque mi hijo sí, pero desde la tele no lo hace. (Ana María, 61 años, José C. Paz Centro)

No, manejo lo mínimo, lo básico puede ver la tele. No sabía que se podía ver el estado del tiempo o del tránsito... o prohibir programas para chicos... como acá no tenemos chiquitos... no sabía. (María, 65 años, Villa Altube)

No obstante, otros entrevistados refirieron conocer la función de interactividad describiendo algunas de sus características y ciertas operaciones que realizaban con la TDA.

Claro, sí, por ejemplo, que puedas mandar a través de la televisión supongamos un Twitter a un programa que esté saliendo en vivo. No, no yo tanto de la parte tecnológica no, no es mi fuerte. (Paula, 44 años, José C. Paz Centro)

Si, engancho la computadora y veo películas, por ejemplo. (...) No, no lo tengo programado pero existe por ejemplo, para usarlo de despertador, de agenda, está, está la función pero no la uso porque eso, eso qué pasa, eso uno lo usa en el teléfono. O podés dejar programado que te grabe un programa, le dejás un pendrive instalado y te lo graba porque el aparatito nuevo de ahora tiene para poner un pendrive para computadora. Podés usar internet con la TDA, vos instalás internet, le ponés el ganchito y tenés internet en la TDA, podés buscar un programa en internet y lo mirás en la tele." (Verónica, 45 años, Barrio Primavera)

Sí, yo uso más el de mi pieza que el de la cocina, pero hay muchas veces que mi vieja me pregunta algo y se lo resuelvo. Lo que ví en el deco es que tiene para sintonizar radios pero no sintoniza ninguna. Eso sería otro modo de interactuar con la TV, pero se ve que todavía no están habilitadas, será como las señales que yo tengo en el LED y no me engancha nada. Hay como un montón de potencialidades que todavía no son acto. Después el deco tiene para colocar un pen drive y podés ver imágenes, tipo un DVD y creo que si pones algún video también te lo lee. (Germán, 26 años, José C. Paz Centro)

Las diferentes operaciones que relatan estos usuarios de la TDA en relación con los servicios de interactividad refieren al uso de aparatos técnicos (pendrive, computadora) que conectados al set top box o decodificador y al televisor permiten programar alguna emisión, ver alguna película, imágenes, etc. Lo que nos interesa destacar aquí es que si bien describen la operatoria para realizar algunas acciones de primer o segundo nivel de 
interactividad con la televisión digital reconocieron que no las usaban y/o que no se encontraban desarrolladas entre las prestaciones que ofrecía la TDA al momento del presente estudio. Es decir, a partir de los escasos servicios que estaban operativos los beneficiarios los reconocían pero quedaban en el plano de la conjetura antes que un uso efectivo.

Algunas de las afirmaciones de los entrevistados permiten reconocer cuáles eran las percepciones e ideas sobre la interactividad entre los usuarios de TDA. Varios entrevistados respondieron que no se les ocurrían tareas o acciones diferentes a las que podían llegar a realizar con la televisión digital en ese momento como por ejemplo comunicarse con programas en vivo a través de alguna red social como Twitter o Facebook.

Lo mismo que ahora, tener un poco de comunicación con un programa en vivo, lo mismo que ahora, capaz que de otra manera, capaz que podés llamar desde la televisión pero la función sería la misma, comunicarse en el momento. (Fátima, 35 años, José C. Paz Centro)

No sé, ni idea, así como hasta ahora no me plantea nada, si hubiera otra opción... por ahí con Smart TV que uno tocara una opción y el locutor dijera otra cosa. Claro, si uno pudiera elegir una historia y buscar distintos finales, en cuanto a eso pero van a pasar muchos años para que sea gratuito y todo." (Daniel, 66 años, Barrio La Pilarica)

No sabía no, no todavía no, el clima sí, pero el tránsito no sabía que... ví que se puede, porque yo te hablo de la nueva viste, de la que es más gordita, que trae otros puertos. Sí, que está la pantalla grande y abajo tenés la pantallita más chiquita y podés cambiar de canal. Claro sí, sí. Y abajo te indica las otras pantallitas, los otros canales, pero vos seguís viendo el que querés ver. (Érica, 20 años, Barrio Primavera)

No, para nada. (...) El hecho de poder participar con los programas que estás mirando. Mirá, sería interesante saber, así como uno aprendió a manejar un coche, como aprendió a trabajar, a tener un oficio, es lindo también poder relacionarse con eso, poder relacionarse con gente, con los jubilados, con los centros de jubilados, con todas esas cosas que hay, sería lindo poder hacerlo. Pero no estamos preparados, qué sé yo, económicamente primero y después para estar pagando viste un montón de cosas que tenés que pagarlo para tenerlo. Comodidades que hay que pagarlas. (Ernesto, 79 años, Mariano Moreno)

Las funciones de la televisión digital que imaginan están asociadas a los primeros grados de interactividad (consulta, programación, segunda pantalla) $\mathrm{y}$, como señalamos anteriormente, a ciertas acciones que reconocen ya sea por contacto con otros usuarios que "saben sobre tecnologías" o bien por alguna experiencia en el uso de los servicios 
ofrecidos por la TDA. En general, podemos decir que las ideas que predominan están relacionadas con los diferentes grados de familiaridad que experimentan los usuarios con las tecnologías digitales: consultas, navegación por internet, programación, grabación de emisiones, uso de redes sociales, entre otras.

Finalmente, de las respuestas de nuestros entrevistados nos interesa destacar las ideas relacionadas con el aprendizaje en el uso de las tecnologías, en particular, con las que proponen la interacción o participación a través de los dispositivos con emisiones, con los conductores de las mismas o con la expectativa de comunicarse con otras personas. Aquellos comentarios que recuperaron la incorporación de prácticas necesarias para usar diferentes tecnologías en la vida cotidiana (manejar autos, operar máquinas o herramientas para trabajar, poner a funcionar electrodomésticos, etc.) y otros que manifestaron cierta disposición personal a relacionarse con pares a través de algún servicio digital. Estas apreciaciones permiten advertir que si bien, nuestros usuarios de TDA dicen no conocer o representarse la función específica de interactividad en la televisión digital pueden, aunque con ciertas limitaciones, arriesgar algunas ideas asociadas a las experiencias con otras tecnologías en el ámbito de la cotidianidad.

Sin embargo, nos llamó la atención que depositaran sus expectativas sobre la posibilidad efectiva de aprovechar la "interactividad" de la televisión digital en la variable económica: "van a pasar muchos años para que sea gratuito y todo", "tenés que pagarlo para tenerlo. Comodidades que hay que pagarlas". En estos discursos la noción de interactividad se vincula no solamente a acciones poco conocidas o escasamente experimentadas sino que la materialización de las mismas depende de un medio de pago para acceder a servicios interactivos.

\subsection{Otros usos de las tecnologías: asociaciones y efectos de desplazamiento}

Entre las características de las prácticas involucradas en el uso de las tecnologías digitales interactivas nos interesó identificar aquellas situaciones en las que los usuarios recurren a diferentes dispositivos técnicos para realizar diversas actividades: aprender, informarse, comunicarse o relacionarse con otros, entretenerse (jugar, mirar películas, series, documentales, escuchar música, etc.), trabajar, entre otras. En esta dirección, entendemos que estos usos se vinculan con otros soportes tecnológicos y las diferentes estrategias de 
capacitación de estos tales como la computadora o la telefonía móvil en tanto forman parte (de modo diferenciado) de la escena doméstica. Es decir, las computadoras personales y los teléfonos móviles son dispositivos técnicos que se encuentran relativamente instalados como parte de los hogares.

Mencionábamos en el apartado 5.2.3 del capítulo V que los hogares del país, durante 2013, se extendió un 71\% el uso de la computadora con un $68 \%$ de usuarios activos y un $65 \%$ de usuarios conectados a internet. Asimismo, la disponibilidad y el uso de telefonía móvil tuvo una penetración de 85 \% que tienen una línea activada y cerca del 40\% tiene un dispositivo de tipo inteligente conectado a internet. Coincidentemente, el estudio de Abramovich, et.al. (2014) en los Partidos de San Miguel, José C. Paz, Moreno y Malvinas Argentinas de la Provincia de Buenos Aires, identificó que el 71\% de las personas utilizaba la computadora con acceso a internet en relación con un $32 \%$ que no poseen conexión a la red de redes. Por otra parte, el uso de telefonía móvil asciende a un $69 \%$ en los hogares. Asimismo, la Encuesta de Inclusión Digital (OUMI:2014 ${ }^{172}$ ) registra un nivel de acceso a las tecnologías significativo:

"Más de la mitad de la muestra alcanza niveles medio y alto. Hemos constatado que hay cierta intervención del Programa Conectar Igualdad (PCI) en esa situación. Entre los encuestados que poseen una netbook (35\%), solamente la mitad declara que se trata de computadoras PCI. El 64\% de quienes poseen una netbook PCI son de NSE bajo".(Cabello y Moyano,2015:6)

Según nuestro estudio, la presencia de la computadora de escritorio en los hogares es relativamente alta. Entre los que afirman que no tienen o si la tienen no funciona encontramos los siguientes relatos:

No, computadora no tengo, internet tampoco tengo. (Marcela, 32 años, Barrio Primavera)

No, porque se me rompió (la computadora). (Fátima, 35 años, José C. Paz Centro)

No, todavía no. (Graciela, 46 años, Barrio Santa Rita)

En relación con los usos que le dan los entrevistados a la computadora, solamente uno de ellos consigue diferenciarla de los usos de internet.

Yo uso mucho la compu para la música, para los videos juegos, para el diseño, tengo todo ahí básicamente. Yo en mi casa no tengo internet, es una decisión que

${ }^{172}$ La Encuesta sobre Inclusión Digital (OUMI: 2014), con una muestra intencional por cuotas de edad, sexo y NSE, de 152 casos que incluyó a residentes de los partidos de San Miguel, José C. Paz y Malvinas Argentinas. 
tomé hace rato y no me arrepiento, la uso acá en el trabajo y en el otro trabajo pero en mi casa no. (Germán, 26 años, José C. Paz Centro)

El resto, en cambio, tiende a responder por los usos que realiza de internet (aunque se le pregunte por la computadora). Encontramos que en general, señalan que lo hacen para entretenerse, informarse y en menor medida para y en el trabajo.

Según el rango etario de los entrevistados, el uso de la computadora y de internet se intensifica. Los más jóvenes dicen hacer un uso frecuente dedicado al entretenimiento (escuchar música o radio, ver películas, usar redes sociales como Facebook o Twitter), informarse (leer alguna noticia, chequear correos electrónicos) o estudiar (búsqueda de contenidos).

Escucho mucha música con la computadora y estudio música. (...). O sea, uso mucho Facebook y escucho mucha música. (...) (internet) Poder estudiar música, poder escuchar música. Generalmente eso es lo que más hago (Nicolás A., 20 años, Altos de José C. Paz)

Sí. Uso las dos cosas es para chequear mails en la compu y seguir mirando. (Preferencia entre PC y TV): No, la televisión. Es como que tenés a mano toda la tecnología entonces te permite hacer varias cosas a la vez. (Érica, 20 años, Barrio Primavera)

En tanto, aquellos entrevistados adultos o adultos mayores aducen que usan en menor medida - o no lo hacen - la computadora y/o internet. Entre quienes usan poco la computadora e Internet, afirman que lo hacen principalmente para informarse (leer noticias, escuchar radio) o chequear correo electrónico y menos para ver alguna película, documental o serie. Particularmente, cuando los entrevistados refieren al uso de Internet señalan que el servicio domiciliario de datos tiene deficiencias que limitan la posibilidad de acceder a lo que buscan.

Es buscar información, no hay nada mágico. (...) No, no por el hecho de que el servicio es malo no puedo ni escuchar la radio. (Daniel, 66 años, La Pilarica)

No, un poco para cada uno porque igual no dispongo de mucho tiempo como para estar en una cosa y la otra, entonces un poquito cada una y ya está. (...) Y cuando tiene velocidad internet, que acá viene en carreta. Abrir el Facebook y el correo. (...) No, no, a veces el diario o el Home Banking por ahí, pero otras cosas no. (Mónica, 51 años, Barrio Santa Rita)

$\mathrm{Si}$, por ejemplo, si no sé algo lo googleo y listo. Inclusive trámites burocráticos que por ahí vos te fuiste y no entendiste o no te explicaron bien y a buscarlo. $\mathrm{O}$ por ejemplo, queríamos hacer bloques de cemento, fuimos a internet, miramos un video. (Verónica, 45 años, Barrio Primavera) 
Más que nada películas de acción, de terror, cuando nos sentamos a mirar no estamos indagando desde lo informativo, no? (...) Por ejemplo con la computadora no, más que nada nosotros que tenemos el equipo de música por ahí yo a la mañana a veces o a la noche, una hora ponéle, más que nada uno consume los medios masivos de comunicación los fines de semana. (Paula, 44 años, José C. Paz Centro)

Ya de por sí tener una computadora, tener aparatos modernos de telefonía, que nosotros vivimos con ese viste, nos criamos con ese. A mí me gusta hablar con este, con esto lo llevo para que ella se quede tranquila cuando voy a cobrar, entonces es para estar intercomunicados los dos, nada más. No, nosotros sabemos prenderla y apagarla y cambiarla de canal. (Ernesto, 79 años, Mariano Moreno)

Cuando consultamos a nuestros entrevistados acerca del uso que le confieren a la computadora en su cotidianidad advertimos que las diferencias de intensidad se ubican según el rango etario, es decir, los jóvenes suelen usarla para diversas actividades: mirar películas, redes sociales, estudiar y los adultos y adultos mayores dicen chequear el correo electrónico, escuchar la radio o buscar noticias. Uno de los hallazgos en relación con el uso de la televisión digital es que estas situaciones de uso no parecen producir efectos de desplazamiento de los consumos culturales identificados. O sea, en sentido amplio, los usuarios no asocian el uso de estos dispositivos técnicos a las prácticas de consumo de medios y tecnologías de información y comunicación si no que lo piensan como una experiencia diferente y a través de la que hacen o pueden hacer diferentes acciones a la que refieren en relación con la televisión digital. En este sentido, la televisión (digital o analógica) no pierde centralidad en los hogares en relación con otros dispositivos técnicos como la computadora o el teléfono móvil. Pero los entrevistados no dejan de usar la computadora o escuchar radio e incluso mirar la televisión analógica para consumir la TDA sino que complementan los usos según la evaluación de necesidades y expectativas sobre cada uno de los dispositivos: búsqueda de información, entretenimiento, comunicación, etc.

\subsection{Los usos de la TDA y las expectativas de inclusión digital}

Para indagar los usos de la televisión digital en la población en estudio y como parte de nuestros objetivos de investigación nos propusimos indagar los procesos de integración de tecnologías interactivas y los vínculos que establecen los usuarios con estas, características de los usos que realizan, efectos de desplazamiento, tipos de usos. 
Los usos efectivos y posibles modificaciones que se realicen de los usos actuales entre los sujetos de nuestro estudio están condicionados por las representaciones y las expectativas que estos construyen de la relación entre las tecnologías digitales y sus prácticas sociales, culturales y políticas. En este sentido, nos interesa recuperar la noción que construye Aprea (2006:89), sobre las representaciones como aquellos modos en que los grupos sociales “( $(.$.$) comprenden, comunican y se relacionan con un fenómeno social$ (...) que como resultado del lugar que ocupan en los procesos de intercambio simbólico (...) actúan como condicionantes de los usos presentes y futuros (...)”.

Por supuesto, no nos referimos aquí a todos los usuarios de tecnologías digitales y de televisión digital porque no nos proponemos generalizar los resultados de la investigación. En efecto, nos centramos en nuestros entrevistados, que pertenecen al conjunto de los que recibieron el beneficio del Plan "Mi TV Digital" en una zona que, en sentido amplio, corresponde a una de las más relegadas del conurbano bonaerense desde el punto de vista de los indicadores socioeconómicos. Allí donde la población pertenece a sectores vulnerables que no participan activamente del sistema de consumo de bienes materiales y simbólicos.

Para conocer la relación que las personas que residen en esta región, y en ese tipo de condiciones, establecen con las tecnologías interactivas nos propusimos analizar los tipos y calidad de usos de las tecnologías que decían realizar los usuarios de la TDA en sus contextos cotidianos ${ }^{173}$.

Antes de continuar con la caracterización de los usos de la televisión digital debemos señalar que entre los aspectos implicados en la noción de usos hemos considerado: situaciones de uso; motivaciones; tipos de aplicaciones más usadas, complementación con otros medios y efectos de desplazamiento; definición de ventajas y desventajas; dificultades percibidas; tiempo de trabajo y tiempo libre; evaluación y expectativas en relación con la vida cotidiana. Parte de estos aspectos los hemos descripto anteriormente. En este apartado, examinaremos algunos de estos rasgos retomando la información que hemos presentado al inicio de esta parte del presente capítulo.

\footnotetext{
${ }^{173}$ Hemos referido en el capítulo IV el concepto de inclusión digital que involucra diferentes dimensiones: acceso, uso, autoafirmación y participación. Sin embargo, aquí nos dedicaremos a registrar las primeras (que retomaremos en la segunda parte de este capítulo) y analizaremos en conjunto con las segundas para completar un análisis más profundo del problema de la inclusión digital.
} 
En principio, los entrevistados se reconocían con destrezas básicas en el uso del receptor digital teniendo en cuenta que los jóvenes y jóvenes adultos admitían menos dificultades que los adultos mayores. Y en el caso del último grupo, si necesitaron ayuda la recibieron por parte de un familiar que, en general, es más joven y que es usuario que generalmente tiene algún dominio de otras tecnologías digitales (PC, telefonía celular). Entendemos que estas percepciones están asociadas a la idea de habilidad ${ }^{174}$ que se entiende como la capacidad y disposición para ejecutar algún tipo de tecnología que implica cierto grado de conocimiento sobre diferentes aspectos vinculados con el televisor. En el caso del uso del televisor, estas destrezas se han construido histórica y socialmente pero también en relación con la vida cotidiana. Sin embargo, están vinculadas a la posición que ocupa el sujeto en el espacio social. Por lo tanto, en el caso de nuestro entrevistados, la pertenencia a sectores socioeconómicos bajos y/o medios bajos con limitado acceso a diversos consumos culturales es un dato significativo que no debemos perder de vista a la hora de pensar el modo en que se relacionan con las tecnologías digitales en general y en particular, con la televisión digital.

No solían usar todas las funciones que posibilita el decodificador tales como consultar información de la programación, una agenda de programas, el estado del tránsito y del tiempo, restringir contenidos no aptos para niños y, en general, tampoco se figuraban cuáles podían ser. Encontramos que les resultaba difícil representarse otras posibilidades diferentes a las asociadas al manejo de la televisión analógica - a través de algún sistema de cable o televisión abierta -, tales como elegir la señal, mejorar la imagen o el sonido, etc.

Recuperamos otra de las categorías indagadas tal como para qué miran televisión: para informarse, entretenerse, etc. Los entrevistados afirmaban que veían televisión, en general, para informarse o para entretenerse mientras realizaban tareas domésticas o estudiaban y no encontraban diferencias entre la analógica y la digital.

Ahora bien, cuando indagamos las impresiones acerca de otros usos posibles de la televisión digital específicamente, no aparecieron ideas asociadas a la interactividad que

\footnotetext{
${ }^{174}$ Tomamos el concepto de habilidad de la propuesta que ha construido González, J: (1999): Tecnología y percepción social: evaluar la competencia tecnológica, en Revista Culturas Contemporáneas, Volumen V, $\mathrm{N}^{\circ}$ 9, Junio.
} 
ofrecía el decodificador digital. En todo caso, las asociaciones las realizaban en vinculación con otros medios conocidos.

A partir de estas primeras conclusiones generales, nos interesa relevar en sentido amplio, los tipos de usos (no usos, usos poco frecuentes y usos frecuentes) para luego reflexionar sobre el modo en que se articulaban con las expectativas de inclusión digital en el discurso de los usuarios de la TDA.

Los beneficiarios de la TDA que manifiestan hacer usos frecuentes de la televisión digital, con cierto dominio de tecnologías digitales (telefonía móvil, computadoras, etc.), pertenecen al grupo de jóvenes y adultos jóvenes. Este tipo de usos lo identificamos en los testimonios que explicitan las diferentes acciones que pueden realizar con el dispositivo digital como actualización de software, manejo del menú digital, grabación de programas o utilización del USB para escuchar música. Si bien, caracterizamos estos usos como frecuentes son meramente instrumentales y están orientados particularmente al entretenimiento. En cambio, los adultos mayores aluden realizar usos poco frecuentes o básicos ligados, como advertimos antes, a aquellos que fueron incorporando con las tecnologías analógicas: encender-apagar el dispositivo, sintonizar y operar los canales.

Cuando nos centramos en las expectativas acerca de los procesos de inclusión digital expresadas en el discurso de los entrevistados aparecen, en un primer análisis, referencias positivas que rondan la idea de acceso a la información que circula en la sociedad con el fin de integración social o cultural.

Y la inclusión digital para mí es como que todos estemos enterados de lo que pasa en todos lados y no que tengamos que pagar como pasaba con canal 13 que la gente afuera tenía que pagar el cable (...) Esto es algo que es para todos, pobres, ricos, medianos, clase media, la clase baja, la clase alta. (...) Sí, puede haber sí, para muchísima gente, para todos los argentinos, para países vecinos para todos, para unirnos entre países vecinos. (Ernesto, 79 años, Mariano Moreno)

No sé. Creo que es algo así como que todos tengamos lo mismo, o podamos tener conexión o ver la tele sin tener que pagar por hacerlo. Eso es que estemos todos incluidos, creo .... (María, 65 años, Villa Altube)

Me parece una especie de medio para que todos podamos ser parte de un algo. Uno, que todos podemos acceder al servicio y otro que el servicio sea lo suficientemente abarcativo para que todos de todas las edades y de todos los gustos podamos ver. (...) Me parece que ya es una inclusión poder abastecer de un servicio gratuito a todas las personas. (Nicolás, A., 20 años, Altos de José C. Paz) 
Considero que sí y más me parece... o sea, no, porque yo no tengo nada pero sé que hay gente que tiene mucho menos, que a lo mejor no tiene no sé, ni televisor color, no sé, me imagino por lo que veo, por lo que escucho, no porque sepa de alguien específico, pero entonces considero que sí, que hay gente, y más que nada a lo mejor que chicos que pueden tener la posibilidad de ver otras cosas, es un servicio que está bueno. (Ana María, 61 años, José C, Paz Centro)

Pero estas ideas acerca de la inclusión digital a través de las tecnologías digitales aparecen fuertemente ligadas a la condición de gratuidad en la disponibilidad de dichas tecnologías. En los relatos se destaca cierto reconocimiento de que el servicio gratuito de la televisión digital tiene la posibilidad de alcanzar a una gran cantidad de personas y/o grupos, de diferentes edades y condiciones socioeconómicas, con información y propuestas de consumos culturales diversos.

Por otra parte, encontramos otra posición entre los entrevistados que desestiman la idea de inclusión digital a partir de la obtención del beneficio de la TDA debido a que consideran que no ofrece todo lo que promete como por ejemplo, variedad de canales.

Para mí es los mismos aparatos que ellos te dieron pero que funcionen como ellos también dicen que es porque supuestamente te incluye, lo tenés que instalarlo y que se vean bien los canales que ellos te prometen que se ven, te dicen que podés ver un montón de canales y en realidad no son un montón. (Nicolás N., 17 años, Villa Altube )

Asimismo, señalan que además de que el Plan "Mi TV Digital" "impone" un cierto tipo de programación (aunque no ahondan en sus características) está dirigido a ciertos grupos sociales como los jubilados y por ende, consideran que no cumple con la expectativa de inclusión de otros o de todos los sectores de la sociedad. En estos relatos sobrevuela la idea de que hay una contradicción en la propuesta de la política pública ya que declama la inclusión digital para todos pero sólo lo hace para algunos en particular: en este caso aluden al conjunto de adultos mayores que perciben la jubilación mínima.

No, yo creo que no, la inclusión pasa por otro lado, porque ahí se está imponiendo desde el gobierno estos canales, la inclusión pasa por otro lado me parece a mí, me parece que se está imponiendo no que se esté incluyendo. (...) Y el hecho de que haya una antena para determinada... porque en realidad es para gente que es jubilada, ¿desde qué lugar hablamos de inclusión?, yo creo que primeramente no se incluye, es algo que se pinta, no lo veo como algo que se incluye, (...) es para determinado grupos sociales, si no sos jubilado, si no tenés determinado sueldo no lo tenés, entonces de qué inclusión estamos hablando?: la diferencia la hace el gobierno. Por ahí eso es una postura más bien política pero bueno, uno no puede separar la ideología política de... porque está todo incluido. (...) Incluirte por ahí 
tecnológicamente pero es contradictorio, porque no es para todos, estamos hablando de lo tecnológico, de lo digital (...) es entre comillas, es como una paradoja, te dicen inclusión digital pero para gente de la tercera edad. El plan abarca a los jubilados que tienen la mínima. Claro, los que tienen la mínima y los que tienen más no. (Paula, 44 años, José C. Paz Centro )

Entre estas percepciones se manifiesta la convicción de que la política pública depende del proyecto político del gobierno que decide atender las necesidades de los jubilados por sobre otros grupos sociales.

Una de las cualidades que se le adjudica a la televisión digital es que puede intervenir y/o modificar aspectos de la vida cotidiana de las personas. Entre nuestra población en estudio, en general, los entrevistados manifiestan que el uso de la televisión digital no transforma sus prácticas en el espacio doméstico. No obstante, las entrevistadas que son integrantes activas de la asociación Mutual Primavera sostienen que la llegada al barrio del Plan Mi TV Digital produce una diferencia: les otorga a los vecinos el derecho de acceder a la televisión de "calidad", a diferentes propuestas de contenidos, conocer otras culturas, etc.

"Y yo creo que es ...por ejemplo cuando pasó lo del Futbol para Todos y que no se entendió mucho, recién ahora se entiende pasaba esto el futbol es popular y es un derecho que lo tienen que ver todos, no? Y con la televisión es lo mismo, por qué tengo que pagar para ver Encuentro? Y me parece que tiene que ver por ahí, digamos...Y la calidad de imagen: yo que soy pobre tengo derecho a ver la misma calidad de imagen del que tiene plata porque es un medio de comunicación. Sí, yo creo que sí, hay que hacer todavía bastante pasos de conciencia en este sentido pero yo creo que sí porque si te cambia la conversación en tu casa ya está. (...) lo que creo que no es algo que te regalan... hay que trabajar. Nosotros cuando entregamos la antena decimos esto es un derecho porque hay un contexto que lo permite, porque hay un gobierno que tuvo la decisión política de hacerlo, porque bueno...esa conciencia hay que trabajarla. (Verónica, 45 años, Barrio Primavera)

Es un cambio de cultura, acceder por medio de la TV a otras culturas, saber que existen otros países y no uno dominante, uno puede elegir lo que le gusta, conocer otras culturas, otra clase de gente, otras realidades. Si creo que sí porque, accedemos a culturas impensadas, otros conocimientos, actitudes. (Érica, 20 años, Barrio Primavera)

Si para mi es mejor que cualquier otra porquería que puedas poner, DIRECT TV, todo eso para mí son porquerías.... aparte por más que tenga más canales todo lo que vos quieras, pero es como un cable, pero es algo nuestro es algo nuestro y es algo que siempre es, para mí es como los 5 canales de aire que éramos, cuando éramos chicas con un poquito más de información y más canales, por eso prefiero mil veces TDA por eso en mi casa en mi pieza esta TDA Y en la pieza de mi hijo bueno, mi hijo tiene DIRECT TV. Es más positiva. (Adriana, 44 años, Barrio Primavera) 
Si yo creo que sí, sirve porque tiene mucha, no sé para otras personas que tienen que tienen muchas...si los comentarios que me hace la gente, porque me parece que la otra tele no muchas cosas... (Marcela, 32 años, Barrio Primavera)

Si bien, en la voz de las entrevistadas el denominador común es que la política pública TDA les ofrece la posibilidad de "acceder" identificamos una diferencia entre el acceso a contenidos y el acceso a la calidad técnica. En el primer caso, en los relatos aparece una valoración explícita en relación al acceso a contenidos culturales nacionales además de conocer también otras culturas.

Prosiguiendo con la indagación sobre las expectativas de inclusión digital encontramos que estas entrevistadas consideraron una de las funciones de la TDA: la interactividad como una característica que "democratiza" acceso a las tecnologías y a los medios de comunicación para los vecinos del barrio, de la comunidad así como también la potencialidad de enriquecer la vida cotidiana.

Qué se yo, un sueño es que en esa cosa interactiva puedan estar todas las voces y cuando hablamos de todas las voces hablamos de todo, que los barrios puedan estar, desde su punto de vista y no sólo desde el punto de vista mediático, de lo que pueda vender o lo que conviene sino de lo que es. Porque cuando el barrio le pone la mirada, le pone la mirada objetiva, lo que es no está pensando en mí me conviene decir ahora esto, no, no yo tengo que decir esto porque pasa, es lo objetivo. (Verónica, 45 años, Barrio Primavera)

Sí creo que sí, me interesa el tema y creo que podría aprender cosas nuevas para aplicarlas en la vida cotidiana y el trabajo. (Érica, 20 años, Barrio Primavera)

En estos casos, las representaciones sobre la televisión digital como medio para incluir a las personas en "riesgo de exclusión digital" se asocian a los sentidos atribuidos a la inclusión social de poblaciones en situación de vulnerabilidad. O sea, las alusiones a las potencialidades de la televisión digital se entienden como vehiculizadoras de procesos de inclusión digital en tanto también tiende a disminuir las desigualdades sociales a partir del acceso a recursos tecnológicos. El hecho de que las entrevistadas participaran como parte del eslabón territorial en la implementación de la política pública de la TDA junto a su activa adhesión al proyecto político de la gestión de Cristina Fernández se presentan como condicionantes de sus percepciones en torno a los beneficios que comporta la televisión digital para producir inclusión digital. 
Hasta aquí, las ideas que surgen del discurso de los usuarios sobre la inclusión digital se apoyan en la disponibilidad y el contacto con los dispositivos técnicos (televisión digital, computadora, telefonía móvil, etc.) y en mucha menor medida, en el uso de estos a fin de una efectiva integración a la vida cotidiana.

Como dijimos al principio de esta sección, nos interesa reflexionar sobre los sentidos que los usos de la televisión digital se relacionan con los procesos de inclusión digital entre nuestros entrevistados. A tal efecto, podemos advertir que los jóvenes y los adultos jóvenes - cuyos usos son relativamente frecuentes- pueden establecer cierta distancia crítica con la idea de la inclusión digital a partir de la desconfianza de las intenciones del gobierno en la propuesta de integración de tecnologías digitales a partir del Plan "Mi TV Digital”. Empero los adultos mayores - con usos menos frecuentes y básicos- se perciben incluidos en tanto beneficiarios de la TDA y le atribuyen sentidos positivos a la obtención y disponibilidad de la televisión digital. Entre quienes también se representan como incluidos se encuentran las integrantes de la Mutual Primavera que tienden a reconocer las condiciones de acceso gratuito como expresión de la garantía de derechos para las mayorías con "riesgos de exclusión".

En la próxima parte del presente capítulo, ahondaremos en el análisis del conjunto de las dimensiones que nos permiten atender los procesos de inclusión digital. 


\section{PARTE II. La TDA en el territorio: la televisión digital llega a casa}

\subsection{Lo bueno y lo malo de la TDA: infraestructura, oferta y ACCESO}

A principios de 2014, en Argentina, la televisión de aire y de pago en los hogares alcanzó más del $97 \%$ de la población (ENCCyED,2013:11). En ese universo, un 70\% poseía televisión por cable que sumado al servicio de TV satelital trepó al 83\% de presencia en los domicilios del país. Mientras se verificó que el 14\% de los usuarios tenía el servicio de televisión por aire y apenas un 7\% contaban con TDA.

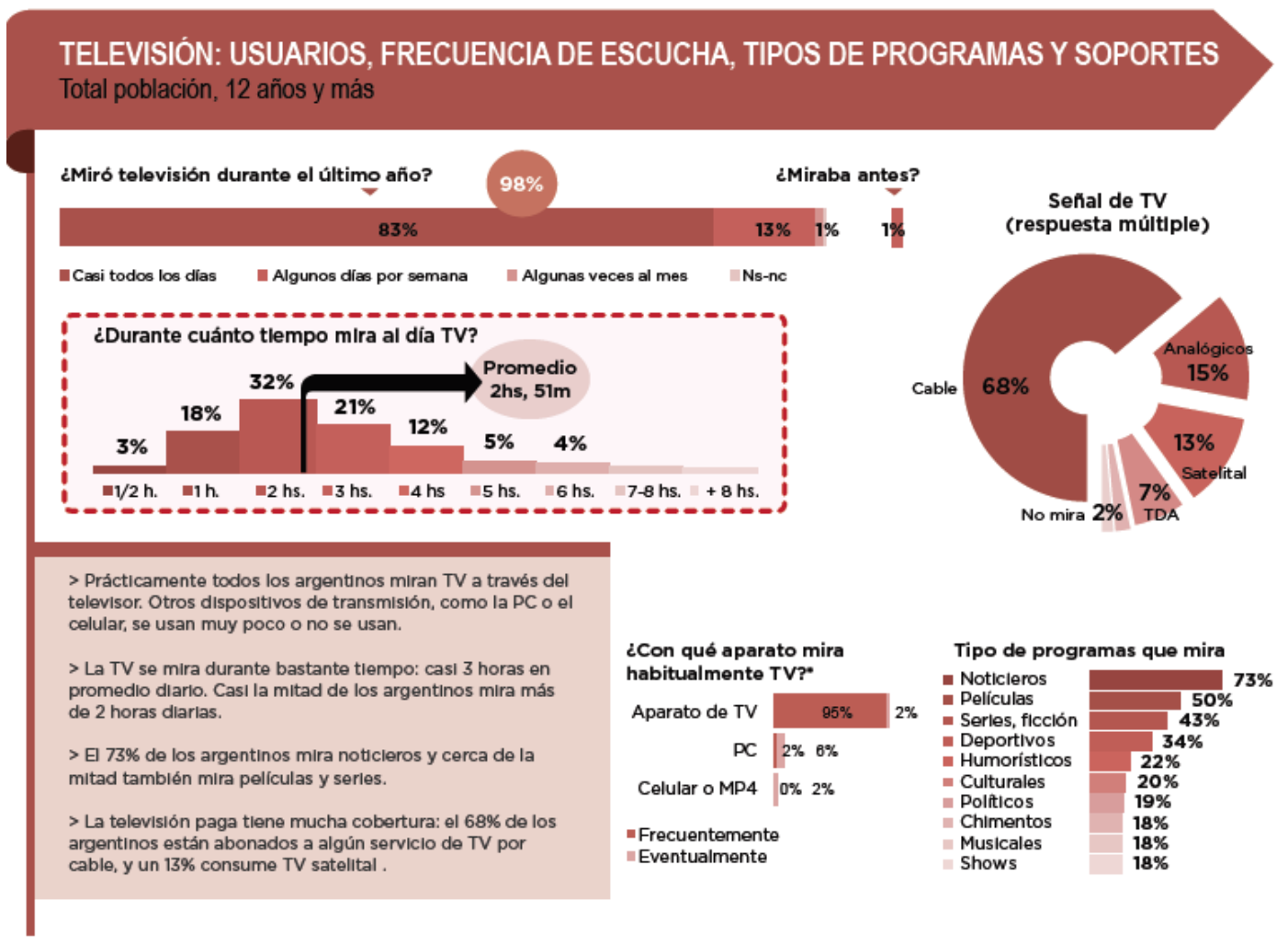

Figura 5 (ENCCyED, 2013:11)

En concomitancia con estos datos en el AMBA, el televisor adquirió una alta penetración en los hogares donde casi el 70\% usa servicios de televisión pagos (por cable o satelital) en tanto, un 7,5\% obtuvieron TDA (con decodificador $y / 0$ sintonizador digital incorporado). Si nos enfocamos en las cifras que arroja la encuesta producida por Abramovich, et.al. (2014) en los partidos de San Miguel, José C. Paz, Moreno y Malvinas Argentinas se mantienen las diferencias entre la disponibilidad de televisión de pago y/o satelital y la de TDA tanto que de los decodificadores digitales entregados (unos 40.000) escasamente un $2 \%$ de los hogares admitía poseer dicho servicio. 


\section{Cuadro 6. Tipo de sistema de TV en el hogar}

\begin{tabular}{|c|c|}
\hline Sistema de TV & Porcentaje \\
\hline TV por cable & $49,43 \%$ \\
\hline TV de aire & $28,68 \%$ \\
\hline Satelital & $18,11 \%$ \\
\hline TDA & $2,26 \%$ \\
\hline Otro & $1,51 \%$ \\
\hline Total & $100 \%$ \\
\hline
\end{tabular}

Fuente: Encuesta sobre TV, cine e Internet en José C. Paz, Malvinas Argentinas, Moreno y San Miguel, UNGS 2013.

Figura 6: Tipo de servicio de TV en hogares de los Partidos de José C. Paz, Malvinas Argentinas, Moreno y San Miguel. (Abramovich, 2013:6)

Sin embargo, hacia finales de 2015, según la ENTIC, en Argentina la televisión tenía una importante presencia en los hogares del territorio nacional seguida por el teléfono móvil y en el total de los partidos del conurbano bonaerense el guarismo ascendía a un 98,4\% de posesión.

El plan de acceso al equipamiento de recepción de la televisión digital, que se propuso cubrir el territorio nacional, requirió de un importante desarrollo de la infraestructura técnica y de producción que abarcó desde el tendido de la red, la instalación de las plantas transmisoras y antenas (TDT y TDS), la distribución de los decodificadores digitales hasta la generación de nuevos contenidos culturales.

La decisión del Estado argentino de dotar recursos técnicos, producir regulaciones normativas y destinar partidas presupuestarias para construir el sistema de medios de comunicación digital se articularon en un conjunto de políticas públicas de inclusión digital basados en planes que se propusieron cubrir las necesidades técnicas (soportes de transmisión y distribución de señales, equipamientos de emisión y recepción, servicios tecnológicos, etc.). Estas iniciativas buscaron superar una situación de “(...) obsolescencia tecnológica, subsidiariedad en el sistema y precariedades edilicias generalizadas" (Linares, 2017:73) con el fin de producir instancias de acceso de los ciudadanos a tecnologías de comunicación e información digitales.

En tiempos de la discusión internacional sobre los desequilibrios de la información entre países centrales y periféricos expresada en el NOMIC, la UNESCO publicó - en 1977- un informe que presentaba indicadores de democratización de la comunicación a partir de los conceptos de "acceso" y "participación”. 
La definición de "acceso" en ese documento refiere a la posibilidad de los ciudadanos de tener contacto con los sistemas de comunicación en al menos (2) dos niveles: elección del material, es decir, la opción de elegir emisiones mediáticas; y retroacción que implica interacción entre emisores y receptores siempre según las reglas impuestas por los productores. En relación con la "participación” se analizan (3) tres niveles: “(...) a) la intervención de la población en la producción de los mensajes, b) la intervención en la toma de decisiones, y c) la contribución para la formulación de planes y políticas de comunicación masiva”. (Rossi, 2016: 5)

Estos indicadores han sido abordados en diversas investigaciones desde la Economía Política de la Comunicación y la Cultura para analizar políticas de comunicación en América Latina y en nuestro país, en particular, sobre la democratización, la descentralización, las industrias infocomunicacionales y los desafíos de la transición digital (Rossi, 2016; Iturralde, 2013, 2015; Linares, 2015, 2016, 2017, Califano, 2009; entre otros).

En nuestro caso, nos interesa revisar esta idea de acceso en tanto involucra la elección sobre una oferta de diferentes tipos de medios de comunicación que requiere garantizar una amplia cobertura territorial. Rossi (2016:5-6) explica el primer nivel de acceso definido por UNESCO del siguiente modo:

“(...) el ideal de acceso se plasmará con la constitución de una trama de soportes masivos en la que cualquier habitante pueda elegir entre diversas formas de comunicación. En materia de radiodifusión, el derecho a recibir información está en primer instancia contemplado por la maximización de cobertura del servicio de radio o TV: que en cualquier punto de un territorio determinado pueda recibirse al menos una señal audiovisual”.

La cobertura del servicio de TDA comprendió, en principio, el tendido de la red, instalación de plantas transmisoras y de antenas (TDT y TDS) en cada una de las provincias. Hacia mediados de 2014, un comunicado ${ }^{175}$ del Ministerio de Planificación Federal, Inversión Pública y Servicios de la Nación celebró la instalación de 85 (ochenta y cinco) Estaciones Digitales Terrestres (EDT) operativas con la promesa de sumar 40

\footnotetext{
175 De la nota periodística del sitio de TELAM, disponible en http://www.telam.com.ar/notas/201408/76393-la-television-digital-abierta-cumplio-cinco-anos.html. [Consultado el 15 de febrero de 2019]
} 
más para el año siguiente. Teniendo en cuenta estas cifras se estimaba una cobertura del 95 (noventa y cinco) \% de población para 2015. (Observacom:2015)

El desarrollo de infraestructura para el funcionamiento (emisión, distribución y recepción) de la televisión digital, según las cifras que hemos reconstruido del período 2014-2015, parece dar cuenta de que se llega a cubrir el primer nivel de acceso. Esto supuso saldar la deuda de extender el servicio de comunicación audiovisual digital a todo territorio nacional.

Sin embargo, la distribución de equipamiento no pareció alcanzar una cobertura similar a la inversión en infraestructura técnica. Como señalamos en el capítulo II los números van entre 1.200 .000 y 1.600.000 decodificadores digitales entregados en el ámbito nacional a fines de 2015. No solamente tuvimos dificultades para encontrar estos datos - entre los producidos por la política pública e investigaciones académicas - sino que aquellos que relevamos específicamente de las fuentes oficiales son cifras generales que no precisan la cantidad entregada por provincia, departamento, partido o localidad. Por ejemplo, en el caso que nos ocupa, la distribución de decodificadores digitales en el Partido de José C. Paz fue relativamente baja alcanzando apenas un 2,26\% contando otras (3) tres localidades aledañas, según los datos recabados Abramovich, y González, (2014).

El segundo paso en la definición de acceso como indicador para la democratización de las comunicaciones, según UNESCO, es brindar una oferta mediática diversa a los receptores lo que en palabras de Rossi, (2016:7): “(...) garantizaría una amplia variedad del número de emisoras o señales de radiodifusión”.

El Plan "Mi TV Digital” desde su inicio ofreció una grilla de programación que incluyó un paquete de 15 señales de distribución nacional y unos 10 canales adicionales para CABA y $\mathrm{AMBA}^{176}$, donde coexistían emisoras de servicio público y comerciales.

Otro de los objetivos del lanzamiento de la TDA fue la promoción de producción nacional de contenidos digitales a partir del cual se crearon plataformas digitales interactivas (BACUA, ACUA, CDA, etc.) que produjeron para fines de 2014 unas “(...) 7.283 horas de programación distribuidas, 4.818 horas emitidas y 58 canales adheridos (...)”. La apuesta al fortalecimiento de la televisión digital con producción federal a partir de la participación de universidades nacionales, productoras independientes, organizaciones

\footnotetext{
${ }^{176}$ El detalle de la parrilla de señales se puede consultar en el apartado 2.4 del capítulo II de este informe
} de investigación. 
sociales, organismos públicos locales junto a nuevas señales públicas no comerciales como Encuentro, PAKA PAKA, TaTeTi, INCAA TV, entre otras, multiplican las posibilidades de recepción de diferentes medios de comunicación digital.

Como hemos señalado hasta aquí, teniendo en cuenta el marco analítico de la Economía Política de la Comunicación y la Cultura, el acceso se encuadra en el desarrollo de infraestructura, distribución de equipamiento y oferta de señales audiovisuales de servicio público. Entendemos que esta definición refiere a lo que en nuestro análisis denominamos acceso físico, es decir, la disponibilidad de tecnologías digitales de la población de un país a través del tendido de servicios básicos y conectividad que ofrecen una diversificación de contenidos audiovisuales.

La garantía de cobertura geográfica, la distribución de equipamiento y oferta de servicios públicos de comunicación provistas por el Estado son aspectos que tomaremos en cuenta para ponerlos en relación con las ideas que los usuarios expresaban acerca de sus experiencias en la obtención del beneficio de la política pública TDA, la disponibilidad del dispositivo en sus hogares y la oferta de señales públicas.

Señalamos en el apartado 7.1.2. de este capítulo, que los entrevistados de este estudio tuvieron conocimiento del Plan "Mi TV Digital" mediante piezas comunicacionales en radio y televisión, por comentarios de familiares o vecinos y en el caso de las integrantes de la Mutual Primavera debido a su rol de intermediación entre la política pública y los habitantes del barrio.

Quienes se enteraron mediante los medios de comunicación masiva no recordaban específicamente algún spot televisivo o cuña radial en particular sin embargo en sus palabras se identifica un tipo de reconocimiento como potenciales beneficiarios dado que cumplían con los criterios y requisitos de la política pública: jubilados, pensionados, perceptores de AUH o planes sociales, etc.

En el caso de aquellos que se informaron por parientes, conocidos o amigos encontramos cierta coincidencia en que esas personas que les comentaron sobre la TDA eran adultos mayores que percibían una jubilación o algún tipo de pensión y en ciertos casos le cedieron su dispositivo porque ya disponían del servicio por otros medios (adquisición de un dispositivo con TDA incorporada). Finalmente, las integrantes de la Mutual Primavera tuvieron un contacto cercano con la TDA ya que coorganizaron los operativos en el barrio y/o salidas colectivas a Tecnópolis. 
Como mencionamos en otros apartados de este informe, las modalidades en que los entrevistados obtuvieron los receptores digitales de TDA fueron distintos: unos fueron a recoger el kit de instalación al correo, otros lo recibieron en sus domicilios mientras quienes integraban organizaciones sociales lo buscaron en algún operativo de entrega o en Tecnópolis.

Las experiencias que relataban los entrevistados que se interesaron por la TDA referían que la tramitación necesaria para obtener el servicio gratuito de televisión digital en sus domicilios fue relativamente sencilla tanto para quienes lo hicieron por el correo como aquellos que lo recibieron en algún operativo de entrega o en su defecto en Tecnópolis.

Cuando tuvieron los set top box en sus domicilios refirieron que la instalación de los decodificadores y las antenas digitales les resultó relativamente fácil más cuando se encontraron con alguna dificultad recurrieron a vecinos o familiares.

La ampliación de la oferta de señales y contenidos audiovisuales de acceso gratuito que posibilitó la TDA fue valorada positivamente entre los beneficiarios de la política pública adultos mayores y miembros de la organización social Mutual Primavera. Mientras que los jóvenes y adultos jóvenes no tuvieron opiniones favorables hacia dicha característica sino más bien cierto disgusto con la promesa del aumento de opciones de señales en la grilla programática.

A esta altura si nos preguntamos qué características asumió la democratización de la comunicación tomando como indicador el primer nivel de acceso entre nuestros entrevistados podemos reconocer que se cumplen los criterios definidos por UNESCO (1977). Partimos de que el desarrollo de la infraestructura, la expansión de la conectividad, la distribución de equipamiento, la producción y oferta de contenidos fueron dimensiones que la política pública de inclusión digital TDA previó para asegurar el acceso a la televisión digital. Relacionando los datos obtenidos en estas dimensiones del acceso y los dichos de los usuarios de TDT en José C. Paz nos encontramos con que la garantía por parte del Estado argentino se orientó proporcionar las condiciones necesarias para que sectores sociales "en riesgo de exclusión digital" tuvieran la posibilidad de disponer de tecnologías digitales en sus hogares.

Siguiendo nuestras presunciones, en este caso, el Estado a través de la implementación de la política pública logró facilitar en parte el acceso físico de sectores "en riesgo de exclusión digital" aunque con algunas deficiencias señaladas por los destinatarios que 
consultamos. Sin embargo no podemos indicar que este tipo de acceso resultara del todo significativo para los propósitos de inclusión digital declarados en la TDA y declamados en el discurso gubernamental del período estudiado.

No obstante incorporamos en nuestro análisis la noción de acceso desde una perspectiva sociocultural siguiendo la trayectoria que trazó de este concepto Cabello (2017) con la construcción de un índice que considera la posesión y usos de un conjunto amplio de dispositivos $^{177}$. En principio, la autora sostiene que es necesario estudiar la dimensión del acceso a las tecnologías no sólo en relación con la disponibilidad de infraestructura, dotación de equipos y/u oferta de servicios sino además con los contextos de usos que a la vez se encuentran relacionados con las características de un entorno tecnocultural que adquiere rasgos específicos cuando nos ubicamos en paisajes periurbanos. Ciertamente esta posición implica trascender el nivel de acceso físico con vistas a comprender los modos en que las personas disponen de tecnologías y las aprovechan en sus cotidianeidades (trabajo, en el hogar o fuera de él, con otros, etc.). En nuestro estudio hemos avanzado sobre el análisis de los usos que los entrevistados dicen realizar de la televisión digital teniendo en cuenta las condiciones socioeconómicas de una localidad del Conurbano Bonaerense que nos dedicaremos a identificarlos en el próximo apartado. Cuando nos detenemos en el papel de las políticas públicas de inclusión digital, la investigadora británica Seale (2009) diferencia el acceso a las tecnologías del acceso de las personas. En el caso de la primera noción es un tipo de acceso que se alcanza a partir de la provisión de tecnologías por parte del Estado mediante la actualización y el mantenimiento permanente de los recursos técnicos y de la infraestructura. Al mismo tiempo, para asegurar el acceso de las personas explica que es necesaria la intermediación de asesores que promuevan en los usuarios habilidades para lograr la autosuficiencia en el manejo de las tecnologías.

Cabello $(2014,2015,2017)$ y Seale $(2009)$ coinciden en que el acceso es una dimensión compleja de las políticas públicas que excede los números de conectividad o posesión de dispositivos digitales y que en el mejor de los casos, los países centrales han producido estadísticas relativamente confiables que al menos dan cuenta de la cantidad de usuarios que disponen o han renovado tecnologías digitales.

\footnotetext{
${ }^{177}$ El índice se compone del siguiente modo: “A partir de las ponderaciones realizadas, los niveles se han conformado considerando cantidad de dispositivos de la siguiente manera: Nivel alto: utilización, media 4.1, posesión, media 13; Nivel medio: utilización, media 2.4, posesión, media 9.5; Nivel bajo, utilización, media 1.4, posesión, media 7.4." (Cabello y Moyano, 2015:6)
} 
Por lo tanto, pensar en el acceso en estos términos involucra incorporar una mirada situada en los usos y no usos que las personas realizan con las tecnologías digitales y en nuestro caso, con la televisión digital.

\subsection{Sobre los USOS y consumos de la televisión digital}

\subsubsection{Situaciones de usos de la TDA: prácticas de usos, no usos, usos poco frecuentes y usos frecuentes}

La disponibilidad de los dispositivos tecnológicos en los diferentes ámbitos de la vida de las personas (en el hogar, en el trabajo, en el espacio público, etc.) es la línea base mínima desde la que podemos analizar el tipo de vínculos que tratamos en esta investigación. Aquí ingresaremos a escrutar algunos aspectos, en la medida que nuestro trabajo de campo nos permitió, de la esfera íntima de los beneficiarios de la TDA en José C. Paz. El ámbito de lo doméstico ha sido estudiado desde la antropología, la sociología, la historia, entre otras materias y campos disciplinares. Nosotros no pretendemos realizar una genealogía del concepto sino que nos importa recuperar algunos rasgos para indagar el modo en que las tecnologías se encuentran dispuestas en el hogar y las lógicas que las personas producen y reproducen en el uso de las tecnologías.

El estudio de la televisión en el espacio doméstico ha sido una de las preocupaciones que encontramos en una variedad de trabajos académicos en el campo de los Estudios Culturales. Entre los autores más relevantes de esta línea de análisis se destaca Raymond Williams que se dedicó a comprender la formación cultural e institucional de la tecnología cuyas bases sienta en "Televisión. Tecnología y forma cultural” (2011). En ese libro inaugura un modo de pensar la tecnología en su devenir histórico y en relación con la compleja trama social y política en la que surge. Discute con el determinismo tecnológico y la posición de la tecnología sintomática ${ }^{178}$ y pone el acento en los usos de las tecnologías para indagar las instituciones que hacen posible su desarrollo en la sociedad.

"La radio y la teledifusión, (...) se desarrollaron para llegar a todos y cada uno de los hogares, aunque en la tecnología no había nada que hiciera inevitable ese

\footnotetext{
178 Según la perspectiva del determinismo tecnológico “(...) las tecnologías se inventan en una esfera diferente y crea nuevos estilos de vida, o bien es una fuerza que actúa por sí misma y suministra los materiales para que surjan nuevos estilos de vida"; asimismo “(..) la perspectiva de la tecnología sintomática supone, de manera semejante, que la investigación y el desarrollo se generan a sí mismos pero más marginalmente.” (Williams, 2011:26)
} 
destino. Pero luego, cuando se la definió como "comunicación de masas", esta nueva forma de comunicación social -la radioteledifusión-quedó oscurecida. (...) lo cual eclipsó que el medio elegido era la oferta de aparatos individuales (...)". (Williams,2011:37-38)

Entonces, teniendo en cuenta que toda “(...) tecnología siempre es, en el sentido más amplio del término, social." (Williams, 1992:185), que siempre es el resultado de las relaciones sociales y los usos en contexto, nos interesa sumar no sólo el lugar y los usos de la televisión sino su disposición física, es decir, el modo en que se hace presente en el espacio doméstico en términos de objeto material.

Morley (2008) revisa la introducción de la televisión analógica en el hogar para analizar el lugar que pasa a ocupar en la vida doméstica advirtiendo que se le ha prestado escasa atención en los estudios sobre los medios. En primer lugar, describe la ubicación física del televisor dentro del hogar que en los inicios del desarrollo de la industria televisiva se construye en torno a la figura del "ama de casa" y el modo en que modificó no sólo la programación sino también la arquitectura del espacio doméstico.

(...) sobre el modelo de la radio: la televisión como "radio con imágenes", donde el relato es conducido por la vía sonora y las imágenes tienen un papel subordinado (...) el ama de casa podía "seguir" el programa mientras continuaba haciendo sus tareas domésticas (...) y estaba potencialmente "disponible" para los anunciantes. (...) no se trató sólo de rediseñar la estrategia de programación, sino también de rediseñar gradualmente la arquitectura doméstica. (Morley, 2008:228)

Cuando analiza la posición del televisor en el hogar contemporáneo se enfoca en su “(...) presencia física como un objeto totémico del mobiliario" (Morley, 2008:229). El televisor en tanto objeto material ha sido integrado en la escena doméstica ubicado en la sala principal o cuarto de estar (living) de la casa ${ }^{179}$. A la vez, ha reorganizado el tiempo doméstico: se fueron adaptando los horarios de comida, de recreación, de estar con la familia a la programación de la televisión.

En la actualidad, con la presencia de tecnologías digitales móviles ${ }^{180}$ (telefonía móvil, televisores móviles, computadoras portátiles, etc.) el aparato se multiplica en el espacio

\footnotetext{
${ }^{179}$ Según Morley (2008) la irrupción del televisor en los hogares modificó la disposición de los muebles y las rutinas domésticas.

${ }^{180}$ Estas tecnologías tienen un carácter personal cuyo diseño permite utilizarlas fuera del hogar que modifican las categorías espaciotemporales. (Yarto, 2010: 174)
} 
de la casa (en la cocina, en las habitaciones) por un lado, y por otro, sale del hogar al espacio público: en comercios, centros de compras, la vía pública, entre otros.

En nuestro caso, detallamos en el punto 3.1. de este capítulo que una pauta que se repite en los hogares de los entrevistados es la presencia de al menos dos televisores, generalmente ubicados en alguna habitación y/o en el espacio compartido entre los integrantes de la familia como living, comedor o cocina-comedor. En este sentido, advertimos que la posición del televisor, en general, compartía las características descriptas más arriba: se distribuía entre los espacios comunes de los integrantes del hogar (living, comedor, cocina-comedor) y en apenas algunos testimonios, en aquellos lugares más íntimos como las habitaciones o dormitorios.

Los lugares donde se ubicaban los televisores analógicos o tradicionales en relación con aquellos que poseían el decodificar digital (TDA) se ordenaban de la siguiente manera: los primeros se situaban tanto en los sitios de encuentro familiar (living, comedor, cocina) como en los espacios de privacidad (las habitaciones individuales o compartidas), mientras que los segundos, se ubicaban preferentemente en el espacio doméstico compartido.

Introduciendo la noción y sus derivaciones de la "economía moral del hogar" $" 181$ planteada por Silverstone, Hirsch y Morley (1996) creemos necesario reconocer el lugar que nuestros entrevistados le asignaban a la televisión digital en relación con la hertziana. Para ello, recuperamos la idea de que el hogar está regido por rutinas temporales/ espaciales de la vida cotidiana - y advierten estos autores que está marcada por el género - que se diferencia de aquellas que operan en la vida pública y en el mercado. Es decir, los sentidos atribuidos a las diferentes tecnologías presentes en el hogar claramente se distinguen de aquellos que se emplean fuera del mismo: sus usos tienden a deslocalizarse en el espacio público. El sistema transaccional del que son objeto las tecnologías en las casas no sólo difiere de aquel que se traza en el afuera sino que visibiliza las relaciones que los sujetos establecen con ellas.

\footnotetext{
${ }^{181}$ Debemos advertir que Silverstone (1996:57) en sus investigaciones distinguió los conceptos de hogar como densidad simbólica, familia como unidad social y casa como unidad económica. En esta tesis no tomaremos esta distinción ya que no nos proponemos realizar un análisis particular de recepción y consumo de las audiencias o el modelo de domesticación de este autor. En cambio, tomamos algunos elementos analíticos que nos ayudan a comprender el lugar que le asignan nuestros entrevistados a la televisión digital en el ámbito doméstico.
} 
Como señalamos más arriba, la televisión analógica y su condición doméstica ha sido analizada en el campo de estudios de la comunicación y la cultura donde encontramos que adquiere un lugar central en los hogares donde se la mira, donde no se la mira o no se le presta atención, donde es el ruido de fondo que acompaña las rutinas, etc. siempre en relación con las posiciones socioeconómicas y culturales de los integrantes de las unidades domésticas.

Volviendo a nuestro análisis, la preferencia de ubicación de la televisión digital (TDA) estaba dispuesta en los espacios en los que los integrantes de las casas comparten su cotidianeidad. Situar el aparato en un ambiente de la casa da cuenta del papel que juega en ese espacio y según las prácticas socioculturales del grupo familiar. Es en ese lugar en el que se producen y reproducen sentidos a los diferentes usos que hacen las personas de las tecnologías en el hogar.

Los vínculos que las personas establecen con las tecnologías están relacionados con las expectativas que sitúan en los aparatos de modo tal que les asignan distintas funciones en sus contextos cotidianos. En los hogares actuales, incluidos aquellos pertenecientes a sectores socioeconómicos de menores ingresos, suelen poseer más de 1 (un) televisor a los que se les atribuyen roles diferenciados. Por ejemplo, en uno de ellos es en el que se los integrantes de las familias se informan, otro se destina para el entretenimiento así como algún otro artefacto se le reserva la función de oficiar de pantalla para conectar una computadora, una consola de juegos, etc.

Ya nos referimos con anterioridad al lugar material y simbólico que ocupa la televisión en el espacio doméstico lo que nos interesa ahora es reflexionar sobre las variadas maneras de usos que admite la televisión digital en los entornos tecnoculturales que estudiamos en esta tesis. Aquí vamos a diferenciar el "consumo", es decir, el para qué y qué miran televisión (sea analógica o digital) del uso vinculado a las operaciones que realizan para utilizar el decodificador digital, efectos de desplazamiento junto al reconocimiento de motivaciones y expectativas.

En la primera parte de este capítulo sostuvimos que las situaciones de uso que los beneficiarios de la TDA realizaban diferían entre los jóvenes o adultos jóvenes y los adultos mayores debido a diferentes motivos: generacionales, socioeconómicos y culturales. 
Quienes se reconocían con mayores destrezas y habilidades para usar la televisión digital fueron los más jóvenes de los entrevistados. Nicolás A. (20 años), Nicolás N. (17 años), Germán (26 años), Paula (44 años), Érica (20 años) mencionaban que saben usar la televisión digital, que no encontraron dificultades para manejar el decodificador digital. A la vez, fueron los que registraban usos con cierta intensidad de computadoras y telefonía móvil en el contexto de sus trabajos, en los espacios educativos que transitaban (escuela secundaria, universidad), en el ámbito doméstico para entretenerse (escuchar música, mirar videos, redes sociales, etc.).

En cambio, los adultos mayores señalaron que se encontraron con obstáculos al tomar contacto con la televisión digital que iban desde la instalación del dispositivo en sus hogares hasta la operación propiamente dicha. Ana María (61 años), Daniel (66 años), Ernesto (79 años), María (65 años) coincidieron en que realizaban operaciones básicas como encender/apagar y cambiar canales que es lo que aprendieron a hacer con los artefactos analógicos. Cuando indagamos sobre usos de otras tecnologías, los mayores usaban en menor medida los ordenadores personales o los teléfonos móviles y si lo hacían era para mantenerse informados o comunicados con algún familiar o amigo.

Si retomamos la propuesta de Seale (2009) para analizar los modos en que las personas deciden usar las tecnologías podemos avanzar en torno a las principales consideraciones sobre esta dimensión que involucra la idea de inclusión digital. La autora diferencia factores tecnológicos (problemas de acceso), personales (habilidades desarrolladas) y contextuales (modos de vida).

En nuestra población en estudio encontramos que el acceso físico estuvo garantizado por la decisión del Estado aunque la implementación de la política pública tuvo dificultades que hemos explicitado en el apartado 2.3 del capítulo II. Entre los problemas se listaron las deficiencias en la entrega de los kit de instalación de la TDT o bien los dispositivos dejaron de funcionar y los usuarios no recibieron el reemplazo correspondiente.

Los factores personales aluden al desarrollo de habilidades a partir del manejo de las tecnologías. Las habilidades técnicas refieren a las destrezas para operar, capacidad de improvisación, la resolución de problemas, entre otras. Teniendo en cuenta la instalación del set top box, entre los entrevistados de nuestro estudio no adujeron haber sufrido demasiados problemas para realizar la conexión de las diferentes piezas (cables, decodificador, antena) aunque como señalamos en el apartado 7.1.2.2. de este capítulo, 
en general, la configuración del software fue apenas tomada en cuenta en los relatos. Ahora bien, la operación del dispositivo (encender/apagar, cambiar de canales, grabar contenidos, interactividad, uso de USB, etc.) diferenciaba a jóvenes y adultos jóvenes de los mayores ya que estos limitaron sus acciones a aquellas que construyeron con la televisión analógica o tradicional de aire o por cable mientras que los primeros mostraron por ejemplo, recursos para la resolución de problemas como pérdida de señal, actualización del software o diferir la programación para consumirla en el tiempo disponible. Por otro lado, podemos identificar las habilidades sociales que son aquellas que se orientan a la asertividad o reconocimiento entre pares y con otros, a la posibilidad de interacción fluida con otros o la integración a nuevos grupos de pertenencia. Los usuarios de TDT que entrevistamos reconocieron apenas que el uso de la televisión digital como de otras tecnologías les permitieran algún tipo de reconocimiento entre sus amigos, familiares y/o compañeros de trabajo; o bien, participar de algún nuevo grupo con intereses similares (comunidades de videojuegos, de adultos mayores, de música, etc.).

En tercer lugar, teniendo en cuenta los factores contextuales como las condiciones de vida: nivel socioeconómico y cultural. En el caso de nuestra investigación, los beneficiarios de la televisión digital pertenecen a sectores sociales con ingresos medios bajos y bajos: percibían algún plan social, integraban alguna organización social productiva donde desarrollaban alguna actividad, jubilados o pensionados. Por lo tanto, encontramos que los usos y los sentidos que les asignaban a las tecnologías digitales estaban vinculados a estas condiciones en tanto por ejemplo, el tiempo que le destinaban era residual en relación con el tiempo de trabajo o actividades domésticas. Cuando hablamos de la televisión digital observamos que si bien el consumo de televisión sigue siendo privilegiado en los hogares reconocemos que esta no ocupa un lugar tan central como lo sigue haciendo la televisión tradicional o analógica con la que se sienten más cómodos porque conocen cómo se opera y en caso de algún inconveniente saben el modo de solucionarlo. 


\subsubsection{Otros usos de las tecnologías: asociaciones y efectos de desplazamiento}

Para explorar los usos de la televisión digital decidimos rastrear si los beneficiarios de la TDA percibían algún tipo de relación entre la operación de la televisión digital y las experiencias con otro tipos de tecnologías como la utilización de computadoras personales o telefonía móvil digital.

En el apartado 7.5 de la parte I de este capítulo señalamos que entre los entrevistados encontramos dos grupos: los jóvenes que consideraban realizar usos de cierta intensidad de la computadora e internet y los adultos junto a los adultos mayores mencionaban que hacían escasos usos de las tecnologías.

En este punto nos detendremos brevemente en un aspecto que nos interesa revisar que refiere a la asociación de los diferentes saberes construidos en torno a la operación de la computadora, Internet o telefonía móvil por parte de los usuarios de TDA. En general, nuestros entrevistados no detallan el tipo de conocimientos adquiridos en el manejo de estos dispositivos tales como el uso de funciones: búsquedas de información, programación de tareas y actividades, escuchar música o ver videos, películas, series, etc. Sin embargo, al momento de referir para qué los usan aparecen menciones que nos permiten reconstruir las asociaciones entre los diferentes usos de las tecnologías en el hogar. Si bien, se reitera cierta diferenciación entre los jóvenes y los adultos identificamos que los únicos que quedan excluidos en este caso son los adultos mayores por las razones que hemos esgrimido en el parágrafo anterior. En cambio, jóvenes y adultos jóvenes reseñaban las diferentes operaciones y saberes a la hora de manejar la computadora o internet. Por ejemplo, Nicolás, A. (20 años) y Nicolás N. (17 años) especificaban que con el uso de la computadora aprendieron a descargar archivos (documentos, videos, series, música), a conectar diferentes aparatos (pantallas, PC o TV) mediante accesorios y cables (VGA, HDMI, USB). Verónica (45 años) además aludía a los saberes que adquirió como usar memorias extraíbles, guardar archivos en la nube hasta sincronizar los dispositivos o aparatos.

Por otra parte, el relato de Ana María (61 años) muestra la relación entre el empleo de un aparato mecánico como la máquina de escribir con el teclado de la computadora aunque con limitaciones en otras funciones. Este conocimiento relativo del manejo de una tecnología antecesora aparece como una ayuda para operar la PC. 
Cuando registramos las expresiones sobre el uso de computadoras e internet señalamos que la constante que se repetía fue que no contaban con un buen servicio de fibra óptica por lo que los usos estaban condicionados por la deficiencia en la conectividad. Las menciones acerca de usos de la telefonía móvil aparecieron por parte de los jóvenes y adultos jóvenes que planteaban que debido a las falencias en el servicio de Internet preferían emplear dicha telefonía ya que contaban con el servicio de datos pago ( $2 \mathrm{G}$ o $3 G)$.

Sin embargo, lo que nos interesa particularmente es advertir si las experiencias construidas con otras tecnologías les facilitaban a los beneficiarios de la TDA el uso de la televisión digital en sus hogares. Entonces, entre nuestra población en estudio, no se evidencia una vinculación o asociación explícita entre los saberes adquiridos para emplear computadora, Internet, teléfonos móviles con la operación de la televisión digital.

Por otro lado, como mencionamos en la primera parte de este capítulo, no notamos que el ingreso de la TDA en los hogares haya generado algún tipo de desplazamiento del uso de otras tecnologías hacia la televisión digital. De hecho, los entrevistados diferencian el uso de las computadoras, Internet o telefonía móvil de la televisión digital. Es decir, con las primeras suelen revisar correo electrónico, descargar películas, ver videos, entre otros. mientras que la segunda parecen usarla del mismo modo que lo hacían con la televisión tradicional o analógica. Es probable que un factor que interviene en los usos de la televisión digital es cierto desconocimiento de todas las funciones y ventajas que ofrece este servicio público. Retomaremos este elemento analítico en las conclusiones del presente capítulo.

\subsubsection{La interactividad es la novedad: sentidos atribuidos y prácticas con la televisión digital en transición}

En el capítulo II de esta tesis presentamos las características técnicas y de infraestructura de la TDT entre las cuales la interactividad es una de las apuestas del servicio de televisión.

En la etapa de lanzamiento y difusión de la política pública TDA, la interactividad aparecía como uno de los rasgos diferenciales que junto a la mejor calidad de imagen y más contenidos de la televisión digital. Por ejemplo, en el spot institucional de septiembre 
de $2010^{182}$ la voz en off menciona los servicios interactivos entre las ventajas ofrecidas por "Mi TV Digital". En la secuencia discursiva dichos servicios se ligaban al aumento de funciones de una televisión que evoluciona. En este caso el enunciador (el gobierno encabezado por la presidenta Cristina Fernández) apela a la idea de que el televidente tendría la posibilidad de "interactuar" con los contenidos audiovisuales aunque no da detalles del modo en que se desarrollará esta función.

Asimismo, decíamos en el apartado 7.4 de la parte I de este capítulo que aún en los documentos de la política pública de inclusión digital TDA las alusiones sobre la función de la interactividad son tan generales que escasamente refieren al intercambio de datos entre los ciudadanos y/o al desarrollo de contenidos interactivos con vistas a actividades productivas, sociales y culturales.

En los inicios de la TDT, tanto en Europa como en Estados Unidos de América ${ }^{183}$, la incorporación de la interactividad ha sido una suerte de imperativo tanto por parte del mercado como un desafío de los gobiernos que llevaron adelante políticas públicas de inclusión digital. Para citar algunos casos, Kantor, Marcaletti y Pafundi (2013) recuperan el Proyecto Galileo implementado en 2012 en Alemania que permitía la participación de los telespectadores del programa homónimo a través de una aplicación interactiva descargada en el teléfono móvil inteligente (smartphone); en Noruega el software interactivo "Interactivity Suite" desarrollado por una empresa para la televisión a través del que los televidentes votaban, subían contenidos para ser emitidos o hacían comentarios; en Reino Unido se combinó Internet con la televisión interactiva de modo que los usuarios podían comprar los productos que aparecían en pantalla a través de su control remoto; y finalmente, Japón desarrolló el sistema híbrido "Hybridcast" que fusionaba la radiodifusión con internet que producían variados servicios centrados en la televisión: acceso a información y participación en programas televisivos en tiempo real.

En nuestro país, la TDA ofrecía la función de interactividad en la botonera del control remoto (que se recibía junto al decodificador digital en el kit de instalación) que, como indicamos en la primera parte del presente capítulo, refiere a un nivel de interactividad básico o de primer nivel aunque no se encontraba habilitada al momento en que realizamos el estudio. En consonancia con esta limitación los beneficiarios de la TDA

\footnotetext{
${ }^{182}$ En el apartado 2.4.1 del capítulo II de esta investigación se encuentra presentado el contenido y análisis de esta pieza promocional de la TDA.

${ }^{183}$ Nos hemos referido a esta situación en el apartado 3.1.2 del capítulo III de este informe de investigación.
} 
que consultamos respondieron que desconocían la oferta de esos servicios interactivos. Algunos autores indican que la interactividad no llegó a ponerse en funcionamiento debido a la celeridad con que se distribuyeron los primeros set top box que aún no contaban con la actualización ${ }^{184}$ necesaria para ofrecer dicho servicio.

Aquí nos interesa distinguir una dimensión propiamente técnica de la interactividad constituida por la infraestructura: en la TDT se implementa por el envío de información a través de ondas hertzianas emitidas hacia los decodificadores o receptores que ya tienen registrados los datos con los que el usuario puede interactuar (estado del tiempo, estado del tránsito, servicios públicos). Como ya advertimos, en la TDA no se encontraba habilitada ninguna función interactiva aunque fuera anunciada en el lanzamiento comunicacional de la política pública.

Por otro lado, y teniendo en cuenta la infraestructura tecnológica necesaria para producir servicios interactivos en la televisión digital no referimos a una dimensión que involucra la comunicación. Para ello, retomamos la propuesta de Rausell Köster (2005) que sostiene que es necesario analizar el discurso interactivo que propone ciertos recorridos definidos por el emisor a través de los soportes técnicos para reconocer los diferentes grados de interactividad que se pueden dar entre los sujetos y las máquinas.

En principio, cuando les preguntamos a los beneficiarios de la TDA si tenían conocimiento específico sobre la interactividad sus respuestas fueron negativas. Sin embargo pudimos advertir una posición entre aquellos que reconocían cierto parentesco con la interactividad a partir de diferentes operaciones que efectuaban con otros dispositivos como con la computadora, Internet o el reproductor de DVD como Verónica (45 años) o Germán (26 años). Asimismo, consultamos a los usuarios de TDA acerca de las ideas que surgían en relación con la interactividad y las asociaciones se reiteraron en dirección con los saberes construidos en torno al uso de otras tecnologías.

En el conjunto de los relatos identificamos que el contacto y conocimiento de diferentes tecnologías como la computadora, telefonía móvil, electrodomésticos proponían itinerarios para realizar ciertos tipos de usos definidos por los dispositivos en los cuales los sujetos tienen una primera elección en torno al momento en que desean ejecutarlos.

\footnotetext{
${ }^{184}$ Posteriormente a la distribución de los decodificadores digitales, las actualizaciones del software para ofrecer servicios interactivos debían realizarse mediante la páginas web de cada uno de los fabricantes de los mismos.
} 
Estos recorridos planteados por los soportes técnicos en el caso de la interactividad de la televisión digital ofician de orientadores a través de los cuales nuestros entrevistados realizan cierto reconocimiento y conjeturas sobre la posibilidad efectiva de usar este tipo de servicios.

En otro orden, nos llamaron la atención ciertos señalamientos que planteaban una distancia económica con la oportunidad de usar la interactividad de la televisión digital. Nuestra presunción es que la interactividad se presenta en el mercado mediático como una novedad que no se encuentra al alcance de todos los consumidores y que sumado a un incipiente desarrollo le imprime un halo de exclusividad que requiere un medio de pago para obtener y usar dicha prestación.

Finalmente, señalaremos al menos dos limitaciones que al momento que realizamos el estudio encontramos en relación con la función de interactividad de la televisión digital terrestre.

Una de las limitantes es técnica referida a un desarrollo tecnológico embrionario sujeto a las características propias del Ginga que aún con las actualizaciones correspondientes ofrecía escasas opciones interactivas.

La otra limitación está relacionada con los hábitos culturales de consumo de la televisión en el hogar de los usuarios. Tal como mencionamos en parágrafos anteriores, que la biografía del aparato está anclada a un régimen usabilidad que tiene características de cierta pasividad. Es decir, mirar televisión puede implicar hacerlo con atención, en distracción, como ruido de fondo, programado (en horarios fijos y determinados), etc. Las escasas acciones que podemos listar es la opción de encender/apagar, cambiar de canal, subir o bajar el brillo o color de la pantalla, administrar el volumen, etc. De hecho, la interactividad requiere la construcción de otros tipos de comportamientos y prácticas que al menos, entre nuestra población en estudio, entendemos que resultaban ajenos.

\subsection{4 ¿Qué ves cuando ves televisión digital?: similitudes y diferencias con la televisión analógica}

En la actualidad, estudios y estadísticas oficiales muestran que la televisión se mantiene como uno de los medios de gran consumo y entre las primeras opciones de ocio tanto en 
Europa como en nuestro continente. (IAM, 2014, 2017; Orozco y Miller, 2017) En Argentina, según la Encuesta Nacional de Consumos Culturales y Entornos Digitales un $98 \%$ de la población del AMBA miró televisión durante el año 2013. La pantalla chica se encendía todos o casi todos los días tanto que casi en “(...) un $80 \%$ de los hogares se mira TV durante un promedio de 2 horas y 47 minutos (...)." (ENCCyED,2013:9) Si bien, para esta tesis no hallamos investigaciones y/o datos sobre visionado o preferencias de programación televisiva en el Partido de José C. Paz presumimos que el consumo de televisión tiene semejanzas con los números arrojados por la ENCCyED (2013).

Cuando consideramos las características de la dieta televisiva entre los entrevistados decíamos que en mayor medida, estaba apoyada sobre una programación generalista compuesta por diferentes géneros y formatos destinada a un público masivo y con una marcada franja de prime time. El encendido se ubicaba, en general, en horarios matinales y nocturnos con una manifiesta tendencia hacia la programación de las principales emisoras de aire (Canal 13, 9, TELEFE, TV Pública, América) y otras de cable (C5N, CN23, Canal Encuentro, etc.). Entendemos que el encendido está vinculado a la actividad que cada televidente desarrolla durante el día: estudios de escuela media, universitarios, trabajo fuera o dentro de la casa, jubilados. Por ejemplo, Ana María (jubilada), Nicolás, N. (estudiante secundario), Paula (trabajadora social), Mónica (empleada), Fátima (empleada) comentaban que miraban preferentemente programas de canales de aire, en menor medida de opciones de pago, por la noche cuando disponían de tiempo luego de culminar las tareas relativas a sus respectivas ocupaciones o mientras realizaban tareas domésticas.

Hasta aquí los hábitos de consumo televisivo concuerdan con un modelo tradicional de ver la televisión tanto en términos de franjas horarias relacionadas con las ocupaciones de los miembros del hogar como con la oferta de programas en canales de aire y otros de cable. Asimismo, en relación con la selección de los contenidos priman los géneros informativos (noticias, documentales y de divulgación) y le siguen las propuestas de entretenimiento ( magazines y reality shows, talk shows, concursos, musicales, humor, entre otros) y en menor medida, los programas deportivos y de ficción (películas y series).

Ahora bien, cuando consultamos sobre las preferencias en torno a la televisión digital notamos que no había diferencias sustantivas con la televisión analógica ya que los usuarios mostraron que optaban por el mismo tipo de programación que miraban en canales de aire y/o de suscripción paga. No había atribuciones distintivas entre una y otra 
televisión. Salvo las integrantes de la organización Mutual Primavera distinguieron las propuestas de contenidos de la TDA atribuyéndole el valor a la producción local o regional por sobre la de las emisoras comerciales de aire, de cable o satelital con programas de formatos importados de otros países. Entendemos que estas valoraciones positivas hacia los contenidos de industria nacional se sostienen en la participación política activa que despliegan las entrevistadas en la mutual junto a las actividades para asegurar el enlace territorial de la política pública de inclusión digital analizada.

Finalmente, los usuarios de TDA decían escoger la programación que habitualmente miraban en la televisión analógica aunque reconocían que en el sistema digital podían acceder a otro tipo de emisoras que proponían contenidos destinados específicamente a adultos mayores, a niños y niñas o de deportes. Sin embargo, entre los aspectos que atravesaron los dichos sobresalieron las dificultades técnicas - problemas de conexión, de imagen o de sintonización- que, según los entrevistados, obstaculizaban en gran medida, el visionado de las emisoras de la televisión digital. Estos problemas parecen intervenir de modo tal que los beneficiarios de la TDA mantuvieron las prácticas y preferencias de visionado ligadas a la televisión hertziana sea de gratuita o de pago antes que la oferta de la parrilla digital. En este sentido, podemos afirmar que aunque los entrevistados dispongan de un servicio gratuito de televisión eligen la televisión comercial que en el Partido de José C. Paz está extendida a través del monopolio de la empresa TELERED de cable mediante el pago de una suscripción.

\subsection{La AUTOCONFIANZA para no quedarse afuera}

El encuentro de las personas con las tecnologías involucra dimensiones culturales, históricas, económicas que se expresan tanto en la construcción de capacidades y habilidades sociales como individuales. Ese encuentro se compone de disposiciones, acciones, actitudes que como sujetos construimos frente y con las tecnologías en los diferentes ámbitos en los que transitamos tanto en el espacio público como en el privado. En el capítulo III hemos registrado al menos dos tipos de estudios sobre las tecnologías que problematizan los procesos de inclusión digital. Por una parte, aquellos que analizan los sistemas comunicacionales, los efectos en el mercado así como también la implementación de las políticas públicas; y por otra parte, otros que indagan sobre el 
acceso, el conocimiento, los usos y representaciones como parte de la inclusión digital. Seale (2009) y Cabello (2014) han avanzado sobre estos últimos abordajes a partir de investigaciones que aportan otras dimensiones analíticas para abordar nuestro objeto de estudio.

En este caso, recuperamos la categoría de autoafirmación que desarrolló Cabello (2014) para estudiar la inclusión digital que desagrega en tres subdimensiones: autopercepción de la competencia, objetivación de la relación que se establece con las tecnologías y actitud respecto de la propia capacidad para conformar redes. En estas tres subdimensiones se encuentra presente la noción de autoconfianza ${ }^{185}$ entendida como las percepciones que tienen los sujetos sobre sus capacidades, los resultados obtenidos, dificultades, ventajas y desventajas en relación con algún objeto, sujeto, evento o problema. Es decir, la autoconfianza se apoya en el conocimiento y habilidad para lograr cierto nivel de rendimiento y/o ejecutar una tarea específica con resultados exitosos.

A continuación teniendo en cuenta este concepto, nos proponemos reconocer las marcas en el discurso de nuestros entrevistados que refieren particularmente a esos procesos de autoconfianza producidos frente al contacto con las tecnologías en su ámbito cotidiano. En el transcurso de nuestra investigación hemos relevado diferentes tipos de usos y prácticas vinculadas a las tecnologías digitales de distinta clase: computadoras, telefonía móvil, DVD, televisión. En general, notamos que las situaciones de usos diferían según los rangos etarios de que se tratara: los jóvenes decían hacer usos de mayor intensidad y conocimiento que los adultos jóvenes y asimismo, en menor medida respecto de los adultos mayores. En esa línea de análisis entendemos que la construcción de habilidades para el manejo de tecnologías no estaba meramente ligada a las edades de las personas que participaron en nuestro estudio sino estaba vinculada con las posiciones sociales que ocupaban y al mayor o menor acceso al consumo de bienes y servicios tecnológicos ofrecidos en el mercado.

Más allá de la intensidad, frecuencia o modalidades que podemos identificar en el contacto, usos y prácticas de las personas con las tecnologías digitales uno de los aspectos, que variados estudios han relevado, concierne a los estados de ánimo negativos: temor, la

\footnotetext{
${ }^{185}$ Nosotros en esta tesis no pretendemos ahondar en las diferentes corrientes teóricas que abrevan en ese término pero nos interesa mencionar, al menos, las principales. La autoconfianza es un concepto extensamente desarrollado y analizado en el campo de la psicología. La tesis de Maslow, A. (1954), fundador de la psicología humanista, sobre la pirámide de las necesidades que las jerarquiza y en el cuarto escalón ubica la autoestima que incluye la confianza, el éxito y el respeto. Por otro lado, Bandura, A. (1977) precisa la noción de autoconfianza definiéndola como aquella creencia en la "capacidad de tener éxito en situaciones específicas o realizar una tarea”.
} 
frustración ante el desconocimiento o la impericia, entre otros, así como también positivos tales como: alegría, confianza, empatía ante la utilización de los dispositivos (Cabello, 2014: 8-9). Otro rasgo está vinculado a la valoración que le confieren las personas a la experiencia con las tecnologías en relación con su vida personal y social: las ventajas y/o desventajas para resolver problemas frecuentes, para compartir con otros (amigos, conocidos, compañeros de trabajo, etc.), para relacionarse con otros.

Volviendo a los relatos de los usuarios de la TDA distinguimos al menos dos posiciones entre los más jóvenes en relación con los más adultos. Los primeros parecían haber construido ciertos grados de familiaridad con el uso de las tecnologías digitales que manifestaban en expresiones de complacencia y agrado. Podemos citar a Germán (26 años) que decía sentirse confiado en el manejo del teléfono móvil, de la televisión digital y en particular, de la computadora que usa para sus estudios o la docencia en escuela media y para entretenerse (descargar películas, música, etc.) mientras que Nicolás, A. (20 años) mostraba satisfacción cuando sentía que lograba buenos resultados en los juegos de consola.

En cambio, los adultos jóvenes establecían cierta distancia con las tecnologías digitales ligada al desinterés o renuencia que en palabras de Paula (44 años): "No tengo mucho tiempo para ocuparme de los problemas de la tele o de la computadora pero voy viendo, en todo caso pregunto, (...) y como no tengo mucha paciencia... no le tengo miedo pero tampoco es que me siento re confiada”; o de Adriana (44 años): “(...) No sé, ni tampoco me interesa (...)" o como Verónica (45 años) que manifiesta que no le presta mucha atención pero advierte que en el caso de la televisión digital le resulta útil porque "(...) ahora el control de la TDA te permite usar para todo, entonces .... tengo todas las funciones."

Mientras que los adultos mayores enunciaron algunos temores que les producían el manejo de las tecnologías digitales. Por ejemplo Ana María (61 años) comentaba que sentía miedo de “(...) hacer lío.” debido a sus dificultades para entender el funcionamiento de las mismas, aunque cuando recibía ayuda o explicación le gustaba y la tranquilizaba. Ernesto (79 años) relataba que el uso de la televisión digital lo hacía sentir, a veces, algo improductivo o inseguro debido al desconocimiento de las funciones y prestaciones que ofrecía.

Acerca de los valores que le adjudicaban los usuarios de la televisión digital de nuestro estudio a las tecnologías digitales observamos que consideraban que tenían algo de importancia en sus vidas personales más allá de que se percibieran con mayor o menor 
pericia para integrarlas a su ámbito cotidiano. En esa línea por ejemplo, Érica (20 años) planteaba que le interesaba y advertía que las tecnologías digitales resultaban necesarias a la vez que facilitaban muchas tareas y habilitaban procesos de aprendizaje. Fátima (35 años) afirmó que el contacto con tecnologías digitales no le modificaban sustantivamente sus rutinas en el hogar pero en otros pasajes sostenía que estaban allí para usarlas y dicha evaluación parece tener rasgos positivos. Otro tanto ocurría en relación con los valores asignados al uso de las tecnologías digitales para vincularse con otros (amigos, familiares, compañeros de trabajo incluso desconocidos): Nicolás, A. (20 años) señalaba que cuando lograba superar dificultades, aprender o descubrir estratagemas le reconfortaba compartirlos con amigos.

Retomando nuestra lectura sobre la dimensión de autoconfianza vamos a recuperar las marcas en los dichos de los usuarios de la TDA que caracterizan este aspecto individual (personal) involucrado en los procesos de inclusión digital.

Entonces, tomando en cuenta que la autoconfianza gravita, en principio, sobre los saberes y prácticas dispuestos en la relación con las tecnologías digitales encontramos que, más allá de las diferencias etarias, nuestros entrevistados se auto percibían con conocimientos limitados y en todo caso, más bien intuitivos a partir de la prueba y error. Mónica (51 años) relataba que entendía cuestiones básicas en el manejo de la televisión digital, Ernesto (79 años) planteaba: “(...) prendíamos, apagábamos y cambiábamos los canales pero cuando teníamos un inconveniente ya se nos quemaban los papeles.”, Fátima (35 años) señalaba: "Conozco todas [funciones de la TDA] pero no sé usar todas, como dije antes, nada más que cambio de canales (...)”, Nicolás, A. (20 años) explicaba que “(...) Por lo menos las básicas [funciones de la TDA], por ahí no me puse a investigar demasiado si tiene más opciones", Graciela (46 años) decía: "No, no, la prendo y después voy cambiando los canales hasta que encuentro lo que a mí me gusta" o María (65 años) indicaba "No hago mucho más, la manejo como las otras. No entiendo muchas cosas que tiene el control, tantos botoncitos que no sé para qué son".

Asimismo, indagando acerca de los estados de ánimo que podía provocar el desarrollo de habilidades en el uso de las tecnologías digitales nos resultó dificultoso identificar emociones de corte positivo tales como: alegría, placer, seguridad, etc. en los mayores. En tanto los más jóvenes sostenían que se sentían confiados o con cierta satisfacción mostrando variados tipos de aplicaciones para distintos objetivos (entretenerse, estudiar, informarse tanto en el ámbito privado -hogar- como en el público -trabajo, universidad, colegio, etc.-). Decíamos más arriba que los adultos jóvenes exhibieron algunas 
reacciones de resistencias o distancias debido al desinterés o a la falta de tiempo para usar mientras que los adultos mayores expresaron una sensación de miedo a producir algún problema que no pudieran resolver en el transcurso de la utilización de las tecnologías digitales.

Entonces, entendiendo que las personas frente a las tecnologías digitales construyen diversas actitudes o disposiciones de afinidad o rechazo, de distancia o de proximidad, la autoconfianza oficia como descriptor del componente personal o individual implicado en capacidad de logro de un objetivo, que en nuestro caso refiere al uso de las tecnologías digitales.

Siguiendo uno de los supuestos que plantea de Cabello (2014:8) sobre los procesos individuales y colectivos para alcanzar la inclusión digital, acordamos que:

“(...) cuando las personas acceden a las tecnologías digitales interactivas y avanzan en grados cada vez más consolidados de apropiación de las mismas sobre todo al integrarlas en sus ideas, sus proyectos y planes de acción-, realizan unos usos en los cuales pueden sentirse alegres, descubrirse hábiles, considerar que tienen algo para decir o mostrar (...), desarrollar su creatividad”.

En ese marco, la autoconfianza se sitúa como aquella creencia que las personas desarrollan en pos de conseguir algo o cumplir algún objetivo propuesto tanto en su vida cotidiana, laboral, educativa, social, etc. que cuando abordamos las prácticas con las tecnologías digitales nos permiten apreciar los límites de quedar de un lado o del otro de esa línea que implica estar incluido o excluido digitalmente.

Considerando la disponibilidad y los usos de la televisión digital entre nuestros entrevistados la autoconfianza no se muestra como una característica predominante en la relación con esta y otras tecnologías digitales (computadora, telefonía móvil, consolas de juegos, etc.). De allí que los usuarios de la TDA en el Partido de José C. Paz expresan escasos grados de familiaridad con las tecnologías que se manifiestan en sensaciones de incomodidad, fracaso, inseguridad hasta un cierto disgusto en el uso y las prácticas contenidas por las mismas. Estos sentidos atribuidos a las tecnologías digitales refuerzan en las personas la idea de que las dificultades que entraña esa relación "los expulsa", "los saca", "se quedan afuera" de una cultura caracterizada por prácticas sociales, culturales, políticas y económicas atravesadas por la digitalización. 


\subsection{La PARTICIPACIÓN de los usuarios de TDA en el entorno tecnocultural}

Los contextos de transición digital en nuestro continente adquieren diferentes características según los espacios sociodemográficos y económicos de los que se trate. Los centros urbanos suelen contar con una disponibilidad y oferta de servicios de todo tipo (urbanos, sociales, económicos, culturales, etc.) donde la infraestructura tecnológica y el acceso a dispositivos técnicos (telefonía móvil, computadoras, televisión digital, satelital, consolas de juego) tiene una densidad considerable. A diferencia de los paisajes periurbanos, en nuestro caso una localidad del Conurbano Bonaerense, que en tanto espacios periféricos comprenden una heterogénea disposición y reducidos usos de tecnologías digitales que traza un mapa de acceso desigual a la provisión de servicios tanto por parte del mercado como por el Estado. La acentuada fragmentación sociodemográfica del territorio (gran población de bajos ingresos con deficientes servicios básicos, bajo nivel de instrucción, desocupación, entre otros, que coexisten junto a un reducido sector de altos ingresos) que convive con un escenario en el cual la distribución y penetración de tecnologías responde a las lógicas de mercado caracteriza un entorno tecnocultural discontinuo con marcados procesos de exclusión.

Retomamos aquí el desarrollo teórico operacional de la investigadora Cabello (2015:5) sobre la participación como indicador de inclusión digital para tratar de comprender “(...) los modos de participación y las distancias que median entre las personas y ese ambiente cultural, en el entendido que serán ampliamente desiguales". No nos dedicaremos a analizar la vinculación de esta dimensión con la idea de ciudadanía (acción colectiva, ejercicio de derechos, equidad en el acceso, etc.) sino que no enfocaremos en las acciones y prácticas de los usuarios de las tecnologías en relación con el consumo de contenidos, de servicios o de redes sociales. Es decir, nos interesa identificar los grados y clase de participación de nuestros entrevistados en su entorno tecnocultural que en principio, siguiendo a Cabello (2008) hemos definido como discontinuo y heterogéneo.

La idea de participación de la que partimos se sostiene en el reconocimiento de los roles que detentan productores y consumidores de las tecnologías digitales en tanto sujetos que interaccionan de modo diferenciado según los recursos de unos y las habilidades o capacidades de otros. En ese contexto, nos interesa revisar los usos de las tecnologías digitales que realizan nuestros entrevistados con el fin de rastrear en qué medida las 
prácticas que producen las personas expresan ciertas distancias o no con el ambiente cultural en el que intervienen.

Aprovechamos a recuperar parte del análisis que hemos expuesto en varios de los apartados precedentes sobre las posiciones que encontramos en este estudio en relación con los usos de las tecnologías digitales en general y en particular con la TDT. Al menos se presentan posturas diferenciadas entre los jóvenes que manifestaban un contacto frecuente y acentuado con las tecnologías digitales en relación con adultos y adultos mayores que revelaban escasa familiaridad con los diferentes dispositivos digitales (computadoras, telefonía móvil, televisión digital, entre otros).

Cuando focalizamos en las prácticas agrupadas en torno al consumo de contenidos (YouTube, TV, cine y radio en línea) de servicios (bancarios, financieros) o de redes sociales (WhatsApp, Facebook, Twitter) nos referimos a las acciones y/o interacciones realizadas a través de dispositivos (computadoras, telefonía móvil, televisión digital) con acceso a Internet.

En primer lugar, encontramos que la búsqueda de contenidos en línea es una tendencia que crece en tanto decrece la edad de los entrevistados de esta investigación en la misma medida que lo hace el uso de diversas tecnologías digitales. Los consumos de canales de películas o series y de música se ubican primero entre las acciones que realizaban con computadoras, telefonía celular y en menor medida en con la televisión digital. Nicolás A. (20 años) comentaba que escuchaba música por internet. Germán (26 años) dice: “(...) hay series de TV que sí las miro, las bajo por internet y las miro en casa, pero las miro después. (...) las pongo en la tele mediante USB y las miro ahí. En cierta manera estaría mirando un servicio que es por internet que es Netflix, estoy mirando contenido de Netflix en mi casa sin internet.” $\mathrm{O}$ “(...) cuando salió Vorterix me acuerdo que lo escuchaba bastante por internet, escuchaba la Metro cuando laburaba en el ciber”. Nicolás, N. (17 años) contaba que como cuando en su casa quiere escuchar música "(...) busco en YouTube el tema y listo". En menor medida, los jóvenes parecen buscar contenidos para informarse sobre algún tema de interés como por ejemplo en el caso de Érica (20 años) que menciona que si ve "(...) alguna noticia que dieron un flash, bueno voy a internet para interiorizarme más de lo que está pasando".

Entre los adultos jóvenes, si bien admiten que miran películas o series en línea notamos que la preferencia se perfila hacia el consumo de información a través de la lectura de diarios en línea o de comunicación vía correo electrónico. Verónica (45 años) señalaba: “(...) Busco películas, así argentinas, viejas que no logré ver y las veo por internet. No 
porque cuando me decido a ver una película conecto internet a la tele y ya está." Paula (44 años), Mónica (51 años) o Adriana (44 años) contaban que consultaban noticias y mensajes por correo electrónico con cierta frecuencia.

En tanto el consumo de contenidos que mostraban los adultos mayores, entre los que disminuye el uso de la computadora y de Internet, se asocia a los medios tradicionales tales como diario en papel o la radio hertziana antes que a los medios digitales.

En relación con la consulta servicios bancarios y/o financieros encontramos que apenas una entrevistada la mencionó como una actividad que realizaba con cierta frecuencia: Mónica, (51 años) afirmaba “(...) a veces el diario o el Home Banking por ahí (...).”

Ahora bien, notamos una marcada inclinación que abarca a jóvenes como adultos jóvenes que dedicaban cierto tiempo a las principales redes sociales para comunicarse con otros e inclusive para informarse. Este tipo de actividad, según las palabras de los entrevistados, la realizaban a través de la telefonía móvil: Érica (20 años) contaba con: “(...) el celu estoy todo el tiempo investigando a ver dónde se puede buscar tal cosa. Y el celular ahora con el WhatsApp que es mucho más ágil entonces vas más rápido.”; Germán (26 años) “(...) Facebook, que lo uso bastante, el uso que le doy tiene que ver más con la cuestión de la música." o Fátima (35 años) que señalaba que: "En el Twitter a veces veo las noticias, de vez en cuando", entre otros testimonios.

Cuando los entrevistados mencionan la búsqueda de información aluden a Internet como un lugar de donde pueden obtener respuestas y extraer o sacar referencias y datos que les interesan. Sin embargo, a través de estas prácticas no parecen representarse más que como consultores o consumidores y no así como productores de información para otros. Es decir, consideran que la navegación por Internet les proporciona la información que necesitan como noticias, música, videos pero no generan contenidos para difundir a otros en línea. Junto a esta caracterización agregamos que los entrevistados no intervenían en comunidades virtuales, foros, videollamadas individuales o grupales, o sea, no realizaban acciones que involucren interacciones con otros en el ciberespacio para diferentes objetivos tales como obtener información, intercambiar experiencias, aprender, etc.

Entonces, entendiendo la participación en el entorno tecnocultural como una dimensión comprendida en los procesos de inclusión digital nos encontramos en condiciones de arriesgar algunas consideraciones sobre los grados y tipos que advertimos entre nuestra población en estudio. 
El entorno tecnocultural que estudiamos tiene entre sus características un escaso acceso y uso de dispositivos digitales yuxtapuesto a una baja e ineficiente conectividad a Internet. En ese ambiente, reconocemos que los usuarios de la TDA detentan un tipo de participación que permite cierto acceso al entorno digital pero en situación de consumidores de productos (de información, audiovisuales, sonoros, etc.) cuyas acciones no se orientan a diseñar y generar interacciones en ese medio. La actividad que predomina entre nuestros entrevistados es la comunicación vía redes sociales (WhatsApp, Facebook, Twitter) que incluye una limitada interactividad y escasa navegación que abona la presunción de que no se manifiesta una participación de rasgos activos que propenda a establecer prácticas interactivas con el entorno tecnocultural.

Finalmente, podemos decir que el grado de participación de los usuarios de la TDA en el ambiente digital en el que desarrollaban su actividad cotidiana tanto en torno a sus relaciones personales, familiares, amicales o laborales, resultaba limitado como para contribuir con procesos de inclusión digital. Entre los obstáculos, que hemos identificado en apartados anteriores, se encuentran los problemas técnicos (desde la instalación del receptor digital a sus usos) y de conectividad (desarrollo deficiente) en de la televisión digital, el escaso desarrollo de los servicios interactivos así como también la incipiente oferta de contenidos, entre otros. De allí que entendemos que este conjunto de dificultades que encontramos en relación con la TDA no favorece el desarrollo de niveles de participación.

\subsection{Oportunidades y expectativas para la inclusión personal y social}

La presencia de las tecnologías digitales en nuestras sociedades es desigual y obedece a los efectos de las lógicas de los mercados, de la intervención de los Estados y/o de las organizaciones públicas no gubernamentales. La disponibilidad y el acceso físico a dichas tecnologías forman parte de un primer escalón -siempre incompleto- en pos de la inclusión en los entornos tecnoculturales mientras que los usos aportan una mirada compleja para advertir los modos en que las integran a sus actividades dentro del espacio doméstico y fuera de él. Las iniciativas de política pública de inclusión digital que distribuyen equipamiento tecnológico se proponen no sólo garantizar el acceso físico sino suturar la brecha digital para los sectores y organizaciones sociales de la sociedad con 
escasa o casi nula capacidad de participar activamente -tanto como consumidores como productores - en el mercado tecno mediático.

Entre los recuerdos sobre la llegada de la TDA a los hogares, nuestros informantes nos contaron que mientras algunos lo recibieron en sus domicilios, otros lo fueron a buscar al correo, a Tecnópolis o en algún operativo en el barrio. La ubicación e instalación del receptor digital en los espacios compartidos en la casa, las lógicas de usos y consumos de la televisión digital reproducen las particularidades de la analógica o tradicional. Una de las cuestiones que debemos señalar aquí es que en el relato de las diferentes experiencias no aparecían rasgos que indicaran que la TDT haya modificado sustantivamente las rutinas personas y actividades familiares dentro del ámbito doméstico. Más bien, parece haberse acoplado a los hábitos hogareños sin demasiadas estridencias.

Pero más allá de que la TDA no haya alterado sustantivamente la escena doméstica, nos interesó conocer las impresiones de los usuarios sobre los beneficios tanto personales como sociales que perciben implicados al momento de enfrentarse con las tecnologías digitales.

Las expectativas de inclusión personal a partir de la televisión digital nuestros entrevistados las vincularon con la posibilidad de aprender con las tecnologías para luego resolver problemas de la vida cotidiana o del trabajo; para adquirir y actualizar conocimientos de distinto tipo como para entretenerse. Es decir, si bien reconocen que la TDA puede favorecer ciertas habilidades y capacidades personales no llegan a representarse incluidos en su entorno tecnocultural.

Decíamos en la parte I de este capítulo que cuando les consultamos sobre las ideas asociadas a la inclusión digital registramos posiciones (integrantes de la organizaciones sociales) que reconocieron que la televisión digital permitía que los diferentes sectores de la población pudieran acceder a un servicio gratuito y con propuestas culturales diversas a partir de una oferta de contenidos producidos para cada región del país. Estas impresiones están ligadas a la idea de que la obtención del beneficio promueve que los sectores socioeconómicos y culturales en "riesgo de exclusión" estén incluidos en el entorno digital. A la vez, aquí subrayamos que en estos discursos aparecen cristalizadas representaciones acerca de los destinatarios de las políticas públicas como "sujetos de derecho". En línea con lo que venimos comentando sobre los contrastes que expresan las entrevistadas en relación con las ventajas de la TDA nos interesa señalar los rasgos que encontramos en dichos señalamientos. De allí, es que entendemos que el interés y la participación política activa de las integrantes de la mutual juegan un rol importante que 
evidencia una reflexión sobre la perspectiva de los derechos económicos, sociales y culturales. En el marco de esta perspectiva de derechos, la inclusión digital se presenta en su discurso como parte de los derechos que el Estado debe asegurar a través de políticas públicas efectivas.

Por otro lado, recuperamos alusiones que se distancian de la concepción de que la implementación del Plan "Mi TV Digital” promueva la inclusión digital de sectores poblacionales que pueden o que se encuentran excluidos. En estos relatos aparece explícitamente una crítica a la política pública y su intención de incluir digital y socialmente sostenida en que la cobertura del beneficio alcanza a un grupo social en particular dejando a otros desprotegidos (por ejemplo, dicen que cubre a los jubilados que cobran la mínima y no a los demás tipo de jubilaciones). Lo que ponen en cuestión aquí es que en todo caso, la inclusión que se percibe es tecnológica (acceso físico) pero que no alcanza para incluir socialmente a todos.

\subsection{Conclusiones del capítulo}

Como planteamos al inicio de este capítulo nos centramos en las valoraciones, sentidos y resignificaciones que los usuarios le adjudican a la televisión digital en sus contextos cotidianos y las conjeturas que esgrimen acerca de la TDA como puerta de ingreso a los procesos de inclusión digital. En esa línea decidimos implementar una serie de entrevistas en profundidad a beneficiarios de "Mi TV Digital” que residieran en el Partido de José C. Paz que agrupamos en tres conjuntos: jubilados y/o pensionados, familiares de jubilados y/o pensionados a los que le cedieron el decodificador digital e integrantes de la organización social Mutual Primavera. Estos criterios conciernen a los requisitos y definiciones de los perceptores de la política pública explicitados en los documentos de la TDA que hemos referido particularmente en el capítulo II de esta tesis. Los entrevistados pertenecían a diferentes rangos etarios: jóvenes, adultos jóvenes y adultos mayores y a sectores socioeconómicos de ingresos bajos y medios bajos.

La indagación en las entrevistas en profundidad se inclinó a conocer los principales aspectos desde la llegada de la televisión digital a los hogares como el lugar que le asignaban y los usos que mencionaban los usuarios de la TDA. Asimismo, nos concentramos en una caracterización de los vínculos que los entrevistados reconocían 
establecer con diferentes tecnologías digitales y las expectativas en pos de la inclusión digital.

Para comprender las relaciones que establecen las personas con las tecnologías digitales en el marco de implementación de políticas públicas de inclusión digital nos centramos en los modos que sus usos se constituyen en prácticas sociales y culturales significativas en contextos de transición digital. Pero estas relaciones no se dan en el vacío sino que se despliegan en un entorno tecnocultural que en nuestro caso, y como hemos explicado anteriormente, se presenta inestable (obsolescencia de los dispositivos) y con altos grados de desigualdades (económicas, sociales y culturales) que afectan sensiblemente el acceso y usos de las tecnologías digitales de los habitantes de zonas periféricas.

Como reiteramos en capítulos anteriores, entre 2009 y 2015, el Estado argentino comenzó a desarrollar la televisión digital a partir de la creación del SATVD-T - junto a la definición de estrategias y acciones para la implementación del sistema de televisión digital terrestre- que permitieron iniciar el proceso de distribución del equipamiento para el acceso a la TDA entre organizaciones sociales, establecimientos estatales y hogares en situación de vulnerabilidad.

Unas de las cuestiones que nos llamó la atención fue que varios beneficiarios de la TDA que percibían una jubilación o pensión habían cedido a algunos de sus familiares el receptor digital y la antena a causa de que habían adquirido un televisor LED mediante el Plan "TV Para Todos". Al indagar sobre este hecho, tanto los familiares como los destinatarios insistieron en que la razón se debía a la renovación de televisor HD apto para TDA aprovechando las facilidades de dicho plan. En esta situación, nuestra conjetura es que la cesión del kit de televisión digital terrestre tuvo que ver con la obtención de un artefacto nuevo pero también con que les resultaba más fácil acceder a la TDA ya que en varios de los aparatos estaba incorporada.

Más allá de las menciones acerca del momento en que se enteraron de la existencia del Plan "Mi TV Digital” y realizaron los trámites de obtención del beneficio, las alusiones sobre el contacto inicial con el dispositivo digital no muestran mayores dificultades para la instalación pero la operación propiamente dicha revela limitaciones asociadas al desconocimiento de funciones y refuerza las prácticas construidas con las tecnologías analógicas (radio y TV hertziana, telefonía fija). Los vínculos que las personas fueron componiendo con esos dispositivos les permitieron, en cierta medida, recuperar 
operaciones básicas como prender-apagar-sintonizar-subir/bajar el volumen para enfrentarse a las tecnologías digitales que se van presentado en sus cotidianidades.

Si bien, la telefonía móvil tiene una alta penetración en los hogares $(89,6 \%$ según la ENTIC:2015), de acuerdo con nuestra investigación, no adquiere una centralidad que configure las diferentes prácticas que los usuarios despliegan con las tecnologías en los ámbitos que transitan: la casa, el trabajo, la escuela, entre otros. La computadora e Internet mantenían porcentajes por debajo del $70 \%$ de presencia por razones no solamente de poder de compra entre los sectores socioeconómicos medios bajos y bajos del conurbano bonaerense sino por una oferta deficiente y de baja calidad de servicios de conectividad. Sin embargo, es la televisión la que permanece en el foco de la escena hogareña que Silverstone, Hirsch, y Morley (1996) describía como el centro del entretenimiento doméstico.

Esta centralidad de la televisión en el ámbito doméstico, que se adecua de acuerdo con las actividades y rutinas que cada integrante del hogar desarrolla como estudiar, trabajar dentro o fuera de la casa, etc., está sostenida en las prácticas operativas (técnicas), de contenidos (visionado) y socioculturales (aprendizaje, entretenimiento, compartir con otros, etc.) construidas con el aparato analógico. Como anticipamos, nuestros entrevistados asociaban las acciones que aprendieron a realizar con el artefacto hertziano a la vez que se auto percibían con algunas limitaciones para operar el decodificador digital y las diferentes funciones que ofrece. Los hábitos de consumo televisivo conservaban los rasgos del visionado tradicional ligado a la programación organizada por horarios fijos y con predominancia de contenidos informativos y de entretenimiento. Estas lógicas de consumo de televisión a la vez permitían compartir, conocer a otros, debatir, recreación, etc. tanto en el espacio doméstico como fuera de él.

Esta caracterización de las condiciones y prácticas vinculadas a los usos de la televisión digital en el Partido de José C. Paz nos habilita a arriesgar las posibles derivaciones que adoptan en el marco de los procesos de inclusión digital enunciados por la política pública TDA.

Partimos de la presunción de que el acceso a las tecnologías digitales, sus usos, los grados de autoconfianza y de participación pueden ser considerados como dimensiones de procesos de inclusión digital cuando se analizan en el nivel de los sujetos. 
Como señalamos en otras oportunidades, el acceso a las tecnologías incorpora dimensiones nuevas que trascienden el mero contacto o disposición con los aparatos y sistemas. La solución a la brecha, la inclusión digital, presupone ese tipo de acceso (contar con las tecnologías) pero no se agota en él. Como plantea Cabello (2017) no alcanza con medir el acceso a la infraestructura técnica (cantidad de dispositivos, tendido de redes, conectividad, etc.) porque limita el reconocimiento de las tramas socioculturales en las que la inclusión digital puede operar. Por eso, sondear los usos que las personas hacen con las tecnologías digitales permite saber qué hacen con ellas, qué sentidos producen, qué les motivan, más allá de que las tengan a disposición o no.

Hemos señalado a lo largo de este capítulo que muchos de los usos se consolidan a través de la actitud exploratoria de los usuarios y de procesos de aprendizaje colaborativo basado en el ensayo y error, en capacitaciones $u$ orientados desde planes y programas estatales de integración de tecnologías.

Los usos de la televisión digital que nuestros entrevistados reconocieron se caracterizaron por desplegar destrezas básicas orientando operaciones meramente instrumentales que diferían en algún grado entre los más jóvenes y los adultos. Situados en esos usos, los beneficiarios del Plan "Mi TV Digital" mostraron dificultades para representarse una de las novedades de la TDT: la interactividad. Apenas pudieron registrar un primer grado de interactividad en torno a la consulta, programación o segunda pantalla, prácticas asociadas la navegación en Internet, uso de redes sociales, de aplicaciones en telefonía móvil y en otros casos, al manejo de otras tecnologías de la vida cotidiana: electrodomésticos, herramientas de trabajo, autos. Si bien, la interactividad es una de las funciones de la televisión digital que al momento del estudio no se encontraba operativa en su totalidad no aparecían ideas que superaran el desconocimiento o algún tipo de experimentación. Las limitaciones técnicas del decodificador digital de la TDA sumado a los hábitos de consumo de la televisión analógica tal como la recepción sin ningún tipo de interacción más que elegir la señal, programa, nitidez de la imagen, etc. alejan en alguna medida las representaciones sobre la interactividad. Entendemos que es la lógica del mercado mediático que talla en esta relación de tal modo que junto a un incipiente desarrollo (aún en los servicios de televisión de cable y satelital de pago) se presenta como un servicio exclusivo que requiere un acceso restringido por un estipendio.

El contacto con las tecnologías digitales puede disponer la construcción de grados de autoconfianza que les permiten a las personas auto percibirse en mejores condiciones 
objetivas y subjetivas para integrarse a su entorno tecnocultural. Fortalecer sus capacidades y habilidades personales y sociales a través de los usos de las tecnologías digitales tiene una potencialidad para no quedarse afuera de un mundo cada vez más digitalizado. Sin embargo, en nuestra población en estudio, encontramos escasos grados de familiaridad y de sensaciones de confianza frente a las tecnologías digitales que en los casos más extremos mostraron hasta desinterés o disgusto en el contacto con las mismas. Estas impresiones por parte de las personas tienden a acrecentar las distancias con las tecnologías digitales que obstaculizan proyectos de autonomía personal y social.

Asimismo, las prácticas y las posiciones que adoptan los usuarios de la TDA no se caracterizan por la producción de informaciones o contenidos sino que como planteamos en este capítulo, refuerzan las condiciones de consumidores de tecnologías y productos en el mercado tecno mediático. El acceso y los usos de la televisión digital identificados en esta investigación colaboran en ordenar perfiles de consumo según las variables que el mercado tecno mediático produce para estos. En nuestro caso, estos perfiles se ajustan a las características de un entorno tecnocultural con baja disponibilidad y oferta de servicios de tecnologías digitales tales como tendido de redes, conectividad, interactividad, etc.

A lo largo de este capítulo fuimos analizando los usos de la televisión digital y sus derivas a la vez que sondeamos las expectativas que producía, entre nuestros informantes, no solo como objeto material y simbólico sino como vehiculizadora de procesos de inclusión digital promovidos a partir de una política pública específica: la TDA.

Las voces, percepciones y opiniones de los usuarios de la televisión digital evidenciaron parte de la trama siempre compleja de las prácticas y de sus experiencias en el marco de la gestión e implementación de las políticas públicas digitales que promueven la difusión de tecnologías entre la población en general y en particular, entre aquellos sectores en "riesgo de exclusión digital". Provisoriamente, podemos afirmar que los hallazgos de investigación a la luz de las perspectivas teóricas que adoptamos permiten desarticularlos y rearticularlos en torno al análisis de la política pública de inclusión digital. 


\section{Capítulo VIII}

\section{La televisión digital en contexto: ¿más y mejor incluidos?}

"A falta de poder cambiar el mundo, uno se contenta con describirlo".

Mattelart (1997:20)

Esta tesis se terminaba de escribir cuando, luego de 4 años de la Alianza Cambiemos, se iniciaba una nueva gestión de gobierno en Argentina con incipientes rasgos de continuidad de las políticas de comunicación con la presidencia de Néstor Kirchner (MC) (2003-2007) y los dos períodos de Cristina Fernández (MC) (2007-2011/2011-2015).

"El inventario de las comunicaciones en la Argentina tras los cuatro años de presidencia de Mauricio Macri es problemático, complejo y desafiante", señala el reconocido especialista Martín Becerra (2019) y conjetura que el modelo que seguirá la nueva gestión será un diseño de políticas públicas que articularán la estructura, la economía de medios y las telecomunicaciones en armonía con los grandes operadores.

Como señalamos en la presentación de esta tesis la gestión del sistema de medios de la Alianza Cambiemos tuvo características marcadas en tanto produjo una centralización de las decisiones en el Poder Ejecutivo, con una fuerte concentración de la estructura mediática (grandes grupos mediáticos con posición dominante) y un claro giro hacia el mercado. Mastrini y Becerra (2019:1) afirman que:

"El mapa de medios cambió durante el macrismo. Dos decretos fueron clave: uno que desactivó la famosa Ley de Servicios de Comunicación Audiovisual, y otro que permitió la expansión a las telecomunicaciones: los grandes operadores en todos los mercados. El discurso de la convergencia (...) favoreció a la concentración: si bien la regla es para todos, pocos están en condiciones de usufructuarla”.

Tras la modificación de la Ley de Servicios de Comunicación Audiovisual, el gobierno anunció que conformaría una comisión redactora para una nueva ley de comunicación convergente y la enviaría al Congreso para su tratamiento. Sin embargo el proyecto, que regularía los sectores audiovisual y de telecomunicaciones, nunca fue girado a la Cámara Baja.

Estas transformaciones en el escenario infocomunicacional tuvieron manifiestas consecuencias en la continuidad de la política pública que nos ocupa. Uno de los efectos 
se evidenció en el desfinanciamiento de la TDA. Según Krakowiak (2018), que analizó los balances de la empresa INVAP encargada de la instalación de las antenas transmisoras, indica:

"En el segundo semestre de 2015, las ventas del segmento Tecnologías de la Información y la Comunicación (TICs) habían trepado a 768,9 millones de pesos (57 millones de dólares, según el tipo de cambio de diciembre de 2015). En el segundo semestre de 2016, cayeron a 473,5 millones (29,4 millones de dólares) y, en los últimos seis meses de 2017, se derrumbaron a 180,8 millones (9,5 millones de dólares). En pesos, la caída fue de 76,5 por ciento en apenas dos años y, en dólares, se derrumbó un 83,4 por ciento".

En relación con la producción de los contenidos para la televisión digital terrestre también se produjeron cambios como por ejemplo el cierre de dos señales públicas como: ACUA Federal y ACUA Mayor, despidos de trabajadores en diferentes áreas de la TDA (administración, contenidos, edición, etc.) y el desmantelamiento de los espacios de producción audiovisual.

También se realizó una reorganización de la grilla que redujo la cantidad y variedad de señales además de que renovó la programación como la del canal Encuentro. Al respecto, Becerra (2016) indicó: “(...) el gobierno ya distorsionó su finalidad educativa y lo transforma en un canal de TV cultural. Esto sin abrir juicio de valor sobre la calidad, la línea editorial y el modelo tercerizado de producción de Encuentro en las gestiones anteriores y en la actual: su función era marcadamente educativa, hoy ya no lo es." En junio de 2016, la señal TeleSur dejó de emitirse en la plataforma de la TDA por decisión de la gestión macrista que además retiró la participación del país en la empresa administradora de dicho canal. Y en 2017, finalizó el programa "Fútbol para todos" que impactó negativamente en la audiencia de la TV Pública y de otras señales de la TDA.

De allí que, los cambios que se fueron produciendo en las políticas públicas y la normativa correspondiente mediante “(...) decretos de necesidad y urgencia, decretos simples y resoluciones, no sólo supone inconsistencias jurídicas sino que revela una fuerte debilidad institucional en nuestro país, así como una incapacidad para trazar políticas de comunicación a largo plazo en función del interés público.” (Califano, 2017:63) En este caso, la principal consecuencia fue la desarticulación de los planes y programas de la televisión digital en todo el territorio nacional hasta el punto de la negligencia y el abandono, como señalara la investigadora Pauloni (2018). La fragilidad institucional sumada al proyecto político de la fuerza gobernante, que guio la toma de decisiones, afectaron no solo la continuidad de las políticas públicas sino que dieron una vuelta de 
timón hacia el mercado en tiempos en que la migración digital aún se encuentra en marcha. La interrupción político-institucional de la TDA fue parte de una política de medios que propició la convergencia digital adaptada para unos pocos actores que dominan el mercado de la comunicación.

A lo largo de esta tesis nos hemos planteado focalizar nuestra atención en los alcances de los procesos de inclusión digital teniendo en cuenta las definiciones de la política pública TDA y los usos y las prácticas de los usuarios en una localidad del conurbano bonaerense. Teniendo en cuenta que los procesos de inclusión digital son procesos complejos que se desarrollan en varias dimensiones complementarias: acceso, uso, autoafirmación y participación, nos propusimos abordar la siguiente hipótesis de trabajo que guió esta investigación: La política pública Televisión Digital Abierta (TDA) (su estructura normativa y técnica, junto a las prácticas vinculadas con sus usos), que privilegia el acceso físico a las tecnologías para sectores sociales "en riesgo de exclusión digital”, resulta insuficiente para promover procesos de inclusión digital entre sus destinatarios.

En este capítulo presentamos una síntesis de los principales hallazgos así como también el trayecto teórico-metodológico que fuimos construyendo durante esta investigación. No pretendemos cerrar este proceso con premisas finales sino que nos interesa explicitar una interpretación sobre nuestro objeto de investigación a partir de los documentos de la política pública y las entrevistas abiertas a usuarios de la televisión digital en el Partido de José C. Paz.

Decíamos en la presentación de la tesis que entendemos que el proceso de investigación se despliega en diferentes niveles de complejidad: dialoga con los problemas hacia adentro de las disciplinas a la vez que discute con los dispositivos formales del diseño (recorte del objeto, definición de los objetivos de indagación, antecedentes, desarticulación y rearticulación de los conceptos en el encuadre teórico) y las condiciones de lo real. De este modo, el método de investigación (que recupera las articulaciones entre lo real sobre un objeto de estudio particular) y el método de exposición (que explicita las decisiones que se han tomado) forman parte del proceso de investigación, tal como hemos anotado al inicio de este trabajo. Escolar (2000:25) retomando a Bourdieu y Wacquant (1987) sostiene que: “Los planteamientos nunca son más o menos definitivos. Justamente la relación entre la investigación concreta y la discusión teórico-metodológica nos lleva a replantear los conceptos desarrollados". La construcción del objeto de estudio no es algo que se haga de una vez y para siempre sino que se trata de un trabajo extenso 
que requiere revisiones, correcciones, reajustes durante el proceso. Por lo tanto, la investigación implica siempre dar cuenta de una o varias de la/s toma/s de decisión/es respecto de lo real que se procura estudiar.

En esa dirección, el objetivo general que organizó esta tesis fue analizar la relación entre los usos de la Televisión Digital Abierta (TDA) y los procesos de inclusión digital de acuerdo con las expectativas expresadas en la política pública, por un lado, y los discursos y prácticas de los usuarios de la población del partido de José C. Paz de la provincia de Buenos Aires durante 2014 y 2015, por el otro.

En nuestro caso, para delimitar y construir teóricamente el objeto de conocimiento recurrimos a la rearticulación de los principales conceptos y debates que dialogan en la tesis; y que ordenan nuestra reflexión teórica.

Para ello, nos propusimos producir un abordaje teórico-metodológico situado, en sentido amplio, en las Ciencias Sociales y en particular, que comprendiera nociones y categorías de perspectivas críticas del campo de estudios de la comunicación que se ubica entre las discusiones entre los Estudios Culturales y la Economía Política de la Comunicación y la Cultura.

La pregunta por los procesos de inclusión digital promovidos por políticas públicas y su relación con los usos de las tecnologías digitales implica entender el modo en que los sujetos establecen relaciones con las mismas en el marco de la digitalización de las industrias infocomunicacionales. En este sentido, como anunciamos en el capítulo IV, decidimos ensayar "conversaciones interdisciplinarias" (Grossberg, 2012) que nos permitieran enfocar las articulaciones manifiestas, y aquellas que no tanto, entre los enfoques que estudian las tecnologías en el marco de los procesos de transición digital. A riesgo de no ofrecer respuestas concluyentes entendemos que indagar las relaciones entre los sujetos y las tecnologías en el escenario de digitalización de la cultura de acuerdo con las expectativas expresadas en las políticas públicas de inclusión digital requiere de diseños flexibles. Sobre esas conversaciones, dice Grossberg (2012:345): “(...) son más difíciles de lo que nos gustaría admitir (...) debemos reconocer que diferentes teorías, métodos e incluso políticas no necesariamente se oponen, que cada uno vuelve algunas cosas visibles y otras invisibles, dan voz a algunas cosas y silencian otras." Por eso, nuestra propuesta de investigación se apoya en este enfoque en tanto que creemos que esta decisión teórico-metodológica puede aportar a la producción de conocimiento con objetos complejos e inestables como las tecnologías digitales y sus contextos de producción y consumo en entornos de migración digital. Parte del esfuerzo por 
comprender si las políticas públicas de acceso a las tecnologías digitales, en nuestro caso, la TDA, en sus definiciones y en su implementación pueden promover procesos de inclusión digital entre sus destinatarios, está dedicado a tratar de ir un poco más allá de la descripción del contexto en que se producen estas relaciones. Se trata de abrir la reflexión para formular preguntas de investigación que permitan profundizar estos aspectos o bien abordar otros que no hemos considerado en este trabajo.

El recorte del objeto de investigación de esta tesis se encuentra sustentado en la pregunta por los modos (usos, prácticas) en que las tecnologías digitales participan de los procesos sociales y culturales a la vez que éstos organizan los contextos particulares donde se insertan y desarrollan las mismas.

Para precisar y abordar este interrogante de indagación hemos desarticulado las nociones “(...) de los corpus teóricos de los cuales provienen. A partir de esta desarticulación conceptual se trata de hacer una lectura problematizadora del concepto, tanto en su contenido como en sus relaciones y jerarquías con otros conceptos.” (Escolar, 1998:2) Por ende, las nociones que ordenaron nuestra propuesta, que construyeron y reconstruyeron el problema a lo largo de la investigación fueron: tecnologías digitales, televisión digital, usos y procesos de inclusión digital.

La articulación de estos conceptos ordenadores básicos, a la vez, nos permitieron problematizar la discusión sobre las políticas públicas de inclusión digital. De este modo, nos propusimos conocer el rol que asumía el Estado, a través de la ejecución de la TDA, y los sentidos atribuidos por los sujetos y sus prácticas en relación con los procesos de inclusión digital.

Ahora bien, para estudiar la política pública TDA - entre 2014 y 2015- a 5 años del apagón analógico, construimos un estudio de caso, a partir del cual consideramos la relación entre los usos de la televisión digital y los procesos de inclusión digital en una zona del periurbano bonaerense donde los indicadores socioeconómicos y culturales muestran rasgos de vulnerabilidad: el Partido de José C. Paz, en la segunda corona del AMBA. En efecto, para explorar las expectativas, los usos, las prácticas recurrimos al análisis de documentos de la TDA, por una parte y por otra, a la implementación de entrevistas abiertas a usuarios de televisión digital residentes en José C. Paz.

Esta investigación se centró en el problema de la inclusión digital como emergente de un contexto de desarrollo de tecnologías y nuevos medios con avanzados procesos de mercantilización y digitalización de la producción cultural que adquirió relevancia en la 
agenda pública de debate a partir de la discusión de la Ley de Comunicación Audiovisual $\mathrm{N}^{\circ} 26.522$.

Hemos comentado en los primeros capítulos que los Estados de los países latinoamericanos fueron incorporando la inclusión digital como meta en un conjunto de planes y programas para trasponer la migración digital. Desde 2010, en Argentina se generaron iniciativas de difusión de tecnologías digitales principalmente en el ámbito educativo con el Programa CONECTAR IGUALDAD así como en otros espacios: los NAC, la TDA, etc. En este marco, partimos de considerar que las políticas públicas de inclusión digital involucran la complejidad propia de la formulación de las mismas sumada a definiciones sobre la inclusión digital que privilegian el acceso a las tecnologías como remedio para la exclusión social. Una de las particularidades que nos interesó considerar fue el rol y las decisiones que se tomaron desde el Estado en tanto actor ineludible para llevar adelante la transición digital. Para ello, recuperamos a Becerra y Mastrini (2006:16) que afirman que:

"Los estudios de economía política de la comunicación presentan una creciente amplitud que abarca el tradicional estudio de la estructura de las industrias culturales, las transformaciones en el sistema productivo y las políticas de medios, pero que también busca indagar en la incidencia de los desarrollos tecnológicos y en cómo las tendencias generales de la economía impacta específicamente en el área de la cultura".

Bajo estas premisas analíticas, consideramos que estas políticas públicas, que se abocan a las cuestiones del campo de la comunicación digital, no son definidas exclusivamente por el Estado sino que se disputan los intereses con el mercado mediático y con la sociedad civil. (Mastrini, 2014a:10) En el capítulo II presentamos la TDA enfocando sus antecedentes, las fases de la migración tecnológica y las modificaciones operadas en el mercado mediático a partir de la decisión del Estado de implementar la política pública. El análisis histórico-político junto a la revisión de las normativas y los documentos de las políticas públicas de inclusión digital, en nuestro caso la TDA, habilitó una lectura crítica que proyectó las características y el desarrollo de la televisión digital sobre la interpretación de los usos y prácticas de los usuarios en el Partido de José C. Paz. Para comprender las significaciones otorgadas por los entrevistados a la televisión digital como uno de los dispositivos para alcanzar la inclusión digital retomamos la perspectiva de los Estudios Culturales. Desde esos bordes exploramos la llegada de la televisión digital a los hogares tomando el análisis de la biografía de los objetos y de la economía moral del hogar según, los autores Silverstone, Hirsch y Morley (1996). Instalada la TDA en las 
casas de los usuarios, nos preguntamos por los usos que realizaban con la televisión digital y los sentidos que proyectaba en relación con la inclusión digital. En este punto, introdujimos una noción de inclusión digital que incorpora una mirada integral: comprende la multidimensionalidad de la relación de los sujetos con las tecnologías en sus contextos cotidianos en el marco de las políticas públicas digitales, dirigidas tanto a la población en general como a aquellos sectores en riesgo de exclusión digital. A lo largo del capítulo VII fuimos centrándonos en las diferentes dimensiones, que siguiendo los planteos de las autoras Seale (2009) y Cabello (2014), identificamos de la inclusión digital: acceso, uso, autoconfianza y participación.

De este modo, para complementar el abordaje esta indagación, sobre las relaciones entre los usos, las prácticas asociadas a la TDA y los procesos de inclusión digital, nunca perdió de vista las definiciones de la política pública en la que se enmarca en el análisis.

\subsection{La TDA: ¿dispositivo de inclusión digital?}

A lo largo de esta tesis nos hemos propuesto problematizar los presupuestos dominantes que gravitan tanto en el discurso de los organismos internacionales como en la retórica de los Estados latinoamericanos sobre las tecnologías como dispositivos de inclusión digital cuya meta principal es la de disminuir la llamada "brecha digital" entre países y fronteras adentro de los mismos.

Estos presupuestos asocian la difusión de la información o la disponibilidad de dispositivos técnicos a la democratización de las sociedades que reeditan con cada salto tecnológico la idea de que las nuevas tecnologías van a generar mejores condiciones de desarrollo económico e inclusión social. Estas premisas, que se encuentran comprendidas en la toma de decisiones política de los Estados, se materializan en un conjunto de políticas públicas cuyo propósito es incluir digitalmente a aquellos sectores en riesgo de exclusión.

En este marco, el proceso de digitalización de las tecnologías no se da de un momento a otro sino que necesita de un contexto de reconversión digital que se caracteriza principalmente por la sustitución gradual de tecnologías analógicas. La transición digital es una iniciativa compleja de la que participan el Estado, el mercado y la ciudadanía. Una parte importante se centra en el impulso del sector público con el liderazgo del Estado que es el encargado de desarrollar políticas públicas (diseño, formulación, ejecución y financiamiento), acordar los marcos jurídicos adecuados, implementar el plan para el 
apagón analógico e impulsar ayudas e incentivos para el reemplazo del equipamiento analógico entre la población. Por otra parte, el sector privado también debe invertir en infraestructura (red, dispositivos técnicos), ofrecer servicios, contenidos digitales y ampliar la cobertura. Las organizaciones sociales igualmente tercian en este proceso aportando su capacidad instalada como intermediarias con la población en riesgo de exclusión digital. A la vez, los ciudadanos deben estar debidamente informados del proceso y aquellos sectores que no cuentan con las condiciones de acceso deben tener garantías para disponer de los artefactos digitales.

En el caso de la TDT, la transición digital incluye la renovación de los dispositivos y la infraestructura técnica, la desconexión de los servicios de televisión analógicos, la coordinación de los sectores involucrados y la comunicación a todos los participantes y en particular, a todos los ciudadanos.

En el período que estudiamos en esta tesis, el proceso de migración digital estuvo liderado por el Estado en diferentes ámbitos de intervención (educación, sistema de medios, desarrollo social). Entre esas iniciativas, se encuentra la puesta en marcha de la TDA.

Como hemos reiterado en varias ocasiones en este trabajo, esta política pública se propuso distribuir gratuitamente más de 1.000 .000 de decodificadores digitales para adaptar televisores analógicos así como también, entregar 28.488 kits satelitales entre sectores sociales con riesgos de exclusión digital en todo el país. A la vez, proyectó instalar hasta unas 85 torres transmisoras terrestres y unas 5000 antenas de TV Digital Satelital. Esta infraestructura tecnológica proyectaba cubrir el $82 \%$ del territorio nacional. Aquí nos interesa tomar nota que en 2015, según el INDEC ${ }^{186}$, por ejemplo la cantidad de jubilados y pensionados ascendía a 6.273.646 que pertenecían a los sectores en riesgo de exclusión definidos por la política pública. En este sentido, llama la atención que la previsión de entrega de receptores para TDA alcanzaba apenas a un $16 \%$ de esa población que era uno de los sectores definidos para recibir el beneficio.

\subsubsection{La cobertura y la distribución para la inclusión digital}

Uno de los primeros interrogantes que surgen con la investigación de una política pública de acceso a tecnologías se vincula con los procedimientos técnicos y administrativos para

\footnotetext{
${ }^{186}$ Se puede consultar en: https://www.indec.gob.ar/indec/web/Nivel4-Tema-4-31-62.
} 
la provisión de dispositivos técnicos entre los potenciales destinatarios. Entre otros puntos, el Informe de AGN (2014:45-47) le observó al Consejo Asesor del Sistema de Argentino de Televisión Digital Terrestre que existían algunas faltas de adecuación entre formularios:

“4.2.2.3.1-El formulario de adhesión al Plan Operativo de Acceso al Equipamiento (Comodato) no es uniforme y presenta deficiencias en su contenido.-El formulario que entrega el Correo Andreani y el publicado en la página web de Solicitud de Adhesión al Plan Operativo de Acceso al Equipamiento para la Recepción de la Televisión Digital Terrestre (o "Abierta”, según la página web) no aclara que, puesto que se trata de un comodato, el equipo debe restituirse al finalizar el período correspondiente.- 4.2.2.3.2.- Existe la omisión de una cláusula en el formulario de adhesión entregado por el Correo Andreani para su firma por parte de los beneficiarios de los equipos receptores STB. Idéntica situación se constató en la publicación expuesta en internet en el sitio oficial "Mi TV Digital". 4.2.2.3.3.Omisión del domicilio del beneficiario, en los datos personales que debe completar como declaración jurada en el formulario de adhesión al recibir el equipo receptor STB".

Estas inconsistencias se sumaron al desconocimiento sobre la cantidad de dispositivos técnicos comprados vía la normativa de la Administración Pública Nacional (APN) y distribuidos por el organismo del Estado pertinente. El Informe de la AGN (N 80/2012, 2014:43-44) concluye sobre las entregas practicadas que:

“4.2.2.1.- No existe certeza de la cantidad de equipos receptores STB que efectivamente se han entregado desde el inicio de la implementación del Plan hasta abril de 2012 inclusive.- (...) 4.2.2.2.- La información que suministra ARSAT carece de documentación sustentatoria.(...) Posteriormente en respuesta a solicitud de AGN, de cuantos equipos de STB se habían entregado en el año 2010 (discriminado por calendario), informa por Nota 22 de marzo de 2013 las mismas cantidades de STB expuestas precedentemente en forma global sin detalle, adjuntándose luego información que supuestamente remite el Correo Argentino donde en dicho período no se informan los datos de entregas realizadas".

En la ejecución de la política existieron estas imprecisiones en los datos de la inversión efectuada y de los decodificadores digitales repartidos que se reiteraron en la indagación de la distribución en la localidad del AMBA que nos propusimos estudiar.

También hemos señalado que en el caso del Partido de José C. Paz no hemos podido contar con estadísticas oficiales sobre el reparto de los set top box. Sin embargo, tomamos una encuesta realizada en los Partidos de José C. Paz, Malvinas Argentinas, Moreno y San Miguel cuyos resultados señalan que se entregaron al menos 40.000 decodificadores pero apenas un $2 \%$ de los hogares relevados en ese estudio tenía dicho servicio en 2014. (Abramovich, et.al. 2014:9) Es decir, la estimación de la disponibilidad de la TDA en los 4 partidos fue muy baja. Si estos números los cotejamos con la alta 
penetración el servicio de televisión paga: Telered (68\%), Cablevisión (8\%) y DIRECTV $(24 \%)$ en la zona la distancia resulta aún mayor.

No obstante, decidimos indagar los datos difundidos en algunos medios digitales locales y de circulación nacional además del sitio oficial del municipio sobre los operativos de distribución de TDA en el Partido de José C. Paz. Según estas fuentes, durante la intendencia de Carlos Urquiaga (2011-2015) se repartieron unos 1.300 decodificadores digitales con sus respectivas antenas aéreas. En parte estos números explican la dificultad que tuvimos para contactar a beneficiarios de la política pública en el Partido de José C. Paz. Comentamos en el capítulo V que nos resultó difícil encontrar beneficiarios por un lado, y por otro, aquellos que decían poseer un decodificador y antena para sintonizar la TDA lo habían adquirido en algún comercio minorista. En este punto, señalamos que algunas de esas personas asociaban a la TDA con una estratagema demagógica del gobierno de Cristina Fernández ya que mencionaban que estaba dirigida exclusivamente a sectores de bajos ingresos de la sociedad para cooptarlos políticamente.

Antes de continuar con estas reflexiones nos interesa señalar que para investigar la TDA en el Partido de José C. Paz introdujimos la noción de entorno tecnocultural (Cabello, 2014). Esta incorporación nos permitió no perder de vista los aspectos económicos, políticos y culturales en los que las personas desarrollaban su vida privada (personal, familiar, amical) y pública (trabajo, participación ciudadana, educación). Entendemos que la disponibilidad de infraestructura, dotación de equipos y/u oferta de servicios más los contextos y situaciones de usos están relacionados con las características del entorno tecnocultural. En el caso que hemos analizado y tal como hemos dicho en otras oportunidades, se trata de una localidad del conurbano bonaerense con una escasa densidad de infraestructura de telecomunicaciones, heterogénea disponibilidad de dispositivos técnicos y reducidos usos de tecnologías digitales proyecta un acceso desigual a la provisión de servicios tecnológicos y culturales tanto por parte del mercado como del lado de la acción del Estado. La fragmentación sociodemográfica del territorio (grandes sectores de la población de bajos ingresos con deficientes servicios básicos, bajo nivel de instrucción, alta desocupación que coexisten junto a un reducido sector de altos ingresos) que se organiza en el marco de un escenario en el que la distribución y penetración de tecnologías y la oferta cultural responde a las lógicas de mercado. De allí que el entorno tecnocultural que estudiamos se caracteriza por la heterogeneidad y marcados procesos de exclusión tanto económica, social como cultural. 
Volviendo a la TDA, el Plan de acceso gratuito "Mi TV Digital", en su reglamento, definía como potenciales destinatarios a establecimientos estatales (educativos, sociales, culturales), organizaciones sociales (asociaciones sin fines de lucro, cooperativas, fundaciones) y a los hogares cuyos titulares percibieran jubilación mínima, pensión, AUH, planes sociales y/o en situación de vulnerabilidad que no estuvieran contenidos en los demás criterios.

De los potenciales destinatarios establecidos en los documentos de la política pública TDA, nosotros nos centramos en los usuarios a los que le habían entregado el receptor digital por su condición de jubilados o pensionados, perceptores de planes sociales por un lado, y por otro, a las integrantes de la organización Mutual Primavera. Varios de aquellos jubilados y pensionados que habían recibido el beneficio cedieron sus decodificadores digitales a familiares que compartían el espacio doméstico (vivían en la misma unidad habitacional o en otra en un terreno compartido). La principal razón que esgrimieron fue que habían adquirido un televisor LED, en 60 cuotas, a través del Plan "TV Para Todos" lanzado en el 2011.

Uno de los primeros hallazgos de esta investigación es que el grupo etario de adultos mayores jubilados y/o pensionados fue el más beneficiado por la implementación de la TDA ya que se encontraban entre los principales destinatarios del plan de acceso gratuito.

\subsubsection{Información y comunicación para la transición digital}

Decíamos más arriba que uno de los requisitos de la transición digital es que la población en general esté informada, en principio, sobre el proceso de reemplazo de los dispositivos analógicos y las consecuencias en el consumo mediático y cultural.

En el marco del lanzamiento del Plan Nacional de Telecomunicaciones "Argentina Conectada", la presidenta (MC) Cristina Fernández anunció el inicio de la TDA, en un acto en el Centro Cultural Kirchner ${ }^{187}$ a partir de la puesta en funcionamiento de las antenas de transmisión de televisión digital terrestre en la provincias de Formosa y de Buenos Aires. En ese acto encabezado por la ex mandataria, junto al ex Ministro de Planificación Federal, Inversión Pública y Servicios, Julio de Vido, que fue transmitido

\footnotetext{
${ }^{187}$ En la fecha en la que se realizó el acto de lanzamiento de "Argentina Conectada" y de la TDA, el Centro Cultural se llamaba Centro Cultural del Bicentenario.
} 
por la Televisión Pública ${ }^{188}$, se plantearon los lineamientos centrales de las políticas públicas de inclusión digital. Con el slogan: “Argentina Conectada”, el ex funcionario, afirmó que ese anuncio formaba parte de las políticas de igualdad en el acceso a los bienes y servicios públicos, a la información, a la difusión y al conocimiento. A la vez, que entre los objetivos mencionó la federalización de la banda ancha, la televisión y la telefonía.

Más allá de la difusión del lanzamiento de la televisión digital en octubre de 2010, parte de los usuarios de la TDA de nuestro estudio llegaron a conocer el plan por medio de la televisión abierta o la radio; otros a través de conocidos o familiares y en el caso de las integrantes de la Mutual Primavera tuvieron contacto directo porque coorganizaban los operativos de entrega en el barrio o los viajes a Tecnópolis.

El reglamento general del Plan Operativo de Acceso a la TDA además de especificar la operatoria de las unidades de planeamiento y coordinación estratégica interna del plan, detallaba los objetivos que determinaban los requisitos que debían cumplir los destinatarios para contar con el beneficio, los trámites administrativos y modos de instalación de los equipos (receptores y antenas). Además, de la distribución de los decodificadores, se extendió una amplia red de estaciones digitales terrestres (EDT) y se apoyó en una importante inversión en infraestructura en internet por medio de la construcción de la Red Federal de Fibra Óptica (REFEFO).

\subsubsection{La concepción sobre "inclusión digital" y sobre "acceso a las tecnologías"}

Explicamos en el capítulo VII que las grandes apuestas de las políticas públicas de inclusión digital estuvieron centradas en la disponibilidad física de las tecnologías digitales (equipos, antenas) y de los servicios de conectividad para toda la población. Se proponían alcanzar la mayor cantidad de hogares y organizaciones públicas del país centralizando su cobertura en el primer nivel de acceso. Es decir, que los servicios de comunicación digital se encuentren a disposición en cantidad y calidad para que los ciudadanos cuenten con la opción de elegir entre ellos. Teniendo en cuenta la definición del primer nivel de acceso entendemos que, en el caso de la televisión digital, la política pública de inclusión se propuso asegurar la disponibilidad de los dispositivos técnicos

\footnotetext{
${ }^{188}$ El desarrollo del acto del anuncio del Plan Nacional de Telecomunicaciones "Argentina Conectada" se puede visualizar en https://www.youtube.com/watch?v=xBkEMAA_3f4.
} 
(kits digitales) sumada la infraestructura (EDT, antenas satelitales, tendido de red) entre los sectores de la población “en riesgos de exclusión”. Aunque a pesar de los propósitos declarados, de la decisión política y del desarrollo de las condiciones materiales, en el Partido de José C. Paz no tuvo alcances significativos.

\subsubsection{Sobre la oferta de contenidos}

Por otro lado, no podemos aseverar que haya cumplido específicamente con el requisito de la oferta diversidad y variedad de contenidos. En principio, la posibilidad de elección sobre los servicios ofrecidos y/o los contenidos digitales emitidos se encontraba condicionada por la lógica comercial del mercado mediático argentino con una alta penetración de televisión por cable o satelital de pago. Y este condicionamiento se sumaba a las apreciaciones negativas que expresaron los jóvenes y adultos jóvenes respecto de la variedad de contenidos en la grilla de programas ofrecidos por la televisión digital.

Sin embargo, nos detuvimos en el relato de las integrantes de la Mutual Primavera ya que diferenciamos un tipo de acceso físico relacionado con la especificidad técnica de la televisión digital (mejor imagen, cantidad de señales, programar el decodificador, etc.) del acceso a los contenidos en el que valoraban muy positivamente la producción nacional y regional de los programas además de la posibilidad de conocer "otras culturas" a través de la TDT. En estos casos, aparentemente el primer nivel de acceso estaría asegurado por la política pública que visiblemente se manifiesta en los sentidos atribuidos por quienes forman parte de esta organización comunitaria territorial que fue sede de diferentes políticas públicas y en particular, coorganizaban los operativos de entrega de la televisión digital en el barrio o las salidas a Tecnópolis. En este marco, advertimos que para las integrantes de la mutual los contenidos ofrecidos por la TDA formaban parte de la inclusión digital en tanto que oficiaban de puerta de entrada a diferentes conocimientos y saberes. Entendemos aquí que se expresa una posición de lectura de carácter político en la que se juegan sentidos producidos por la actividad que desarrollan estas mujeres en torno a la organización y al territorio. Es decir, se distancian de aquellas visiones en las que se construyen un perfil de televidente cuya actividad se limita a la elección entre la programación y a las ventajas técnicas de la televisión digital identificado con el consumo de televisión tradicional. 


\subsubsection{Usos de TDA e inclusión digital}

Desde nuestro abordaje teórico-metodológico, la mirada sobre el acceso a las tecnologías clasificado en los dos niveles -elección y retroacción- precisa abarcar las situaciones de usos y las prácticas vinculadas a la televisión digital. En esa dirección, Cabello (2017:256) sostiene que la medición del primer nivel de acceso debe ser superada y que “(...) se impone comprender qué tipos de vínculos (materiales y simbólicos) establecen las personas con las tecnologías y cuáles son las distancias que se identifican al respecto entre grupos sociales, regiones, organizaciones, tipos de familias y otros aspectos."

La pregunta acerca de qué usan, cómo usan, qué sentidos producen con las tecnologías digitales son parte de las tramas socioculturales donde esta tesis pone su foco de interés. En los usos de la televisión digital que hemos reconocido una distancia en la relación que establecen con otras tecnologías digitales (computadora, telefonía móvil, consolas de juegos, etc.). En cambio, esa distancia se manifiesta de diferente modo según el rango etario: por ejemplo, los más jóvenes aprovechan algunas funcionalidades del decodificador digital que los adultos y adultos mayores desconocen o les resulta dificultoso manejar. Para los más grandes, siempre hay quienes forman parte del mundo de las tecnologías: maridos, los hijos, los jóvenes a quienes recurren para pedir ayuda. Es decir, el mundo de las tecnologías es de los varones y los más jóvenes porque son a los que se les atribuye el saber y el manejo de los artefactos de la casa.

Muchas veces la distancia también se expresa en el temor a "romper" el aparato que se supone que está vinculado a la inexperiencia, a no haber tomado contacto con los procesos de producción mediados por tecnologías o a que no han desarrollado la confianza necesaria para respecto del dominio de las mismas.

De este modo, se produce una posición de extrañamiento respecto de las tecnologías digitales que les permiten usos suficientemente limitados como encender, apagar el receptor digital, elevar/reducir el volumen o cambiar de señal. Estos usos que fuimos identificando a lo largo de esta tesis, se caracterizan por ser instrumentales. Sirven para operar los dispositivos técnicos en sus funciones básicas pero les resulta más complicado pensar o efectuar otros usos posibles tanto de las tecnologías digitales como de la televisión digital en particular. 


\subsubsection{Televisión digital y televisión analógica}

Ahora bien, una de las consideraciones que estamos en condiciones de realizar es que la televisión digital es integrada al contexto cotidiano del mismo modo en que lo está la analógica. No encontramos diferencias intrínsecas que nos indiquen que la televisión digital modifica sustantivamente los usos que se le asignan a la hertziana. Entendemos que los usos que las personas realizan con la televisión digital no parecen posicionarlas en una situación diferente, particularmente en el despliegue de competencias tecnológicas o en una atribución de sentido distinto en sus vidas cotidianas.

Los usos de la TDT, de cierto modo, se reimprimen en aquellos construidos con la televisión tradicional que no dejan de ocupar un lugar central alrededor de la cual se desarrolla la vida cotidiana: estar con otros, estudiar, comer, entretenerse, descansar, etc. Decíamos en el capítulo anterior que la centralidad de la televisión en el hogar se ordena a partir de las prácticas operativas (técnicas) del dispositivo, de contenidos (la oferta de programación) y socioculturales (aprendizajes, compartir con otros, etc.).

Según nuestro estudio, la televisión conserva un modelo tradicional de visionado por parte de los grupos familiares en términos de las preferencias: tiempos, programación y géneros. El visionado preferentemente se realiza por la noche y en horario del primetime. El tiempo de permanencia frente al televisor era de 3 horas en promedio pero iba aumentando a medida que se ampliaba el rango etario: los jóvenes solían mirar menos televisión que los adultos mayores debido a las actividades que cada grupo desarrollaba: trabajar, estudiar, entretenerse fuera o dentro de la casa. Los programas que mencionaban mirar los usuarios de la TDA se volcaban al género informativo y de entretenimiento (espectáculos deportivos, películas, series). Las preferencias estaban orientadas a la producción nacional o regional como por ejemplo, las señales PAKA PAKA, TeleSur y DeporTV. Sin embargo, algunos entrevistados indicaron que escogían mirar la programación de la televisión del cableoperador contratado (Telered) o satelital (DIRECTV) ya que la TDT no ofrecía la variedad de señales que prometía o bien debido a fallas técnicas como pérdida de señal, imagen pixelada o intermitencias en la emisión. En este marco, el tipo de programación elegida por los usuarios se volcaba a la televisión generalista con una programación de contenidos variados (educativos, informativos, entretenimiento, etc.) dirigida a un público general (niños, adultos, jóvenes).

Por otra parte, los usos de la TDA no parecen producir efectos de desplazamiento según los entrevistados. En efecto, los usuarios no renunciaban a usar la computadora (los más 
jóvenes) o escuchar radio (los adultos y adultos mayores) e incluso mirar la televisión analógica para consumir la TDA sino que complementaban según lo que evaluaban de la funcionalidad de cada dispositivo: entretenimiento, comunicación con otros, información, etc.

A estas características de la televisión digital se suma la innovación técnica de la interactividad. Cuando analizamos las referencias a la interactividad en los documentos de la política pública no aparecían explícitamente sino que se presentaban de modo difuso. En cambio, la estrategia de comunicación de la política ponía énfasis en la novedad de la oferta de servicios interactivos que contenía el dispositivo técnico digital. El Estado ya había puesto en marcha Argentina Conectada aunque los servicios interactivos estaban limitados a las mínimas funciones. En el plan se destacaba que la estrategia de implementación del SATVD-T, entre sus objetivos, apuntaba a fomentar el uso de los servicios interactivos para promover el intercambio de datos entre los ciudadanos así como entre los lineamientos generales para ejecutar la política pública de inclusión digital se proponen desarrollar contenidos digitales interactivos. Los usuarios de la TDA llegaban a reconocer algún nivel de interactividad (consultar servicios básicos, el clima, la información local, etc.) aunque, como mencionamos en otros capítulos, estaban referidas más a suposiciones que a usos efectivos.

\subsubsection{Los vínculos de las personas con las tecnologías}

En la línea con el análisis sobre los usos que los jóvenes efectuaban, los grados de familiaridad que fueron construyendo con las tecnologías se manifestaron en expresiones de satisfacción e interés. Mientras que los adultos y adultos mayores mostraban cierta distancia enunciando cierta indiferencia y resistencia.

Entre las particularidades de la relación que las personas establecen con las tecnologías se encuentran los saberes y las habilidades que van adquiriendo a medida que van usándolas en su cotidianidad. La valoración que le asignan y los estados de ánimos que les producen la vinculación con las tecnologías digitales forman parte de la dimensión de autoconfianza que abordamos en la tesis. Los usuarios de la TDA manifestaron sensaciones de cierta incomodidad, inseguridad hasta desinterés en los usos de las tecnologías digitales. Podemos observar que estas impresiones dan cuenta que para nuestros entrevistados aún el acceso y uso de las tecnologías digitales en general y en 
especial de la televisión digital, no alcanzaban para estar "incluidos" o para no "quedarse afuera" del entorno tecnocultural en el que desarrollaban sus vidas personales, familiares y sociales. Estos sentimientos tienden a amplificar la distancia que establecían con las tecnologías pero fundamentalmente solían obstaculizar la posibilidad de desarrollar proyectos personales y sociales que les permitieran sentirse incluidos.

Finalmente, en relación con la dimensión de la participación mencionamos en el capítulo VII que del desarrollo teórico-metodológico de Cabello (2015) tomaríamos las acciones y prácticas de los usuarios de las tecnologías en relación con el consumo de contenidos, de servicios o de redes sociales en el entorno tecnocultural. Esta subdimensión reconoce los principales rasgos de la cultura digital: la disposición de dispositivos y sus usos asociados. Cuando observamos el modo en que los usuarios de la TDA intervenían o participaban en su entorno tecnocultural advertimos cierta recurrencia en la que la frecuencia de contacto con las tecnologías aparece como uno de los factores que indican los diferentes grados de familiaridad con las tecnologías digitales. Teniendo en cuenta el consumo de contenidos (YouTube, TV, cine y radio en línea); de servicios (bancarios, financieros) o de redes sociales (WhatsApp, Facebook, Twitter) encontramos que se reitera cierta regularidad en cuanto a las prácticas que van decreciendo a medida que aumenta la edad de los usuarios. Los más jóvenes desplegaban diferentes actividades a través y con los medios digitales en tanto que los mayores se inclinaban más hacia los analógicos tales como la televisión tradicional, el diario en papel, la radio hertziana. En este marco, los usuarios de la TDT accedían con ciertas limitaciones al entorno tecnocultural: lo hacían en calidad de consumidores de bienes y servicios tecno mediáticos (de información, audiovisuales, sonoros, etc.) pero no hemos detectado que lo hubieran hecho en situación de producción de contenidos, por ejemplo. De hecho, notamos que una de las actividades que incluía un mínimo grado de interactividad y escasa navegación en internet fue la comunicación vía redes sociales como WhatsApp, Facebook, Twitter. Entonces, considerando los usos y prácticas de los usuarios de la TDA el grado de participación en y con el entorno cultural es relativamente bajo e insuficiente para avanzar hacia procesos de inclusión digital a través del acceso de las tecnologías digitales. 


\subsection{La transición digital. Derechos e inclusión}

Uno de los desafíos de desarrollar esta investigación fue tratar de aproximarnos a caracterizar el proceso de transición digital en el escenario social, político, económico y cultural en el que se estaba desplegando la ejecución de la TDA. La puesta en marcha por parte del Estado de políticas públicas, que apostaban a la integración de tecnologías digitales entre los sectores socioeconómicos con riesgos de exclusión, fue una de las singularidades que adquirió la agenda global de la Sociedad de la Información en nuestro país.

La Agenda Digital Argentina, presentada en mayo de 2009, que orientó la definición e implementación de las políticas de acceso a las tecnologías digitales:

“(...) buscó dar nuevo impulso al desarrollo de TIC en el país. Esta agenda fue presentada como plan presidencial para una estrategia nacional de inclusión digital y apropiación de los beneficios de la sociedad de la información y del conocimiento. Propone sustentar en las nuevas herramientas tecnológicas una mejora continua de la calidad de la educación, del gobierno, del comercio y de la salud - entre otros ámbitos - para incrementar la transparencia, la productividad y la competitividad, y fortalecer una democracia con más oportunidades de participación para todos los habitantes del país.” Peña, Mazzitelli, Pou, (2012:19)

El proceso formación de las políticas públicas no solamente resulta complejo sino que comprende un movimiento entre las demandas de interés público, el mercado y los propios organismos estatales. Las fases de las políticas (desde la inclusión en la agenda pasando por su ejecución hasta la evaluación) involucran a actores múltiples y que conforman diferentes grupos de interés. Teniendo en cuenta las tensiones y la coexistencia de estos actores en los diferentes momentos de las políticas públicas, el Estado argentino impulsó variadas iniciativas que propendían a generar procesos de inclusión digital entre los sectores sociales con riesgos de exclusión.

Argentina, con la promoción de la televisión digital, apuntó a democratizar la comunicación y fortalecer la producción nacional: “(...) se trata de una decisión política única en la región, [que] se apuesta a la producción de contenidos locales como modos de competir con los operadores privados, y el monoteísmo Miami de la televisión por cable y satelital.", afirma Rincón (2013:162). De hecho, la TDA se posiciona como una política pública con características distintivas, en comparación con las de otros países latinoamericanos, en virtud de la capacidad distributiva del Estado que invierte en infraestructura y entrega receptores con el fin de acercar las tecnologías digitales a los 
sectores en riesgo de exclusión. Es el Estado nacional que planifica, regula, gestiona y respalda la transformación tecnológica de la televisión digital con el propósito de disminuir la desigualdad entre los "incluidos" y los "excluidos".

En el transcurso de este estudio hemos distinguido al menos 3 etapas de la política pública: la difusión y el reconocimiento por parte de los destinatarios, la instalación del decodificador digital y la situación de usos y consumo en el hogar.

El momento del lanzamiento de la TDA formó parte de un conjunto de decisiones tomadas por parte del Estado para modificar la estructura del mercado mediático aunque "Los indicadores de concentración, (...) se mantuvieron estables o, (...), en algunos casos (TV de pago) se incrementaron, fenómeno vinculado a cómo fue aplicada la ley audiovisual por parte del gobierno que la impulsó, en los años posteriores a su aprobación.” (Becerra y Mastrini, 2017: 82) Es decir, el estímulo de la televisión digital gratuita por parte del Estado convivió con el expandido mercado televisivo pago. En este contexto se fue construyendo el reconocimiento de los beneficiarios de la TDT articulado con las condiciones sociales y culturales en la que desarrollaban sus prácticas cotidianas.

La centralidad de la política pública TDA radica en su finalidad de producir inclusión digital a partir del acceso a las tecnologías y de una infraestructura adecuada para las garantizarlo. Uno de los efectos que provoca es la desmercantilización de la comunicación en términos no solo de disponibilidad de dispositivos sino también en relación con los contenidos televisivos como señala Vargas (2014:152). Es decir, que el acceso a las tecnologías no está sujeto a la esfera del mercado. El potencial desmercantilizador de la política pública reside en que la prestación debe asegurar el derecho al acceso a los recursos técnicos junto a la promoción de usos y prácticas necesarias para intervenir y participar de la sociedad digital.

Pero ya hemos insistido en varias ocasiones que la inclusión digital no se consigue únicamente con la posesión e instalación del set top box o algunos usos y consumos básicos.

El acceso es una de las condiciones iniciales de las políticas públicas de inclusión digital que recordamos que se compone de la distribución, el mantenimiento y la actualización del equipamiento y los servicios tecnológicos digitales. No obstante, la TDA contó con algunas dificultades para cumplir con este requisito en tanto no parece haber habido un conocimiento cabal sobre la cobertura que alcanzó el beneficio en el territorio nacional además de las inconsistencias en la implementación de la distribución de los decodificadores que detallamos en párrafos anteriores. Los problemas listados por los 
entrevistados fueron que los decodificadores dejaron de funcionar; mala recepción de la señal digital que impedía el visionado y equipamientos con deficiencias técnicas provistos mediante planes sociales.

Si bien resulta evidente que el acceso tal como lo entendemos en esta tesis parece haber sido asegurado de modo precario no podemos dejar de señalar que en el reconocimiento de algunos de los usuarios de la TDA en el Partido de José C. Paz se visibiliza una valoración altamente positiva de la política pública. Las integrantes de la organización social diferenciaron el beneficio de disponer de tecnologías digitales - que de otra manera no las hubieran podido obtener- de acceder a diferentes contenidos de producción nacional e internacional. Por otro lado, como miembros de la organización participaban de los operativos de entrega en los barrios o en Tecnópolis.

Entendemos que este rol de intermediación en la gestión de la política en el territorio les permitieron auto percibirse como sujetos de derecho y no solamente como beneficiarias. En su discurso la entrega de receptores para ver televisión digital está asociada al acceso a las condiciones mínimas de inclusión digital que el Estado debe garantizar. En esa línea, aunque con algunas diferencias, esta percepción es en parte compartida por los adultos mayores en tanto reconocían positivamente la prestación de servicios y recursos por parte del Estado. Creemos que tanto las integrantes de Mutual Primavera como los adultos mayores fueron interpelados por la política pública TDA de diferentes maneras. Por una parte, mediante la difusión en los organismos públicos o el sistema público de medios (TV Pública, Radio Nacional, TELAM) y por otra, a través de las acciones diferenciadas para que el equipamiento llegara a sus destinatarios como operativos o el envío a domicilio por correo. Estas interpelaciones, junto a otros factores, colaboraron en la construcción del reconocimiento de la percepción de derechos en condiciones de ciudadanos.

En cambio, los jóvenes y jóvenes adultos se distanciaban de la idea de derecho y se ubicaban en el lugar del beneficiario, ese sujeto que fue seleccionado para recibir una prestación o servicio por parte del Estado. En algunas alusiones, se manifestaron muy alejados de la propuesta de inclusión de la TDA ya que consideraban que imponía cierta programación, que no cumplía con la ampliación de la oferta de contenidos y que se centraban en algunos sectores sociales por sobre otros.

Los usos de la televisión digital identificados se separan, desde el punto de vista del análisis, de la apropiación e integración en la vida cotidiana y se relacionan con los usos clásicos de la televisión tradicional. Las prácticas que proyectan esos usos se pueden 
reconocer en la dieta televisiva que conservaba las características asociadas al visionado fijado por franjas horarias y tipos de géneros propuestas por las emisoras, según las actividades formales e informales de los integrantes del hogar (trabajo, estudio, ocio); así como también en la ubicación del aparato en los espacios compartidos y en la limitada operación del decodificador digital (encender, apagar, cambiar de señal, elevar o disminuir el sonido, etc.). Asimismo, la política pública TDA no hace referencias a los usos propiamente dichos pero en la lectura analítica se muestra un sesgo instrumental centrado en la definición de las tecnologías digitales como herramientas para alcanzar la inclusión digital mediante el acceso. De ahí, que nos encontramos en condiciones de plantear que resulta que el modo limitado en que están expresados los usos en la política pública no presenta grandes diferencias con aquellos que reconocimos en nuestra población en estudio. Sin embargo, estimamos que tanto en el diseño y formulación de las políticas públicas de inclusión digital como en las prácticas de los beneficiarios encontramos escasos elementos que nos permitan decir que estos usos pudieran generar las condiciones necesarias para incluir digitalmente a diferentes sectores de la población y en menor medida, aquellos en riesgo de exclusión.

Pues bien, las percepciones de autoconfianza entre los usuarios de la televisión digital tampoco adquieren una fuerte impronta en la relación con las tecnologías digitales y se manifiestan en alusiones a la inseguridad y temor sedimentados especialmente en el desconocimiento de las funciones específicas de los dispositivos técnicos. Este aspecto de las relaciones entre los usuarios y las tecnologías presenta rasgos de fragilidad que entendemos están estrechamente vinculados con el entorno tecnocultural heterogéneo, inestable con procesos de exclusión tanto económica, social y cultural.

Como señalamos anteriormente, los grados y los tipos de participación se limitaban al consumo de contenidos, productos y servicios tecnológicos ofrecidos por el mercado (oferta y demanda) por un lado y por el Estado, en el caso de la TDA. En concomitancia las dificultades para integrar las tecnologías digitales a los proyectos personales tendieron a condicionar también las posibilidades de participación activa del entorno tecnocultural de los usuarios. Los grados de participación tecnocultural que relevamos se encontraban reducidos a algún tipo de elección de productos digitales y/o contenidos brindados por el mercado como la oferta con reducida disponibilidad de aparatos digitales de baja gama: telefonía móvil, computadoras, videojuegos, etc. Y en el caso que nos ocupa, los beneficiarios acceden a la posibilidad de convertir el televisor analógico en digital a través del set top box distribuidos por la TDA. 
Inauguramos este último capítulo con la pregunta que contiene la hipótesis, que organiza esta tesis y que su vez, nos permite abrir otros interrogantes para continuar abordando la problemática de las tecnologías, la inclusión digital y las políticas públicas en futuras investigaciones.

En esta tesis nos propusimos pensar las tecnologías digitales en tanto dispositivos tecnológicos que comprenden la materialidad física de los artefactos ligada a las lógicas de usos, producción, consumo y distribución que se configuran en el escenario digital en el que se insertan. En otros términos, estos dispositivos se inscriben y coproducen las dinámicas de las relaciones sociales, políticas, culturales y económicas en las que las personas desarrollan su cotidianidad.

Iniciado el siglo XXI, la televisión digital fue una de las tecnologías, que junto a las computadoras, recibió un fuerte impulso por parte del Estado argentino para avanzar hacia la inclusión de la mayor cantidad de grupos sociales en contextos de transición digital. Esta iniciativa, a través de la implementación de la TDA, se propuso poner a disposición decodificadores digitales entre los sectores en riesgo de exclusión.

Las expectativas sobre el alcance de la televisión digital como instrumento para transitar hacia la inclusión digital se encuentran expresadas tanto en los documentos oficiales como en el discurso construido de la política pública tal como fuimos exponiendo a lo largo de estas páginas. En principio, habiendo indagado usos y prácticas de los destinatarios de la TDA entendemos que el lugar material y simbólico de la TDT no registra modificaciones significativas en las vidas cotidianas de las personas con las que hemos estado trabajando. La decisión de atender a los sectores en riesgo de exclusión digital (jubilados y/o pensionados, perceptores de planes sociales, AUH, establecimientos escolares, organizaciones sociales, población vulnerable) definía no solamente un perfil de beneficiarios de política pública focalizada sino desde el punto de vista de consumidores de tecnologías. Consumidores cuya actividad está restringida a la obtención de dispositivos técnicos en el mercado u otorgado por parte del Estado. El objeto de consumo de esas tecnologías, en estos casos, va desde agilizar tareas diarias, trabajar, estudiar hasta entretenerse pero el uso es estrictamente utilitario a partir del manejo de las funciones elementales de los ingenios técnicos.

Resulta dificultoso aseverar que la entrada de la televisión digital en los hogares permitió a los usuarios percibirse o sentirse incluidos en la cultura digital (salvo en algunas escasas excepciones como las integrantes de la organización social). Como hemos señalado, en diferentes momentos de este trabajo, las representaciones sobre las tecnologías digitales, 
en particular las vinculadas a la idea de inclusión digital, ejercen ciertos condicionamientos en los usos posibles de modo que la mera disponibilidad y el contacto con los dispositivos tecnológicos (televisión digital, computadoras, telefonía móvil) se muestran insuficientes para lograr una integración provechosa de las mismas en los proyectos e intereses personales de los usuarios.

Asimismo, la política de acceso al equipamiento para la televisión digital en nuestro país procuró, desde el Estado, achicar la brecha tecnológica con el objeto de conseguir la inclusión digital a medida que se afrontaba la reconversión digital. Entre las características de la implementación de la TDA encontramos que los resultados, en términos de cobertura e infraestructura fueron relativos y de hecho, parecerían no haber producido un impacto específico entre los beneficiarios. Al mismo tiempo la televisión digital compitió permanentemente con la penetración de la televisión de pago y satelital en todo el territorio nacional y básicamente, no alcanzó para desplazar la centralidad de la televisión analógica.

No obstante, esta política pública no escapa a las condicionalidades que han definido a otras del mismo tenor en la región latinoamericana: focalizadas en una fuerte inversión en infraestructura (equipamiento y conectividad), dirigidas a sectores vulnerables de la sociedad, herramientas de desarrollo social y cultural y con un propósito democratizador amplio como premisa central.

En palabras de González (2008:61) la introducción de tecnologías digitales:

“(...) ha sido aplicada sin reservas a lo largo del mundo empobrecido y desde luego, por toda América Latina como una clara y vertical decisión que los gobiernos de toda la región han adoptado como una herramienta casi milagrosa para enfrentar muchos de los rasgos y rezagos de una modernidad muy tardía y como forma de "inclusión digital" decidida desde fuera y con escasa o nula intención de conversar y escuchar a las comunidades y a sus pobladores en sus territorios."

En este punto es ineludible hablar del modo en que opera el objetivo de inclusión digital en los instrumentos de políticas en nuestros países y en particular, en Argentina. Mencionábamos con anterioridad que una de las principales finalidades buscadas por estas políticas de equipamiento de tecnologías digitales fue incidir sobre las distintos tipo de brechas: sociales, culturales, etc. Por el contrario, nosotros sostenemos que la accesibilidad a las tecnologías digitales no garantiza la superación de las distintas desigualdades presentes en nuestras sociedades. Estas desigualdades se expresan en múltiples dimensiones (educación, salud, trabajo, vivienda, infraestructura, 
territorialidad, medioambiente, transporte, etc.), son de carácter complejo y se relacionan dinámicamente con otros temas como la pobreza, la marginalidad, la vulnerabilidad y la exclusión. (Kessler, 2014). Por otra parte, sabemos que tampoco asegura la reducción de los diferentes tipos de exclusión social, cultural, económica, digital.

De este modo, políticas públicas de inclusión digital basadas en el acceso a las tecnologías pueden mejorar el equipamiento tecnológico de los hogares, habilitar algunos usos y apropiaciones de los dispositivos diferentes a los frecuentes pero difícilmente logren suturar exitosamente las distancias sociales, económicas, culturales entre las personas.

Recapitulando: la inclusión digital no se restringe estrictamente al desarrollo de habilidades y competencias digitales de las personas sino que requiere, al menos, garantizar el acceso, promover los usos fructíferos, generar mayores grados de autoconfianza y de participación del entorno tecnocultural.

El mandato de la política pública de inclusión digital se ajustó al acceso universal con el fin de garantizar vía la red pública, la disponibilidad de al menos un servicio básico de telecomunicaciones en cualquier hogar. (Rossi, 2016:12) No obstante, la preferencia por parte de los destinatarios no fue la prevista por las proyecciones establecidas por la gestión de la política. Entre las causas, hemos identificado los inconvenientes con la recepción de señales, con instalación y operación de los decodificadores o bien la escasa oferta de contenidos de la programación en comparación con la grilla comercial.

En otro orden, la TDA proyectó como una iniciativa estatal que apostaba al reconocimiento de los derechos de los ciudadanos a acceder gratuitamente a servicios y productos digitales diversos, de calidad y de factura nacional a lo largo y ancho del territorio nacional. En el caso, del Partido José C. Paz, entre los hallazgos de esta investigación, sindicamos las valoraciones positivas que las integrantes de la organización social expresaron sobre la percepción del kit digital que refuerzan la idea del beneficio de la política pública como derecho social básico. En estas apreciaciones se muestra el cariz de derecho ciudadano -en tanto derecho protegido y viabilizado por el Estado- que le asignan a la TDA. Ellas se perciben como "sujetos de derecho" y no como merecedoras de la asistencia por parte de un Estado con rasgos clientelares. De allí que entendemos que la posición que ellas ocupan, en relación con la organización junto su práctica política en el territorio, construyen estas representaciones que se apoyan en el rol de planificador del Estado en su función distributiva o redistributiva a fin de proveer igualdad de oportunidades para todos los ciudadanos del país. 
Ese carácter distributivo del Estado se evidencia en la administración, planificación y gestión del espacio radioeléctrico, la inversión estatal para digitalizar la infraestructura y distribuir el equipamiento necesario para la televisión digital. Pero sustancialmente, se manifiesta en la desmercantilización del acceso no solo al dispositivo técnico sino además a los contenidos audiovisuales por parte de los potenciales destinatarios de la TDA.

En este marco, entre las personas destinatarias de la TDA con las que trabajamos a lo largo de esta investigación, hemos identificado al menos tres posiciones en relación con la idea de la inclusión digital. Una posición que llamamos participante como la que asumen las integrantes de la organización social cuyas representaciones políticas y el trabajo comunitario en el territorio contribuyen a significar la inclusión digital como derecho social y cultural ineludible. Otra posición que denominamos interesada compartida por los jubilados quienes no llegan a interpretar estrictamente la inclusión digital pero se les representa que está asociada a la presencia del Estado proveedor. Y por último, la posición crítica que responde a las expresiones planteadas por los jóvenes y los adultos jóvenes para quienes la TDA asegura un tipo de inclusión tecnológica (acceso físico) pero que no alcanza necesariamente a los sectores sociales en riesgo de exclusión. El análisis expuesto hasta aquí se sustenta en la conjetura de que la implementación de política pública de acceso TDA -compuesta por su formulación, su estructura normativa y técnica sumadas las prácticas y sus usos - tuvo rasgos de precariedad que no permitieron, entre otras cuestiones, avanzar hacia procesos de inclusión digital. Entendemos que la disponibilidad, los usos, el contacto con la televisión digital permiten avanzar hacia mayores grados de autoconfianza que a su vez, redundan positivamente en las vidas personales de los destinatarios. Que al mismo tiempo mejoran sus posibilidades de participación no solo como consumidores de productos y servicios digitales sino como productores de los mismos. O sea, que las personan puedan aprovechar las ventajas que su entorno tecnocultural les ofrece y sortear los inconvenientes que pudieran surgir en ese contexto. Pero sustantivamente, sostenemos que es necesario que los beneficiarios de la política pública de inclusión digital sean considerados y que logren autoconsiderarse como sujetos de derecho desde la toma de decisiones hasta la ejecución de la misma.

Decíamos al inicio de este capítulo que nos encontramos transitando un momento de alternancia política en nuestro país. La nueva gestión gobernante de la Coalición del Frente de Todos ha anunciado hace días que se retomó el desarrollo del satélite ARSAT 3, tercer satélite argentino de la flota geoestacionaria que brindará banda ancha sobre el territorio argentino. Indudablemente, esta iniciativa tiene rasgos de continuidad con las 
políticas públicas de comunicación de los períodos 2003-2011 y 2011-2015. Estimamos que la reanudación del desarrollo tecnológico por parte del Estado tiene el objetivo de reconstruir las políticas públicas de comunicación en un sentido muy diferente a las delineadas durante los 4 años de macrismo. Sin embargo, según Becerra (2017), una de las deudas pendientes será poner en la agenda pública de discusión una ley de convergencia digital que incorpore, entre otros aspectos, a todos los actores implicados: estatales, con fines de lucro y sin fines de lucro.

En estas reflexiones finales queremos compartir algunos aportes, producto de esta investigación, a fin de esbozar algunas líneas de trabajo futuro sobre la televisión digital, sus usos y los procesos de inclusión digital.

En principio, teniendo en cuenta que el acceso es el primer peldaño para comenzar a discutir la inclusión digital resulta necesario que las políticas públicas deben asegurar tanto los dispositivos técnicos como el mantenimiento y su actualización. Entonces, para fortalecer los procesos de inclusión digital “(..) las actividades (...) deben ser permanentes (...) En otras palabras el acceso necesita ser sostenido.” (Seale, 2012:4) La formulación de políticas públicas de comunicación demanda la construcción de abordajes interdisciplinarios para indagar los procesos de inclusión/exclusión digital en los que dialoguen los análisis sobre la producción, distribución, usos y consumo de los dispositivos tecnológicos con la participación de los usuarios en calidad de actores protagónicos. Se requieren de enfoques que centren el eje en las relaciones que establecen las personas con las tecnologías digitales teniendo en cuenta las características de los entornos tecnoculturales en los que desarrollan sus vidas. Se trata de volver la mirada hacia los destinatarios: partir de sus motivaciones, del acceso a diferentes tipos de recursos (económicos, culturales, sociales), de las capacidades y habilidades construidas con las tecnologías. Una visión que sitúa a las personas como sujetos activos con oportunidades de participar e intervenir en sus entornos tecnoculturales en pos de potenciar su inclusión en el mundo digital.

La inclusión digital es el discurso central en este tipo de políticas que ubican sus objetivos en la distribución de equipamiento, desarrollo de infraestructura y extensión de conectividad. El reto es franquear el nivel de la disponibilidad de las tecnologías, del acceso (elección del material y la retroacción) y de la participación (en producción de mensajes, en toma de decisiones, formulación de políticas de comunicación) para incorporar la perspectiva de los destinatarios en el diseño sino fundamentalmente en la ejecución de los planes y programas. Entendemos que para llevar a cabo estas premisas 
se precisa de un trabajo profundo y con la intervención de diferentes campos disciplinares que van desde la comunicación, los estudios culturales pasando por la sociología y la antropología. Aclaramos que no desconocemos que las demandas sociales, en el ámbito de las decisiones del Estado, necesitan de respuestas adecuadas y siempre en tiempos acotados pero estimamos que esta propuesta podría enriquecer la definición de las políticas públicas de inclusión digital.

¿Cuáles son los criterios técnicos y políticos para promover procesos de inclusión digital a partir de la instrumentación de planes y programas estatales? ¿Cuáles son los rasgos de las políticas públicas de inclusión digital que permitan superar la difusión de tecnologías entre la población en riesgo de exclusión? ¿Cuáles son las estrategias para diseñar políticas públicas de inclusión digital que estimulen la participación de los destinatarios en calidad de ciudadanos y no de meros consumidores? Estos son algunos de los interrogantes que se abren a partir de esta tesis y claramente existen más cuestiones para abordar. Por lo tanto, nos interesa señalar que es importante profundizar y continuar líneas de investigación que ajusten conceptual y metodológicamente estudios sobre el desarrollo y que puedan aportar al diseño de procesos de inclusión digital impulsados por agencias estatales y sus derivaciones entre sus beneficiarios.

Finalmente, el presidente Alberto Fernández (2019-2023), en los primeros meses de gestión, aún no ha tomado decisiones sustantivas en torno al sistema de medios de comunicación y al plan de inclusión digital. Sin dudas, una de las medidas que se tomarán será la prolongación de la red federal de fibra óptica y el relanzamiento de la TDA para concluir la cobertura de todo el territorio nacional.

En ese marco, presumimos que este nuevo escenario político propiciará el debate público para fortalecer las instituciones que serán las encargadas de llevar adelante políticas públicas de inclusión digital eficientes y de largo aliento que promuevan la democratización de la sociedad. 


\section{Referencias bibliográficas}

\section{Bibliografía citada:}

\section{En papel:}

Agustín Lacruz, M.C. y Clavero Galofré, M. (2010): Indicadores sociales de inclusión digital: brecha y participación ciudadana, en Derecho, gobernanza y tecnologías de la información en la sociedad del conocimiento, pp. 143-166. Prensas Universitarias de Zaragoza, España.

Aguerre, C. y otros (2010): "Problemas teórico metodológicos en los estudios de la apropiación de las Tecnologías de Información y Comunicación en el caso de jóvenes de sectores populares urbanos". Publicado en Actas de las VIII Jornadas Latinoamericanas de Estudios Sociales de la Ciencia y la Tecnología. 2010. Universidad Nacional de Quilmes. ISBN: 978-987-558-200-2.

Albornoz, L. (2000): (coord. y co-autor) Al fin solos: la nueva televisión del Mercosur, Ed. CICCUS- La Crujía, Buenos Aires.

Albornoz, L. y García Leiva, M.T. (2012): La televisión digital terrestre. Experiencias nacionales y diversidad en Europa, América y Asia, Colección Inclusiones, La Crujía. Buenos Aires.

Albornoz, L. y Hernández, P. (2009): “La radiodifusión entre 1995-1999: concentración, desnacionalización y ausencia del control público", en Mastrini, G. (editor) (2009): Mucho ruido, pocas leyes. Economía y políticas de comunicación en la Argentina, Segunda edición ampliada, La Crujía. Buenos Aires.

Álvarez, A.; Martínez, A. y Méndez, A. (1993): Tecnología en acción, Editorial Rap.

Barcelona.

Andonegui, F. y Samaniego, F. (2019): "Políticas de inclusión digital en la región de Latinoamérica", en Políticas públicas e inclusión digital: un recorrido por los Núcleos de Acceso al Conocimiento, Lago Martínez, S. B. [et al.]; -1a ed.- Ciudad Autónoma de Buenos Aires. ISBN 978-987-86-1517-2

Aprea, G. (2004): “Los documentales y la noción de dispositivo", Jornadas de Política y Cultura, Instituto del Desarrollo Humano, Universidad Nacional de General Sarmiento. Buenos Aires.

Atkin, D. J.; Neuendorf, K.; Jeffres, L. W. Y Skalski, P. (2003): «Predictors of Audience Interest in Adopting Digital Television», The Journal of Media Economics, 16 3: 159173.

Bachelard, G. (1984): La formación del espíritu científico. Contribución a un psicoanálisis del conocimiento objetivo. Siglo XXI. Buenos Aires. 
Badillo, A. (2012): "Francia: politización y concentración", en Albornoz, A. y García Leiva, M.T. (eds.) La televisión digital terrestre. Experiencias nacionales y diversidad en Europa, América y Asia, Colección Inclusiones, La Crujía. Pp.101-125. Buenos Aires.

Bandura, A. (1977): Self-efficacy: toward a unifying theory of behavioral change. Psychological Reveiw, 84. 191-251.

Becerra, M. (2000), "De la divergencia a la convergencia en la sociedad informacional: fortalezas y debilidades de un proceso social inconcluso", en Zer n 8 , Facultad de Ciencias Sociales y de Comunicación, Universidad del País Vasco, Bilbao, p. 93-112.

Becerra, M. (2003): Sociedad de la Información: Proyecto, Convergencia, Divergencia, Norma, Buenos Aires.

Becerra, M. (2010): "Contexto de regulación y televisión digital”, en Miranda, A., Santagata, G y Guérin, A. (Ed.) (2010): Pensar los medios en la era digital. Iberoamérica frente al desafío de la convergencia”. $1^{\circ}$ ed. Colección: Inclusiones. La Crujía. Buenos Aires. Pp. 289-296.

Becerra, M. (2011): "La Televisión Digital Terrestre en Argentina: entre la geopolítica regional y la iniciativa estatal", en Badillo Matos, Á. y Sierra, F. (eds.) (2011): "La transición a la televisión digital terrestre en Iberoamérica: diagnóstico y prospectiva". Ciespal. Quito. Pp. 193-221.

Becerra, M. (2015): De la concentración a la convergencia. Políticas de medios en Argentina y América Latina", Paidós. Buenos Aires.

Becerra, M. et.al. (2014): Uso y consumo de la Televisión Digital Terrestre en Argentina. Un estudio en los municipios de San Fernando y Quilmes. / Universidad Nacional de Quilmes, Bernal.

Becerra, M. y Mastrini, G. (2006): La Economía Política de la Comunicación vista desde América Latina, en Revista de la Asociación de Posgraduados en Comunicación, Diciembre. www.compos.com.br/e-compos.

Bell, M. (2010): "TheUK'sFreeview HD dilema and the DVB-T2 solution", en International Journal of Digital Television, 1, (3), Pp.273-287.

Benítez Larghi, S. y otros (2012): "La apropiación del acceso a computadoras e Internet por parte de jóvenes de sectores populares urbanos en la Argentina", en Proenza, F.J. (Ed.). Tecnología y Cambio Social. El impacto del acceso público a las computadoras e Internet en Argentina, Chile y Perú. IDRC-CRDI; IEP, Lima. Pp. 18-67.

Berger, P. y Luckmann, T. (1989): La construcción social de la realidad. Amorrortu Editores. Décima reimpresión. Buenos Aires.

Besse; J. (2011): "Proceso y diseño en la construcción del objeto de investigación: las costuras de Frankestein o un entre-dos que no hace dos", en Cora, E. y Besse, J. (coord.) (2011): Epistemología fronteriza. Puntuaciones sobre Teoría, Método y Técnica en Ciencias Sociales. EUDEBA. Buenos Aires. 
Bettetini, G. y Colombo, F. (1995): Las Nuevas Tecnologías de la Comunicación. Paidós. Barcelona. ISBN: 8449301947, 9788449301940.

Bhalla, A. y Lapeyre, P. (1997): Social exclusion: towards an analytical and operational framework, Development and Change, 28(3), 413-434.

Bizberge, A. (2010): “Televisión Digital Terrestre ¿cambio de estatuto de la radiodifusión?”. Prometeo. Buenos Aires.

Bizberge, A., Mastrini, G. y Becerra, M., (2011): "La Televisión Digital Terrestre en Argentina: entre la geopolítica regional y la iniciativa estatal", en Badillo Matos, A. y Sierra Caballero, F. (Editores), La transición a la televisión digital terrestre en Iberoamérica: diagnóstico y prospectiva, Editorial "Quipus", CIESPAL Quito-Ecuador. Pp. 193-221.

Bolaño, C., Mastrini, G. y Sierra, F. (eds) (2005): Economía Política, Comunicación y Conocimiento. Una perspectiva crítica latinoamericana, La Crujía Buenos Aires.

Bolter, J. D. y Grusin, R. (2000), Remediation. Understanding New Media, MIT Press. Cambridge (MA).

Bouquillion, P.,Miège, B.,Morizet, C. (2006): “À propos des mouvementsrécents (20042005) de concentration capitalistiquedans les industries culturalles et médiatiques", en Le Temps des medias, 1, Pp. 5-16.

Bourdieu, P. y Wacquant, L. (1987): Respuestas por una antropología reflexiva. Grijalbo. México.1995.

Bourdieu, P. et. al. (2002): El Oficio de Sociólogo. Presupuestos epistemológicos. Siglo XXI. Buenos Aires.

Brown, A. y Picard, R, (eds.) (2005): Digital Television in Europe, Lawerence Erlbaum Associates, London, New Jersey.

Buckingham, David (2008). "Alfabetizaciones en medios digitales” en Más allá de la tecnología. Manantial. Buenos Aires.

Bunge. M. (1998): Las ciencias sociales en discusión: una perspectiva filosófica. Editorial Sudamericana. Buenos Aires.

Busaniche, B. (2004): Bestiario de la sociedad de la información, Ponencia presentada en el Coloquio Internacional Democracia y Ciudadanía en la sociedad de la Información: Desafíos y articulaciones regionales. 23, 24 y 25 de junio de 2004. Escuela de Ciencias de la Información. Universidad Nacional de Córdoba. Córdoba.

Bustamante, E. (2003): "Hacia un nuevo sistema mundial de comunicación”, Gedisa. Barcelona.

Caballero, L. (2007): TDT. Valencia: Tirant lo Blanch.

Cabello, R. (2008): Las redes del juego. Prometeo-UNGS. Buenos Aires.

Cabello, R. (2008): Argentina Digital, UNGS y Biblioteca Nacional. Buenos Aires. 
Cabello, R. (2009): "Mundos alternativos", en Morales, S. y Loyola, M. (Coord.), Los jóvenes y las TIC, UNC. Córdoba. Pp. 81-98. ISBN 978-987-24953-2-9.

Cabello, R. (2014): Informe final del proyecto de investigación: Observatorio de Usos de Medios Interactivos. Fase Inicial. Instituto del Desarrollo Humano. Universidad Nacional de General Sarmiento.

Cabello, R. (2014): Reflexiones sobre inclusión digital como modalidad de inclusión social, en VIII Jornadas de Sociología de la UNLP, 3,4 y 5 de diciembre de 2014. La Plata. Buenos Aires.

Califano, B. (2009): Medios y políticas de comunicación en Argentina bajo el gobierno de Néstor Kirchner 2003-2007. - 1a ed. - Buenos Aires. ISBN 978-987-05-7083-7.

Callon, M. (2001): "Redes Tecno-económicas e irreversibilidad", en Redes, Vol. 8, № 17, Editorial de la UNQ, Pp. 85-126. Buenos Aires.

Cantú, A y Cimadevilla, G. (1998): “Orientación, Consumo, Recepción y Uso de los medios. Una propuesta de articulación conceptual", en Revista brasileira de Ciencias da Comunicaçao, Vol. XXII, Nro. 2, julio-dezembro, Pp. 41-54. Sao Paulo. Brasil.

Cantú, A. (1997) Consumo, Recepción y Usos. Un juego de implicaciones, en III Jornadas Nacionales de Investigadores en Comunicación. "Comunicación: campos de investigación y prácticas". Universidad Nacional de Cuyo. Noviembre 1997. Mendoza.

Carlón, M. (2004): Sobre lo televisivo. Dispositivos, discursos y sujetos. La Crujía. Buenos Aires.

Castellón A., L. y Jaramillo C., O. (22-24 de abril de 2002). Las múltiples dimensiones de la brecha digital. Coloquio Panamericano. Industrias Culturales y diálogos de las civilizaciones en las Américas. Montreal.

Castro, C. (2008): “El Modelo Híbrido Japonés - Brasileño de TV Digital - Interactividad, interoperabilidad y robustez para inclusión social", en Revista Diálogos de la Comunicación, N$^{\circ} 77$, Julio - Diciembre 2008.

Cheresky, I. (2007): "Los desafíos democráticos en América Latina en los albores del siglo XXI", en Cheresky, I. (comp.). Elecciones presidenciales y giro político en América Latina, Manantial. Buenos Aires.

Compaine, B. (2001): The Digital Divide. Facing a crises or creating a myth? Cambridge: MIT Press Sourcebooks. Massachussets.

Crovi Druetta, D. (2002): El discurso de la brecha digital ¿Promesa de futuro o salto al vacío? Revista TRAM(P)AS de la comunicación y la cultura, 4, 29-32. Buenos Aires.

Crovi Druetta, D. (Coord.) (2004): Sociedad de la información y el conocimiento. Entre lo falaz y lo posible. UNAM y La Crujía Ediciones., Pp. 17 - 56. Buenos Aires. Argentina. 
Cumbre Mundial sobre la Sociedad de la Información. Documentos Finales. Ginebra 2003 - Túnez 2005. Unión Internacional de Telecomunicaciones (UIT), Ginebra. (2005)

De Charras, D. y Mastrini, G. (2005): 20 años no es nada: del NOMIC a la CMSI. Anuario ININCO/Investigaciones de la Comunicación N ${ }^{\circ}$ 17, vol. 1, Caracas, Venezuela.

De Moraes, D. (2011): La cruzada de los medios en América Latina. Gobiernos progresistas y políticas de comunicación. Paidós. Buenos Aires.

De Moragas Spá, M. (2011): Interpretar la Comunicación. Estudios sobre medios en América y Europa, Gedisa, Barcelona.

De Souza Minayo, M.C. (2009): La artesanía de la investigación cualitativa. $1^{\circ}$ ed. Lugar Editorial. Buenos Aires.

Dupagne, M. (2002): «Adoption of High-Definition Television in the United States: An Edsel in the Making? » en LIN, C. A./ATKIN, D. J. (eds), Communication Technology and Society. Audience Adoption and Uses: 279-305. Creeskill, NJ, Hampton Press.

Durlak, J. (1987). "A typology for interactive media". En MCLAUGHLIN, Margaret (Ed). Communication Yearbook 10. Newbury Park: Sage publications.

Dussell, I. y Quevedo, L. A. (2011): VI Foro Latinoamericano de Educación; Educación y nuevas tecnologías: los desafíos pedagógicos ante el mundo digital. 1a ed. Santillana. Buenos Aires.

Elizalde, L. (2006): Tecnología, sociedad y comunicación. Hacia un modelo integrado de los efectos y determinaciones de las tecnologías de la comunicación. En Doxa Comunicación Nº 4. ISSN: 1696-019X Pp.113-135. ISSN: 1696-019X. CEU Ediciones. Madrid.

Escolar, C. (2000): “La investigación en geografía. Epistemología de la construcción de datos". En Escolar, C. (compiladora) Topografías de la investigación. Métodos, espacios y prácticas profesionales. EUDEBA. Buenos Aires. Pp.179-186. ISBN 950-23-1075-6.

Escolar, C. (2000): Palabras introductorias, en Escolar, C. (2000): Topografías de la investigación. Métodos, espacios y prácticas profesionales. EUDEBA. Buenos Aires. Pp.21-28. ISBN 950-23-1075-6.

Feenberg, A. (1991): Critical Theory of Technology, Oxford University Press. Nueva York.

Feenberg, A. (2005): “Teoría crítica de la tecnología”, CTS. En Revista Iberoamericana de Ciencia, Tecnología y Sociedad, Vol. 2, N5, Pp. 109-123. Consejo Nacional de Investigaciones Científicas y Técnicas. ISSN: 1668-0030 ISSN Electrónico: 1850-0013. Argentina.

Fernández Alonso, I., Capurro Robles, M., Sanmartín Navarro, J., Blasco Gil, J. (2009): Políticas de implantación de la TDT en Europa y efectos sobre la reconfiguración de los mercados de televisión. Los casos de Reino Unido, Francia, Italia y Alemania, Sphera Pública, Núm. 9, 2009, Universidad Católica San Antonio de Murcia, Pp. 15-54. España. 
Finquelievich, S. (2007): "Innovación, tecnología y prácticas sociales en las ciudades: hacia los laboratorios vivientes" Artículo publicado en CTS, Cienc. Tecnol. Soc. v.3 n.9, Mayo/ago. 2007, Ciudad Autónoma de Buenos Aires.

Franquet, R.; Ribes, X.; Fernández Quijada, D.; Soto, M.T. (2009): “Servicio público e interactividad en la TDT: la política del laissez faire, laissez passer", en Sphera Publica, 9, Universidad Católica San Antonio de Murcia, p. 191- 205. Murcia.

Galindo Cáceres, J. (2008): Comunicación, Ciencia e Historia, Mc Graw Hill, Madrid.

Galperín, H. (2004). New Television, Old Politics: The transition to digital TV in United States and Britain. Cambridge University Press. England.

Gambina, J. (2013): Crisis de capital. (2007/2013) La crisis capitalista contemporánea y el debate sobre alternativas. Buenos Aires, FISyP (Fundación de Investigaciones Sociales y Políticas).

García Leiva, M. T. (2008): Políticas públicas y televisión digital. El caso de la TDT en España y en el Reino Unido, Col. Politeya, estudios de Política y Sociedad. Ed. Consejo Superior de Investigaciones Científicas (CSIC). Madrid.

García Leiva, M. T. (2010): Theintroduction of TDT in LatinAmerica: Politics and policies. International Journal of Digital Television, 1(3), 327-344.

Garnham, N. (1979): “Contribución a una economía política de la comunicación de masas", en De Moragas, M. (ed.) Sociología de la Comunicación de masas. Gustavo Gili. Barcelona.

Garnham, N. (1997): "Economía política y estudios culturales: ¿reconciliación o divorcio?", en Causas y Azares n6, Causas y Azares, p. 33-46. Buenos Aires.

Géliga Vargas, J. (2006): “Acceder, cruzar, nivelar: disyuntivas escolar ante la brecha digital", en Cabello, R. (Coord.) Yo con la computadora no tengo nada que ver, Prometeo y UNGS. Buenos Aires. Pp. 41-88.

Getino, Octavio (2000), Las industrias culturales en el Mercosur: incidencia económica y sociocultural, intercambios y políticas de integración regional, Organización de Estados Americanos, Buenos Aires.

Glasser, B. y Strauss, A. (1967): El desarrollo de la teoría fundada. Aldin. Chicago, Illinois.

Gradin, A, y Hoop, M. (2007): "Planes sociales, contraprestación y sujetos "merecedores" de asistencia", en IV Jornadas de Jóvenes Investigadores. Instituto de Investigaciones Gino Germani, Facultad de Ciencias Sociales, Universidad de Buenos Aires, Buenos Aires.

Goffman, E. (1972) -1959-: La Presentación de la Persona en la Vida Cotidiana. Amorrortu. Buenos Aires.

Gomes, R. (2007): “Análisis e interpretación de datos de investigación cualitativa", en De Souza Minayo, Ma. C. (Ed). Investigación Social. Teoría, método y creatividad. 2a Reimpresión. Lugar Editorial. Buenos Aires. Pp. 85-114. 
Gómez, L. (comp.) (2012) "Construyendo Historia (S). Ver para creer en la Televisión. Relatos y Narraciones en la Televisión Digital Argentina”. Ediciones EPC, La Plata, noviembre de 2012. ISSN: 978-95034-0921-3.

González, L. (2013): La TV Digital Argentina: Un nuevo mapa en materia comunicacional. Escenario de disputas de poder. Proyecto de Promocional de Investigación y Desarrollo. Secretaría de Ciencia y Técnica. Universidad Nacional de La Plata.

González, L. (2014): Políticas públicas de Inclusión tecnológico/digital. Procesos formativos en escuelas públicas de la provincia de Buenos Aires: TV digital y Conectar Igualdad, proyecto de investigación. Centro de Investigación y Desarrollo en Comunicación, Industrias Culturales y Televisión (CEID-TV) de la Universidad Nacional de la Plata (UNLP).

González, L. et.al. (2014): La democratización de la comunicación en la era digital. Anuario de investigaciones 2013, noviembre 2014. ISSN 2408-3992.

Goodwing, P. (2005): "United Kingdom: never mind the policiy, feel the growth", en Brown, A. y Picard, R, (eds.), Digital Television in Europe, Lawerence Erlbaum Associates, London, New Jersey.

Gröndahl, A. (2002): Digitales Fernsehen in den nordischen Ländern, Media Perspektiven, $\mathrm{N}^{\circ}$ 9, Pp. 460-472.

Grossberg, L. (1997), "Estudios culturales versus economía política, ¿quién más está aburrido con este debate?", en Causas y Azares no 6. Pp. 47-60. Buenos Aires.

Grossberg, L. (2010): Estudios Culturales. Teoría, política y práctica. Ed. Letra Capital. Serie Estudios Culturales. Valencia. ISBN 978-84-937163-4-9.

Grossberg, L. (2012): Estudios Culturales en tiempo future. Cómo es el trabajo intelectual que require el mundo de hoy. Ed. Siglo XXI. Buenos Aires. ISBN 978-987-629-231-2.

Gunter, B. (2004): «The prospects for e-government on digital television», New Information Perspectives, 56 4: 222-233

Hanley, P. y Viney, R. (2003): «Pressing the Red Button: consumers and digital television», Cultural Trends, 43 and 44: 37-60.

Hart, J. (2004). Technology, Television and Competition. The politics of Digital TV. Cambridge University Press. England.

Hass, M. (2004): Rundkunf in Scheweden. Historie und Gegenwart. Medienpolitik und Anbieterstruktur, LIT Verlag, Berlin.

Hernández Aguirre, M.I. (2010): "Estado del Arte, Generación y Uso del Conocimiento sobre Televisión Digital Terrestre (TDT) en Colombia", en Razón y Palabra. Revista Electrónica. $\mathrm{N}^{\circ}$ 70. Año 14, noviembre-diciembre 2009-enero 2010. Disponible en http://www.razonypalabra.com.mx 
Hughes, T. (1996): "El impulso tecnológico". En: Smith, M.R. y Marx, L. (Eds.). Historia y Determinismo Tecnológico. Alianza, 1996. Madrid.

IIPE-UNESCO (2006): La integración de las Tecnologías de la Información y la Comunicación en los Sistemas Educativos. Estado del arte y orientaciones estratégicas para la definición de políticas educativas en el sector”. UNESCO. Buenos Aires.

Jaffrot, E. (2010): "Digitalización: oportunidades para la tecnología nacional", en Miranda, A., Santagata, G y Guérin, A. (Ed.) (2010): Pensar los medios en la era digital. Iberoamérica frente al desafío de la convergencia". $1^{\circ}$ ed.Colección: Inclusiones. La Crujía. Buenos Aires. Pp. 277-288.

Jensen, J.F. (1998): “The Concept of 'Interactivity' in 'Interactive Television' and 'Interactive Media'”. A JENSEN, J.F.; TOSCAN, C. (eds.). Interactive Television. TV of the Future or the Future of TV? Aalborg University Press. Pp. 25-66. Aalborg.

Jonsson, P. (2001): Ettmediepolicyteoretisktperspektiv med utvecklingenavmarksänd digital teveiSverigesomempirisk illustration. PaperpresenteratpåIslandskonferensen 1113 augusti 2001.

Kantor, D., Marcaletti, M. y Pafundi, L. (2013): Televisión Digital Interactiva: Desarrollo y perspectivas. Eduntref. Universidad Nacional de Tres de Febrero. Buenos Aires.

Kellner, D. (1998): "Vencer la línea divisoria: estudios culturales y economía política", en Ferguson, Marjorie y Peter Golding (eds.) Economía política y estudios culturales, Bosch, Pp. 185-212. Barcelona.

Krakoviak, F.; Mastrini, G.; Becerra, M. (2012): “Argentina: razones geopolíticas y perspectivas económicas", en Albornoz, A. y García Leiva, M.T. (2012): "La televisión digital terrestre. Experiencias nacionales y diversidad en Europa, América y Asia", Colección Inclusiones, La Crujía. Buenos Aires. Pp. 195-219.

Lacabanne, R. (2010): ¿Qué entendemos por interactividad? en Red Mercosur de Facultades de Diseño y Arte Multimedial, Terceras Jornadas Interuniversitarias, Área Transdepartamental de ArtesMultimediales - IUNA. Buenos Aires.

Lago Martínez S, (Comp.) (2012): Ciberespacio y Resistencias, Exploración en la cultura digital, Hekht, Buenos Aires.

Lago Martínez, S. (2012): Inclusión digital en la educación pública argentina. El Programa Conectar Igualdad. Revista Educación y Pedagogía, Medellín, Universidad de Antioquia, Facultad de Educación, vol. 24, núm. 62, enero-abril, 2012, pp. 205-218.

Lago Martínez, S. (2019): "Presentación”, en Políticas públicas e inclusión digital: un recorrido por los Núcleos de Acceso al Conocimiento, Lago Martínez, S. B. [et al.]; -1a ed.- Ciudad Autónoma de Buenos Aires. ISBN 978-987-86-1517-2.

Lange, A. (2005): "La situation financière des entreprises de télévision de l'Unioneuropéenne (1999-2004), en Reflets et perspectivs de la vie économique , 2005, vol. XLIV, número 4, Pp. 73-85. 
Larrégola, G. (1998). De la televisión analógica a la televisión digital, Libros de Comunicación global. Barcelona.

Latour, B. (1992): "Introducción. Abrir la caja negra de Pandora". En: Ciencia en acción. Cómo seguir a los científicos e ingenieros a través de la sociedad. Pp. 1-17. Editorial Labor. Barcelona.

Levis, D. (2007): "Enseñar y aprender con informática/enseñar y aprender informática. Medios informáticos en la escuela argentina" en R. Cabello y D. Levis (edits.). Medios Informáticos en la Educación a principios del siglo XXI. Prometeo. Buenos Aires.

----------(2009). La Pantalla Ubicua. Televisores, computadoras y otras pantallas. La Crujía (segunda edición revisada y ampliada). Buenos Aires.

Lévy, P. (1992), Le tecnologiedell'intelligenza, Bolonia: Synergon (ed. Orig.: Les Technologies del'intelligence, La Découverte, 1990), París. Pp. 40.

Linares, A. (2015): "Acceso y participación en la convergencia. Indicadores de un escenario dinámico", en VIII Seminario Regional (Cono Sur) ALAIC "Políticas, actores y prácticas de la comunicación: Encrucijadas de la investigación en América Latina”. 27 y 28 de agosto 2015.Córdoba, Argentina.

Linares, A. (2016): “Acceso y participación ciudadana. Una actualización de indicadores para la democratización de las comunicaciones", en Revista Intercom - RBCC. São Paulo, v.39, n.3, p.37-54, set./dez. 2016.

Linares, A. (2017): "La infraestructura para el acceso ciudadano en los medios estatales de la Argentina (2003-2009)", en Revista Austral Comunicación. Volumen 6 número 1 (junio 2017): 73-106. ISSN 2313-912.

Luhmann, N. (1994), "Inclusión-Exclusión", en Acta Sociológica No. 12, septiembrediciembre de 1994. UNAM-FCPyS, México. Pp. 11-39.

Luhmann, N. (2007): La sociedad de la sociedad. México, Herder-UIA.

Lull, J. (1997). "Cultura e identidad en el siglo XXI”. Diálogos de la Comunicación. 48, 57-67.

MacBride, S. et. al. (1980). Un solo mundo, voces múltiples: comunicación e información en nuestro tiempo. Informe de la UNESCO. Fondo de Cultura Económica, México.

Majó, J. (2012): "Evolución de las tecnologías de la comunicación”, en De Moragas, M. et.al. (ed.) (2012): La comunicación: de los orígenes a Internet. Editorial Gedisa. Barcelona.

Marshall, D. (2004), New Media Cultures, Arnold Publishers, Londres.

Martín Barbero, J. (1987). De los medios a las mediaciones. Comunicación, cultura y hegemonía. Editorial Gustavo Gili S.A. México. 
Martínez Veiga U. (2008): "Genealogía del concepto de Exclusión social. La situación europea”, en Revista Trabajo Social Hoy, Monográfico: Trabajo Social para la Inclusión, Colegio Oficial de Diplomados en Trabajo Social y Asistentes Sociales de Madrid. Madrid.

Maslow, A, (1954): Motivación y personalidad. Ediciones Díaz de Santos. Madrid.

Mastrini, G. y Becerra, M. (2006): Periodistas y magnates. Estructura y concentración de las industrias culturales, Prometeo, Buenos Aires.

Mastrini, G. (editor) (2009): Mucho ruido, pocas leyes. Economía y políticas de comunicación en la Argentina, Segunda edición ampliada, La Crujía. Buenos Aires.

Mastrini, G. et.al. (2014): Uso y consumo de la Televisión Digital Terrestre en Argentina. Un estudio en los municipios de San Fernando y Quilmes. 1ed. Universidad Nacional de Quilmes. Bernal, Provincia de Buenos Aires.

Mastrini, G. y Becerra, M. (2009): "Panorama de las políticas infocomunicacionales en la Argentina de 2008", en Cuadernos de Políticas Culturales: Indicadores Culturales 2008, Instituto de Políticas Culturales de la Universidad Nacional de Tres de Febrero, Caseros, Pp. 161-169. ISBN 978-987-1172-45-0, Junio de 2009.

Mastrini, G. y Becerra, M. (2009): Los monopolios de la verdad, Prometeo, Buenos Aires.

Mastrini, G., Becerra, M., Bizberge, A. y Krakowiak, F. (2012): El Estado como protagonista del desarrollo de la TDT en Argentina. Cuadernos de Información 31, 6978. DOI: $10.7764 / \mathrm{cdi} .31 .455$.

Mastrini, G., Loreti, D. y Baranchuk, M. (2007): Participación y democracia en la sociedad de la información, Prometeo, Buenos Aires.

Mattelart, A. (1997): "Utopía y realidades del vínculo global para una crítica del tecnoglobalismo", en Revista Diálogos de la comunicación, №. 50, 1997. ISSN 18139248. Perú.

Mattelart, A. y Mattelart, M. (1997): Historia de las Teorías de la Comunicación, Paidós. Barcelona.

Mattelart, A. (2002): "Los avatares de las políticas públicas", en Historia de la sociedad de la información. Paidós. Buenos Aires.

McChesney, R.W. (1998) "Convergencia de Medios y Globalización", en DK Thussu (ed.) Los imperios electrónicos: Medios Globales y Resistencia Local. Arnold. Londres. McQuail, D. (1975): Communication. Longman. Londres-New York.

Mead, G. H. (1934): Espíritu, persona y sociedad, Paidós. Buenos Aires.

Medina, E. (1983): "La polémica internalismo/externalismo.”, en: Revista Española de Investigaciones Sociológicas, No 23. Madrid. Pp. 53-76. Morales, S. y Cabello, R. (ed.) (2011): Enseñar con Tecnologías. Nuevas miradas en la formación docente. Prometeo. Buenos Aires. 
Miranda, A., Santagata, G y Guérin, A. (Ed.) (2010): Pensar los medios en la era digital. Iberoamérica frente al desafío de la convergencia". $1^{\circ}$ ed. Colección: Inclusiones. La Crujía. Buenos Aires.

Morales, S. y Cabello, R. (ed.) (2011): Enseñar con Tecnologías. Nuevas miradas en la formación docente. Prometeo. Buenos Aires.

Morley, D. (2008): "La televisión no tanto un medio visual como un objeto visible", en Medios, Modernidad y Tecnología. Gedisa, Barcelona. Pp. 226-234.

Mosco, V. (1996) The Political Economy of Communication. Sage Publications, Inc., London.

Mosco, V. (2006): La Economía Política de la Comunicación. CIC: Cuadernos de Información y Comunicación, 11, pp. 57-79. Madrid.

Murdock, G. y Golding, P. (1974): "For a Political Economy of Mass Communications". Socialist Register.

Nazareno, M. (2010): ¿¿Hace la izquierda la diferencia? La política socio-económica en el 'giro a la izquierda' de América Latina" en Estudios, $N^{\circ} 23-24$, enero-diciembre.

Pauloni, S. (Ed.) (2013): TV Digital: Un diálogo entre disciplinas y multipantallas. Ediciones de Periodismo y Comunicación. La Plata, ISBN978 9503410486.

Pauloni, S. et.al. (2014): Televisión Digital Terrestre Argentina: entre lo técnico y lo politico. Anuario de investigaciones 2013. Noviembre 2014. ISSN 2408-3992.

Pérez Zalazar, G. (2004): "El estado del arte de la brecha digital”, en Hacia la sociedad de la Información y el Conocimiento. Memorias de PANAM II. Pp. 137-143. Universidad Nacional Autónoma de México, México D.F.

Pinch, T. y Bijker, W. (2008): "La construcción social de hechos y de artefactos: o acerca de cómo la sociología de la ciencia y la sociología de la tecnología pueden beneficiarse mutuamente", en Thomas, H. y Buch, A. (Comp.) Actos, actores y artefactos: sociología de la tecnología. 1a. Ed. Universidad Nacional de Quilmes, Bernal. Provincia de Buenos Aires.

Powel, A (2001): Falling for the Gap: Whatever happened to the digital divide?. En Compaine, B. (Ed.). The Digital Divide. Facing a crises or creating a myth? (pp. 309314). Cambridge. MIT Press Sourcebooks. Massachussets.

Prado, E. (2010): “Del flujo al stock. Desafíos de la digitalización para las políticas de comunicación", en Pensar los medios en la era digital. Iberoamérica frente al desafío de la convergencia". $1^{\circ}$ ed.Colección: Inclusiones. La Crujía. Buenos Aires. Pp. 33-53.

Prado, E. y García, R. (2003): La apuesta por los brodcasters y por la alta definición. Panorama de la TDT en los Estados Unidos, en Telos, 57, Pp. 53-70.

Kessler, G, (2014): Controversias sobre la desigualdad: Argentina, 2003-2013. Fondo de Cultura Económica. Bs.As. 
Rafaeli, S. (1988): "Interactivity: from new media to communication". En Hawkins, Robert, John WIEMANN y Suzanne PINGREE (Eds). Advancing communication science: merging mass and interpersonal process. Pp. 110-134. Newbury Park: Sage.

Rausell Köster, C. (2005): A propósito del discurso interactivo. Analisi 32, Barcelona, Pp.147-161.

Ribés Alegría, M. (2007): “Quiero TV: La primera experiencia de TDT en España”, en El desarrollo de la televisión digital en España. Marzal, J. y Casero, A. (eds.) La Coruña, Netbiblo.

Rincón, O. (2013): "No son los contenidos, son las narrativas, las estéticas y los formatos", en Pensar la televisión Pública. ¿Qué modelos para América Latina?, Comp. Guerin, y otros. Ed. La crujía, Bs. As.

Rincón, O. (2010): “¡A contar! Televisión digital y ciudadanías”, en Pensar los medios en la era digital. Iberoamérica frente al desafío de la convergencia". $1^{\circ}$ ed. Colección: Inclusiones. La Crujía. Buenos Aires. Pp. 25-32.

Rincón, O. (Comp.) (2005): Televisión pública: del consumidor al ciudadano. $1^{\circ} \mathrm{ed}$. La Crujía. Buenos Aires.

Robinson, S. (2006): Reflexiones sobre la inclusión digital. Nueva Sociedad, N¹95. P.126-140.

Rodríguez Gallardo, A. (2006): La brecha digital y sus determinantes. UNAM, Centro Universitario de Investigaciones Bibliotecológicas. México.

Rodríguez Miranda, C. (2011): “TDT en Argentina y Chile: las dinámicas de poder en el proceso de selección del estándar tecnológico ISDB-TB”, en América Latina Hoy, Vol. 59, pp. 33-51. Ediciones Salamanca. Salamanca.

Rofman, A. (comp.) et.al. (2010): Sociedad y territorio en el conurbano bonaerense: un estudio de las condiciones socioeconómicas y sociopolíticas de cuatro partidos: San Miguel, José C. Paz, Moreno y Morón. - 1a ed. - Universidad Nacional de General Sarmiento. Los Polvorines.

Roger, E. (1962): Difusión de Innovaciones. Free Press. New York.

Ros, C. et.al. (2014): Inclusión digital y prácticas de enseñanza en el marco del Programa Conectar Igualdad para la formación docente del nivel secundario, coordinado por Ros C. 1a ed. Ministerio de Educación de la Nación. Buenos Aires.

Sádaba Chalezquer, M.R. (2000): "Interactividad y comunidades virtuales en el entorno de la world wide web". Comunicación y sociedad. Vol. XIII, Nº1, Pp. 139166.Universidad de Navarra. Pamplona.

Saltalamacchia, H. (1992): Historia de Vida, Ediciones Cijup, Caguas, Puerto Rico.

Samaja, J. (2004): Proceso, Diseño y Proyecto en investigación científica. Cómo elaborar un proyecto sin confundirlo con el diseño ni con el proceso, JVE Ediciones, Buenos Aires. 
Sanguinetti, L. (2010): "Políticas públicas para la sociedad de la Información: la digitalización de los servicios digitales", en Miranda, A., Santagata, G y Guérin, A. (Ed.) (2010): Pensar los medios en la era digital. Iberoamérica frente al desafío de la convergencia". $1^{\circ}$ ed. Colección: Inclusiones. La Crujía. Buenos Aires. Pp. 113-118.

Scolari, C. (2008): Hipermediaciones: Elementos para una Teoría de la Comunicación Digital Interactiva. Editorial Gedisa. Barcelona.

Seale, J. (2009) Digital Inclusion. A research briefing by the Technology Enhanced Learning Phase of the Teaching and Learning Research Programme, University of Southampton. Disponible en http://www.tlrp.org/docs/DigitalInclusion.pdf

Segovia, A. (2001): La estructura de los medios de comunicación en Estados Unidos: análisis crítico del proceso de concentración multimedia, Tesis Doctoral, Universidad Complutense de Madrid, ISBN: 84-669-2229-6. Madrid.

Serrano Santoyo, A. \& Martínez, E. (2003): La brecha digital: mitos y realidades. Editorial. UABC. México.

Servaes, J. (2000): “Comunicación para el desarrollo: tres paradigmas, dos modelos”, en Revista Temas y Problemas de Comunicación, Nro. 10, pp.5-28. Río Cuarto, Córdoba.

Servon, L. (2002). Bridging the Digital Divide. Blackwell Publishing. Inglaterra.

Siles González, I. (2004): "Sobre el uso de las tecnologías en la sociedad. Tres perspectivas teóricas para el estudio de las tecnologías de la comunicación", en Revista Reflexiones 83 (2): 73-82, ISSN: 1021-1209.

Simmel, G. (2002) -1917-: Cuestiones Fundamentales de Sociología. Editorial Gedisa. Barcelona. Smith, M. R. y Marx L. (Eds.) (1996): Historia y determinismo tecnológico. Alianza. Madrid. Pp. 14-16.

Smythe, D. (1983/1977): Las comunicaciones, agujero negro del marxismo occidental. Canadian Journal of Political and Social Theory, vol. 1, No 3.Toronto. Versión en español.

Sotillo, J. A. (2010): Prólogo, en: AYLLON, B. y SURASKY, J. (Coords.): La cooperación Sur-Sur en Latinoamérica. Utopía y realidad. Libros de la Catarata. Madrid.

Sourbati, M. (2004): «Digital television, online connectivity and electronic service delivery: implications for communications policy (and research)», Media, Culture \& Society, 26 4: 585-590.

Stark, M. (2011): "Can the BBC live to be 100? PublicServiceBroadcastingafter Digital Switchover”, en International Journal of Digital Television, 2, (2), Pp. 181-200.

Suárez Candel, R. (2010): Las políticas públicas para la implementación de la TDT: pertinencias, tendencias y buenas prácticas. Estudio Comparado de Suecia y España, Tesis Doctoral. Universitat Pompeu Fabra. Barcelona.

Suárez, A. L; Palma Arce, C. (2010): "Condiciones de vida en el Conurbano Bonaerense. Los partidos de Morón, San Miguel, Moreno y José C. Paz", en Rofman, A. (comp.) et.al. (2010): Sociedad y territorio en el conurbano bonaerense: un estudio de las condiciones socioeconómicas y sociopolíticas de cuatro partidos: San Miguel, José C. Paz, Moreno y Morón. - 1a ed. - Universidad Nacional de General Sarmiento. Los Polvorines. 
Silverstone, R., Hirsch, E. y Morley, D. (1996): “Tecnologías de la información y la comunicación y la economía moral", en Los efectos de la nueva comunicación. El consumo de la moderna tecnología en el hogar y en la familia. Bosch Casa Editorial, España. Pp. 39-57.

Szurmuk, M. y Mckee Irwin, R., (2009): Diccionario de Estudios Culturales Latinamericanos. Siglo XXI. Instituto Mora. México.

Thomas, H. (2012): “Tecnología, Desarrollo, Democracia. Sistemas Tecnológicos Sociales y Ciudadanía Socio-Técnica", en Juárez, P. (Coord.): Tecnología, Desarrollo y Ciudadanía. Cinco años de la iniciativa Feria de tecnologías sostenibles. Pp. 14-39. Universidad Nacional de Quilmes, Bernal. ISBN: 978-987-558-292-7.

Thomas, H.; Fressili, M.; Lalouf, A. (2008): Presentación. Estudios sociales de la tecnología: ¿hay vida después del constructivismo?, en Redes, vol. 14, núm. 27, mayo, 2008, pp. 59-76, Universidad Nacional de Quilmes, Provincia de Buenos Aires.

Thwaites Rey, M. (2010): “Después de la globalización neoliberal: ¿Qué Estado en América Latina?” en OSAL. CLACSO. Año XI, N 27, abril. Buenos Aires.

UNICEF (2013): Estado del arte sobre el desarrollo cognitivo involucrado en los procesos de aprendizaje y enseñanza con integración de las TIC. UNICEF. Buenos Aires.

Urquiza García, R. (2009): Televisión Digital Terrestre en Europa y Estados Unidos: Una Comparativa entre modelos de negocio, Tesis Doctoral, Universidad Complutense de Madrid, Madrid. ISBN: 978-84-692-7629-7.

Vargas, T. (2018): "Comunicación de gobierno: aportes para su comprensión”, en Massoni, S., Uranga, W., Longo, V. (2018). Políticas Públicas y Comunicación. Una cuestión estratégica. Nueva Editorial Universitaria - U.N.S.L., ISBN 978-987-733-1226. San Luis. Provincia de San Luis.

Vera Balanza, M.T. y Subires Mancera, M.P. (2013): "Análisis y evaluación de los niveles de inclusión digital en Andalucía. Balance actual y retos de futuro", en Estudios sobre el Mensaje Periodístico. Vol. 19, Núm. especial marzo, Pp.511-521., Servicio de Publicaciones de la Universidad Complutense. Madrid.

Vieytes, R. (2004): Metodología de la investigación en organizaciones, mercado y sociedad. Editorial de las Ciencias. Buenos Aires.

Vorderer, P.; Knobloch, S. Y Schramm, H. (2001): «Does Entertainment Suffer From Interactivity? The Impact of Watching an Interactive TV Movie on Viewer's Experience of Entertainment», Media Psychology, 3: 343-363.

Watzlawick, P.; Beavin, J.H.; Jackson, D. D. (1971) (2002): Teoría de la comunicación humana, Tiempo Contemporáneo, Buenos Aires.

Weber, I. y Evans, V (2002).: «Constructing the meaning of digital television in Britain, the United States and Australia», New Media \& Society, 4 4: 435-456. 
Williams, R. (1992): “Tecnologías de la comunicación e instituciones sociales”, en Historia de la Comunicación. Vol.2. Desde la Imprenta a nuestros días. Bosch Casa Editorial. Barcelona. Pp. 183-209.

Williams, R. (2011): Televisión. Tecnología y forma cultural. Paidós. Buenos Aires.

Winocur, R. (2009): Robinson Crusoe ya tiene celular. Siglo XXI. México.

Wolf, M. (1994): Los efectos sociales de los media. $1^{\circ}$ ed. Paidós, Buenos Aires.

Wolf, M. (2007): La investigación de la comunicación de masas. Críticas y perspectivas. $1^{\circ}$ ed. $1^{\circ}$ reimp. Paidós, Buenos Aires.

Yarto, C. (2010): "Limitaciones y alcances del enfoque de domesticación de la tecnología en el estudio del teléfono celular", en Revista Comunicación y Sociedad, Nueva época, núm. 13, enero-junio, 2010, pp. 173-200. Guadalajara, México. ISSN 0188-252.

Zallo, R. (1988): Economía de la Comunicación y la Cultura. Akal, Madrid.

Zemelman, H. (1994): "Racionalidad y ciencias sociales", en Círculos de reflexión latinoamericana en ciencias sociales. Cuestiones de teoría y método. Anthropos. Barcelona.

\section{En formato electrónico}

Abramovich, A.L.; Barnes, C.; Borello, J.; González, L.; Martínez, M.; Poplavsky, C. y Quintar, A. (2014): Consumos culturales y producción audiovisual en el Noroeste del Conurbano. Instituto del Conurbano, Universidad Nacional de General Sarmiento. Disponible en: http://composi.info/produccin-y-consumo-audiovisual-en-el-noroestedel-conurbano.html. [Consulta: 29 de septiembre de 2015].

Aguilar Villanueva, L. F. (2009): "Marco para el análisis de las políticas públicas". En Mariñez, Freddy y Garza, Vidal: Política pública y democracia en América Latina del análisis a la implementación. Porrúa, México, D. F., en http://politicas-ypublicas.blogspot.com.ar/2011/10/basicos-de-politica-publica.html. [Consulta el: 8 de agosto de 2015]

Agustín Lacruz, M.C. y Clavero Galofré, M. (2011): "Sociedades digitales y nuevas alfabetizaciones: Políticas públicas de inclusión y alfabetización digital", en Cabezudo Rodríguez, Nicolás (Coord.) Inclusión digital: perspectivas y experiencias. Zaragoza, Prensa Universitarias de Zaragoza, Pp. 253-274. Disponible en: http://zaguan.unizar.es/record/5993/files/ART-2011013.pdf. [Fecha de consulta: 19 de octubre de 2013]

Amado. S. (2015): "El Programa Conectar Igualdad en el nivel superior: desafíos y perspectivas en la formación docente", en Lago Martínez, S. (Coord.) De tecnologías digitales, educación formal y políticas públicas: aportes al debate. - 1a ed. -Teseo. Ciudad Autónoma de Buenos Aires. Disponible en: http://www.editorialteseo.com. [Consulta: 30 de abril de 2015]. 
Amin, S. (2001): "Capitalismo, imperialismo, mundialización”, en Resistencias Mundiales (De Seattle a Porto Alegre). CLACSO. Buenos Aires. Disponible en: http://bibliotecavirtual.clacso.org.ar/clacso/se/20100726091549/2amin.pdf. [Consulta: 29 de agosto de 2016]. ISBN : 950-9231-60-6.

Area Moreira, M. (2009): Introducción a la tecnología educativa. Universidad de la Laguna. Disponible en: https:/campusvirtual.ull.es/ocw/file.php/4/ebookte.pdf. [Consulta: 2 de marzo de 2014].

Arditi, B. (2009): El giro a la izquierda en América Latina: ¿una política post-liberal? Ciências Sociais Unisinos, 45 (Septiembre-Diciembre). Disponible en:http://www.redalyc.org/articulo.oa?id=93812729006. ISSN 1519-7050. [Consulta el: 2 de agosto de 2015]

Argañaraz, C.; Castaño, O.; Castro, C.; De Leo, W.; Mallaina, F.; Sabadini, J.P. (2010): La Televisión Digital Terrestre interactiva (TDTi). Herramienta de inclusión digital en Argentina en Reflexión Académica en Diseño y Comunicación $N^{\circ}$ XIV. [ISSN: 16681673] Pp. 16-29. Disponible en: http://www.fido.palermo.edu. [Consulta: 5 de septiembre de 2013].

Becerra, M. (28 de septiembre de 2019): "Comunicaciones sin beneficio de inventario." Letra P. Disponible en: https://www.letrap.com.ar/nota/2019-9-28-11-18-0comunicaciones-sin-beneficio-de-inventario. [Consulta: 30 de septiembre de 2019]

Becerra, M. (2016): “Creación de "Contenidos Públicos Sociedad del Estado", en Quipu. Políticas, economía y tecnologías de comunicación. Disponible en: https://martinbecerra.wordpress.com/2016/12/05/macri-decreta-cambios-en-encuentroy-paka-paka/. [Consulta: 21 de diciembre de 2019].

Becerra, M. et.al. (2014): Argentina. Regulación y políticas públicas para la TV digital, Disponible en: www.observacom.org. [Consulta: 20 de diciembre de 2014].

Becerra, M. (2013): "Comunicación y medios a 30 años de 1983. Balance y perspectivas de la metamorfosis", en Comunicación, políticas e industria: Actas del VIII Congreso Internacional de la Unión Latina de Economía Política de la Información, la Comunicación y la Cultura. ISBN: 978-987-558-266-8. Buenos Aires. Pp. 41-54. Disponible en: http://ulepicc.com/wp-content/uploads/VIII-Congreso-ULEPICC-Librode-Actas-QUILMES-Argentina.pdf. [Consulta: 25 de junio de 2014].

Becerra, M., Marino, S. y Mastrini, G. (2012): Cartografía Digital Media: Argentina, Disponible en: www.opensocietyfoundations.org. [Consulta: 25 de septiembre de 2013].

Becerra, M. y Mastrini, G., (2011): Transformaciones en el sistema de medios de Argentina en el Siglo XXI. Working Paper $\mathrm{N}^{\mathrm{o}}$ 21. Disponible en: http:// http://www.plataformademocratica.org/Arquivos/Plataforma_Democratica_Working_Pa per_21_2011_Espanhol.pdf. [Consulta el 1 de marzo de 2014]

Becerra, M. (2003): La Sociedad de la Información. Portal de la comunicación. Aula Abierta / Lecciones básicas. InCom-UAB: El portal de los estudios de comunicación. Disponible en: http://www.portalcomunicacion.com/lecciones_det.asp?id=11. [Consulta: 26 de junio de 2013]. ISSN 2014-0576. 
Benítez Larghi, S. y Winocur, R. (2016): "Inclusión digital: una mirada crítica sobre la evaluación del modelo Uno a Uno en Latinoamérica". Editorial Teseo. 1a ed . - Ciudad Autónoma de Buenos Aires. Disponible en: https://www.editorialteseo.com/?s=ben\%C3\%ADtez+larghi. [Consulta: 10 de septiembre de 2017]. ISBN 978-987-723-116-8.

Bennardis, A. (1999): Gestión municipal en el Conurbano Bonaerense. En Blutman, G. (comp.). Investigaciones sobre reforma del Estado, Municipios y Universidad. $1^{\mathrm{a}}$ ed. Buenos Aires: Facultad de Ciencias Económicas, Universidad de Buenos Aires, P.p. 89147. Disponible en: http://www.economicas.uba.ar/wpcontent/uploads/2016/01/Gesti\%C3\%B3n-municipal-en-el-conurbano-bonaerense.pdf. [Consulta: 20 de septiembre de 2015].

Bjoerner, T. (2003): "The early interactive audience of a regional TV station in Denmark», European Conference on Interactive Television: from Viewers to Actors?, 24 Abril 2003, Brighton (UK), 2003, On line: http://www.brighton.ac.uk/interactive/euroitv/euroitv03/Papers/Paper11.pdf. [Consulta: 20 de junio de 2013].

Born, G. (2002): «Public service broadcasting and digital television in the UK: the BBC, Channel 4, and the politics of positioning», RIPE@2002. Broadcasting \& Convergence: Articulating a New Remit, 17-19 Enero, Finland, 2002, On line: http://www.yle.fi/keto/ripe2002/papers/born.pdf. [Consulta: 22 de junio de 2013].

Borón, A. (2003): Estado, capitalismo y democracia en América Latina. Colección Secretaría Ejecutiva, Clacso, Buenos Aires. ISSN: 950-9231-88-6. Disponible en: http://www.clacso.org/español/libros/estado/estado.[Consulta el 4 de marzo de 2015].

Boyd, F. (2003): «BBC in search of audiences: public service and the challenges of digitalisation», en TARKKA, M. (eds), Digital television and the consumer perspective. Report from the seminar 'Digital television as a consumer platform', Tórshavn, Faroe Islands, September 12-14, 2002: 18-20. Helsinki, National Consumer Research Centre, $2003 . \quad$ On line: http://www.kuluttajatutkimuskeskus.fi/docs/pdf/34_2003_discussionpapers_dtv.pdf. [Consulta: 22 de junio de 2013].

Brandao Joly, A. V. (2003): «Interactividad en la televisión digital. Un estudio preliminar», Razón y Palabra, 31, 2003. Disponible en: http://www.razonypalabra.org.mx/anteriores/n31/ajoly.html. [Consulta: 21 de junio de 2013].

Bulla, G. y Hernández, P. (2013): “Aportes para el desarrollo de la Televisión Digital Abierta". Informe de I+D del Programa Polos Audiovisuales Tecnológicos, Publicado en CD.

Cabello, R. (2006): "Sobre los usos de los "juegos en red" en áreas periurbanas de Buenos Aires", en Revista Latinoamericana de Ciencias de la Comunicación, Sao Paulo, Nro. 6, Pp. 176-185. [Consulta: 8 de junio de 2013]. 
Cabello, R (2008): "Pliegues en la tecnocultura", en Revista Question, Publicación académica de la Facultad de Periodismo y Comunicación Social de la UNLP, Nro., 17, verano de 2008. Disponible en http://www.perio.unlp.edu.ar/question/ [Consulta: $17 \mathrm{de}$ junio de 2012].

Cabello, R. (Coord.) (2013): Migraciones Digitales: Comunicación, educación y tecnologías digitales interactivas, Publicación Electrónica UNGS. [Consulta: 28 de octubre de 2013].

Cabello, R. y Moyano, R., (2015): "Estudio de las relaciones entre inclusión digital e inclusión social, en M. Cárcar (Comp.). Políticas, actores y prácticas de la comunicación: encrucijadas de la investigación en América Latina. Actas del VIII Seminario Regional del Cono Sur de la Asociación Latinoamericana de Investigación en Comunicación (ALAIC). Córdoba: Escuela de Ciencias de la Información de la Universidad Nacional de Córdoba. Asociación Latinoamericana de Investigación en Comunicación (ALAIC). Disponible en :http://www.alaic2015.eci.unc.edu.ar/files/ALAIC/EJE6/alaic\%20626.pdf. [Consulta: 19 de mayo de 2017]

Cabello, R. (2017): La vida en los bordes. Reflexiones sobre el acceso a las tecnologías y la inclusión digital. Psicología, Conocimiento y Sociedad, 7(2), 252-278. Disponible en: http://revista.psico.edu.uy/. [Consulta: 1 de abril de 2018]

Cabero, J. (1998): «Las aportaciones de las nuevas tecnologías a las instituciones de formación continuas: Reflexiones para comenzar el debate. http://tecnologiaedu.us.es/bibliovir/pdf/85.pdf. [Consulta: 9 de octubre de 2012].

Cabrera Cabrera, P.J. (2005): Nuevas Tecnologías y la exclusión social. Un Estudio sobre las Posibilidades de las TIC en la lucha por la inclusión social, en España. Fundación Telefónica. Madrid. Disponible en: https://www.ohchr.org/Documents/Issues/CulturalRights/ConsultationEnjoyBenefits/U NESCONUEVAS_TECNOLOGIASyExclusionsocial.pdf. [Consulta el: 20 de diciembre 2014]

Camacho, K. (2006): La brecha digital. Disponible en: http://vecam.org/article550.html.[Consulta: 7 de septiembre de 2014].

Califano, B., (2017): "Políticas de medios y tecnologías de la información: de Argentina Digital a las modificaciones de Cambiemos", en Labate, C. y Arrueta, J.C. (comp.): La comunicación digital: redes sociales, nuevas audiencias y convergencia: desafíos y oportunidades para la industria, el Estado y los usuarios - 1a ed .Editorial de la Universidad Nacional de Jujuy - San Salvador de Jujuy. Disponible en: http://editorial.unju.edu.ar/descarga/item/la-comunicacion-digital-2.html. [Consulta: 30 de septiembre de 2019]

Califano, B. (2015): "Perspectivas conceptuales para el análisis del Estado y las políticas de comunicación", en Revista Austral Comunicación de la Facultad de Comunicación de la Universidad Austral. Vol. 4. $\mathrm{N}^{\circ}$ 2. Pp.251-286. Disponible en: https://ojs.austral.edu.ar/index.php/australcomunicacion/article/view/135. [Consultado el: 15 de junio de 2017) ISSN 2313-9137. 
Carman, M. (2017): "El activismo proteccionista, o las disímiles imputaciones de dignidad a animales y humanos", en Etnografías Contemporáneas, Año 3, No 4, pp. 128 155.

http://www.unsam.edu.ar/revistasacademicas/index.php/etnocontemp/article/view/217. [Consulta:10 de septiembre de 2017].

Cimadevilla, G. (2007): "Nuevos medios, legitimaciones, dominios. Algunas falacias de la sociedad de la información". Boletín de la Biblioteca de la Nación, Medios y Comunicación, 123, 105-118. Buenos Aires. Disponible en: http://bcn.gob.ar/labiblioteca/publicaciones/boletin-de-la-ben/no-123-medios-y-comunicacion-2017.

[Consulta: 12 de noviembre de 2017].

Cuadros Rodríguez, J.; Arias García, S.; Valencia Arias, A. (2015): "La comunicación pública como estrategia orientadora en los procesos de participación ciudadana de los jóvenes", en Revista Encuentros, Universidad Autónoma del Caribe, 13 (1), pp. 111-122. Disponible en: http://www.scielo.org.co/pdf/encu/v13n1/v13n1a09.pdf. [Consulta:29 de marzo de 2018].

Cubillos Vargas, D. (2009) Inclusión digital: estudio comparado de políticas públicas de Colombia y Brasil, en Actas III Conferencia ACORN-REDECOM, 4y 5 de Septiembre de 2009, México D.F., México. Disponible en: http://www.acornredecom.org/papers/acornredecom2009cubillos.pdf. [Consulta: 21 de agosto de 2013].

Damásio, M. J. (2003): «Uses of interactive television in educational settings: evaluating the media impact», European Conference on Interactive Television: from Viewers to Actors?, 2-4 Abril, Brighton (UK), 2003, On line: http://www.brighton.ac.uk/interactive/euroitv/euroitv03/Posters/Poster4.pdf. [Consulta: 21 de junio de 2013].

Dugharte, L. (2015): "De Internet, computadoras portátiles, softwares y contenidos. Un análisis comparativo de planes "una computadora, un alumno" en tres provincias de la Argentina.". Tesis de Doctorado. Doctorado en Ciencias Sociales. Disponible en: https://repositorio.flacsoandes.edu.ec/handle/10469/8494 [Consulta: 21 de junio de 2017]. Facultad Latinoamericana de Ciencias Sociales sede Académica Buenos Aires.

De Moragas, M. (2017): “Interpretar los cambios en la comunicación”, en Chasqui. Revista Latinoamericana de Comunicación N. ${ }^{\circ}$ 133, diciembre 2016-marzo 2017 (Sección Tribuna, pp. 23-30) Ecuador: CIESPAL. Disponible en: https://revistachasqui.org/index.php/chasqui/article/view/2999. [Consulta: 1 de octubre de 2019]. ISSN 1390-1079 / e-ISSN 1390-924X.

De Piero, S. (2012): "Los años Kirchneristas: recentralizar el Estado", en Revista Aportes para el Estado y la Administración gubernamental, Año 18 - $\mathrm{N}^{\circ} 30$, ISSN 0328-5855. Buenos Aires. Pp. 169-179.

Deharbe, D. (2014): “Casos de estudios: "Mi TV Digital”. Apropiación y uso del decodificador digital en la ciudad de Paraná", en Revista Trampas de la Comunicación y la Cultura. Nuevas lógicas de ver y de hacer televisión en la Argentina y en Brasil. América Latina Digital. Noviembre 2013/Febrero 2014. Disponible en: http://www.revistatrampas.com.ar/2014/trampas-77-2014. [Consulta: 10 de mayo de 2014]. 
Dholakia, R. et.al. (2000): "Interactivity and revisits to websites: a theoretical framework". En RITIM (Research Institute for Telecomnunication and Information Marketing). College of Business Administration. Kingston: University of Rodhe Island. Disponible en: http://ritim.cba.uri.edu/wp2001/wpdone3/Interactivity.PDF. [Consulta: 9 de mayo de 2015].

Díaz De Salas, S., Mendoza Martínez, V.M., Porras Morales, C. M. (2011): una guía para la elaboración de estudios de caso. Razón y Palabra [en línea] 2011, 16 (Febrero-Abril): Disponible en: $<$ http://www.redalyc.org/articulo.oa?id=199518706040> ISSN 16054806. [Consulta: 11 de abril de 2017]

Dussel, I. (2014), "Programas educativos de inclusión digital. Una reflexión desde la teoría del actor en red sobre la experiencia de Conectar Igualdad (Argentina)", Versión. Estudios de Comunicación y Política, núm. 34, septiembre-octubre. Pp. 39-56, en $<$ http://version.xoc.uam.mx/>. [Consulta: 10 de marzo de 2015].

Escolar, C. et. al. (1995): "Redes para "pescar" lo real (un abordaje teórico-metodológico para el análisis de políticas públicas)", en Revista Ciencia Ergo Sum, Vol.2, N 1, Pp. 3440, en http://cienciaergosum.uaemex.mx/index.php/ergosum/issue/view/276/showToc. [Consulta: 11 de agosto de 2014].

Escolar, C. (1998): Epistemología del trabajo de campo en geografía: problemas en torno a la construcción de los datos. Biblio 3W. Revista Bibliográfica de Geografía y Ciencias Sociales Universidad de Barcelona [ISSN 1138-9796] No; 96, 10 de junio de 1998. Disponible en: http://www.ub.edu/geocrit/b3w-96.htm\#uno. [Consulta: 10 de agosto de 2015].

Feenberg, Andrew (2005) "From essentialism to constructivism: philosophy of technology at the crossroads", en www.sfu.ca Versióntraducida al españoldisponibleen ww.hipersociologia.org.ar.[Consulta: 21 de julio de 2013].

Fernández Quijada, D. (2008): "Televisión de pago a la italiana", en Eptic, X (3). Disponible en: http://www.http://www.griss.org/esp/recursos_cv.asp?id_cv=14. [Consulta: 9 de mayo de 2015].

Fonseca Hidalgo, J. (2013): Interactividad vs Inmersión: retos narrativos de la TV Digital, en Memoria $1^{\circ}$ Congreso Centroamericano de Comunicación. 19 al 23 de agosto. Costa Rica. Disponible en http://www.http://www.ppc.ucr.ac.cr/pdf/memoria_congreso.pdf. [Consulta: 9 de mayo de 2015].

Freeman, J. Y Lessiter, J. (2003): «Using attitude based segmentation to better understand viewer's usability issues with digital and interactive tv», European Conference on Interactive Television: from Viewers to Actors?, 2-4 Abril 2003, Brighton (UK), 2003, On line: http://www.brighton.ac.uk/interactive/euroitv/euroitv03/Papers/Paper3.pdf . [Consulta: 21 de junio de 2013].

García Vargas, A., Ficoseco, V., Gaona, M., López, A. y Zubia, G. (2014): "Democratización, políticas de acceso y vida cotidiana. Experiencias de reconocimiento 
de la TDA en contextos populares urbanos (San Salvador de Jujuy, Argentina)", en Revista Oficios Terrestres. Año 20 - Vol. 1 - N. 31 Julio-Diciembre 2014. Disponible en: https://perio.unlp.edu.ar/ojs/index.php/oficiosterrestres/article/view/2449. [Consulta: 1 de agosto de 2015]. ISSN 1853-3248.

González, J. (2008): "Digitalizados por decreto: cibercultur@ o inclusión forzada", en América Latina Estudios sobre las Culturas Contemporáneas, vol. XIV, núm. 27, junio, 2008, pp. 47-76. Universidad de Colima. México. Disponible en: http://www.redalyc.org/articulo.oa?id=31602703 [Consulta: 3 de septiembre de 2019)

González, N. (2017): "La televisión digital Argentina a dos años del apagón. Retrocesos e incertidumbres", en "Transiciones de la escena audiovisual. Perspectivas y disputas", (comp.) González Z Néstor, Nicolosi, A., Universidad Nacional de Quilmes. Provincia de Buenos Aires. Disponible en:

https://ridaa.unq.edu.ar/bitstream/handle/20.500.11807/725/ME_2017_mecda_004.pdf? sequence $=1 \&$ isAllowed $=y$. [Consulta: 12 de noviembre de 2018]. SBN 978-987-558462-4.

González Frígoli, M. y Poiré, M.J. (2011): “Transformaciones, debates y nuevos interrogantes al ritmo de la sociedad de la información ", en González Frígoli, M. et. al. compilado por Martín González Frígoli ; Laura Otrocki ; María Julia Poire ; edición a cargo de Carlos Giordano ; María Silvina Souza ; Verónica Vidarte Asorey. - $1^{\mathrm{a}}$ ed. Universidad Nacional de La Plata. Facultad de Periodismo y Comunicación Social. La Plata. Disponible en: http://sedici.unlp.edu.ar/handle/10915/70081. [Consulta: 9 de noviembre de 2017]. ISBN 978-950-34-0792-9.

Guerra, M., Nicolai, C., Jordán, V. y Hilbert, M.R. (2008): Panorama Digital 2007 de América Latina y el Caribe .Avances y desafíos de las políticas para el desarrollo con las Tecnologías de Información y Comunicaciones. Colección Documentos. CEPAL/ECLAC. Santiago de Chile. Disponible en: http://www.cepal.org/SocInfo y http://www.dirsi.net. [Consulta: 4 de julio de 2016]

Hernández Aguirre, M.I. (2010): "Estado del Arte, Generación y Uso del Conocimiento sobre Televisión Digital Terrestre (TDT) en Colombia", en Razón y Palabra. Revista Electrónica. $\mathrm{N}^{\circ}$ 70. Año 14, noviembre-diciembre 2009-enero 2010. Disponible en: http://www.razonypalabra.com.mx. [Consulta: 4 de agosto de 2013].

Himmelstein, H. Y Aslama, M. (2002): «From Service to Access: Reconceiving Public Television's Role in the New Media Era», RIPE@2002. Broadcasting \& Convergence: Articulating a New Remit, 17-19 Enero, Finland, 2002, On line: http://www.yle.fi/keto/ripe2002/papers/himmelstein.pdf. [Consulta: 18 de junio de 2013].

Hujanen, T. (2204): "Content Production as the New Identity of Public Service Broadcasting: The Case of Digital Television», RIPE@2004. Mission, Market and Management: Public Service Broadcasting and the Cultural Commons., 3-5 Junio, Copenhagen and Arhus (Denmark), 2004a, On line: http://www.yle.fi/keto/ripe/Programme/Hujanen.pdf. [Consulta: 20 de junio de 2013].

Isuani, F. (2012): Instrumentos de políticas públicas: Factores claves de las capacidades estatales. Documentos y aportes en administración pública y gestión estatal, (19), 51-74. 
Disponible en: http://www.scielo.org.ar/scielo.php?script=sci_arttext\&pid=S185137272012000200003\&lng=es\&tlng=es. .[Consulta el 30 de marzo de 2015].

Iturralde, E. (2015): "La descentralización como elemento fundamental en el proceso de democratización de los medios de comunicación en Argentina”, Revista Question. Vol. 1, N. ${ }^{0} \quad 47$ (julio-septiembre 2015). Disponible en: https://perio.unlp.edu.ar/ojs/index.php/question/article/view/2577/2267. [Consulta: 16 de julio de 2018]

Iturralde, E. (2013): “La noción de participación en el campo de la comunicación", en Revista Argentina de Humanidades y Ciencias Sociales. Volumen 11, N. 2 (2013). ISSN 1669-1555. Disponible en: https://www.sai.com.ar/metodologia/rahycs/rahycs_v11_n2_07.htm\#arriba15. [Consulta: 15 de julio de 2018]

Izquierdo Castillo, J. (2017): “¿Quién ve la televisión? Revisión del modelo generalista en el espacio mediático convergente", en Revista Trípodos, $N^{\circ}$ 40. Barcelona. PP. 3154ISSN: 1138-3305.

Labate, C. (2013): Políticas de comunicación en Argentina y Brasil: perspectivas y tendencias de la TV digital. Ponencia presentada en el 14.0 Encuentro "Comunicación e Industria Cultural: Tendencias, Escenarios y Oportunidades", organizado por la Federación Latinoamericana de Facultades de Comunicación Social (FELAFACS), Lima. Perú. 15 al 18 de octubre de 2012. CD de ponencias.

Lago Martínez, S. (coord.) (2019): Políticas públicas e inclusión digital: un recorrido por los Núcleos de Acceso al Conocimiento. Editorial Teseo. 1a ed.- Ciudad Autónoma de Buenos Aires. Disponible en:

https://www.teseopress.com/politicaspublicaseinclusiondigital/. [Consulta: 8 de noviembre de 2019] ISBN 978-987-86-1517-2.

Levis, D. (2017): Inclusión digital no es inclusión social: De la ilusión de libertad al hiperconsumismo tecnototalitario, en Revista. Psicología, Conocimiento y Sociedad, 7(2), 279-308. Disponible en: http://revista.psico.edu.uy/. [Consulta: 1 de noviembre de 2017]. ISSN: 1688-7026.

Maglieri, A. (2018): "Políticas de TDA con señal de ajuste", en XXII Jornadas Nacionales de Investigadores en Comunicación, Red Nacional de Investigadores en Comunicación. Universidad Nacional de Jujuy. Disponible en: http://redcomunicacion.org/politicas-detda-con-senal-de-ajuste/. [Consulta: 1 de marzo de 2019]. ISSN 1852-0308.

Marino, S. et.al. (2015): Diagnóstico Sobre el Acceso del sector sin fines de lucro a medios audiovisuales en la Argentina 2014. Licencias, autorizaciones, Permisos y Fondos concursables. Mimeo, Bernal, Programa de Investigación "Industrias Culturales y espacio Público: Comunicación y política en la Argentina "y Maestría en Industrias Culturales, Políticas y Gestión- Universidad Nacional de Quilmes. Disponible en: http://es.scribd.com.doc/259387029/Diagnostico-sobre-el-acceso-del-sector-sin-finesde-lucro-a-medios-audiovisuales-en-la-Argentina-2014-Investigacion-del-grupo-sobreIndustrias-Cultur. [Consulta: 30 de abril de 2015] 
Martínez Carazo, P.C. (2006): El método de estudio de caso: estrategia metodológica de la investigación científica. Pensamiento \& Gestión [en línea] 2006, (julio): Disponible en: $<$ http://www.redalyc.org/articulo.oa?id=64602005> ISSN 1657-6276. [Consulta: 9 de junio de 2017]

Mastrini, G. y Becerra, M. (2019): “Más dueños que nunca". Revista Anfibia. Recuperado de: http://revistaanfibia.com/ensayo/mas-duenos-nunca/. [Consulta: 3 de octubre de 2019)

Mastrini, G. et.al. (2014): Argentina. Regulación y políticas públicas para la TV digital, Disponible en: www.observacom.org. [Consulta: 20 de diciembre de 2014].

Mastrini, G. (2014a): "Notas para un análisis de las políticas de comunicación en la región”, GT 6: Economía Política de las Comunicaciones. XII Congreso ALAIC. Pontificia Universidad Católica del Perú. Lima. Perú. Disponible en: http://congreso.pucp.edu.pe/alaic2014/wp-content/uploads/2013/09/GT6-GuillermoMastrini.pdf .[Consultado el: 15 de junio de 2017)

Mastrini, G. (2014b): Las industrias culturales en Argentina. Tesis de Doctorado. Facultad de Ciencias de la Información. Departamento de Periodismo III: Universidad Complutense de Madrid. Madrid. Disponible en: https://eprints.ucm.es/24687/1/T35195.pdf .[Consultado el: 10 de agosto de 2017)

Mastrini, G., Becerra, M., Bizberge, A., Krakowiak, F. (2012): El Estado como protagonista del desarrollo de la TDT en Argentina. Cuadernos de Información, (Diciembre $\quad$-Sin mes). Disponible en: $<$ http://www.redalyc.org/articulo.oa?id=97124883006 $>$ ISSN 0716-162x [Consulta el 26 de julio de 2013].

Medeiros Neto, B. (2007): The Monitoring and Evaluation of the Brazilian Digital Inclusion

Medrano, C.; Palacios, S. y Aierbe, A. (2007): Los hábitos y preferencias televisivas en jóvenes y adolescentes: un estudio realizado en el País Vasco, Revista Latina de Comunicación, 62. Enero Diciembre 2007. Disponible en: http://www.ull.es/ publicaciones/latina/ [Consultado el 20 de marzo de 2017].

Murolo, L. (2014): Hegemonía de los sentidos y usos de las tecnologías de la comunicación por parte de jóvenes del Conurbano Bonaerense Sur. Estudio realizado en Quilmes 2011-2014. Tesis de Doctorado. Facultad de Periodismo y Comunicación Social. Universidad Nacional de La Plata. Disponible en http://www.sedici.unlp.edu.ar. [Consulta: 28 de abril de 2015].

Olarte Encabo, S. (2017): Brecha digital, pobreza y exclusión social, en Revista andaluza de trabajo y bienestar social. Año 2017, Número 138. Pp. 285-313. Disponible en: https://dialnet.unirioja.es/servlet/articulo?codigo $=6552396$. [Consulta: 5 de octubre de 2018)

Orozco, G. y Miller, T. (2017): La Televisión más allá de sí misma en América Latina. Comunicación y sociedad, (30), 107-127. Disponible en: http://www.scielo.org.mx/scielo.php?script=sci_arttext\&pid=S0188-

252X2017000300107\&lng=es\&tlng=es. [Consulta: 8 de noviembre de 2019]. 
O'Reilly, T. (2005), What is Web 2.0. Design Patterns and Business Models for the Next Generation of software. Disponible en: http://www.oreillynet.com/ipt/a/6228.

Peña, P., Mazzitelli, M.G., Pou, D.S. (2012): "Las mujeres y las tecnologías de la información y las comunicaciones en la economía y el trabajo". CEPAL, Documento de proyecto. Santiago de Chile. Disponible en: http://www.cepal.org/Socinfo. [Consulta: 10 de diciembre de 2019)

Pauloni, S. (2018): “A 9 años de la creación de la TDA: de orgullo a abandono", en Prensa. Facultad de Periodismo y Comunicación UNLP. 30/08/2018. Disponible en: https://perio.unlp.edu.ar/node/7602. [Consulta: 1 de diciembre de 2018]

Picard, R. G. (2004): "Why Should I Pay the License Fee? Issues of Viewers as Customers in the Twenty-First Century», RIPE@2004. Mission, Market and Management: Public Service Broadcasting and the Cultural Commons., 3-5 Junio, Copenhagen and Arhus (Denmark), 2004, On line: http://www.yle.fi/keto/ripe/Programme/Picard.pdf. [Consulta: 18 de junio de 2013].

Pittaluga, L. y Rivoir, A. (2013): “Contribución de Plan Ceibal a la reducción de la brecha digital y a la inclusión social", en Rivoir, A. (Coord.) (2013): "Plan Ceibal e Inclusión Social. Perspectivas Interdisciplinarias". Plan Ceibal, UDELAR. Montevideo. ISBN 978-9974-83-83-0-7.

Disponible en: http://www.ceibal.edu.uy/art\%C3\%ADculo/noticias/institucionales/nuevolibroplanceib aleinclusionsocial. [Consulta: 4 de febrero de 2014].

Pizarro, R. (2001): "La vulnerabilidad social y sus desafíos: una mirada desde América Latina". CEPAL - SERIE Estudios estadísticos y prospectivos. Santiago de Chile. Disponible en: https://repositorio.cepal.org/bitstream/handle/11362/4762/S0102116_es.pdf. [Consulta: 19 de agosto de 2018]. ISSN 1680-8770

Program - GESAC. Sociologia da Universidade de Brasília. Disponible en: https://www.academia.edu/11043468/The_Monitoring_and_Evaluation_of_the_Brazili an_Digital_Inclusion_Program_GESAC. [Consulta: 7 de mayo de 2014].

Ramos Calderón, J.A. (2012): “ Inclusión/exclusión: una unidad de la diferencia constitutiva de los sistemas sociales", en Iberofórum. Revista de Ciencias Sociales de la Universidad Iberoamericana. Año VII, No. 14. Julio-Diciembre de 2012. Pp. 72-99. ISSN: 2007-0675. Universidad Iberoamericana A.C., Ciudad de México. Disponible en: http://www.uia/iberoforum. [Consulta: 20 de abril de 2015].

Ribés, M. (2006): "Nuevos servicios prestados a través del televisor. Quiero Televisión, el precedente de esta historia". Universitat Jaume I, Castellón. Disponible en: $<$ http://hdl.handle. net/10803/10468> [Consulta: 17 de junio de 2013].

Rizo, M. (2011): El interaccionismo simbólico y la Escuela de Palo Alto. Hacia un nuevo concepto de comunicación. Disponible en http://www.portalcomunicacion.com/lecciones_det.asp?id=17\#sthash.Chy0Fczr.dpuf.[ Consulta: 27 de marzo de 2015]. 
Rodríguez Miranda, C. (2010): “TDT, Una promesa de entrada a la Sociedad de la Información. Caso Argentina”, en Razón y Palabra. Revista Electrónica. $\mathrm{N}^{\circ} 76$. Julio 2011. Disponible en http://www.razonypalabra.com.mx

Rodríguez Miranda, C. (2013): Desafíos para la implementación de la televisión digital terrestre en Argentina. Ponencia presentada en el 14.0 Encuentro "Comunicación e Industria Cultural: Tendencias, Escenarios y Oportunidades", organizado por la Federación Latinoamericana de Facultades de Comunicación Social (FELAFACS), Lima. Perú. 15 al 18 de octubre de 2012. CD de ponencias. [Consulta el 10 de abril de 2015]

Rofman, A., (2014): Territorio, Sociedad y Política en la Región Metropolitana de Buenos Aires, Boletín electrónico $\mathrm{N}^{\circ} 1$ del Observatorio del Conurbano Bonaerense. Disponible en: www. http://www.observatorioconurbano.ungs.edu.ar. [Consulta: 10 de octubre de 2015].

Rosas Pineda, K. L. (2012-2013): “Genealogía de los Estudios Culturales”, en Razón y Palabra. Primera Revista Electrónica en América Latina Especializada en Comunicación. Comunicación y Derechos Humanos. Disponible en: http://www.razonypalabra.org.mx. [Consulta: 7 de diciembre de 2014].

Rossi, D. (2016): Acceso y participación: el desafío digital. Entre la garantía de derechos y la restauración desreguladora”, CECSO, UBA. Disponible en: http://politicasyplanificacion.sociales.uba.ar/textos-de-la-cursada/ [Consulta: 10 de julio de 2018]

Rossi, D. (2013): El desafío de la televisión digital terrestre en Argentina: participación y desconcentración. Ponencia presentada en el 14.0 Encuentro "Comunicación e Industria Cultural: Tendencias, Escenarios y Oportunidades", organizado por la Federación Latinoamericana de Facultades de Comunicación Social (FELAFACS), Lima. Perú. 15 al 18 de octubre de 2012. CD de ponencias. [Consulta el 15 de marzo de 2015]

Rost, A. (2004): "Un estudio del hipertexto en tres periódicos digitales". Verso e reverso. Revista da comunicação. Número especial Medios Digitales, Nro. 38. São Leopoldo RS- Brasil: Unisinos, Universidade do Vale do Rio do Sinos. ISSN: 0103-141. Disponible en: http://www.versoereverso.unisinos.br/. [Consulta: 8 de junio de 2015].

Sampaio, J.T. "Inclusão digital". Disponible en: http://www.sampa.org.br/default.asp?zera=0. [Consulta: 20 de junio de 2013].

Schmucler, H. (1997), "Recuerdo de lo que no fue". Quaderns del CAC, No 21. Disponible en: http://www.cac.cat/pfw_files/cma/recerca/quaderns_cac/Q21schmucler_ES.pdf. [Consulta: 17 de marzo de 2014].

Schultz, T. (200): "Mass media and the concept of interactivity: an exploratory study of online forums and reader email". Media, culture \& society. Vol. 22, No2, marzo, pp 205221. London: Sage. [Consulta: 10 de junio de 2015].

Seale, J. (2009) Digital Inclusion. A research briefing by the Technology Enhanced Learning Phase of the Teaching and Learning Research Programme, University of 
Southampton. Disponible en http://www.tlrp.org/docs/DigitalInclusion.pdf. [Consulta: 14 de octubre de 2014].

Sena Correa, E. (2009): Inclusión digital en Paraguay ¿Utopía o realidad?, en II Conferencia internacional sobre Brecha digital e Inclusión social, 28-30 de octubre de 2009, Madrid. Disponible en:

http://earchivo.uc3m.es/bitstream/handle/10016/12747/brecha_digital_inclusion_digital. pdf? sequence $=1$. [Consulta: 10 de febrero de 2014].

Severson, P (2004) En gökunge i publicservice-boet? Publikens roll i digitaliseringenavmarksändtelevision (A cuckoobird in thepublicservice-nest? Theaudience role in thedigitization of terrestrialtelevision". Academicdissertationfor PhD. Uppsala Studies in Media and Communication 3. Uppsala: Uppsala university, InstitutionforInformationStudies. Link: http://uu.divaportal.org/smash/get/diva2:164856/FULLTEXT01. [Consulta: 5 de julio de 2013].

Shore, C. (2010): "La antropología y el estudio de la política pública: reflexiones sobre la "formulación" de las políticas", en Revista Antípoda No 10, Enero - junio de 2010, Pp. 21- 49. ISSN: 1900-5407, en http://dx.doi.org/10.7440/antipoda10.2010.03. [Consulta: 11 de agosto de 2014].

Silverstone, R. (1990): "De la sociología de la televisión a la sociología de la pantalla. Bases para una reflexión global", Telos, $\mathrm{N}^{\circ}$. 22, Fundesco. Madrid. Disponible en http://www.infoamerica.org/documentos_pdf/silverstone03.pdf. [Consulta: 15 de mayo de 2015].

Soldano, D., (2014): "El conurbano bonaerense como expansión, desigualdad y promesa", en Revista de la Facultad de Ciencias Sociales UBA. N ${ }^{\circ}$ 86. Pp. 12-16. Disponible en: http://www.sociales.uba.ar/wp-content/uploads/S86-DOSSIERSOLDANO.pdf. [Consulta: 10 de septiembre de 2015].

Stillo, M. (2012): Los discursos sobre la inclusión digital. Reconsideraciones sobre la Brecha Digital como categoría de desarrollo. Commons. Revista de Comunicación y Ciudadanía Digital, Vol 1, No 1. Disponible en: http://www.http://reuredc.uca.es/index.php/cayp/article/view/430. [Consulta: $12 \mathrm{de}$ octubre de 2014].

Suárez Baldo, C. (2017): “Televisión Digital Abierta en la escuela pública Desafíos actuales y locales del campo comunicación y educación", Tesis de Maestría. Magister en Comunicación y Educación. Universidad Nacional de La Plata. Disponible en: http://sedici.unlp.edu.ar/bitstream/handle/10915/59596/Documento_completo__.pdfPDFA.pdf? sequence=3\&isAllowed=y. [Consulta: 5 de noviembre de 2018] .

Subirats, J., et.al. (2004): Pobreza y exclusión social. Un análisis de la realidad española y europea. Colección Estudios Sociales. Núm.16. Fundación "La Caixa". Disponible en: http://www. estudios.lacaixa.es. [Consulta: 25 de junio de 2015].

Tarkka, M. (2003): «Digital television and theconsumerperspective. Report from the seminar 'Digital television as a consumer platform', Tórshavn, Faroe Islands, September 12-14, 2002», Helsinki, National Consumer Research Centre, 2003. On line: 
http://www.kuluttajatutkimuskeskus.fi/docs/pdf/34_2003_discussionpapers_dtv.pdf. [Consulta: 18 de junio de 2013].

Theodoropoulou, V. (2002): «'The raise or the fall of interactivity? Digital Television and the 'first generation' of the digital audience in the UK», RIPE@2002. Broadcasting \& Convergence: Articulating a New Remit, 17-19 Enero, Finland, 2002, On line: http://www.yle.fi/keto/ripe2002/papers/theodoropoulou.pdf. [Consulta: 18 de junio de 2013].

Uranga, W. (2011): Sin comunicación no hay políticas públicas democráticas. Disponible en: http://www. washingtonuranga.com.ar/. [Consulta: 15 de octubre de 2015].

Van Dijk, J. (2006): "Digital divide research, achievements and shortcomings. Poetics", 34(4-5), 221-235. Disponible en: http://doi.org/10.1016/j.poetic.2006.05.004. [Consulta: 25 de julio de 2014].

Warschauer, M. (2004). Technology and Social Inclusion. Rethinking the digital device. On line: https://www.researchgate.net/publication/31775276_Technology_and_Social_Inclusion _Rethinking_the_Digital_Divide_M_Warschauer. [Consulta: 30 de marzo de 2017 ].

V. Navarrete y F. da Silva, et.al. (2006): Introducción a las técnicas cualitativas de investigación aplicadas en salud. Universidad de Barcelona. Materials 168. Disponible en: https:// booksgoogle.com.ar/. [Consulta: 11 de agosto de 2015].

Vila, M. C. (2014): Políticas, recepción y mediación de la TDA en familias beneficiadas por la AHU. Estudios de casos en la provincia de San Juan, ponencia presentada en las XVIII Jornadas Nacionales de Investigadores en Comunicación. Red Nacional de Investigadores en Comunicación. Universidad de las Artes (UNA). 9, 10 y 11 de octubre de 2014. Disponible en: https://una.edu.ar/assets/files/file/critica-de-arte/2014/2014-caprograma-jornadas.pdf. [Consulta: 9 de diciembre de 2014].

Webster, F. (2006): "La sociedad de la información revisitada", en Biblioteca Universitaria, Vol. 9, $\mathrm{N}^{\mathrm{o}} 1$ (ENE-JUN), Pp. 22-44. Disponible en: http:// https://www.redalyc.org/articulo.oa?id=28590105. [Consulta: 11 de octubre de 2016] ISSN 0187-750X.

Wiio, J. (2004): «From the Information Society to a Society of Information: Public Service Digital Television as a Player in the Knowledge Society of the Future», RIPE@2004. Mission, Market and Management: Public Service Broadcasting and the Cultural Commons., 3-5 Junio, Copenhagen and Arhus (Denmark), 2004, On line: http://www.yle.fi/keto/ripe/Programme/Wiio.pdf. [Consulta: 20 de junio de 2013].

Zeller, N. (1997): Reseña de la Política de Reforma del Estado 1989 a 1996. Serie I. Desarrollo Institucional y Reforma del Estado. Documento N58. Dirección Nacional De Estudios y Documentación Dirección de Estudios e Investigación. Instituto Nacional de la Administración Pública (INAP). Disponible en: http://www. http://www.um.edu.ar/catedras. [Consulta el 18 de marzo de 2015]

\section{Consultas Sitios web}


OBSERVACOM (Observatorio Latinoamericano de Regulación, Medios y Convergencia). www.observacom.org.

OSF (Open Society Foundations). www.opensocietyfoundations.org.

TDA (Televisión Digital Abierta). www.tda.gob.ar. (Última consulta en diciembre de 2015)

\section{Informes Técnicos}

AIMC (2014). Resumen general de resultados EGM. Abril 2013 a marzo 2014.

Disponible en: <http://www.aimc.es/-Datos-EGM-Resumen-General-.html>. [Consulta: 5 de noviembre de 2018]

AIMC (2017). Resumen general de resultados EGM. Abril 2016 a marzo 2017.

Disponible en: <http://www.aimc.es/-Datos-EGM-Resumen-General-.html>. [Consulta: 5 de noviembre de 2018]

CEPAL (2013): Lista de indicadores para el eLAC201. Colección Documentos de Proyectos. CEPAL. Disponible en: https://www.cepal.org/es/publicaciones/4052-listaindicadores-elac2015-version-2013. [Consulta: 4 de julio de 2016]

LAMAC (2015): Consejo Latinoamericano de Publicidad en Multicanales (Latin American Multichannel Advertising Council). Disponible http://www.lamac.org/system/articles/pdfs/000/000/086/original/Pay-TV-Fact-Sheet-

ARGENTINA-mayo-2015.pdf?1521140960. [Consulta: 20 de febrero de 2016]

Loreti, D., De Charras, D. y Lozano, L. (2019): Evaluación Legal Media Ownership Monitor Argentina. Rerporteros Sin Fronteras y Tiempo Argentino. Disponible en: http://argentina.momrsf.org/fileadmin/Editorial/Argentina/Infografics/Analisis_Legal_Arg_ESP.pdf. [Consulta: 9 de diciembre de 2019)

INDEC (2013) "Encuesta Nacional sobre Acceso y Uso de Tecnologías de la Información y la Comunicación (ENTIC). Resultados del tercer trimestre de 2011". Disponible en http://www.indec.gov.ar. [Consulta: 14 de noviembre de 2015].

Informe Auditoría General de la Nación Argentina (AGN) N 80/2012 (2014). Disponible en: https://www.agn.gov.ar/files/informes/2014_069info.pdf. [Consulta: 29 de abril de 2015]

MAUTIC (2019). Acceso y uso de tecnologías de la información y la comunicación. EPH. Cuarto trimestre de 2018. Informes Técnicos. Vol. 3. n 86. Ciencia y tecnología. Vol. $3, \mathrm{n}^{\mathrm{o}}$ 1. Instituto Nacional de Estadística y Censos (INDEC). Disponible en: https://www.indec.gob.ar/uploads/informesdeprensa/mautic_05_19CF6C49F37A.pdf.

[Consulta: 30 de octubre de 2019]. ISSN 2545-689X .

OBSERVACOM (2015): "El ocaso de la TV digital terrestre en Argentina”. Disponible en:https://www.observacom.org/el-ocaso-de-la-tv-digital-terrestre-en-argentina/

[Consulta: 16 de julio de 2018] 
SInCA (2013): Encuesta Nacional de Consumos Culturales y Entorno Digital (ENCCyED). Audiovisual. Disponible en: https://www.sinca.gob.ar. [Consulta: 3 de febrero de 2015].

PNUD (1999): Informe sobre Desarrollo Humano 1999. Madrid, Mundi Prensa.

\section{Normativa}

\section{Leyes}

Ley de Servicios de Comunicación Audiovisual N²6.255, (10/10/2009). Boletín Oficial de la República Argentina, N 31.756.

Ley $\mathrm{N}^{\circ}$ 26.359. Modificación de Impuestos Internos. (23/11/2009). Boletín Oficial de la República Argentina, N³1.786.

\section{Decretos}

Decreto $\mathrm{N}^{\circ} 252 / 2000$. Creación del Programa Nacional para la Sociedad de la Información. Objetivo. Modificación de los Decretos Nro. 1018/98 y 1293/98. (17/3/2000). Boletín Oficial de la República Argentina, Nº 29.363.

Decreto $N^{\circ} 512 / 2009$. Creación Grupo de Trabajo Multisectorial, que tendrá por finalidad concertar e impulsar la "Estrategia de Agenda Digital de la República Argentina". (12/5/2009). Boletín Oficial de la República Argentina, Nº 31.651.

Decreto $N^{\circ} 1148 / 2009$. Creación el Sistema Argentino de Televisión Digital Terrestre. (1/9/2009). Boletín Oficial de la República Argentina, N 31.727.

Decreto $\mathrm{N}^{\circ}$ 364/2010. Declaración de interés público la Plataforma Nacional de Televisión Digital Terrestre. (17/3/2010). Boletín Oficial de la República Argentina, $N^{\circ}$ 31.865

Decreto $N^{\circ} 459 / 10$. Creación del Programa "Conectar Igualdad.com.ar" de incorporación de la nueva tecnología para el aprendizaje de alumnos y docentes. (7/4/2010). Boletín Oficial de la República Argentina, №31.877.

Decreto N. ${ }^{o}$ 1552/2010. Crea el Plan Nacional de Telecomunicaciones "Argentina Conectada" y la Comisión de Planificación y Coordinación Estratégica de dicho Plan. Declara de interés público el desarrollo, implementación y la operación de la RED FEDERAL DE FIBRA ÓPTICA. (28/10/2010). Boletín Oficial de la República Argentina, $\mathrm{N}^{\circ} 32.016$.

Decreto $\mathrm{N}^{\circ} 835 / 2011$. Autoriza a prestar servicios de uso de infraestructura, multiplexado y transmisión para Televisión Digital Terrestre. (23/6/2011). Boletín Oficial de la República Argentina, N³2.176.

\section{Resoluciones}

Resolución $N^{\circ} 1785 / 2009$. Acuerdo para la conformación del Consejo Asesor del Sistema Argentino de Televisión Digital Terrestre. (24/9/2009). Boletín Oficial de la República Argentina, $\mathrm{N}^{\circ} 31.744$. 
Resolución $N^{\circ}$ 2161/2010. Reglamento de la Comisión de Planificación y Coordinación Estratégica del Plan Nacional de Telecomunicaciones. (9/12/2010). Boletín Oficial de la República Argentina, N³2.044.

Resolución $N^{\circ}$ 938/2014. Plan Nacional de Servicios de Comunicación Audiovisual Digitales. (28/8/2014). Boletín Oficial de la República Argentina, №32.956.

\section{Documentos Operativos}

Argentina Conectada. Planificación Estratégica Plan Nacional de Telecomunicaciones Argentina Conectada. Comisión de Planificación y Coordinación Estratégica del Plan Nacional de Telecomunicaciones. "Argentina Conectada". Disponible en: www.argentinaconectada.gob.ar. Última consulta en diciembre de 2015.

Manual Operativo para la Implementación del Plan de Acceso a la Televisión Digital Abierta Satelital "Mi Tv Digital Satelital”, Documento N², Consejo Asesor del Sistema Argentino Televisión Digital Terrestre. Disponible en: www.tda.gob.ar/contenidos/normativa_tda. Última consulta en diciembre de 2015.

Planificación Estratégica para la implementación del SATVD-T (vigencia 2009-2019), Consejo Asesor del Sistema Argentino Televisión Digital Terrestre. Acta Aprobatoria $\mathrm{N}^{\circ}$ 2. (9/12/2009). Disponible en: www.tda.gob.ar/contenidos/normativa_tda. Última consulta en diciembre de 2015.

Reglamento General del Plan Operativo de Acceso al Equipamiento para la Recepción de la Televisión Digital Abierta "Mi Tv Digital” del Plan Estratégico del Sistema Argentino de Televisión Digital Terrestre, Consejo Asesor del Sistema Argentino Televisión Digital Terrestre, Acta Aprobatoria N $\mathrm{N}^{\mathrm{N}} 3$ (20/04/10) 20. Disponible en: www.tda.gob.ar/contenidos/normativa_tda. Última consulta en diciembre de 2015.

\section{Artículos periodísticos}

Obarrio, M. (14 de junio, 2010). Empezó el reparto de decodificadores de TV del Gobierno. Sección Política. La Nación. Recuperado de: https://www.lanacion.com.ar/politica/empezo-el-reparto-de-decodificadores-de-tv-delgobierno-nid1274826

Bossi, J. (15 de febrero, 2011) El Gobierno abrirá más canales de TV. Sección Política. La Nación. Recuperado de: https://www.lanacion.com.ar/politica/el-gobierno-abriramas-canales-de-tv-nid1350154

Cristina presentó el plan oficial para ofrecer Internet y TV digital. (19 de octubre, 2010). Sección política. Clarin. Recuperado de: http://www.clarin.com/politica/cristinapresento-internet-tv-digital_0_HJdOdqipDQx.html

Krakowiak, F. (4 de mayo, 2010). Un regalo para el Mundial. Sección Economía. Página 12. Recuperado de: https://www.pagina12.com.ar/diario/economia/2-145087-2010-0504.html

Krakowiak, F. (2018): "La Televisión Digital Abierta, a la deriva”, Letra P. Recuperado de: https://www.letrap.com.ar/nota/2018-3-4-12-28-0-la-television-digital-abierta-a-laderiva. 
Los LCD van primero a los jubilados. (22 de junio,2011). Sección El País. Página 12. Recuperado de: https:/www.pagina12.com.ar/diario/elpais/1-170592-2011-06-22.html

Dos antenas más, y ya llegan a 19. (22 de junio,2011). Sección El País. Página 12. Recuperado de: https://www.pagina12.com.ar/diario/elpais/1-170593-2011-06-22.html

La TV digital oficial debutará con los beneficiarios de planes sociales y cinco canales. (24 de marzo, 2010). Revista Fortuna. Recuperado de: https://fortuna.perfil.com/201003-24-23058-la-tv-digital-oficial-debutara-con-los-beneficiarios-de-planes-sociales-ycinco-canales/

\section{Artículos propios}

González Gartland, G., "Usos de la televisión digital: un estudio en una localidad del Conurbano Bonaerense", en Revista Question, N 41. Verano 2014. ISSN 1669-6581.

González Gartland, G.: "Usos de la televisión digital en estudio en una localidad del Conurbano Bonaerense", ponencia presentada en las XVII Jornadas de la Red de Investigadores en Comunicación. "Repensar el rol de los investigadores en un escenario comunicacional de transición", 12, 13 y 14 de septiembre de 2013. Universidad Nacional de General Sarmiento - Provincia de Buenos Aires.

González Gartland, G., "La TDT en Argentina: ¿herramienta de inclusión digital?”, ponencia presentada en el 14.0 Encuentro "Comunicación e Industria Cultural: Tendencias, Escenarios y Oportunidades", organizado por la Federación Latinoamericana de Facultades de Comunicación Social (FELAFACS), Lima. Perú. 15 al 18 de octubre de 2012.

González Gartland, G., "La TDT en Argentina: Un estudio exploratorio", ponencia presentada en el X Enacom. Encuentro Nacional de Carreras de Comunicación "La comunicación en tiempos contemporáneos. Memorias, tradiciones, horizontes", organizado por el Departamento de Comunicación Social de la Universidad Nacional de Misiones (UNaM) y Federación Argentina de Carreras de Comunicación Social (FADECCOS), Posadas, Misiones, 5, 6 y 7 de septiembre de 2012.

\section{Bibliografía Consultada:}

Badillo Matos, Á. y Sierra, F. (eds.) (2011): "La transición a la televisión digital terrestre en Iberoamérica: diagnóstico y prospectiva”. Ciespal. Quito.

Burnett, R. y Marshall, D. (2003): Web Theory. An introduction, Routledge. Londres.

Cabello, R. (Coord.) (2006): Yo con la computadora no tengo nada que ver, Prometeo y UNGS.

Cabello, R. (2008): "TIC, Educación y Desarrollo. El papel de la integración de los medios informáticos en la formación docente", en Cimadevilla, G. (Comp.), Comunicación, tecnología y desarrollo, Río Cuarto, ALAIC y UNRC, Pp. 169-186. Buenos Aires. 
Cabello, R. (2006): "Sobre los usos de los "juegos en red" en áreas periurbanas de Buenos Aires", en Revista Latinoamericana de Ciencias de la Comunicación, Sao Paulo, Nro. 6, Pp. 176-185.

Castellón A., L. y Jaramillo C., O. (22-24 de abril de 2002). Las múltiples dimensiones de la brecha digital. Coloquio Panamericano. Industrias Culturales y diálogos de las civilizaciones en las Américas. Montreal.

Castells, Manuel (1997). La era de la Información: Economía, sociedad y cultura, Alianza Editorial. Madrid.

Elías, N. (1998): La sociedad de los padres y otros ensayos. Grupo Editorial Norma, Bogotá.

Gaitán Moya, J. y Piñuel Raigada, J., (1998): Técnicas de investigación en Comunicación Social. Elaboración y registro de datos, Síntesis. Madrid.

Hernández Ochoa, E. (2007): “Transición de la tecnología analógica a la digital”, en Huber, R. y Villanueva, E. (Coords.) (2007): "Reforma de Medios Electrónicos. ¿Avances O Retrocesos?“", UNAM-Fundación Konrad Adenauer, México.

Hine, C (2004): Etnografía virtual, Editorial UOC, Barcelona.

Mc Quail, D. (1983): Teoría de la Comunicación de Masas. Paidós. Barcelona.

Morley, D. (2008): Medios, Modernidad y Tecnología. Gedisa, Barcelona.

Mosco, V. (1996): La economía política de la comunicación: Repensar y Renovación. SAGE Publications. ISBN 0803985614, 9780803985612.

Norris, P. (2003): The worldwide digital divide: information poverty, the Internet and development. Harvard University, John F. Kennedy. School of Government. Massachusetts.

Orihuela, J. L. (2005): "Topología de los cibermedios", en Salaverría, R. (ed.), Cibermedios. El impacto de Internet en los medios de comunicación en España, Comunicación Social Ediciones y Publicaciones. Sevilla.

Orozco Gómez, G. (Coord.) (2013): TV Morfosis 2. Convergencia y escenarios para una televisión interactiva, Tintable. México D.F.

Padua, J. (1993): Métodos y técnicas de la investigación en ciencias sociales, Fondo de Cultura Económica. México D.F.

PiñuelRaigada, J. y Gaitán Moya, J. (1995): Metodología General. Conocimiento científico e investigación en la comunicación social, Síntesis. Madrid.

Prensky, M. (2001): Digital natives, digital inmigrants. On the horizon, Vol. 9, NBC University Press, EE.UU. 
RausellKöster, C. (2005): A propósito del discurso interactivo. Analisi 32, Barcelona, Pp.147-161.

Renaud, A. (1990): Comprender la imagen hoy. Nuevas imágenes, nuevo régimen de lo visible, nuevo imaginario. En AAVV. Videoculturas de fin de siglo, Cátedra. Madrid.

Robinson, S. (2006): Reflexiones sobre la inclusión digital. Nueva Sociedad, $N^{\circ} 195$. P.126-140.

Schelsky; H. (1967): El hombre en la civilización científica: y otros ensayos. Editorial Sur. Buenos Aires.

Scolari, C. (2008): Hipermediaciones: Elementos para una Teoría de la Comunicación Digital Interactiva, Gedisa. Barcelona.

Searle, J. (1997): La construcción de la realidad social. Ediciones Paidós Ibérica. ISBN 978-84-493-0421-7.

Thomas, H. (1999): “Tecnología y Sociedad”, en Kreimer, P. y Thomas, H., Aspectos sociales de la ciencia y la tecnología. Universidad Virtual de Quilmes. Bernal, Provincia de Buenos Aires.

Urresti, M (edit.), (2008), Ciberculturas Juveniles: los jóvenes, sus prácticas y sus representaciones en la era de Internet, La Crujía. Buenos Aires.

Williams, R., (1992): “Tecnologías de la comunicación e instituciones sociales", en Williams, R. (Comp.) Historia de la comunicación. Vol.2 De la imprenta a nuestros días, Bosch.3. Barcelona.

Wolton, D., (1999), Internet et après. Une théorie critique des nouveaux médias, Flammarion. France. 
ANEXOS 


\section{ANEXO I \\ Formularios e instructivos de la TDA}

A continuación se presentan diferente tipo de documentos que componían la lógica de procedimientos para la obtención del beneficio de la política pública TDA tales como: formulario de solicitud de equipos receptores terrestres (TDT) y/o satelitales (TDS), de reclamos y/o sugerencias, así como también el instructivo para completar el formulario de solicitud para escuelas y organizaciones sociales.

A) Formulario de solicitud de Hogares (Receptor de señales digitales para TDT / TDS)

\section{FORMULARIO DE SOLICITUD DE HOGARES}

(Receptor de señales digitales para TDT / TDS)

EL PRESENTE FORMULARIO REVISTE CARÁCTER DE DECLARACIÓN JURADA, DEBIENDO SER COMPLETADO SIN OMITIR, ENMENDAR NI FALSEAR NINGÚN DATO.

Atención: Este formulario se debe completar en letra imprenta mayúscula sin tachaduras ni enmiendas.

El presente Formulario deberá ser completado por aquellas personas que cumplan con alguno de los siguientes requisitos.

(Marcar con una cruz la opción que corresponda)

Percibir Haber Previsional Mínimo (Jubilación y/o pensión nacional, provincial y/o local.) Percibir Asignación Universal por Hijo

Percibir Pensión No contributiva (Invalidez, Mayor de 70 años o Madre de 7 hijos o más)

Percibir Programa y/o Plan Social

Todo aquel interesado que, por su situación socioeconómica considere pertinente realizar la solicitud.

1. Datos del Solicitante 
TV

CUIT/CUIL:
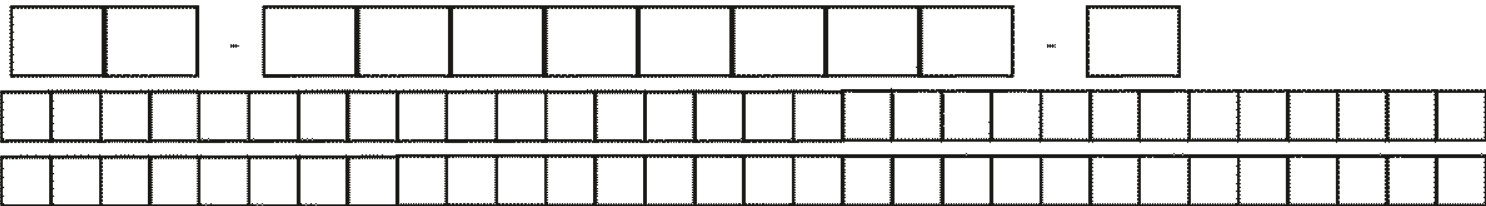

Tipo Doc

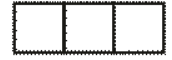

Nro. Documento

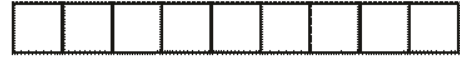

Sexo

$\square$ Masculino $\square$ Femenino $\quad$ Estado Civil \begin{tabular}{lll|l|l|l|l|l|l|l|}
$\square$ \\
\hline
\end{tabular}

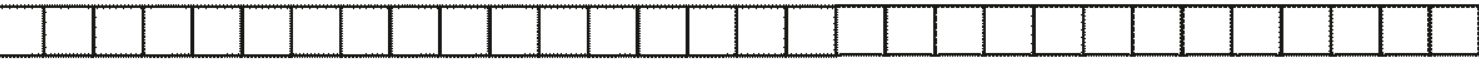

Máximo nivel educativo alcanzado

Domicilio - Calle o Ruta

Número o $\mathrm{Km}$

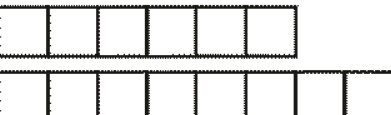

Piso

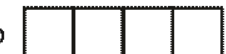

Dpto \begin{tabular}{l|l|l|l|l|l|l|l}
\hline & & & \\
\hline
\end{tabular}

Otros Datos

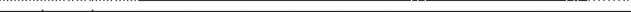

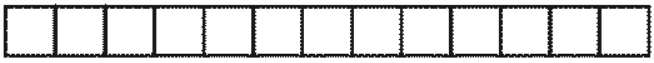

Partido/Comuna

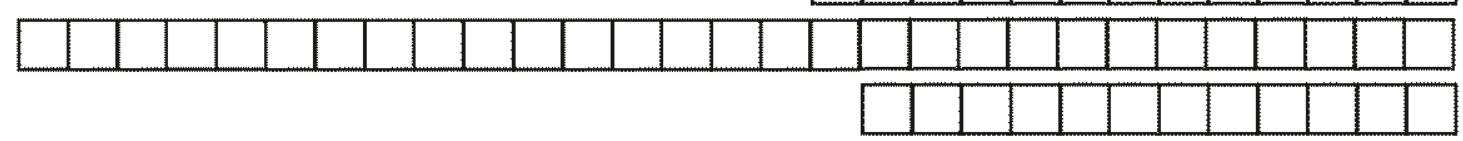

Email

Nombres

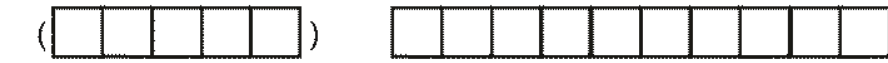

Apellidos

Nacionalidad

Fecha Nac.

Ocupación

Cód. Postal

Localidad

Partido/Comuna

Provincia

Teléfono

\section{Integrantes del Grupo Conviviente}

(Aclaración: No detallar datos del Solicitante en la primera fila). 


\begin{tabular}{|c|c|c|c|c|c|c|}
\hline $\begin{array}{l}2.1 \\
\text { Nombre y apellido }\end{array}$ & $\begin{array}{l}2.2 \\
\text { Tipo y } N^{\circ} \text { de } \\
\text { documento }\end{array}$ & $\begin{array}{l}2.3 \\
\text { Edad }\end{array}$ & $\begin{array}{l}2.4 \\
\text { Estudia? } \\
\text { (tachar lo } \\
\text { que no } \\
\text { corresponda) }\end{array}$ & $\begin{array}{l}2.5 \\
\text { Máximo o } \\
\text { nivel } \\
\text { educativo } \\
\text { alcanzado. }\end{array}$ & $\begin{array}{l}2.6 \\
\text { Ocupación }\end{array}$ & $\begin{array}{l}2.7 \\
\text { Relación } \\
\text { con } \\
\text { solicitante }\end{array}$ \\
\hline \multirow[t]{4}{*}{ - -------- } & --------- & ----- & $\mathrm{Si}-\mathrm{No}$ & --------- & --------- & SOLICITANTE \\
\hline & & & Si - No & & & \\
\hline & & & $\mathrm{Si}-\mathrm{No}$ & & & \\
\hline & & & $\mathrm{Si}$ - No & & & \\
\hline
\end{tabular}

\begin{tabular}{|c|c|c|c|c|c|c|}
\hline $\begin{array}{l}2.1 \\
\text { Nombre y apellido }\end{array}$ & $\begin{array}{l}2.2 \\
\text { Tipo y } N^{\circ} \text { de } \\
\text { documento }\end{array}$ & $\begin{array}{l}2.3 \\
\text { Edad }\end{array}$ & \begin{tabular}{|l}
2.4 \\
Estudia? \\
(tachar lo \\
que no \\
corresponda)
\end{tabular} & $\begin{array}{l}2.5 \\
\text { Máximo nivel } \\
\text { educativo } \\
\text { alcanzado. }\end{array}$ & $\begin{array}{l}2.6 \\
\text { Ocupación }\end{array}$ & $\begin{array}{l}2.7 \\
\text { Relación } \\
\text { con } \\
\text { solicitante }\end{array}$ \\
\hline & & & Si - No & & & \\
\hline & & & $\mathrm{Si}-\mathrm{No}$ & & & \\
\hline & & & $\mathrm{Si}-\mathrm{No}$ & & & \\
\hline & & & $\mathrm{Si}-\mathrm{No}$ & & & \\
\hline & & & $\mathrm{Si}-\mathrm{No}$ & & & \\
\hline & & & $\mathrm{Si}-\mathrm{No}$ & & & \\
\hline & & & $\mathrm{Si}-\mathrm{No}$ & & & \\
\hline & & & $\mathrm{Si}-\mathrm{No}$ & & & \\
\hline
\end{tabular}

2.8. Indique los siguientes datos del jefe o jefa de hogar Nombres Apellidos

Tipo y Numero de Documento

\section{Datos Socio-económicos}

3.1. Ingreso neto mensual de todos los miembros del hogar (Aclaración: Indicar en números cantidad de \$) Ingreso total en \$:

\section{4. ¿Usted o algún miembro de su hogar, percibe ingreso de carácter económico nacional, provincial y/o local?}

4.1. Especificar la Institución que lo otorga. 
$\square$ Jubilación. Institución que la otorga

Pensión

Otro (Especificar)

\section{Usted o algún miembro de su hogar, ¿es beneficiario de algún Programa y/o Plan social de carácter nacional, provincial y/o local?}

5.1. Especificar Plan/Programa e Institución que lo otorga. (Aclaración: Indicar con una cruz y detallar según corresponda). ADJUNTAR FOTOCOPIA DEL COMPROBANTE DEL ÚLTIMO COBRO / CONSTANCIA OFICIAL

$\square \mathrm{Si} \quad \square$ No Nombre

\section{Condición de la vivienda}

6.1 La vivienda que su grupo familiar habita es (Aclaración: Indicar con una cruz y detallar
$\square$ Propia $\square$ Prestada $\square$ Alquilada $\square$ Ocupada de hecho $\square$ Cedida por trabajo

Otro (Especificar)

6.2 Cantidad de ambientes que posee la vivienda (Aclaración: Indicar en números cantidad de ambientes sin considerar el baño y la cocina) Cantidad ambientes:

6.3 ¿Su vivienda posee retrete con descarga de agua? (Aclaración: Indicar con una cruz según corresponda)

Si $\square$ No

6.4 La vivienda que habita, ¿ forma parte de alguno de los siguientes Planes o Programas de vivienda? (Aclaración: Indicar con una cruz y detallar según corresponda)

Otro(Especific

\section{ARGENTINA}

$\square$ FONAVI $\square$ PROMEBA $\square$ Planes Federales de Vivienda

7. Cobertura de salud (Aclaración: Indicar con una cruz y detallar según corresponda) 7.1 Usted posee:

Obra Social Especificar

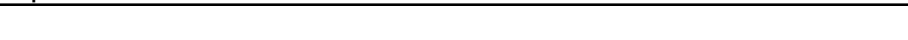

Prepaga Especificar

Ninguna (Concurre a Hospital Público)

Otro 


\title{
TV
}

7.2 ¿ Alguno de los miembros de la vivienda se encuentra comprendido en alguna de estas situaciones? (Aclaración: Indicar con una cruz y detallar según corresponda)
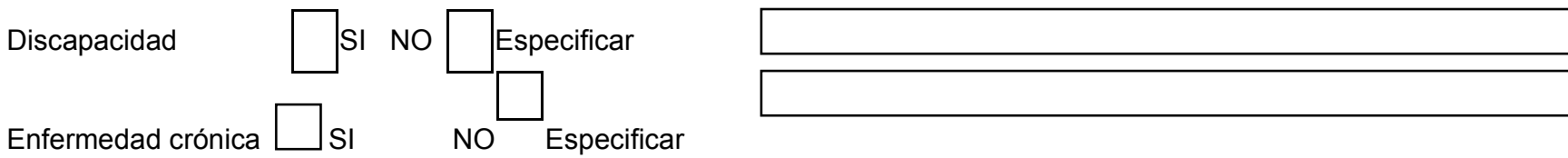

Declaro bajo juramento que la información consignada en la presente es correcta y completa, y ha sido confeccionada sin omitir ni falsear dato alguno siendo fiel expresión de la verdad. Solo podrá recibir el receptor de Televisión Digital Terrestre la persona solicitante en el domicilio denunciado.

\section{SELLO DE SUCURSAL \\ Firma y aclaración del solicitante \\ C.A.}

\section{DOCUMENTACIÓN RESPALDATORIA}

Deberá acompañar con el presente Formulario de Solicitud la siguiente documentación:

1 Copia del DNI, LC, LE, tirilla o denuncia de hurto o extravío del solicitante.

1 Copia de la Documentación que avale la presente Solicitud en carácter de solicitante del beneficio.

Ejemplo: Comprobante de cobro de haberes, Certificado de discapacidad, Comprobante del último cobro de Plan o Programa Social y/o Vivienda, tarjeta de Asignación Universal por Hijo.

Para realizar cualquier consulta sobre la presente solicitud contactarse al número telefónico 130 Centro de Atención Telefónica de

\author{
ANSES o al número telefónico \\ 0-800-888-MiTV (6488) o \\ en el sitio \\ www.tvdigitalargentina.g
}

TALÓN PARA EL BENEFICIARIO
ob.ar


B)

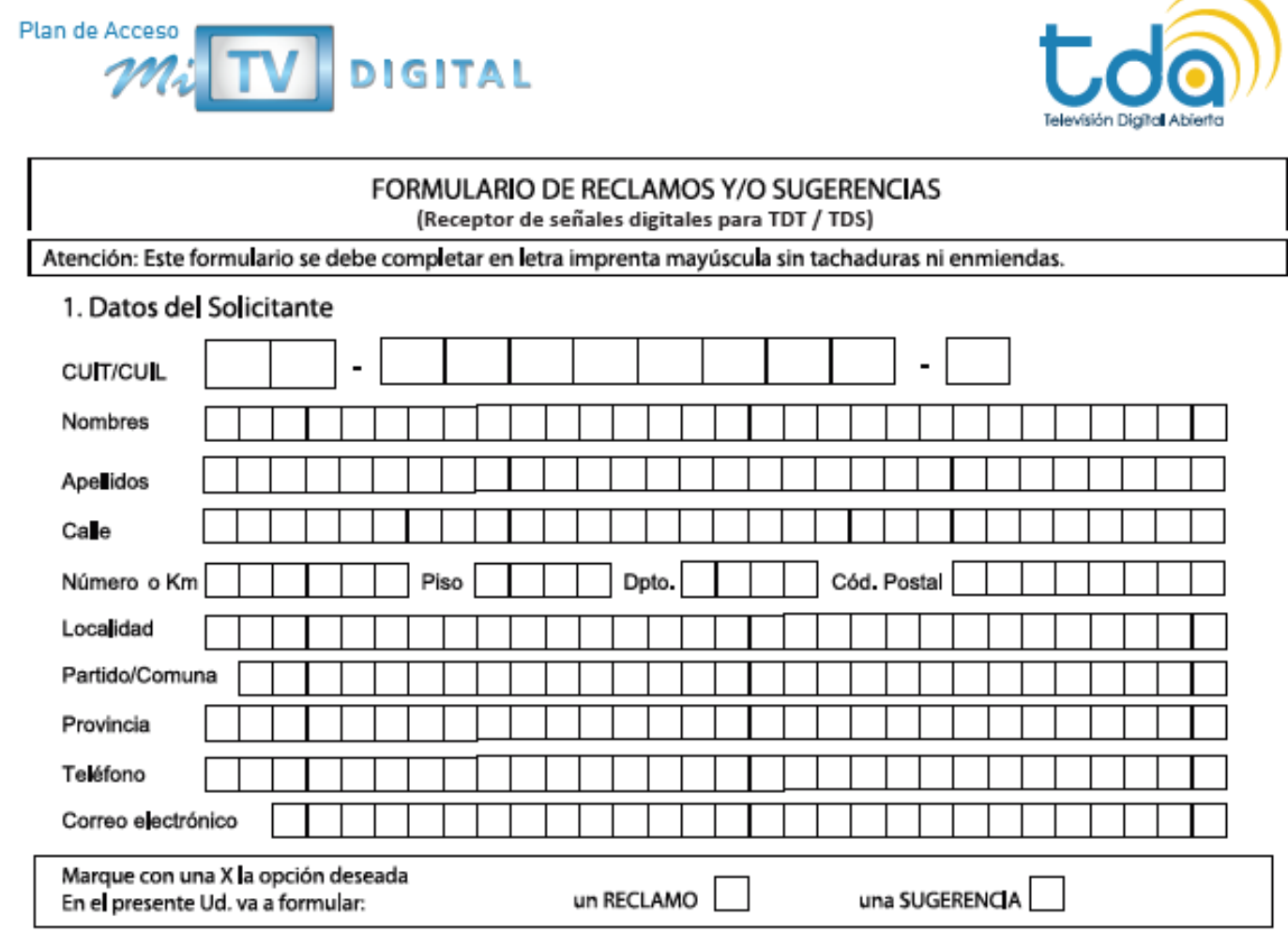

2. Escriba con letra imprenta mayúscula la Sugerencia o Reclamo

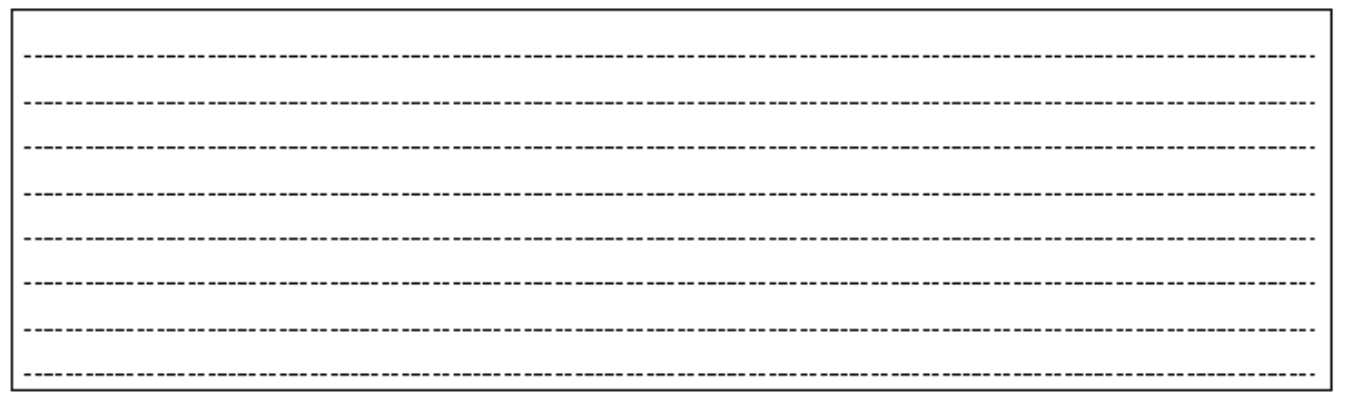

En el caso de acjuntar información o documentación complementaria enumere su contenido:

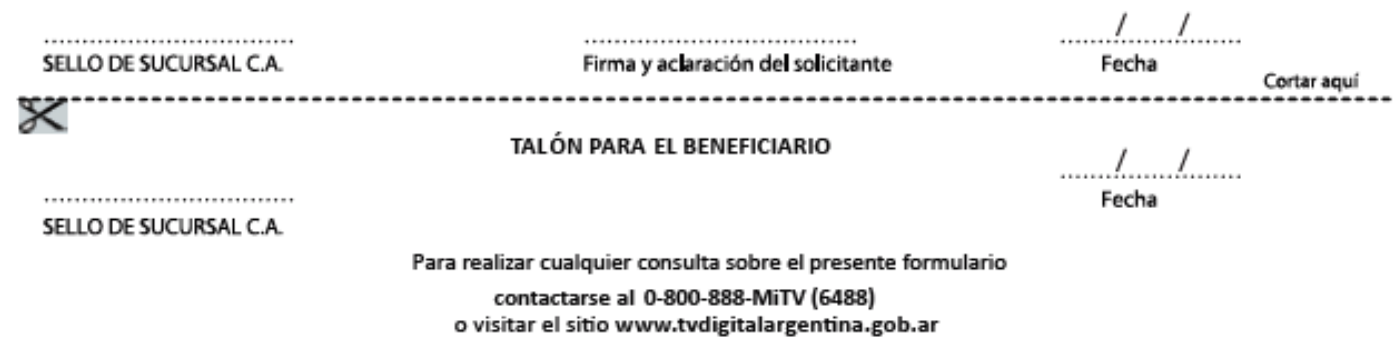

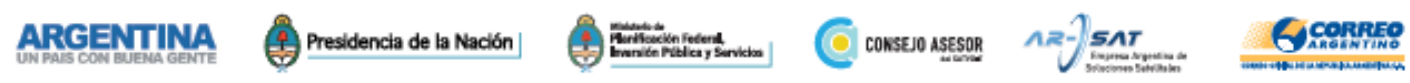


C)

\section{INSTRUCTIVO PARA COMPLETAR FORMULARIO DE SOLICITUD DE ESTABLECIMIENTOS ESTATALES / ORGANIZACIONES SOCIALES PARA LA TV DIGITAL TERRESTRE}

(Receptor de señales digitales para TDT / TDS)

Elpresente instructivotiene como objetivo principal unificarcriterios que permitan a los solicitantes completar de forma correcta y sistemática la información requerida en el Formulario de solicitud.

\section{Institución / Organización}

CUIT/CUIL: Consignar $N^{0}$ de la Código Único de Identificación Laboral (CUIL)/ Código ÚnicodeIdentificación Tributaria(CUIT) correspondiente al Establecimiento Estatal / Organización Social.

Denominación o razón social: Consignar denominación o Razón social (Según Inscripción en la Inspección General de Justicia)

Calle: Indicar nombre de calle donde se encuentra ubicada el Establecimiento Estatal / Organización Social según la documentación respaldatoria entregada.

Número o Km.: Indicar $\mathrm{N}^{0}$ de calle/ Km. del domicilio donde se encuentra ubicado el Establecimiento Estatal/ Organización Social, según la documentación respaldatoria entregada.

Piso: Indicar $\mathrm{N}^{\mathrm{o}}$ de piso del domicilio donde se encuentra ubicado el Establecimiento Estatal / Organización Social.

Dpto: Indicar departamento del domicilio donde se encuentra ubicado el Establecimiento Estatal / Organización Social.

Cód. Postal: Consignar N. ${ }^{\circ}$ de Código postal correspondiente.

Teléfono: Indicar $\mathrm{N}^{\mathrm{o}}$ telefónico correspondiente al Establecimiento Estatal/ Organización Social.

Localidad: Consignar nombre de la localidad en la que se encuentra ubicado el Establecimiento Estatal/ Organización Social.

Partido/Comuna: Consignar partido o comuna en la que se encuentra ubicado el Establecimiento Estatal/Organización Social.

Provincia: Consignar la Provincia en la que se encuentra ubicado el Establecimiento Estatal/ Organización Social.

Otros Datos: Indicar aquellos datos referenciales que permitan la ubicación/ identificación del domicilio del Establecimiento Estatal/ Organización Social (En el caso de no poseer nombre/ Número de calle, etc)

E-Mail: Indicar correo electrónico correspondiente al Establecimiento Estatal/ Organización Social.

Página Web: Consignar página Web correspondiente al Establecimiento Estatal/ Organización Social. 


\section{Datos del Apoderado}

CUIT/CUIL: Consignar $\mathrm{N}^{0}$ del Código Único de Identificación Laboral (CUIL)/Código ÚnicodeIdentificación Tributaria(CUIT)correspondiente al apoderado.

Nombre y Apellido: Consignar nombre y apellido completo del apoderado.

Cargo: Indicar el cargo que ocupa, el apoderado, dentro del establecimiento estatal u organización social.

Calle: Indicar nombre de la calle, según conste en documentación respaldatoria entregada.

Número o Km.: Indicar $\mathrm{N}^{\circ}$ de calle/ Km. del domicilio del apoderado, según la documentación respaldatoria entregada.

Piso: Indicar $\mathrm{N}^{\circ}$ de piso del domicilio.

Dpto: Indicar departamento del domicilio.

Cód. Postal: Indicar N. ${ }^{\circ}$ del correo Postal correspondiente.

Teléfono: Consignar N. ${ }^{\circ}$ telefónico del apoderado.

Localidad: Consignar nombre de la localidad.

Partido/Comuna: Consignar Partido/ comuna al que pertenece el domicilio del apoderado.

Provincia: Consignar nombre de la Provincia

3. Mencione las actividades que desarrolla habitualmente el Establecimiento/ Organización.

Describir brevemente, y de forma prioritaria, aquellas actividades comunicacionales, educativas, de inclusión tecnológica, recreativas. y/u otras vinculadas con la temática que se desarrollan en el establecimiento estatal/ organizaciónsocial.

\section{Describir las Actividades que se realizarán luego de la recepción del equipo solicitado.}

Describir brevemente aquellas actividades que se planifican realizar luego de la recepción del equipo solicitado.

\section{Cantidad/promedio mensual de personas que participan activamenteen el Establecimiento/Organización}

En el caso de establecimientos educativos consignar cantidad discriminando y especificando entre alumnos y profesores Participantes/Alumnos: Indicar en números la cantidad de personas que participan en la Organización Social. En el caso de Establecimientos Estatales educativos indicar $\mathrm{N}^{\mathrm{o}}$ de alumnos que concurren al mismo.

Docentes: En el caso de Establecimientos Estatales educativos indicar en números, la cantidad de docentes que posee el Establecimiento. 
6. Cantidad aproximada/promedio esperada de personas beneficiarias directas de las actividades a realizar.

Indicar en números la cantidad o el promedio previsto de personas que se verán beneficiadas de las actividades que se realizaran luego de la recepción del equipo solicitado.

7. Cantidad de Paquetes de equipamiento receptor de señales digitales solicitadas.

Indicar, en números, la cantidad solicitada de paquetes de equipamiento receptor.

7.1. Justificación parasolicituddemásde4(CUATRO)codificadores.

\subsubsection{Cantidad solicitada:}

En el caso de solicitar más de 4 (cuatro) codificadores, indicar en números la cantidad requerida.

\subsubsection{Justificación del requerimiento}

Describir brevemente las causas del requerimiento. 


\section{ANEXO II \\ Listado de spots de propaganda del lanzamiento de TDA y artículos periodísticos analizados}

Los archivos pueden consultarse en el DVD que acompaña el presente informe de tesis

\section{Producción audiovisual sobre el lanzamiento y desarrollo de la TDA en el país}

- "Plan de Acceso". Spot de propaganda de TDA, con fecha 24/09/2010, disponible en https://www.youtube.com/watch?v=_Q2xucl1B2I (Consultado el 9 de septiembre de 2015).

- "Institucional". Spot de propaganda de TDA, con fecha 24/09/2010, disponible en https://www.youtube.com/watch?v=bis9DR0o9Ew (Consultado el 20 de agosto de 2015).

- “TV Digital Argentina. Mi TV Digital”, Spot de propaganda de TDA. 24/8/2011, disponible en https://www.youtube.com/watch?v=1jCr_cvujUQ. (Consultado el 12 de noviembre de 2014).

- "Como conecto mi Deco", Spot de propaganda de TDA. 19-8-2011, disponible en https://www.youtube.com/watch?v=-nEhj-NDgKs (Consultado el 12 de noviembre de 2014).

- "TV digital", Spot de propaganda de TDA. 18/3/2011, disponible en https://www.youtube.com/watch?v=OruVZK4J-_U; “TDA”,.(Consultado el 12 de noviembre de 2014)

- Spot de propaganda TDA. 27/10/2011, disponible en https://www.youtube.com/watch?v=2ymopEdvaOY. (Consultado el 12 de noviembre de 2014)

- Spot de propaganda de TDA, con fecha 25/06/2014, disponible en https://www.youtube.com/watch?v=IoVFIWgSmg8 (Consultado el 9 de septiembre de 2015).

\section{Artículos periodísticos sobre el lanzamiento de la TDA en el país}

- Obarrio, M. (14 de junio, 2010). Empezó el reparto de decodificadores de TV del Gobierno. Sección Política. La Nación. Recuperado de: https://www.lanacion.com.ar/politica/empezo-el-reparto-de-decodificadores-de-tv-delgobierno-nid1274826

- Bossi, J. (15 de febrero, 2011) El Gobierno abrirá más canales de TV. Sección Política. La Nación. Recuperado de: https://www.lanacion.com.ar/politica/el-gobierno-abriramas-canales-de-tv-nid1350154

- Cristina presentó el plan oficial para ofrecer Internet y TV digital. (19 de octubre, 2010). Sección política. Clarín. Recuperado de: http://www.clarin.com/politica/cristinapresento-internet-tv-digital_0_HJdOdqipDQx.html 
- Krakowiak, F. (4 de mayo, 2010). Un regalo para el Mundial. Sección Economía. Página 12. Recuperado de: https://www.pagina12.com.ar/diario/economia/2-145087-2010-0504.html

- Los LCD van primero a los jubilados. (22 de junio, 2011). Sección El País. Página 12. Recuperado de: https://www.pagina12.com.ar/diario/elpais/1-170592-2011-06-22.html

- Dos antenas más, y ya llegan a 19. (22 de junio,2011). Sección El País. Página 12. Recuperado de: https://www.pagina12.com.ar/diario/elpais/1-170593-2011-06-22.html

- La TV digital oficial debutará con los beneficiarios de planes sociales y cinco canales. (24 de marzo, 2010). Revista Fortuna. Recuperado de: https://fortuna.perfil.com/201003-24-23058-la-tv-digital-oficial-debutara-con-los-beneficiarios-de-planes-sociales-ycinco-canales/ 


\section{ANEXO III \\ Corpus de análisis}

En el DVD se presentan los spots de propaganda considerados en el capítulo II, los documentos oficiales de las políticas públicas de comunicación y la transcripción de las entrevistas de inclusión digital relevadas y analizadas en el capítulo VII de esta tesis. 


\section{ANEXO IV}

Ficha básica para la sistematización de documentos escritos: Política Pública de Inclusión Digital de Argentina

\begin{tabular}{|c|c|c|c|c|c|c|}
\hline Documento & \multicolumn{6}{|c|}{ Nombre de la política pública a analizar } \\
\hline \multicolumn{7}{|c|}{ 1. Descripción } \\
\hline \multicolumn{7}{|l|}{ Organismo } \\
\hline \multicolumn{7}{|l|}{ Fecha de publicación } \\
\hline \multicolumn{7}{|l|}{ Dirección URL de acceso } \\
\hline \multicolumn{7}{|l|}{ Cantidad de páginas } \\
\hline \multicolumn{7}{|c|}{ 2. Referencias a temas } \\
\hline & \multicolumn{2}{|c|}{ Menciones } & \multicolumn{2}{|c|}{$\begin{array}{c}\text { Cantidad de } \\
\text { menciones }\end{array}$} & \multicolumn{2}{|c|}{ Definición de referencia } \\
\hline \multicolumn{7}{|l|}{ Tecnologías digitales/TIC } \\
\hline \multicolumn{7}{|l|}{ Inclusión digital } \\
\hline \multicolumn{7}{|l|}{ Exclusión digital } \\
\hline \multicolumn{7}{|l|}{ Acceso } \\
\hline \multicolumn{7}{|l|}{ Brecha digital } \\
\hline \multirow{2}{*}{\multicolumn{7}{|c|}{ 3. Relaciones entre temas }} \\
\hline & & & & & & \\
\hline \multicolumn{7}{|l|}{$\begin{array}{c}\text { Tecnologías digitales de } \\
\text { vincula con }\end{array}$} \\
\hline \multicolumn{7}{|l|}{$\begin{array}{l}\text { Inclusión digital se vincula } \\
\text { con }\end{array}$} \\
\hline \multicolumn{7}{|l|}{$\begin{array}{c}\text { Exclusión digital se } \\
\text { vincula con }\end{array}$} \\
\hline \multicolumn{7}{|l|}{ Acceso se vincula con } \\
\hline \multicolumn{7}{|l|}{$\begin{array}{l}\text { Brecha digital se vincula } \\
\text { con }\end{array}$} \\
\hline \multicolumn{7}{|l|}{$\begin{array}{c}\text { Beneficiarios se vincula } \\
\text { con }\end{array}$} \\
\hline \multicolumn{7}{|c|}{ 4. Encuadre en leyes/decretos } \\
\hline Menciones & $\begin{array}{c}\text { Ley } \\
26.522 / 09 \\
\end{array}$ & & reto & $\begin{array}{c}\text { Decreto } \\
364 / 10 \\
\end{array}$ & $\begin{array}{l}\text { Decreto } \\
1148 / 09 \\
\end{array}$ & $\begin{array}{c}\text { Resoluciones } \\
\text { AFCA }\end{array}$ \\
\hline \multicolumn{7}{|l|}{ Tecnologías digitales/TIC } \\
\hline \multicolumn{7}{|l|}{ Inclusión digital } \\
\hline \multicolumn{7}{|l|}{ Exclusión digital } \\
\hline \multicolumn{7}{|l|}{ Acceso } \\
\hline \multicolumn{7}{|l|}{ Brecha digital } \\
\hline Beneficiarios & & & & & & \\
\hline
\end{tabular}


Ficha básica para la sistematización de documentos escritos: cobertura informativa sobre presentación, lanzamiento y difusión de la TDA

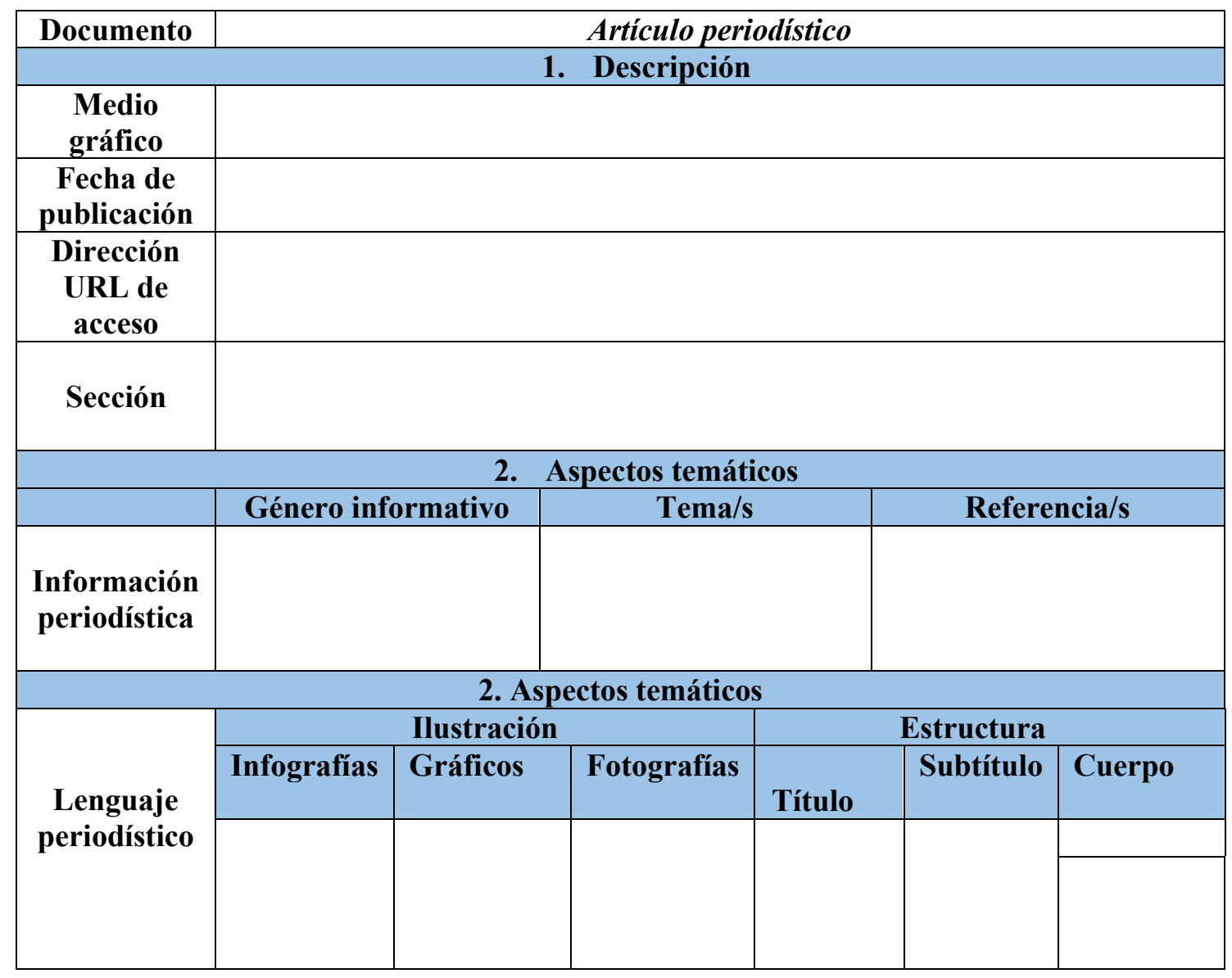


Matriz descriptiva de documentos audiovisuales

\begin{tabular}{|c|c|c|c|}
\hline $\begin{array}{c}\text { Pieza } \\
\text { Audiovisual }\end{array}$ & Registro sonoro & $\begin{array}{c}\text { Registro } \\
\text { visual }\end{array}$ & Observaciones \\
\hline & & & \\
Título & Transcripción & Descripción & \\
& & & \\
& & & \\
\hline
\end{tabular}




\section{ANEXO V \\ Instrumento utilizado para las entrevistas en profundidad}

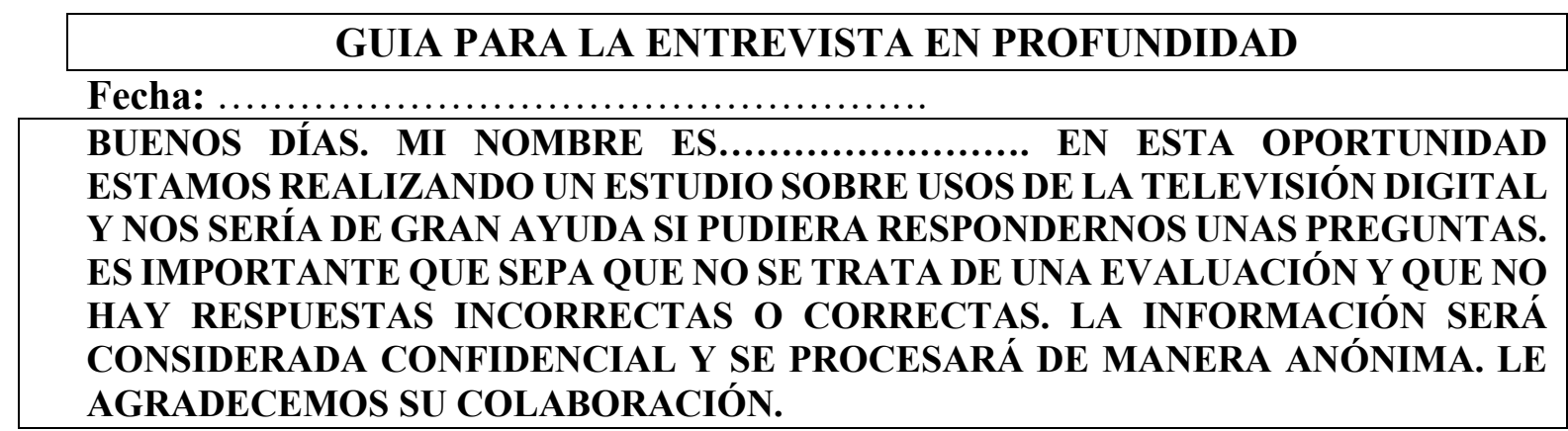

Nombre:

Edad:

Dirección:

(Entrevistador/a: Si el entrevistado/a no desea revelar su dirección postal, se puede preguntar por la intersección de calles o ubicación de su domicilio en el barrio-cerca/lejos del centro comercial, de alguna institución educativa, centro de salud, etc.)

Localidad/Barrio:

Dato de contacto:(Teléfono/e-mail)

Composición del hogar:

Posición/rol que ocupa dentro del hogar:

Ocupación/trabajo:

Nivel educativo alcanzado: PRIMARIO-SECUNDARIO-TERCIARIO-UNIVERSITARIO/INCOMPLETOCOMPLETO

Identificar cómo conoció el Plan “Mi TV digital” y recibió el beneficio.

○ ¿Hace cuánto tiempo tiene televisión digital (TDA o decodificador digital)? ¿Cómo se enteró del Plan "Mi TV digital”? ¿De qué modo se enteró de que Ud. podría ser un beneficiario del Plan "Mi TV digital" (¿televisión, por radio, por la prensa, por la web, por algún familiar, vecino o conocido, etc.?

- ¿Cómo obtuvo el decodificador para televisión digital: lo fue a buscar a algún centro de distribución? ¿Cuál? ¿Al Correo Argentino, a través de la página "Mi TV Digital", ¿a través de la línea gratuita para beneficiarios (0800-888 MITV (6488)? ¿De otro modo?

- ¿Cuáles fueron los pasos que tuvo que realizar para postularse como beneficiario del Plan? ¿Cómo y dónde recibió el decodificador digital?

- A la hora de instalar o configurar el receptor para señal para televisión digital: ¿lo hizo solo/a? ¿acudió a alguien? ¿a quién? ¿acudió al sitio de internet del Plan, 
línea gratuita para beneficiarios, blog o redes sociales, familiares o conocidos, medios de comunicación? ¿Le resultó fácil o difícil la tarea de instalarlo? ¿Puede explicar por qué?

(Entrevistador/a: repreguntar - si es necesario- sobre la instalación del decodificador digital)

1. Caracterizar los tipos de usos de la televisión digital que realiza la población de José C. Paz de la provincia de Buenos Aires.

\section{Identificar consumos de televisión digital}

○ ¿Cuántos televisores tiene en su hogar? SI LA RESPUESTA ES AFIRMATIVA ¿En qué lugar (espacio físico) de su hogar se encuentra el aparato que posee receptor para televisión digital? ¿En qué tipo de aparato (tradicional, LED, ¿Smart TV) tiene conectado el decodificador para ver televisión digital? ¿Cuál de los televisores prefiere ver: el tradicional/analógico o el digital? ¿Por qué?

- ¿Puede Ud. comentar las características de la televisión digital? ¿Cuáles son?

- Según su opinión, ¿cuáles son las principales diferencias entre la televisión digital y la tradicional? ¿Encuentra diferencias entre imágenes analógicas y las de alta definición? ¿Cuáles?

- ¿Suele ver televisión digital a través de dispositivos móviles (celular o TV portátil)? SI LA RESPUESTA ES AFIRMATIVA ¿Cuánto tiempo dedica a ver televisión digital en el celular o TV portátil? SI LA RESPUESTA ES NEGATIVA ¿por qué?

○ ¿Hace cuánto tiempo que ve televisión digital? ¿Cuánto tiempo al día le dedica al visionado de televisión? ¿Con quién/es suele ver televisión: familiares, amigos, pareja, etc.?

- ¿Qué tipo de emisoras ve preferentemente en la televisión digital: abiertas (señal/antena), deportivas, series y películas, infantiles, culturales, noticias, políticas?

○ ¿En qué rango(s) horarios preferentemente mira la televisión: Mañana (06:0014:00), Tarde (14:00-20:00), Horario central (20:00-00:00), ¿Nocturno (00:00-06:00)? PUEDE SELECCIONAR MÁS DE UNA ALTERNATIVA.

- ¿Qué tipo de programas o emisiones privilegia en los horarios que indicó anteriormente? ¿Por qué? ¿Los contenidos de esos programas son diferentes a los de la televisión tradicional (analógica)? ¿Por qué?

2. Indagar las condiciones y prácticas vinculadas con los usos de la televisión digital entre la población en estudio.

\section{Identificar los usos que se realizan de la televisión digital}

○ ¿Sabe usar la televisión digital? SI LA RESPUESTA ES AFIRMATIVA ¿Cómo? ¿Le parece fácil usar la televisión digital? ¿Por qué? ¿Ud. cree que la usa bien? ¿Por qué? SI LA RESPUESTA ES NEGATIVA ¿Por qué cree que no sabe usar la televisión digital? ¿Qué hace cuando quiere ver televisión digital? ¿Le pide a alguien (familiares, amigos, etc.) que le ayude?

$\circ$ ¿Es diferente ver televisión digital que la tradicional/analógica? ¿Por qué? ¿Cuáles son las diferencias que puede enumerar?

- Una de las funciones de la televisión digital es la "interactividad": ¿conoce está función? ¿Ud. la usa? ¿Cómo? ¿Usarla modifica o cambia en algo lo que hace con la televisión habitualmente? ¿Cuál? ¿En qué sentido? 
○ ¿Conoce todas las funciones del dispositivo de la televisión digital? (consulta de programación, el estado del tránsito y del tiempo, restringir contenidos no aptos para niños) SI LA RESPUESTA ES AFIRMATIVA ¿Cuáles? ¿Las usa? ¿Con qué frecuencia? ¿Esas funciones tienen ventajas o desventajas respecto de los de la televisión tradicional? ¿Por qué? ¿Cuáles? SI LA RESPUESTA ES NEGATIVA: ¿por qué le parece que no conoce todas las funciones? ¿Qué tipo de funciones le parece que desconoce?

- ¿Qué hace cuando decide ver la televisión: la prende para ver qué hay, ve la guía de programas, ¿prende y ve cualquier programa o emisión?

- Cuando ve televisión ¿realiza otra actividad: trabajar, charlar con alguien, hablar por teléfono, usar la computadora, ¿etc.? ¿Son las mismas actividades que realiza/aba cuando ve/ía la televisión tradicional/analógica? ¿Por qué cambiaron? ¿Lo atribuye a las características de la televisión digital? ¿Por qué?

○ ¿Para qué mira televisión digital: para aprender, para entretenerse, para informarse, ¿etc.?

○ ¿Espera realizar otros usos de la televisión digital? ¿Cuáles? ¿Cree Ud. que la televisión digital puede ofrecer otros servicios en el futuro? ¿Cuáles?

\section{Identificar posibles efectos de desplazamiento en las prácticas de consumo de medios y tecnologías de información y comunicación.}

Reconocer los usos vinculados con otras tecnologías: asociaciones y efectos de desplazamiento

○ PARA USUARIOS DE COMPUTADORAS: ¿Cuándo usa la computadora, suele mirar televisión? ¿qué hace con cada uno (computadora y TV)? ¿cree que le dedica más tiempo a la computadora que a la televisión? ¿Por qué? ¿siempre fue así? ¿cómo era antes? ¿por qué cambió? ¿Qué le gusta más de usar la computadora? ¿le parece que desde que usa la computadora usa también algún otro medio o tecnología al que antes no prestaba atención? ¿cuál? ¿por qué?

O PARA USUARIOS DE INTERNET: ¿Cuándo usa Internet, suele mirar televisión? ¿Mira televisión por Internet o mira televisión digital? ¿cuándo? ¿qué mira? ¿con quién? ¿cree que le dedica más tiempo a Internet que a mirar televisión digital? ¿Por qué? ¿siempre fue así? ¿cómo era antes? ¿por qué cambió? ¿Qué le gusta más de usar Internet? ¿le parece que desde que usa Internet usa también algún otro medio o tecnología al que antes no prestabas atención? ¿cuál? ¿por qué? ¿qué otros tipos de medios consume por Internet, el diario, radio, por ejemplo? ¿cuál/es? ¿con qué frecuencia? ¿dejó de consumir algún medio o tecnología desde que usa Internet? ¿Por qué?

4. Analizar los sentidos atribuidos a la noción de inclusión digital, así como sus vinculaciones con los usos de la TDA, tal como se manifiestan en los discursos de los usuarios.

Reconocer las dimensiones de la inclusión digital: acceso, uso, autoafirmación, reflexividad y participación.

- Según su opinión: ¿encuentra ventajas y/o desventajas (técnicas, de uso) de la televisión digital? ¿Cuáles?

○ ¿Sabe si otras personas que Ud. conoce tienen televisión digital? ¿Son familiares, amigos, vecinos? Con esas personas: ¿han conversado sobre las ventajas de poseer televisión digital? ¿Cuáles? ¿y sobre las desventajas? ¿Cuáles? 
- ¿Encuentra algún cambio en su vida cotidiana a partir de que tiene televisión digital? SI LA RESPUESTA ES AFIRMATIVA ¿Cuál/es? ¿Le permite hacer diferentes cosas que antes no hacía? SI LA RESPUESTA ES AFIRMATIVA ¿Cuáles? Esas cosas diferentes que hace con la televisión digital: ¿le permiten sentirse confiado/a en el manejo de otras tecnologías en general (celular, PC, Play o Xbox)? SI LA RESPUESTA ES AFIRMATIVA ¿En qué sentido? ¿le permiten sentirse más independiente/autónomo en el manejo de tecnologías? ¿En qué sentido? ¿le permiten solucionar otros problemas (técnicos, de la vida cotidiana, etc.)? ¿Cuáles?

- Antes conversamos sobre la función de interactividad de la televisión digital: ¿qué se imagina que podrá hacer en unos años? ¿Cree que le permitirá hacer cosas diferentes de las que hace actualmente? ¿Cuáles?

- En general, se dice que la TDA sirve para lograr la "inclusión digital" para todos los argentinos: ¿qué le parece a Ud. que quiere decir esto? Con sus palabras: ¿qué significa la inclusión digital? ¿Cree que tener televisión digital la/o incluye digitalmente? ¿Por qué? ¿En qué sentido? ¿Cree que existe alguna función de la televisión digital que puede servir para lograr la inclusión digital? ¿Cuál? ¿De qué modo? 


\section{ANEXO VI \\ Entrevista realizada al ex coordinador general del Consejo de Televisión Digital Terrestre de Argentina}

\section{GUIA PARA LA ENTREVISTA}

\section{Objetivos de la entrevista:}

- Describir las problemáticas y/o demandas sociales implicadas en el diseño y la formulación del Sistema Argentino de Televisión Digital Terrestre.

- Identificar y caracterizar los aspectos específicos que comprenden el diseño y gestión de la política pública TDA.

- Examinar los sentidos políticos construidos en la política pública TDA a partir de su formulación y gestión en el período 2009-2015.
Estamos realizando un estudio sobre la televisión digital terrestre en Argentina. En este caso, nos interesa
conocer y comprender las modalidades y características que asumió la definición y gestión de la política
pública TDA $^{189}$ entre 2009 y 2015.

Nombre y apellido del entrevistado: Osvaldo Nemirovsci

Cargo en relación con la TDA: Coordinador General del Consejo de Televisión Digital Terrestre en Argentina

Cargo/actividad actual:

1. ¿Recuerda Ud. cómo surgió la iniciativa para implementar la televisión digital terrestre en Argentina? Nos interesa conocer las características del surgimiento de dicha iniciativa.

2. ¿En qué período ocupó el cargo en la TDA?

3. ¿Cuál fue su rol en la TDA? ¿Cómo lo definiría?

4. ¿Cuáles fueron las características de su gestión en el cargo que ocupó en la TDA? ¿Percibió obstáculos (técnicos, políticos, organizacionales, etc.) para desarrollar las tareas propias de su cargo? ¿Cuáles? ¿De qué modo los resolvió?

5. Según su opinión: ¿cuáles fueron los principales valores/ideas expresado/as en la TDA? ¿Qué problemas o demandas sociales alcanzó?

6. ¿Cuáles fueron los objetivos principales de la TDA en relación con los problemas identificados?

7. ¿A quiénes se dirigía la TDA? ¿Cuáles fueron los criterios para definir a los destinatarixs de dicha política pública?

8. ¿Con qué otras políticas considera que se articuló institucional o simbólicamente? ¿En qué sentido?

9. ¿Qué otra política pública que no haya dependido de su área le resultó importante en relación con los valores/ideas de la TDA?

10. ¿Cuáles fueron los obstáculos o actores (sindicatos, organizaciones sociales, sector privado, etc.) que alteraron o no estaban de acuerdo con la TDA? ¿Por qué? ¿En qué sentido?

\footnotetext{
${ }^{189}$ Nos referimos a la TDA como aquella política pública que contiene un conjunto de planes y programas así como también servicios de Televisión Digital Terrestre.
} 
11. ¿Quiénes eran sus aliadxs?

12. ¿Cómo evalúa dicha iniciativa? ¿Cómo mide sus resultados o impacto?

13. Considera que ¿se podría haber realizado alguna modificación o medida complementaria? ¿En qué sentido?

14. Según su opinión y experiencia: la TDA ¿permitió incluir digitalmente a los sectores en "riesgos de exclusión" en Argentina? ¿De qué modo?

15. Considera que la TDA ¿tendió a democratizar la comunicación? ¿En qué sentido?

Nombre y apellido del entrevistado: Osvaldo Nemirovsci

Cargo en relación con la TDA: Coordinador General del Consejo de Televisión Digital Terrestre en Argentina

Fecha: 27 de enero de 2020.

1. ¿Recuerda Ud. cómo surgió la iniciativa para implementar la televisión digital terrestre en Argentina? Nos interesa conocer las características del surgimiento de dicha iniciativa.

1) Hubo varios motivos que impulsaron el pensar en la digitalización de nuestra TV abierta. Brasil avanzaba en su proyecto digital y eso nos ponía en demora para el mismo fin dentro de Mercosur. Por otro lado existía desde los tiempos de Menem una resolución que ponía la digitalización en el marco del sistema americano Advanced Televisión Systems Committee-ATSC que si bien no había avanzado contaba con el apoyo del grupo Clarín y tenía un transmisor digital que efectuaba pruebas. Por esos tiempos también empresas europeas reunidas en un consorcio de norma digital propia, DVB-T acá sostenido por Telefé y con lobby de la embajada española, comenzó a mostrarse con fuerza. Era necesario definir con que estándar íbamos a digitalizar. Se juntaron datos, reuniones y experiencias con todos. Ahí aparece la norma japonesa ISDB-T y consideramos que reunía mejores condiciones técnicas en cuanto a su robustez y ventajas. Y, un dato clave, no tenía costo en la transmisión a celulares.

2. ¿En qué período ocupó el cargo en la TDA?

2) Entre septiembre 2009 y diciembre 2015.

3. ¿Cuál fue su rol en la TDA? ¿Cómo lo definiría?

3) Mi tarea fue coordinar a los espacios institucionales públicos y privados que participaban del proyecto. Desde los ministerios de la Nación hasta las Universidades, cámaras empresariales vinculadas, provincias, organismos públicos descentralizados y empresas como INVAP y ARSAT. Y por supuesto el equipo de profesionales, técnicos y empleados del Consejo de TDA. Y básicamente darle una comprensión política a esta decisión tecnológica.

4. ¿Cuáles fueron las características de su gestión en el cargo que ocupó en la TDA? ¿Percibió obstáculos (técnicos, políticos, organizacionales, etc.) para desarrollar las tareas propias de su cargo? ¿Cuáles? ¿De qué modo los resolvió?

4) Debo reconocer que a pesar de ser una política innovativa y original no tuvo fuertes rechazos e incluso en aquellos sectores que podrían ver amenazados su nicho de comercio, como los cableoperadores, no hubo actitudes negativas. Algunos detalles menores como discutir con Aduana cambio de aranceles para insumos que se precisaban 
para la infraestructura de TDA. Pero en general, viví un periodos largo de más de 6 meses de gestión, con calma y total apoyo del Poder Ejecutivo, tanto de Presidencia como el Ministerio de Planificación.

5. Según su opinión: ¿cuáles fueron los principales valores/ideas expresado/as en la TDA? ¿Qué problemas o demandas sociales alcanzó?

5) Estimo como valioso la posibilidad de multiplexar señales y llevar más contenido a los televidentes. Quien no podría abonar el cable estaba condenado a ver, en forma irregular y con pésimas condiciones canales abiertos, que en todo el país no llegaban a los 35 habiendo provincias donde solo se transmitía uno y exclusivamente para su zona primaria dejando al resto de su geografía sin poder ver otra cosa que TV paga, tanto por cable como por satélite. A eso hay que sumarle espacios del país donde no llegaba nada. Existían para entonces millones de habitantes a los que un sistema como el que impulsábamos les garantizaría ver más señales, en forma gratuita. Y el plan que desarrollamos de entregar conversores gratuitos, les permitía acceder a TDA sin tener que cambiar su viejo televisor. El hecho de que la digitalización permita que de $6 \mathrm{MHZ}$ en sistema VHF pudiéramos sacar 3 o señales en UHF era la clave del programa.

6. ¿Cuáles fueron los objetivos principales de la TDA en relación con los problemas identificados?

6) Lograr que más gente viera mejor televisión. Llegamos a más gente, no creo que hayamos completado el segundo objetivo, a pesar de buenos intentos que tuvimos con planes de contenidos en asociación con las Universidades Nacionales mediante un programa de nodos en todo el país.

7. ¿A quiénes se dirigía la TDA? ¿Cuáles fueron los criterios para definir a los destinatarixs de dicha política pública?

7) Hubo que priorizar sujetos sociales. Elegimos sectores marginados, tanto en lo geográfico como en lo social y económico como en el aspecto que hace a las personas con discapacidad. Hacia ellos volcamos esfuerzo. Quien nunca había visto televisión que pudiera ver, quien veía mal que vea en mejores niveles de pantalla (pixelado, color). Y vincular a las PcD a la televisión. En ese sentido trabajamos con jubilados de menor haber, tributarios de AUH, poblaciones alejadas, escuelas rurales, pueblos originarios.

8. ¿Con qué otras políticas considera que se articuló institucional o simbólicamente? ¿En qué sentido?

8) En general con aquellas que durante 2009/2015 ampliaron derechos. De cualquier forma destaco que, a mi criterio, nunca se terminó de entender desde aéreas de gobierno de la comunicación cual era el real sentido de la TDA. Por ejemplo, la Secretaría de Comunicación.

9. ¿Qué otra política pública que no haya dependido de su área le resultó importante en relación con los valores/ideas de la TDA? 
9) Algunas llevadas adelante por RTA, los concursos para contenidos del INCAA y algunas decisiones de ANSES (incluir TDA en el plan Conectar Igualdad, hubo computadoras a las que se les incluyó una solución interna que les permitía ver TDA).

10. ¿Cuáles fueron los obstáculos o actores (sindicatos, organizaciones sociales, sector privado, etc.) que alteraron o no estaban de acuerdo con la TDA? ¿Por qué? ¿En qué sentido?

10) Hubo algunas quejas pero era muy difícil oponerse públicamente a una avance tecnológico de tamaña importancia. El mundo iba cerrando su ciclo analógico y Argentina no podía no hacerlo. Las quejas fueron de algunos canales privados que solicitaban créditos para adquirir sus transmisores digitales. Un pavada i Ya que el costo de los mismos era totalmente razonable para empresas de medios tan fuertes como ellos! Por el contrario, todos los agremiados en tareas vinculadas al mundo audiovisual veían en esta posibilidad de ampliar señales, un lugar de expansión para sus profesiones. Obviamente a más cabales, más contenidos, más trabajo para actores, locutores, directores, guionistas, escenógrafos, iluminadores etc. Así también como una despertar de nuevas posibilidades para empresas metalúrgicas vinculadas a la informática, fabricantes nacionales de cable de antena, de antenas, de conversores.

11. ¿Quiénes eran sus aliados?

11) En términos de institución, el Ministerio de Planificación en su más alto nivel (o sea el Ministro Julio de Vido), no tanto algunos funcionarios carentes de capacidad política y social para ver el proyecto en su integralidad. Los sindicatos del sector antes mencionado. Las universidades. Algunos gobernadores que entendieron que significaba TDA y trabajaban para tener su Estación Digital Terrestre y no ayudaban con sus gestiones.

12. ¿Cómo evalúa dicha iniciativa? ¿Cómo mide sus resultados o impacto?

12) Fue una revolución no muy visible. Fue, desde1951 el hecho más importante como innovación tecnológica en el mundo comunicacional del país. Fue positivo. Sus resultados también se aprecian en la cantidad de gente que sigue viendo TDA, que pide por más contenidos en sus pantallas y que se quejan porque en su zona ha dejado de emitirse.

13. Considera que ¿se podría haber realizado alguna modificación o medida complementaria? ¿En qué sentido?

13) Si, lo más importante hubiese sido que la digitalización se expresar en muchas más señales. Pensamos en 220 para todo el país que podrían haberse concursado y con eso rompíamos el esquema mezquino y pequeño de solamente 35 canales abiertos en toda Argentina y, por ejemplo, desde 1960 que no se concursaba una frecuencia nueva en Capital Federal. Podríamos haber roto esa lógica de pocos canales y en manos de poderosos. Teníamos las condiciones infraestructurales para hacerlo, podíamos en las más de 80 EDT estaciones digitales terrestres, subir nuevas frecuencias. Podíamos...pero no lo hicimos. En el apagado y sordo debate que hubo en el ejecutivo nacional sobre este tema, perdimos lo que queríamos 220 nuevas señales que empoderaran un nuevo radiodifusor como sujeto social y que, a su vez, democratizara y ampliara la televisión 
argentina. Algunos preferían la TDA como forma de "ver mejor" en Alta Definición" y hasta allí llegaba su conocimiento y otros preferíamos más señales en definición estándar.

14. Según su opinión y experiencia: la TDA ¿permitió incluir digitalmente a los sectores en "riesgos de exclusión" en Argentina? ¿De qué modo?

14) Diría que sí, con alguna relatividad en el logro. La distribución de millones de conversores a sectores sociales y económicos vulnerados, los acercó al universo digital. No sé si alcanzó para incluirlos.

15. Considera que la TDA ¿tendió a democratizar la comunicación? ¿En qué sentido?

15) Absolutamente. Democratiza la imagen. Con lo digital se ve igual un color en el mejor departamento de Recoleta en Caba que en un televisor de un barrio humilde de Formosa. Por otro lado abrió la posibilidad de que quienes no podían abonar TV paga pudiesen ver muchas más señales. "Abrió ventanas que estaban cerradas para los pobres". Los programas de aliento a nuevos contenidos acercaron miles de protagonistas novedosos en el mundo televisivo. Actores, estudiantes de diseño y de carreras audiovisuales, guionistas, camarógrafos. Todos ellos realizaron su experiencia en el mundo de la televisión. Un sueño del que habían estado alejados por siempre. Fue la experiencia más democrática que tuvo nuestra televisión abierta. 